NBSIR 77-854

\title{
LIQUEFIED NATURAL GAS RESEARCH
}

NIST
PUBLICATIONS REFERENCE at the

NATIONAL BUREAU OF STANDARDS

PROGRESS REPORT FOR THE PERIOD

1 JULY - 31 DECEMBER 1976

D.E. Diller, Editor

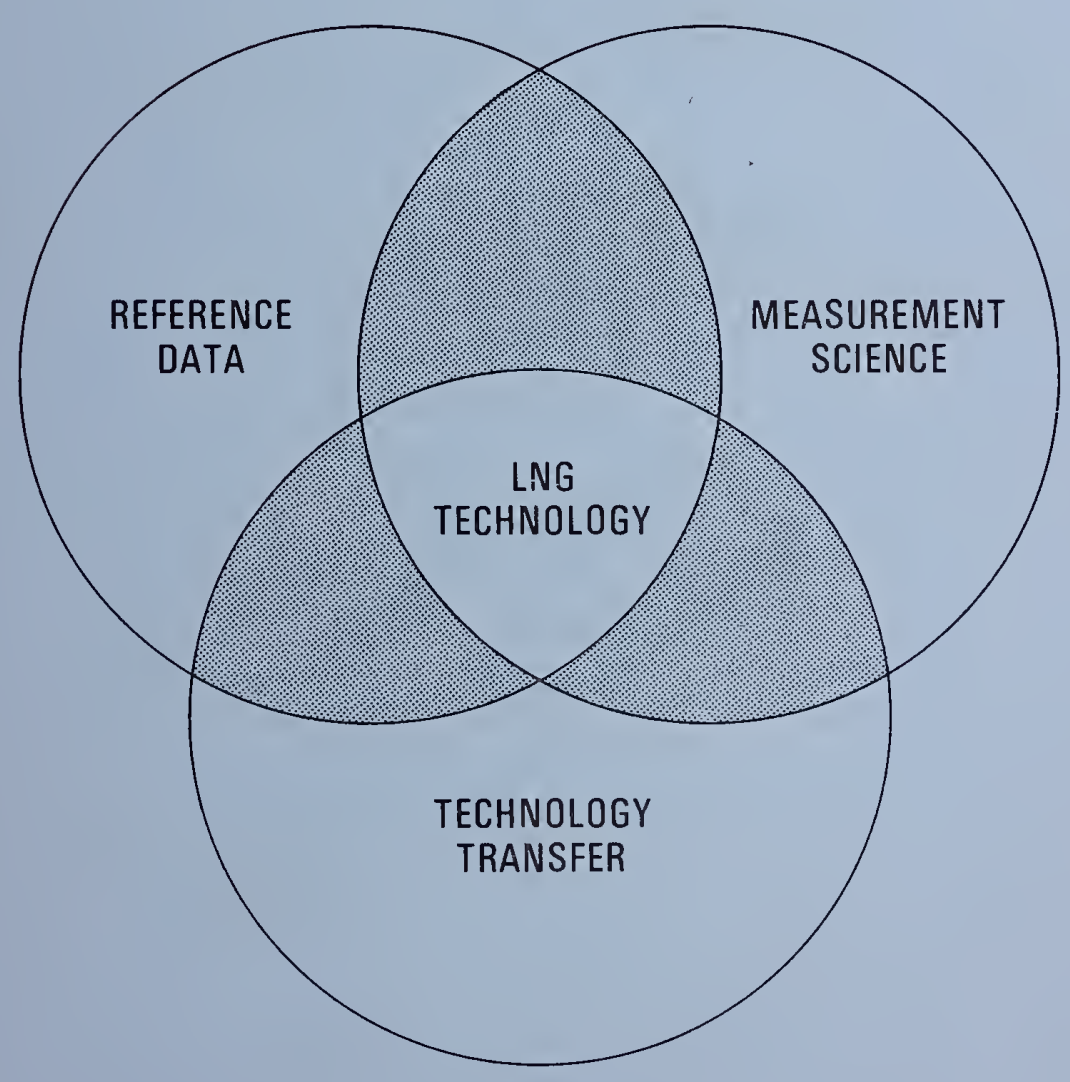

no. $77-854$

1977 


\section{NBSIR 77-854}

\section{LIQUEFIED NATURAL GAS RESEARCH at the}

\section{NATIONAL BUREAU OF STANDARDS}

D.E. Diller, Editor

Cryogenics Division Institute for Basic Standards

National Bureau of Standards

Boulder, Colorado 80302

Progress Report for the Period

1 July-31 December, 1976

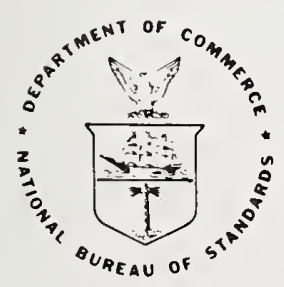

U.S. DEPARTMENT OF COMMERCE, Juanita M. Kreps, Secretary Dr. Betsy Ancker-Johnson, Assistant Secretary for Science and Technology NATIONAL BUREAU OF STANDARDS, Ernest Ambler, Acting Director 
Prepared for:

Americar Gas Association, Inc.

1515 Wilson Boulevard

Arlington, Virginia 22209

LNG Density Project Steering Committee

(in cooperation with the American Gas Association, Inc.)

Pipeline Research Committee

(American Gas Association, Inc.)

Federal Power Commission

Bureau of Natural Gas

Washington, DC 20426

U. S. Department of Commerce

Maritime Administration

Washington, DC 20235

U. S. Department of Commerce

National Bureau of Standards Institute for Basic Standards

Boulder, Colorado 80302

U. S. Department of Commerce National Bureau of Standards

Office of Standard Reference Data

Washington, DC 20234

U. S. Department of Commerce

National Bureau of Standards

Office of International Standards

washington, DC 20234

LNG Sampling Measurements Supervisory Committee

National Aeronautics and Space Administration

Lewis Research Center

Cleveland, Ohio 44135

American Bureau of Shipping

45 Broad Street

New York, NY 10004 
Twenty-five cost centers, supported by six other agency sponsors in addition to NBS, provide the basis for liquefied natural gas (LNG) research at NBS. During this six-month reporting period the level of effort was 20 man-years/year with funding expenditures of over $\$ 500,000$. This integrated progress report to be issued in January and July is designed to:

1) Provide all sponsoring agencies with a semi-annual and an annual report on the activities of their individual programs.

2) Inform all sponsoring agencies on related research being conducted at the Cryogenics Division of NBS-IBS.

3) Provide a uniform reporting procedure which should maintain and improve communication while minimizing the time, effort and paperwork at the cost center level.

The contents of this report will augment the quarterly progress meetings of some sponsors, but will not necessarily replace such meetings. Distribution of this document is limited and intended primarily for the supporting agencies. Data or other information must be considered preliminary, subject to change and unpublished; and therefore not for citation in the open literature.

Key words: Cryogenics; liquefied natural gas; measurement; methane; properties; research. 
I. REFERENCE DATA

a) THERMOPHYSICAL PROPERTIES DATA FOR PURE COMPONENTS AND MIXTURES OF LNG COMPONENTS (American Gas Association, 2750574 and Inc.; NASA Lewis Research Center)

b) FLUID TRANSPORT PROPERTIES (NBS-Office of Standard Reference Data)

c) PROPERTIES OF CRYOGENIC FLUIDS (NBS)

2750141

d) PROPERTIES OF CRYOGENIC FLUID MIXTURES (NBS: NBS-Office of Standard Reference Data; $A G A$ )

2750142 ,

e) DENSITIES OF LIQUEFIED NATURAL GAS

2751574 MIXTURES (LNG Density Project steering Committee - AGA)

f) PROGRAM FOR REDUCING THE COST OF LNG SHIP HULL CONSTRUCTION -- PHASE II SHIP STEEL IMPROVEMENT PROGRAM (Maritime Administration)

2751430

II. MEASUREMENT SCIENCE

a) CUSTODY TRANSFER - LNG SHIPS

2750460

(Maritime Administration)

b) HEATING VALUE OF FLOWING LNG (Pipeline

2756579 Research Committee - AGA)

2757574 and

C) LNG DENSITY REFERENCE SYSTEM

(American Gas Association, Inc.;

2750161

National Bureau of Standards)

d) LNG SAMPLING MEASUREMENT STUDY (LNG

2750575 Sampling Measurements Supervisory Committee)

III. TECHNOLOGY TRANSFER

a) SURVEY OF CURRENT LITERATURE ON LNG AND METHANE (American Gas Association, Inc. )

2759574

b) LIQUEFIED NATURAL GAS TECHNOLOGY TRANSFER

2750403, (Maritime Administration; American Gas 2751403 , 2752403 , Association, Inc.; American Bureau of Shipping)

2750570 , 2754574 and 2758574

C) OIML JOINT SECRETARIAT ON LNG MEASUREMENTS (American Gas Association, Inc.; NBS-Office of International Standards; NBS-Cryogenics Division) 
III. TECHNOLOGY TRANSFER (continued)

d) FEDERAL POWER COMMISSION CONSULTATION (FPC) 2750404

IV. BIBLIOGRAPHY

V. APPENDICES

A. Straty, G.C., and Tsumura, R., "Phase transition and melting pressures of solid ethane," J. Chem. Phys. 64,859 (1976).

B. Straty, G.C., and Tsumura, R., "PVT and vapor pressure measurements on ethane," J. Res. Natl. Bur. Stds. $80 \mathrm{~A}, 35$ (1976).

C. Weber, L.A., "Dielectric constant and the derived Clausius-Mossotti function for compressed gaseous and liquid ethane," J. Chem. Phys. 65, 446 (1976).

D. Roder, H.M., "The heats of transition of solid ethane," J. Chem. Phys. 65, 1371 (1976).

E. Roder, H.M., "Measurements of the specific heats, $\mathrm{C}_{\sigma}$ and $\mathrm{C}_{\mathrm{V}}$, of dense gaseous and liquid ethane," J. Res. Natl. Bur. Stds. 80A, 739 (1976).

F. Diller, D.E., "LNG densities for custody transfer," Proceedings, International School for Hydrocarbon Measurement, Jniversity of Oklahoma, April 12-14, 1977.

G. Haynes, W.M., Hiza, M.J., and Frederick, N.V., "Magnetic suspension densimeter for measurements on fluids of cryogenic interest," Rev. Sci. Instrum. 47, 1237 (1976).

H. Haynes, W.M., "A simplified magnetic suspension densimeter for absolute density measurements," Rev. Sci. Instrum. 48,39 (1977).

I. Haynes, W.M., and Hiza, M.J., "Measurements of the orthobaric liquid densities of methane, ethane, propane, isobutane and normal butane," J. Chem. Thermodynamics (in press, 1977).

J. Hanley, H.J.M., Haynes, W.M., and McCarty, R.D., "The viscosity and thermal conductivity coefficients for dense gaseous and liquid methane," J. Phys. Chem. Ref. Data (in press, 1977).

K. Hanley, H.J.M., "Prediction of the viscosity and $\mathrm{K}-1$ thermal conductivity coefficients of mixtures," Cryogenics 16, 643 (1976).

L. Tobler, R.L., and Reed, R.P., "Fracture mechanics parameters for a 5083-0 aluminum alloy at low temperatures," Journal of Materials for Engineering and Technology (submitted, 1977).

M. McHenry, H.I., "Ship steel weldments for low temperature service," Welding Journal 55, 387 (1976).

N. Younglove, B.A., and Siegwarth, J.D., "Cryogenic $\mathrm{N}-1$ fluids density reference system: provisional accuracy statement," NBSIR 77-852 (January 1977).

O. Mann. D. B., "What's new in LNG measurement and instrumentation" Pipeline Industry 45, 21 (1976). 
1. Title. THERMOPHYSICAL PROPERTIES DATA FOR PURE COMPONENTS AND MIXTURES OF LNG COMPONENTS

Principal Investigators. R. D. Goodwin, H. M. Roder, G. C. Straty, R. Tsumura*, W. M. Haynes, and R. D. McCarty

2. Cost Center Number. 2750574, 2750548

3. Sponsor Project Identification. American Gas Association, Inc., Project BR-50-10. National Aeronautics and Space Administration, Lewis Research Center, Purchase Order C-78014-C.

4. Introduction. Accurate phase equilibrium, equation of state (PVT), and thermodynamic properties data are needed to design and optimize gas separation and liquefaction processes and equipment as well as heat transfer calculations. Accurate data for the pure components and selected mixtures of hydrocarbon systems will permit developing comprehensive accurate predictive calculation methods which take into account the dependence of the thermophysical properties of mixtures on the composition, temperature, and density.

This project will provide comprehensive accurate thermophysical properties data and predictive calculation methods for compressed and liquefied hydrocarbon gases and their mixtures to support the development of LNG technology at NBS and throughout the fuel gas industry. It will also serve as the base for a comprehensive mixtures prediction methodology.

5. Objectives or Goals. The objectives of our work are the determination of comprehensive accurate thermophysical properties data and predictive calculation methods for the major pure components and selected mixtures (methane, ethane, propane, butanes, and nitrogen) of liquefied natural gas and hydrocarbon mixtures at temperatures between $90 \mathrm{~K}$ and $300 \mathrm{~K}$ and at pressures up to $350 \mathrm{MPa}(5000 \mathrm{psi})$. Our goal is to provide a range and quality of data that will be recognized as definitive or standard for all foreseeable low temperature engineering calculations.

6. Background. Liquefied natural gas is expected to supply an increasing percentage of the United States' future energy requirements. It is likely that massive quantities of liquefled natural gas will be imported during the years 1976 - 1990. Ships and importation terminals are being built for transporting, storing, and vaporizing liquefied natural gas for distribution. Accurate physical and thermodynamic properties data for compressed and liquefied natural gas and hydrocarbon mixtures are needed to support these projects. For example, accurate compressibility and thermodynamic properties data are needed to design and optimize liquefaction and transport processes; accurate data for the heating value, which for liquefied natural gas mixtures depends on the total volume, the density, and the composition, are needed to provide a basis for equitable custody transfer. Accurate mixtures prediction methods are needed for use in automated heat transfer calculations.

Accurate thermodynamic properties data for liquefied gas mixtures must be based on precise compressibility and calorimetric measurements; compressibility data give the dependence of thermodynamic properties on pressure and density (at fixed temperatures); calorimetric data give

* Consejo Nacional de a guest worker with Institute for Basic 
the dependence of thermodynamic properties on temperature (at fixed pressures and densities). It is impossible, however, to perform enough compressibility and calorimetric measurements directly on multicomponent mixtures to permit accurate interpolation of the data to arbitrary composition, temperatures and pressure. Instead, thermodynamic properties data for multicomponent mixtures usually must be predicted (extrapolated) from a limited number of measurements on the pure components and their binary mixtures. This project was initiated to provide the natural gas and aerospace industry with comprehensive accurate data for pure compressed and liquefied methane, the most abundant component in LNG mixtures. We have published National Bureau of Standards Technical Note 653, "Thermophysical Properties of Methane, From 90 to $500 \mathrm{~K}$ at Pressures to 700 Bar," by Robert D. Goodwin (April 1974), and National Bureau of Standards Technical Note 684, "Thermophysical Properties of Ethane, From 90 to $600 \mathrm{~K}$ at Pressures to 700 Bar," by Robert D. Goodwin, H. M. Roder, and G. C. Straty (August 1976). These reports contain the most comprehensive and accurate tables available for the thermophysical properties of pure gaseous and liquid methane and ethane, and provide accurate basis for calculating thermophysical properties data for LNG and hydrocarbon mixtures.

7. Program and Results.

\subsection{Ethane, Specific Heat Data -- H. M. Roder}

This phase of the program is complete. Two manuscripts describing the results of the research have been published:

H. M. Roder, Measurements of the Specific Heats, $C_{\sigma}$ and $C_{V}$ of Dense Gaseous and Liquid Ethane, J. Res. Nat. Bur. Stand. (U.S.), Vol 80A, No. 5, 739-59 (Sep-Oct 1976).

H. M. Roder, The Heats of Transition of Solid Ethane, J. Chem. Phys. Vol 65, No. 4, 1371-3 (Aug 1976).

\subsection{Ethane, Sound Velocity Data -- R. Tsumura, G. C. Straty}

Sound speed measurements on ethane have been completed. Measurements were made on both the saturated and compressed fluid in a temperature range from near the triple point $(\sim 91 \mathrm{~K})$ to $320 \mathrm{~K}$ and to pressures of $35 \mathrm{MPa}$. A systematically increasing disagreement between data for the saturated liquid obtained at $1 \mathrm{MHz}$ and $10 \mathrm{MHz}$ as the triple point temperature is approached has been explained as a wave-guide effect due to experimental geometry.

A manuscript entitled "Speed of Sound in Saturated and Compressed Fluid Ethane," by R. Tsumura and G. C. Straty has been prepared and submitted to CRYOGENICS for publication.

\subsection{Ethane, Thermophysical Properties Data -- R. D. Goodwin}

The manuscript, National Bureau of Standards Technical Note 684, "Thermophysical Properties of Ethane, From 90 to $600 \mathrm{~K}$ at Pressures to 700 Bar," by R. D. Goodwin, H. M. Roder, and G. C. Straty (August 1976) has been published and distributed.

\subsection{Propane, Thermophysical Properties Data -- R. D. Goodwin}

Available, published physical properties data, acquired through our Cryogenic Data Center, have been evaluated and formulated as required for thermal computations. These numerous properties now have been used to compute a complete set of Provisional tables of thermodynamic functions. 
The manuscript, "Provisional Thermodynamic Functions of Propane, From 85 to $700 \mathrm{~K}$ at Pressures to $700 \mathrm{Bar}, "$ is $50 \%$ complete. Present plans are to publish these provisional tables as a National Bureau of Standards Internal Report by mid-1977.

\subsection{Propane, Experimental Measurements -- W. M. Haynes}

A magnetic suspension densimeter, which has been used previously (Rev. Sci. Instr. 47, 1237 (1976)) for measurements on liquids (including mixtures) at temperatures between 95 and $300 \mathrm{~K}$ and at pressures to $3.5 \mathrm{MPa}$ ( $500 \mathrm{psi})$, is being modified for PVT measurements on liquid propane at pressures to $35 \mathrm{MPa}$ (5000 psi). Significant differences between the two apparatus are noted here. A capacitor with slotted concentric cylinders will be located just above the density sensor in the high pressure cell for simultaneous dielectric constant measurements on liquid propane. Major modifications have been carried out on an existing cryostat so that it is compatible with the high-pressure magnetic suspension densimeter.

A copper equilibrium cell with a prototype window assembly for use at pressures to $35 \mathrm{MPa}$ ( $5000 \mathrm{psi}$ ) has been fabricated. This type of window assembly has been tested at pressures to 6,250 psi at room temperature and liquid nitrogen temperature. The assembly was cycled between these temperature limits four times and no leaks were detected.

A new differential capacitance sensor, designed to be minimally sensitive to changes in the dielectric constant of the test fluid, is being evaluated as a detector of the motion of the magnetic buoy that serves as the density sensor. It has at least the sensitivity to changes in the position of the buoy as the linear differential transformer used in the previous work.

The auxiliary systems for handling of the test fluids including those for pressure measurements have been assembled and tested. An oil dead weight gauge will be used for most pressure measurements. Two spiral quartz Bourdon gauges and a double revolution Bourdon gauge have been calibrated against an air dead weight gauge and will be used to measure the vapor pressure of the liquid propane in the cell and the vapor pressure of liquids in vapor bulbs that are used to monitor temperature gradients along the length of the cell.

Major tasks to be completed before PVT data for propane are obtained are as follows:

a) Performance tests on magnetic suspension densimeter circuitry including servo system, differential capacitance sensor, support coil, etc.

b) Final assembly of capacitor and differential capacitor sensor inside the sample holder.

c) Installation of sample cell and associated components (guard ring, shields, capillary tubes, vapor bulbs, thermocouples, platinum resistance thermometer, etc.) inside cryostat.

d) Wiring of cryostat, sample cell, and sensors for measuring density, dielectric constant, and temperature.

e) Alignment of cryostat, sample cell, support coil, microscope, and buoy for control and determination of buoy-coil separation distance.

f) Capabilities for simultaneous measurements of density, temperature, pressure, and dielectric constant. These tests will include measurements on well-characterized fluids. 
7.6 Calculational Methods -- R. D. McCarty

Four available calculation methods have been evaluated and optimized under another project (2752574) from the standpoint of predicting orthobaric liquid densities of LNG-like mixtures at pressures below about $2 \mathrm{MPa}(290 \mathrm{psi})$. These methods are now being examined for predicting the thermophysical properties of mixtures over a wide range of temperatures and pressures. Available data in the literature for the methane-nitrogen system have been compiled for use in evaluating the extended corresponding states method. Thus far, efforts have concentrated on mapping PVT properties as a logical first step prior to examining the utility of the method in calculating other thermodynamic properties.

8. Problem Areas. None.

9. Funding. July 1 - December 31, 1976.

Man-years expended

Equipment and/or Services Purchased

1.8

Total Reporting Period Cost

$14.3 \mathrm{~K} \$$

Balance Remaining

$109.8 \mathrm{~K} \$$

$75.2 \mathrm{~K} \$$

10. Future Plans.

Objectives and Schedule: Quarter

1

2

Measure, analyze and report

ultrasonic velocity data

for ethane.

Analyze and report available physical properties data for propane.

Prepare and performance test PVT and dielectric constant properties apparatus for propane.

Perform PVT and dielectric constant measurements on propane and on methane-nitrogen mixtures.

Evaluate and optimize promising calculation methods for the thermodynamic properties of mixtures of LNG components.

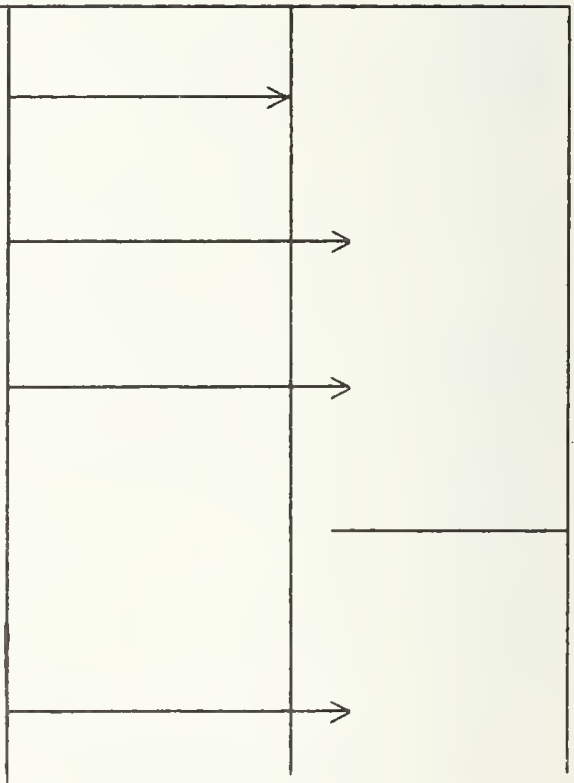


1. Title. FLUID TRANSPORT PROPERTIES

Principal Investigator. Howard J. M. Hanley

2. Cost Center Number. 2750124

3. Sponsor Project Identification. NBS-Office of Standard Reference Data

4. Introduction. Methods for predicting the transport properties of fluid mixtures are unreliable and data are scarce. Prediction methods are neeảed, however, to supply the necessary design data needed to increase efficiency and reduce costs.

5. Objectives or Goals. The long range or continuing goal of the program is to perform a systematic study of the theories and experimental measurements relating to transport properties, specifically the viscosity and thermal conductivity coefficients, of simple mixtures over a wide range of experimental conditions. The specific objectives of the program include: 1) the systematic correlation of the transport properties of simple binary mixtures and the development of prediction techniques, 2) development of a mixture theory for the dilute gas region and the dense gas and liquid regions, 3) extension of the theory and prediction techniques to multicomponent systems, and 4) suggested guidelines for future areas of experimental work.

6. Background. A continuing program has successfully expanded the stateof-the-art of transport phenomena for pure fluids. Information for pure fluids is required as a prerequisite for mixture studies. The theory of transport phenomena has been developed and applied to produce practical numerical tables of the viscosity, thermal conductivity and diffusion coefficients of simple fluids: Ar, $\mathrm{Kr}, \mathrm{Xe}, \mathrm{N}_{2}, \mathrm{O}_{2}, \mathrm{~F}_{2}, \mathrm{He}, \mathrm{H}_{2}, \mathrm{CH}_{4}$. Recent work has extended this approach to ethane. It has been shown that a successful mixture program can emerge from combining the results for pure fluids with equation of state studies. The equation of state work is being carried out by other investigators in this laboratory.

7. Program and Results. A procedure to predict the transport properties of mixtures has been developed via corresponding states. (1) The method has been shown to be satisfactory. The program has been expanded by the addition of James C. Rainwater, a NBS/NRC Postdoctoral Research Fellow who will investigate the theoretical background. Progress has already been made in this direction. A paper reporting the transport properties of ethane has been submitted to the Journal of Physical and Chemical Reference Data for publication.

8. Problem Areas. The lack of suitable experimental mixture transport properties data for comparison purposes is the main problem. Also equation of state (PVT) data for mixtures are needed.

9. Funding. July 1 - December 31, 1976.

$\begin{array}{lll}\text { Allocation } & 60.0 \mathrm{~K} \$ & \text { OSRD } \\ \text { Labor } & 0.4 \mathrm{MY} & 22.8 \mathrm{~K} \$ \\ \text { Other Costs } & & 7.3 \mathrm{~K} \$ \\ \quad \text { Total } & & 30.1 \mathrm{~K} \$\end{array}$

10. Future Plans. The transport properties of propane and ethylene will be investigated. The corresponding states predictive procedure for mixtures will be expanded in line with the concurrent equation of state studies.

References

1. H. J. M. Hanley, Cryogenics 16, 643 (1976). 
1. Title. PROPERTIES OF CRYOGENIC FLUIDS

Principal Investigators. G. C. Straty, B. J. Ackerson, and D. E. Diller

2. Cost Center Number. 2750141

3. Sponsor Project Identification. NBS

4. Introduction. Accurate thermophysical properties data and predictive calculation methods for cryogenic fluids are needed to support advanced cryogenic technology projects. For example, liquefied natural gas is expected to supply an increasing percentage of the United States' energy requirements through 1990. Liquefaction plants, ships and receiving terminals are being constructed to transport and store natural gas in the liquid state (LNG). Accurate thermophysical properties data for LNG are needed to design low temperature processes and equipment. Accurate data will benefit the energy industries and the consumer by providing for safe and efficient operations and reduced costs.

5. Objectives or Goals. The objectives of this project are to provide comprehensive accurate thermodynamic, electromagnetic and transport properties data and calculation methods for technically important compressed and liquefied gases (hellum, hydrogen, oxygen, nitrogen, methane, ethane, etc.) at low temperatures. Precise compressibility, calorimetric and other physical property measurements will be performed to fill gaps and reconcile inconsistencies. Definitive interpolation functions, computer programs and tables will be prepared for engineering calculations. The immediate goals of this work are to obtain accurate sound velocity and thermal diffusivity data for compressed and liquefied gases by using laser light scattering spectroscopy techniques. Sound velocity data are useful for testing the consistency of volumetric, calorimetric and thermodynamic properties data, and are potentially useful for density gauging applications. Thermal diffusivity data are required for performing thermodynamic and heat transfer calculations.

6. Background. When light is incident on a perfectly homogeneous fluid, the reradiated (scattered) light field sums to zero in all but the exact forward direction. For a "real" fluid, however, fluctuations, arising through various mechanism, destroy the perfect homogeneity and results in the scattering of light in other directions as well. For example, thermally activated density fluctuations (phonons), propagating with the characteristic velocity of sound, give rise to scattered light which is Doppler shifted in frequency from the incident light frequency and whose spectrum contains information on the sound velocity and attenuation. Local non-propagating temperature fluctuations, which decay diffusively, give rise to scattered light in a narrow frequency band about the incident light frequency and whose spectrum contains information on the lifetime of the fluctuations (thermal diffusivity). Since the frequency shifts are generally very small, it was not until the advent of the lasers with their extremely well defined frequency, that practical experiments using these phenomena were possible.

The application of laser light scattering techniques to obtaining thermophysical properties data was initiated to complement and check other measurement methods and to solve measurement problems inherent in more conventional methods. For example, laser light scattering techniques permit measurements of sound velocities for fluids under conditions for which sound absorption is too large to perform ultrasonic measurements; laser light scattering techniques permit measurements of thermal diffusivities under conditions for which convection interferes with measurements of thermal conduction. The feasibility of light scattering experiments to obtain data on binary diffusion coefficients has also been demonstrated. 
Program and Results. An apparatus has been assembled for laser light scattering spectroscopy measurements on compressed and liquefied gases (76-300 K, $35 \mathrm{MPa})$. The apparatus consists of a high pressure optical cell, a cryostat refrigerated by means of liquid nitrogen, an argon ion laser and low-level light detection equipment.

The light scattered from fluctuations in the fluid can be analyzed with either digital autocorrelation techniques for the examination of the very narrow lines associated with scattering from temperature fluctuations (Rayleigh scattering) or with a scanned Fabry Perot interferometer for the measurement of the Doppler frequency shifts associated with the scattering from propagating density (pressure) fluctuations (Brillouin scattering).

Apparatus for photon-counting and digital autocorrelation has been assembled, interfaced with computer facilities and programmed to enable on-line data accumulation and analysis. Initial problems associated with signal modulations from excessive building vibrations have been solved by levitating the apparatus on an air suspension system. A small, highly stable capacitor has also been designed, constructed and installed inside the scattering cell to permit the dielectric constant of the scattering fluid to be determined, which should allow more accurate fluid densities to be obtained for use in the data analysis. Apparatus tests on well characterized, strongly scattering, test fluids have been made to verify data analysis programs.

Extensive thermal diffusivity data have been obtained for methane, primarily along the critical isochore, over the temperature interval of $190 \mathrm{~K}$ to $220 \mathrm{~K}$. Replicate measurements indicating accuracies approaching about 5 percent are now being achieved in this region. The range of measurements in the critical region is expected to be substantially increased with the use of the aforementioned capacitor method of density determination which will negate the necessity for measurements along an isochore (i.e., the critical isochore). Some measurements in regions more removed from the critical point have also been made.

8. Problem Areas. Light scattering has proven to be a valuable tool for obtaining thermal diffusivity data on fluids. This is particularly true in a broad temperature and density range around the critical point, where more conventional experimental methods fail or are severely limited. The intensity of the scattered light however decreases drastically as one moves away from the critical region. Data accuracy in this region becomes limited by the statistical nature of the scattering process and the ability to maintain stability and precise experimental parameters over the extended periods of time necessary for data accumlation.

We are currently investigating other experimental techniques, which could be used to complement the light scattering measurements, in order to provide sufficiently accurate data in regions where light scattering methods are expected to be unsatisfactory, and which could be used for mutual confirmation of data in the regions of overlap. Preliminary investigations have suggested that the recently refined(1) transient hot wire measurement method of thermal conductivity determinations may be well suited for measurements on fluids in the liquid state at low temperatures. This possibility is being investigated and considered further. 
9. Funding. July 1 - December 31, 1976
Man-years expended
0.5
Equipment and/or Services Purchased
$10.8 \mathrm{~K} \$$
Total Reporting Period Cost
$47.8 \mathrm{KS}$
Balance Remaining
$61.7 \mathrm{~K} \$$

10. Future Plans.

\begin{tabular}{l|l|l|} 
Objectives and Schedule: Quarter & \multicolumn{1}{|c}{1} \\
\hline $\begin{array}{l}\text { Measure, analyze and report } \\
\text { thermal diffusivity } \\
\text { coefficient data for } \\
\text { methane in the critical region. }\end{array}$ & & \\
\cline { 2 - 3 }
\end{tabular}

References

1. J. J. De Groot, J. Kestin and H. Sookiazian, Physica 75, 454 (1974). 
1. Title. PROPERTIES OF CRYOGENIC FLUID MIXTURES

Principal Investigators. M. J. Hiza, W. M. Haynes, A. J. Kidnay (parttime), and R. C. Miller (part-time).

2. Cost Center Numbers. 2750142, 2750145 and 2754574

3. Sponsor Project Identification. NBS, NBS (OSRD), AGA

4. Introduction. Accurate thermodynamic properties data and predictive calculation methods for mixtures of cryogenic fluids are needed to design and optimize low temperature processes and equipment. This project provides new experimental measurements on equilibrium properties and compilations of evaluated equilibrium properties data which are suitable for direct technological use or for the evaluation of predictive calculation methods.

5. Objectives or Goals. The overall objectives of this project are to provide critically evaluated data, original and from other sources, on the phase equilibria and thermodynamic properties of cryogenic fluid mixtures. The program has been divided into the following elements:

a) Preparation of a comprehensive bibliography on experimental measurements of equilibrium properties for mixtures of selected molecular species of principal interest in cryogenic technology.

b) Selection and/or development of methods for correlation, evaluation and prediction of equilibrium properties data.

c) Retrieval and evaluation of experimental data for specific mixture systems selected on the basis of theoretical and/or technological importance.

d) Preparation of guidelines for future research based on the deficiencies noted in (a), (b), and (c).

e) Performing experimental research to alleviate deficiencies and provide a basis for improvement of prediction methods.

6. Background. A physical equilibria of mixtures research project was established in the Cryogenics Division in 1959. The initial effort, based on a bibliographic search and other considerations, was directed toward the acquisition of new experimental data on the solid-vapor and liquid-vapor equilibria and physical adsorption properties for a limited number of binary and ternary mixtures of components with widely separated critical temperatures. Most of the systems studied included one of the light hydrocarbon species -- methane, ethane, or ethylene (ethene) -with one of the quantum gases -- helium, hydrogen, or neon. The data for these systems led to significant improvements in the predictions of physical adsorption equilibrium and a correlation for the prediction of deviations from the geometric mean rule for combining characteristic energy parameters. In addition, significant new information was obtained for interaction third virial coefficients which was used in a correlation by one of our consultants, J. M. Prausnitz. The approach taken in this work has been as fundamental as possible with the intention of having an impact on a broad range of mixture problems.

Recent efforts have been directed toward problems associated with systems containing components with overlapping liquid temperature ranges, such as the nitrogen + methane system. 
7. Program and Results. The recent progress is summarized as follows:

a) A paper reporting new liquid-vapor equilibria measurements for the methane + ethane and the methane + ethylene systems is in press in the Journal of Chemical Thermodynamics.

b) Data on the liquid-vapor equilibria, Henry's constants, excess Gibbs functions, liquid phase heats of mixing and excess volumes have been compiled, evaluated, and correlated for the methane + ethane system. A paper discussing this work is now in editorial review. When released, this paper will be submitted to the Journal of Physical and Chemical Reference Data.

c) An equation of state, recently proposed by Peng and Robinson, has been optimized to represent the phase equilibria data for the nitrogen + methane and methane + ethane systems. The optimized equation has now been used to generate the nitrogen + methane K-values and liquid and vapor equilibrium compositions for inclusion in the LNG Materials and Fluids Data Handbook.

d) An empirical excess volume model has been developed based on orthobaric liquid density measurements for the pure components and binary mixtures completed in the ING density project. This model has been tested on multicomponent ING mixtures data and appears to be a simple and reliable method for predicting LNG densities from 105 to $120 \mathrm{~K}$. A short paper discussing the development of this model is in preparation.

8. Problem Areas. None.

9. Funding. July 1 - December 31, 1976

Man-years expended

0.7

Equipment and/or Services Purchased

$1.2 \mathrm{~K} \$$

Total Reporting Period Cost

Balance Remaining

10. Future Plans.

Objectives and Schedule: Quarter

1

2

Evaluate, correlate and report

liquid-vapor equilibrium properties data for methaneethane mixtures.

Evaluate promising calculation methods for IVE and PVTx properties of methane-nitrogen mixtures.

Prepare and report graphs of liquid-vapor equilibrium properties data for methanenitrogen mixtures.

Analyze and report total vapor pressure data and orthobaric liquid densities for methaneethane mixtures.

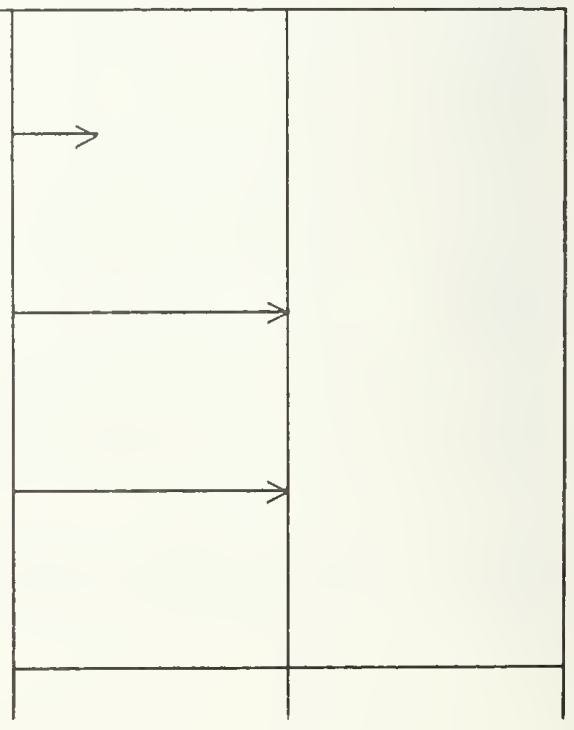


Prepare and performance test phase equilibria apparatus for total vapor pressure measurements of methaneisobutane mixtures.

\begin{tabular}{|l|l|}
\hline & \\
\hline & \\
\hline
\end{tabular}


1. Title. DENSITIES OF LIQUEFIED NATURAL GAS MIXTURES

Principal Investigators. M. J. Hiza, W. M. Haynes, R. D. McCarty and

W. R. Parrish

2. Cost Center Numbers. 2751574

3. Sponsor Project Identification. LNG Density Project steering Committee; American Gas Association, Inc., Project BR-50-11.

4. Introduction. Accurate density measurements and calculation methods for liquefied natural gas mixtures are needed to provide a basis for custody transfer agreements and for mass, density, and heating value gauging throughout the fuel gas industry.

The basis for the custody transfer of natural gas is its heating value. It is difficult to determine and agree on the heating value of extremely large volumes of natural gas in the liquid state. For example, methods for calculating the heating value of a liquefied natural gas mixture require knowing its density, which in turn depends on its composition, temperature, and pressure. As the compositions of LNG mixtures vary considerably, depending on the sources of the gas and the processing conditions, accurate methods are needed for calculating liquid densities at arbitrary compositions, temperatures and pressures. The accuracy is important because of the extremely large volumes of liquid involved.

5. Objectives or Goals. The objectives of this work are to perform accurate $(0.1 \%)$ and precise $(0.02 \%)$ measurements of the densities of saturated liquid methane, ethane, propane, butanes, nitrogen and their mixtures mainly in the temperature range 105-140 K, and to test and optimize methods for calculating the densities of LNG mixtures at arbitrary compositions and temperatures.

6. Background. This project is being carried out at NBS because of the realization that equitable custody transfer agreements could be reached more readily if the density measurements and the evaluation and development of calculation methods were performed by independent professionals of established reputation.

An apparatus incorporating a magnetic suspension technique has been developed for absolute density measurements on liquids and liquid mixtures, particularly at saturation, for temperatures between 90 and $300 \mathrm{~K}$. The estimated imprecision of measurement is less than $0.02 \%$ and the estimated inaccuracy is less than $0.1 \%$.

7. Program and Results.

7.1 Measurements. All measurements on pure flulds as well as binary and multicomponent mixtures have now been completed. Three papers have been prepared reporting the results of the pure component measurements. $(1,2,4)$ A paper on the binary mixture results is in the final stages of review. (3)

A paper on the multicomponent mixture results is in the final stages of preparation. In addition, two papers on the magnetic suspension densimeter have been published. $(4,5)$

7.2 Calculational Methods. Four promising methods of calculating the densities of liquid mixtures have been tested, modified and optimized utilizing the pure component and binary mixture data reported above. The four methods are a corresponding states method, a cell model, a hard-sphere model and a graphical method. Computer programs have been written for all four methods and these have been used to calculate densities for comparison with the data for the mixtures measured. The calculated results agree with the experimental data to within $0.1 \%$ for 
all multicomponent mixtures except those containing methane and butanes but no nitrogen. If nitrogen is present the inaccuracies reduce to $0.1 \%$ or less.

A report has been prepared on the calculational methods work and is currently in the review process. A summary report of the entire project is also in preparation and a two-part paper has been submitted to the LNG-5 Conference in Dusseldorf, Germany, August 1977.

8. Problem Areas. At this time, a definite answer cannot be given as to why there is an inconsistency between calculated and measured data for multicomponent mixtures containing butanes. Further work is being done on the calculational methods under another project (2750548). In addition, it is hoped that new measurements can be made at a later date on the butane-containing mixtures.

9. Funding. July 1 - December 31, 1976

$\underline{2751574}$ (measurements)

Man-years expended

Equipment and/or Services Purchased

0.3

Total Reporting Period Cost

$1.1 \mathrm{~K} \$$

Balance Remaining

$21.4 \mathrm{~K} \$$

$0.2 \mathrm{~K} \$$

$\underline{2752574}$ (calculation methods)

Man-years expended

0.1

Equipment and/or Services Purchased

$0.8 \mathrm{~K} \$$

Total Reporting Period Cost

$3.2 \mathrm{~K} \$$

Balance Remaining

$0.0 \mathrm{~K} \$$

10. Future Plans.

Objectives and Schedule: Quarter

1

2

Prepare multicomponent mixtures data paper.

Prepare project summary report.

Prepare paper for presentation at LNG-5 Conference.

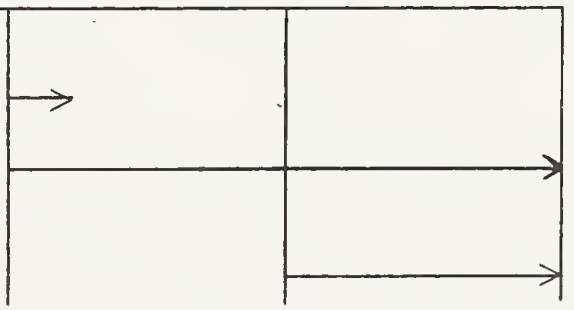

\section{References}

1. W. M. Haynes and M. J. Hiza, Orthobaric Liquid Densities of Normal Butane from 135 to $300 \mathrm{~K}$ as Determined with a Magnetic Suspension Densimeter, Advan. Cryog. Eng. 21, 516-21 (Plenum Press, New York, 1976).

2. W. M. Haynes and M. J. Hiza, Measurements of the Orthobaric Liquid Densities of Methane, Ethane, Propane, Isobutane, and Normal Butane, J. Chem. Thermodynamics (Feb 1977).

3. M. J. Hiza, W. M. Haynes and W. R. Parrish, Orthobaric Liquid Densities and Excess Volumes for Binary Mixtures of Low Molecular Weight Alkanes and Nitrogen Between 105 and $140 \mathrm{~K}$, J. Chem. Thermodynamics (to be submitted).

4. W. M. Haynes, M. J. Hiza and N. V. Frederick, Magnetic Suspension Densimeter for Measurements on Fluids of Cryogenic Interest, Rev. Sci. Instrum. 47, No. 10, 1237-50 (Oct 1976).

5. W. M. Haynes, A Simplified Magnetic Suspension Densimeter for Absolute Density Measurements, Rev. Sci. Instrum. 48, 39 (1977). 
1. Title. PROGRAM FOR REDUCING THE COST OF LNG SHIP HULL CONSTRUCTION -PHASE II SHIP STEEL IMPROVEMENT PROGRAM

Principal Investigators. H. I. McHenry, M. B. Kasen, and R. P. Reed

2. Cost Center Number.

2753430 - LNG Ship Hull Materials (Shipyard Contracts)

2751430 - LNG Ship Construction Materials (Metallurgical Evaluation)

2752430 - LNG Ship Hull Materials (Fracture Properties)

3. Sponsor Project Identification. Maritime Administration Misc. P. 0 . 400-58073.

4. Introduction. Construction of LNG tankers requires the use of fine grain normalized steels for the part of the hull structure that is cooled by the cargo to temperatures in the range of 0 to $-50^{\circ} \mathrm{F}$. Several ABS steels have satisfactory base plate properties but extreme care must be exercised during welding to avoid degradation of the steel adjacent to weld (the heat affected zone) to a level of toughness below U. S. coast Guard requirements. Significant cost problems are being encountered by U. S. shipyards due to the resulting inefficient low-heat-input welding procedures that must be employed to meet the fracture requirements in the heat affected zone.

The feasibility of reducing the cost of LNG ship hull construction was investigated in Phase I of this project, leading to the Phase II program described below.

5. Objective. The objectives of the Phase II program are 1) to have the four major plate producers supply three LNG shipyards with production heats of. ABS steels modified to possess improved transverse fracture properties at low temperatures, 2) to have the LNG shipyards evaluate these plates by qualifying optimum welding procedures in accordance with the USCG requirements, and 3) to provide a metallurgical evaluation of factors that influence heat affected zone toughness in the improved steels.

6. Background. Early in 1974, the Welding Panel of MarAd's Ship Production Committee recommended that a program be conducted to reduce the cost of ship hull construction. NBS was requested by MarAd to propose such a program to the LNG subcommittee of the Welding Panel at a meeting in Boulder in August. In mid-October, MarAd approved the initial phase of NBS's recommended program, i.e., to survey the problem and the technology available for its solution. On the basis of this survey and as the result of a meeting of the Welding Panel in March, 1975, a coordinatedprogram involving the LNG shipyards, the steel suppliers, and NBS was recommended to MarAd and to the Welding Panel. This program was approved and work started in May 1975. Cost-sharing contracts for the evaluation of the improved steels were awarded in 1975 to the three participating shipyards: Avondale Shipyards, Inc., Newport News Shipbuilding and Drydock Co. and General Dynamics-Quincy Shipbuilding Division.

7. Program and Results. Steel deliveries to the three LNG shipyards were completed in August 1976. The properties of the steels delivered in this reporting period are summarized below: 


\author{
Steel rrade \\ V-062 (low sulfur) \\ $\mathrm{V}-062$ (SSC)
}

ASTM A537A-Mod (SSC)
Steel Co.

Armco

Armco

Bethlehem

\section{Plate}

1/2-in-thick

1-in-thick

1/2-in-thick

1-in-thick

1/2-in-thick

1-in-thick

Each of the shipyards started the weld evaluation test program during this reporting period. A status meeting was held at Newport News Shipyard on November 3, 1976. The 17 attendees included representatives of four shipyards (Newport News, General Dynamics/Quincy, Avondale and Bethlehem Sparrows Point), four steel producers (Bethlehem, Armco, Lukens and U.S. Steel), ABS, MarAd and NBS. The initial results indicate that ABS grades $V-051, V-062$ and $C S$ are significantly improved by sulfide shape control and that this improvement is reflected in the Charpyimpact toughness of the heat affected zone (HAZ). In the case of ASTM A537A-Mod steel, the base plate properties are significantly improved, but the HAZ toughness at $-60^{\circ} \mathrm{F}$ is worse than the HAz toughness in conventional A537A-Mod.

A contract was signed with Lukens Steel Company to evaluate Cb-treated V-051 steel with and without sulfide shape control. Lukens will provide the steel and perform the weld evaluation. It was originally intended that a shipyard would conduct the weld evaluation, but the shipyards contacted did not want to participate on a cost-sharing basis.

8. Problem Areas. The A537A-Mod steel procured by General Dynamics for this program does not meet the requirements for $-60^{\circ} \mathrm{F}$ applications. It may be necessary to downgrade this steel to grade Cs for use to $-30^{\circ} \mathrm{F}$. The cost of downgrading is a potential program expense of nearly $\$ 6000$.

9. Funding. July 1 - December 31, 1976 .

\begin{tabular}{lcc} 
Cost Center & Cost to $12 / 31 / 76$ & \multicolumn{2}{c}{ Balance } \\
\cline { 2 - 3 } 2753430 & $144 \mathrm{K \$}$ & $19 \mathrm{~K} \$$ \\
2751430 & $61 \mathrm{~K} \$$ & $17 \mathrm{~K}$ \\
2752430 & $43 \mathrm{~K} \$$ & 17
\end{tabular}

10. Future Plans. The shipyard evaluation should be completed by June 30 , 1977 and work should start on the comparative testing program (Phase II of the Ship steel Improvement Program). 
1. Title. CUSTODY TRANSFER - LNG SHIPS

Principal Investigators. R. S. Collier and J. D. Siegwarth

2. Cost Center Number. 2750460

3. Sponsor Project Identification. Maritime Administration, Misc. P.O. \#400-58074, \#400-69012.

4. Introduction. In response to a request from the U.S. shipbuilding industry, NBS is conducting an independent design review of the shipboard custody transfer systems under the sponsorship of the Maritime Administration and in cooperation with the major U.S. shipbuilding companies.

5. Objectives. The objectives of this program are to 1) Identify the major technical areas relating to uncertainties in the measurement of total mass and total heating value, 2) Estimate uncertainties in the total mass and total heating value due to these identified factors, 3) Develop a proposed testing program for custody transfer system components, and 4) Investigate improved gauging techniques.

6. Background. Calendar year 1974 funding provided for the initial review of ships designated by MA Design LG8-S-102a MA Hulls 289, 290, 291. The current funding provides for an extension of this program to include ships of other designs which are being built by the major U.S. shipbuilding companies and also to verify tank survey and gauging methods for LNG custody transfer.

7. Program and Results. A. Working relationships with four major U. S. shipbuilders have been initiated. Most of the problem areas which are common to custody transfer systems of all types have been identified and are listed as follows:

1. Density
a) accuracy
b) rangeability
c) stability

2. Tank Strapping (Tank Surveys)

a) thermal effects

b) loading factors

c) measurement techniques

3. Convection (Non-Uniform Density)

a) density or composition stratification

b) possible isolation of measurement stillwells

4. Tank Weathering

a) time changes in composition, stratification, etc.

b) composition measurement

c) sampling

5. Liquid Level/Total Volume Measurement

6. Pressure and Temperature Measurements (gradients included).

7. Electronic Signal Conditioning, Data Reduction, Analysis and Readout 
B. Progress - The procedures for NBS involvement in evaluating the multiple station photogrammetry were established with representatives of the ship owners, the shipyard and tank fabrication facility, and the survey contractors. Considerations of production schedules and physical accessability to the inner tank surfaces have been reasonable constraints to NBS activity at the tank construction site.

Gauge rods were manufactured and two prototype rods were tested during an actual photogrammetric survey. As a result of this test only minor problems were encountered and it is felt the entire complement of ten gauge rods may be deployed during one of the next two surveys without interference with the survey procedure. Nominal length measurements were taken between targets on the ends of these rods and arrangements were made with the NBS Dimensional Metrology Section in Gaithersburg, MD for more precise measurements at the conclusion of the program.

At NBS' request, twelve extra targets were painted on the inner tank surface for use as redundant surface coordinate data. This is part of a program to determine whether as many as 100 extra targets per tank will be necessary or whether the present number of targets is sufficient. The extra targets will be used to evaluate the closeness of fit to a tank surface calculated from the original set of targets.

Surveys were obtained between targets located in the mid, and upper regions of the tank using a solid aluminum rod held to the tank surface with positive vacuum suction cups. These measurements were taken with the use of construction scaffolding in the later stages of tank construction. Surface temperatures were recorded.

Photographic plates were examined with an $x-y$ plotting microscope using equipment of the NBS Dimensional Metrology section. It was determined that the $3 \sigma$ uncertainty for an inexperienced operator to find the center of the target was approximately $2 \mu \mathrm{m}$; and with care could be improved by a factor of 2 to the order of 1 um. This corresponds in actual coordinate dimensions to well within the $\pm 1.2 \mathrm{~mm}$ for specifying the coordinate location. Of course, this is just one aspect of the coordinate determinations but probably the most important one.

Arrangements were made for obtaining the target coordinate data on computer cards in a form where programs for calculating the model for the tank surface may be utilized.

The program of $R F$ gauging was continued with measurement on a $35 \mathrm{ft}$ diameter aluminum ING container in cooperation with the Cincinnati Gas and Electric Company. This is part of a program to establish scaling laws between the resonance modes for extremely large tanks and their laboratory size models. (If these laws are obtained, calibration curves for the large tanks can be obtained from data taken on the models). The primary frequencies of the $35 \mathrm{ft}$ diameter tank were, within experimental error, exactly those calculated from measurements of the tank size. Extra modes were obtained which were thought to be due to guy wires stretched across the tank diameter; this was confirmed by similar rigging of the laboratory model. It appears now, at least for aluminum tanks, that the scaling laws for the empty tanks are completely predictable.

It also appears that $\mathrm{RF}$ resonance measurement may be useful in measuring some of the major dimensions of a large tank independently of other measurement methods. 
8. Problem Areas. A long baseline measurement in a horizontal direction is deemed necessary in order to minimize the estimated uncertainties in coordinate location. This may be difficult to do within the desired accuracy. Tape or wire measurements and microwave methods have been considered along with $\mathrm{RF}$ resonance methods.

9. Funding. July 1 - December 31, 1976

$\begin{array}{lc}\text { Man-years expended } & 0.5 \\ \text { Total Cost } & 36.7 \mathrm{K \$} \\ \text { Balance Remaining } & 4.0 \mathrm{~K} \$\end{array}$

10. Future Plans.

1. NBS will install a sufficient number of gauge rods on one of the next two photogrammetric surveys in order to complete the assessment of the photogrammetric technique to measure coordinate differences in the lower and upper portions of the tank.

2. We will continue to assess the ability of RF resonance measurements to give major dimensions of the empty tank and also to evaluate its potential as a method of gauging LNG.

3. We will continue to work with the shipbuilders to assess the effects of loading and stresses due to thermal contractions on the projected tank capacity.

4. Depending on the continued funding of this program, we will analyze the coordinate data as it comes from the photogrammetric procedure and evaluate results using independent data from the gauge rods and the redundant coordinates in order to complete the assessment of the empty tank survey accuracy. 
1. Title. HEATING VALUE OF FLOWING LNG

Principal Investigators. J. A. Brennan and J. M. Arvidson

2. Cost Center Number. 2756579

3. Sponsor Project Identification. Pipeline Research Committee (American Gas Association) PR-50-48.

4. Introduction. This project will test instrumentation for making heating value measurements in actual applications of flowing LNG. Information from projects currently underway by Younglove (cost center 2757574) on densimeters and by Haynes and Hiza (cost center 2751574) on mixture densities will be utilized where appropriate to provide state of the art information.

5. Objectives. The objective of this program is to measure total heating value of LNG flowing in a pipeline by the integration of individual measurements of flow, density and specific heating value. Flow measurement requires determination of flowmeter performance in line sizes larger than presently available calibration facilities. Therefore, a secondary objective is to establish appropriate flowmeter scaling laws.

6. Background. The LNG flow facility at NBS will be utilized to evaluate the response of the individual elements in the heating value measurement. Different compositions of LNG will be prepared to provide a range of densities and temperatures sufficient to determine any dependencies. A limited amount of sampling work is included to determine the relative importance of this parameter to the overall measurement.

Flowmeter scaling is being done utilizing the cryogenic and the water flow facilities at NBS and private LNG peak shaving facilities. This portion of the program is behind schedule because of scheduling problems at the private LNG facilities.

7. Results. A. Tests at NBS.

Three separate densitometer tests were run in liquid nitrogen on the NBS liquid nitrogen flow facility. The shift in performance referred to in the last report continued to occur each time the densitometer was thermally cycled between room temperature and liquid nitrogen temperature. There were seven such cycles during these nitrogen tests but the densitometer had been cycled many more times during tests on other instrumentation.

The magnitude of the densitometer performance shifts did decrease during the last series of tests and the shifts were bi-directional. This probably indicates the performance is stabilizing but not yet stable. No similar performance characteristics were detected in the first densitometer so nothing can be said about how typical this performance might be. The performance will continue to be closely monitored and additional data on other densitometers obtained whenever possible.

The densitometer was reinstalled in the LNG facility so that tests could be run on the integrated system. System integration was done by monitoring the individual elements of the measurement station with a mini-computer system and appropriate computations made to indicate heating value on a rate basis. Some problems were experienced in obtaining a suitable signal from the calorimeter but subsequent discussions with the manufacturer have indicated possible solutions. These solutions will be tried during the next test. In the interim,heating value measurements were entered into the computer manually. Since the heating value cannot change rapidly this procedure was not difficult to do for these tests, but it is not a satisfactory solution to the problem. 
Shortly after starting the tests some of the computer peripheral equipment started to malfunction. This problem finally resulted in the loss of the computer altogether, so the major purpose of the test could not be completed. The test was not terminated, however, since there was other information that could be obtained that would be useful in future tests.

of significant importance was the ability to get additional data on the densitometer. This was done by extending the test over several days and allowing the composition to change due to boil off from one day to the next. Density changes within the day were obtained primarily by changes in the LNG temperature. LNG density was calculated from an analysis of a sample withdrawn from the LNG. A check on the analysis was also made by calculating the heating value based on the analysis and comparing it with the heating value measured with the calorimeter.

Initially the comparisons between the two heating values were pretty good -- usually within the experimental error. As the LNG weathered, the comparisons became worse. The weathering observed in these tests was much worse than in any normal LNG facility because we were looking for wide variations in the compositions and density. Therefore, the discrepancies observed in the heating value may never occur in a normal LNG installation but are of sufficient importance to warrant further investigation.

Additional testing on the NBS LNG flow facility will be done in conjunction with some testing required on a LNG sampling project (cost center 2750575). In that way more timely control can be exercised since the gas analysis will be conducted on a more timely basis. During this series of tests the computer will also be used to integrate the signals from the individual components of the measurement system. The turbine flowmeter will be removed from the flow loop during these tests to facilitate the installation of the sampling probes required for the other project. This change will not affect the test on the measurement station since the turbine flowmeter is not used for that purpose.

Results of all the tests will be published in a separate report after the tests are completed.

B. Tests at Transco.

The new instrumentation on the gas phase flow measurements was installed at the Transco peak shaving facility in Carlstadt, NJ in october. This instrumentation includes measurements on orifice $\Delta \mathrm{P}$, line pressure, gas temperature, ambient temperature and elapsed time. Both a 16 inch and the 12 inch meter runs were instrumented. Recordings of these data will be on magnetic tape which will be returned to NBS for processing.

Recording of the data from the liquid flow measurements was expanded to include the data from the sonic flowmeter as well as the second sensor on the vortex shedding flowmeter. These data plus the output from the first sensor on the vortex shedding flowmeter, the liquid temperature and pressure and the elapsed time are also recorded on magnetic tape for processing at NBS.

Recording of the liquid and gas phase measurements are on separate recorders but they are synchronized so that each recording is started at the same time. Data is recorded on all measurements every ten seconds.

The system was checked out during vaporizer tests on December 1 and 2, 1976. Everything appeared to work normally during these tests and the preliminary data reduction looks good. Data will continue to be recorded during any send out for the remainder of the season and the results should be available for the next report.

C. Installation at Southern Energy.

A twelve inch vortex shedding flowmeter has been ordered for installation at the Southern Energy Company's Elba Island import terminal. This flowmeter will be installed between the storage tanks and the vaporizers and 
will measure the flow of LNG to the vaporizers. This measurement will be compared to the vaporized gas measurement in the same way that the measurements are compared at the Transco facility.

At the import terminal not only will data on a larger flowmeter be available but, in addition, much more data will be available. Since the import terminal will operate continuously, data will be available as required for as long as desired.

In addition to the flowmeter the installation at Southern will include a densitometer and temperature and pressure instrumentation. All of the instrumentation will be installed during the construction phase of the terminal and ready for use when the terminal becomes operational.

8. Problem Areas. None.

9. Funding. July 1 - December 31, 1976.

Man-years Expended

1.0

Total Reporting Period Costs

$86.0 \mathrm{~K} \$$

Balance Remaining

$40.0 \mathrm{~K} \$$

10. Future Plans. Additional component integration tests on the NBS LNG facility will be run in conjunction with tests on another LNG project. Flowmeter field tests at the peak shaving facility will continue whenever possible for the remainder of this send out season. Flowmeter installation at Southern Energy will be completed as soon as possible. 
1. Title. LNG DENSITY REFERENCE SYSTEM

Principal Investigators. Ben Younglove, John Arvidson and J. D. Siegwarth.

2. Cost Center Number. 2757574, 2750161

3. Sponsor Project Identification. American Gas Association, Inc., Project BR-50-10; National Bureau of Standards

4. Introduction. A density reference system has been developed to evaluate the ability of commercially available instruments to measure densities of LNG directly. Density is an essential measurement in determining the total energy content of natural gas reservoirs. This effort is oriented towards metrology, whereas the output from cost center 2751574 will provide basic reference data on pure liquids and mixtures, to evaluate methods for calculating the density indirectly.

5. Objectives. The objective of this research is to provide a system for evaluating the density measurement capability of commercially available meters. From the commercial meters we will attempt to select one or two capable of performance as transfer standards, in order to provide traceability of accuracy to field density measurement systems.

6. Background. The density reference system project was initiated in 1973. Since that time the reference system has been designed, constructed, and is now in operation, evaluating commercial density metering systems.

7. Program and Results. Additional methane density data were acquired and the provisional accuracy report for the LNG density reference system has been completed, reviewed and approved for publication as an NBSIR report. The accuracy of a future density measurement has been established as $+0.21 \%$. A second densimeter test has been planned for the same set of densimeters and most of the densimeters have been remounted, recalibrated by the vendor, readjusted or whatever else was required to obtain the best results. Modifications to the density reference system include: the crystal disconnect is now in the liquid so no mass and bouyancy corrections are required for the suspension, and the stirrer speed has been increased and the stirrer converted to turbine pump to shorten sample equilibrium time. The balance will be monitored in the future to ascertain that the measured weights lie within the balance range.

8. Problem Areas. The cause of the small occasion-to-occasion shift in density measurement has not been located yet. Perhaps the change in the crystal suspension arrangement will have eliminated this problem. Monitoring the absolute weight may help locate it.

9. Funding. July 1 - December 31, 1976

Man-years Expended

Total Project cost

0.2

$11.0 \mathrm{~K} \$$

10. Future Plans. The four commercial densimeters previously tested will be retested after the Archimedes type has been recalibrated and the vibrating plate type has been remounted to the cryostat. The readout parameter has been changed in the capacitance type. The results of this retest will be reported in the next period. 
1. Title. LNG SAMPLING MEASUREMENT STUDY

Principal Investigator. W. R. Parrish

2. Cost Center Number. 2750575

3. Sponsor Project Identification. LNG-Sampling Measurements Supervisory Committee.

4. Introduction. Composition is used to determine both the heating value and the quantity (through density) of LNG shipments. Thus, any error in composition doubles when calculating the total heating value and dollar value of a LNG tanker cargo. Compositions are determined by sampling LNG, on either a batch or continuous basis, and analyzing the vaporized mixture. Although several sampling techniques exist, none have received widespread acceptance in the LNG industry. Also, a standard technique has not been established for analyzing the vaporized sample.

5. Objectives or Goals. The objectives of this work are to evaluate existing sampling techniques appropriate to LNG systems and to recommend the most accurate analytical technique. Only sampling devices applicable to pipelines are being considered. The sampling techniques are judged on:

a) representativeness of sample,

b) insensitivity of results to composition, temperature, pressure, degree of liquid subcooling, flow rate and operator, and

c) simplicity.

Initial evaluations will be made in a laboratory-scale apparatus; final evaluation of the most promising sampling techniques will be performed in the LNG flow facility.

6. Background. This work is being performed at NBS because there is a need to determine the best means for obtaining the composition of LNG shipments. Current LNG buying contracts include specifications on when and how many liquid samples are to be taken but omit the sampling technique to be used. The evaluation of sampling techniques by impartial professionals will lead to the acceptance of the most accurate composition determination method by all parties involved in LNG custody transfer.

7. Program and Results. An evaluation of techniques for analyzing LNG type mixtures has been completed. Gas mixtures, prepared gravimetrically in this laboratory were analyzed by mass spectrometry (MS) and by gas chromatography (GC). The standard deviation in the heating values computed from the compositions obtained by MS ranged between 1.5 to 2 percent. By comparison the standard deviation in the heating values calculated from the GC analysis was 0.06 percent; the average error in computed heating values was 0.03 percent. The evaluation of the GC technique failed to show any composition, operator or day-to-day biases for mixtures comparable to Algerian LNG.

Construction of the laboratory apparatus was completed and two sampling probes, a pitot tube and a side tap, have been evaluated. Although the data have not been thoroughly evaluated, it appears that both probes can be used to collect a representative sample from a flowing LNG stream.

The apparatus is being modified to accommodate several different kinds of sample collecting and conditioning devices. Evaluation of these devices will begin shortly. We expect to begin evaluating the most promising sampling systems in the LNG flow facility in February 1977. 
8. Problem Areas. None.

9. Funding. July 1 - December 31, 1976.

Man-years expended

Total reporting period cost

0.8

Balance remaining

$60.0 \mathrm{~K} \$$

$27.0 \mathrm{~K} \$$

10. Future Plans.

Objectives and Schedule: Quarter 1

2

Evaluate sampling techniques in laboratory scale apparatus

Evaluate most promising sampling techniques in the LNG flow facility 
1. Title. SURVEY OF CURRENT LITERATURE ON LNG AND METHANE

Principal Investigator. Neil A. Olien

2. Cost Center Number. 2759574

3. Sponsor Project Identification. American Gas Association, Inc., Project BR-50-10.

4. Introduction. It is important that all NBS personnel working in LNG, as well as the AGA and others, keep up with what is going on throughout the world in the LNG field. This project is designed to provide the current Awareness and other information services to allow workers to keep abreast of new research and other developments.

5. Objectives or Goals. We will publish and distribute each April, July, October, and January a listing of all significant papers, reports, and patents relating to methane and LNG properties and technology. The references will be listed under convenient subject headings. The Quarterly will be distributed to all interested AGA member companies and be made available to the general public on a subscription basis. In addition, LNG related information will be entered into the Cryogenic Data Center's Information System for quick retrieval. A continuing awareness of the current publication scene is maintained for any new periodicals to be reviewed cover-to-cover. Finally we will update and make available comprehensive bibliographies on the properties and technology of LNG. There are three bibliographies involved: methane properties, methane mixtures properties, and processes and equipment involving methane and LNG. These three will be updated annually.

6. Background. In 1969 we made a thorough review of the world's publications to determine which periodicals and abstracting services should be scanned cover-to-cover to adequately encompass the LNG field. The result is that we now scan over 330 primary publications and nearly 25 secondary publications. Of these, approximately one-third are directly related to LNG. In addition, we have increased our coverage of the energy field to include hydrogen as a future fuel. Much of this information is also pertinent to LNG and as such is listed in our LNG-related publications. Our Current Awareness Service has been published weekly since 1964 (beginning in 1975 the publication became biweekly) and the Liquefied Natural Gas Survey has been published quarterly since 1970 .

7. Program and Results. Four issues of the LNG Quarterly are prepared each year and distributed. There are now 126 subscriptions going to AGA Member Companies and 163 to other subscribers.

The three comprehensive bibliographies mentioned in section 5 have been reviewed and shortened, and more selective bibliographies have resulted. The latest versions were completed as of January 1, 1976.

B-1371 THE THERMOPHYSICAL PROPERTIES OF METHANE AND DEUTERO-METHANE IN THE SOLID, LIQUID AND GASEOUS PHASES - A SELECTED BIBLIOGRAPHY. Indexed by property, phase and author, 80 pages (Jan 1976). (\$8.00).

B-1372 THE THERMOPHYSICAL PROPERTIES OF METHANE MIXTURES - A SELECTED BIBLIOGRAPHY. Indexed by property, system and author, 140 pages (Jan 1976). (\$10.00).

B-1264 PROCESSES AND EQUIPMENT INVOLVING LIQUEFIED NATURAL GAS AND METHANE - A SELECTED BIBLIOGRAPHY. Indexed by subject and author, 76 pages (Feb 1975). $(\$ 8.00)$. 
B-1367 Supplement to B-1264, indexed by subject and author, 40 pages (Jan 1976). (\$5.00).

Over the past five years we have distributed over 430 copies of these and the comprehensive bibliographies. A bibliography on LNG Patents was supplied to AGA in May, 1975. Two supplements to this were also completed, one in July 1975 and one in January 1976.

8. Problem Areas. None.

9. Funding. July 1 - December 31, 1976.

$\begin{array}{cc}\text { Labor } & 5.5 \mathrm{~K} \$ \\ \text { Other Costs } & \frac{1.4 \mathrm{~K} \$}{6.9 \mathrm{~K} \$} \\ \text { Total } & 1.2 \mathrm{~K} \$\end{array}$

10. Future Plans. Issue 76-4 was delivered to the printer on January 7 , 1977. In January 1977 we will update the three LNG bibliographies mentioned above (B-1371, B-1372, B-1367). In addition we will prepare a new bibliography on LNG related patents which will replace the one prepared in May 1976 as well as the two supplements. 
1. Title. LIQUEFIED NATURAL GAS TECHNOLOGY TRANSFER

Principal Investigator. D. B. Mann

2. Cost Centers. 2750403,2751403,2752403,2750570,2754574 and 2758574.

3. Sponsor Project Identification. Maritime Administration Miscellaneous Purchase Order No. 400-69012; American Gas Association, Inc. Project BR 50-10; American Bureau of Shipping, letter dated 21 November 1975 .

4. Introduction. The liquefied natural gas program at the Cryogenics Division of NBS-IBS/Boulder represents an investment by industry and Government agencies of over $\$ 5$ million over the past six years. This investment was designed to develop reference quality properties data for both fluids and materials, instrumentation and measurement technology for the use of the LNG and related industries. Information developed under this program must be transmitted to the ultimate user in a timely and useful format. The classical publication methods of NBS most certainly provide the scientist and research engineer information in a form most useful to the academic or near academic community. However, as a result of extensive assessments of user requirements, it was found that an additional effective mode for technology transfer would be an LNG Materials and Fluids Data Book. A complete outline and planned table of contents has appeared in previous semi-annual reports. The Maritime Administration of the Department of Commerce and the American Bureau of Shipping have agreed to sponsor the first year's efforts on the materials section and the American Gas Association. Inc. has agreed to sponsor the section on fluids and fluid mixtures. The project was begun on April 1 , 1976.

5. Objectives. The Liquefied Natural Gas Materials and Fluids Data Book will provide a method of quick dissemination of property data and related information for the effective generation, utilization and transportation of LNG. The object is to improve technology transfer from the current NBS Cryogenics Division LNG physical measurements program to the users, including federal agencies, the states and industry. For the purpose of this data book, liquefied natural gas is defined as a cryogenic mixture (at less than approximately $150 \mathrm{~K}$ ) of hydrocarbons, predominantly methane, with less than a total of $20 \%$ of the minor components ethane, propane, iso and normal butane, and nitrogen as an inert contaminant. LNG materials will be those associated with the liquefaction, transport and storage of liquefied natural gas.

6. Background. The Data Book is only one of a number of information dissemination methods used to provide workers in the liquefied natural gas (LNG) industry with properties data of known quality in a format consistent with the requirements of the intended user. In the case of the LNG Data Book, the intended audience is the field engineer, plant manager, ship designer or process engineer interested in a ready reference of assessed quality for data to be used in conceptual design, process monitoring, process analysis, and intercomparisons where precision and accuracy are secondary to specific problem solutions. The hierarchy of accuracy and precision will be defined and traceable through reference to scientific and engineering literature.

Data is classified into three groups by the NBS Cryogenics Division.

Group 1. Data which has been generated experimentally by NBS or has been assessed, evaluated or experimentally verified by NBS.

Group 2. Data which has been assessed and evaluated by NBS. 
Group 3. Data available in the scientific engineering literature through the NBS Cryogenic Data Center or elsewhere. No NBS evaluation or assessment has been made at this date.

In general, all data included in the LNG Data Book will be from groups 1 and 2. No new assessments or correlations are anticipated or required for this work.

Data will be presented primarily in graphical form. Tables and analytical expressions will be used only where absolutely necessary. Graphs and charts will be in loose-leaf form for ease of updating and additions. This form will also allow immediate implementation for data already available under the NBS LNG program and will provide a convenient form for the output of data from existing projects. The data book will not be a substitute for traditional publications in the scientific literature where measurement science, technique, precision and accuracy are paramount, but will provide the data and references for the necessary assessment by the user.

The publication of both graphical and tabular data will be in a dual system of physical units. These units will be the traditional LNG industry British system of BTU, pound, degree Fahrenheit and the SI system of joule, kilogram and kelvin. It is the intent to give equal weight to each system of units.

Nine structural metals have been selected with additions possible upon consultation with the sponsors. Primary emphasis in the liquid section will be data on pure methane, pure nitrogen, and methane-nitrogen mixtures.

7. Program and Results. A three-post expandable post binder and special graphics have been selected, purchased and delivered. Over $80 \%$ of the graphic material has been completed, which includes three of the six wall size multi-property diagrams on nitrogen and methane.

8. Problem Areas. None.

9. Funding. July 1 - December 31, 1976.

Labor - Man years expended

Funds expended

Balance remaining
1.0

$77.0 \mathrm{K \$}$

$43.0 \mathrm{K \$}$

10. Future Plans. The first edition of the Data Book should be completed and distributed by April with the first printing of 750 copies. A second edition of the Data Book or an extended supplement seems to be assured by the anticipated continuing support of existing sponsors and the addition in sponsorship by the NBS Office of Standard Reference Data. Supplementary data will include properties on non-structural materials, insulations, pure ethane and mixtures of methane, nitrogen and ethane. 
1. Title. OIML JOINT SECRETARIAT ON LNG MEASUREMENTS

Principal Investigator. Douglas Mann

2. Cost Center Number. 2750104

3. Sponsor Project Identification. American Gas Association, Inc.; NBS-Office of International Standards; and NBS-Cryogenics Division.

4. Introduction. The liquefied natural gas program of the National Bureau of Standards Cryogenics Division has, over the past five years, provided the gas industry and interested Government agencies with properties data on materials and fluids, instrumentation, and measurement assistance in the support of commerce in this significant and growing segment of the supplementary fossil energy supply. Support of this program by the American Gas Association, Inc. and Federal Government agencies such as the Maritime Administration (MarAd), NASA, GSA, Federal Power Commission and the NBS-Office of Standard Reference Data has provided a basis for the national acceptance of the results of the NBS LNG program. Through the U.S. membership in the International Organization of Legal Metrology there exists, at the present time, an opportunity to extend, internationally, the utility of data and measurement practice developed under our joint Government/industry program. We have been requested (by OIML membership) to establish an LNG Measurement secretariat within OIML which, if implemented, would provide a significant international forum for the results of our joint work. It is believed that a joint secretariat with the LNG industry would provide the most effective means of accomplishing these objectives.

5. Objectives or Goals. Our objective is to accomplish the following goals within the next three years.

a) To establish U.S. (NBS) thermophysical properties data for LNG as the standard data in international usage.

b) To establish U.S. (NBS) materials property data used in fabrication and construction of LNG facilities (liquefiers, storage, transport) as the standard data in international usage.

c) To establish U.S. (NBS) approved measurement technology and instrumentation as related to LNG (pressure, temperature, density, liquid level, flow) as the standard in international LNG trade. The precedent has been established with the successful completion of the joint NBS-CGA cryogenic flow measurement program which has resulted in the adoption of a cryogenic flow measurement code by the National conference on weights and Measures. We wish to extend this code on an international basis.

d) To establish and maintain the leadership of U.S. science, engineering, and industry in the research, technology, manufacture and marketing of instruments and measurement systems for liquefied natural gas.

6. Background. OIML was founded in 1955 to promote intergovernmental cooperation in the field of legal metrology which relates to the compatibility of standards of measurement and the legislation and government regulations which may affect such standards of measurement. OIML recommends uniform international requirements for scientific and measurement instruments used in industry and commerce and works out model laws and regulations for consideration by member nations; and, in addition, serves as a center of documentation and information exchange in legal metrology. At present 43 nations are members of this intergovernmental organization.

The United states joined OIML in 1972 (the senate by resolution of August 11, 1972 gave its advice and consent to the accession of the U.S. to the convention establishing OIML). The responsibility for managing U.S. participation in OIML was assigned to the Department of Commerce 
and has since been delegated by the Department to the National Bureau of Standards (NBS). Under the general guidance of the Department of state and the secretary of Commerce, NBS is directly responsible for formulating and implementing U.S. policy towards OIML. U. S. participation in the organization is deemed important for two reasons: First, to protect and enhance some $\$ 1$ billion worth of scientific and measurement instruments exported each year by U. S. firms and to insure equity in the trade of commodities measured by these instruments; and second, to maintain the U.S. as the world leader in the field of metrology.

In the spring of 1975 at a meeting in Paris of the International committee of Legal Metrology, the French and U.S. representatives discussed the possibility of creating a new Reporting Secretariat No. 13 on "Liquefied Natural Gas (LNG) Measurement." The U. S. representative, W. E. Andrus, Jr. of NBS, agreed to explore the possibility with U. S. industry and interested government agencies. These discussions resulted in a decision to propose a joint Secretariat with the American Gas Association and NBS-Cryogenics Division in order to best accomplish the tasks. These conclusions were reached during several meetings extending through the latter part of 1975 and early 1976.

7. Program and Results. The final organizational meeting was held at NBS Boulder in August 1976 attended by representatives of the American Gas Association, the American Petroleum Institute and the NBS Office of International Standards Program. At this meeting $\mathrm{Mr}$. Lee Hillburn, an employee of the Phillips Petroleum Company was selected as the A.G.A. co-technical advisor for the secretariat on LNG Measurements. Mr. Douglas Mann has been designated as the NBS co-technical advisor.

Mr. D. E. Edgerly, NBS Special Assistant for International Standards Program, indicated that the secretariat for LNG Measurements will be proposed to the International Committee in October and will be assigned to the Pilot Secretariat No. 5 "Measurements of Volumes of Liquids." The Pilot secretariat has not been assigned to a country but currently the U.S., West Germany and France are involved in assuming this Secretariat.

The first task of the Working Secretariat on LNG Measurements will be to provide a definition of the scope of the secretariat on LNG Measurements. consideration will be given to both static and dynamic measurement methods.

8. Problem Areas. None.

9. Funding. July 1 - December 31, 1976.

Labor - Man years expended

Funds expended

Balance remaining

0.1

$11.0 \mathrm{KS}$

$22.0 \mathrm{~K} \$$

10. Future Plans. A draft scope for the LNG Measurements Secretariat will be generated and circulated to interested industry and government agencies prior to submission to the NBS Office of International standards. 
1. Title. FEDERAL POWER COMMISSION CONSULTATION

Principal Investigators. D. B. Chelton, T. R. Strobridge and A. F. Schmidt.

2. Cost Center Number. 2750404

3. Sponsor. Federal Power Commission - Bureau of Natural Gas -- letter agreement dated 4 June 1973.

4. Goals. The Cryogenics Division will provide consultation and advisory services to the Federal Power Commission on the cryogenic safety and the design aspects of current applications before the FPC for authorization of LNG terminal and storage facilities. These services cover properties of cryogenic environments, insulation systems, cryogenic safety, thermodynamics, heat transfer, instrumentation, and cryogenic processes such as refrigeration and liquefaction.

5. Background. Cost Center initiated July 7, 1973.

6. Program and Results. The status of those facilities presently under the jurisdiction of the Federal Power Commission and subject to our review are outlined in the following table.

Elements of the facilities that are subject to review are the land-based cryogenic storage tank components, bounded by the tanker or barge, the inlet and distribution pipelines. These include, but are not limited to the transfer lines, the storage tanks, the vaporizers and the process piping as it interacts with the storage tanks. It is essential that the reviews cover the operation, maintenance and emergency procedural

philosophies for each terminal. Based upon these studies, reports are submitted to the staff of the FPC setting forth the technical evaluations and conclusions on each proposal.

Emphasis is placed on the safety aspects of the facilities including their possible interactions with the surrounding areas. The impact of engineering design such as appropriate use of existing technology and material selection for structural integrity must be assessed. The basis of review includes vartous codes and standards, prior experience, precedent and engineering knowledge. Vapor cloud generation and plume dispersion is considered a subject beyond our area of expertise.

7. Funding.

$$
\begin{array}{lr}
\text { June } 30 \text { - December 31, } 1976 & 40 \mathrm{~K} \$ \\
\text { Anticipated Man-years of Effort FY } 77 & 0.8 \\
\text { FY } 77 & 50 \mathrm{~K} \$
\end{array}
$$

3. Future Plans. At the present time there are several pending applications, but detailed information is not yet available. It is anticipated that additional facilities will be reviewed as applications are made to the Federal Power Commission. 


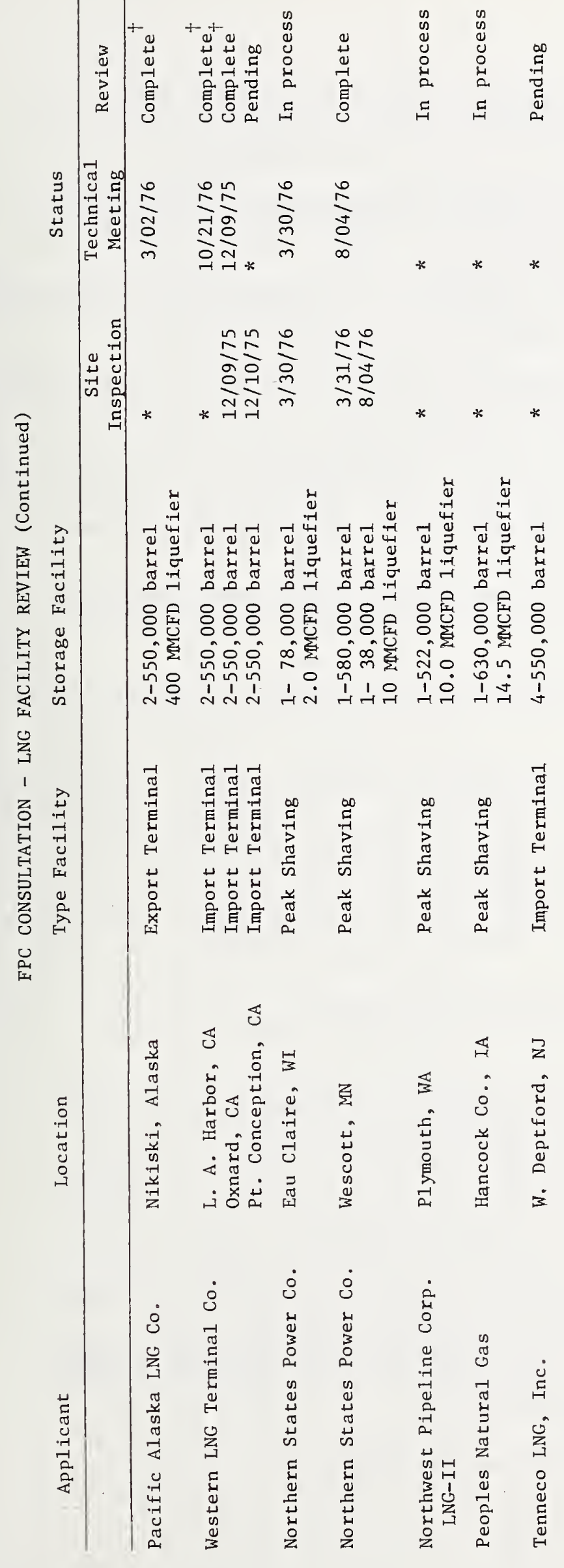


NBS Reports and Publications Related to LNG Technology

1. Goodwin, R.D., "An equation of state for thermodynamic properties of fluids," Proceedings, Fifth International CODATA Conference, University of Colorado, June 28-July 1, 1976.

2. Goodwin, R.D., Roder, H.M., and Straty, G.C., "Thermophysical properties of ethane from 90 to $600 \mathrm{~K}$ at pressures to 700 bar," NBS Technical Note 684 (August 1976).

3. * Straty, G.C., and Tsumura, R., "Phase transition and melting pressures of solid ethane," J. Chem. Phys. 64, 859 (1976).

4. * Straty, G.C., and Tsumura, R., "PVT and vapor pressure measurements on ethane," J. Res. Natl. Bur. Stds. B0A, 35 (1976).

5. Tsumura, R., and Straty G.C., "Speed of sound in saturated and compressed fluid ethane," Cryogenics (in press, 1977).

6. "Weber, L.A., "Dielectric constant and the derived Clausius-Mossotti function for compressed gaseous and liquid ethane," J. Chem. Phys. 65, 446 (1976).

7. * Roder, H.M., "The heats of transition of solid ethane," J. Chem. Phys. 65, 1371 (1976).

8. * Roder, H.M., "Measurements of the specific heats, $C_{\sigma}$ and $C$, of dense gaseous and liquid ethane," J. Res. Natl. Bur. Stds. 80A, 739 (1976).

9. Roder, H.M., "The PVT surface of simple liquids at densities near melting," Proceedings of the Fifth International CODATA Conference, University of Colorado, June 28-July 1, 1976.

10. Diller, D.E., "Thermophysical properties data research on compressed and liquefied gases at the NBS Cryogenics Division," Advan. Cryog. Eng. 21, 522 (1976).

11. *Diller, D.E., "LNG densities for custody transfer," Proceedings, International School for Hydrocarbon Measurement, University of Oklahoma, April 12-14, 1977.

12. Haynes, W.M., and Hiza, M.J., "Orthobaric liquid densities of normal butane from 135 to $300 \mathrm{~K}$ as determined with a magnetic suspension densimeter," Advan. Cryog. Eng. 21, 516 (1976).

13. *Haynes, W.M., Hiza, M.J., and Frederick, N.V., "Magnetic suspension densimeter for measurements on fluids of cryogenic interest," Rev. Sci. Instrum. 47, 1237 (1976).

14. *Haynes, W.M., "A simplified magnetic suspension densimeter for absolute density measurements," Rev. Sci. Instrum. 48, 39 (1977).

15. "Haynes, W.M., and Hiza, M.J., "Measurements of the orthobaric Iiquid densities of methane, ethane, propane, isobutane and normal butane," J. Chem. Thermodynamics (in press, 1977).

* See attached reprints or preprints in appendices. 
16. Hiza, M.J., Haynes, W.M., and Parrish, W.R., "Orthobaric liquid densities and excess volumes for binary mixtures of low molecular weight alkanes and nitrogen between 105 and $140 \mathrm{~K}, " \mathrm{~J}$. Chem. Thermodynamics (submitted 1977).

17. Parrish, W.R., and Hiza, M.J., "On the consistency of liquid-vapor equilibria data for binary mixtures of methane with the light paraffin hydrocarbons," Adv. Cryog. Eng. 21, 485 (1976).

18. Miller, R.C., Kidnay, A.J., and Hiza, M.J., "Liquid + vapor equilibria in the methane + ethene and methane + ethane systems from 150 to 190 $\mathrm{K}, " \mathrm{~J}$. Chem. Thermodynamics (in press, 1977).

19. "Hanley, H.J.M., Haynes, W.M., and McCarty, R.D., "The viscosity and thermal conductivity coefficients for dense gaseous and liquid methane," J. Phys. Chem. Ref. Data (in press, 1977).

20. Hanley, H.J.M., Gubbins, K.E., and Murad, S., " A correlation of the existing viscosity and thermal conductivity coefficients of gaseous and liquid ethane," J. Phys. Chem. Ref. Data (in press, 1977).

21. Hanley, H.J.M., and Cohen, E.G.D., "Analysis of the transport coefficients of simple dense fluids: the diffusion and bulk viscosity coefficients," Physica 83A, 215 (1976).

22. Hanley, H.J.M., Sengers, J.V., and Ely, J.F., "On estimating thermal conductivity coefficients in the critical region of gases," Thermal Conductivity 14, Proc. 14th Int. Conf., Storrs, Conn. June 2-4, 1975, (Plenum Press, New York, 1976).

23. *Hanley, H.J.M., "Prediction of the viscosity and thermal conductivity coefficients of mixtures," Cryogenics 16, 643 (1976).

24. *Tobler, R.L., and Reed, R.P., "Fracture mechanics parameters for a 5083-0 aluminum alloy at low temperatures," Journal of Materials for Engineering and Technology (submitted, 1977).

25. *McHenry, H.I., "Ship steel weldments for low temperature service," Welding Journal 55, 387 (1976).

26. McHenry, H.I., and Reed, R.P., "Fracture behavior of the heat affected zone in $5 \% \mathrm{Ni}$ steel weldments," Welding Journal (in press, 1977).

27. McHenry, R.I., "Fracture mechanics and its application to cryogenic structures," Advances in Cryogenic Engineering, 22, (in press, 1977).

28. Clark, A.F., Haynes, W.M., Deason, V.A., and Trapani, R.J., "Low temperature thermal expansion of barium ferrite." Cryogenics 16, 267 (1976).

29. "Younglove, B.A., and Siegwarth, J.D., "Cryogenic fluids density reference system: provisional accuracy statement," NBSIR 77-852 (January 1977).

30. *Mann, D. B., "What's new in LNG measurement and instrumentation" Pipeline Industry 45,21 (1976). 

APPENDICES

A through 0 



\author{
G. C. Straty and R. Tsumura ${ }^{\dagger}$
}

\begin{abstract}
National Bureau of Standards, Institute for Basic Standards, Cryogenics Division, Boulder, Colorado 80302 (Received 29 September 1975)

The melting pressures of ethane at 14 temperatures from near the triple point to $95.50 \mathrm{~K}$ and pressures to $32.0 \mathrm{MPa}$ are reported. A triple point temperature of $90.348 \pm 0.005 \mathrm{~K}$ is obtained from the data which is in agreement with the determination of Clusius and Weigand (1940) but in substantial disagreement with other determinations. Qualitative evidence has been obtained which indicates the existence of a previously unrecognized solid phase transition along a boundary roughly parallel to the melting line at a temperature about $0.5 \mathrm{~K}$ below the melting temperature, suggesting that some previous melting point determinations may have been influenced by a misinterpretation of the effects of this transition.
\end{abstract}

\section{INTRODUCTION}

Although a number of melting point determinations have been reported for ethane, ${ }^{1-4}$ there still exists considerable disagreement on the correct triple-point temperature. Furthermore, no accurate data for the melting pressures above about $4.3 \mathrm{MPa}$ exist. Clusius and Weigand $^{1}$ in 1940 reported the measurement of the melting line of ethane to a maximum pressure of $4.27 \mathrm{MPa}$ and obtained a triple-point temperature of $90.35 \mathrm{~K}$. Other determinations of the melting temperature, ${ }^{2-4}$ however, yielded values in the vicinity of $89.9 \mathrm{~K}$.

In this paper we report new measurements of the melting pressures of ethane at 14 different temperatures to a maximum pressure of $32.8 \mathrm{MPa}$ at $95.5 \mathrm{~K}$. The data have been represented by a Simon equation which has been used to obtain the triple-point temperature of $90.348 \pm 0.005 \mathrm{~K}$ in excellent agreement with the earlier data of Clusius and Weigand. ${ }^{1}$ Qualitative evidence has been obtained which indicates the existence of a solidphase transition along a $(P, T)$ boundary roughly parallel to the melting line at a temperature about $0.5 \mathrm{~K}$ below the melting temperature, suggesting that some previous determinations of the melting point may have been influenced by a misinterpretation of the effects of this transition.

\section{EXPERIMENTAL PROCEDURES}

The ethane used in these experiments was commercially available research grade with minimum purity certified by the supplier at $99.98 \%$. This purity was verified by chromatographic analysis. Temperatures were measured with a platinum resistance thermometer calibrated by the National Bureau of Standards on the IPTS-1968. Pressures were determined by referencing, through differential pressure transducers, to oil pressures derived from a precision oil dead-weight gauge accurate to within the greater of $500 \mathrm{~Pa}$ or $0.015 \%$. The apparatus and instrumentation was similar to that used previously in this laboratory $y^{5}$ with small modifications to be discussed.

Measurements of the pressure as a function of temperature along the melting line of other fluids such as $\mathrm{H}_{2}, \mathrm{O}_{2}, \mathrm{~F}_{2}$, and $\mathrm{CH}_{4}{ }^{\mathrm{b}-\theta}$ have been performed routinely in this laboratory as part of programs to accurately characterize technically important cryogenic fluids. For such measurements, it has only been necessary to fill the cell with compressed liquid to the maximum pressure, at a temperature slightly above the freezing temperature corresponding to that pressure, and to then measure the pressure as the temperature is reduced. The slope of the pressure-temperature locus changes dramatically as the liquid begins to freeze indicating that the two-phase condition exists in the cell. Measurements along the freezing line can then be made. The normal temperature gradient along the filling capillary and the small solid fraction in the cell during these measurements have been sufficient to prevent solid from plugging the capillary. Furthermore, upon solidification there is usually a sufficient change in density so that the solid-liquid boundary can be traversed over a considerable pressure range from near the filling pressure to low pressures near the triple point.

Initial attempts to use these procedures for ethane were unsuccessful because of experimental difficulties associated with the somewhat unusual properties of ethane. In attempting to obtain samples in the two-phase region by filling at higher pressures and cooling to the melting line, considerable subcooling was observed before the onset of freezing. When freezing began, a solid plug would apparently form in the filling capillary, isolating the pressure measurement system from the cell. To remedy this, the capillary was brought into the cell through a reentrant cavity machined into the stainless steel cell closure and was provided with a heater. In this configuration, a considerable temperature difference could be maintained between the massive copper cell body and the filling capillary.

Several attempts were made to obtain data with this modification. The samples were prepared by filling at moderate pressure, cooling to well below the expected triple point to ensure solidification and then taking data while warming. Data obtained in this way clustered about a line as indicated by $\bullet$ in Fig. 1. These data suggested a triple point temperature of about 89.9 $\mathrm{K}$, consistent with some earlier determinations, ${ }^{2-4}$ and were initially interpreted incorrectly as representing the melting line. Attempts to make measurements above about $4 \mathrm{MPa}$ by warming were found to be impossible, however, since this pressure corresponds to the vapor pressure of ethane at the ambient laboratory temperature and when this pressure was exceeded, considerable mass transfer out of the cell was associated with the condensation of liquid into the external portions 


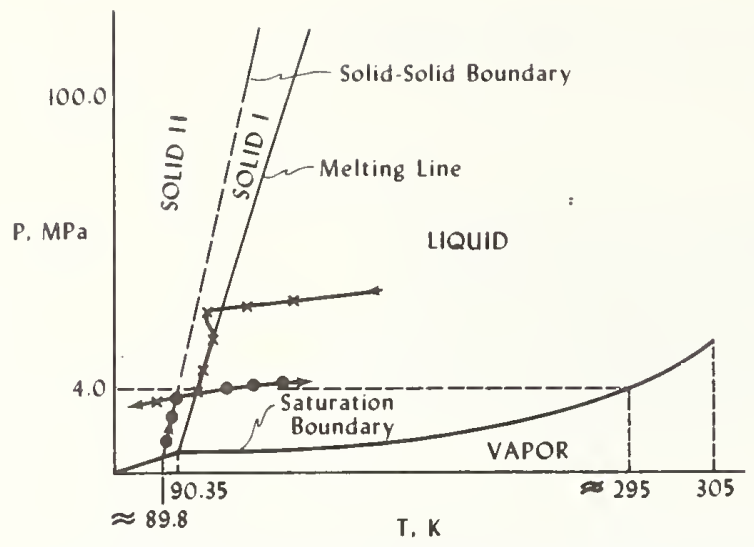

FIG. 1. Schematic phase diagram in the $P T$ plane for ethane. The solld-solid boundary above $100.0 \mathrm{MPa}$ was observed by Webster and Hoch (Ref. 11). The solld-solld boundary below 4. $0 \mathrm{MPa}$ from this work. Path of typlcal data before apparatus modifications: - data obtained by warming, $\mathrm{X}$ data obtained by cooling. For a more complete explanation, see text.

of the system. Attempts to obtain data by cooling from high pressure and temperature were also unsatisfactory since the data then clustered about a second curve indicated in Fig. 1 by $X$. In either case, it was impossible to cross the pressure of about $4.0 \mathrm{MPa}$ because of the mass transfer problem. Both sets of measurements were also unsatisfactory because of large scatter and lack of adequate reproducibility. The indications of what appeared to be segments of two separate melting curves were also difficult to explain at first.

The behavior was, however, understood upon closer examination. For measurements below the pressure of $4.0 \mathrm{MPa}$, almost all of the ethane in the system resided in the cell, resulting in a sample almost entirely in the solid phase. Heat applied to the capillary was sufficient to ensure that pressure communication with the cell was always maintained, and the data obtained were, in fact, a manifestation of a solid transition along a boundary $(\bullet$ Fig. 1) roughly parallel to the true melting curve but about $0.5 \mathrm{~K}$ lower. The higher pres- sure line (X, Fig. 1) traversed a portion of the true melting line. The lack of reproducibility and large scatter were found to be associated with large cell temperature gradients imposed by an unnecessarily high power input to the capillary heater.

To verify this interpretation of the results, additional modification to the apparatus was made. The cell volume was increased to over $50 \mathrm{~cm}^{3}$ while the volume of the external portions of the system were minimized to less than $1 \mathrm{~cm}^{3}$. In addition, these external portions were heated to about $330 \mathrm{~K}$, well above the ethane critical temperatures of $305 \mathrm{~K}$.

With these modifications it was then found possible to fill the cell with liquid at the highest pressure of interest, to cool sufficiently to initiate solidification, and to then traverse the melting line in either direction without encountering the difficulty at $4 \mathrm{MPa}$ as found previously. Under these conditions, the solid fraction in the cell was always small. The heat input to the capillary necessary to prevent plugging was also found to be very small or zero, consistent with the experience with other fluids. Data were highly reproducible with minimum scatter, and were found to coincide roughly with the high pressure portion of the curve observed previously and its extension to lower pressures.

\section{THE MELTING LINE}

The results of the melting line measurements were fitted to the Simon melting pressure equation,

$$
P=P_{t}+P_{0}\left[\left(T / T_{t}\right)^{6}-1\right],
$$

where the subscript $t$ refers to the triple point, and $P$ and $T$ are the pressure and temperature. The value of $P_{t}=1.2 \mathrm{~Pa}$ was taken from a vapor pressure correlation for ethane by Goodwin ${ }^{10}$ at the triple point temperature of $90.35 \mathrm{~K}$. The parameters ylelding the best fit were the following:

$$
\begin{aligned}
& P_{t}=1.2 \mathrm{~Pa} \text { (Ref, 10), } \\
& P_{0}=255.97 \mathrm{MPa}, \\
& T_{t}=90.348 \mathrm{~K}, \\
& \epsilon=2.179 .
\end{aligned}
$$

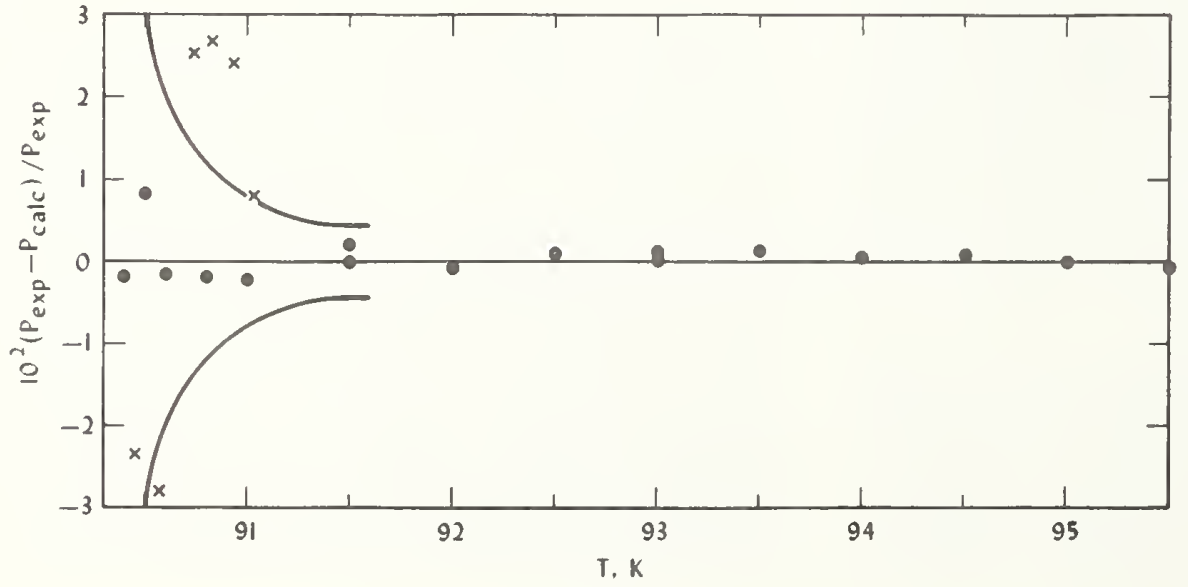

J. Chem. Phys., Vol. 64, "'). ?. 15 January 1976
FIG. 2. Deviations of experimental melting pressures from. the Simon equation, $\bullet$, this work, X, Ref. 1. The solld line corresponds to the range of pressure resulting from a difference of $\pm 0.005 \mathrm{~K}$ in temperature. 
TABLE I. Ethane melting pressures and deviations from Eq. (1).

\begin{tabular}{lcr}
\hline \hline & & \multicolumn{1}{c}{$P_{\text {exp }}-P_{\text {calc }}$} \\
$T(\mathrm{~K})$ & $P(\mathrm{MPa})$ & $P_{\text {exp }}$ \\
\hline 90.40 & 0.3231 & -0.189 \\
$90.45^{2}$ & 0.6181 & -2.345 \\
90.50 & 0.9496 & +0.810 \\
$90.57^{2}$ & 1.338 & -2.804 \\
90.60 & 1.558 & -0.182 \\
$90.64^{2}$ & 1.895 & 4.549 \\
$90.74^{2}$ & 2.493 & 2.551 \\
90.80 & 2.795 & -0.219 \\
$90.83^{2}$ & 3.070 & 2.690 \\
$90.93^{2}$ & 3.698 & 2.411 \\
91.00 & 4.035 & -0.247 \\
$91.03^{2}$ & 4.266 & 0.801 \\
91.50 & 7.182 & 0.196 \\
91.50 & 7.145 & -0.317 \\
92.00 & 10.30 & -0.095 \\
92.50 & 13.49 & 0.081 \\
93.00 & 16.66 & 0.008 \\
93.00 & 16.67 & 0.091 \\
93.50 & 19.89 & 0.117 \\
94.00 & 23.09 & 0.024 \\
94.50 & 26.35 & 0.064 \\
95.00 & 29.59 & -0.026 \\
95.50 & 32.85 & -0.107 \\
\hline \hline
\end{tabular}

${ }^{2}$ Reference 1.

The experimental results and their deviations from the equation are given in Table I. These deviations are plotted in Flg. 2 along with the data of Clusius and Weigand ${ }^{1}$ for comparison. The derived triple point temperature of $90.348 \pm 0.005 \mathrm{~K}$ is in excellent agreement with $90.35 \pm 0.03 \mathrm{~K}$ obtained by Clusius and Weigand. 1

It is interesting to note that experiments performed by completely freezing a solid sample and then warming through the melting transition resulted in values for the triple point of about $89.9 \mathrm{~K}^{8-4}$ while those of Clusius and Weigand, ${ }^{1}$ made by cooling the liquid until freezing, resulted in a higher melting temperature. This suggests that the measurements performed by warming the solid from low temperature may have been misinterpreted and that the effect of the solid transition has been responsible for obtaining such low melting points. This would, of course, be the situation for specific heat type experiments if the heat of transition was incorrectly interpreted as a large pre-melting effect or as the heat of fusion.

\section{SOLID-SOLID TRANSITION}

When measurements were made with a small solid fraction in the cell and with very low heater power to the capillary, as was necessary for the melting line measurements, it was, of course, impossible to observe the solid transition due to the unavoidable plugging of the capillary. However, if the cell were filled to a large solid fraction, and by using fairly large heater power to the capillary, pressure communication with the cell could be maintained and the solid transition could be detected. The necessary large gradients imposed on the cell, however, introduces considerable uncertainty in the temperature determinations and the observations can only be considered qualitative.

An additional check on the existence of the solid transition was made by observing the temperature as a function of time as the cell, filled with solid, was slowly warmed. A number of runs using various constant input powers to the cell were made and in each case distinct changes in the warming rate were observed at about $89.8 \mathrm{~K}$ associated with the solid transformation and at about $90.3 \mathrm{~K}$ corresponding to melting . Based on these qualitative results, it appears that the solid-solid boundary is roughly parallel to the melting line at a temperature about $0.5 \mathrm{~K}$ lower. This is not inconsistent with the measurements of Webster and Hoch ${ }^{11}$ who detected a definite solid transformation above about $100.0 \mathrm{MPa}$. Experimental difficulties prevented them from making measurements below 100.0 $\mathrm{MPa}$ but from their data and from certain theoretical considerations, they predicted a solid-solid-liquid triple point for ethane at lower pressure. No evidence for such a triple point below our maximum pressure of 32. $8 \mathrm{MPa}$ was observed in this work, and the solidsolid boundary, in fact, appears to continue to low pressure.

Note: After the completion of this work, we learned of some visual observations and dilatometric measurements on solid ethane by Professor D. Eggers ${ }^{12}$ who confirms the existence of a plastic-crystalline phase in a temperature range extending to about $0.45 \mathrm{~K}$ below the melting temperature. He has found this isotropic phase to be thermodynamically stable and not a metastable phase formed only under certain special conditions. ${ }^{13}$ We thank Dr. Eggers for discussing his work with us prior to publication.

*This work was carried out at the National Bureau of Standards under the sponsorship of the American Gas Association, Inc.

tConsejo Nacional De Ciencia Y Tecnologia (CONACYT) Mexico City. Currently a guest worker with the Cryogenics Division, National Bureau of Standards, Institute for Basic Standards.

${ }^{1}$ K. Clusius and K. Weigand, Z. Phys. Chem. B 46, 1 (1940).

${ }^{2}$ R. Wiebe, K. H. Hubbard, and M. J. Brevoort, J. Am. Chem. Soc. 52, 611 (1930).

${ }^{3}$ R. K. Witt and J. D. Kemp, J. Am. Chem. Soc. 59, 273 (1937).

${ }^{4}$ L. J. Burnett and B. H. Muller, J. Chem. Eng. Data 15, 154 (1970).

${ }^{5}$ See for example G. C. Straty, and R. Prydz, Rev. Sci. Instrum. 41, 1223 (1970).

${ }^{6}$ R. D. Goodwin, J. Res. Nat. Bur. Stand. C 65, 231 (1961).

${ }^{7}$ L. A. Weber, J. Res. Nat. Bur. Stand, A 74, 1 (1970).

${ }^{8}$ R. Prydz and G. C. Straty, Nat. Bur. Stand. (U. S.) Tech. Note 392 (Revised 1973).

${ }^{9}$ R. D. Goodwin, Nat. Bur. Stand. (U.S.) Tech. Note 653 (1974).

${ }^{10}$ R. D. Goodwin, Natl. Bur. Stand. (U. S.) Interim Report, NBSIR 74-398 (1974).

${ }^{11}$ D. S. Webster and M. J. R. Hoch, J. Phys. Chem Solids 32, 2663 (1971).

${ }^{12}$ D. F. Eggers, Jr., J. Phys. Chem. 79, 2116 (1975).

${ }^{13}$ For an example of metastable behavior, see for example, W. F. Giauque and J. B. Ott, J. Am. Chem. Soc, 82, 2689 (1960). 



\title{
JOURNAL OF RESEARCH of the National Bureau of Standards - A. Physics and Chemistry Vol. 80A, No. 1, January-February 1976 \\ PVT and Vapor Pressure Measurements on Ethane*
}

\author{
G. C. Straty and R. Tsumura** \\ Institute for Basic Standards, National Bureau of Standards, Boulder, Colorado 80302
}

(October 15, 1975)

\begin{abstract}
New measurements of the vapor pressures and $P V T$ properties of ethane are reported. PVT determinations have been made from near the triple point to $320 \mathrm{~K}$ at pressures to $33 \mathrm{MPa}$. The density range investigated extends to more than three times the critical density. The new measurements of the vapor pressures of ethane extend from $160 \mathrm{~K}$ to near the critical point.
\end{abstract}

Key words: Density: ethane: vapor pressure: $P V T$.

\section{Introduction}

Liquefied fuel gases, such as LNG, are expected to play an increasing role in satisfying future energy requirements. Accurate thermophysical properties data for these liquefied gas mixtures are necessary for the design of liquefaction plants, transport equipment, shipping and receiving terminals, and for custody transfer. The near infinite variations in mixture compositions encountered with these fuel gases rule out completely experimental or strictly computational approaches for determining these properties. Calculation methods, based on accurate, wide range pure component data and selected mixtures data are being developed in a number of laboratories, and appear to offer the only reliable and economical approach for the generation of the necessary thermophysical properties.

This paper reports new measurements of vapor pressures and PVT properties of pure ethane. The measurements have been made as part of a compre. hensive program to provide the required experimental data and to develop suitable calculation techniques for mixture properties determinations. PVT measurements have been made from near the triple point $(90.348 \mathrm{~K}$ ) [1] ${ }^{1}$ to $320 \mathrm{~K}$ at pressures up to $33 \mathrm{MPa}$. The density range extends to more than three times the critical density. The new measurements of the vapor pressures extend from $160 \mathrm{~K}$ to near the critical temperature (305 K).

\footnotetext{
* This worh wav carried out at the National Bureau of Standards under the sponsorship of the American fias Association. Inc.

**Consejo Varional De (iencia Y Tecnologia ICONACYT) Mexico City. Currently a guest worher with the Cryogenics Division. National Bureau of Standards, Institute for Basir Standards.

1 Figures in hrackets indicate the literature references at the end of this paper.
}

\section{Experimental Detail}

To measure single-phase densities, the gas expansion technique was used. A series of pressure-temperature observations are made on a nearly constant density sample of fluid confined in a cell of accurately calibrated volume. When either the maximum pressure or maximum temperature is reached, the fluid is expanded, to low pressure, into large calibrated volumes maintained at an accurately known temperature above room temperature. The density can then be determined from the cell volume and the compressibility factor $(P V / R T)$ of the ethane at the conditions of the expansion volumes.

The ethane used was commercially available research grade with specified minimum purity of 99.98 percent. This purity was verified by chromatographic analysis. Temperatures were measured on the IPTS (1968) with a platinum resistance thermometer calibrated by the National Bureau of Standards. Pressures above about $3 \mathrm{MPa}$ were measured by referencing to oil pressures derived from an oil dead weight gauge accurate to within 0.015 percent. Lower pressures were measured with a precision fused quartz bourdon tube gauge which had been previously calibrated against an air dead weight gauge accurate to within 0.01 percent. The apparatus and procedures were similar to those used previously in this laboratory for measurements on several other cryogenic fluids [2-5] and have been described in detail [6-8]. Slight modification to existing apparatus was necessary because of the higher critical temperature of ethane. Those external parts of the system which contained fluid during a measurement were heated to well above the critical temperature (typically $330 \mathrm{~K}$ ) in order to reduce the relative density of the fluid residing in these parts, permitting a more accurate adjusted density to be computed. 


\section{Results}

With the techniques used here, each experimental PVT "run" consists of a number of pressure-temperature ubservations lying along a near-isochoric path. About 50 such runs were made covering a density range of from about 1.5 to over $21.5 \mathrm{~mol} / \mathrm{l}$. Each run consisted of from 5 to 16 PVT points, depending on the density. Measurements were always made at fixed temperatures to permit direct analysis in terms of isotherms. A total of over $450 P V T$ data points was determined. These data are tabulated along isotherms in table 1 .

TABLE 1. PVT data for ethane

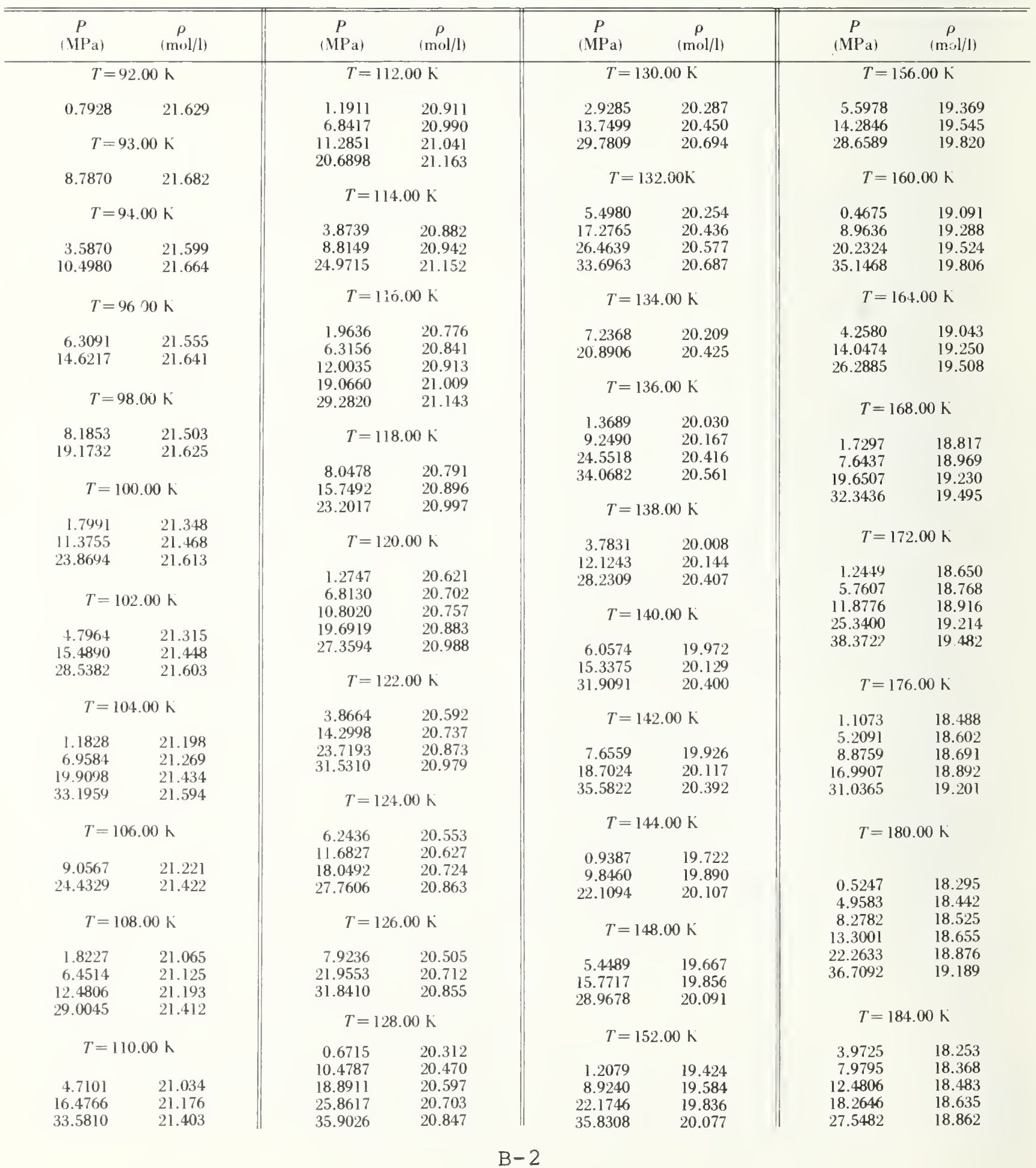


TABLE 1. PVT data for ethane-Continued

\begin{tabular}{|c|c|}
\hline $\begin{array}{c}P \\
\mid\left(H^{\prime} \mathrm{i}\right)\end{array}$ & | \\
\hline \multicolumn{2}{|c|}{$T=188.011 \mathrm{~h}$} \\
\hline 1.9817 & 18. \\
\hline 7.2058 & 18. \\
\hline 11.9718 & 18. \\
\hline 17.2059 & 18. \\
\hline 23.3273 & 18. \\
\hline 32.8340 & 18. \\
\hline
\end{tabular}

$$
T=192.00 \mathrm{~K}
$$

$\begin{array}{rr}0.9865 & 17.815 \\ 5.5964 & 17.977 \\ 10.6669 & 18.128 \\ 16.5186 & 18.302 \\ 22.0330 & 18.447 \\ 28.3464 & 18.607\end{array}$

$$
T=196.00 \mathrm{~K}
$$

$\begin{array}{rr}0.4943 & 17.619 \\ 4.4533 & 17.775 \\ 8.4330 & 17.903 \\ 14.9662 & 18.104 \\ 21.1586 & 18.286 \\ 26.8669 & 18.434 \\ 33.3677 & 18.595\end{array}$

$$
T=200.00 \mathrm{~K}
$$

$\begin{array}{rr}0.6801 & 17.445 \\ 3.5738 & 17.581 \\ 7.3933 & 17.709 \\ 12.2367 & 17.866 \\ 19.4175 & 18.087 \\ 25.8517 & 18.273 \\ 31.6945 & 18.423\end{array}$

$$
T=204.00 \mathrm{~K}
$$

$\begin{array}{rr}3.7760 & 17.411 \\ 6.7420 & 17.524 \\ 10.6983 & 17.658 \\ 16.4076 & 17.846 \\ 23.9051 & 18.074 \\ 30.2305 & 18.262 \\ 36.4896 & 18.412\end{array}$

\begin{tabular}{rr}
\multicolumn{2}{c}{$T=208.00 \mathrm{k}$} \\
0.5897 & 17.079 \\
6.8033 & 17.354 \\
9.6616 & 17.461 \\
14.6253 & 17.634 \\
20.6552 & 17.831 \\
28.3791 & 18.062 \\
35.0871 & 18.251
\end{tabular}

$$
T=212.00 \mathrm{~K}
$$

$\begin{array}{rr}3.4269 & 17.048 \\ 9.6570 & 17.293 \\ 13.3583 & 17.434 \\ 18.6673 & 17.619 \\ 24.9088 & 17.819 \\ 32.8419 & 18.051\end{array}$

P 
TABIE L. PT data for ethane-tinutinued

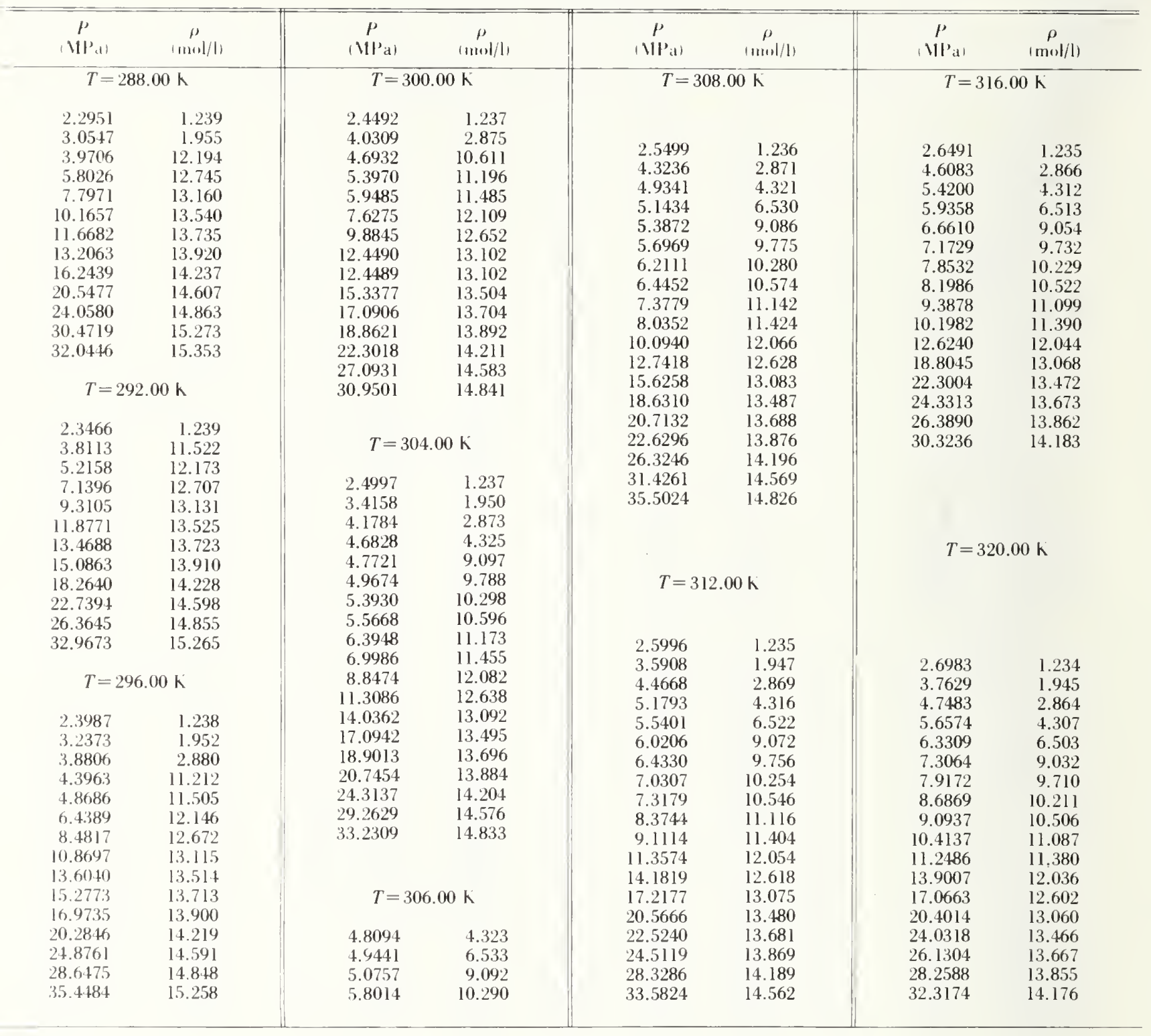

Although romparison with data from other sources is, in reneral, impossible without multiple interpola. tions, the agreement has been deduced by examining the density deviations of the various data sets $[9,10]$ from densitien calculated from an equation of state for "thane tur to Godwin [11]. The agreement is fouml to be, in general, within the combined experimental error. Maximum difference occur in the critical region where the equation of state representation is expected to be less satisfactory and where the experimental densities are subject to increasing uncertainty. Estimated uncertainty in the experimental densities in this work is typically \pm 0.1 percent at the lowest temperatures, increasing to \pm 0.2 percent at higher temperatures and lower densities, becoming as muc' as \pm 1.0 percent in the critical region.
New vapor pressure measurements also have been made at $5 \mathrm{~K}$ intervals from 160 to $300 \mathrm{~K}$ and are given in table 2. At each temperature, the pressure was measured at least twice with some ethane being removed from the cell between measurements. Identical pressure observations indicated that the two-phase condition existed in the cell.

A vapor pressure equation of the form

$$
\ln \left(P / P_{t}\right)=A_{\chi}+B_{\chi}{ }^{2}+C_{x}{ }^{3}+D_{\chi}^{4}+E_{\chi}(1-\chi)^{3 / 2}
$$

was fit to all available data for ethane [12]. Here, $\chi=\left(1-T_{l} / T\right) /\left(1-T_{l} / T_{c^{\circ}}\right)$, and $P$ and $T$ are the pressure and temperature and $t$ and $c$ refer to the triple and critical points. Coefficients giving the best fit were found to be the following: 
$A=10.67324$

$B=8.33782$

$C-3.08489$

$D=-0.65857$

$E=6.04955$

$P_{t}=1.14 \times 10^{-5} \mathrm{bar}$

$T_{1}=90.348 K[$ Ref 1$]$

$T_{r}=305.330 \mathrm{~K}[\operatorname{Ref} 10]$

TABLE 2

\begin{tabular}{c|c||c|c}
\hline $\begin{array}{c}T \\
(\mathrm{k})\end{array}$ & $\begin{array}{c}P \\
\mathrm{kPa}\end{array}$ & $\begin{array}{c}T \\
(\mathrm{~K})\end{array}$ & $\begin{array}{c}P \\
\mathrm{kPa}\end{array}$ \\
\hline 160.00 & 21.502 & 230.00 & 700.48 \\
165.00 & 30.670 & 235.00 & 825.96 \\
170.00 & 42.870 & 240.00 & 966.60 \\
175.00 & 58.636 & 245.00 & 1124.4 \\
180.00 & 78.734 & 245.00 & 1124.8 \\
180.00 & 78.706 & 250.00 & 1300.0 \\
185.00 & 103.84 & 250.00 & 1301.9 \\
190.00 & 134.63 & 250.00 & 1302.1 \\
190.00 & 134.72 & 250.00 & 1301.8 \\
195.00 & 172.21 & 255.00 & 1495.0 \\
195.00 & 172.26 & 260.00 & 1670.3 \\
200.00 & 217.26 & 265.00 & 1947.9 \\
200.00 & 217.32 & 270.00 & 2208.0 \\
205.00 & 270.93 & 275.00 & 2493.1 \\
205.00 & 271.00 & 275.00 & 2493.2 \\
210.00 & 334.13 & 280.00 & 2804.6 \\
210.00 & 334.17 & 280.00 & 2806.2 \\
210.00 & 333.98 & 285.00 & 3144.3 \\
210.00 & 333.99 & 290.00 & 3513.5 \\
215.00 & 407.34 & 298.15 & 4190.9 \\
220.00 & 492.16 & 298.15 & 4188.9 \\
225.00 & 589.73 & 300.00 & 4353.5 \\
\hline
\end{tabular}

Deviations of the experimental vapor pressures from those calculated from this equation for the various data sets $[9,10,13]$ are shown in figure 1 .

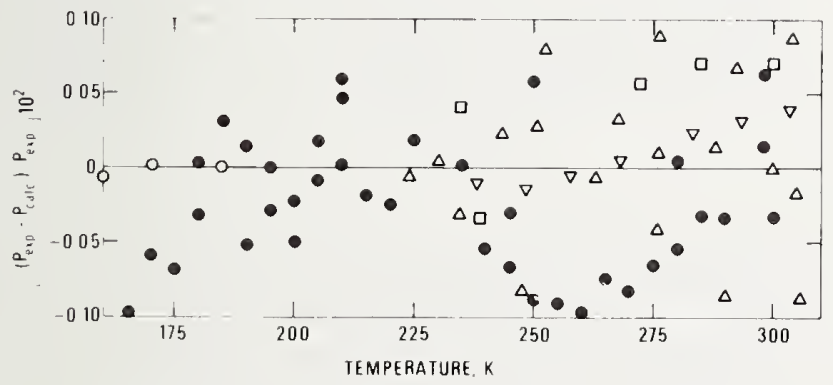

FI,URE 1. Deviations of vapor pressures from eq. 1.

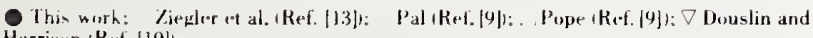
Harrision + Re+1. $\{10\}$.

\section{Summary}

We have made new wide-range measurements of the vapor pressures and $P V T$ properties of ethane. These are the only dat a currently available which cover the entire temperature range from the triple point to $320 \mathrm{~K}$. In addition, these data are the only accurate $P V T$ data available for the compressed liquid below about $190 \mathrm{~K}$. The data are being used along with other available data to refine the calculation of thermodynamic functions for ethane and as input to, and as a check upon, new calculation methods for predicting liquefied natural (fuel) gas properties being studied in this and other laboratories.

\section{References and Notes}

(1) Straty, (. C., and Tsumura, R., J. Chem. Phys., 64, 859 (I976). [2] Weber, L. A., J. Res. Nat. Bur. Stand. (U.S.), 74A (Phys. and Chem.). No. 1, 93-129 (Jan.-Feb. 1970).

[3] Prydz R., and Straty, G. C. Nat. Bur. Stand. (U.S.), Tech. Note 392, 197 pages (Revised 1973).

[4] Goodwin, R. D., Nat. Bur. Stand. (U.S.) Tech. Note 653, 280 pages (April 1974).

[5] Weber, L. A., NASA SP-3088/NBSIR 74-374 (1975).

[6] Goodwin, R. D., J. Res. Nat. Bur. Stand. (U.S.), 65C, (Eng. and Instr.), No. 4, 231-243, (Oct.-Dec. 1961).

[7] Straty, G. C., and Prydz, R., Rev. Sci. Inst. 41, 1223 (1970).

[8] Goodwin and Prydz, R., J. Res. Nat. Bur. Stand. (U.S.). 76A (Phys. and Chem.), No. 2, 81-101 (Mar.-Apr. 1972).

[9] Pope G. A., (also reports vapor pressure and PVT data of A. K. Pal). P1.D. Thesis, Dept. of Chemical Engineering, Ric University, Houston, Texas (July 1971).

[10] Douslin, D. R., and Harrison, R. H., J. Chem. Thermo 5, 491 (1973).

[11] Goodwin, R. D., NBSIR 74-398 (1974). Goodwin has used a nonanalytic equation of state to correlate previously available data on ethane and to calculate provisional thermodynamic functions. Experimental data from this worh are being used to fill in gaps in previously published data and to refine the equation of state to permit more accurate calculations of thermodynamic properties to be made. We defer extensive comparisons between data sets and a more elaborate analysis for inclusion in a final report in preparation.

[12] Further refinements in the correlation are expected which will probably alter slightly the final values of the constants. The deviation plot, however, is representative of the agreement among data sets. Coefficients for this equation will be included in the final report. See also reference [8].

[13] Ziegter, W. T., Kirk, B. S., Mullins, J. C., and Berquest. A. R., Tech. Rept. No. 2, Project A-764, Eng. Expt. Sta. Ceoryia Inst. Tech.: Atlanta, Georgia, December 1964.

(Paper 80Al-878) 



\title{
Dielectric constant data and the derived Clausius-Mossotti function for compressed gaseous and liquid ethane*
}

\author{
L. A. Weber \\ National Bureau of Standards, Institute for Basic Standards, Cryogenics Division, Boulder, Colorado 80302 \\ (Received 25 March 1976) \\ Measurements are presented for the dielectric constant of ethane in the saturated liquid and compressed \\ fluid states at temperatures between 95 and $323 \mathrm{~K}$. Pressures ranged up to 390 bar. The data, which have \\ an estimated uncertainty of $0.01 \%$, are combined with accurate density data from several sources to \\ produce the Clausius-Mossotti function over a wide range of temperature and density. An analytical \\ expression of the Clausius-Mossotti function is given, and the consistency of the available density data is \\ discussed.
}

\section{INTRODUCTION}

This paper presents dielectric constant measurements and the derived Clausius-Mossotti function for ethane. Measurements were made on the saturated liquid from the triple point to near the critical point and on seven compressed fluid isotherms in the range $95-323.15 \mathrm{~K}$. The data range in pressure up to 390 bar and in density from 0.036 to 3.16 times the critical density. This work is part of a series which previously has included data on hydrogen, ${ }^{1}$ oxygen, ${ }^{2}$ fluorine, ${ }^{3}$ nitrogen, ${ }^{4}$ and methane. ${ }^{5}$

Measurements of the dielectric constant, combined with accurate density data for gases and liquids, provide useful information about molecular polarizabilities and molecular interactions. ${ }^{\circ}$ Such measurements are generally combined to form the Clausius-Mossotti (CM) function, $(1 / \rho)(\epsilon-1) /(\epsilon+2)$, where $\epsilon$ is the dielectric constant and $\rho$ is the density. The CM function has the property of being nearly a constant, generally varying only about one percent over a wide range of density and temperature for nonpolar molecules. A knowledge of the CM function provides a convenient and sensitive way of determining density from accurate dielectric constant measurements. ${ }^{7}$ In addition, dielectric constant data can provide a convenient and sensitive intercomparison between independent PVT measurements, even in situations where the PVT data are widely separated in temperature.

\section{EXPERIMENTAL}

The dielectric constant measurements were made with the highly stable cylindrical capacitor developed by Younglove and Straty, ${ }^{8}$ which has a vacuum capacitance of about $33 \mathrm{pF}$. The curve of its vacuum capacitance versus temperature has proven to be stable to within one part in $10^{5}$. The dielectric constant $\epsilon$ is given by the ratio $C / C_{0}$, where $C$ is the capacitance with fluid between the plates and $C_{0}$ is the vacuum capacitance at the same temperature. The capacitance was measured with a three-terminal ac bridge. Uncertainty in the determination of the dielectric constant is estimated to be less than $0.01 \%$. Temperatures were measured with a platinum resistance thermometer calibrated on the IPTS 1968 scale and were reproducible to $0.001 \mathrm{~K}$. The overall accuracy varied from 0.005 at the lowest temperatures to $0.03 \mathrm{~K}$ for the room temperature measurements. Pressures were measured with an oil dead weight gauge having an accuracy of about 0.01 percent. The sample holder and cryostat are described elsewhere. ${ }^{5, \theta}$ The sample used was $99.99 \%$ pure ethane which was passed through a molecular sieve trap to remove any water.

\section{RESULTS}

The dielectric constant of the saturated liquid was measured at 34 temperatures between 95 and $295 \mathrm{~K}$.

TABLE I. Dielectric constant and calculated Clausius-Mossotti values of saturated liquid ethane.

\begin{tabular}{|c|c|c|c|}
\hline $\begin{array}{l}T \\
(\mathrm{~K})\end{array}$ & $\begin{array}{l}\rho \times 10^{3} \\
\left(\mathrm{~mol} / \mathrm{cm}^{3}\right)\end{array}$ & $\epsilon$ & $\begin{array}{l}\mathrm{CM} \\
\left(\mathrm{cm}^{3} / \mathrm{mol}\right)\end{array}$ \\
\hline 95.00 & $21.520^{2}$ & 1.93563 & 11.047 \\
\hline 100.00 & 21.341 & 1. 92576 & 11.050 \\
\hline 105.00 & 21.159 & 1. 91590 & 11.054 \\
\hline 110.00 & 20.975 & 1.90606 & 11.059 \\
\hline 115.00 & 20.793 & 1. 89612 & 11.062 \\
\hline 120.00 & 20.602 & 1.88952 & 11.101 \\
\hline 125.00 & 20.419 & 1.87661 & 11.074 \\
\hline 130.00 & 20.232 & 1. 86687 & 11.080 \\
\hline 135.00 & 20.046 & 1.85700 & 11.084 \\
\hline 140.00 & 19.857 & 1. 84713 & 11.089 \\
\hline 145.00 & 19.667 & 1. 83721 & 11.094 \\
\hline 150.00 & 19.475 & 1. 82729 & 11.099 \\
\hline 155.00 & 19.281 & 1. 81729 & 11.104 \\
\hline 160.00 & 19.086 & 1. 80725 & 11.109 \\
\hline 165.00 & 18.887 & 1.79714 & 11.115 \\
\hline 170.00 & 18.687 & 1. 78696 & 11.121 \\
\hline 175.00 & 18.484 & 1.77669 & 11.126 \\
\hline 180.00 & 18.279 & 1.76628 & 11.131 \\
\hline 185.00 & 18.070 & 1.75576 & 11.136 \\
\hline 190.00 & 17.861 & 1.74516 & 11.140 \\
\hline 200.00 & 17.429 & 1. 72349 & 11.148 \\
\hline 210.00 & 16.971 & 1.70104 & 11.161 \\
\hline 220.00 & 16.499 & 1.67786 & 11.171 \\
\hline 230.00 & 15.997 & 1.65352 & 11.181 \\
\hline 240.00 & 15. 464 & 1. 62780 & 11.191 \\
\hline 250.00 & 14.890 & 1.60036 & 11.199 \\
\hline 260.00 & 14.261 & 1. 57076 & 11.208 \\
\hline 270.00 & 13.549 & 1.53778 & 11.220 \\
\hline 275.00 & $13.186^{\mathrm{b}}$ & 1. 51962 & 11.196 \\
\hline 280.00 & 12.747 & 1.49994 & 11.206 \\
\hline 285.00 & 12.258 & 1.47809 & 11.214 \\
\hline 290.00 & 11.699 & 1.45318 & 11. 218 \\
\hline 295.00 & 11.024 & 1. 42343 & 11.220 \\
\hline
\end{tabular}

${ }^{2}$ Densities from Ref. $10 . \quad{ }^{b}$ Densities from Ref. 11. 
TABLE $\Pi$. Dielectric constant and calculated Clausius-Mossotti values of compressed liquid and gaseous ethane.

\begin{tabular}{|c|c|c|c|c|}
\hline $\begin{array}{l}T \\
(\mathrm{~K})\end{array}$ & $\begin{array}{l}P \\
\text { (bar) }\end{array}$ & $\epsilon$ & $\begin{array}{l}\rho \times 10^{3} \\
\left(\mathrm{~mol} / \mathrm{cm}^{3}\right)\end{array}$ & $\begin{array}{l}\mathrm{CM} \\
\left(\mathrm{c} \mathrm{m}^{3} / \mathrm{mol}\right)\end{array}$ \\
\hline 120.00 & 304.927 & 1.90928 & $21.026^{\mathrm{a}}$ & 11.062 \\
\hline 120.00 & 171.351 & 1.89966 & 20.848 & 11.066 \\
\hline 120.00 & 66.985 & 1.89165 & 20.705 & 11.066 \\
\hline 160.00 & 360.454 & 1.84490 & 19.827 & 11.083 \\
\hline 160.00 & 358.376 & 1.84471 & 19.824 & 11.083 \\
\hline 160.00 & 36.520 & 1.81160 & 19.171 & 11.107 \\
\hline 160.00 & 36.628 & 1.81161 & 19.171 & 11.107 \\
\hline 200.00 & 377.816 & 1.78020 & 18.564 & 11.118 \\
\hline 200,00 & 256.633 & 1.76482 & 18.266 & 11.122 \\
\hline 200.00 & 151.137 & 1.74954 & 17.965 & 11.127 \\
\hline 200.00 & 69.172 & 1.73601 & 17.689 & 11.137 \\
\hline 200.00 & 13. 071 & 1.72560 & 17.472 & 11.147 \\
\hline 240.00 & 392.029 & 1.71687 & 17.305 & 11.145 \\
\hline 240.00 & 294.735 & 1.70044 & 16.975 & 11.151 \\
\hline 240.00 & 211.148 & 1.68411 & 16.645 & 11.156 \\
\hline 240.00 & 115.755 & 1. 66165 & 16.186 & 11.164 \\
\hline 240.00 & 62.930 & 1.64649 & 15. 869 & 11.172 \\
\hline 240.00 & 30.356 & 1.63563 & 15.637 & 11.181 \\
\hline 280.00 & 376.142 & 1.64857 & 15.919 & 11.166 \\
\hline 280.00 & 253.274 & 1. 61794 & 15.274 & 11.182 \\
\hline 280.00 & 165.058 & 1.58855 & 14.653 & 11.193 \\
\hline 280.00 & 100.002 & 1.55858 & 14.016 & 11.199 \\
\hline 280.00 & 54.692 & 1.52795 & 13.355 & 11.205 \\
\hline 320.00 & 380.835 & 1.58441 & 14.579 & 11.183 \\
\hline 320.00 & 196.092 & 1.51088 & 12.962 & 11.226 \\
\hline 320.00 & 113.562 & 1.44096 & 11.402 & 11.239 \\
\hline 320.00 & 79.146 & 1. 36772 & 9.711 & 11.244 \\
\hline 320.00 & 67.649 & 1. 29621 & 7.894 & 11.256 \\
\hline 320,00 & 62,595 & 1.22571 & 6.220 & 11.249 \\
\hline 320.00 & 56.260 & 1.15041 & 4.235 & 11.274 \\
\hline 320.00 & 40.699 & 1. 07576 & 2.194 & 11.227 \\
\hline 323.15 & 318.351 & 1.55939 & $14.051^{b}$ & 11.185 \\
\hline 323.15 & 243. 358 & 1.52894 & 13.389 & 11.195 \\
\hline 323.15 & 204.702 & 1.50940 & 12.959 & 11.201 \\
\hline 323.15 & 184.435 & 1.49630 & 12.668 & 11.205 \\
\hline 323.15 & 163.787 & 1.48155 & 12.339 & 11.210 \\
\hline 323.15 & 132,020 & 1.45243 & 11.684 & 11.216 \\
\hline 323.15 & 109.032 & 1.42223 & 10.993 & 11.223 \\
\hline 323.15 & 94.055 & 1. 39319 & 10.321 & 11.227 \\
\hline 323.15 & 84.177 & 1. 36464 & 9.650 & 11.230 \\
\hline 323.15 & 77.255 & 1.33429 & 8.924 & 11.235 \\
\hline 323.15 & 72.719 & 1. 30433 & 8.195 & 11.238 \\
\hline 323.15 & 69.510 & 1. 27426 & 7.455 & 11.236 \\
\hline 323.15 & 66.909 & 1. 24358 & 6.686 & 11.231 \\
\hline 323.15 & 64.448 & 1.21258 & 5.893 & 11.229 \\
\hline 323.15 & 61.725 & 1.18186 & 5.089 & 11. 231 \\
\hline 323.15 & 58.073 & 1.15018 & 4.246 & 11.227 \\
\hline 323.15 & 52.652 & 1.11762 & 3.362 & 11.221 \\
\hline 323.15 & 44.559 & 1.08526 & 2. 466 & 11.207 \\
\hline 323.15 & 34.222 & 1.05686 & 1.662 & 11.191 \\
\hline 323.15 & 62.010 & 1.18469 & 5.166 & 11.225 \\
\hline 323.15 & 54.090 & 1.12503 & 3. 566 & 11.220 \\
\hline 323.15 & 38.024 & 1. 06621 & 1.929 & 11.196 \\
\hline 323.15 & 24.604 & 1.03699 & 1.089 & 11.185 \\
\hline 323.15 & 16.106 & 1.02249 & 0.6660 & 11.174 \\
\hline 323.15 & 10.202 & 1. 01362 & 0.4046 & 11.170 \\
\hline 323.15 & 6.027 & 1.00782 & 0.2326 & 11.171 \\
\hline
\end{tabular}

${ }^{2}$ Densities from Ref. 15.

${ }^{\mathrm{b}}$ Densities from Ref. 11 .

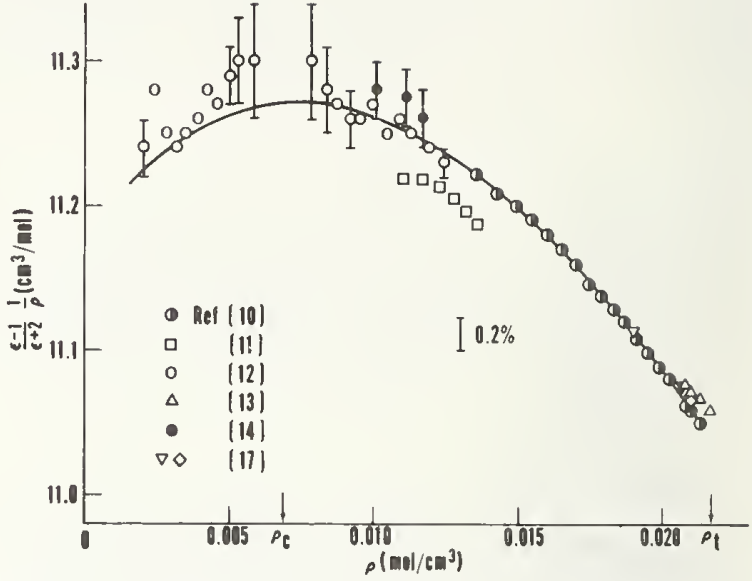

FIG. 1. Clausius-Mossotti function for the saturated liquid and vapor derived from our $\epsilon$ measurements combined with densities from the references cited. References 12 and 13 are independent $\epsilon-\rho$ measurements. The curve represents the fit of Eq. (2).

The results are given in Table I. Measurements were also made along seven isotherms between 120 and $323.15 \mathrm{~K}$ at pressures up to 390 bar. The results are shown in Table II. Because the cylindrical capacitor was mounted vertically, measurements in the vicinity of the critical point (approximately $305.3 \mathrm{~K}$ ) were not attempted. Due to the configuration of the sample holder it was also not possible to make measurements in the saturated vapor.

The dielectric constant data for the saturated liquid were combined with available densities to produce the Clausius-Mossotti function, shown in Fig. 1. For temperatures up to $270 \mathrm{~K}$ the densities of Haynes and $\mathrm{Hiza}^{10}$ and of Canfield et al. ${ }^{17}$ were used. At temperatures above $270 \mathrm{~K}$ the density data of Douslin and Harrison, ${ }^{11}$ represented by their smooth curve, were used. Also shown in the figure are the independent density-dielectric constant data of Sliwins $\mathrm{ki}^{12}$ for the saturated liquid and vapor near the critical point and the liquid CM data of Pan, Mady, and Miller ${ }^{13}$ near the triple point. Three points derived from the saturated liquid density curve given by Burton and Balzarini ${ }^{14}$ are shown. The error bars on these points indicate the uncertainty involved in estimating densities from the figure given in their publication.

The single phase isothermal CM function data are plotted in Fig. 2. The isotherms at temperatures from 120 to $320 \mathrm{~K}$ made use of the PVT data of Straty and Tsumura, ${ }^{15}$ and the $C M$ data at $323.15 \mathrm{~K}$ made use of the densities of Douslin and Harrison ${ }^{11}$ at that temperature. Also shown is the single CM datum of Watson, Rao, and Ramaswamy ${ }^{16}$ at a pressure of one atmosphere at $298 \mathrm{~K}$. The is othermal density data were fit ted with polynomials of the form,

$$
P=R T \rho+\sum_{i} A_{i} \rho^{i},
$$

for the purpose of smoothing and interpolation. At temperatures below the critical, the polynomials were 
constrained at the saturation boundary to the densities from Ref, 10 and 12. The density was then calculated by an iterative procedure for a given pressure.

\section{ACCURACY AND COMPARISONS}

The calculated CM function is extremely useful for intercomparing sets of PVT data. In Fig. 1 the saturated liquid densities of Sliwinski are seen to be highly consistent with those of Haynes and Hiza. Sliwinski's estimated uncertainty in CM of $0.1 \%$ increasing to $0.4 \%$ nearest the critical point is shown in the figure. In the range $270-295 \mathrm{~K}$ Douslin's densities a re seen'to be $0.2 \%$ $0.3 \%$ higher than the others. The Burton and Balzarini results agree with those of Sliwinski within the uncertainty with which we could estimate the former. The Miller et al. densities are in agreement with those of Haynes and Hiza near the triple point to within about $0.1 \%$. The data of Canfield et al. ${ }^{17}$ lie between those of Miller et al. and those of Haynes and Hiza at 108 and $115 \mathrm{~K}$ and agree very well with those of Haynes and Hiza at $161 \mathrm{~K}$.

In Fig. 2 the isothermal CM data are compared with the best estimate of the saturation curve from Fig. 1. The isotherms between 120 and $280 \mathrm{~K}$, using the densities of Straty and Tsumura, are seen to be in good agreement with the saturation curve. The small variation with temperature at a given density has been observed for other fluids and is believed to be real. Their density data at $320 \mathrm{~K}$ may be compared directly with the density data given by Douslin and Harrison at $323.15 \mathrm{~K}$ (assuming negligible dependence of $\mathrm{CM}$ on temperature over this small range), and it is seen that the latter's densities are again systematically higher by about $0.2 \%$. The error bars indicate the deviations which would be introduced by a $0.01 \%$ uncertainty to the dielectric constant. All of the newer data are in good agreement with the datum of Watson, Rao, and Ramaswamy, ${ }^{16}$ reported in 1934.

Our dielectric constants are consistently smaller than those of Sliwinski by about $0.014 \%$, which is about equivalent to the precision of his data. Our measure-

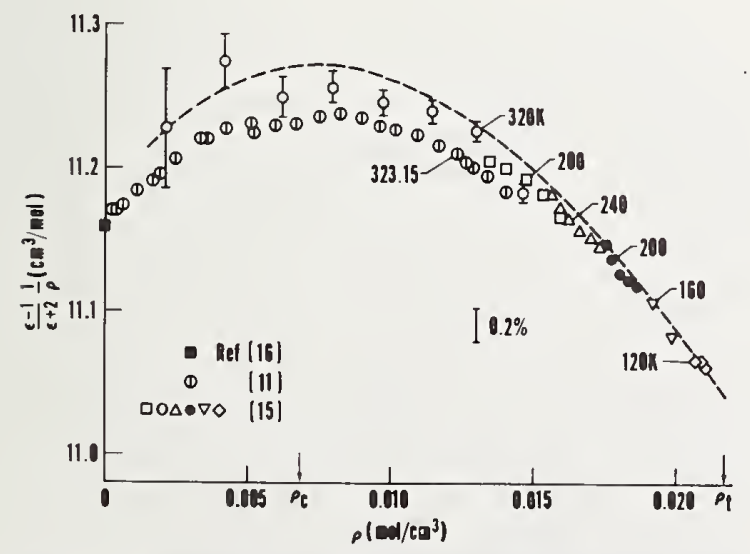

FIG. 2. Clausius-Mossotti function for the single phase fluid making use of densities from the references cited. The curve is for saturation conditions, from Fig. 1.
TAB LE III. Parameters for Eq. (2); density in $\mathrm{mol} / \mathrm{cm}^{3}$, temperature in kelvin.

\begin{tabular}{cc}
\hline \hline$A$ & $11.180 \pm 0.005$ \\
$B$ & $30.7 \pm 2.1$ \\
$C$ & $-1627 \pm 77$ \\
$D$ & $-0.021 \pm 0.003$ \\
\hline
\end{tabular}

ments are also smaller by about $0.018 \%$ than those of Miller et al., who used a capacitor similar to ours. Since, in each case, the agreement is within the combined uncertainty of the authors, these differences are not considered significant.

The dielectric constant measurements presented here, in combination with the saturated liquid densities recorded by Haynes and Hiza and the PVT data recorded by Straty and Tsumura, along with the independent measurements recorded by Sliwinski have been fitted with the equation,

$$
C M=\frac{\epsilon-1}{\epsilon+2} \frac{1}{\rho}=A+B \rho+C \rho^{2}+D T \rho
$$

to provide an analytical expression for the results. The very precise $P V T$ data recorded by Douslin and Harrison were not included because of their large systematic deviation from the others. The coefficients given in Table III are estimated to reproduce the ClausiusMossotti function of ethane to within $0.1 \%$.

In Table III, the parameter $A$, which is related to the molecular polarizability, is much larger than the corresponding parameter for methane and for the diatomic gases previously measured in this laboratory. This is to be expected based on considerations of molecular size. The molecular polarizability is calculated to be $4.43 \times 10^{-24} \mathrm{~cm}^{3}$. The dielectric second virial coefficient, $B$, is also considerably larger than the coefficient found for the smaller molecules. Sliwinski found $11.22,20$, and -1460 for the values of $A, B$, and $C$ from an analysis of his data alone. His value for $B$ should be compared with the quantity $(B+D T)$ from Table III. At room temperature this quantity has a value of about 24. However, little reliance should be placed on the significance of the value of $B$ given here as it is based upon only one supercritical isotherm.

\section{CONCLUSIONS}

We have used a highly stable cylindrical capacitor to measure the dielectric constant of ethane over a wide range of density and temperature. The derived $\mathrm{CM}$ function has been used to intercompare the available $P V T$ data for ethane, and an analytical expression has been given to relate density, temperature, and the dielectric constant.

*This work was carried out at the National Bureau of Standards under the sponsorship of the American Gas Association, Inc. ${ }^{1}$ J. W. Stewart, J. Chem. Phys. 40, 3297 (1964).

${ }^{2}$ B. A. Younglove, J. Res. Natl. Bur. Stand. See. A 76, 37 (1972).

${ }^{3}$ G. C. Straty and B. A. Younglove, J. Chem. Phys. 57, 2255 
(1972).

${ }^{4} J$. F. Ely and G. C. Straty, J. Chem. Phys, 61, 1480 (1974).

${ }^{5}$ G. C. Straty and R. D. Goodwin, Cryogenics 13, 712 (1973).

${ }^{6}$ C. J. F. Böttcher, Theory of Electric Polarization (Elsevier, New York, 1973), Vol. 1, and references cited therein.

${ }^{7}$ L. A. Weber, Phys. Rev. A 2, 2379 (1970)

${ }^{8}$ B. A. Younglove and G. C. Straty, Rev. Sci. Instrum. 41, 1087 (1970)

${ }^{9}$ D. E. Diller, J. Chem. Phys. 47, 3096 (1968).

${ }^{10}$ W. M. Haynes and M. J. Hiza (unpublished data).

${ }^{11}$ D. R. Dousiin and R. H. Harrison, J. Chem. Thermodyn.
5, 491 (1973)

${ }^{12}$ P. Sliwinski, Z. Phys. Chem. 68, 91 (1969).

${ }^{13}$ W. P. Pan, M. H. Mady, anó R. C. Miller, AIChE J. 21, 283 (1975).

${ }^{14} \mathrm{M}$. Burton and D. Balzarini, Can. J. Phys. 52, 2011 (1974).

${ }^{15} \mathrm{G}$. C. Straty and R. Tsumura (to be published).

${ }^{16} \mathrm{H}$. E. Watson, G. G. Rao, and K. L. Ramaswamy, Proc. R. Soc. London Ser. A 143, 558 (1934).

${ }^{17}$ C. Chui and F. B. Canfield, Trans. Faraday Soc. 67, 2933 (1971); M. J. Shanaa and F. B. Canfield, Trans. Faraday Soc. 64, 2281 (1968). 


\title{
The heats of transition of solid ethane*
}

\author{
Hans M. Roder \\ Cryogenics Division, National Bureau of Standards, Institute for Basic Standards, Boulder, Colorado 80302 \\ (Received 3 May 1976) \\ The existence of a solid-solid transition in ethane is now generally accepted. A value for the heat of \\ transition, $2437 \pm 35 \mathrm{~J} / \mathrm{mol}$ at $89.774 \mathrm{~K}$, together with a new value for the heat of fusion, $279 \pm 6 \mathrm{~J} / \mathrm{mol}$ at \\ $90.337 \mathrm{~K}$, is reported in this work. The sum of the new values is in excellent agreement with the earlier \\ measurements, provided that the heat required to raise the temperature of the solid between transitions is \\ included. The transition temperatures are in agreement with the most recent determinations of other \\ authors.
}

\section{INTRODUCTION}

Several recent papers address the question of a solidsolid phase transition in ethane at temperatures close to the triple point. Webster and $\mathrm{Hoch}^{1}$ detected a definite transition at high pressures, above about $100 \mathrm{MPa}$. However, these authors predicted that a solid-solid transition does not occur at zero pressure. Eggers ${ }^{2}$ showed that two different solid phases existed down to zero pressure and identified the new phase as a plasticcrystalline form. At the same time Straty and Tsumura, ${ }^{3}$ while attempting to remeasure the melting pressures of ethane, found evidence of a solid phase transition along a pressure-temperature boundary roughly parallel to the ordinary melting curve but approximately $0.5 \mathrm{~K}$ lower.

In connection with ongoing measurements of the specific heats of liquid ethane, ${ }^{4}$ it appeared possible and worthwhile to measure the heats of transition of ethane. We have determined new enthalpy differences for the solid-solid transition and for the heat of fusion. In addition, values for the specific heat of solid and liquid ethane were obtained from the experiment, as well as an estimate for the specific heat of the solid at temperatures between the two transitions. The sum of enthalpy for the solid-solid transition. the new heat of fusion, and the heat required to change temperatures between the two solid phases is in excellent agreement with earlier measurements by Witt and Kemp ${ }^{5}$ who apparently identified the total as the "heat of fusion."

\section{APPARATUS}

The apparatus used is a constant volume adiabatic calorimeter fully described by Goodwin. ${ }^{6}$ The essential features are a spherical sample holder, a filling capillary, a heating/cooling interceptor ring, an adiabatic shield, and a platinum resistance thermometer mounted externally on the sample holder. The instrument has been used to measure the specific heats of hydrogen, ${ }^{7,8}$ oxygen, ${ }^{9,10}$ fluorine, ${ }^{11,12}$ and methane. ${ }^{13}$ Measurements of $C_{v}$ and $C_{\text {sat }}$ for liquid ethane are in progress. While not specifically designed for solidified gases the system has been used to intercompare the heat capacity of solid argon ${ }^{7}$ with excellent results. Minor modifications to the original system have been described by Goodwin and Weber. ${ }^{9}$ The only change made for the present experiment was to connect the heater voltage leads to the same potentiometer as the heater current leads. This left the other potentiometer available for a continuous display of temperature. The new connection degrades the accuracy of the power measurement to about $0.2 \%$. However, in view of other effects the inaccuracy in the powe $r$ measurement is not a limiting restriction.

\section{PROCEDURE}

The experiment consisted of running a cooling curve from several $K$ above the triple point to several $K$ below on one day, and a heating curve covering the same temperature range on the following day. A continuous display of temperature vs time was obtained on a recorder for each run. Temperatures were measured with a platinum resistance thermometer calibrated by the National Bureau of Standards on the IPTS-1968. The sample holder had been filled during a regular specific heat run with 1.432 moles of ethane. The ethane used in these experiments was commercially available research grade with minimum purity certified by the supplier at $99.98 \%$. This purity was verified by chromatographic analysis. Nominal volume of the sample holder is about $73 \mathrm{~cm}^{3}$. Thus, near the triple point the sample holder was about $90 \%$ full. With the very low vapor pressure of ethane, a negligible amount of sample resides in the filling capillary. Using liquid nitrogen as refrigerant, cooling was applied by placing helium gas in the space around the sample holder. This space is normally under vacuum. Using the known specific heat of saturated liquid ethane $e^{4}$ the cooling applied to sample and holder was estimated to be somewhat over $1.1 \mathrm{~W}$. Of course, as the temperature difference between sample holder and nitrogen bath decreased, the applied refrigeration decreased also. Total cooling time was about $1 \frac{1}{2} \mathrm{~h}$.

For the heating curve the pertinent events taken from the recorder charts are summarized in Table I. The applied power was chosen to be approximately $\frac{1}{4}$ that of the cooling, namely $0.2764 \mathrm{~W}$, in order to reduce thermometer offsets as much as possible. Total heating time was $5 \mathrm{~h}$ with power readings taken every 10 min. For a period of $30 \mathrm{~min}$ in the middle of the run the power was turned off to observe thermometer equilibration. A similar observation was made at the end of heating after all of the sample had melted. The final drift of the thermometer is quite in keeping with the normal specific heat runs on the liquid where equilibration times of up to $30 \mathrm{~min}$ are common. During the heating period both the interceptor ring heater and the 
TABLE I. Events during heating.

\begin{tabular}{|c|c|c|}
\hline Time $(\min )$ & Events & Comments \\
\hline 137. & Power on & $86.466 \mathrm{~K}$ at start \\
\hline 174.75 & $\begin{array}{l}\text { Onset of solid-solid } \\
\text { transition }\end{array}$ & \\
\hline 347. & \multirow{2}{*}{$\begin{array}{l}\text { Check thermometer } \\
\text { equilibration }\end{array}$} & \multirow{5}{*}{$\begin{array}{l}\text { Temperature lower } \\
\text { by } 0.315 \mathrm{~K}\end{array}$} \\
\hline 377. & & \\
\hline $415.3 \pm 3$ & $\begin{array}{l}\text { End of solid-solid } \\
\text { transition }\end{array}$ & \\
\hline 427.12 & Onset of melting & \\
\hline 451.25 & End of melting & \\
\hline 475 . & \multirow{2}{*}{$\begin{array}{l}\text { Check thermometer } \\
\text { equilibration }\end{array}$} & $\begin{array}{l}\text { Final thermometer drift } \\
0.46 \mathrm{~K}\end{array}$ \\
\hline 491. & & $\begin{array}{l}\text { Final temperature } \\
94.505 \mathrm{~K}\end{array}$ \\
\hline
\end{tabular}

adiabatic shield heater were under automatic control, as they normally are during a specific heat run.

\section{RESULTS}

The initial portion of the cooling curve is shown in Fig. 1. Any lingering doubts about one vs two transitions are resolved. The two transitions, liquid to solid and solid to solid, are clearly in evidence. A schematic representation of what would be expected under ideal conditions is shown in the upper portion of Fig. 1. It is obvious that the thermometer is not in equilibrium with the sample in this portion of the experiment. At the onset of each transition the thermometer recovers to a value quite close to the transition temperature but still offset from it. Maximum amount of thermometer offset in the cooling experiment is about $100 \mu \mathrm{V}$, or approximately $0.5 \mathrm{~K}$. Most of the results are, therefore calculated from the heating curve with information from the cooling curve being used to estimate errors in the measurements.

The temperature and heats of transition are given in Table II. The temperatures are taken from the heating curve at the point where the slope changes at the onset
TABLE II. Temperatures and heats of transition of ethane.

\begin{tabular}{|c|c|c|c|}
\hline$\frac{\text { Transition }}{\text { Liquid-solid }}$ & \multirow{2}{*}{$\begin{array}{l}\text { Transition } \\
\text { temperatures } \\
\text { (K) } \\
\text { This experiment } \\
\text { Eggers } \\
\text { Straty and Tsumura }\end{array}$} & \multicolumn{2}{|c|}{$\begin{array}{l}\text { Heats of transition } \\
(\mathrm{J} / \mathrm{mol})\end{array}$} \\
\hline Liquid-solid & & $\begin{array}{l}90.333 \pm 0.05 \\
90.27 \\
90.348\end{array}$ & $279 \pm 6$ \\
\hline Solid-solid & $\begin{array}{l}\text { This experiment } \\
\text { Eggers } \\
\text { Straty and Tsumura }\end{array}$ & $\begin{array}{l}89.774 \pm 0.13 \\
89.82 \\
89.8\end{array}$ & $2437.5 \pm 35$ \\
\hline
\end{tabular}

of each transition. This is also the point where the temperature curve stays flat for the longest period of time. The heats of transition are calculated from the elapsed time between phase changes, the applied power, and the amount of sample. The only time which cannot be established with any degree of precision is the end of the solid-solid transltion, as indicated in Table I. It is the uncertainty in the end of this transition which leads directly to the rather large uncertainty in the heat of the solid-solid transltion. The uncertainty in the new heat of fusion $279 \pm 6 \mathrm{~J} / \mathrm{mol}$ is estimated from the uncertainty in the power measurement $0.2 \%$ and a maximum uncertainty of $0.5 \mathrm{~min}$ in the time that this power is applied. The uncertainty can be confirmed from the cooling curve. We had estlmated the amount of cooling applied to be $1.1 \mathrm{~W}$ from the known heat capacity of saturated liquid ethane and the heat capacity of the empty calorimeter. This value together with the elapsed time yields a value of $285 \mathrm{~J} / \mathrm{mol}$ for the heat of fusion on cooling.

To calculate values of specific heat one needs, in addition to the elements above, the heat capacity of the empty calorimeter. The se values are available." Values for the speclflc heat of solld and liquid ethane calculated from the heating curve are given in Table III. The agreement between this experiment and others $\mathrm{s}^{4,5}$ for liquid ethane is excellent, $0.3 \%$. The specific heat of solid ethane below the lower transition is in very good agreement wlth the earlier measurements by Witt and Kemp. ${ }^{5}$ The agreement found here, and the fact

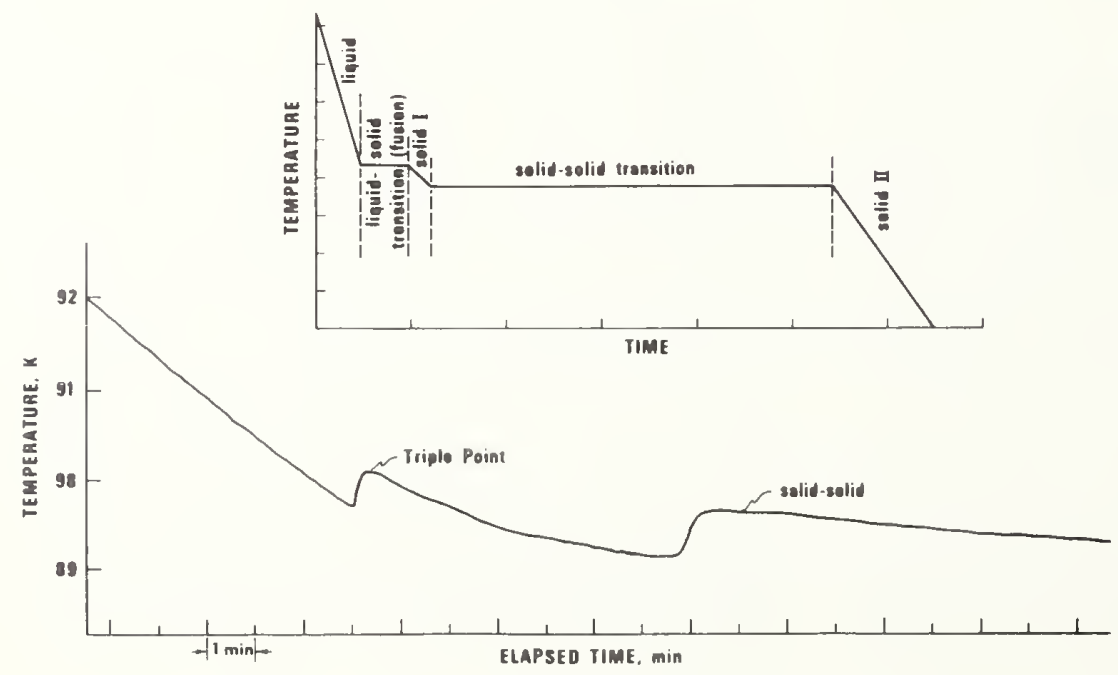

FIG. 1. The initial portion of the cooling curve.

J. Chem. Phys., Vol. 65, No, 4, 15 August 1976 
TABLE III. Specific heats of ethane.

\begin{tabular}{lllll}
\hline \hline & \multirow{2}{*}{ Temperature range } & \multicolumn{3}{c}{ Specific heats $(\mathrm{J} / \mathrm{mol}-\mathrm{K})$} \\
Phase & $(\mathrm{K})$ & This exper iment & Others & Ref. \\
\hline Liquid & $90.3-94$ & $68.5 \pm 1$ & 68.3 & 4 \\
& & & 68.3 & 5 \\
Solid & $89.7-90.3$ & $214 \pm 70^{\mathrm{a}}$ & & \\
Solid & $86.4-89.7$ & $91.5 \pm 7$ & $87.1^{\mathrm{b}}$ & 5 \\
\hline \hline
\end{tabular}

The heat capacity of the empty calorimeter is $43.95 \mathrm{~J} / \mathrm{K}$ for this interval.

${ }^{\mathrm{b}}$ At $86.73 \mathrm{~K}$.

that a highly purified sample was used, suggests that the rise in heat capacity is an intrinsic property of pure ethane. It also suggests that the impurity content of Witt and Kemp ${ }^{5}$ was probably much lower than the $0.5 \%$ that they estimated from "premelting." The uncertainty of the specific heat of the solid between the two transitions is quite large. There is a definite indication of the end of the solid-solid transition on the heating trace, however; the time associated with the end of $t_{1}$ ' transition is smeared out over an interval of about 6 min.

\section{DISCUSSION}

We note that our system is not especially appropriate for these measurements. An instrument speclflcally designed to measure heats of fusion should be thin walled, should provide ail isothermal sample space, i. e., have internal vanes and the thermometer should be mounted inside the sairsple holder in intimate contact with the samp!e being tested. As a result, the lack of precise knowledge of the sample temperature was disconcerting, but not unexpected. In both cooling and heating experiments the thermometer indication is running ahead of the true sample temperature. In Fig. 1 the thermometer recovers toward the proper temperature at the onset of each phase change but does not quite reach the actual values of the sample temperature. With the much lower power used for the heating experiment, the off set experienced at the onset of a phase change is expected to be the minimum possible, hence the transition temperatures were taken at the very beginning of each phase change. To provide an estimate of the temperature error we averaged the temperatures from both heating and cooling curves at the fixed points obtaining $90.29 \mathrm{~K}$ for the triple point and 89. $65 \mathrm{~K}$ for the lower transition. The difference between these values and the ones given in Table $\Pi$ are taken as an indication of the temperature errors at the fixed points, namely 0.05 and $0.13 \mathrm{~K}$.

The imprecision in sample temperature, however, does not carry over into the heat measurements. The indications of a phase change given by the thermometer trace are very sharp, and with the exception noted in Table I, the phase changes can be determined to better than $0.5 \mathrm{~min}$. Earlier measurements of the heat of fusion of ethane $e^{5,14}$ were made before the existence of two solid phases was known. We can compare the earlier measurements to the sum of the heat of solid-solid transition, the heat required to raise the temperature of the solid between transitions, and the new heat of fusion. The values are $2858^{5}$ and $2854 \mathrm{~J} / \mathrm{mol}$ for the present experiment. The agreement $0.14 \%$ is excellent.

The higher temperature solld has been identified as a plastlc crystal ${ }^{1,2}$ and is thus associated with a change In positional order only. The solid-solid transition is assoclated with a change ln the long-range orientational order. The entropy or enthalpy change for the melting transition is, therefore, expected to be much less than that of the solid-solid transition. Our experiment confirms this, the ratio of the heat of fusion to the heat of transition being nearly 1 to 9 .

*This work was carried out at the National Bureau of Standards under the sponsorship of the American Gas Association, Inc.

${ }^{1}$ D. S. Webster and M. J. R. Hoch, J. Phys. Chem. Solids 32, 2663 (1971).

${ }^{2}$ D. F. Eggers, Jr., J. Phys. Chem. 79, 2116 (1975).

${ }^{3}$ G. C. Straty and R. Tsumura, J. Chem. Phys. 64, 859 (1976).

${ }^{4}$ H. M. Roder, J. Res. Natl. Bur. Stand. U.S. (to be published).

${ }^{5}$ R. K. Witt and J. D. Kemp, J. Am. Chem. Soc. 59, 273 (1937).

${ }^{6}$ R. D. Goodwin, J. Res. Natl. Bur. Stand. U.S. Sect. C 65, 231 (1961).

${ }^{7}$ B. A. Younglove and D. E. Diller, Cryogenics 2, 283 (1962).

${ }^{8}$ B. A. Younglove and D. E. Diller, Cryogenics 2, 348 (1962).

${ }^{9}$ R. D. Goodwin and L. A. Weber, J. Res. Natl. Bur. Stand. U.S. Sect. A 73, 1 (1969).

${ }^{10}$ R. D. Goodwin and L. A. Weber, J. Res. Natl. Bur. Stand. U. S. Sec. A 73, 15 (1969).

${ }^{11}$ R. D. Goodwin and R. Prydz, J. Res. Natl. Bur. Stand U.S. Sect. A 74, 499 (1970).

${ }^{12}$ R. Prydz and R. D. Goodwin, J. Res. Natl. Bur. Stand. (U.S.) Sect. A 74, 661 (1970).

${ }^{13}$ B. A. Younglove, J. Res. Natl. Bur. Stand. (U.S.) Sect. A 78,401 (1974).

${ }^{14} \mathrm{R}$. Wlebe, K. H. Hubbard, and M. J. Brevoort, J. Am. Chem. Soc. 52, $611(1930)$. 



\title{
Measurements of the Specific Heats, $C_{\sigma}$, and $C_{v}$, of Dense Gaseous and Liquid Ethane
}

\author{
Hans M. Roder \\ Institute for Basic Standards, National Bureau of Standards, Boulder, Colorado 80302 \\ (August 20, 1976)

\begin{abstract}
The specific heats of saturited licuid ethane, $C_{\sigma}$, have been measured at 106 temperatures in the temperature range $93 \mathrm{to} 301 \mathrm{~K}$. The -pecific heats at constant volume, $C_{\mathrm{w}}$, have been meatured it 19 densities ranging from 0.2 to 3.1 times the critical density, at temperatures between 91 and $330 \mathrm{k}$, with pressures to 33.3 MPat at 200 PVT states in all. The uncertainty of mot of the meamements is estimated to be less than 2.0 pereent. As the critical point is approsched the uncertainty rises to alout j.0 percent. The measurement were performed to provide input data for accurate calculations of the thermodrnamic properties for ethane. Ther are believed to be the mot comprebensive specific heat measurements avalialsle for the liquid and vilpor states of ethane.
\end{abstract}

liey words: Constant rolume: ethane; heat capacity ; liquid; saturated liquid; specific heat: vapor.

\section{Introduction}

For the calculation of the thermodynamic properties of a fluid, properties such as intemal energy, enthalpy, entropy, and relocity of round. expecially at temperatures less than critical, one needs either the latent lieat of raporization or a sperific heat along a path travering the temperatures of interent. Heat capacity measurement are much easier to make than latent heat measurement-, and they are not restricted to the liquid-rapor curve but can be made at temperatures and densitien in the single phase fluid region as well.

For ethane, the specific heat of the saturated liquict, $C_{\sigma}$, was measured from 9.3 to $301 \mathrm{~K}$, and -pecific heats at constant rolume, $C_{r}$, were measured on 19 isochores with den-ities ranging from $1.5 \mathrm{~mol} / \mathrm{l}$ to $21 \mathrm{~mol} / \mathrm{with}$ temperatures from 91 to $330 \mathrm{~K}$ and presires up to $3.3 \mathrm{MPa}[1]{ }^{1}$

In a forthcoming publication Goodwin [2] uses the present results together with extensive $P^{\prime} V T$ data to construet a complete thermodynamic network for ethane from the triple point to $600 \mathrm{ki}$ with presirues up to $70 . \mathrm{MPa}$.

\section{Experimental Method}

The basics of the specific heat experiment are deceptively simple. The heat capacity of a sample of fluid is determined in principle as follows. A sample holder is filled with a known amount of *This work was carried out at the National Bureau of Standards under the
sponsorship of the American (ias $\Lambda$ ssociation.

1 Figures in brackets indicate the litcrature references at the end of this paper. sample, $\lambda$, and is placed in an adiabatic environment. If we now apply a carefully measured amount of heat, $Q$, to the sample holder, then the temperature of sample and holder will rive to a new ralue, from an initial temperature. $T_{1}$, to a final temperature, $T_{2}$, the change in temperature being $\Delta T$. 'T'o obtain the heat capacity of the sample we must account for the heat aborbed by the container. This is accomplished by condueting a second experiment with the sample holder empty to find the heat capacity of the empty container, $C_{0}$. With

$$
C_{0}^{\prime}=\frac{Q_{\mathrm{MT}}}{\Delta T_{\mathrm{MT}}}
$$

the desired specific heat of the sample can be calculated from

$$
C=\frac{Q-C_{0}^{r} \cdot \Delta T}{\Delta T \cdot N} .
$$

Thus, the parameter's we must measure in the experiment are $C_{0}, Q, \Delta T$, and $N$.

\section{Apparatus and Procedures}

The apparatus used is a constant volume adiabatic calorimeter fully described by Goolwin [3]. The essential features are a spherical sample holder, a filling capillary, a heating/cooling interceptor guard ring, an adiabatic shield, and a platinum resistance themometer mounted on the sample holder. Calorimeter and cryostat are shown in figure 1. The refrigerants used were liquid nitrogen, ice, and cold 
water. 'The instrument has been used to measure the specific heats, $C_{\sigma}$ and $C_{r}$, of hydrogen $[4,5]$, oxygen $[6,7]$, fluorine $[8,9]$, and methane $[10]$. Measurements of the heat of fusion and of the solid. colicl trunsition in ethane with this apparatus have been reported elsewhere [11]. Minor modifications. to the system have been described by Goodwin and Weber [6].

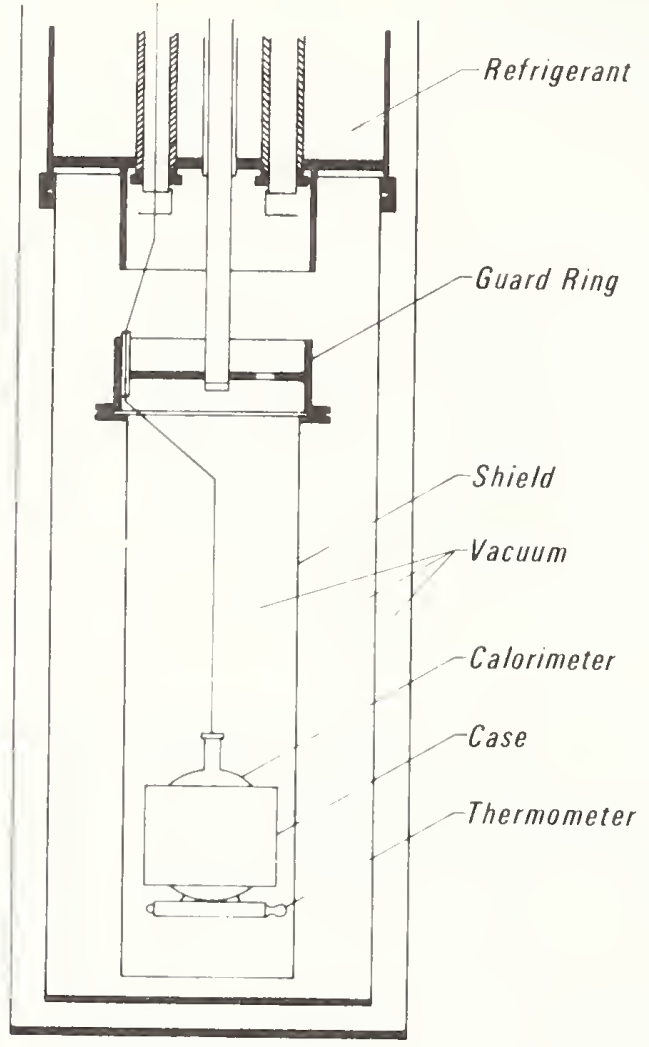

Fistor 1. Calorimeter and rryostal,

The major experimental parameters are (), $\Delta T$, and $\Lambda$. 'These are measured as follows. We obtain the calorimetric heating rate from nearly simultaneous readings of the potential and current applied to the calorimeter heater. 'The time of the heating interval is mensures by an electronic counter triggered by the potential across the calorimeter heater. Temperatures are measured with the platinum resistance thermometer. 'Tlye thermometer was calibrated by the NBS' Temperature Section. Temperatures are on the IP'TS-68 scale. The temperature of the acliabatice shield and guard ring are controlled to the sample temperature with difference thermocouples and automatic power regulation. 'The amount of sample is determined from an observed temperature $T$ and pressure $P$ in the single-phase domain, from the bomb volume at this $T, P$, and from the fluid density derived from an equation of state [2].

The ethane used in these experiments was commercially available research grack with minimum purity certified by the supplier at 99.98 percent. This purity was verified by chromatographic analysis.
The procedures used for measurement of the empty calorimeter, for loaling of the sample, and for the specific heat measurements are the same as those used previously [4-10] except for filling the sample holder at low densities, and in the sequence of measurements. Differences in the filling of the calorimeter arise because the critical temperature of ethane is above room temperature. 'The ethane supply tank is normally at room temperature, about $296 \mathrm{~K}$ and the corresponding supply presiture, vapor pressure, is about $4 \mathrm{MPa}$. Fillings with liquid densities down to $12 \mathrm{~mol} / \mathrm{l}$ are determined by selecting the temperature of the calorimeter, as before. However, different techniques har to be used to achieve densities below $12 \mathrm{~mol} / \mathrm{l}$. One was to raine the filling pressure by placing the ethane supply tank in a hot water bath, up to $40^{\circ} \mathrm{C}$. 'The other was to fill the sample holder around $12 \mathrm{~mol} / \mathrm{l}$, heat it to a temperature above critical, and then bleed it in small increments down to the desired density.

The sequence of measurements adopted was to conduct the $C_{\sigma}$ and $C_{n}$ measurements with a single filling rather than with different fillings as was the practice before. In this scheme the sample holder is filled to a known density in the single phase region and is then cooled to a temperature where both liquid and vapor are present in the calorimeter. Heating intervals are applied to the two plase sample, the data reduction vields values of $C_{\sigma}$. During these measurements both liquid and vapor densities are changing, grachally filling the sample holder. From that point on the data reduction is carried out to yield values of $C_{r}$. The heating interval in which the sample holder contains both two phase and single phase fluid is ralled the "breakthrough" point. $\AA$ sharp change in rate of temperature rise cau be seen on a recorder trace of calorimeter temperature, and botl guatel ring and shichl heaters slow a slight "bump" on the recorder traces of the differential thermocouples corresponding to a cliange in power requirement.

\section{Calculations and Adjustments}

The data resluction applicable to this experiment las been desmibed in detnil by Goodwin and Wober $[6,7]$. However, for ethane the separate programs of $C_{\sigma}$ and $C_{n}$ were combined and a phasefinder developed that would pinpoint the "breakthrough" point of each filling. "The phasefincter, the filling comblition: and the PVT conditions at which each point was measured are based on the equation of state by Goodwin [2].

One of the primary experimental parameters is the total amount of sample in the system, $N$. The pressure and temperature at filling are measured, the corresponding density is calculated from the PVT surface, and $N$ is evaluated from a knowledge of the calorimeter volume, and the various ancillary volumes such as capillary, connector, and valve volumes. As mentioned before, the critical point of ethane, at $305.33 \mathrm{~K}$, is above room temperature. A number of fillings and experimental measurements 
were made between 305 and $3: 30$ K. For these rums the portion of the sample in the rapillaty is not negligible, and has to be aceomented for aceurately. Ali of the "nulisanes" volumes were revised, in furticulat the valve volume which, nominally at room temporature, was larome than previonsly estimatrel. 'To paltially alleviate the problem the valve was flermostaterl at $40^{\circ}{ }^{\circ}$, ambl a varjable valve temperature was included in the data reduction routine- 'The amoment in the capillary is determined by as-monine a temperature di-tribution along the capillatr. Thi- distribution was changed to accommorlate a vallable temperature at the valve end.

soveral otlere correstions made in the programs are reviewerl hriefly. The ealorimeter volume elepende both on temperature, themal expansion, and on presme $[4,6]$. Sinne the sample holder is a thin -tainless steel splace it stretches as the presime

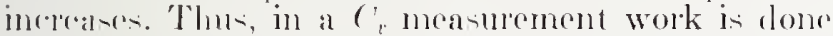
by the sample due to the increase in sample volume. 'lihic romeretion deroloper ly Walkel [12] ranges from 0.5 to 5 pereent of tlie resilting $C^{\prime}$ value. Hewrere, it can be marle acemrately. 'The density for earhe o; measurement is ralculated form the filling density alter correcting for sample holder (xpan-ion and the amount compresied into the filling capillaty [7]. In the case of a ${ }_{\sigma}^{*}$ measmement the reflects of the latent heat of vapolization and heat absorbed by the rapor must be subtracted $[4,6, s]$. 'This true of correcetion has been deriver by $11000[1: 3]$.

It is worthwhile to mention that of the there -late valiables, presime, trmperature, and den-ity, only temperature is moastures during the moasmemont of at serefle herat point. 'The amomnt of sample in the ralorimeter is used to establish tle density and

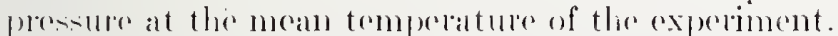
Hlile the total amome of sample lemains eomstant,

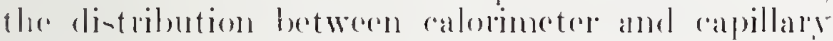
rlanere from point to point berames the ralori-

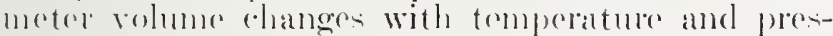

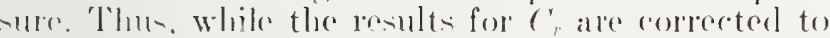

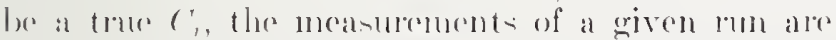

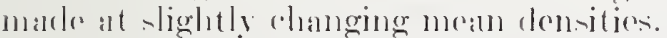

( imvature arljustmente lave berm marle for the rovalure at tomperatures aloura $101.5 \mathrm{~K}$. Arljust-

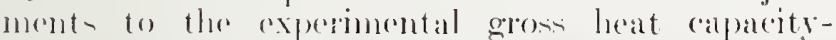

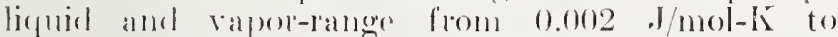
()..366 . I mol-k, or up to 0.16 pereent of the total valur of ('o. ('mvature arljustmente for tlo valure of (' wore not significant, and wore, therefore, omiterl.

\section{Heat Capacity of the Empty Calorimeter}

Farly entimater rovalerl that moler the best of cincumintanese 50 pereont of the applied heat is

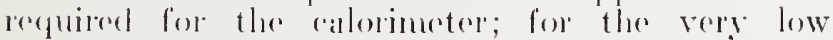

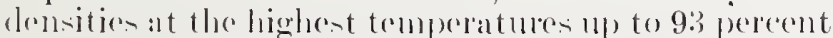
of the lantine eroes to raise the temperature of the ralorinetre. Since the critical temperature of ethane

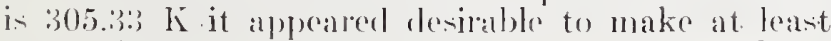
somo of the ('omeasurements at temperatures above critical. An upper limit of $33.3 \mathrm{~S} \mathrm{~h}$ is imposecl by the facet that the platimum resistance thermonoter is mometed with IVoorl's metal, which melts at $65^{\circ} \mathrm{C}$

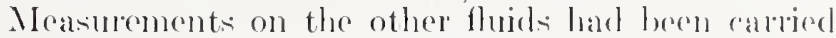
out to only $300 \mathrm{~K}$, therefore, an extemion of the measmements on the empty calorimoter were inclicated.

Remeasuring the heat capacity of the calomimetre $C_{0}$ provider an opportunity to conduet arlitional checks of the sytem with regarel to sistematic crrolis, and to see if the precision of the measmenent:could be improverl. The measmements of the hoat capacity of the empty ealorimeter inclucles laror and smatl $\Delta T^{\prime}$ 's from is to $0.5 \mathrm{~K}$; larese and small applied powers, from 1.0 to 0.23 W; lums witle deliberate temperature offects in both gamel rine and sholel temperatures, :3 K $(100 \mu \mathrm{V})$ hot amrl coldi as well as different coolante in the refrigerant tank, rouns 2, 3, 4, witl ire and rmas 5, 6, 7 with linuid nitrogen. 'The resulte of theso measurements, some 92 points, are shown in table 1. The applied temperature rlifferences aro small momgh so that a curvature colreretion is not requimed. Intereomparison of the lata is achereet loy using the functional reperesentation developerd by Goodwin and Weber [6].

$$
\operatorname{Loge}_{c}\left(C_{0}^{r} / 50\right)-\sum_{i=1}^{8} C_{i} \cdot(100 / T)^{i-1} .
$$

Values of the eoeflicients, ${ }^{\prime}{ }_{i}$, are given in the hearliner of talile 1 .

Points 208 through 304 ale included in table 1 to show the most extreme valiation in $J T$. 'They were not lusel to obtain the roefficionte, $C$, because durine these rums one of the olec. amplifiel's laal a large bias which was not coreceterl mut the stat of run 4. The analytical emre represents the heat capscitios of the empty ralorimeter with an imprecision of 0.07 pereont. 'To the level of 0.1 pereent

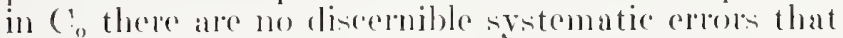
can be related to the size of the $\Delta T$, the size or rate of the applion heation, the temperature gradient of the capillaty, or to tomperature erors in shiedel or gratul ling systems. 'The igleement of the present values with those measurel by Gooklwin and Weber [6] is well within the imprecision of the separate measurements. In the temperature range 87 to $320 \mathrm{k}$ the wnecetainty in the fuantity $\left.\left(Q-C_{0}\right\lrcorner T\right) / \Delta T$ will range from 0.04 to $0.08 . \mathrm{J} / \mathrm{K}$ die to the uncertainties in $C_{0}^{\prime}$ alonic

\section{Results}

The results to be presented incluele values for the specific lieat of saturated liquid ethane, values for the specific heat of single phase ethane, both in complesicel liguid and in gascous states, mond a limited sot of measmements on methane, mate for pulposes of comparison. As mentioned above, both $C_{\sigma}$ and

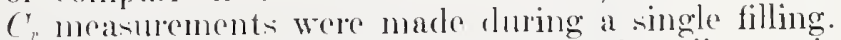
Table 2 gives the loading conditions for all experimental runs; the rums are shown in density-temperature coorlinates in figure 2. 'Temperature and pres- 


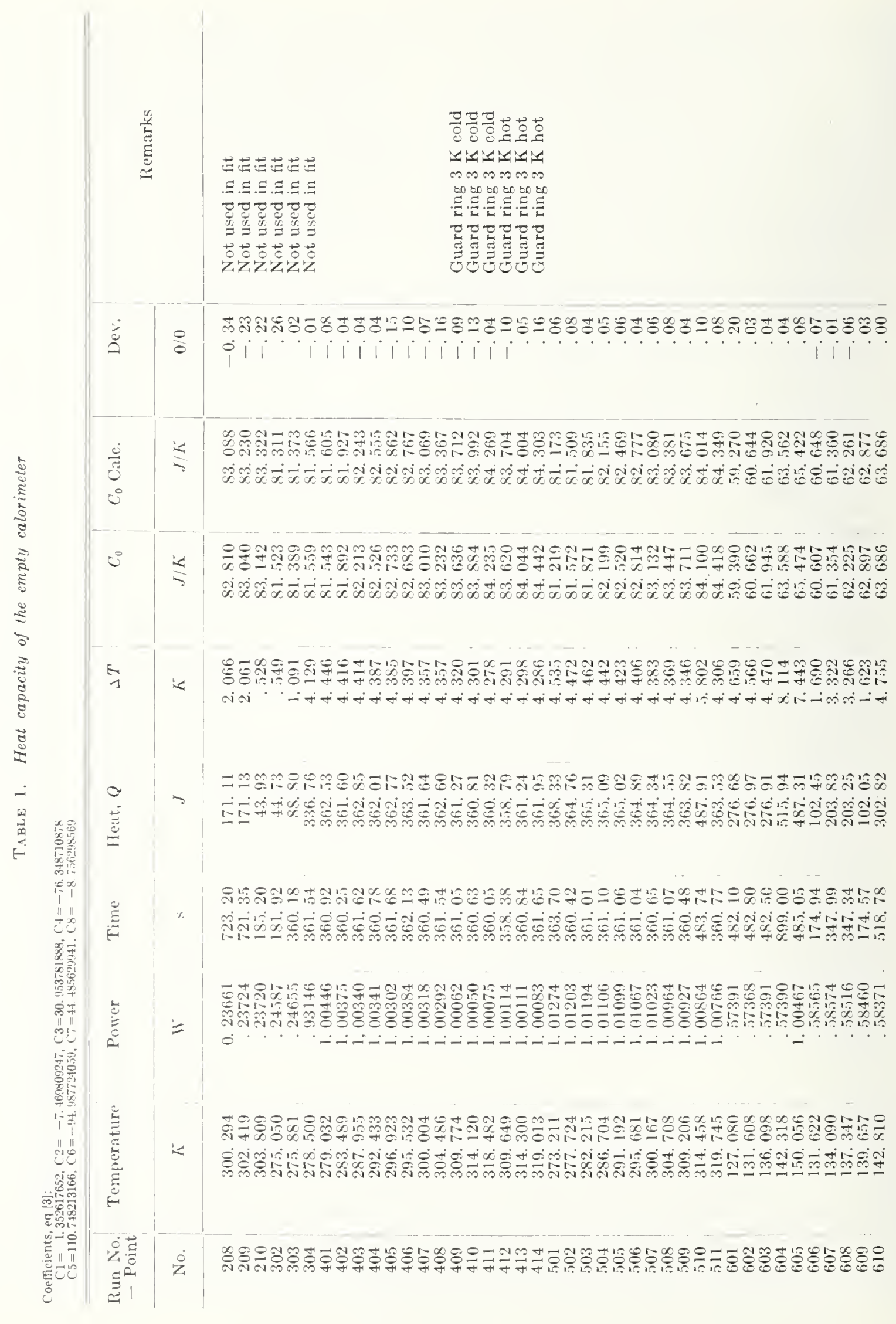




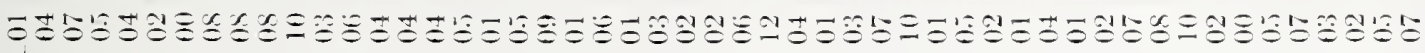

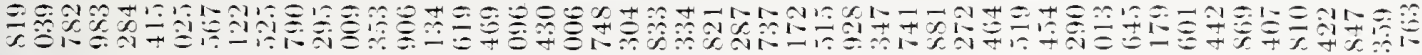

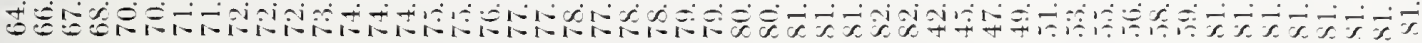

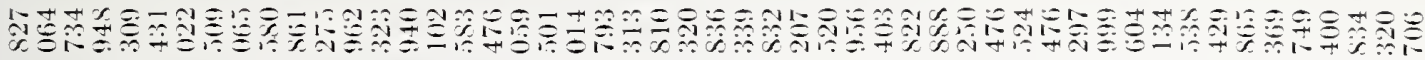

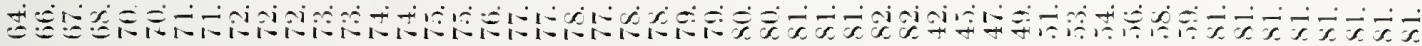

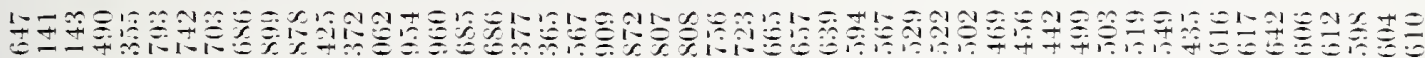
ه

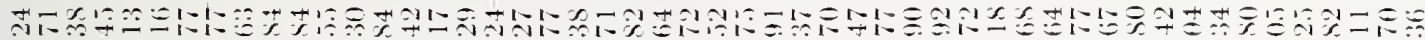

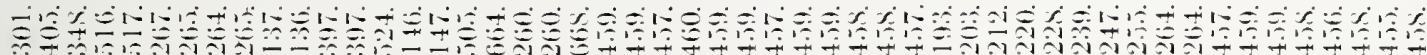

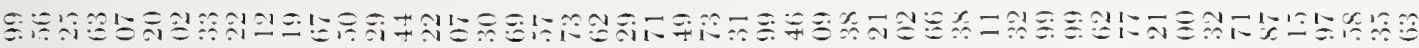

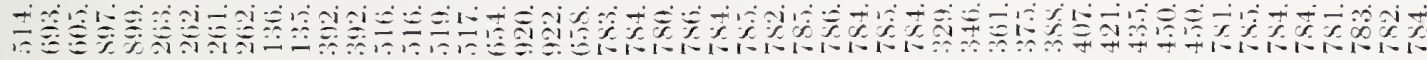

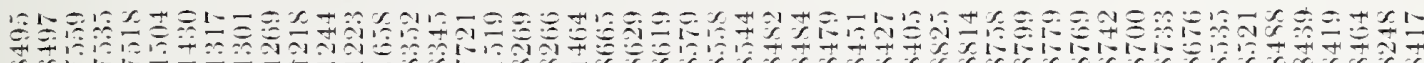

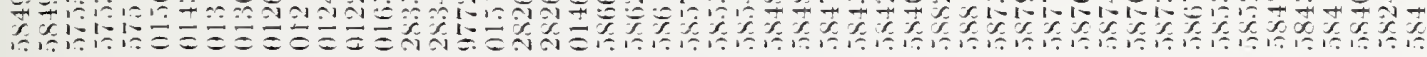
-

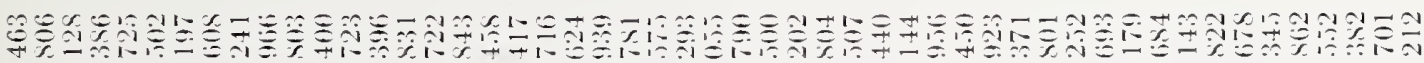

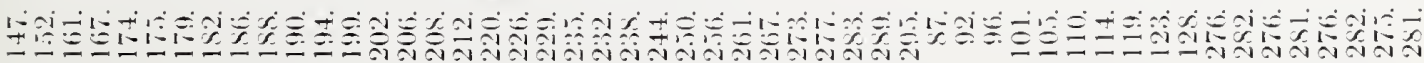

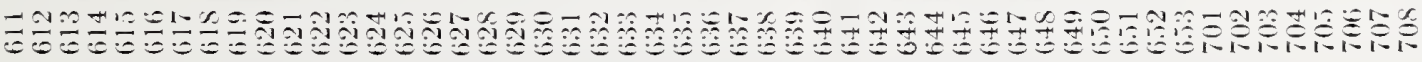


T.unL. 2. Calorimeter loading conditions for the measuremont runs

\begin{tabular}{|c|c|c|c|c|c|c|c|c|}
\hline \multirow{3}{*}{$\begin{array}{l}R u n \\
\text { Nu. }\end{array}$} & \multirow{2}{*}{ Pressure } & \multirow{2}{*}{ 1)encity } & \multirow{2}{*}{ Trmperature } & \multirow{2}{*}{$\begin{array}{l}\text { Cislorimeter } \\
\text { volnunce }\end{array}$} & \multirow{2}{*}{$\begin{array}{l}\text { Tot:sl } \\
\text { simple }\end{array}$} & \multirow{2}{*}{$\begin{array}{c}\text { Valve } \\
\text { temperature }\end{array}$} & \multicolumn{2}{|c|}{ Breakthrough conditions } \\
\hline & & & & & & & Density & Temperature \\
\hline & MPal & $\mathrm{mol} / \mathrm{l}$ & $K$ & $\mathrm{~cm}^{3}$ & mol & $K$ & $\mathrm{~mol} / \mathrm{l}$ & $\kappa$ \\
\hline 1 & 4. 0952 & 14. 641 & $2 . \overline{8} .899$ & 73.238 & 1. 0730 & $296.4 i$ & 14. 659 & 2.54 .048 \\
\hline 2 & 3.8329 & 20.998 & 110.512 & 72.794 & 1. 5289 & 296.45 & 21.013 & 105.627 \\
\hline 3 & 4. $075: 3$ & 16.13 .5 & 231.874 & 73.150 & 1. 1811 & $29(i .45$ & 16.157 & 227.207 \\
\hline 4 & 3. 89996 & 19.648 & 147.427 & 72.8992 & 1. 4326 & 296.45 & 19. $66 ; 44$ & 144.870 \\
\hline$i$ & 2.3023 & 18. $92: 3$ & 165.524 & 72.928 & 1. 3802 & 314.6 .5 & 18.932 & 16i3. 802 \\
\hline 6 & 3.8980 & 17.985 & 190.218 & 73.018 & 1. 3135 & 314.5 & 18.001 & 186.776 \\
\hline 7 & 3.4113 & 16.912 & 214.723 & 73.089 & 1. 2363 & 314.27 & $16.92 \pi$ & 211.275 \\
\hline 8 & 4. 0396 & 15. 0.59 & 251.910 & 73.215 & 1. 1028 & 314.19 & 1.5 .071 & 247,239 \\
\hline 9 & 3.9223 & 14. 001 & 268.047 & 73.267 & 1. 0261 & 314.16 & 14.010 & 263.866 \\
\hline 10 & $3.917 x$ & 12.9 .10 & 280.749 & $7 \therefore 308$ & .9495 & 314.00 & 12.9 .56 & 277.448 \\
\hline 11 & 3.9875 & 11. 978 & 289.559 & 73.339 & .8786 & $31: 3.42$ & 11. 981 & 287.411 \\
\hline 12 & 5. 3477 & 万. 886 & 310.707 & $73.42 . ;$ & .4325 & 314.15 & 5. 889 & 305.158 \\
\hline 13 & 5. 0159 & 4. 610 & 308.612 & 73.414 & $3: 3 \times 7$ & 313.15 & 4. 612 & $30: 3.177$ \\
\hline 14 & 4. 9.503 & 9.179 & 304.928 & 73.401 & 6740 & 313. ing & 9.181 & 303.179 \\
\hline 15 & 5. 4isici & 3. 269 & 329.810 & 73.491 & 2406 & 313.25 & 3.277 & 290.609 \\
\hline 16 & 5. 2186 & $11.04 \%$ & 299.922 & 73.387 & 8109 & 313.25 & 11.0 .33 & 294.671 \\
\hline 17 & (j. 01.58 & 7. 884 & 313.979 & 73.444 & .5796 & 313.17 & 7. 894 & $30.5,106$ \\
\hline 18 & 4. 01370 & 20.298 & 129.892 & $72 . \times 4)$. & 1. 47900 & 236.45 & 20.314 & 127.574 \\
\hline 19 & 3.2471 & 1. 583 & 319.878 & 73.431 & $.116 i 3$ & 313.75 & 1. & 274.2 .78 \\
\hline
\end{tabular}

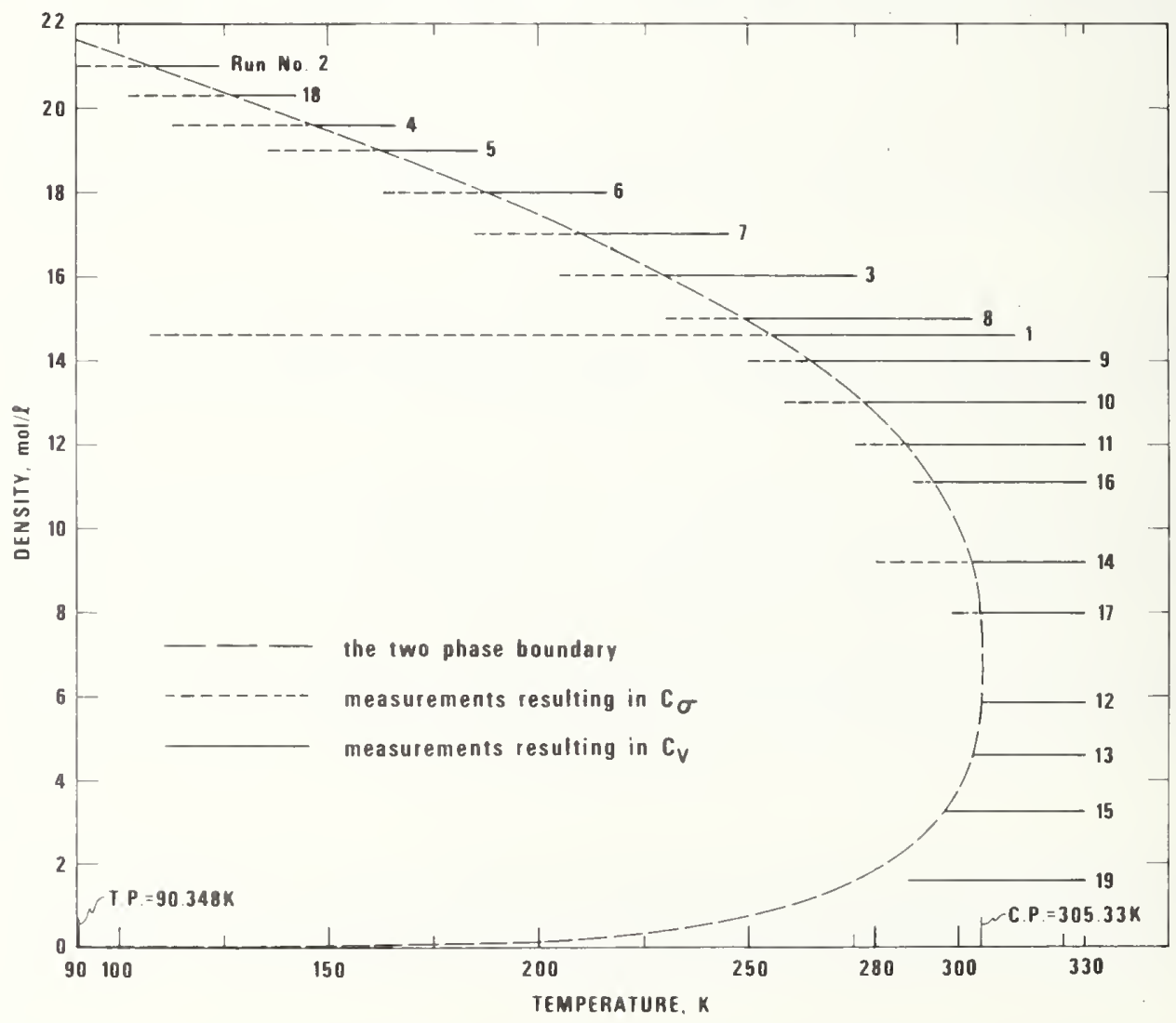

Figuri: 2. The locus of experimental runs in the density-temperature plane.

the two phase boundary

measurcments resulting in $C$ 
sure, obtainel by computation from laboratory observations, are in effect divect measmementi. The rolume of the calorimeter is computed, the density is obtainerl from the equation of state [2]. The total mumber of moles, $N$, inclucles the amount in capillary and valve with the upper stem temperature cofual to the indicated valve temperature. Breakthrough density and temperature define the point on the saturation boundary applicable to the run in question. 'The values are calculated from the equation of state, the loading conclitions and the vapor presiure by considering the variation of calorimeter volume with temperature and pressiure.

\subsection{Performance Tests: The Specific Heats $C_{1}$ and $C_{\text {, }}$ of Methane}

Prior to making measurement: on ethane we made a limited sot of measurements on methane. The purpose was to check on the operation of the instrument by comparion to the values previously meanured ly Founglove [10]. Several values of $C_{\sigma}$ and 29 valucs of ${ }^{r}$. were measumed at three diflerent filling densities and at willely differing temperatures. Results und comparisons are shown in table 3. 'Two conclusions can be drawn from the measurements on methane. (one is rather surporising, namely that the values of the specific lieats calculated from the raw lata will differ, if slightly different $P^{\top} T$ surfares are used in the rata reduction process. 'The other is experterl, mamely that the vahues of the specific heat: repend rirectly on the ralues neasures for the heat (apacity of the empty calorimeter.

To calculate the present results, which are shown in rolumn 5 of table: 3 , we used Goolwin's most rorent lommulation of the /PrT suface of methane

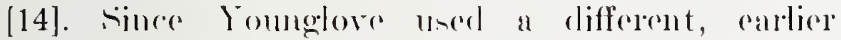

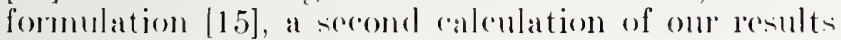

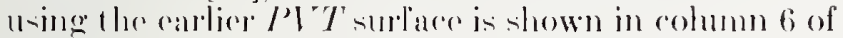

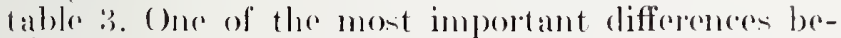
twern then two /'I'T surlares is the asignment of

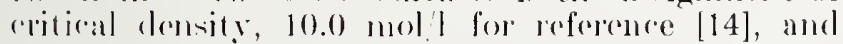
10.15 mol I lor reforence [15]. 'Tho intereompantisom

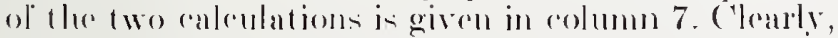
beth $\left(\begin{array}{c}\sigma \\ \text { and }\end{array}\right.$

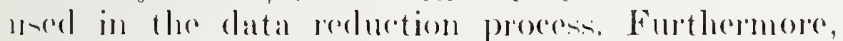

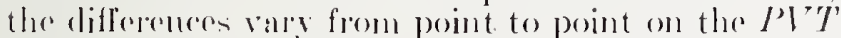
surfares. Rereomputing all of Yommglove's results witle tho two diflorent /'l'T surfares loads to maxi-

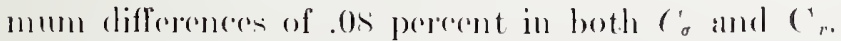
Areorelingly, the most romsiatent was to compalre tho prosent resulte with those of Yomglove [10] is

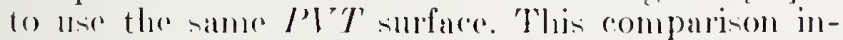
volves rolummes of and 10 of table :3, with differences given in rolumm 11. The disagerement between tho two cral explanations were considered, only one of which is rli-played in table :3. Thore exists a romsistent officet, 0.4 pereent, betweon the ('s meanued in the romrse of this rxperiment and that measured by

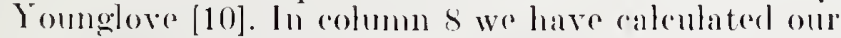
present results on methane using lomblove's [10] values for ('c and Goodwin's earlier formulation of the I'VT surface [15]. Column 9 shows the departure of the values in rolumm is foom those in reolumn 6 . Finalls, a romparison of columns 9 and 11 sllgerets if not quantitutivoly, then at least qualitatively, that indered the difference in the values of the $C_{0}$ is the explanation for the difference between the present measurements and those of lommglome [10].

\subsection{The Specific Heats, $C_{\sigma}$, of Saturated Liquid Ethane}

The specific heat of saturated licquid ethane was measmed for 106 temperatures. 'The lowest was 93.7 K, the triple point is $90.348 \mathrm{~K}$, the highest tomperature was 301.5 li, the critical point is 305.33 K. Values of $C_{\sigma}^{\prime}$ along witl the experimental conditions, experimental parameters, and the various correction terms are given in table 4 . A plot of $C_{\sigma}$ is shown in figure 3. 'The moasmements for Co were made with $\Delta T$ betwoen $: 3$ and $5 \mathrm{kolvin,}$ and with loalings such that at rach tomperature ( ${ }_{\sigma}$ is defined by at loast two different fillings (see rolumn 11 , tablo 4). ("urvature corpections were necessary only at temperatures above 101 li. 'The resulte for $C_{\sigma}$ are represonterl with an malytical equation as follows:

$$
C_{c}=C_{1}+C_{2} T+C_{3} T /\left(T_{c}-T\right)^{0.6}+C_{4} / T+C_{5} / T^{2}
$$

where $T$ is the critical tomperature, $305.3 .3 \mathrm{~K}$ and values of the coofficients are given in the heading of table 4. Talues ralrulated from eq. (4) and differences between oxperimental and calculated values expresied in pereont are atso given in table 4. 'The standarel deviation of the entire fit is $0.3 \mathrm{~J} / \mathrm{mol}-\mathrm{li}$. For tomperatmes brlow 260 li the imprerision in the experiment is \pm 0.1 pereent, not much larger than that experiencol for measmements of tho cmptr culorimeter. ('onsirlering all solures the astimated mocertaints in the measured value of $C_{\sigma}{ }_{\sigma}$ is about 0.5 perecrit gencrally, increasing to about 5 porent within a fow kolvin of the rritical point

Comparison with the earlier measurements of Wicbe ret al. [16], and Witt and Kemp [17] is made using eq (4) for interpolation. Differenres in $C_{\sigma}$ are shown in tabla 5. "Ther are negligible at low temperatures but increase gradually to 5 percent at the highest temperatures of comparison. 'The explanation of the difforeness lios in the different PVT surfares used to evaluate the experimental data and correction terms, in particular the rather large difference in asignnent of the critical density, $6.80 \mathrm{~mol} / \mathrm{l}$ this experiment and $6.99 \mathrm{~mol} / \mathrm{l}$ for the other authors.

\subsection{The Specific Heats, $C_{i}$, of Dense Gaseous and Liquid Ethane}

The specific heats at constant volume werc measured at 19 densitics ranging from 0.2 to 3.1 times the critical density, at temperatures between 91 and $3: 30 \mathrm{~K}$, and with pressures to $33.3 \mathrm{MPa}$. As shown in figure 2, a given density is limited either by the maximum allowable system pressure, about 


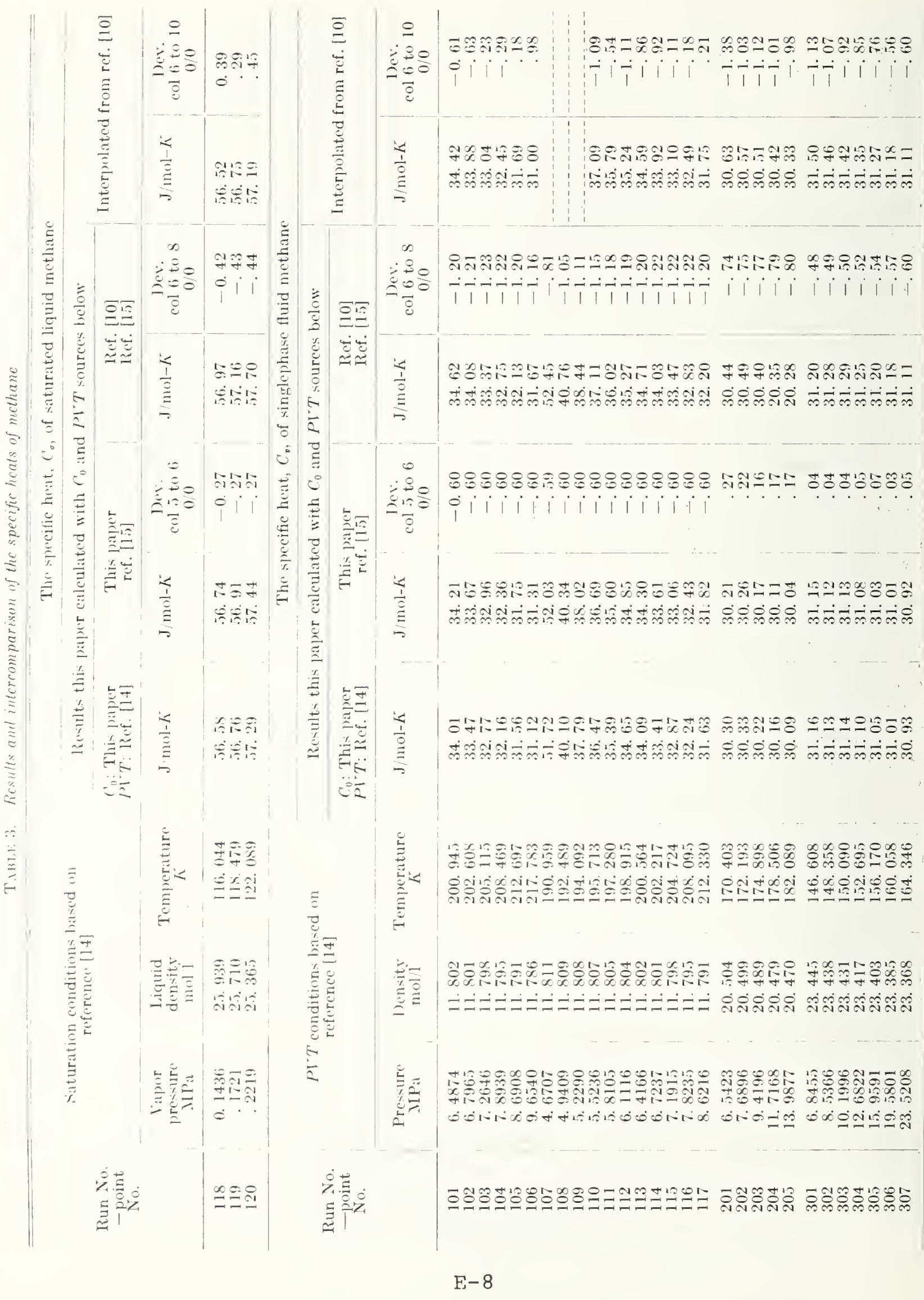




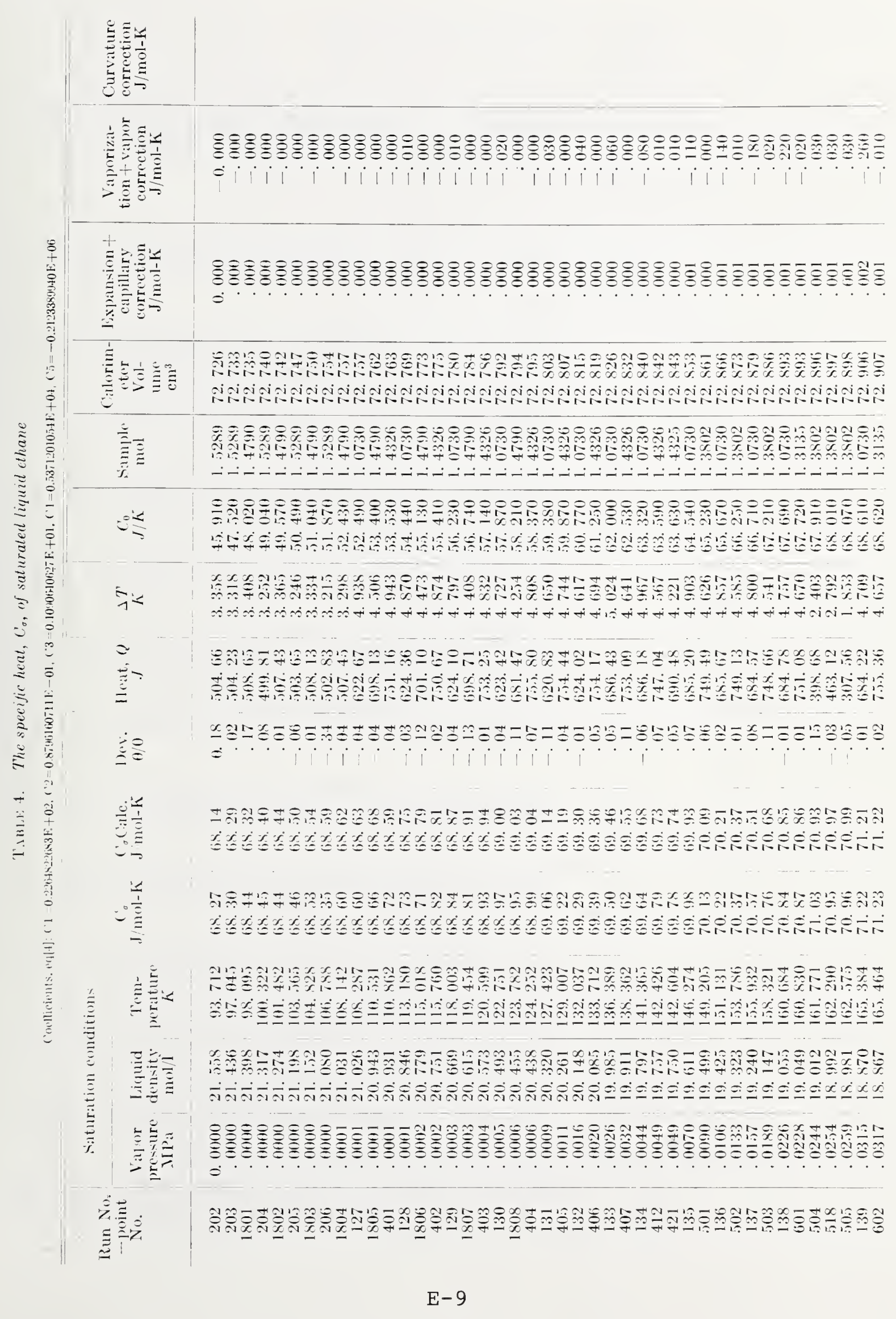




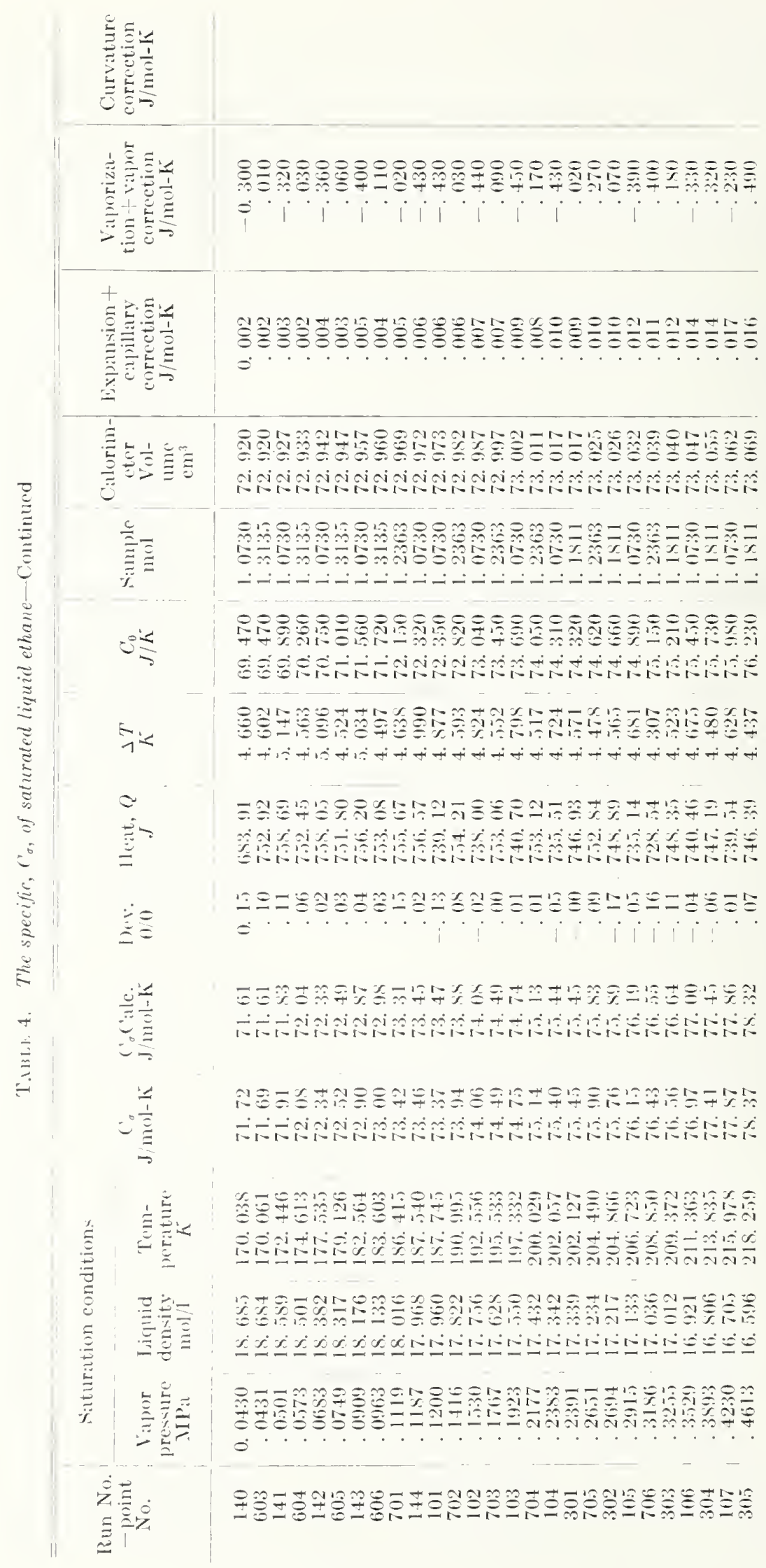




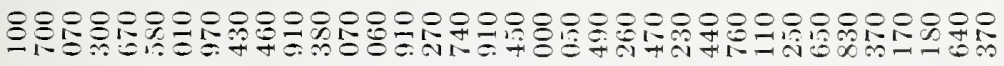

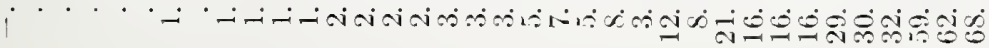

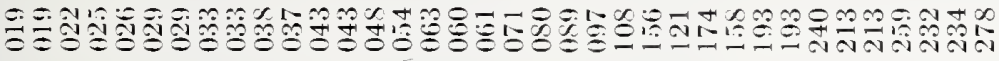

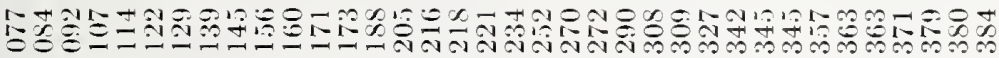

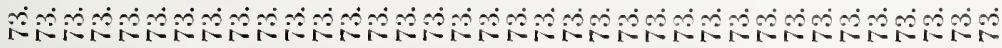

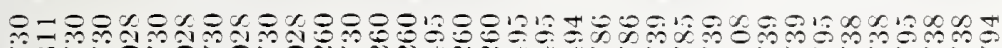
승

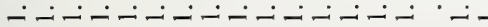

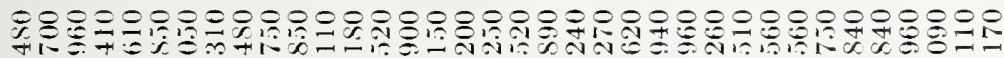

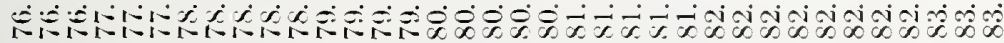

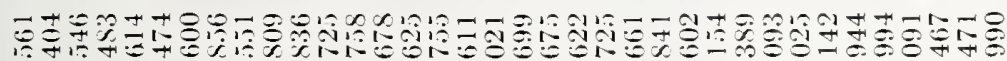

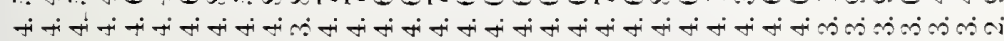

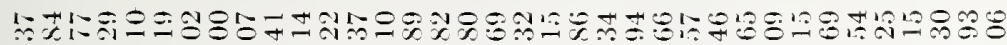

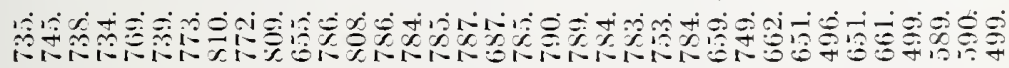

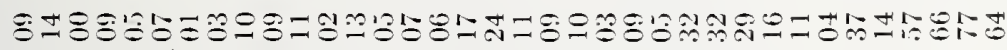

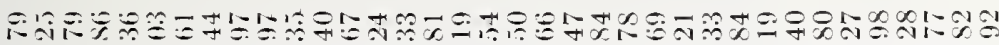

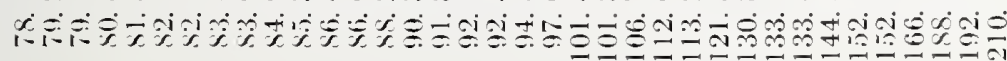

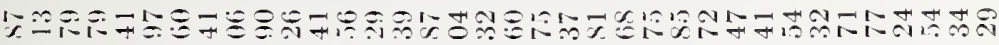

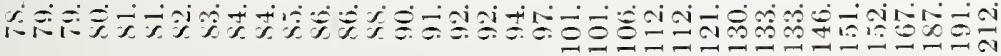

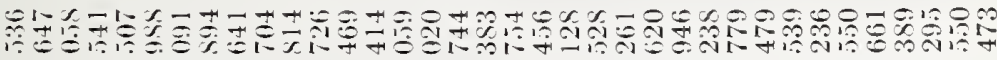

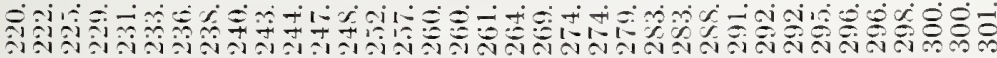

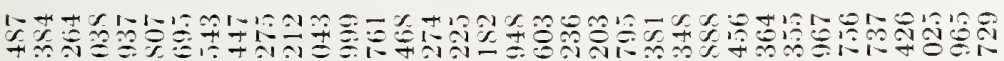

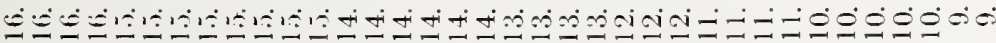

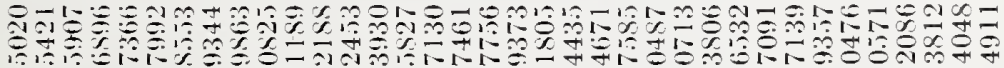

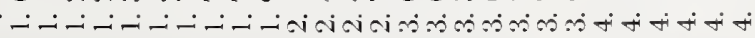

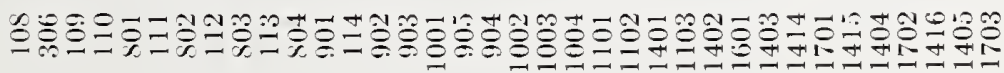


$35 . \mathrm{Pa}$, which in turn leads to a maximum pressure of 33 MPa at the mean temperature of the experiment, or by the upper limit in temperature, $330 \mathrm{~K}$. Values of $\dot{C}_{r}$ along with the experimental conditions, the major experimental paraneters, and the correction term are given in table 6. The temperature and density dependence of $C_{r}$ is illustrated in figure 4. For a wite range of densities to either side of the critical density the specific heat increases sharply as the coevistence enevelope is approarched. At liquirt den-ities far removerl from critical the temperature dependenee is relatively weak.

T.IBI.I: 5. Comparison of the calculated $C_{\sigma}$ with results of others

\begin{tabular}{c|c|c|c}
$\begin{array}{c}\text { Tempera- } \\
\text { ture } K\end{array}$ & $\begin{array}{c}\text { Co-caleulated } \\
\text { this paper } \\
\text { Jimol-K }\end{array}$ & $\begin{array}{c}C_{0} \text { from the } \\
\text { literature } \\
\mathbf{J} / \text { mol-K }\end{array}$ & $\begin{array}{c}\text { Difference } \\
\text { in } 0 / 0\end{array}$ \\
\hline & Reference $[16]$
\end{tabular}

\begin{tabular}{|c|c|c|c|}
\hline 96.77 & 68.27 & 68.46 & -0.3 \\
\hline 96.82 & 68.28 & 68.76 & -.7 \\
\hline $98.09 ;$ & 6.8 .332 & 68.55 & -.3 \\
\hline 101.54 & 68.44 & 68.71 & -.4 \\
\hline 107.08 & 68.60 & 68.63 & -.0 \\
\hline $10 \times .6 .5$ & 68.64 & 68. 5.5 & .1 \\
\hline 11.5 .74 & 68.81 & 68.67 & .2 \\
\hline 116.19 & 68. 82 & 68.45 & . i) \\
\hline 122. 70 & 69.00 & 69.13 & -.2 \\
\hline 123.60 & 69.02 & 69.17 & -.2 \\
\hline 128.08 & 69.16 & 69. & -.6 \\
\hline $12 \times .4 !$ & 69.17 & 69.51 & -.5 \\
\hline 132. 6i. & 69. 32 & 69.84 & -.8 \\
\hline 138.00 & $69.5: 3$ & 69.89 &.$- j$ \\
\hline $13 x .18$ & 69.54 & 70.01 & -.7 \\
\hline 138.31 & 69. & 69.84 & -.4 \\
\hline 142.43 & 69.73 & 70.10 & -.5 \\
\hline 143.36 & 69.78 & 70.0 .5 & -.4 \\
\hline 151.75 & 70.24 & 69.97 & .4 \\
\hline 1.22 .60 & $70 .: 30$ & 70.14 & .2 \\
\hline 154.99 & 70. $4 \pi$ & 70. 26 & .3 \\
\hline 156.98 & 70.18 & 70.26 & .5 \\
\hline 1.77 .42 & 70.61 & 70.10 & .7 \\
\hline 160.10 & 70.80 & 71.10 & -.4 \\
\hline 162. (ii) & 70.99 & 71.18 & -.3 \\
\hline 164.49 & 71.14 & 71.73 & -.8 \\
\hline 16.5 .93 & 71. 26 & 71. 31 & -.1 \\
\hline 168.093 & 71.44 & 71.60 & -.2 \\
\hline 170.18 & 71.62 & 71.77 & -.2 \\
\hline 172.45 & 71.79 & 71.77 & .0 \\
\hline 172. (i9) & 71.85 & 72. 1.) & -.4 \\
\hline $17 \times .17$ & 72.39 & 72.82 & -.6 \\
\hline 181.50 & 72.75 & 73.07 & -.4 \\
\hline 182.043 & 72.81 & 7:3. 32 & -.7 \\
\hline 190,60 & 73. 7.5 & 73.53 & .3 \\
\hline 199.86 & 7.5 .11 & 74.37 & 1. 0 \\
\hline $205 . \mathrm{KS}$ & 76.56 & 75.66 & 1. 2 \\
\hline 212.80 & 77.26 & 75.96 & 1. 7 \\
\hline 220. 4is & 78.78 & 77.80 & 1. 2 \\
\hline 225.76 & 80.67 & 80.61 & .1 \\
\hline $236 \% .21$ & 82.65 & 82.32 & .4 \\
\hline 244. (61 & 8.5 .28 & 83.96 & 1. 6 \\
\hline 2.52 .53 & 88.29 & 87. 14 & 1.3 \\
\hline 2.5 .22 & 90.89 & 88.44 & 2. 7 \\
\hline 265.25 & 94.80 & 92.33 & 2. 6 \\
\hline $273.06 j$ & 100.53 & 98.11 & 2. 4 \\
\hline 278.07 & 105.41 & 101.333 & 3. 9 \\
\hline 284.07 & 113.41 & 109. 12 & 3.8 \\
\hline 291.27 & 129. & 122.69 & 5. 1 \\
\hline 294.8 .5 & 142.89 & 13\%. 79 & 5. 0 \\
\hline
\end{tabular}

T.1BLE: 5. Comparison of the calculated $C_{0}$ with results of othersContinued

\begin{tabular}{c|c|c|c}
$\begin{array}{c}\text { Temper:- } \\
\text { ture } K\end{array}$ & $\begin{array}{c}\text { Co-calculated } \\
\text { this pajer } \\
\mathbf{J} / \text { mol-K }\end{array}$ & $\begin{array}{c}C_{0} \text { from the } \\
\text { literature } \\
\mathbf{J} / \text { mol-K }\end{array}$ & $\begin{array}{c}\text { Difference } \\
\text { in } 0 / 0\end{array}$ \\
& & \\
\hline
\end{tabular}

Reference [17]

\begin{tabular}{|c|c|c|c|c|}
\hline 91.59 & 68. 03 & 68.30 & & -0.4 \\
\hline 92.97 & 68.10 & 68.46 & & -.5 \\
\hline 94.94 & 68.20 & 68.38 & $:$ & -.3 \\
\hline 96.60 & 68.27 & 68. 25 & & \\
\hline 98.23 & 68.33 & 68.88 & & -.8 \\
\hline 98.89 & 68. 35 & 68.38 & & -.0 \\
\hline 100.49 & 68.41 & 68.34 & & .1 \\
\hline 104.0.5 & 68.51 & 68.59 & & -.1 \\
\hline 106.67 & 68. & 68.88 & & -.4 \\
\hline 109. 24 & 68. 6.5 & 68.92 & & -.4 \\
\hline 111.67 & 68.71 & 69.13 & & -.6 \\
\hline 114. 20 & 68.77 & 69.01 & & -.3 \\
\hline 116.24 & 68.82 & 69.17 & & -.5 \\
\hline 119.33 & 69.90 & 69.30 & & $\therefore 6$ \\
\hline 122.72 & 69.00 & 69. 43 & & -.6 \\
\hline 125.96 & 69.09 & 69.59 & & -.7 \\
\hline 129.47 & 69.20 & 69. 35 & &.$- i$ \\
\hline 134.49 & 69.39 & 69.64 & & -.4 \\
\hline 138. 72 & 69.56 & 69.76 & & -.3 \\
\hline 142.83 & 69.75 & 69. 89 & & -.2 \\
\hline 145.97 & 69.91 & 70.05 & & -.2 \\
\hline 149.80 & $70.1: 3$ & 70.31 & & -.3 \\
\hline 153.58 & 70.36 & 70.77 & . & -.6 \\
\hline 157.95 & 70.6 .5 & 70.77 & & $\div .2$ \\
\hline 162.82 & 71.01 & 71.02 & & -.0 \\
\hline 167.43 & 71.38 & 71.52 & & -.2 \\
\hline 172. 02 & 71.79 & 71.56 & & .3 \\
\hline 176. .54 & 72. $2: 3$ & 72.06 & & .2 \\
\hline 180.88 & 72.68 & 72.11 & & \\
\hline
\end{tabular}

Representation of the specific heat has been achieved by Goodwin [2] who correlates the available J'T data, the sperifie heats of the icleal gas, the sperifie heat of the saturated liquid from this experiment, and selected ralues of ${ }^{\prime}{ }^{\prime}$ from rums 1,8 , and 9. Values of ('. 'alculated from his equation of state and differences betwern experimental anel ealeulated values expresied in pereent are given in table 6. A scan of rolumm 7 in table 6 reveals that the agreement betwoen exporimental and ralculated values is excellent orer much of the J'PT nominal 2 pereent or lesis. It is only in the region near the critical point where the experimental heat (apacities increane drastically that the representation is not able to matel the experimental surface of ( ${ }^{\prime}$, repartures reach values of up to 18 percent. 'The agrement for the very lowest density, rom 19, is particulary gratifying since for this rum the experimental merertainti in $r$ is about 2 percent, whereas the calculation of $C^{\prime}$. from ideal gas and a very small P'T $T$ contribution should have very little error attarched to it.

Experimental measurements of specific lieats have been mate by other author's [18,19], however these measurements are measurements of the specific: heat at constant pressure, ${ }^{\prime}{ }_{p}$. The values can be compared only indirestly to the present measure- 


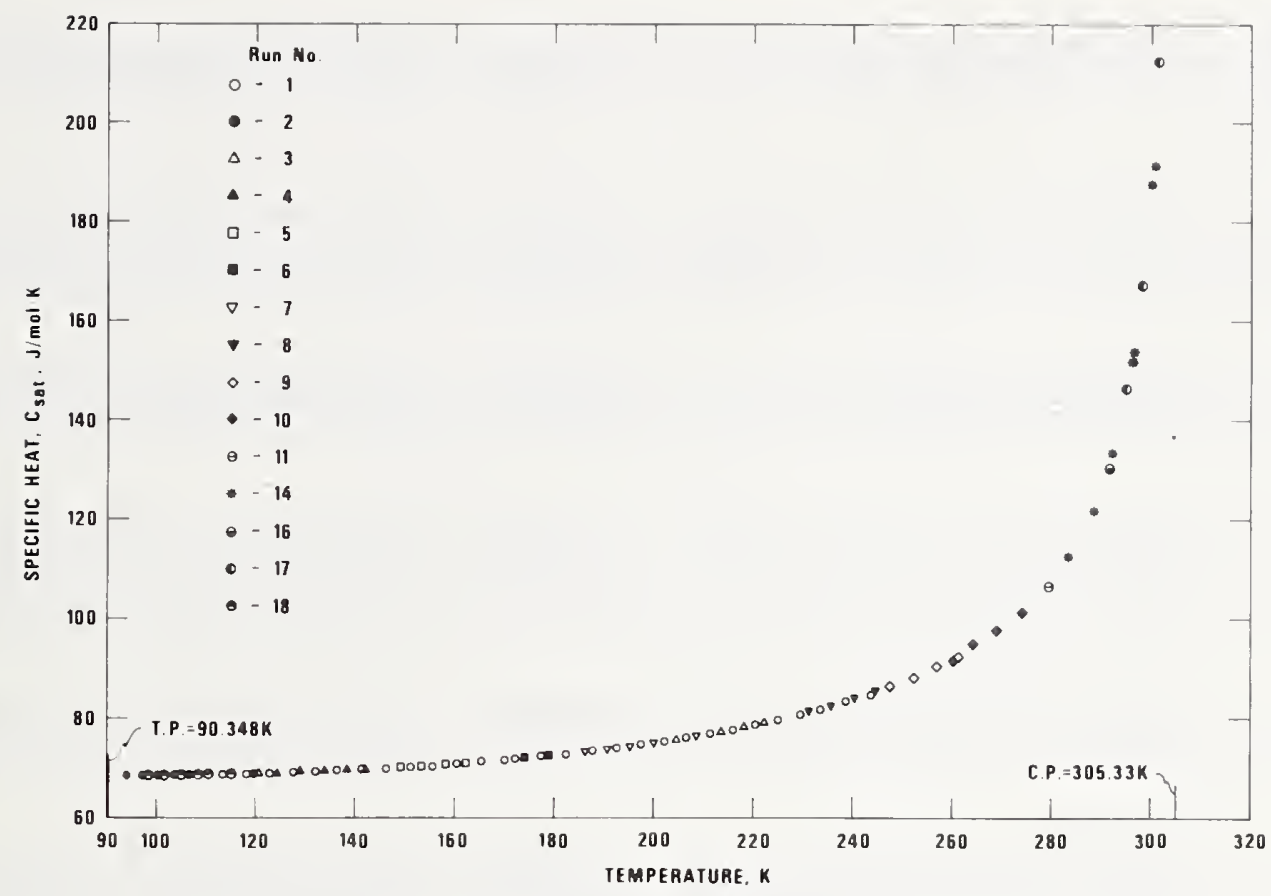

Figure 3. The specifie heats, $\mathrm{C}_{\sigma}$, of saturated liquid ethane.

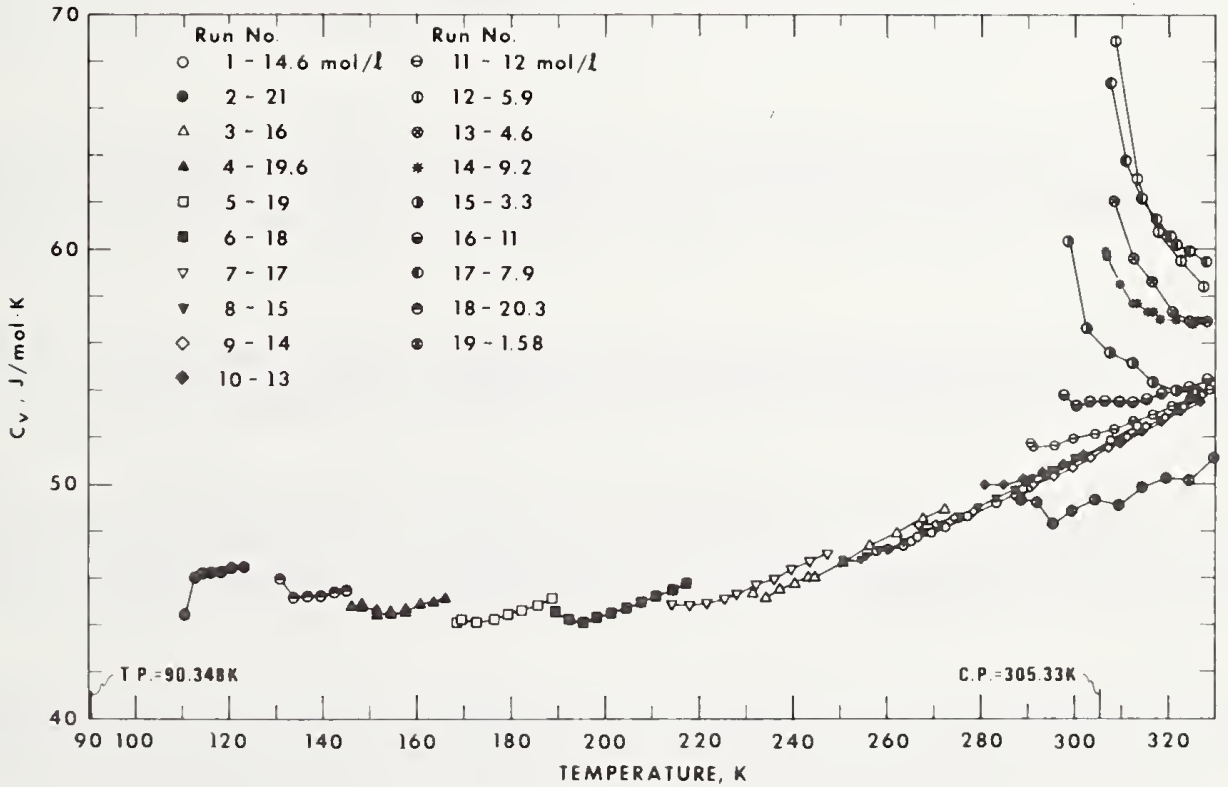

Figunl: 4. The specifie heats, $\mathrm{C}_{v}$, of dense gaseous and liquid ethane.

menti through the nise of a $I^{\prime} V^{2} T$ surface. Since ${ }^{g}{ }_{p}$ mrasmemonte are normally made along isobars while ('r measurements are made along isochores, the most appropriate $P^{T} T$ states for comparisons are at those values of pressure and density common to both sets of data. For the results of Furtado [18] and the present measurements this intercomparison is given in table 7 . The pressures are taken 


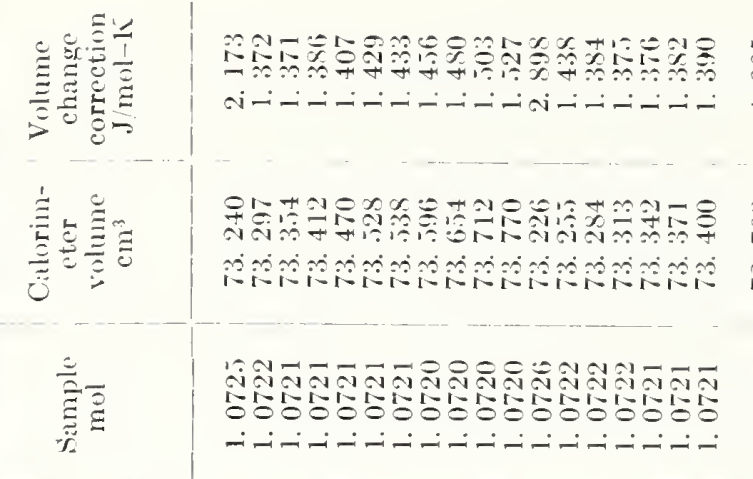

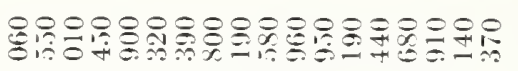

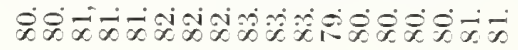

Fis

$\propto$

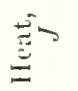

$\stackrel{20}{0}$

픈

证 $\Xi \frac{1}{5}$

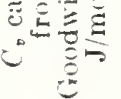

$\tilde{E}$

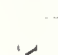

$-\frac{\frac{1}{c}}{\equiv}$

5

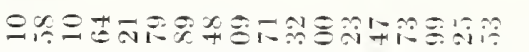

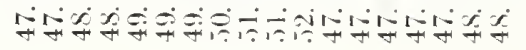

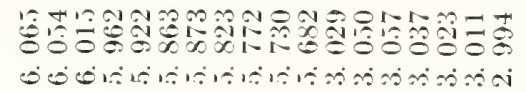

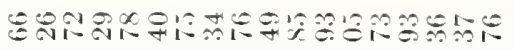

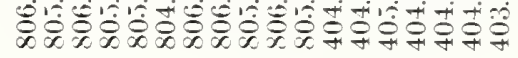

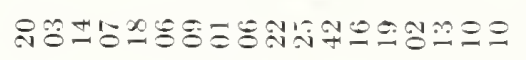
○ं

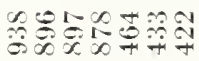

- - - - arioi

손ㄱำ

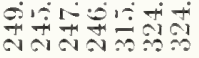

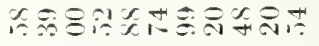

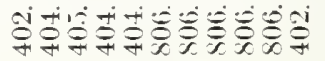

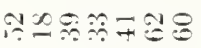

joiroioioio

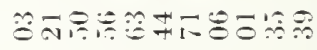
$-$

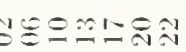

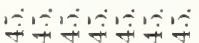

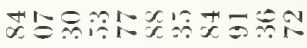

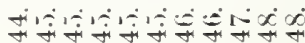

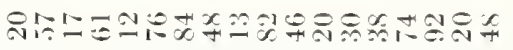

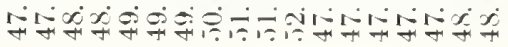

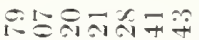

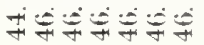

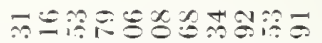

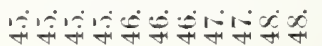

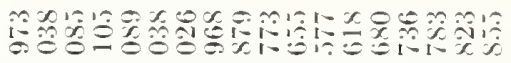

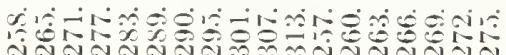

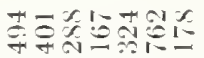

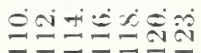

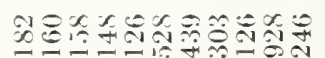

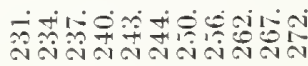

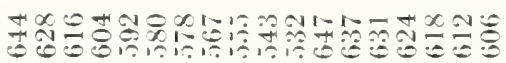

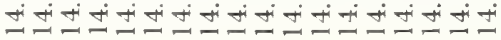

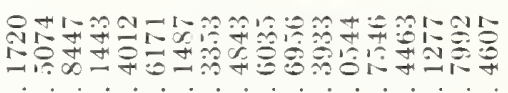

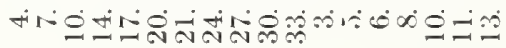

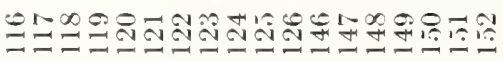

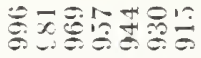
คें்

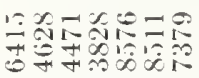
ar:

คํำำลำส

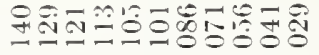
$\dot{0} \dot{0} \dot{0} \dot{0} \dot{0} \dot{0} \dot{0}$

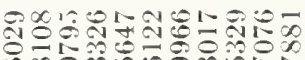

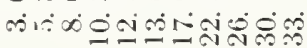

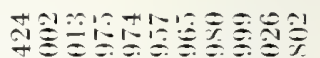

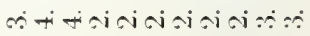

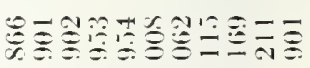

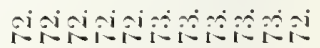

수워ำ

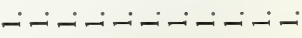

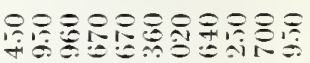

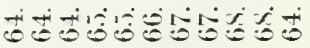

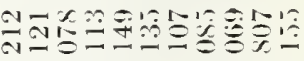
मे

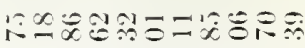

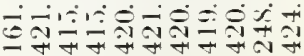

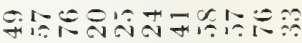
ง

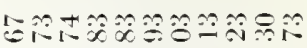

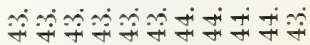

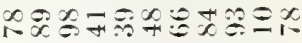

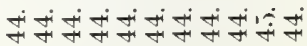

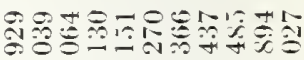

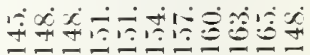

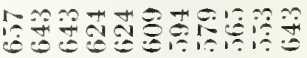

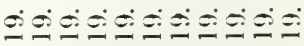

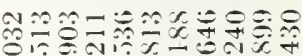

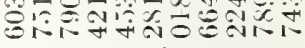

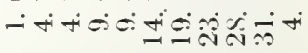

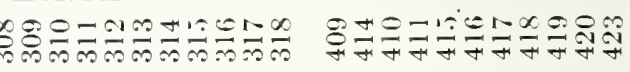




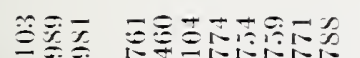

arai diangiariari

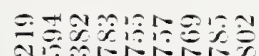

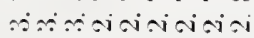

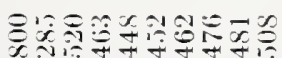

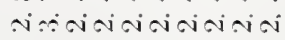

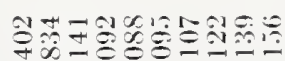
ง

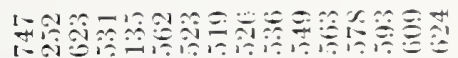

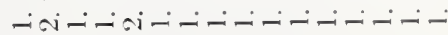

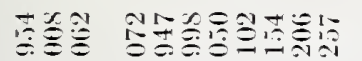
กู่

10.

- -

尽是全

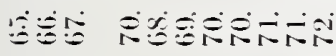

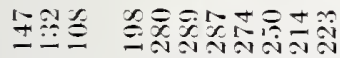

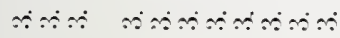

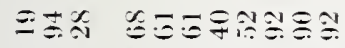

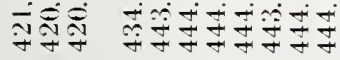

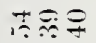
- $-\dot{-}$

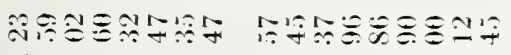
งisisi-i-i-

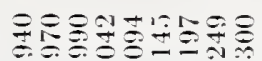
iิ

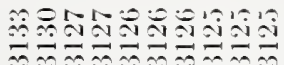

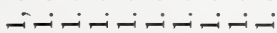

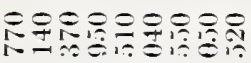

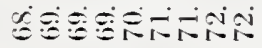

ดิง में

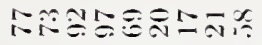

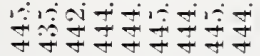

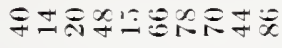

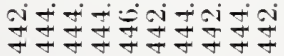

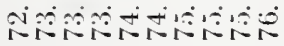

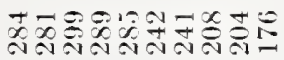

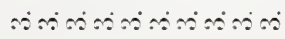

Propers

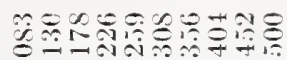

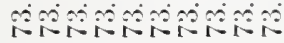

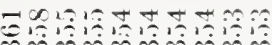

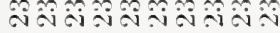

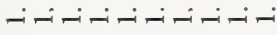

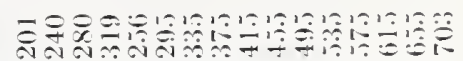

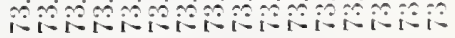

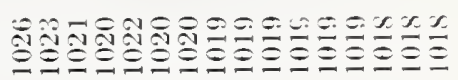

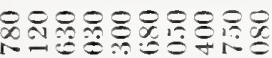

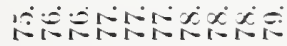
$\therefore 9+1-\alpha=0 \%$

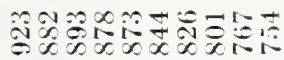

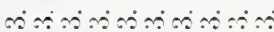

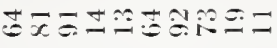

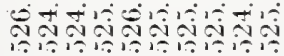

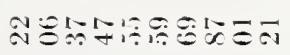

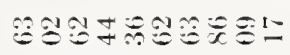
oi-

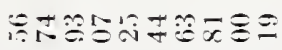

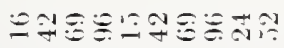

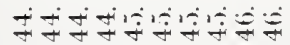

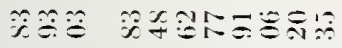

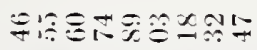

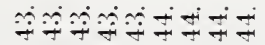

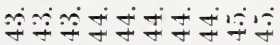

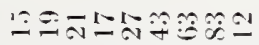

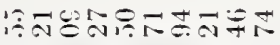

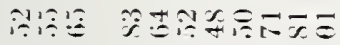

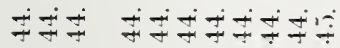

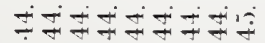

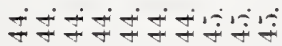

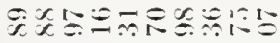

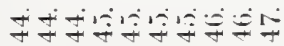

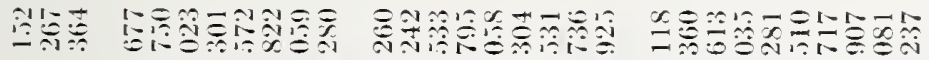

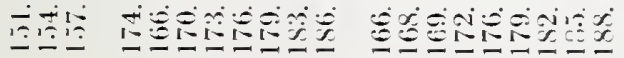

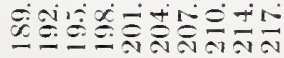

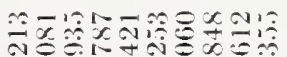

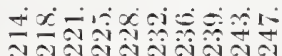

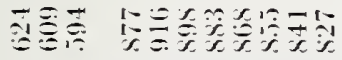

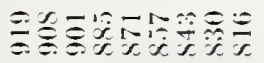

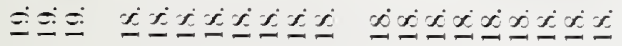

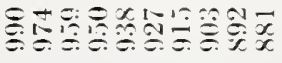

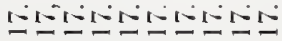

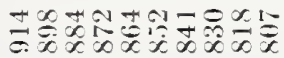
0000000000

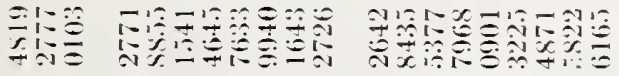
过自

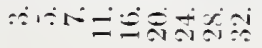

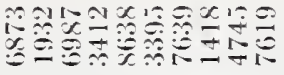
สน

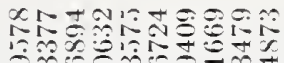
ois 0

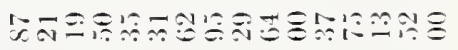

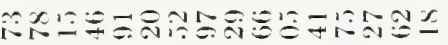

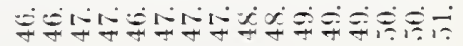

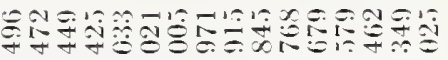

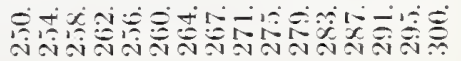

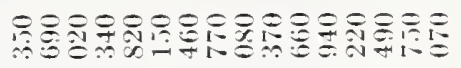

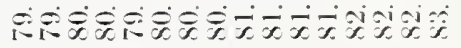

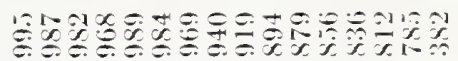
ט

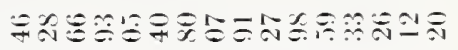

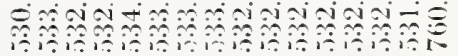

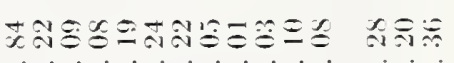

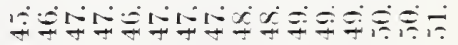

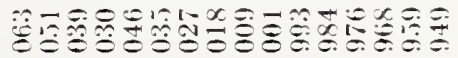

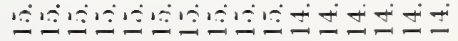

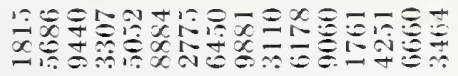

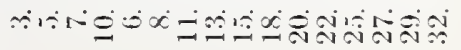

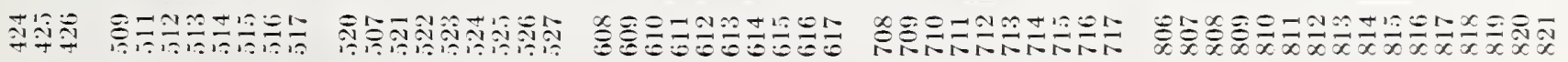




\begin{tabular}{|c|c|c|c|c|}
\hline \multicolumn{2}{|c|}{ 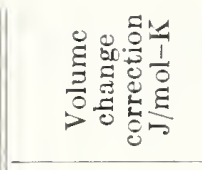 } & 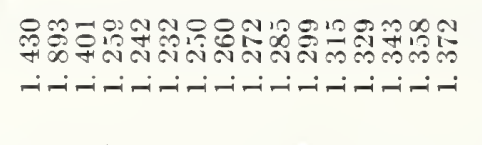 & 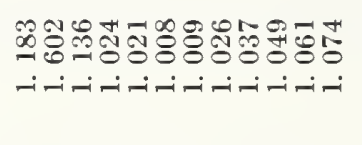 & 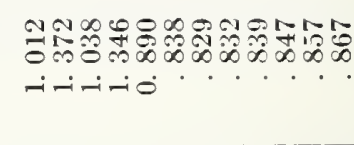 \\
\hline \multicolumn{2}{|c|}{ 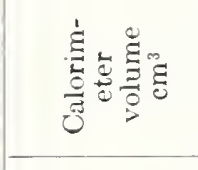 } & 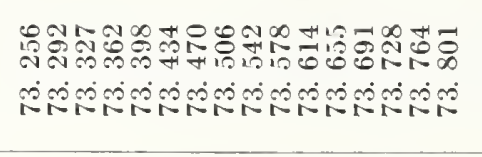 & 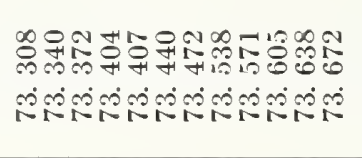 & 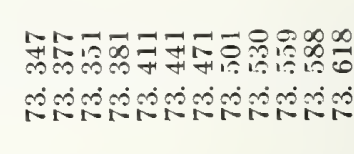 \\
\hline \multicolumn{2}{|c|}{ 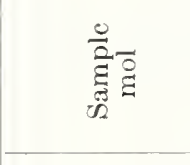 } & 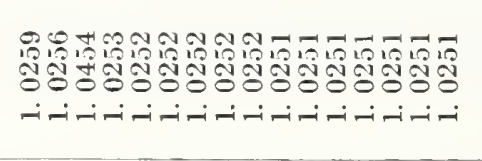 & 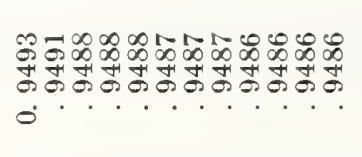 & 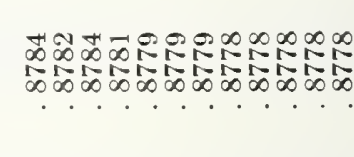 \\
\hline \multicolumn{2}{|r|}{$i \lesssim$} & 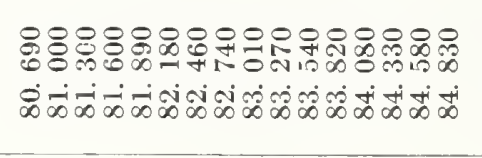 & 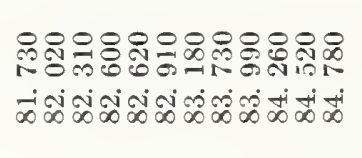 & 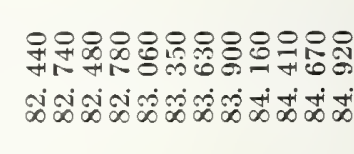 \\
\hline & 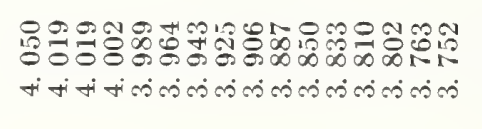 & 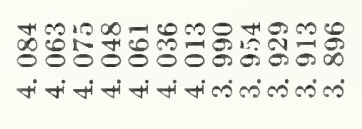 & 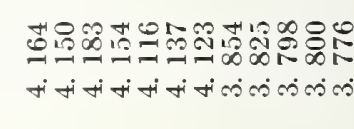 \\
\hline \multirow{2}{*}{\multicolumn{2}{|c|}{ 롱응 }} & 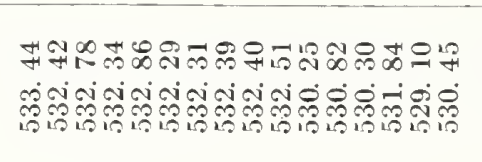 & 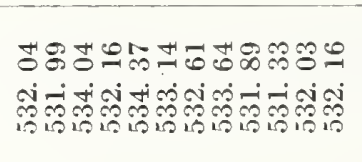 & 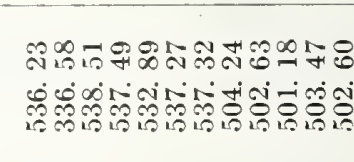 \\
\hline & & 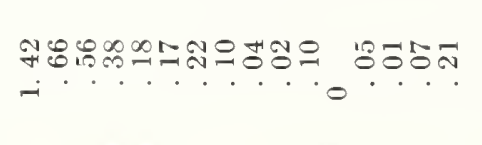 & 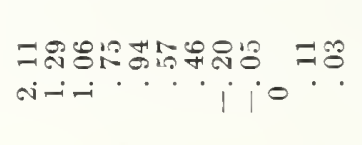 & 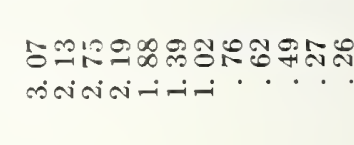 \\
\hline \multicolumn{2}{|c|}{ 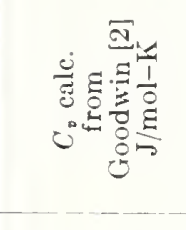 } & 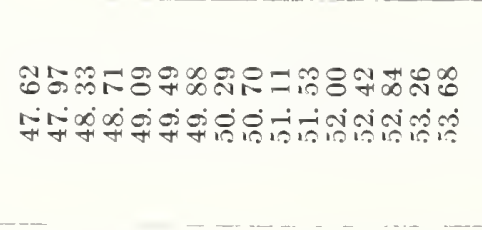 & 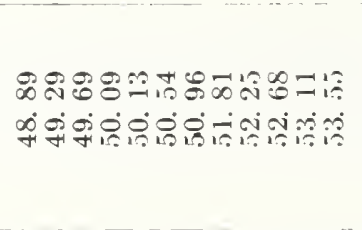 & 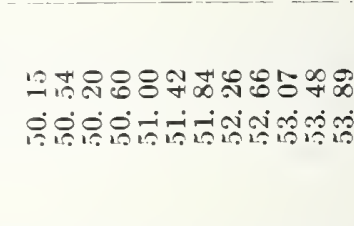 \\
\hline \multirow{4}{*}{ 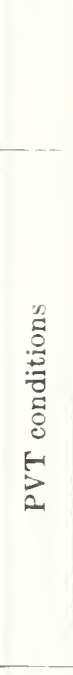 } & 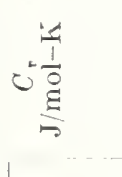 & 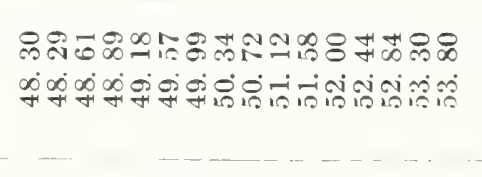 & 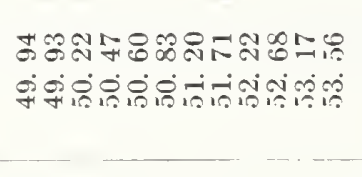 & 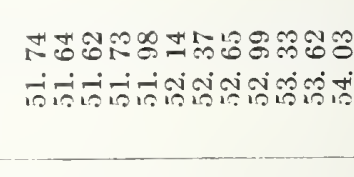 \\
\hline & & 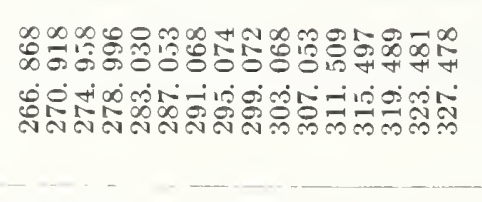 & 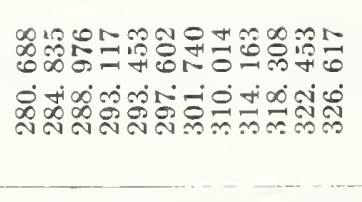 & 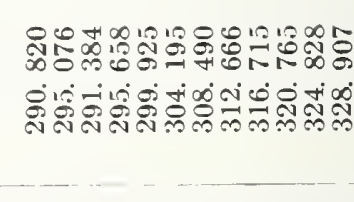 \\
\hline & 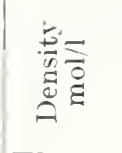 & 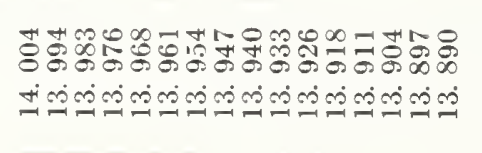 & 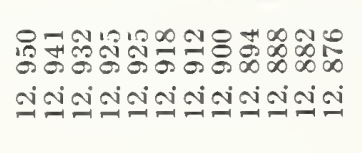 & 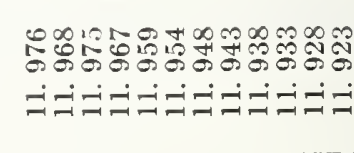 \\
\hline & 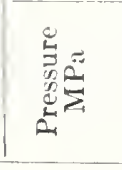 & 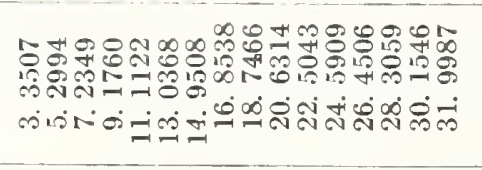 & 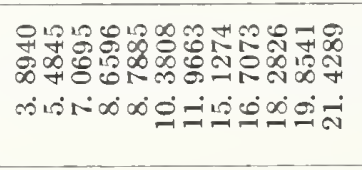 & 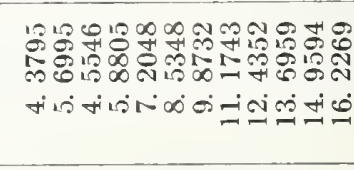 \\
\hline \multirow{2}{*}{\multicolumn{2}{|c|}{ 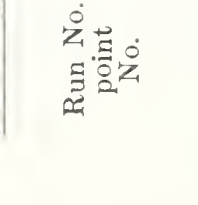 }} & 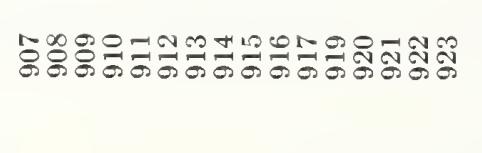 & 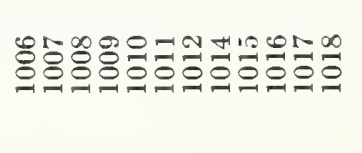 & 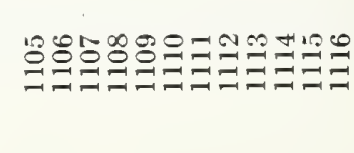 \\
\hline & & & & \\
\hline
\end{tabular}




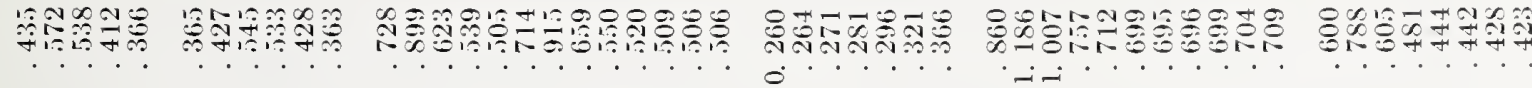

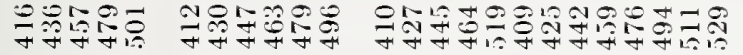
นิน

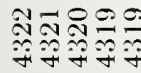

ช่⿻日禸 bo

$\infty+\infty \infty \infty \infty \infty$

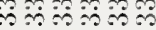

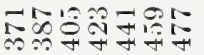
ใน

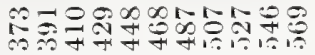

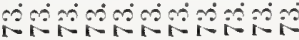

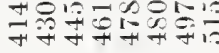
นิน

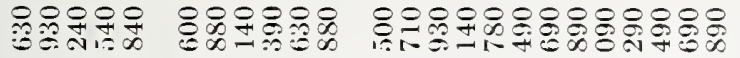

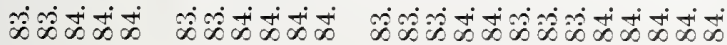

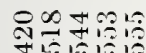
சுஷ் ச் ச்

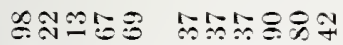
ठ்ல்

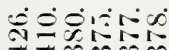

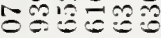

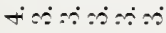

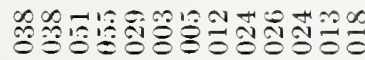
में

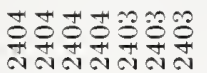
$\dot{0}$

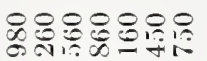

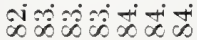

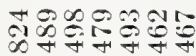

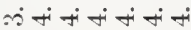

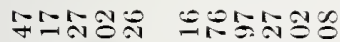

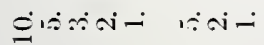

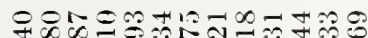

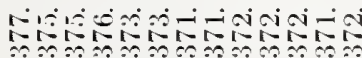

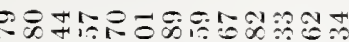
வिம்

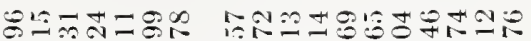
งis.

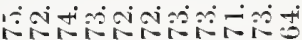

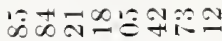
Tiล

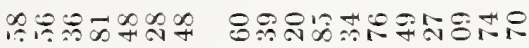
Noi- $\dot{i}-\dot{1}$

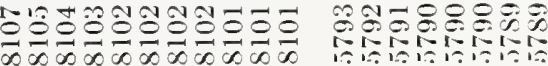

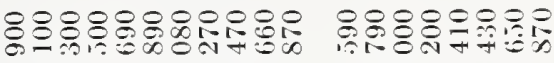

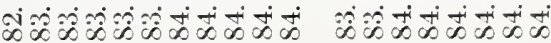

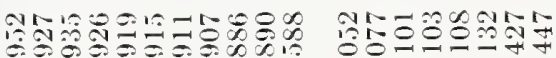
dicisicicicicicician
オํำ

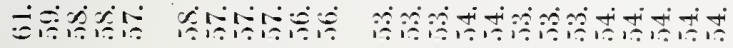

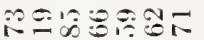

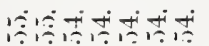

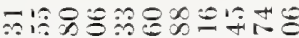

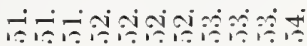

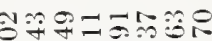

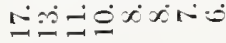

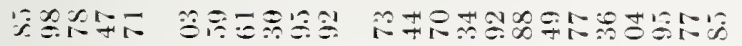

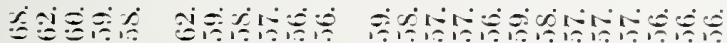

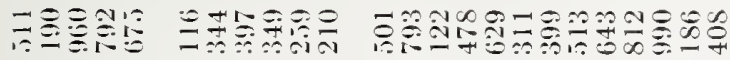

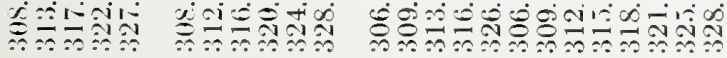

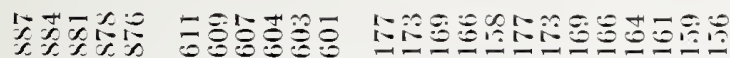
$\therefore 1 \div 1 \div 1 \div$

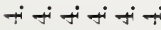

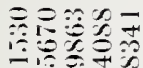
$\therefore 1 \div \div=0$

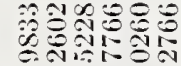
$+1 \therefore 1500$

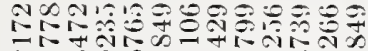

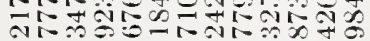
$\therefore 1 \div 000100010 \infty \infty$

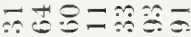
80

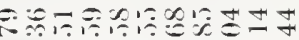

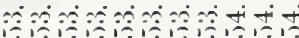

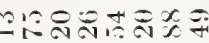

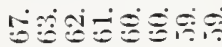

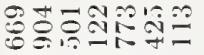
कீंல்

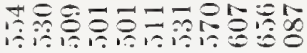
ஸீ人்

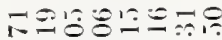

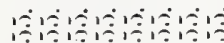

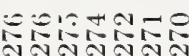
$\therefore \rightarrow 00000000$

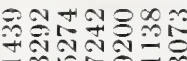

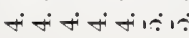

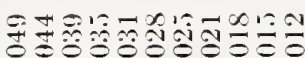

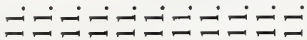

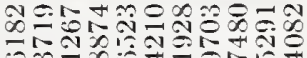

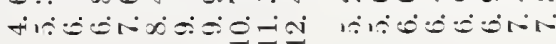

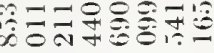

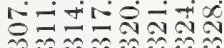

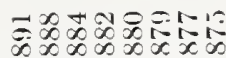

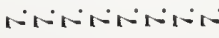

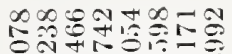




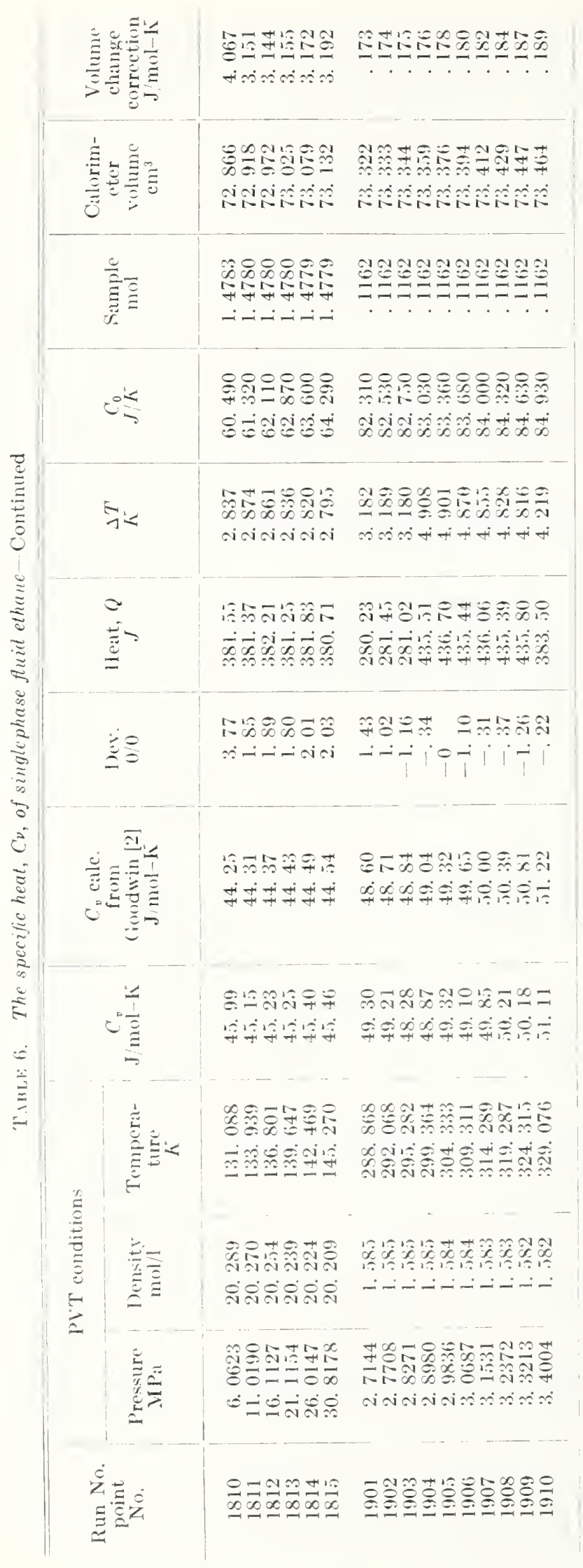


T.131: 7. Interemparison of $C_{v}$ and $C_{p}$

\begin{tabular}{|c|c|c|c|c|c|c|c|}
\hline $\begin{array}{l}\text { Proure } \\
\text { MPP: } \\
\text { rif. }[1, i]\end{array}$ & $\begin{array}{c}\text { bensity } \\
\text { mol! } \\
\text { This pitprer }\end{array}$ & $\begin{array}{c}\text { Trmperinture } \\
K \\
\text { from eq. } \\
\text { rof. }[2]\end{array}$ & $\begin{array}{l}C^{y} \\
\text { J/nol-K } \\
\text { intorpol. } \\
\text { this paper }\end{array}$ & $\begin{array}{c}P I T \text { Contr. } \\
\mathrm{J} / \mathrm{mol}-\mathrm{K} \\
\text { calc. } \\
\text { ref. [2] }\end{array}$ & $\begin{array}{c}C_{D}^{\prime} \\
J / \mathrm{mol}-K \\
\text { calc } \\
\text { col. } 4,5\end{array}$ & $\begin{array}{l}C^{r} \\
y / m(1) K \\
\text { intarpol } \\
\text { ref }[18]\end{array}$ & $\begin{array}{l}\text { Diff } \\
\text { lect }\end{array}$ \\
\hline $\begin{array}{r}\text { 3. } 4474 \\
\text { 6. } x(945 \\
10.3421 \\
13.7 x(4.5\end{array}$ & $\begin{array}{l}14.647 \\
14.630 \\
14.617 \\
14.60 .5\end{array}$ & $\begin{array}{l}257.677 \\
263.928 \\
270.176 \\
276.459\end{array}$ & $\begin{array}{l}47.19 \\
47.41 \\
48.00 \\
48.5 .1\end{array}$ & $\begin{array}{l}44.44 \\
41.87 \\
39.64 \\
37.72\end{array}$ & $\begin{array}{l}91.64 \\
89.28 \\
87.64 \\
86.27\end{array}$ & $\begin{array}{l}90.43 \\
88.29 \\
\times 7.15 \\
86.01\end{array}$ & $\begin{array}{r}1.3 \\
1.1 \\
-.6 \\
.3\end{array}$ \\
\hline $\begin{array}{r}\text { (i. } 89.45 \\
13.759 .5\end{array}$ & $\begin{array}{l}20.983 \\
20.962\end{array}$ & $\begin{array}{l}112.10 .5 \\
115.407\end{array}$ & $\begin{array}{l}4.5 .94 \\
46.19\end{array}$ & $\begin{array}{l}23.41 \\
23.17\end{array}$ & $\begin{array}{l}\text { (69) } 35 \\
\text { (69. } 36\end{array}$ & $\begin{array}{l}\text { 6is. } 35 \\
65.34\end{array}$ & 1. 1 \\
\hline $\begin{array}{r}\text { (3. } \times 945 \\
13.7 \times 95\end{array}$ & $\begin{array}{l}16.125 \\
16.100\end{array}$ & $\begin{array}{l}235,582 \\
244.770\end{array}$ & $\begin{array}{l}4.5 .31 \\
46.08\end{array}$ & $\begin{array}{l}34.72 \\
32.80\end{array}$ & $\begin{array}{l}80.103 \\
78.88\end{array}$ & $\begin{array}{l}79.59 \\
79.09\end{array}$ & $\begin{array}{r}-.6 \\
.3\end{array}$ \\
\hline $\begin{array}{r}\text { 1. } 7237 \\
\text { 6. } 8945 \\
13.799 .5\end{array}$ & $\begin{array}{l}\text { 19. 6.56 } \\
19.634 \\
19.611\end{array}$ & $\begin{array}{l}146.01 .5 \\
149.4 .50 \\
153.9 .14\end{array}$ & $\begin{array}{l}\text { 44. } 79 \\
44.69 \\
44.46\end{array}$ & $\begin{array}{l}26.12 \\
25.80 \\
25.39\end{array}$ & $\begin{array}{l}70.91 \\
70.49 \\
69 . \times .5\end{array}$ & $\begin{array}{l}(69.97 \\
70.06 \\
70.00\end{array}$ & $\begin{array}{r}1.4 \\
-.4 \\
.2\end{array}$ \\
\hline $\begin{array}{r}\text { (i. } 89.45 \\
13.7 \times 9.5\end{array}$ & $\begin{array}{l}18.904 \\
18.879\end{array}$ & $\begin{array}{l}169.041 \\
174.296\end{array}$ & $\begin{array}{l}\text { 44. } 22 \\
44.80\end{array}$ & $\begin{array}{l}27.18 \\
26.63\end{array}$ & $\begin{array}{l}71.40 \\
71.44\end{array}$ & $\begin{array}{l}71.43 \\
70.922\end{array}$ & ${ }^{0}-.7$ \\
\hline $\begin{array}{r}\text { (5. } 8948 \\
13.759 .5\end{array}$ & $\begin{array}{l}17.971 \\
17.945\end{array}$ & $\begin{array}{l}193.014 \\
199.373\end{array}$ & $\begin{array}{l}\text { 44. } 16 \\
\text { 44. :38 }\end{array}$ & $\begin{array}{l}29.20 \\
28.38\end{array}$ & $\begin{array}{l}73.36 \\
72.76\end{array}$ & $\begin{array}{l}74.195 \\
72.67\end{array}$ & $\begin{array}{r}1.0 \\
-.1\end{array}$ \\
\hline $\begin{array}{r}\text { 6. } 894.4 \\
13.789 .7\end{array}$ & $\begin{array}{l}16.896 \\
16.869\end{array}$ & $\begin{array}{l}218.724 \\
226.616\end{array}$ & $\begin{array}{l}\text { 44. } 89 \\
45.20\end{array}$ & $\begin{array}{l}32.10 \\
30.77\end{array}$ & $\begin{array}{l}76.999 \\
75.97\end{array}$ & $\begin{array}{l}76.4 .5 \\
76.03\end{array}$ & .7 \\
\hline $\begin{array}{r}\text { 3. } 4474 \\
\text { (3. } 89145 \\
\text { 10. } 3421 \\
\text { 13. } 789.5\end{array}$ & $\begin{array}{l}1.5 .062 \\
15.044 \\
15.030 \\
1.5 .017\end{array}$ & $\begin{array}{l}2.50 .932 \\
256.692 \\
262.445 \\
268.213\end{array}$ & $\begin{array}{l}46.72 \\
46.98 \\
47.46 \\
48.00\end{array}$ & $\begin{array}{l}41.53 \\
39.74 \\
37.78 \\
36.22\end{array}$ & $\begin{array}{l}8.5 .26 \\
8(i .53 \\
85.24 \\
84.22\end{array}$ & $\begin{array}{l}87.42 \\
8.5 .99 \\
84.71 \\
8.3 .83\end{array}$ & $\begin{array}{r}-1.0 \\
-.6 \\
-.6\end{array}$ \\
\hline $\begin{array}{r}3.4474 \\
\text { (i. } 8948 \\
10.3421 \\
13.759 .9\end{array}$ & $\begin{array}{l}14.004 \\
13.98 .3 \\
13.971 \\
13.9 .8\end{array}$ & $\begin{array}{l}267.065 \\
274.251 \\
2 \$ 1.42: 3 \\
288.629\end{array}$ & $\begin{array}{l}48,30 \\
48.74 \\
49.06 \\
4 ! .74\end{array}$ & $\begin{array}{l}30.15 \\
413.23 \\
43.00 \\
40.33\end{array}$ & $\begin{array}{l}98.44 \\
94.77 \\
92.06 \\
90.07\end{array}$ & $\begin{array}{l}97.38 \\
93.993 \\
91.31 \\
69.97\end{array}$ & $\begin{array}{r}-1.1 \\
-.9 \\
-.8 \\
-4\end{array}$ \\
\hline $\begin{array}{r}\text { 4. } 9160 \\
6.8945 \\
8.6161 \\
10 .: 3421 \\
13.75 ! 4.5\end{array}$ & $\begin{array}{l}12.944 \\
12.9333 \\
12.925 \\
12.918 \\
12.90 .5\end{array}$ & $\begin{array}{l}28,3.37 \\
25,518 \\
293.012 \\
297.507 \\
30(0.513\end{array}$ & $\begin{array}{l}49.24 \\
50.22 \\
50.44 \\
50.83 \\
51.49\end{array}$ & $\begin{array}{l}60 .(i 2 \\
56.10 \\
52.78 \\
49.93 \\
45.28\end{array}$ & $\begin{array}{l}110.51 \\
106.31 \\
103.21 \\
100.76 \\
916.75\end{array}$ & $\begin{array}{r}106.99 \\
104.85 \\
102.07 \\
100.07 \\
95.46\end{array}$ & $\begin{array}{r}3.3 \\
1.4 \\
-1.1 \\
-.7 \\
-1.4\end{array}$ \\
\hline 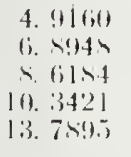 & $\begin{array}{l}11.97: 3 \\
11.96 ; 1 \\
11.99 .44 \\
11.946 \\
11.9333\end{array}$ & $\begin{array}{l}292.545 \\
298.929 \\
304.461 \\
309.999 \\
321.071\end{array}$ & $\begin{array}{l}51.49 \\
51.96 \\
52.15 \\
52.47 \\
53.35\end{array}$ & $\begin{array}{ll}80 . & 27 \\
70 . & 21 \\
(33.3 . & (i 1 \\
58 . & 39 \\
50 . & 62\end{array}$ & $\begin{array}{l}131.76 \\
122.17 \\
11.5 .76 \\
111.86 \\
103.97\end{array}$ & $\begin{array}{r}129.01 \\
* 109.17 \\
113.57 \\
109.53 \\
103.25\end{array}$ & $\begin{array}{r}2.1 \\
\text { * 11. } \\
-1.9 \\
-1.2 \\
-7\end{array}$ \\
\hline i. 640 is & ㄷ. $88: 3$ & 314.0966 & (i2. 31$)$ & 40.4 .02 & $46 i t .31$ & 501.97 & 7.1 \\
\hline $\begin{array}{l}6.49+4 \\
\therefore \text { (i) }\end{array}$ & $\begin{array}{l}\text { 9. 166 } \\
9.158\end{array}$ & $\begin{array}{l}316.310 \\
326.292\end{array}$ & $\begin{array}{l}57.35 \\
56.89\end{array}$ & $\begin{array}{l}171.78 \\
116.333\end{array}$ & $\begin{array}{l}229.12 \\
173.22\end{array}$ & $\begin{array}{r}* 197.27 \\
164.57\end{array}$ & $\begin{array}{r}*-16.1 \\
-5.3\end{array}$ \\
\hline $\begin{array}{l}\text { 4. } 6978 x \\
\text { 4. } 11601 \\
\therefore 1711\end{array}$ & $\begin{array}{l}3.274 \\
3.272 \\
3.271\end{array}$ & $\begin{array}{l}310.787 \\
316.6 \times 5 \\
322.812\end{array}$ & $\begin{array}{l}5.5 .29 \\
54.33 \\
53.89\end{array}$ & $\begin{array}{l}94.73 \\
80.07 \\
69.26\end{array}$ & $\begin{array}{l}1.30 .03 \\
134.42 \\
123.1 .5\end{array}$ & $\begin{array}{l}149.97 \\
134.19 \\
123.24\end{array}$ & $\begin{array}{r}-0 \\
-.2 \\
-.1\end{array}$ \\
\hline 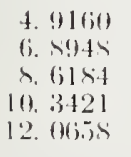 & $\begin{array}{l}11.047 \\
11.0035 \\
11.027 \\
11.020 \\
11.013\end{array}$ & $\begin{array}{l}298.730 \\
306.527 \\
313.282 \\
320.026 \\
326.749\end{array}$ & $\begin{array}{l}53.57 \\
53.59 \\
53.59 \\
53.56 \\
53.94 \\
54.30\end{array}$ & $\begin{array}{c}116.03 \\
91.41 \\
78.02 \\
65.58 \\
61.53\end{array}$ & $\begin{array}{l}169.50 \\
145.00 \\
131.58 \\
122.53 \\
115.85\end{array}$ & $\begin{array}{l}162.31 \\
142.31 \\
127.85 \\
119.45 \\
11.5 .11\end{array}$ & $\begin{array}{r}-4.5 \\
-1.9 \\
-2.9 \\
-2.6 \\
-.6\end{array}$ \\
\hline $\begin{array}{l}\text { 5. } 646 \text { (ix } \\
\text { (i. xig4t }\end{array}$ & $\begin{array}{l}\text { 7. } \sin x \\
\text { 7. } \sin \theta\end{array}$ & $\begin{array}{l}311.18 .7 \\
320.609\end{array}$ & $\begin{array}{l}\text { (i.3. } 62 \\
\text { (i). (i) }\end{array}$ & $\begin{array}{l}309.77 \\
217.16\end{array}$ & $\begin{array}{l}573.39 \\
277.77\end{array}$ & $\begin{array}{l}527.29 \\
273.8 .7\end{array}$ & $\begin{array}{l}3.7 \\
-1.4\end{array}$ \\
\hline $\begin{array}{l}\text { (i. } x(94 x \\
13.75(1)\end{array}$ & $\begin{array}{l}\text { 20. } 286 ; \\
20.26 i 1\end{array}$ & $\begin{array}{l}131.5 .74 \\
13.5 .496\end{array}$ & $\begin{array}{l}4.5 .81 \\
4 \div .14\end{array}$ & $\begin{array}{l}24.64 \\
24.33\end{array}$ & $\begin{array}{l}70.45 \\
69.47\end{array}$ & $\begin{array}{l}69.02 \\
69.04\end{array}$ & $\begin{array}{r}-2.1 \\
-.16\end{array}$ \\
\hline
\end{tabular}

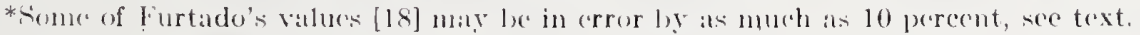


from reference [18], the densities from the present measurements. A temperature corresponding to the $P$ and $\rho$ of an intersection is obtained from the equation of state [Goodwin, 2], and experimental values of $C_{v}$ and $C_{p}$ are interpolated from the two sets of data. 'The comparison is completed by calculating a value of $C_{p}$ from

$$
C_{p}=C_{0}+\frac{T\left(\frac{\partial P}{\partial T}\right)_{\rho}^{2}}{\rho^{2}\left(\frac{\partial P}{\partial \rho}\right)_{T}} .
$$

The second term in equation 5 is the contribution from the PI'T surface. It is clear from table 7 that in ahmost all cases the PVT rontribution to $C_{p}$-calculated is as large or larger than the value of $C_{v}$. The mean deviation between calculated and experimental $r_{p}$ for the 50 intersections is just under 2 percent. 'This implies that the thermodynamic consistency between experimental $C_{v}$ and $C_{p}$ measurements is indeed excellent, i.e., at least as good as 2 percent, but quite probably much better than that for two reasons. First, a large part of the total disclepancy must be assigned to error's in the PVT surface derivatives. Second, some of the values presented by Furtado [18] may be in error by as much as 10 percent. A detailed example is as follows.

In our table 7 u comparison is male at $6.8948 \mathrm{MPa}$ (1000 psia) and $298.929 \mathrm{~K}\left(78.40^{\circ} \mathrm{F}\right)$. Furtado's closest smoother value of $C$ taken from his table VIII-5 at $6.8948 \mathrm{MPa}(1000 \mathrm{pria})$ and $299.817 \mathrm{~K}$ $\left(80^{\circ} \mathrm{F}\right)$ is $111.84 \mathrm{~J} / \mathrm{mol}-\mathrm{K} \quad\left(0.889 \quad \mathrm{~B}^{\prime} \mathrm{T} / \mathrm{lb}-{ }^{\circ} \mathrm{F}\right)$ This value rhanges to $124.06 \mathrm{~J} / \mathrm{mol}-\mathrm{K}$ if interpolated from his table VIII-3, a table of smoothed enthalpies, or to $122.4 \mathrm{~J} / \mathrm{mol}-\mathrm{K}$ if interpolated from his figure VIII-6, a plot of $r^{r}$ versus temperature for the 1000 psia isobar. 'Thus the inconsistencies in Furtado's values, depending on how they are obtained, are at times as latge at 10 perrent.

\section{Discussion}

It is readily apparent that ancerurate values of $C_{0}$ ure essential if we wish to obtain areurnte values of rither $\left({ }_{\sigma}\right.$ or $\left({ }_{v}\right.$. A rhange of 0.1 percent in $C_{0}$, for exumple, will result in a rhange of 1 percent in the values of ( ${ }_{r}$ calculated for roun 19. The temperature. increment, $\Delta T$, is evalunter at the midclle of the heating interval by extrapolating the temperature drift rates just before heating and after su equilibrating time lins elapsed. Since the drift is linear the statistic's of the extrapolation can be used to estimate an uncertainty in the $\Delta T$. For the first 14 points of (n the alverage slope uncertainty was $0.19 \times 10^{-3}$ $\mathrm{K} / \mathrm{min}$, since the average elapsed time to the center of the measurement interval is about $20 \mathrm{~min}$, the average uncertainty in $\Delta T$ turns out to be $\pm 0.004 \mathrm{~K}$. This in turn implies that if we seek 0.1 pereent precision in the specific heats the $\Delta T$ must be $4 \mathrm{~K}$ or larger. The choice of $\Delta T$, as shown in tables 4 and 6 , was based on this consideration and on the idea that there ought to be at least 5 points per experimental run. The imprecision in the temperature time data is attributed to the exact setting or resetting of the platinum thermometer current rather than potentiometer inaccuracy. Potentiometer inaccuracy was actually reduced from values given by Goodwin and Weber [6] to a maximum of $0.003 \mathrm{~K}$ by consideration of a potentiometer calibration. Heat leak to and from the sample is estimated to be less than 0.1 percent by considering the difference in drift rates before heating and after equilibration has been reached. Shield temperatures lag at the start of the heating interval by about $0.02 \mathrm{~K}$. They lag again at the end of the heating interval after the power is turned off. The two lags compensate to produce a nearly adiabatic environment during the entire heating interval. Deliberate changes of temperature along the capillary were introduced to see if the applied heat, and therefore the results could be changed. In run 14 points 1401-1413 were obtained with liquid nitrogen in the refrigerant tank. 'These points were duplicated for 1414-1425 using eold water as coolant. 'The results, as shown in tables 4 and 6 , are virtually identical. However, when we applied deliberate heating to the capillary, actunlly quite drastic heating $100 \mathrm{ma}$ to a $140 \Omega$ heater, the results changerl. Points 508-517 differ from those obtained in a duplicate run 520-527 without heating the capillary by 1 percent at the lowest temperature. The difference disappears entirely at the highest temperature of the run. However, rather than changing the applied heat, heating the capillary apparently changes the distribution of sample between calorimeter snd stem.

The same problem, distribution of sample between calorimeter and stem, is thought to give rise to the curvature of the runs. Rums $18,4,5,6$, and 7 show a definite curvature as to two phase boundary is approached, see figure 4 , if compared to the values calculated by Goodwin [2]. The curvature seems to abate at pressures above the critical pressure, or at a point where mass change between calorimeter and stem has stabilized. It is possible that a heat of vaporization correction to $Q$ should be inclurled for the $C_{v}$ calculation as long as sample is being transferred from calorimeter to stem. It should be noted that the correction term, columm 13 of table 6 , is irregular for the first few points of the rums in question.

Sample distribution is also thought to explain the departure of point 208 from the rest of run 2 . The possibiity exists that for rum 208 the capillary was frozen, because if point 208 is recalculated with zero stem volume the value of $C_{v}$ is increased by about 2.5 percent.

We had hoped to employ the breakthrough point to resolve the problem of sample ristribution. Experimental breakthrough temperatures agree well with calculaterl values; densities and total sample agree to a point where we are conficlent that the calorimeter volume has not changed. However, to calculate $C_{\sigma}$ and $C_{v}$ values from a breakthrough point requires that we know the time of breakthrough 
exactly in order to proportion the applied heat ?. There is simply too much lag in the response of the recorders to permit an accurate determination of the breaktluongli time.

The imprecision in the experiment depents primarily on the imprecision of $C_{0}^{r}$ and on the amount of sample since in most cases the $\Delta T$ is around $4 \mathrm{~K}$. For liguid densities the imprecision from point to point along an isochore is about 0.1 percent with occasional differences as large as 0.3 pereent. For demsitien less than eritical the imprecision, the valiation of $C_{r}$. point to point from a smooth curve, incerases to about 1 pereent. 'The inaceuracy or' merertaintro of the presont measurements is estimated from the compalison to the experiments of others and from the comparion to values ralculated from the $P^{\prime 2} T$ rolmation. We consider the excellent agresment between the present results and the experiments of othors $[10,16,17,18]$, in particular the agreement with experinental values of $C_{p}$, and we consider the remult of aldiberately introducing changes in the present experiment. It is difficult to see how systematis:

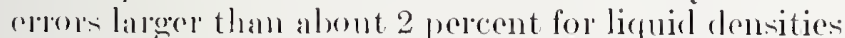
or lareger tian 5 perent for vapor densities close to critical condel remain undetected in the present experiment.

\section{References}

[1] The i. 1. (international system) unit of pressure is the

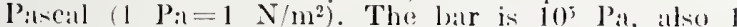
atm $=1.0132 .5 \times 10^{5}$ Pa, $111, / \mathrm{in}^{2}=6894.7 .57 \mathrm{P}: 1$ drane $\mathrm{cm}^{2}=10^{-1} \mathrm{~Pa}$ : sere Page, ('. Hl. and Vigoureux, 1’., Nat. Bur. Stand. (U.S.), S'sere. Publ. 330, (Jan.

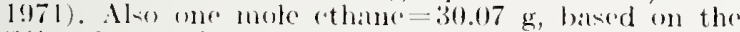
I'( 'seale and the natural isotopie aloundanee averages: *re Romy, 1L., Chem. Berichte 101, 1 (1968).
[2] Goodwin, R. D., lioder, II. M., and sitraty, (i. (c) Nat. Bur. Stand. (l'.t.), Teeh. Nete bist in prese), for provisional data see Goudwin, R. 1). Nate Bur. stind. (['...), NBSIL 74-39s (I Juno 1974). (Avilalle as COM 74-11717 from the National Technical Information fierviees, sipringfield, VA 22161.)

[3] Goodwin, R. I)., J. Res. Nat. Bur. Stand. (U.S.) 650 (Eng. and Instr.), No. 4 231-243 (Oct-1)e 1961)

[4] loungheve, B. A., and Diller, D, L., Cryogenies 2, $283(1962)$

[ii] Younglove, B. A., and Diller, D. E., Cryogenies, 2 , $348(1962)$

[6] Ciondwin, R. D., and Weber, L. A., J. Res. Nat. Bur. Stand, (U.S.) 73A, (Phys. and Chem.), No. 1, 1-1:3 (Jan.-Fel). 1969).

[7] Goodwin, R. D., and IVeloer, l. A., J. Res, Nat. Bur. Ftand. (U.S.) 73A, (Phys. and Chem.), No. 1, 15-24 (Jan.-Fels, 1969).

[R] (ioodwin, R. D., and Prydz, R., J. Res. Bur. Stand. (U.S.) 74A, (Phy's. and Chem.), No. 4, 4!99-50.5 (July-Aug. 1970).

[9] Prydz, R., and Goodwin, R, 1), J. Res. Nat. Bur. Stand. (U.S.) 74A, (Phys. and Chem.), No. 5, 661-66.5 (scpt.-Oct. 1970).

[10] Younglove, B. A., J. lice. Nat. Bur. Stand. ([..s.) 78A, (Phys. and Chem.) No. 3, 401-420 (Mary-June 1974).

[11] Roder, 11. 11., J. ('hem. I'hys. 65, 1:371 (1976)

[12] IV alker, P'. A., Dissertation (University of London, 19.56).

[1:3] ILoge, H. J., J. Re.s. Nat. Bur. Stand. (U.S.) 36, 11]-118, (1946) RP1693.

[14] Ciocodwin, IR. D., Nat. Bur. Stand. (U.S.), Tech. Note 6.33208 pages (April 1974).

[1.5] Goodwin, R. 1)., and Prydz, R., J. Res. Nat. Bur. Stand. (U.S.) 76A, (l'hys. and C'hem.), No. 2, 81-102 (Nir.-Apr. 1972).

[16] Wirbe, R., IIubluard, K. II, and Brevoort, M. J., J. Am. Chem. Soc. 52, (111) (1930).

[17] Witt, R. K., and Kimp, J. 1)., J. Ans. Chens. Soe. 59, $27: 3(1937)$.

[18] Furtado, A., Ph.1). Thesis, Department of Chom. lingine ring, University of Michigan (Bece 1973).

[19] Bior, K., Kunze, J., and Maurer, (i., to be pulslished, J. ('hem. Thermodynamies 8, s.57 (1976).

(Paper 80A5-915) 

LNG DENSITIES FOR CUSTODY TRANSFER ${ }^{* \dagger}$

\author{
Dwain E. Diller \\ Cryogenics Division \\ Institute for Basic Standards \\ National Bureau of Standards \\ Boulder, Colorado 80302
}

\begin{abstract}
Accurate LNG densities are required for equitable custody transfer contracts and operations. Mathematical models and direct reading densimeters for use on LNG type mixtures are being evaluated at the National Bureau of Standards. Accurate (0.1\%) orthobaric 1iquid density data have been obtained for LNG components and their mixtures and are being used to optimize and evaluate four published mathematical models. A density reference system has been constructed and is being used to evaluate commercially available densimeters. Recent progress on these tasks is summarized and discussed.
\end{abstract}

Key words: Custody transfer; densimeter; density; 1iquefied natura1 gas; mathematical model.

* This work was carried out at the National Bureau of Standards under the sponsorship of British Gas Corp., Chicago Bridge and Iron Co., Columbia Gas Service Corp., Distrigas Corp., Easco Gas LNG, Inc., E1 Paso Natural Gas., Gaz de France, Marathon Oil Co., Mobil R\&D Corp., Natural Gas Pipeline Co., Phillips Petroleum Co., Shell International Gas, Ltd., Sonatrach, Southern California Gas Co., Tennessee Gas Pipeline, Texas Eastern Transmission Co., Tokyo Gas Co., Ltd., and Transcontinental Gas Pipe Line Corp., through a grant administered by the American Gas Association, Inc.

$+\quad$ This work was carried out at the National Bureau of Standards under the sponsorship of the American Gas Association, Inc. 
Dwain E. Diller

\section{INTRODUCTION}

LNG is typically bought and sold on the basis of its heating value. Important elements in calculations of the heating value of LNG in tanks and pipelines include tank volume and liquid level, flow rate, density, composition, temperature, pressure and specific heating value of the vaporized liquid. The density of the liquid is required in all heating value calculations. The basis for determining the density is usually agreed to in custody transfer contracts, which may involve several companies and countries. LNG densities can be either calculated from a mathematical model, as a function of composition and temperature (or pressure), or measured directly in a tank or pipeline. During the course of a typical contract the density will be determined many times with systematic errors benefiting one of the contractual parties. An inaccuracy of $1 \%$ in the density of a $125,000 \mathrm{~m}^{3}$ LNG cargo is currently worth approximately $\$ 40,000$. An inaccuracy of less than $0.1 \%$ in the density has been selected as a reasonable goal for this calculation or measurement.

CALCULATION OF THE DENSities OF LNG TYPE MIXTURES *

Calculation of the densities of LNG with a mathematical model has several advantages and disadvantages. An advantage is that the model can be based on the most accurate available density measurements performed under ideal laboratory conditions. A disadvantage is that use of the model depends on knowledge of the mixture composition, which may be difficult or inconvenient to obtain with sufficient accuracy. Another disadvantage is that accurate mathematical models, which cover a large range of mixture compositions, temperatures and pressures, are fairly difficult to use. 
The molar volume $V_{\text {mix }}$ of a fluid mixture can be written

$\mathrm{V}_{\operatorname{mix}}=\sum \mathrm{x}_{i} \mathrm{~V}_{i}+\mathrm{V}^{\mathrm{E}}$

where $x_{i}, V_{i}$ and $V^{E}$ are conventionally the mole fractions, molar volumes of the constituents, and the excess volume respectively, all at the temperature and pressure of the mixture. For LNG type mixtures $\mathrm{V}^{\mathrm{E}}$ is typically negative and $1-2 \%$ of $\mathrm{V}_{\mathrm{mix}}$. Therefore an accurate mathematical model for $\mathrm{V}_{\mathrm{mix}}$ (or $\mathrm{V}^{\mathrm{E}}$ ) is required to achieve an inaccuracy of less than $0.1 \%$ in the density. Several promising models for calculating accurate densities of LNG type mixtures have been published. They include the Klosek and McKinley excess volume correlation [1], the modified cell model [2], the modified corresponding states model [3], and the modified hard sphere equation of state model [4]. The detalls of these models are given in the references. The mathematical models must be based on and tested against accurate density measurements for LNG components and their mixtures. For contractual purposes it is desirable that the measurements and evaluation be carried out by an independent third party.

Until recently there have been few accurate $(0.1 \%)$ density measurements available for liquefied LNG components and their mixtures in the normal boiling temperature range (110-115 K) of LNG type mixtures. To obtain the additional data needed a magnetic suspension densimeter has been constructed and performance tested for measurements in the temperature range 90-300 $\mathrm{K}$ at pressures to $5 \mathrm{MPa}$ (725 psi) [5], and a comprehensive program of orthobaric liquid density measurements has been carried out on six LNG components (methane, ethane, propane, isobutane, normal butane and nitrogen) [5,6], on 29 compositions of 13 binary mixtures [7], and on 13 multicomponent mixture compositions [8], including several LNG type mixtures. This work has been carried out by W. M. Haynes, M. J. Hiza, and others at the National Bureau of Standards. The measurements 
on the pure components, at temperatures mainly between 95 and $160 \mathrm{~K}$, have an estimated imprecision less than $0.02 \%$ and an estimated inaccuracy of approximately $0.1 \%$. The estimated imprecision is primarily based on the standard deviation obtained for 123 measurements on liquid methane. The estimated inaccuracy of a single density measurement on liquid methane was taken as the square root of the sum of the squares of the systematic error plus an allowance of three times the standard deviation for random error. The measurements on the binary and multicomponent mixtures, at temperatures mainly between 105 and $140 \mathrm{~K}$, have a typical estimated inaccuracy of approximately $0.1 \%$ and a maximum estimated inaccuracy of $0.16 \%$. The derived excess volumes $\mathrm{V}^{\mathrm{E}}$ of the binary mixtures can be classified into several quantitatively distinguishable groups: in the temperature range of these measurements the alkane mixtures without methane have excess volumes which are less than $0.1 \%$ of $\mathrm{V}_{\text {mix }}$, the alkane mixtures containing methane have excess volumes up to $3 \%$ of $V_{m i x}$, and the nitrogen-alkane mixtures have excess volumes up to $10 \%$ of $\mathrm{V}_{\operatorname{mix}}$.

The modified Klosek and McKinley correlation, the modified corresponding states model and the modified hard sphere equation of state model are being. optimized and evaluated by R. D. McCarty at the National Bureau of Standards. The modified cell model is being optimized and evaluated by M. A. Albright at the Phillips Petroleum Company. Within various composition range limitations these models have correlated most of the NBS data within their estimated inaccuracies. The results are now being prepared for publication.

DIRECT READING DENSIMETERS FOR LNG TYPE MIXTURES ${ }^{\dagger}$

Direct reading densimeters for use on LNG type mixtures also have several advantages and disadvantages. Advantages include the relative simplicity of use (knowledge of the mixture composition is not required) and the possibility of continuously monitoring the density. Disadvantages include the need for. calibration of densimeters now commercially available and the difficulty of obtaining sufficient information on the calibration and performance of a 
particular densimeter. For contractual purposes it is desirable that the performance of types of available densimeters be evaluated by an independent third party. Accordingly, an apparatus [9] for evaluating the performance of types of commercially available densimeters on LNG components and their mixtures has been constructed and tested at the National Bureau of Standards. This work has been carried out by B. A. Younglove and others. The direct reading densimeters to be evaluated are placed in a density reference system (DRS) containing carefully characterized liquefied gases and are compared against an accurate absolute densimeter based on Archimedes' principle. The accessible temperature range of the DRS is 80 to $300 \mathrm{~K}$ and the pressure limit is 7 bars ( $~ 100 \mathrm{psi}$. The estimated inaccuracy of the reference densimeter is less than $0.21 \%$. The estimated inaccuracy was based on the sum of the known sources of systematic error, $\pm 0.026 \%$, plus three times the standard deviation, $\pm 0.062 \%$, based on 71 independent measurements using eight different samples of liquid methane ( $99.97 \%$ pure). The direct reading densimeters can also be compared with densities calculated from measurements of the composition and temperature and a mathematical density model. Tests have been performed on commercially available densimeters based on Archimedes' principle, on dielectric property measurements, and on the frequency response of several vibrating elements. The results are now being prepared for publication.

\section{SUMMARY AND CONCLUSIONS}

Comprehensive accurate orthobaric liquid density data have been obtained for six LNG components and their mixtures and are being used to optimize and evaluate four promising calculation methods. Within various composition limitations these models have correlated most of the data within their estimated inaccuracies. Several significant differences between the measured and calculated densities still remain, and efforts to resolve these differences are continuing.

A density reference system has been constructed and is being used to evaluate the performance of commercially available densimeters for use on LNG type mixtures. Several types of densimeters look promising for obtaining direct density measurements on LNG in tanks and pipelines within the estimated inaccuracy of the reference densimeter. 


\section{REFERENCES}

1. J. Klosek and C. McKinley, Densities of Liquefied Natural Gas and of Low Molecular Weight Hydrocarbons, Proc. First Int. Conf. on LNG, IGT, Chicago (1968), Session 5, paper 22.

2. M. A. Albright, A Model for the Precise Calculation of Liquefied Natural Gas Densities, NGPA Technical Publication TP-3 (1973).

3. J. Mollerup and J. S. Rowlinson, The Prediction of Densities of Liquefied Natural Gas and of Lower Molecular Weight Hydrocarbons, Chem. Eng. Sci. $29,1373(1974)$.

4. J. B. Rodosevich and R. C. Miller, Calculation of LNG Excess Volumes by a Modified Hard-Sphere Model, Adv. Cryog. Eng. 19, 339 (1974).

5. W. M. Haynes, M. J. Hiza and N. V. Frederick, A Magnetic Suspension Densimeter for Measurements on Fluids of Cryogenic Interest, Rev. Sci. Instr. 47, 1237 (1976).

6. W. M. Haynes and M. J. Hiza, Measurements of the Orthobaric Liquid Densities of Methane, Ethane, Propane, Isobutane and Normal Butane, J. Chem. Thermo. (in press) (1976).

7. M. J. Hiza, W. M. Haynes and W. R. Parrish, Orthobaric Liquid Densities and Excess Volumes for Binary Mixtures of Low Molecular Weight Alkanes and Nitrogen Between 105 and $140 \mathrm{~K}$, to be submitted to J. Chem. Thermo.

8. M. J. Hiza and W. M. Haynes, unpublished data.

9. B. A. Younglove and J. D. Slegwarth, Cryogenic Fluids Density Reference System Provisional Accuracy Statement, unpublished data. 


\title{
Magnetic suspension densimeter for measurements on fluids of cryogenic interest*
}

\author{
W. M. Haynes, M. J. Hiza, and N. V. Frederick \\ National Bureau of Standards, Institute for Basic Standards, Cryogenics Division, Boulder, Colorado 80302 \\ (Received 24 June 1976)
}

An apparatus incorporating a magnetic suspension technique has been developed for density measurements on liquids and liquid mixtures, particularly at saturation, at temperatures between 90 and $300 \mathrm{~K}$ and at pressures to $5 \mathrm{MPa}$ (approximately $50 \mathrm{~atm}$ ). The feasibility of adapting this method, previously used at room temperature, for low temperature use had been demonstrated in an earlier study with a density measurement on saturated liquid nitrogen near its normal boiling point. The present apparatus, which is significantly improved, and in most respects different from the earlier model, is described in detail. It includes a cryostat for continuous wide-range temperature control, a windowed equilibrium cell particularly suited for studies of liquid mixtures, and a new electronic servocircuit with a linear differential transformer for position control of the magnetic buoy. Extensive tests and density measurements have been carried out to evaluate the performance of this apparatus. Densities of saturated liquid nitrogen between 95 and $120 \mathrm{~K}$ and saturated liquid methane between 105 and $160 \mathrm{~K}$ are reported. The estimated standard deviation of a single density measurement is less than $0.02 \%$. The total systematic error in the measurement process from known sources is approximately $0.05 \%$. The total uncertainty of a single density measurement, which is taken as three times the standard deviation plus the systematic error, is approximately $0.1 \%$. Comprehensive comparisons of the present results with previous experimental data are presented.

\section{INTRODUCTION}

With the advent of large-scale liquefaction and global transport of natural gas, accurate equilibrium liquidphase densities have become important for custody transfer. The density data for liquefied natural gas mixtures and their components have been generally characterized by the existence of large discrepancies (approximately $0.5 \%$ ) between different sets of data for the pure components and by a limited amount of mixture data. Hence, an apparatus has been developed to provide accurate, consistent, and comprehensive density data for liquefied natural gas mixtures and their predominant pure components at saturation conditions. These measurements will serve as a data base for testing and optimizing selected mathematical models (correlations) useful in predicting the densities of liquefied natural gas. In the present paper the apparatus and experimental procedures are described in detail and representative measurements for two components of liquefied natural gas are presented.

A magnetic suspension densimeter, which is based on an application of Archimedes' principle, has been selected for the present measurements primarily because this instrument is suitable for an independent, direct determination of the density of a saturated liquid over wide ranges of temperature and pressure within the precision and accuracy required for anticipated technical applications. In an earlier study, ${ }^{1}$ the feasibility of adapting the magnetic suspension technique for density measurements at low temperature was demonstrated with a measurement on saturated liquid nitrogen near its normal boiling point. The present apparatus (see Fig. 1 for a scaled assembly drawing), which is a much improved version of the earlier model, incorporates a three-coil support system, ${ }^{2}$ a cryostat for temperature control at any temperature between 90 and $300 \mathrm{~K}$, a windowed equilibrium cell suitable for projected studies on liquid mixtures at pressures to $5 \mathrm{MPa}$, and a new electronic servocircuit with a linear differential transformer that serves as a position sensor for a barium ferrite magnetic buoy.

The present work has included an extensive evaluation of the use of a magnetic suspension densimeter for absolute density measurements. (Here the term "absolute density" is used to indicate that cryogenic fluids were not used to calibrate the instrument.) Results of performance tests along with densities for saturated liquid nitrogen between 95 and $120 \mathrm{~K}$ and saturated liquid methane between 105 and $160 \mathrm{~K}$ are presented in this paper to demonstrate the low temperature performance of this new apparatus. The estimated standard deviation of a single density measurement is less than $0.02 \%$. The total uncertainty of a single measurement, which is taken as the sum of the systematic error and three times the standard deviation. is approximately $0.1 \%$.

In Sec. II the general principles of a magnetic 


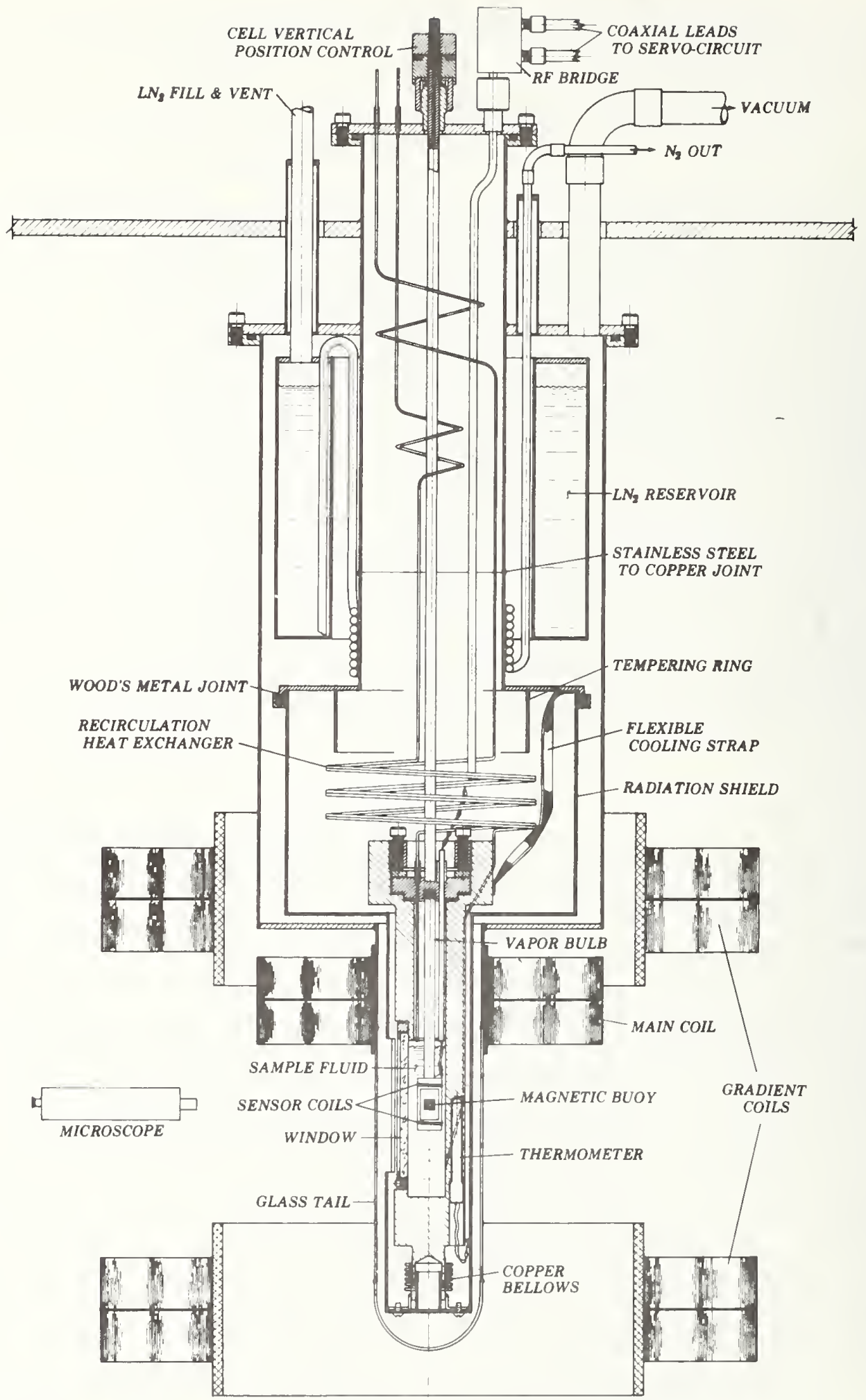

Fig. 1. Assembly drawing (approximately to scale) of a magnetic suspension densimeter for cryogenic fluids.

suspension densimeter are outlined. Section III is devoted to a detailed description of the experimental apparatus. A comprehensive discussion of the experi- mental procedures and measurements is given in Sec. IV. In Sec. V a summary of performance tests carried out in evaluating the instrument is presented. This sec- 
tion also deals with the uncertainties in the density measurements. Finally, the experimental data for saturated liquid nitrogen and methane, along with comparisons with independent measurements, are reported in Sec. VI.

\section{PRINCIPLES OF OPERATION}

A piece of magnetic material is magnetically suspended in a fluid at a stable equilibrium position through the use of a closed-loop servosystem. When the float (or buoy) is in free support, there are three forces acting on it. In the present system the magnetic float is more dense than the fluid in which it is suspended; thus, an upward magnetic force is added to the buoyancy force to balance the downward gravitational force.

In the present work a three-coil (air-core) system ${ }^{2}$ is used to supply the magnetic force. The three coils are aligned coaxially. Each coil is symmetric about an axis in common with the cylindrical axis of the magnetic buoy. The three coils consist of a main coil, which supplies the major part of the field necessary to lift the float, and a pair of gradient coils. The horizontal position of the float. which is in the shape of a right circular cylinder (length/diameter $>1$ ) magnetized along its cylindrical axis, is maintained by the axially symmetrical, diverging field of the main coil. The magnetic force on the ferromagnetic buoy is given by

$$
F_{\mathrm{mag}}=M \frac{d H}{d Z},
$$

where $M$ is the total magnetic moment of the buoy and $d H / d Z$ is the variation of the external field intensity along the common cylindrical axis of the coils. For the present system the float is a permanent magnet for which the total magnetic moment (excluding temperature dependence) can be represented by

$$
M=M_{0}+M_{l}(H),
$$

where $M_{0}$ is the permanent moment, and $M_{l}(H)$ is the induced moment resulting from an applied field.

At a fixed position along the cylindrical axis of an aircore solenoid,

$$
H=k I
$$

and

$$
\frac{d H}{d Z}=k^{\prime} I
$$

where $I$ is the solenoid current and $k$ and $k^{\prime}$ are constants dependent upon the number of turns and dimensions of the coil.

As mentioned earlier, the float is supported at a position relative to the main coil such that its horizontal position is fixed. This results in the float being supported at a distance below the main coil slightly larger than the inside radius of this coil. The float is sup- ported approximately midway between the gradient coils. These coils are connected in series such that their magnetic field intensity contributions cancel at the float position. (For a Helmholtz coil arrangement the magnetic fields would add at the midpoint.) Thus, the magnetic field intensity at the float position is due solely to the main coil contribution. Similarly, the magnetic field gradients of the gradient coils add at the float position.

For this three-coil arrangement and with a constant main coil current $\left(I_{M}\right)$ (and subsequently the magnetic moment of the float does not change), the density of the fluid $(\rho)$ is related to the gradient coil current $\left(I_{G}\right)$ by the following relation:

$$
\rho=A+B I_{G},
$$

where $A$ and $B$ are constants to be determined by calibration with fluids of known density. This relationship is valid whether the float is magnetically hard or soft. Knowledge of the mass and volume of the float is not required to obtain relative density results using Eq. (5). However, since the magnetic moment of the float is temperature dependent, the constants $A$ and $B$ would have to be determined at each temperature of interest.

At low temperatures at least two fluids of known density, one of which may be "vacuum," are needed for calibrating the instrument for use in performing relative density measurements. However, the densities of low temperature fluids are not known to sufficient accuracy to permit them to be used as calibration fluids and, in fact, this had been one of the major motivations for developing an independent technique for density measurements on cryogenic fluids.

In the previous work by Haynes and Stewart, ${ }^{1}$ a new method was demonstrated for determining absolute densities using the same three-coil arrangement, but which is dependent upon the magnetic properties of the buoy material. If one uses a permanent magnetic material for the float and its induced moment is zero or, at least, very small compared to the permanent moment, then the magnetic force on the float is given by the relation,

$$
F_{\mathrm{mag}}=C^{\prime} I_{M}+D^{\prime} I_{G},
$$

where $C^{\prime}$ and $D^{\prime}$ are constants depending on the relative position of the coils and float, the magnetic moment of the float, and the dimensions and number of turns of the support coils. One should note that for Eq. (6) the main coil current $\left(I_{M}\right)$ is not held constant. Now the density of the fluid is given by the expression,

$$
\rho=\left(m-C I_{M}-D I_{G}\right) / V,
$$

where $m$ and $V$ are the mass and volume of the float. The acceleration of gravity has been included in the constants $C$ and $D$. (The mass and volume of the float must be determined by independent measurements.) The validity of this equation can be tested experimentally. For measurements in a vacuum, Eq. (7) reduces to the following relation: 


$$
m=C I_{M}+D I_{G} \text {. }
$$

It should be emphasized that the critical assumption in deriving Eq. (7) is that there is no induced moment in the buoy resulting from changes in the magnetic field intensity over the range of magnetic fields needed for the density measurements. (For the present measurements this includes fields between 0.006 and 0.016 T.)

The current in the gradient coils has been measured as a function of the current in the main coil while the float was suspended at a constant height in a given fluid, usually vacuum, at constant temperature. The currents were fitted by the method of least squares to either Eq. (6) or Eq. (8). The quality of this fit indicated the validity of the assumption concerning the dependence of the magnetic moment upon the magnetic field. (Results will be presented in a later section.) For the present measurements the main coil current, and thus the magnetic field. could be varied over a range amounting to $25 \%$ of its maximum value. The minimum ratio of $I_{M} / I_{G}$ was determined by the loss of horizontal stability of the float.

From the above discussion it should be apparent that relative density measurements using Eq. (5) ( $I_{M}$ constant) can be carried out to complement the results of absolute measurements using Eq. (7) with the same three-coil arrangement. In performing measurements using Eq. (7) for which the main coil current is varied over a considerable range, it is experimentally difficult to fix or determine the position of the main coil from vacuum to iiquid measurements within the desired precision. This problem does not arise when making relative density measurements for which the main coil current is held constant. In principle, both procedures should give identical density ratios for the same fluids at constant temperature. In practice, the relative density measurements can be carried out to deduce the systematic error in the absolute density measurements that depends on the magnitude of the main coil current. These tests have been performed in the present work and will be discussed in a later section.

\section{APPARATUS}

\section{A. General considerations and cryostat}

An assembiy drawing (approximately to scale) of the major components of the apparacus is shown in Fig. 1. The general dimensions and configuration of the cryostat and equilibrium cell were determined by the dimensions and configuration of the main coil and the two gradient coils. (See Table I for coil dimensions.)

Criteria considered essential, and which have been satisfied, in the design of the apparatus are as follows: (a) all materials of construction in ciose proximity to the magnetic suspension assembiy are nonmagnetic: (b) the entire assembly is rigidly supported so that the relative position of the buoy, microscope, and support coils
TABle I. Parameters of support coils.

\begin{tabular}{lcc}
\hline & Main coil & Gradient coils \\
\hline Length & $6.0 \mathrm{~cm}$ & $6.2 \mathrm{~cm}$ \\
Inside diameter & $7.4 \mathrm{~cm}$ & $25.4 \mathrm{~cm}$ \\
Outside diameter & $20.24 \mathrm{~cm}$ & $38.6 \mathrm{~cm}$ \\
Number of turns & 5000 & 5000 \\
\hline
\end{tabular}

can be maintained; (c) the magnetic buoy and the liquid level are visible within a windowed cell capable of withstanding working pressures up to $5 \mathrm{MPa}$; (d) the volume occupied by the liquid sample within the cell is sufficiently large to render the unavoidable vapor volume of the access tubing, etc., insignificant within the accuracy goals of experiments involving liquid mixtures; (e) temperature gradients along the length of the working space of the cell are monitored and reduced to a practical minimum. i.e.. less than a total of $10 \mathrm{mK}$; (f) the rate of refrigeration of the equilibrium cell is adjustable and continuous; and ( $\mathrm{g}$ ) the temperature of the cell can be controlled at any temperature between 90 and $300 \mathrm{~K}$.

A concrete block structure provides a stable support for the cryostat, the coils, and the microscope. The cryostat assembly is suspended from an aiuminum plate that spans the top of the concrete structure. The stainless steel central support tube of the cryostat is attached to this aluminum plate with a brass collar (not shown in Fig. 1). The lower end of the stainless steel tube is soldered to a copper tube to which a heat exchanger is soldered.

Refrigeration is provided by continuous transfer of liquid nitrogen from the cryostat reservoir through the heat exchanger. Regulation of the refrigeration rate is accomplished by controlling the nitrogen vent rate to the atmosphere.

Refrigeration is supplied to the bottom of the equilibrium cell through the copper radiation shield and to the top of the cell through two copper braided straps. The radiation shield, which contains a slit aperture in a position corresponding to the cell window, is attached to a copper plate at the top of the shield with Wood's metal to facilitate removal of the shield and alignment of the shield within the glass tail section. The glass tail is connected to the. stainless steel vacuum jacket through a stainless steel-to-glass transition joint.

\section{B. Equilibrium cell}

The equilibrium cell, made of electrolytic tough pitch copper, has an overall length of approximately $30 \mathrm{~cm}$, including the copper-plated bellows at the bottom. The cell closure is a compression fitting with a silver-plated, solid copper O-ring. The closure plug, threaded backing ring, and compression screws are stainless steel. The top of the cell is held in alignment by a stainless steel tube, which is brazed to the closure plug and extends through the uppermost cryostat plate. The upper end of the cell support tube 
is threaded through a nut and bearing assembly to allow small adjustments in the vertical position of the cell and thus the vertical position of the magnetic buoy. The bottom of the cell is thermally anchored to the radiation shield by mechanical attachment of a flanged bellows section. A thin coat of commercially available conducting grease is used to enhance thermal contact between the bellows flange and the shield. Two thermal links of copper braid are also mechanically attached to the top of the cell from the top plate of the radiation shield using thin coats of conducting grease between the contact surfaces.

The outside diameter of the main part of the cell is $4.13 \mathrm{~cm}$ and that of the closure section is $7.60 \mathrm{~cm}$. The internal working space is $1.99 \mathrm{~cm}$ in diameter and approximately $20 \mathrm{~cm}$ long. More than half of the internal volume, however, is occupied by the magnetic buoy-sensor coils assembly $\left(\sim 10 \mathrm{~cm}^{3}\right)$ and the vapor bulb $\left(\sim 35 \mathrm{~cm}^{3}\right)$. The vapor bulb is a slip fit in the top section of the cell and is attached directly to the closure plug. The internal free volume of the cell is approximately $20.5 \mathrm{~cm}^{3}$. Anticipating measurements on mixtures, the volume $\left(\sim 0.3 \mathrm{~cm}^{3}\right)$ in the annulus between the vapor bulb and the cell wall has been made as small as possible. since this is normally part of the vapor volume.

The electrical lead-throughs for the sensor coils consist of three No. 32 coated copper wires encapsulated with an epoxy adhesive in a copper capillary tube. This tube extends through the closure plug to the bottom of the vapor bulb. The epoxy adhesive, an alumina-filled resin with elevated temperature curing agent, was selected based on an earlier study ${ }^{3}$ of low temperature properties of epoxy adhesives. By pressurizing with helium gas while the adhesive was hot, the entire length of the capillary tube was filled with adhesive to minimize the available vapor volume in the equilibrium cell.

The cell window was designed to allow viewing the liquid sample from the base of the vapor bulb down to $2 \mathrm{~cm}$ from the bottom of the liquid space. The viewing slit is $0.6 \mathrm{~cm}$ wide $\times 7.5 \mathrm{~cm}$ long. The window consists of a piece of tempered Pyrex ${ }^{4}$ glass of $0.32-\mathrm{cm}$ thickness with semicircular ends and chamfered edges. The seal between the glass and the cell is made with indium wire compressed in a racetrack groove machined in a flat surface on the cell. The glass is compressed against the indium seal with a hardened beryllium copper plate secured by stainless steel screws. A rubber asbestos pad is placed between the beryllium copper plate and the glass to relieve thermal and mechanical strains. The inaximum working pressure of the equilibrium cell is limited by the maximum working pressure of the window.

\section{Magnetic buoy}

The buoy is a barium ferrite $\left(\mathrm{BaFe}_{12} \mathrm{O}_{19}\right)$ magnet in the shape of a right circular cylinder magnetized along its cylindrical axis. Its length and diameter are approximately 0.64 and $0.51 \mathrm{~cm}$, respectively.

Barium ferrite is a magnetically hard, ceramic material with a density of approximately $5 \times 10^{3} \mathrm{~kg} / \mathrm{m}^{3}$. It is somewhat porous and has a high electrical resistivity. The buoy used in the present work has been permanently magnetized in a saturation field of $1 \mathrm{~T}$. After initial cycling over maximum ranges of temperature $(90-300 \mathrm{~K})$ and magnetic field intensity $\left(0-1.3 \times 10^{4}\right.$ $\mathrm{A} / \mathrm{m}$ ) the barium ferrite magnet exhibited no hysteresis over the ranges of currents and temperatures needed in the density measurements. The magnet is operating in a very small segment $\left(5-13 \times 10^{3} \mathrm{~A} / \mathrm{m}\right)$ of a broad hysteresis loop. The slope of the $B$-vs- $H$ curve is small and constant. The change in the magnetic moment of the float with temperature varies from $0.2 \% / \mathrm{K}$ at $300 \mathrm{~K}$ to $0.1 \% / \mathrm{K}$ at $100 \mathrm{~K}$, as determined from the present measurements in vacuum. This variation in the magnetic moment with temperature results in a random error in the density of approximately $0.002 \%$ at $100 \mathrm{~K}$, increasing to $0.004 \%$ at $300 \mathrm{~K}$. This estimate is based on a reproducibility in the temperature of $2 \mathrm{mK}$ from vacuum to liquid measurements.

Since the barium ferrite magnet is porous, it must be coated with a material which does not allow fluid to penetrate into the buoy. Copper was found suitable for this purpose. After a piece of barium ferrite was ground into the shape of a right circular cylinder with chamfered edges $(0.25 \mathrm{~mm}$ deep), a conducting layer of copper was uniformly plated onto the ceramic magnet by chemical reduction. On top of this conducting layer, copper was electroplated to a thickness of approximately $0.25-0.50 \mathrm{~mm}$; a much thicker coating resulted at the edges. Then most of the copper was removed with a diamond tool until the copperplated barium ferrite magnet was in the shape of a right circular cylinder without chamfered edges. The final buoy had a minimum of $0.06 \mathrm{~mm}$ of copper over the cylindrical surface and the end faces and at least $0.25 \mathrm{~mm}$ on the edges where the magnet had been chamfered. The edges were built up to a thicker coating since the plating strength would be weakest at these locations. (For density measurements it is not necessary that the plating be symmetric about the center of mass of the buoy.) Gold was flashed $\left(10^{-3} \mathrm{~mm}\right)$ over the entire copper surface as a protective coating.

\section{Electromagnetic support coils}

Each of the coils is composed of two separate coils of 2500 turns of epoxy-coated aluminum foil of approximately $0.025-\mathrm{mm}$ thickness. The foil for the main coil has a width of $2.5 \mathrm{~cm}$ while that for the gradient coils is $3.0 \mathrm{~cm}$. Selected coil parameters are given in Table I.

Each of the gradient coils is rigidly supported by three aluminum rods resting on the concrete structure. The gradient coils have a separation distance of approximately $23 \mathrm{~cm}$. No effort has been made to control the 


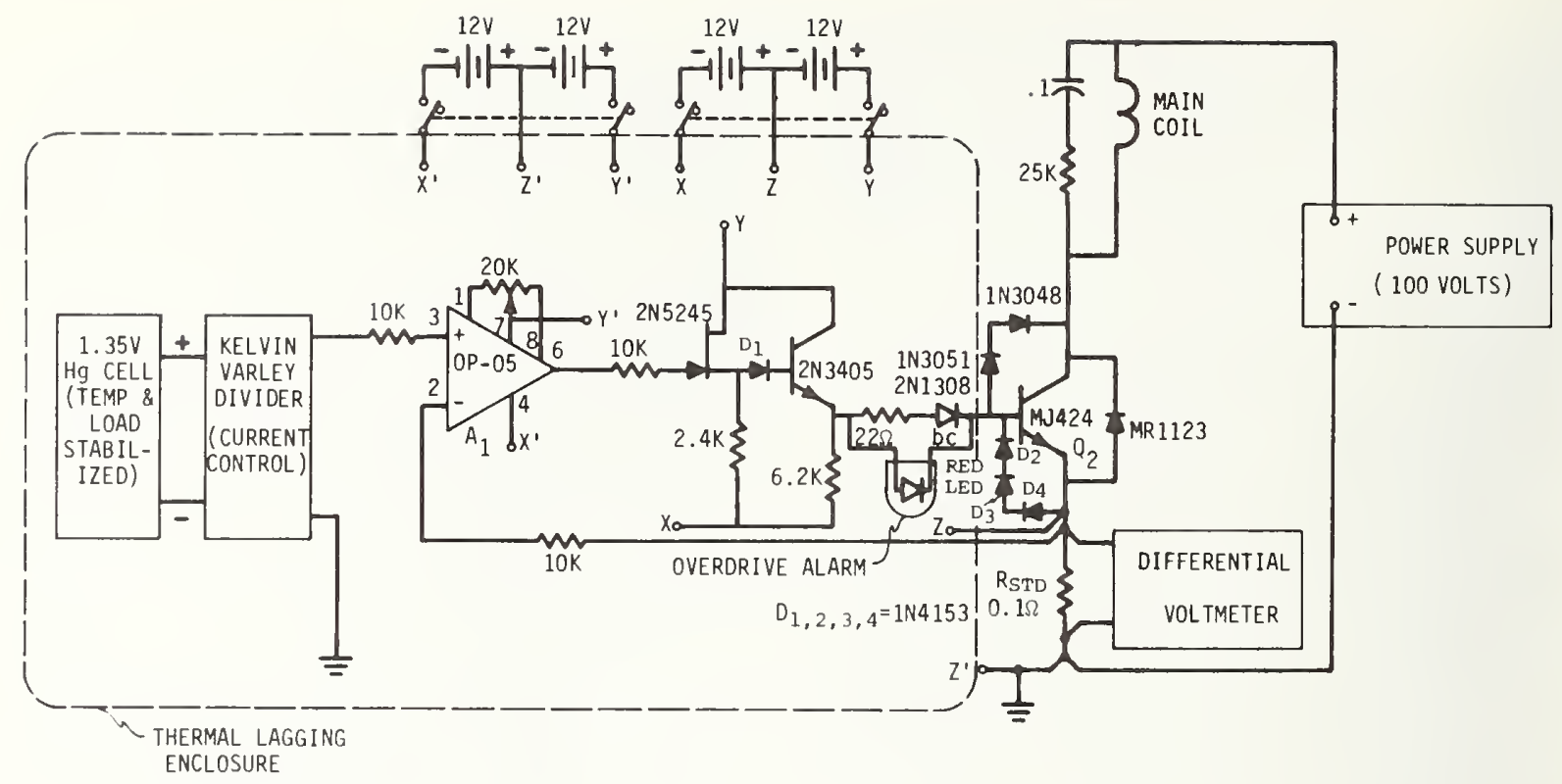

FIG. 2. Current control circuit for main coil.

position of the gradient coils except through the control of the laboratory temperature. The $d H / d Z$ of the gradient coils changes very slowly $\left(2.5 \times 10^{-4} / \mathrm{cm}\right)$ from a maximum at the float position. Since the change in $d H / d Z$ with position for the main coil is two orders of magnitude larger than that for the gradient coils, special care has been taken to minimize changes in the position of the main coil.

First, the main coil is supported at its midplane so that thermal expansion effects inside the coil are minimized. A circular copper plate has been soldered to the brass tube on which the main coil is wound. A coil of aluminum foil (2500 turns) is clamped tightly to each side of the copper plate with a thin layer of vacuum grease between the aluminum foil and copper for maximum thermal contact. The copper plate (and thus the coil) is supported by quartz rods extending to the concrete structure. Thus, any changes in the position of the midplane of the coil due to room temperature changes would be negligible. Copper plates with cooling water have been placed on the outside faces of each section of the main coil such that the average temperature of the main coil is below room temperature for maximum current ( 1 A). However, for absolute density measurements, the temperature of the main coil changes from vacuum to liquid measurements (1.2 K for nitrogen at $100 \mathrm{~K}$ ) since a larger current is required to support the float in vacuum than in the liquid for a given gradient coil current.

\section{E. Support system electronics}

The current in the main coil, which contributes the major portion of the magnetic force necessary to lift the buoy, is provided by the circuit of Fig. 2. The circuit functions as follows: The main coil current flows through a stable resistor $R_{S T D}(0.1 \Omega)$ in the emitter of $Q_{2}$ (the current-controlling transistor). The voltage developed across $R_{\text {STD }}$ is compared with a reference voltage from a Kelvin-Varley voltage divider by amplifier $A_{1}$. The output of $A_{1}$ drives the base of $Q_{2}$ and controls the current through $\mathbf{R}_{\mathrm{STD}}$ and the main coil. Since the loop gain of this circuit is exceedingly high $\left(>10^{6}\right)$ and the thermal drifts are very low, the long-term stability of the main coil current is of the order of $0.001 \%$. This current controller has a temperature coefficient of the order of $5 \mathrm{ppm} / \mathrm{K}$ and a sensitivity to power supply variations of less than $2 \times 10^{-6} \mathrm{~A} / \mathrm{V}$. A slow drift of the coil current of $2.5 \times 10^{-6} \mathrm{~A} / \mathrm{h}$ has negligible effect on the density measurements since the main coil current is measured each time that the gradient coil current is determined. (It should be noted that the precision and accuracy of the density results depend on the short-term stability and not the absolute accuracy of the standard resistor.)

The gradient coils are included in a control circuit (Figs. 3 and 4) that senses and maintains the vertical position of the buoy. The requirements for stability of a magnetic support or levitation system are discussed in detail in Refs. 5 and 6 and will not be repeated here. Suffice it to say that the characteristic equation for a magnetic levitation system has a root with a positive real part, and for system stability the plot of the frequency response of the characteristic equation (the Nyquist plot) must encircle the origin once in the counterclockwise sense. This is accomplished by the dual-lead network composed of $R_{1}, R_{2}, C_{1}$, and $C_{2}$ in Fig. 4. A dual-lead network is required for this system since minimization of the steady state offset or buoy position change requires at least a first-order integrator 


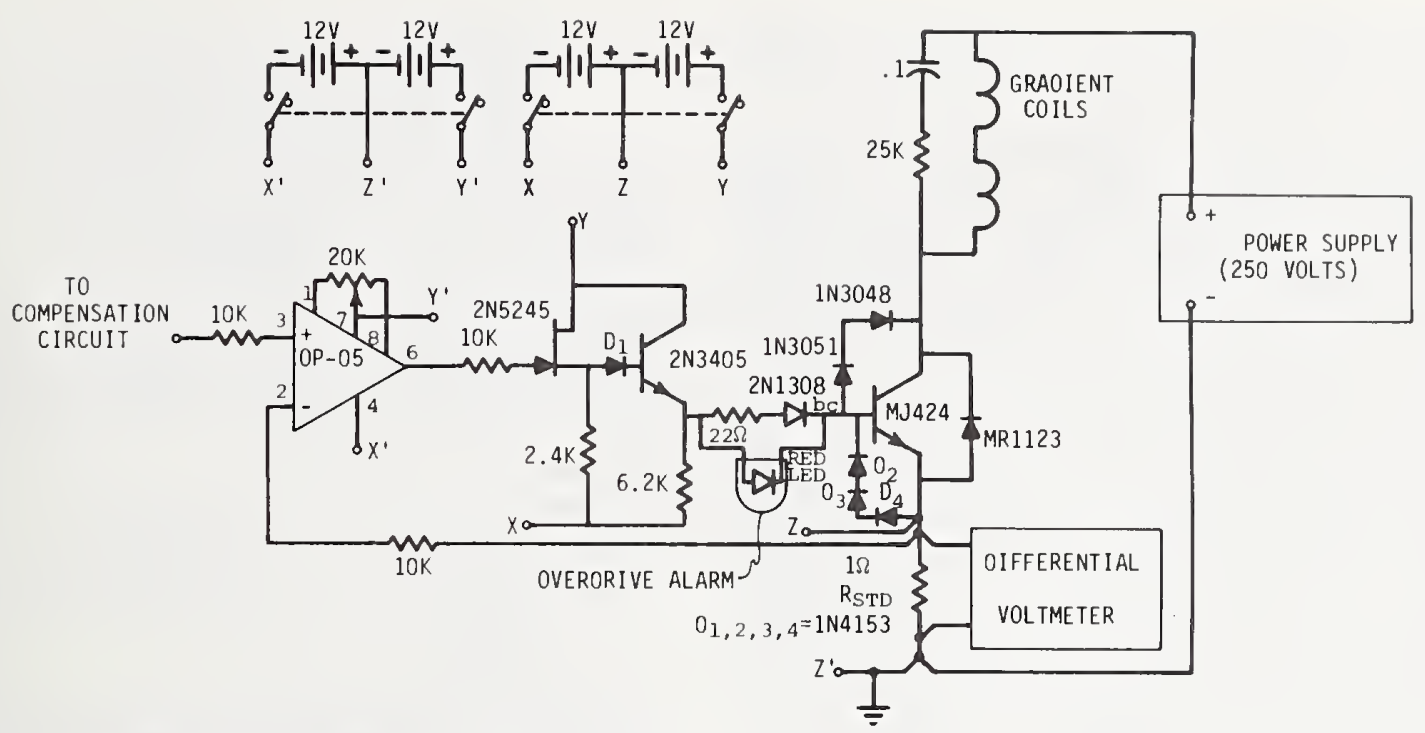

Fig. 3. Current control circuit for gradient coils.

in the control loop. This integrator consists of amplifier $A_{2}$ and $R_{1}$ and $C_{2}$. The additional resistor $R_{3}$ is required to stabilize the combined integrator and dual-lead network. A block diagram of the electronics is presented in Fig. 5 to complement the detailed circuit diagrams in Figs. 2-4. The circuit diagrams are presented in detail since this circuit is considerably different from any found in the literature. It should be noted that the

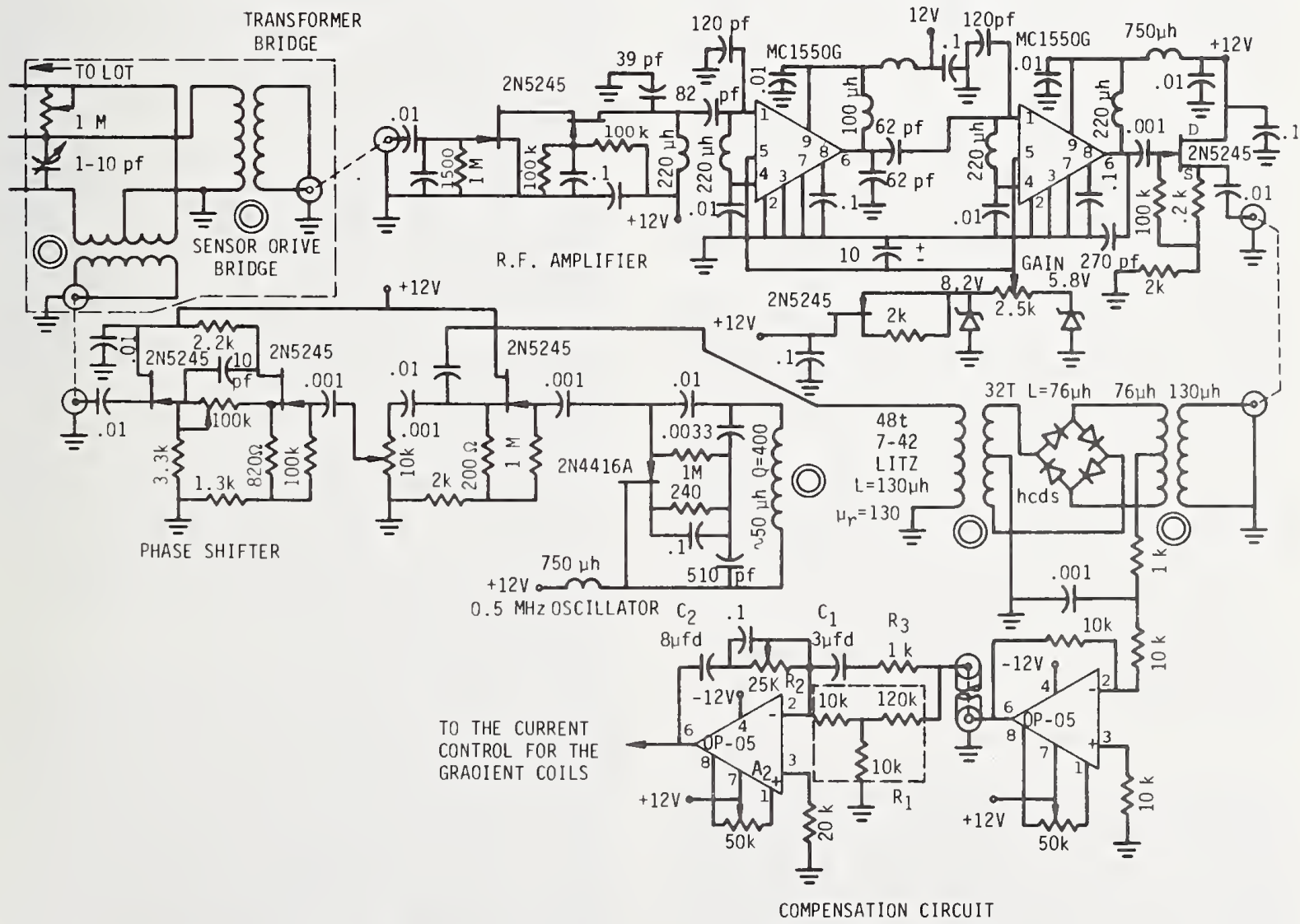

Fig. 4. Position sensor electronics and compensation circuit. 
current control amplifier for the main-coil constantcurrent source is the same as that for the gradient coils.

Perhaps the most interesting part of the support system is the position sensor. In the past, position sensing has been accomplished by either optical ${ }^{7,8}$ (light beam-photomultiplier tube arrangement) or electronic ${ }^{1,9-12}$ (inductance pickup coil or differential transformer) means. The requirements of small size, low power dissipation, high sensitivity, the ability to withstand high pressure and low temperatures, and exceptional dimensional integrity resulted in the use of a linear differential transformer (LDT) wound on a machinable glass ceramic form. The LDT consists of a pair of coils equally spaced about a transverse rectangular opening in the ceramic form inside which the buoy is suspended. Each coil is wound with 34 turns of double silkwrapped 50/44 Litz wire in circumferential grooves of $2.8-\mathrm{mm}$ width and $6.1-\mathrm{mm}$ depth. The outside diameter of the coils and the ceramic holder is $17.3 \mathrm{~mm}$. The complete transformer assembly has been potted with a low-viscosity epoxy resin to prevent intrusion of the pressurized fluid into the windings.

The sensitivity of the LDT as measured at the phasesensitive detector (synchronous detector) is of the order of $\mathrm{I} \mathrm{V} / \mathrm{mm}$. The noise voltage at the sensor amplifier input is less than $10^{-6} \mathrm{~V} / \mathrm{Hz}^{1 / 2}$. The operational amplifiers in the compensation circuit have very low offset drifts and are thermally lagged to a large copper block in the amplifier chassis. Consequently, the vertical movement of the buoy due to operational amplifier drifts and rf amplifier noise is less than $10^{-5} \mathrm{~mm}$.

The LDT is the major component of a ratio-transformer-type bridge. Part of the bridge is located at the top of the cryostat and is connected to the LDT through long coaxial lines. The bridge is constructed so as to remove proximity effects of the outer conductors of the coaxial lines. The neutral position of the buoy is controlled by a small variable capacitor between the center lead and one side of the LDT. Conductance balance is achieved with a resistor connected across the capacitor. Unbalance in the LDT due to the inductance of the long leads is minimized by tuning the two halves of the LDT to resonance with matched capacitors (as large as possible for the $0.5-\mathrm{MHz}$ exciting signal). These capacitors are connected near the LDT outside the sample cell but inside the vacuum space.

\section{EXPERIMENTAL MEASUREMENTS AND PROCEDURES}

\section{A. Temperature and pressure}

The techniques and instrumentation for the measurement and control of the temperature and pressure are standard. The primary temperature sensor, calibrated on the IPTS 1968, is a platinum resistance thermometer secured in a well at the base of the equilibrium cell with Wood's metal. The calibration of the thermometer

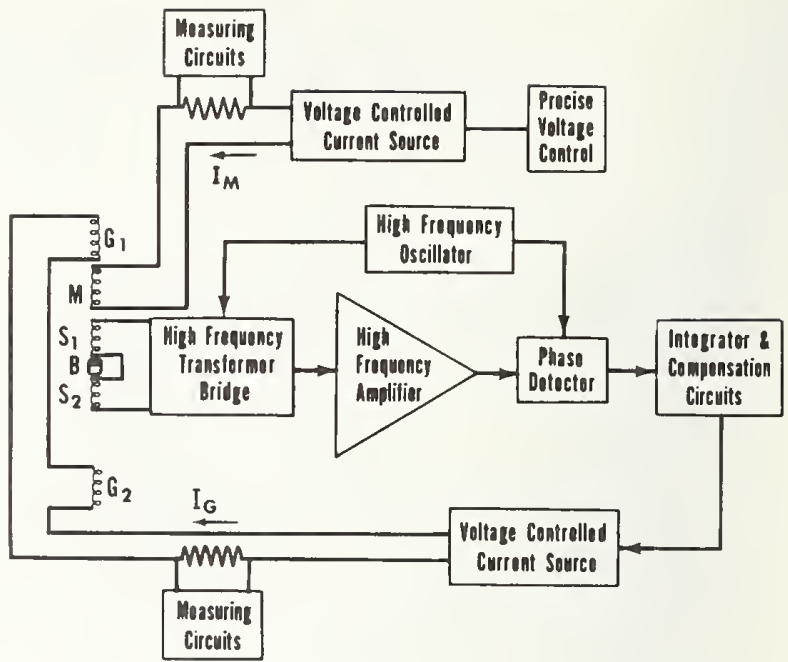

FIG. 5. Block diagram of a magnetic suspension densimeter: $\mathrm{G}_{1}, \mathrm{G}_{2}$ - gradient coils; $\mathrm{M}-$ main coil: $\mathrm{S}_{1}, \mathrm{~S}_{2}-$ sensing coils: $\mathrm{B}-$ magnetic buoy.

has been checked against vapor pressure measurements on liquid methane and nitrogen.

The uncertainty of the calibration is approximately $0.002 \mathrm{~K}$. Due to the specifications of the potentiometric measuring system, uncertainties in the temperature amount to a maximum of $0.010 \mathrm{~K}$ at $110 \mathrm{~K}$, increasing to $0.030 \mathrm{~K}$ at $300 \mathrm{~K}$. The temperature of the sample holder is controlled to better than $0.005 \mathrm{~K}$, approximately the same as the reproducibility of the temperature measurements.

A current of $1 \mathrm{~mA}$ for the thermometer is supplied by an electronic constant current source. The voltage drop across a $100 \Omega$ calibrated standard resistor in series with the thermometer is monitored continuously with a six-digit differential voltmeter. With this setup the uncertainty and repeatability of the current is approximately $0.002 \%$. The voltmeter is checked periodically against a microvolt potentiometer using a calibrated standard cell.

The total uncertainty in the reported temperatures in Sec. VI is believed to be less than $0.03 \mathrm{~K}$. (At room temperature it would be less than $0.04 \mathrm{~K}$.) The $0.03-\mathrm{K}$ total uncertainty consists of approximately $0.025-\mathrm{K}$ systematic error and $0.005-\mathrm{K}$ random error. The systematic error was determined from the uncertainties in the calibration of the thermometer and in the potentiometric measuring system.

The temperature of the cell is regulated by balancing coarsely variable cooling with precisely controlled electric heating. A control heater near the bottom of the cell is connected to a de power regulator, which is part of a measuring/regulation system that also includes a six-dial microvolt potentiometer and a microvolt amplifier. A second heater at the top of the cell is connected to a manual power supply. Independent heaters at the top and bottom of the cell are used to minimize temperature gradients along the length of the cell. 
Temperature gradients are detected by monitoring the vapor pressure of the liquid in the vapor bulb.

Pressures below 7 bars are measured with a 0 - to 7-bar spiral quartz Bourdon gauge. This gauge has a resolution of less than $3.5 \times 10^{-4}$ bar. It has been calibrated against an air dead-weight gauge giving an uncertainty of approximately $0.1 \%$ over the full range. For pressures above 7 bars, a double-revolution 0- to 20-bar Bourdon gauge is used. It has also been calibrated against the air dead-weight gauge and can be read to the nearest 0.005 bar.

Vapor pressure measurements have been used in the present work primarily as a means of monitoring temperature gradients. They have also been used as a check against the calibration of the platinum resistance thermometer. In general, the vapor pressures for methane have been consistently lower than those of Prydz and Goodwin. ${ }^{13}$ This pressure difference corresponds to a temperature difference of $0.01-0.02 \mathrm{~K}$. The discrepancies between the nitrogen vapor pressures of the present work and those of Wagner ${ }^{14}$ correspond to an average temperature difference of less than 0.015 $K$. with no particular trend observed.

\section{B. Position of buoy}

The accuracy and precision of the density measurements depend on being able to suspend the float at the same position relative to the support coils in vacuum and in the test liquid at the same temperature. A $125 \times$ filar micrometer microscope is used to determine the position of the float. It has a resolution of approximately $5 \times 10^{-4} \mathrm{~mm}$. The maximum error in the position determination is $2 \times 10^{-3} \mathrm{~mm}$, which corresponds to an error in density of less than $0.03 \%$.

This error includes approximately equal contributions from the alignment of the microscope, so that the "apparrent" position of the float is independent of the inder of refraction of the fluid inside the sample cell, and from the repositioning of the float for vacuum and liquid measurements. The first contribution would be a yystematic error while the second is random. The precivion of the density measurements depends primarily on the reproducibility of the position of the buoy from vacuum to liquid measurements.

As mentioned above, the microscope must be aligned so that the "apparent" position of the float does not depend on the index of refraction of the fluid inside the sample cell. In viewing the float inside the cell one must look through the glass tail of the cryostat and the sample holder window. The "apparent" position of the float would be dependent on the refractive index of the fluid inside the cell unless the light rays are perpendicular to the interface between the test liquid and the inside surface of the sample holder window.

The procedure for adjusting or aligning the microscope is as follows. First, the float is positioned at rest on the ceramic holder at the same horizontal position as when in support. Then a fiducial mark on the float is observed under two experimental conditions, i.e., with the float first immersed in gas and then immersed in liquid. Both methane and nitrogen were used to carry out this procedure. During this procedure the microscope tilt is adjusted so that the "apparent" position of the float does not depend on the refractive index of the fluid inside the cell within the resolution of the microscope. The temperature of the cell is controlled to better than $0.0 \mathrm{I} \mathrm{K}$ during these observations. Care is taken to ascertain that the float is observed through the same parts of the windows as during the density measurements. Necessarily a different part of the float is observed. This presents no special problem since there are diamond tool marks the entire length of the float that can be used as reference lines. This procedure has been repeated frequently during the course of the reported measurements. It has been found that a readjustment of the microscope tilt is necessary only if the apparatus is perturbed by disassembly.

\section{Volume of buoy}

Absolute density measurements [Eq. (7)] with a magnetic suspension densimeter require a determination of the volume of the magnetic buoy. In the past this has been accomplished either by using distilled water as a reference fluid of known density ${ }^{15}$ or by making direct length and diameter measurements on a uniformly constructed float. ${ }^{1}$ Here the volume has been determined by the first method.

The volume $\left(0.13485 \mathrm{~cm}^{3}\right.$ at $\left.300 \mathrm{~K}\right)$ of the magnetic buoy was determined within $0.02 \%$. The distilled water was vacuum distilled to remove air. Any problems with bubbles inside the cell were rectified by pressurizing the water with helium gas. The volume of the buoy has been measured three times at $300 \mathrm{~K}$ and once at $290 \mathrm{~K}$. These four measurements gave a standard deviation of $0.005 \%$ using thermal expansion data for barium ferrite to calculate the volume change from 290 to $300 \mathrm{~K}$. This resulted in a $99 \%$ confidence interval of $\pm 0.015 \%$. The systematic error in the volume determination depends on the uncertainty in the density of water. This should be less than $0.005 \%{ }^{16}$

The present paper reports density data for cryogenic fluids. Thermal expansion data for barium ferrite were used to calculate the volume of the float at low temperatures. Recently the linear thermal expansion of polycrystalline barium ferrite was measured at this laboratory at temperatures from 76 to $293 \mathrm{~K}$ with a quartz tube dilatometer. ${ }^{17}$ The volume of the float at 100 $\mathrm{K}$ is approximately $0.4 \%$ less than the room temperature value.

Barium ferrite is somewhat anisotropic and its thermal expansion was measured both parallel and perpendicular to the magnetization direction. An anisotropy of 15-20\% was observed. The estimated overall uncertainty of the thermal expansion measurements would correspond to an error of $6 \%$ in the adjustment to the volume. This would produce an uncertainty of approximately 
$0.02 \%$ in the volume at $120 \mathrm{~K}$. The uncertainty in the adjustment to the volume due to the contraction of the copper plating is negligible.

The effect of pressure on the volume of the float is negligible at the highest pressures encountered in the present work. The bulk modulus for barium ferrite should be less than that for copper, which is I.35 $\times 10^{11} \mathrm{~Pa}{ }^{18}$ This value would correspond to a volume correction of approximately $0.001 \%$ at $2.5 \mathrm{MPa}$, the vapor pressure of nitrogen at $120 \mathrm{~K}$.

\section{Mass of buoy}

The mass of the magnetic buoy was determined with a 10-g capacity equal-arm microbalance. A calibrated class $M$ weight set was used in the weighings. Precautions were taken to assure that the copper plating and gold protective coating provided an impervious barrier to liquids under pressure. The buoy was rapidly cycled between room temperature and $76 \mathrm{~K}$. It was then immersed in liquid ethanol at 5-atm pressure and room temperature for $4 \mathrm{~h}$. The buoy was weighed twice after removal from the ethanol bath. The average of these weighings was $9 \mu \mathrm{g}$ higher than the mean of the initial four weighings. A significantly larger increase in the mass was expected if the plating on the float contained a pinhole that allowed ethanol to penetrate into the porous ceramic. Thus, at room temperature, the metallic coating appeared to be impervious after thermal cycling. The reproducibility of liquid methane density measurements (see experimental results) after many cycles between room temperature and $100-140 \mathrm{~K}$ is further evidence of the resistance of the metallic coatings to damage from thermal cycling.

The final mass of the magnetic buoy $(0.73706 \mathrm{~g})$ was taken as the mean of all weighings, including the weighings after immersion in ethanol, corrected for air buoyancy. A $99 / 6$ confidence interval for the six weighings. hased on a standard deviation of $6 \mu \mathrm{g}$, was $\pm \mathrm{I} 0$ $\mu g$. The systematic errol in the mass determination, resulting primarily from the weight set calibration, is helieved to be less than $5 \mu \mathrm{g}$.

\section{EVALUATION OF PERFORMANCE OF MAGNETIC SUSPENSION DENSIMETER}

\section{A. Performance tests}

The use of Eq. (7) for obtaining absolute densities has again been verified experimentally ${ }^{1}$. The gradient coil current has been measured as a function of the main coil current over a range of approximately $20 \%$ of the maximum main coil current. These measurements were carried out while supporting the float in a given fluid (including vacuum) at constant height at a fixed temperature. The various pairs of $I_{M}$ and $I_{G}$ were fittec by the method of least squares to Eq. (7). The residual standard deviation, with the gradient coil current as the dependent variable, was less than $10^{-5} \mathrm{~A}$. Examination of the residuals showed that they were random and well approximated by a normal probability distribution. These results demonstrated that within the precision of the current measurements the magnetic moment of the barium ferrite float is independent of the magnetic field intensity over the range of fields $(0.006-$ 0.0 I6 T) considered in the present work.

Other coil configurations have been tried that gave results that substantiated the observations given above. First the bottom gradient coil was disconnected resulting in a two-coil system. The values of the constant $(C)$ in Eq. (7) for the two- and three-coil arrangements under otherwise identical experimental conditions were in agreement within the experimental uncertainty. In other words, the magnetic moment of the float (contained in $C$ ) remains constant for significantly different magnetic field intensities.

Next the pair of approximately identical (gradient) coils were connected to the constant current source in a Helmholtz arrangement. The main coil was connected into the servosystem. The float was first supported at a constant height at fixed temperature by the force supplied by only the main coil. The float was located at the midpoint of the Helmholtz coils while the current in the Helmholtz coils was increased to $0.6 \mathrm{~A}$. There was an insignificant change in the main coil current $\left(10^{-4} \mathrm{~A}\right)$ for this relatively enormous change in the magnetic field intensity (about an order of magnitude more than for the typical data point). The results of these tests demonstrated that this technique could be used for absolute density measurements.

In carrying out density measurements with this technique, the position of the main coil must remain fixed over a wide range of currents for the vacuum and liquid measurements. This means that the "constant" $k$ ' in Eq. (4) and the constants, $C$ and $D$, in Eq. (7) must be independent of the current in the coil. It was hoped that the measures exercised in controlling the temperature and position of the main coil (see Sec. III D) would result in such behavior. It was experimentally impracticable to determine if $k^{\prime}$ was a constant by monitoring the position of the coil. However, the effect of a change in the current in the main coil on the density measurements could be obtained in another manner. As shown in Sec. II the fluid density is linearly proportional to the current in the gradient coils if the main coil current is held constant. Not only is the position of the main coil fixed, but also the magnetic field intensity at the midpoint of the gradient coils (float position) is constant. Relative measurements [Eq. (5)] carried out with vacuum, nitrogen, methane, and propane at $110 \mathrm{~K}$ were not consistent with the density ratios computed from absolute measurements [Eq. (7)] for the same fluids. These results showed that the "constants" ( $k$ ', $C$, and $D$ ) vary slightly with the main coil current. This variation produces a density error relative to the difference between main coil currents for vacuum and liquid measurements (constant $I_{G}$ ) of approximately $1.4 \% / \mathbf{A}$. This corresponds to a density adjustment of $0.1-0.2 \% /\left(\mathrm{g} / \mathrm{cm}^{3}\right)$ to the results from $\mathrm{Eq}$. 


\begin{tabular}{|c|c|c|c|c|c|c|}
\hline \multirow[b]{3}{*}{ Systematic errors } & \multicolumn{6}{|c|}{ Percent error in density } \\
\hline & \multicolumn{2}{|c|}{ Methane } & \multicolumn{2}{|c|}{ Nitrogen } & \multicolumn{2}{|c|}{ Normal butane } \\
\hline & $105 \mathrm{~K}$ & $160 \mathrm{~K}$ & $95 \mathrm{~K}$ & $120 \mathrm{~K}$ & $135 \mathrm{~K}$ & $300 \mathrm{~K}$ \\
\hline Mass of float (Sec. IV D) & \pm 0.002 & \pm 0.002 & \pm 0.002 & \pm 0.002 & \pm 0.002 & \pm 0.002 \\
\hline Volume of float at $300 \mathrm{~K}(\mathrm{Sec} . \mathrm{VV} \mathrm{C})$ & \pm 0.02 & \pm 0.02 & \pm 0.02 & \pm 0.02 & \pm 0.02 & \pm 0.02 \\
\hline Thermal expansion coefficient of barium ferrite (Sec. IV C) & \pm 0.022 & \pm 0.017 & \pm 0.023 & \pm 0.021 & \pm 0.020 & \pm 0.001 \\
\hline Position of float (Sec. IV B) & \pm 0.015 & \pm 0.018 & \pm 0.010 & \pm 0.012 & \pm 0.009 & \pm 0.009 \\
\hline Position of main coil. determined from relative & & & & & & \\
\hline measurements. Eq. (5) (Sec. V A) & \pm 0.02 & \pm 0.02 & \pm 0.02 & \pm 0.02 & \pm 0.02 & $\begin{array}{l} \pm 0.02 \\
+0.008\end{array}$ \\
\hline Temperature of sample fluid ( $\mathrm{Sec}$. IV A) & \pm 0.010 & \pm 0.021 & \pm 0.023 & \pm 0.076 & \pm 0.004 & \pm 0.008 \\
\hline Three times standard deviation & \pm 0.045 & \pm 0.054 & \pm 0.030 & \pm 0.036 & \pm 0.027 & \pm 0.027 \\
\hline Total uncertaintya & \pm 0.09 & \pm 0.10 & \pm 0.07 & \pm 0.12 & \pm 0.06 & \pm 0.06 \\
\hline
\end{tabular}

a The total uncertainty was determined from the square root of the sum of the squares of the systematic errors added to three times the standard deviation.

(7). Since all measurements are based on the volume determination using distilled water as a reference fluid of known density, the adjustment must be applied relative to this point.

A further check on this density-dependent adjustment was accomplished by measuring the densities of two other fluids of known density at room temperature. The densities of liquid samples of normal pentane and ethanol were determined by the Mass and Volume Section of the Mechanics Division of the National Bureau of Standards in Washington, DC, to an estimated inaccuracy of less than $0.01 \%$. Measurements on these fluids at $300 \mathrm{~K}$ with the present apparatus using Eq. (7), combined with the adjustment based on the relative density measurements at low temperature, gave densities that agreed with the reference values to better than $0.02 \%$. Thus, the densities presented in this paper based on absolute measurements [Eq. (7)] have been adjusted slightly to be consistent with the results of

[Aвı.t 1II. Experimental results for saturated liquid nitrogen (molecular weight $=28.0134)$.

\begin{tabular}{|c|c|c|c|}
\hline \multirow{2}{*}{$\begin{array}{c}T \\
(K)\end{array}$} & \multirow{2}{*}{$\begin{array}{c}\rho_{i \cdot \mathrm{rl}} \\
(\mathrm{mol} / \mathrm{l})\end{array}$} & \multirow{2}{*}{$\begin{array}{c}\rho_{\text {cale }} \\
(\mathrm{mol} / \mathrm{l})\end{array}$} & \multirow{2}{*}{$\frac{100\left(\rho_{\mathrm{exp}}-\rho_{\text {(alke }}\right)}{\rho_{\text {("alk }}}$} \\
\hline & & & \\
\hline 95.000 & 25.6731 & 25.6755 & -0.009 \\
\hline 100.000 & 24.6400 & 24.6391 & 0.004 \\
\hline 105.000 & 23.4998 & 23.4988 & 0.005 \\
\hline 110.000 & 22.2079 & 22.2071 & 0.004 \\
\hline 115.000 & 20.6719 & 20.6748 & -0.014 \\
\hline 120.000 & 18.6818 & 18.6856 & -0.020 \\
\hline 100.000 & 24.6361 & 24.6391 & -0.012 \\
\hline 105.000 & 23.4963 & 23.4988 & -0.011 \\
\hline 110.000 & 22.2044 & 22.2071 & -0.012 \\
\hline 115.000 & 20.6787 & 20.6748 & 0.019 \\
\hline 120.010 & 18.6800 & 18.6808 & -0.004 \\
\hline 95.075 & 25.6624 & 25.6605 & 0.007 \\
\hline 100.075 & 24.6207 & 24.6229 & -0.009 \\
\hline 100.075 & 24.6279 & 24.6229 & 0.020 \\
\hline 105.075 & 23.4841 & 23.4807 & 0.015 \\
\hline 110.075 & 22.1840 & 22.1862 & -0.010 \\
\hline 115.075 & 20.6490 & 20.6492 & -0.001 \\
\hline 117.575 & 19.7356 & 19.7326 & 0.015 \\
\hline 120.075 & 18.6525 & 18.6497 & 0.015 \\
\hline
\end{tabular}

relative measurements [Eq. (5)]. The density difference between the relative and absolute measturements, expressed in terms of the difference in main coil currents between the vacuum and liquid points $\left(I_{1}-I_{f}\right)$ for a constant gradient coil current, is independent of temperature. The temperature dependence of the magnetic moment of the float must be included if the difference is expressed in terms of density.

The relative measurements were carried out using the same experimental setup and parameters (mass, volume, and position) as the absolute measurements. Thus the total uncertainty in the adjustment determination should only include the random error in the measurement process. Thus an estimated uncertainty of $\pm 0.02 \%$ in the adjustment is based on the comparisons with the reference fluids since this density difference was larger than a $99 \%$ confidence interval from a fit of the differences between relative and absolute measurements.

\section{B. Error analysis}

Evaluation of the experimental parameters involved in the present work showed that the uncertainty in the density measurements depends primarily on the uncertainties in the determination of the volume of the float, the relative position of the float and the main coil, and the temperature of the sample fluid. The precision of the density measurements is inversely proportional to the difference between the density of the fluid and the density of the float. This variation with density cannot be observed for the measurements reported in this paper because of the density range covered. The precision also varies with temperature, corresponding to the change in the magnetic moment of the float with temperature.

Table II summarizes the uncertainties in the density measurements for the nitrogen and methane results presented in this paper. Normal butane is also included in this table, primarily to show the performance of the instrument at higher temperatures. Normal butane densities, determined with this instrument at tempera- 
tures between 135 and $300 \mathrm{~K}$. will be presented in a forthcoming paper.

The standard deviation given in the table for methane at $105 \mathrm{~K}$ was based on twelve measurements. The other standard deviations were computed relative to the density and temperature of this point. Standard deviations at the other temperatures and densities could not be estimated from statistical analysis since sufficient repetitive measurements were not taken for these points. Measurements on more dense fluids, such as argon and krypton. have demonstrated the expected variation of the precision with density. Measurements near room temperature, especially those on distilled water, have exhibited the expected improvement in the precision as the temperature is increased.

The total uncertainty of a single density measurement was taken as the square root of the sum of the squares of the systematic errors plus an allowance of three times the standard deviation for random error.

\section{EXPERIMENTAL RESULTS}

\section{A. Nitrogen}

The experimental saturated liquid densities for nitrogen are presented as a function of temperature (IPTS 1968) in Table III. The explanation for some of the nitrogen points not being at integral temperatures involves the presence of a temperature gradient along the length of the cell in some of the initial measurements with this apparatus. Each of the data points was taken from a new charge of nitrogen. For each datum point the vacuum measurements were carried out immediately before or after the liquid measurements. The same procedure was used for methane. The three data sets for nitrogen over the temperature range of $95-$ or $100-120 \mathrm{~K}$ were obtained at approximately six-month intervals. Of the two data sets at integral temperatures. one was taken with methane, and the other with nitrogen, in the vapor bulb. The third set was taken with no liquid in the vapor bulb. (For the 120.(1)] $K$ point a light temperature gradient was applied toremove bubbles from the sample liquid inside the cell.

The nitrogen samples were taken from commercially available, research grade gas. A purity upecification of 99.99 mol's was given by the supplier. The gas has heen analyzed chromatographically with a thermal conductivity detector and found to be within the specified purity. The nitrogen gas was passed through a room temperature molecular sieve trap. primarily for removal of water.

The saturated liquid densities $(\rho)$ of nitrogen have been fitted as a function of temperature $(T)$ by the method of least squares to an equation of the following form:

$\rho-\rho_{r}=a\left(1-\frac{T}{T_{r}}\right)^{0.35}+\sum_{i=1}^{3} b_{i}\left(1-\frac{T}{T_{r}}\right)^{1+(i-1) / 3}$.
TABIE IV. Parameters of Eq. (9) for nitrogen.

$a=19.39217^{\mathrm{a}}(0.11)^{\hat{\gamma}_{2}} \quad b_{3}=23.32977(4.8) \quad p_{1}=11.21 \mathrm{~mol} / 1$

$b_{1}=26.01408(2.5) \quad T_{r}=126.20 \mathrm{~K} \quad \sigma=0.016 \%$

$b_{2}=-39.49759(6.5)$

a These coefficiens $\left(a, b_{1}, b_{2}, b_{3}\right)$ and those in Table VI were obtained from a least-squares program in which the experimental densities in $\mathrm{g} / \mathrm{cm}^{3}$ to five digits were converted to molar densities within the program.

Standard errors of coefficients in parentheses.

$\rho_{c}$ and $T_{r}$ are selected values of the critical density and temperature and $a, b_{i}$ are coefficients determined by least squares. Equation (9) consists of a scaling law modification $^{19}$ to a generalized Guggenheim equation. ${ }^{20}$ The parameters of Eq. (9) for nitrogen. along with the residual standard deviation $(\sigma)$ of the fit and the standard errors of the coefficients, are given in Table IV. The standard errors of the calculated densities in Table 1[1 are not presented since they are significantly smaller than the standard deviation. The main purpose of the above expression is to facilitate comparisons with independent measurements. The choice of the critical point parameters is arbitrary in the sense that the critical point density can be varied by as much as $5 \%$ and the critical point temperature by $0.2 \%$ without changing the fit of the data within the estimated precision of the present measurements. For nitrogen the critical point values were obtained from the PVT data compilation of Jacobsen ${ }^{21}$.

In Fig. 6 independent experimental data available in the literature are compared with the expression representing the present nitrogen data over the temperature range of the present measurements. The present data are also shown. The experimental temperatures

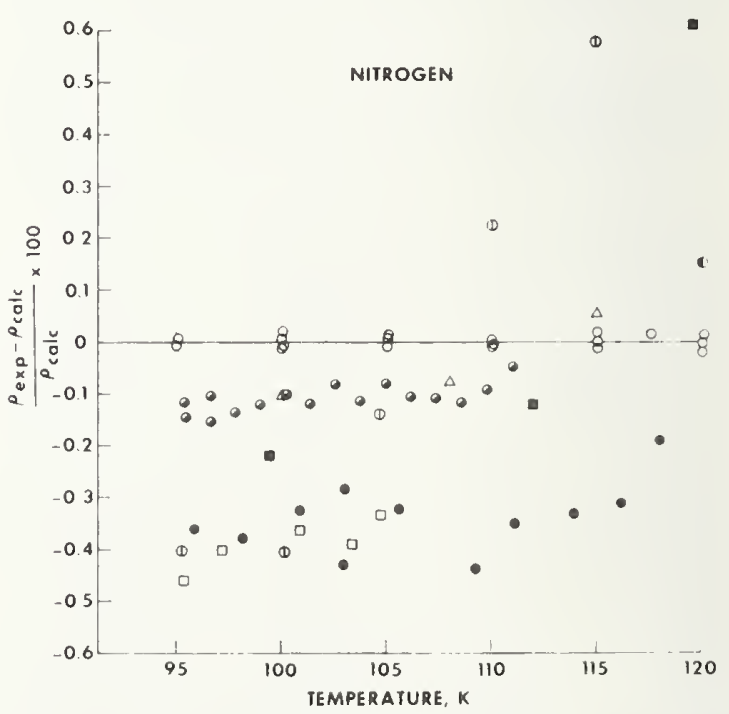

Fig. 6. Deviation plol of experimental densities of saturated liquid nitrogen compared with values calculated from Eq. (9) using parameters from Table IV: $\bigcirc$ presen! data. Brauns, ${ }^{22} \uparrow$ Weber. ${ }^{2: 3}$ $\triangle$ Rodosevich and Miller, ${ }^{24}$ Goldman and Scrase, ${ }^{25} \square$ Terry e't at. . ${ }^{26}$ (1) Sireelt and Siaveley. ${ }^{27}$ Malhias et $a l^{24}$ 
TABLE V. Results for saturated liquid methane (molecular weight $=16.04303$ )

\begin{tabular}{cccc}
\hline \hline $\begin{array}{c}\text { Temperature } \\
(\mathrm{K})\end{array}$ & $\begin{array}{c}\text { Mean density } \\
(\mathrm{mol} / \mathrm{I})\end{array}$ & $\begin{array}{c}\text { Standard } \\
\text { deviation } \\
(\%)\end{array}$ & $\begin{array}{c}\text { Number of } \\
\text { data points }\end{array}$ \\
\hline 105.000 & 26.9458 & 0.015 & 12 \\
110.000 & 26.4985 & 0.019 & 11 \\
115.000 & 26.0443 & 0.014 & 12 \\
120.000 & 25.5721 & 0.016 & 17 \\
125.000 & 25.0845 & 0.016 & 18 \\
130.000 & 24.5775 & 0.017 & 16 \\
135.000 & 24.0540 & 0.016 & 23 \\
140.000 & 23.5067 & 0.018 & 5 \\
145.000 & 22.9312 & 0.014 & 2 \\
150.000 & 22.3218 & - & 2 \\
160.000 & 20.9876 & - & 5 \\
\hline
\end{tabular}

of other measurements have not been adjusted to the temperature scale of the present results.

The data of Brauns, ${ }^{22}$ Weber, ${ }^{23}$ and Rodosevich and Miller, ${ }^{24}$ each obtained with a technique different from that used here, fall within $0.15 \%$ of the present results. The densities of Goldman and Scrase ${ }^{25}$ and Terry et $a l{ }^{26}$ are consistently lower than the present results by approximately $0.3-0.4 \%$. This pattern is also followed for methane by Terry et al., and preliminary analysis of recent results for argon and krypton obtained with the magnetic suspension densimeter indicate comparisons with Terry et al., for these fluids exhibit the same behavior.

\section{B. Methane}

Methane has been used as a control fluid throughout the entirety of a project that has included density measurements on six pure fluids and, at least, thirty mixtures of these components. As a result, well over one hundred data points have been accumulated for saturated liquid methane, primarily in the temperature range $105-150 \mathrm{~K}$. Although these experimental data are not presented in this paper, the results of an analysis of the methane data are helpful in evaluating the performance of the magnetic suspension densimeter used in the present work. More than ten data points were obtained at each $5-\mathrm{K}$ interval between 105 and $135 \mathrm{~K}$. The mean of the experimental densities, along with the standard deviation and the number of points at each temperature, are given in Table V. (The standard deviations are not given at 150 and $160 \mathrm{~K}$ since there are only two data points at each of these temperatures.) Each of the data points represents a new methane sample. The vapor bulb contained liquid methane for all points.

TABLE V1. Parameters of Eq. (9) for methane.

\begin{tabular}{rlll}
\hline$a=18.65812$ & $(0.035)^{\mathrm{a}}$ & $T_{c}=190.555 \mathrm{~K}$ \\
$b_{1}=6.712030$ & $(0.21)$ & $\rho_{c}=10.16 \mathrm{~mol} / \mathrm{I}$ \\
$b_{2}=-0.9472020$ & $(0.20)$ & $\sigma=0.016 \%$ \\
\hline
\end{tabular}

a Standard errors of coefficients in parentheses.
The liquid samples were obtained from either of two cylinders of different batches of commercial, research grade methane. The purity for each cylinder as specified by the supplier is 99.99 mol\% minimum. Analyses in this laboratory substantiated these specifications. As with nitrogen the methane gas was passed through a room temperature molecular sieve trap to remove moisture and any heavy contaminants not detected by analysis.

The 123 experimental data points have been fitted by the method of least squares to Eq. (9). Only three coefficients were needed to fit the methane data within the precision of the measurements. The fourth term in the equation was not statistically significant. The coefficients of Eq. (9), the standard errors of the coefficients, the residual standard deviation $(\sigma)$ of the fit, and a selected critical density ${ }^{28}$ and temperature ${ }^{30}$ are given in Table VI for methane. Equation (9), with the coefficients for methane, has been used to compare the present results with experimental data from independent investigators. The methane data from the present work are not shown on the deviation plot because of the large number of points. All of the experimental densities of methane obtained in the present work will be presented in tabular form in a future publication.

For saturated liquid methane there have been considerably more measurements than for saturated liquid nitrogen. All of the other measurements were obtained with techniques different from that of the present work. Some of the older, less precise data have been included in Fig. 7 for the sake of completeness. It is satisfying that the relatively recent data of Orrit and Olives, ${ }^{31}$ McClune, ${ }^{32}$ Goodwin and Prydz, ${ }^{33}$ and Shana'a and

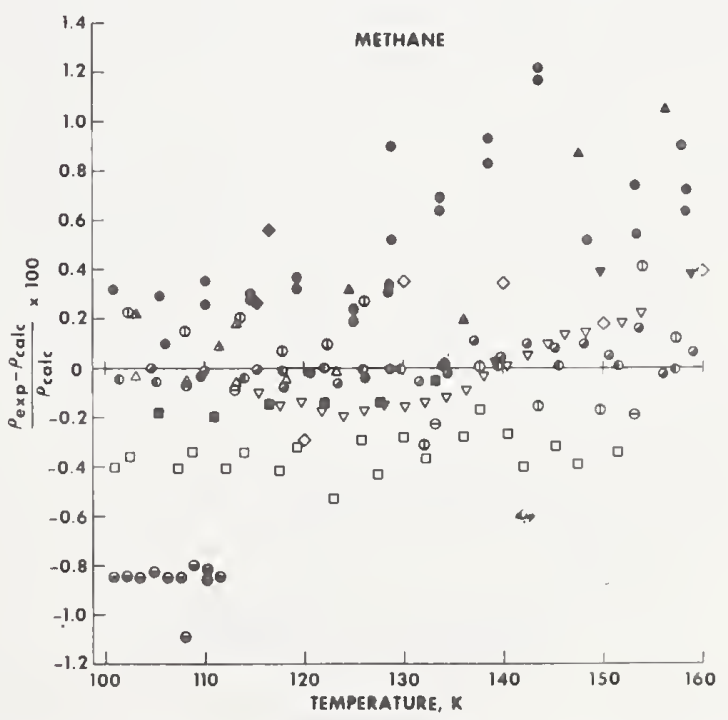

Fig. 7. Deviation plot of experimental densities of saturated liquid methane compared with values calculated from Eq. (9) using parameters from Table VI: $\square$ Terry et al. ${ }^{2 B} \bigcirc$ Orrit and Olives. ${ }^{31}$ $\triangle$ McClune, ${ }^{32} 0$ Goodwin and Prydz, ${ }^{33} \otimes$ Shana'a and Canfield, ${ }^{34}$ $\nabla$ Vennix ${ }^{35}$ (1) Grigor, ${ }^{38} \nabla$ Davenport et $a l .{ }^{37}$ Klosek and McKinley, ${ }^{38} \ominus$ Sinor and Kurata, ${ }^{38} \Delta$ Jensen and Kurata, ${ }^{40} \Delta$ Bloomer and Parent, ${ }^{11} \odot$ Fuks et al., ${ }^{42} \bigcirc$ Keyes et al., ${ }^{43}$ Moran, $^{44} \diamond \mathrm{Van}$ Itterbeek et al. ${ }^{43}$ 
Canfield ${ }^{3+}$ agree with the present results within $0.1 \%$. However, as mentioned earlier, the densities of Terry et $a l .{ }^{26}$ are systematically lower than the present results by $0.3-0.4 \%$. The extrapolated densities of Vennix ${ }^{35}$ at approximately 150 and $160 \mathrm{~K}$ are $0.4 \%$ larger than the present results although the discrepancy at $140 \mathrm{~K}$ is approximately $0.01 \%$.

\section{Other fluids}

To demonstrate the performance of the magnetic suspension densimeter at low temperature, this paper presents only a representative cross section of the data that have been taken in the present work. Data have recently been obtained for other pure fluids (ethane, propane, isobutane, normal butane, argon, and krypton) over a density range extending to $2.3 \mathrm{~g} / \mathrm{cm}^{3}$ (krypton) and over a temperature range extending to $300 \mathrm{~K}$ (isobutane and normal butane). These data will be published in the near future.

\section{ACKNOWLEDGMENTS}

The authors would like to express their appreciation to the following individuals who have made significant contributions to the development of this apparatus. M. R. Cines of Phillips Petroleum Co., Chairman of the LNG Density Project Steering Committee, was instrumental in the development of support for this project. W. G. Layne, D. L. Smith, and A. N. DiSalvo assisted in the design and fabrication of the apparatus. J. E. Cruz designed some of the electronics associated with the refrigeration and temperature control systems. J. R. Whetstone determined the densities of liquid samples of normal pentane and ethanol. which were used as reference fluids. P. V. Tryon assisted with the statistical analysis of the data.

\footnotetext{
I his work was carried out at the National Bureau of Standards under the sponsorship of British Gas Corp. . Chicago Bridge and lron (a.. Columbia Gas Service Corp.. Distrigas Corp. Fanco Gas I VG, Inc. El Paso Natural Gas, Gaz de France. Marathon ()il Co.. Mothil R and D Corp.. Nitural Gas Pipeline Co. Phillip Petroleum Co.. Shell International Gas. Ltd.. Sonatrach. Southern Cillilornia Gas Co.. Tennessee Gas Pipeline. Texas Fastern Tramsmisson Co.. Tokyo Gas Co. I Id.. and Transcontinental Gas Pipe Linc Corp. through a grant administered by the American Gals Association. Inc.

W. M. Haynes and J. W. Stewart. Rev. Sci. Instrum. 42, $1142(1971)$.

J. W. Beims, Rev. Sci. Instrum. 40, 167 (1969).

R. M. McClintock and M. J. Hizal. Mod. Plast. 35, 172 (1958)

The use ol a trade name for clarity and completeness does not
}

signify an endorsement or recommendation by the National Bureau of Standards.

5 J. B. Breazeale, Ph.D. thesis, University of Virginia (I955).

${ }^{6} \mathrm{H}$. S. Morton, Jr., Ph.D. thesis, University of Virginia (1953).

7 J. P. Senter, Rev. Sci. Instrum. 40, 334 (1969).

* J. W. Beams. C. W. Hulburt, W. E. Lotz, Jr., and R. M. Montague, Jr., Rev. Sci. Instrum. 26, 1181 (1955).

S. P. Almeida and T. H. Crouch, Rev. Sci. Instrum. 42, 1344 (1971).

${ }^{10}$ M. G. Hodgins and J. W. Beams, Rev. Sci. Instrum. 42, $1455(1971)$

" J. L. Hales, J. Phys. E 3, 855 (1970).

${ }^{12}$ S. C. Greer, M. R. Moldover, and R. Hocken. Rev. Sci. Instrum. 45, 1462 (1974).

${ }^{13}$ R. Prydz and R. D. Goodwin, J. Chem. Thermodyn. 4, 127 (1972).

${ }^{14}$ W. Wagner, Cryogenics 13, 470 (1973).

${ }^{15}$ J. W. Beams and A. M. Clarke, Rev. Sci. Instrum. 33, 750 (1962).

${ }^{16}$ M. Menaché and G. Girard, Metrologia 9, 62 (1973).

${ }^{17}$ A. F. Clark, W. M. Haynes, V. A. Deason, and R. J. Trapani, Cryogenics 16, 267 (1976).

${ }^{18} \mathrm{G}$. Simmons and H. Wang. Single Crystal Elastic Constants and Calculated Aggregate Properties: A Handhook (MIT Press, Cambridge. MA, 1971), p. 181.

1: R. D. McCarty, Natl. Bur. Stand. (U.S.) Intern. Rept. 74-357 (1974).

${ }^{20}$ Y. C. Hou and J. J. Martin. AlChE J. 5, 125 (1959).

${ }^{21}$ R. T. Jacobsen, Ph.D. thesis, Washington State University (1972).

22 P. Brauns (private communication, 1973).

${ }^{23}$ L. A. Weber, J. Chem. Thermodyn. 2, 839 (1970).

${ }^{24}$ J. B. Rodosevich and R. C. Miller, AlChE J. 19, 729 (1973).

$25 \mathrm{~K}$. Goldman and N. G. Scrase. Physica 44, 555 (1969).

${ }^{26}$ M. J. Terry, J. T. Lynch, M. Bunclark, K. R. Mancell. and L. A. K. Staveley, J. Chem. Thermodyn. 1, 413 (1969).

${ }_{27}$ W. B. Streett and L. A. K. Staveley, Adv. Cryog. Eng. 13, $363(1968)$.

${ }^{2 k}$ E. Mathias, H. K. Onnes, and C. A. Crommelin, Commun. Leiden 145C, 19 (1914).

29 J. D. Olson, J. Chem. Phys, 63, 474 (1975).

${ }^{30}$ R. D. Goodwin. Natl. Bur. Stand. (U.S.) Tech. Note No. 653 (1974).

$31 \mathrm{~J}$. Orrit and J. Olives, distributed at 4 th International Conference on Liquefied Natural Gas, Algeria (1974).

32. C. R. McClune, Cryogenics 16, 289 (1976).

33 R. D. Goodwin and R. Prydz. J. Res. Natl. Bur. Std. (U.S.) 76A, 81 (1972).

it M. Y. Shana a and F. B. Canfield. Trans. Faraday Soc. 64, 2281 (1968).

35 A. J. Vennix, Ph.D. thesis, Rice University (1965).

${ }^{36}$ A. F. Grigor. Ph.D. thesis. Pennsylvania State University (1966).

3 A. J. Davenport. J. S. Rowlinson, and G. Saville. Trans. Faraday Soc. 62, 322 (1966).

${ }_{34} \mathrm{~J}$. Klosek and C. McKinley. Proceedings of the First Intcrnational Conference on LNG. Chicago (1968), Paper 22.

34 J E. Sinor and F. Kurata. J. Chem. Fng. Data 11, I (1966).

to R. H. Jensen and F. Kurata, J. Petrol. Technol. 21, 683 (1969).

" O. T. Bloomer and J. D. Parent. Chem. Eng. Progr. Symp. Ser. 49, 11 (1952).

42 S. Fuks. J. C. Legros, and A. Bellemans. Physica 31, 606 (1965)

${ }_{13}$ F. G. Keyes, R. S. Taylor and L. B. Smith. J. Math. Phys 1, 2II (1922).

t D. W. Moran, Ph.D. thesis, Imperial College, University of London (1959).

45 A. Van Itterbeek, O. Verbeke, and K. Staes, Physica 29, 742 (1963). 


\title{
Simplified magnetic suspension densimeter for absolute density measurements*
}

\author{
W. M. Haynes \\ National Bureau of Standards, Institute for Basic Standards, Boulder, Colorado 80302 \\ (Received 24 September 1976)
}

\begin{abstract}
A magnetic suspension densimeter, incorporating three support coils, has been reduced to a system using only one coil. This simplifies considerably the design of the apparatus and the procedures involved in the measurements. This instrument can be used for absolute density measurements; i.e., it does not have to be calibrated with reference fluids of known density.
\end{abstract}

During the past two decades the magnetic suspension densimeter ${ }^{1-17}$ has evolved into a versatile research instrument that has been used routinely for liquid density measurements to a precision of ten parts per million. (Reference 14 presents a detailed review of the principles, applications, and development of the magnetic densimeter.) In the original design (Fig. 1) of the instrument a piece of soft ferromagnetic material is suspended in a fluid of unknown density by the magnetic force produced by a single solenoid. The magnetic force on the buoy is given by the relation

$$
F_{\text {max }}=M \frac{d H}{d Z},
$$

where $M$ is the magnetic moment of the buoy, $H$ is the axial magnetic field intensity of the air core solenoid, and $Z$ is the distance along the vertical. The density $(\rho)$ of the fluid is related to the current $(I)$ in the support coil by

$$
\rho=A+B I^{2}
$$

where $A$ and $B$ are constants to be determined by calibration of the instrument with reference fluids of known density. The above relation is based on the assumption that the magnetic moment of the buoy is linearly proportional to the magnetic field intensity.

It is not unusual for the magnetic susceptibility of the magnetically soft material of the buoy to vary slowly with $H$. Thus a relatively large number of reference fluids are required to calibrate a one-coil instrument to maintain a given precision over its entire operating range. The precision is inversely proportional to the difference between the density of the fluid and the density of the buoy. To cover an extended density range it is necessary to construct and calibrate buoys of different densities. The calibration of the instrument must be checked periodically to test the buoy material for hysteresis.

These procedural tasks were reduced considerably with the development of a three-coil support system ${ }^{5}$ (Fig. 2) which allows variations in $d H / d Z$ while $H$ is held constant. The three-coil arrangement consists of a main coil, which supplies the major part of the force necessary to support the buoy, and a pair of gradient coils connected in such a way that at the buoy position their magnetic fields cancel and their magnetic field gradients add. The magnetic moment of the buoy is held constant; it depends only on the stability of the constant current source that supplies the main coil current. In the first applications of the three-coil arrangement (with a magnetically soft buoy) the instrument still had to be calibrated but now the density range for a given buoy was increased significantly over that for a single-coil system. Also the calibration was simplified since the density was linearly proportional to the current in the gradient coils for a constant main coil current. The buoy may be either magne tically soft or hard for the three-coil system.

Recently, in the adaptation of the magnetic suspension densimeter for use at low temperatures, ${ }^{11,17}$ the same three-coil arrangement (Fig. 2) was employed to determine the force on a magnetic material in a noruniform field; i.e., it was used to determine the variation of the magnetic susceptibility of the buoy material with $H$ over the range of magnetic fields needed for the density measurements. It was found that the magnetic force on a barium ferrite buoy could be represented by the expression

$$
F_{\text {mag }}=M\left(\frac{d H_{M}}{d Z}+\frac{d H_{G}}{d Z}\right)=C I_{M}+D I_{G},
$$

where the subscripts denote the main and gradient coils.

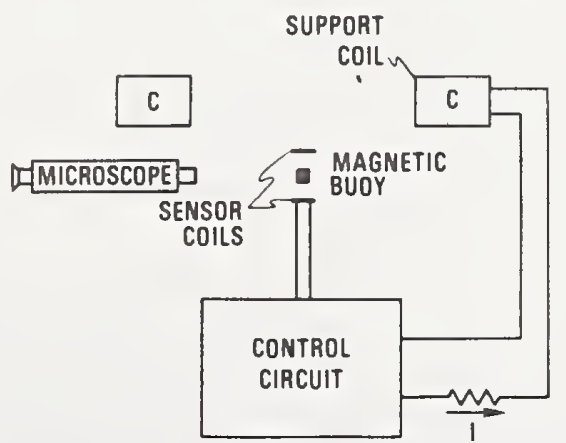

Fig. 1. Schematic diagram of a magnetic suspension densimeter with one support coil. 
This result demonstrated that, over the range of magnetic fields considered $(0.006-0.016 \mathrm{~T})$, there was no induced moment in the barium ferrite buoy (a magnetically hard material with a permanent moment). Therefore, it was possible to determine fluid densities without the use of calibration fuids. The instrument constants $[C, D$ in Eq. (3)] could be determined from measurements of the gradient coil current as a function of the main coil current while the buoy was supported at a fixed position at constant temperature in vacuum. The mass and volume of the buoy must be determined from independent measurements.

Now that it had been determined with the three-coil arrangement (Fig. 2) that the magnetic moment of the barium ferrite buoy was independent of the magnetic field strength over the range of magnetic fields needed for the desired density measurements, the instrument could be simplified considerably by reducing to a onecoil system (Fig. 1). The magnetic force on the buoy depended only on the magnetic field gradient $(d H / d Z)$ and not on the magnetic field intensity $(H)$. Thus the single (main) coil was connected into the servosystem and the gradient coils were eliminated.

It should be noted that a one-coil system can be used for absolute density measurements as long as the variation in the magnetic moment of the buoy with magnetic field intensity is known. This information could be obtained by techniques other than that used in the present work, e.g., a vibrating sample magnetometer. This is mentioned to emphasize that, with a knowledge of $M(H)$ of the magnetic buoy material, the initial apparatus design could be simplified significantly with the use of only one coil.

To carry out density measurements with the one-coil system with a barium ferrite buoy, first the current necessary to support the buoy in vacuum $\left(I_{V}\right)$ at a given position and temperature must be determined. Then the current necessary to support the buoy in a liquid $\left(I_{f}\right)$ of unknown density at the same position and temperature is measured. The density of the fluid is related to this current ratio by

$$
\rho=\frac{m}{V}\left(1-\frac{I_{f}}{I_{v}}\right)
$$

where $m$ and $V$ are the mass and volume of the buoy. It should be emphasized that no reference fluids are required for calibration of the one-coil system (or the three-coil system) used in the present work. However, the volume of the float may best be determined near room temperature using distilled water as a reference fluid of known density and, in fact, this procedure was used in the present work. ${ }^{17}$

There are several obvious advantages of the onecoil system over one using three coils; most are involved with the experimental design and procedures. With elimination of the two gradient coils and the alignment problems associated with them, the design and construction of the apparatus are much simpler. The constant current source is no longer needed. The

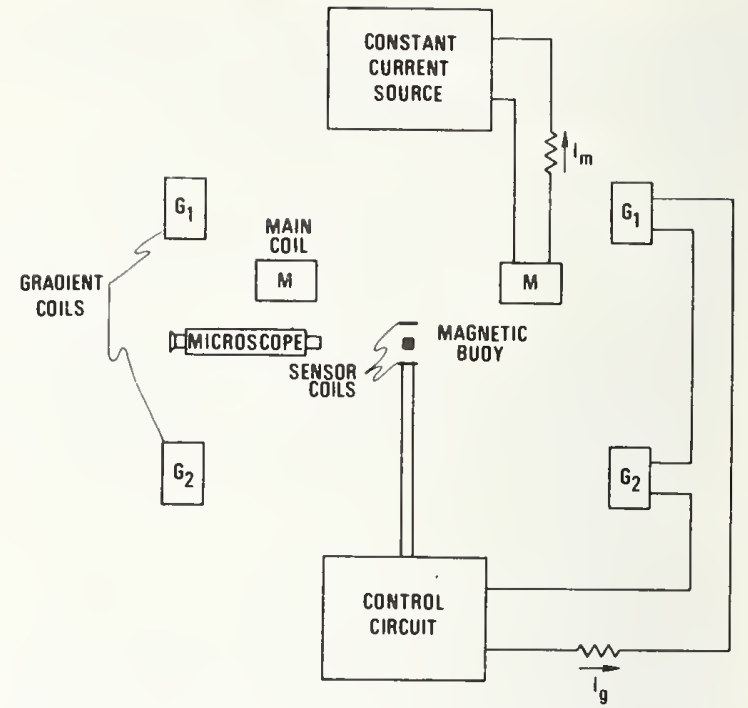

FIG. 2. Schematic diagram of a magnetic suspension densimeter with three support coils.

vacuum points for a single-coil system require only a single current measurement, while those for a three-coil system require a series of measurements of $I_{M}$ and $I_{G}$ while holding the buoy at a fixed position. Then the currents must be fitted by the method of least squares to Eq. (3) to obtain the instrument constants. Also the error analysis is less complicated with a one-coil system.

There is one inherent disadvantage in the method for obtaining absolute densities with either the one-coil or three-coil systems where the magnetic force depends only on $d H / d Z$. The change in $d H / d Z$ with position is significantly larger than the change in the product of $H$ and $d H / d Z$ with position. Thus a very precise determination $\left(10^{-3} \mathrm{~mm}\right)$ of the separation distance of the main coil and buoy was required in the present work and has been described in Ref. 17.

Experimental densities have been determined for saturated liquid argon and methane at temperatures between 100 and $120 \mathrm{~K}$ with both the three-coil and one-coil systems. The results agreed within the imprecision of the measurements, which was approximately $0.015 \%$ for methane and $0.005 \%$ for argon. Thus the simpler one-coil system is now utilized for all density measurements with the present instrument.

The servosystem that is used with the single coil was originally connected to the gradient coils in the threecoil system. No modifications to the servosystem as described in Ref. 17 were required for its use with the single coil.

The present series of density measurements in this laboratory with the magnetic suspension densimeter represented a nontypical use of the instrument. In the past the instrument has been used for highly precise (usually less than $0.001 \%$ ) measurements over a short density range at a single temperature. Here a relatively modest precision (less than $0.02 \%$ ) was the result of 
measurements over large density $\left(0.3-2.3 \mathrm{~g} / \mathrm{cm}^{3}\right)$ and temperature $(95-300 \mathrm{~K})$ ranges with a single buoy. The total uncertainty of the present measurements was approximately $0.1 \%$.

In order to obtain the highest precision and accuracy with the present instrument it was necessary to perform vacuum measurements immediately before or after the liquid measurements. The possible use of the instrument without repeating the vacuum measurements for each datum point has been investigated. In other words the precision and accuracy of the instrument has been estimated, based on a single series of vacuum measurements as a function of temperature at the beginning (and/or end) of a set of density measurements without regard to the temperature and magnetic field cycling of the buoy. The separation distance of the coil and the buoy must be maintained throughout the set of measurements.

In the present setup the position of the main coil was fixed as described in Ref. 17. The position of the float was determined with a $125 \times$ microscope and the buoy could be returned to a desired position either electronically or mechanically. Over a period of several months during the course of density measurements at low temperatures on several different fluids, the sample cell was cycled between approximately 100 to $130 \mathrm{~K}$ and $300 \mathrm{~K}$ more than twenty times. The standard deviation of the vacuum measurements at low temperatures was of the order of $0.05 \%$ with no systematic trend observed. This was a measure of the thermal hysteresis of the magnetic moment of the barium ferrite buoy over rather large temperature cycles. This result demonstrated that densities with a total uncertainty of approximately $0.2 \%$ could be expected without repeating vacuum measurements for each datum point. Thus, for density data in which the highest precision and accuracy are not required, the use of a one-coil system and a barium ferrite buoy would result in a relatively simple and efficient measurement process that requires few vacuum measurements.

* This work was carried out at the National Bureau of Standards under the sponsorship of British Gas Corp., Chicago Bridge and Iron Co., Columbia Gas Service Corp., Distrigas Corp., Easco Gas LNG, Inc., E1 Paso Natural Gas, Gaz de France, Marathon Oil Co., Mobil R and D Corp., Natural Gas Pipeline Co., Phillips Petroleum Co., Shell International Gas, Ltd., Sonatrach, Southern California Gas Co., Tennessee Gas Pipeline, Texas Eastern

Transmission Co., Tokyo Gas Co., Ltd., and Transcontinental Gas Pipe Line Corp., through a grant administered by the American Gas Association, Inc.

' J. W. Beams, C. W. Hulburt, W. E. Lotz, Jr., and R. M. Montague, Jr., Rev. Sci. Instrum. 26, 1181 (1955).

2 J. W. Beams and A. M. Clarke, Rev. Sci. Instrum. 33, 750 (1962).

${ }^{3}$ A. M. Clarke, D. W. Kupke, and J. W. Beams, J. Phys. Chem. 67, 929 (1963).

'D. V. Ulrich, D. W. Kupke, and J. W. Beams, Proc. Nat. Acad. Sci. U.S.A. 52, 349 (1964).

5 J. W. Beams, Rev. Sci. Instrum. 40, 167 (1969).

J. P. Senter, Rev. Sci. Instrum. 40, 334 (1969).

${ }^{7}$ P. F. Fahey, D. W. Kupke, and J. W. Beams, Proc. Nat. Acad. Sci. U.S.A. 63, 548 (1969).

${ }^{8}$ A. M. Wims, D. McIntyre, and F. Hynne, J. Chem. Phys. 50, 616 (1969).

${ }^{9}$ R. Goodrich, D. F. Swinehart, M. J. Kelly, and F. J. Reithel, Anal. Biochem. 28, 25 (1969).

10 J. L. Hales, J. Phys. E 3, 855 (1970).

11 W. M. Haynes and J. W. Stewart, Rev. Sci. Instrum. 42, 1142 (1971).

${ }^{12}$ S. P. Almeida and T. H. Crouch, Rev. Sci. Instrum. 42, 1344 (1971).

${ }^{13}$ M. G. Hodgins and J. W. Beams, Rev. Sci. Instrum. 42, 1455 (1971).

${ }^{14}$ D. W. Kupke and J. W. Beams, Methods Enzymol. 26, 74 (1973).

15 S. C. Greer. M. R. Moldover, and R. Hocken, Rev. Sci. Instrum. 45, 1462 (1974).

${ }^{18}$ S. C. Greer, T. E. Block, and C. M. Knobler, Phys. Rev. Lett. 34, 250 (1975).

17 W. M. Haynes, M. J. Hiza, and N. V. Frederick, Rev. Sci. Instrum 47, 1237 (1976). 

MEASUREMENTS OF THE ORTHOBARIC LIQUID DENSITIES

of methane, ETHANE, PROPANE, ISOBUTANE, AND

NORMAL BUTANE ${ }^{a}$

by

W. M. Haynes and M. J. Hiza

Cryogenics Division

National Bureau of Standards

Institute for Basic Standards

Boulder, Colorado 80302

Send proofs to: W. M. Haynes

Cryogenics Division, 275.02

National Bureau of Standards

Boulder, Colorado 80302

Short Title: Liquid Densities of $\mathrm{CH}_{4}, \mathrm{C}_{2} \mathrm{Il}_{6}, \mathrm{C}_{3} \mathrm{H}_{8}$,

$\mathrm{iC}_{4} \mathrm{H}_{10}$, and $\mathrm{nC}_{4} \mathrm{H}_{10}$

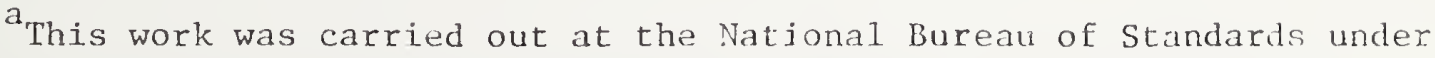
the sponsorhip of British Gas Corp., Chicago Bridge and Iron Co., Columbia Gas Service Corp., Distrigas Corp., Easco Gas LNG, Inc., El Paso Natural Gas., Gaz de France, Marathon Oil Co., Mobil R\&D Corp., Natural Gas Pipeline Co., Phillips Petroleum Co., Shell International Gas, Ltd., Sonatrach, Southem California Gas Co., Tennessee Gas Pipeline, Texas Easteri Transmission Co., 'Tokyo Gas Co., Ltd., and Transcontinental Gas Pipe Line Corp., through a grant administered by the American Gas Association, Inc. 
The orthobaric liquid densities of the major components of natural gas have been determined with a magnetic suspension densimeter. This paper reports results for methane (105 to $160 \mathrm{~K}$ ), ethane (100 to $270 \mathrm{~K})$, propane (100 to $288 \mathrm{~K}$ ), isobutane (115 to $300 \mathrm{~K}$ ), and normal butane (135 to $300 \mathrm{~K}$ ). The imprecision of the measured densities is approximately 0.015 percent; the estimated overall uncertainty is 0.1 percent at low temperatures and decreases to 0.06 percent at $300 \mathrm{~K}$. A simple expression has been used to represent the densities as a function of temperature. Comprehensive. comparisons with the experimental results of other investigators are presented. 


\section{Introduction}

Liquefied natural gas (LNG) is expected to become an increasingly important commodity on the world energy market. The basis for sale of LNG is its total heating value, which requires a knowledge of both density and composition. A project was initiated at this laboratory to provide orthobaric (saturated) liquid densities for the major components of LNG, and for mixtures of these components. The density data will be used to develop a mathematical model or correlation that predicts the density of LNG type mixtures with an inaccuracy of 0.1 percent, given a knowledge of the composition and temperature of the 1iquid. In the development of an accurate mathematical model (correlation), it is important to have both an accurate and an internally consistent set of density data.

Before this project was started there were significant temperature ranges for which saturated (orthobaric) liquid density data did not exist for some of the major components of LNG. For nitrogen and methane there were discrepancies as large as 0.5 per cent between different sets of data. Not only was it important to fill in gaps, but also to provide new independent measurements of sufficient accuracy to help resolve inconsistencies.

In this paper orthobaric liquid densities for methane, ethane, propane, isobutane, and normal butane are reported. Data for nitrogen were presented in an earlier paper ${ }^{(1)}$. Major emphasis has been placed on the low temperature region of 105 to $140 \mathrm{~K}$; however, measurements have been carried out to $160 \mathrm{~K}$ for methane, to $270 \mathrm{~K}$ 
for ethane, to $288.7 \mathrm{~K}$ for propane, and to $300 \mathrm{~K}$ for isobutane

and normal butane. The densities have been represented as a function of temperature with an expression that is used to facilitate comparisons with other measurements.

The present measurements were carried out with a magnetic (1) suspension densimeter. In this method a magnetic buoy is freely suspended in the liquid of interest by the force generated from the axial magnetic fields of air-core solenoids. The motion of the buoy is controlled by the automatic regulation of a servocircuit. The magnetic force necessary to maintain the buoy at a given position is inversely proportional to the buoyant force on the buoy. Thus, using Archemedes' principle, along with measurements of the mass and volume of the buoy, the density of the liquid is obtained.

\section{Experimental}

The expeximental apparatus and its operation have been described in detail elsewhere ${ }^{(1)}$. At low temperatures the experimental procedures for the measurements on the hydrocarbons other than methane differed significantly from those for nitrogen and methane. The density of a given fluid is deternined from measurements of the magnetic force necessary to support a barium ferrite buoy in a vacuum and in the fluid at the same position and temperature. For nitrogen and methane the vacuum measurements were performed immediately before or after the liquid measurenents. At low temperatures it has been found impossible to evacuate the sample cell within a reasonable length of time after it has been filled with one of the heavier hydrocarbons. "Most of the liquid can be 
removed by pressurizing with helium gas; however, a liquid film is left on the surfaces, including those of the buoy, inside the ce11. The buoy cannot be brought into suport until the film is removed. Thus, for the heavy hydrocarbons at low temperaturei, the vacuum points must be obtained before the liquid measurements.

So that more than one data point could be obtained in a given day for a heavy hydrocarbon at low temperatures, vacuum points were obtained at two temperatures separated by $5 \mathrm{~K}$ before 1 iquid was condensed into the cell. Then the liquid measurements were performed at each of these temperatures. Performance tests had demonstrated that the barium ferrite buoy does not exhibit any detectable hysteresis at low temperatures within the precision of the current measurements for a temperature range of, at least, $20 \mathrm{~K}$. After the vacuum and liquid measuremeats were performed for one of the heavy hydrocarbons at low temperatures the cell was warmed to a temperature above the normal boiling point of the test fluid for evacuation.

Methane was used as a control fluid during the heavy hydrocarbon measurements at low temperatures. Each day a new methane data point was taken to insure that the warm-up and cool-down of the apparatus did not affect the apparent position of the buoy from liquid-to-vacuum measurements. The position of the buoy was determiried with a high-powered microscope that had been adjusted initially so that the apparent position of the buoy did not depend on the index of refraction of the fluid inside the cell. It was found that the temperature cycling of the cell had no detectable effect on the apparent buoy position. 
Some of the data presented in this paper were taken with a one-coil system instead of the three-coil arrangement described in the apparatus paper ${ }^{(1)}$. The evolution to the use of only one coil is discussed in reference 2 .

All of the gases were of research grade quality. The minimum purities as specified by the suppliers were 99.9 mol percent for isobutane and normal butane and $99.99 \mathrm{~mol}$ percent for methane, ethane, and propane. The gases were analyzed chromatographically with a thermal conductivity detector and found to be within the specified purities except for isobutane. It was found that the isobutane contained approximately 0.15 percent normal butane. This relatively large amount of normal butane impurity has a negligible effect $(<0.01$ percent) on the density results.

The methane gas was passed through a room temperature molecular sieve trap to remove moisture and any heavy contaminants not detected by analysis. The other hydrocarbon gases were normally not passed through a molecular sieve trap.

\section{Results}

The experimental orthobaric liquid densities of methane, ethane, propane, isobutane, and normal butane are presented as a function of temperature (International Practical Temperature Scale-1968) in tables 1-5. The relatively large number of data points for methane at any given temperature resulted from the use of methane as a control fluid throughout the entirety of this project. Although the mean experimental densities of methane have been given in an earlier paper ${ }^{(1)}$ they are presented again here, along with other information 
(calculated densities, etc.), so that the orthobaric liquid densities of all the low molecular weight alkanes investigated in the present work are included in a single paper. All of the experimental points for methane will be presented in a future report (3). Each methane point was taken from a new filling of the cell. For the other hydrocarbons no more than two data points were taken from a single filling.

The experimental densities $(\rho)$ have been fitted as a function of temperature ( $\mathrm{T}$ ) to the following expression,

$$
\rho-\rho_{c}=a\left(1-\frac{T}{T_{c}}\right)^{0.35}+\sum_{i=1}^{3} b_{i}\left(1-\frac{T}{T_{c}}\right)\left(1+\frac{i-1}{3}\right)
$$

which incorporates a scaling law modification ${ }^{(4)}$ to a generalized Guggenheim equation ${ }^{(5)}$. The coefficients $\left(a, b_{i}\right)$, determined by least squares, and selected values of the critical temperature $\left(\mathrm{T}_{\mathrm{c}}\right)$ and density $\left(\rho_{c}\right)$ for each fluid are given in table $6^{(6-11)}$. Only three coefficients were needed to fit the methane data, which covered a relatively small temperature range compared to that for the other fluids.

The residual standard deviations of the fit to equation (1) for each fluid are given in table 6. These values substantiate the estimate of the imprecision of the density measurements, which is approximately 0.015 percent. The estimated inaccuracy in the densities is 0.1 percent at low temperatures and decreases to 0.06 percent at $300 \mathrm{~K}$. The total uncertainty in the reported 
temperatures is estimated to be less than $30 \mathrm{mK}$ at $100 \mathrm{~K}$ and less than $40 \mathrm{mK}$ at $300 \mathrm{~K}$. These uncertainty limits in the temperature correspond to a maximum uncertainty of $0.02 \%$ in the density for the data reported in this paper. A detailed error analysis of the magnetic suspension densimeter used in the present work has been given elsewhere ${ }^{(1)}$.

Equation (1), along with the parameters given in table 6 , has been used for comparisons of the present results with independent experimental data $(8,12-25)$. Deviation plots for ethane, propane, isobutane, and normal butane are presented in figures 1 through 4. The deviation plot for methane was presented in an earlier paper ${ }^{(1)}$; thus, it is not included here.

In comparing the results of other investigators with equation (1) some general trends are observed. Below $140 \mathrm{~K}$ the densities of Shana'a and Canfield(12), Chui and Canfield(13), Orrit and olives (14), Rodosevich and Miller (15), McClune ${ }^{(16)}$, and Klosek and McKinley (17) are generally lower than the present results by 0.05 to 0.1 percent. Exceptions to this trend are as follows: for isobutane the densities of Rodosevich and Miller ${ }^{(15)}$ between 114 and $120 \mathrm{~K}$ are larger (maximum of 0.1 percent) than the present results and exhibit a significant.ly different temperature dependence; and for ethane the change in density with temperature reported by Klosek and McKinley ${ }^{(17)}$ is appreciably larger than that observed in the present work.

Above $140 \mathrm{~K}$ the data of Chui and Canfield(13), Orrit and Olives (14), and McClune (16) differ from the present results by less than 0.05 percent. At higher temperatures (above $280 \mathrm{~K}$ ) the data of 
Sliwinski (8) for propane, isobutane, and normal butane generally differ from the present results by less than 0.05 percent. The orthobaric liquid densities reported by Douslin and Harrison for ethane at temperatures between 248 and $263 \mathrm{~K}$ were systematically larger than the present results by 0.3 to 0.35 percent. Some of the older, less precise (but frequently used) data have been included on the deviation plots for the sake of completeness.

Although klosek and McKinley ${ }^{(17)}$ give densities for isobutane and normal butane at temperatures between 105 and $133 \mathrm{~K}$, these densities are not experimental, and therefore, are not plotted on figures 3 and 4. A few comments on the reliability of the omitted values are appropriate. Their densities were obtained from the Francis equation (26). For normal butane at temperatures below its triple point temperature, their results were systematically higher by less than 0.2 percent than the densities obtained through extrapolation of the present data ${ }^{(27)}$. However, their isobutane densities at temperatures between 116 and $133 \mathrm{~K}$ were 1.5 percent higher than those of the present work.

\section{Summary}

This research has provided accurate and self-consistent measurements of the orthobaric liquid densities of methane, ethane, propane, isobutane, and normal butane at temperatures down to $100 \mathrm{~K}$. Most of the measurements recently reported by other workers differ from the present data by less than 0.1 percent. In subsequent papers, density measurements on liquefied mixtures of the major components of liquefied natural gas will be reported. 


\section{Acknowledgment}

The authors would like to acknowledge R. D. McCarty and M. J. Brown for assistance with the correlation and reduction of the data. 
1. Haynes, W. M.; Hiza, M. J.; Frederick, N. V. Rev. Sci. Instrum. (to be published).

2. Haynes, W. M. Rev. Sci. Instrum. (submitted for publication).

3. Methane data are available from authors upon request and will be published in a Nat. Bur. Stand. (U.S.) report.

4. McCarty, R. D. Nat. Bur. Stand. (U.S.), Internal Rept. $74-357, \underline{1974}$.

5. Hou, Y.C.; Martin, J. J. A.I.Ch.E. J. 1959, 5, 125.

6. Goodwin, R. D. Nat. Bur. Stand. (U.S.), Tech. Note 653, 1974.

7. O1son, J. D. J. Chem. Phys. 1975, 63, 474.

8. Sliwinski, P. Z. Phys. Chem. (Frankfurt) 1969, 63, 263.

9. Das, T. R.; Eubank, P. T. Advances in Cryogenic Engineering $1973,1,208$.

10. Das, T. R.; Reed, Jr., C. O.; Eubank, P. T. J. Chem. Eng. Data $1973,18,253$.

11. Das, T. R.; Reed, Jr., C. 0.; Eubank, P. T. J. Chem. Eng. Data $1973,18,244$.

12. Shana'a, M. Y.; Canfield, F. B. Trans. Faraday Soc. 1968, 64,2281

13. Chui, C. H.; Canfield, F. B. Trans. Faraday Soc. 1971, 67, 2933.

14. Orrit, J.; Olives, J. distributed at 4 th International Conference on Liquefied Natural Gas, Algeria, 1974. 
15. Rodosevich, J. B.; Miller, R. C. A.I.Ch.E. J. 1973, 19, 729.

16. McClune, C. R. Cryogenics 1976, 16, 289.

17. Klosek, J.; McKinley, C. Proc. First International Conference on LNG, Paper 22, Chicago, 1968.

18. Douslin, D. R.; Harrison, R. H. J. Chem. Thermodynamics $1973,5,491$.

19. Maass, O.; Wright, C. H. J. Am. Chem. Soc. 1921, 43, 1098.

20. Jensen, R. H.; Kurata, F. J. Petrol. Technol. 1969, 21, 683.

21. Kahre, L. C. J. Chem. Eng. Data 1973, 18, 267.

22. Tomlinson, J. R. Natural Gas Processors Assoc. Tech. Publ. TP-1, Tulsa, Oklahoma, 1971.

23. Seeman, F.-W.; Urban, M. Erdöl und Kohle Erdgas Petrochemie $1963,16,117$.

24. Tech. Comm., Nat1. Gas. Assoc. Am. Ind. Eng. Chem. 1942, 34,1240 .

25. Van der Vet, A. P. Congress Modial du Petrol., Paris, Vol. II, p. 515, 1937.

26. Francis, A. W. Ind. Eng. Chem. 1957, 49, 1779.

27. Haynes, W. M.; Hiza, M. J. Advances in Cryogenic Engineering, Vol. 21. Timmerhaus, K. D. and Weitzel, D. H., editors. Plenum Press, New York, 1976, p. 516. 
Table 1. Orthobaric liquid densities of methane, where $\mathrm{T}$ is the temperature (IPTS-1968), $\rho_{\exp }$ is the mean experimental density for $n$ observations at a given temperature, and $\rho_{\text {calc }}$ is the density calculated from equation (1).

\begin{tabular}{|c|c|c|c|c|}
\hline $\mathrm{T} / \mathrm{K}$ & $\rho_{\text {exp }} / \operatorname{mol} \ell^{-1}$ & $\mathrm{n}$ & $\rho_{\text {calc }} /$ mol $e^{-1}$ & $\begin{array}{l}\text { Maximum } \\
\text { value of } \\
100\left(\rho_{\text {exp }}{ }^{-\rho_{\text {calc }}}\right)\end{array}$ \\
\hline & & & & $\rho_{\text {calc }}$ \\
\hline 105.000 & 26.9458 & 12 & 26.9456 & 0.030 \\
\hline 110.000 & 26.4985 & 11 & 26.5005 & 0.035 \\
\hline 115.000 & 26.0443 & 12 & 26.0429 & 0.028 \\
\hline 120.000 & 25.5721 & 17 & 25.5712 & 0.036 \\
\hline 125.000 & 25.0845 & 18 & 25.0839 & 0.037 \\
\hline 130.000 & 24.5775 & 16. & 24.5790 & 0.036 \\
\hline 135.000 & 24.0540 & 23 & 24.0540 & 0.031 \\
\hline 140.000 & 23.5067 & 5 & 23.5060 & 0.024 \\
\hline 145.000 & 22.9312 & 5 & 22.9311 & 0.024 \\
\hline 150.000 & 22.3218 & 2 & 22.3243 & 0.014 \\
\hline 160.000 & 20.9876 & 2 & 20.9857 & 0.037 \\
\hline
\end{tabular}


Table 2. Orthobaric liquid densities of ethane, where $T$ is the temperature (IPTS-1968), $\rho_{\text {exp }}$ is the experimental density, and $\rho_{\text {calc }}$ is the density calculated from equation (1).

\section{$\mathrm{T} / \mathrm{K}$}

100.000

105.000

110.000

115.000

120.000

125.000

130.000

135.000

140.000

150.000

160.000

170.000

180.000

190.000

200.000

210.000

220.000

230.000

240.000

250.000

260.000

270.000

$$
\rho_{\text {exp }} / \text { mol } l^{-1}
$$

21.3408

21.1585

20.9746

20.7927

20.6022

20.4186

20.2317

$20.046 \mathrm{l}$

19.8566

19.4751

19.0857

18.6867

18.2793

17.8612

17.4289

16.9713

16.4988

15.9973

15.4642

14.8899

14.2610

13.5493

$$
\rho_{\text {calc }} / \operatorname{mol} e^{-1}
$$

21.3388

21.1568

20.9742

20.7907

20.6063

20.4208

20.2343

20.0466

19.8575

19.4748

19.0850

18.6869

1.8.2787

17.8586

17.4240

16.9720

16.4989

15.9994

15.4670

14.8919

14.2598

13.5477 $100\left(\rho_{\exp }-\rho_{\mathrm{cal} c}\right)$

$\rho_{\text {calc }}$

0.009

0.008

0.002

0.010

$-0.020$

$-0.011$

$-0.013$

$-0.002$

$-0.005$

0.002

0.004

$-0.001$

0.003

0.015

0.028

$-0.004$

$-0.001$

$-0.013$

$-0.018$

$-0.013$

0.008

0.012 
Table 3. Orthobaric liquid densities of propane, where $\mathrm{T}$ is the temperature (IPTS-1968), $\rho_{\text {exp }}$ is the experimental density, and $\rho_{\text {calc }}$ is the density calculated from equation (1).

$\mathrm{T} / \mathrm{K}$ $\rho_{\text {exp }} / \operatorname{mol} e^{-1}$ $\rho_{\mathrm{calc}} / \mathrm{mol} e^{-1}$ $\frac{100\left(\rho_{\exp }-\rho \operatorname{calc}\right)}{\rho_{\text {calc }}}$

$\begin{array}{ll}100.075 & 16.3065 \\ 105.075 & 16.1872 \\ 110.075 & 16.0718 \\ 115.075 & 15.9557 \\ 120.075 & 15.8411 \\ 125.075 & 15.7250 \\ 130.075 & 15.6085 \\ 135.075 & 15.4910 \\ 140.075 & 15.3751 \\ 145.075 & 15.2588 \\ 150.075 & 15.1400 \\ 200.000 & 13.9560 \\ 240.000 & 12.9271 \\ 270.000 & 12.0733 \\ 280.000 & 11.7622 \\ 288.706 & 11.4790\end{array}$

16. 3048

16.1885

1.6.0723

15.9562

15.8401

15.7241

15.6080

15.4918

15.3755

15.2590

15.1424

13.9524

12.9285

12.0742

11.7631

11.4775
0.011

$-0.008$

$-0.003$

$-0.003$

0.006

0.006

0.003

$-0.005$

$-0.002$

$-0.002$

$-0.016$

0.026

$-0.010$

$-0.008$

$-0.008$

0.013 
Table 4. Orthobaric liquid densities of isobutane, where $\mathrm{T}$ is the temperature (IPTS-1968), $\rho_{\text {exp }}$ is the experimental density, and $\rho_{\text {calc }}$ is the density calculated from equation (1).

$\mathrm{T} / \mathrm{K}$

$$
\rho_{\exp } / \operatorname{mol} e^{-1}
$$

$\rho_{\mathrm{calc}} / \mathrm{mol} \ell^{-1}$

12.7305

12.6489

120.075

125.075

130.075

135.075

140.075

145.075

150.075

228.000

288.706

290.000

300.000
12.5687

12.4850

12.4015

12.3215

12.2353

12.1534

10.8273

9.6676

9.6411

9.4300
12.7313

12.6491

12.5669

12.4846

12.4022

1.2.3197

12.2372

12.1544

10.8263

9.6687

9.6417

9.4287 $\frac{100\left(\rho_{\exp }-\rho_{\text {calc }}\right)}{\rho_{\text {calc }}}$

$-0.006$

$-0.001$

0.015

0.003

$-0.005$

0.014

$-0.015$

$-0.008$

0.009

$-0.012$

$-0.007$

0.014 
Table 5. Orthobaric liquid densities of nomal butane, where $T$ is the temperature (IP'TS-1968), $\rho_{\exp }$ is the experimental density, and $\rho_{\text {calc }}$ is the density calculated from equation ( 1 ).

$\mathrm{T} / \mathrm{K}$

$$
\rho_{\exp } / \operatorname{mol} e^{-1}
$$

$$
\rho_{\mathrm{calc}} / \mathrm{mol} \ell^{-1}
$$

$$
\frac{100\left(\rho_{\exp }-\rho_{c a l c}\right)}{\rho_{\text {calc }}}
$$

135.075

140.075

145.075

150.075

155.075

160.075

165.075

170.075

230.000

288.706

290.000

300.000
12.6517

12.5706

12.4920

12.4089

12.3299

12.2484

12.1634

12.0839

11.0911

10.0325

10.0067

9.8103
12.6524

12.5714

12.4904

12.4093

12.3283

12.2471

12.1659

12.0846

11.0905

10.0324

10.0073

9.8099
$-0.005$

$-0.006$

0.013

$-0.003$

0.014

0.010

$-0.020$

$-0.005$

0.005

0.001

$-0.007$

0.004 


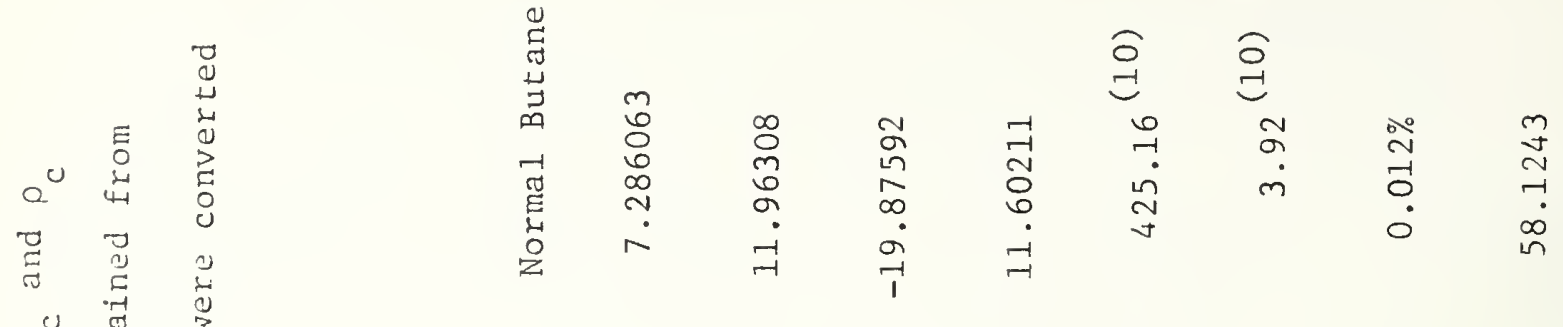

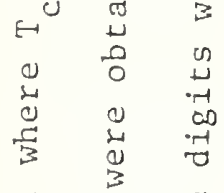

$$
\begin{aligned}
& \text { त्राल लि } \sum_{\text {ते }}^{0} \\
& + \text { iे }
\end{aligned}
$$

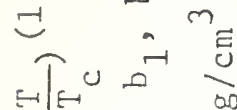

$$
\begin{aligned}
& \begin{array}{lll}
1 & j & 0 \\
- & 0 & 0
\end{array}
\end{aligned}
$$

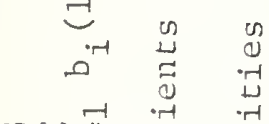

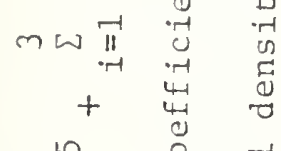

$$
\begin{aligned}
& \text { m 0 } \\
& \text { 나의 }
\end{aligned}
$$

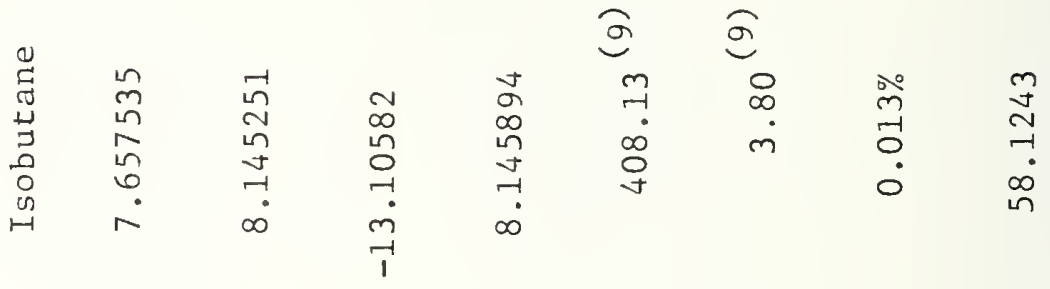

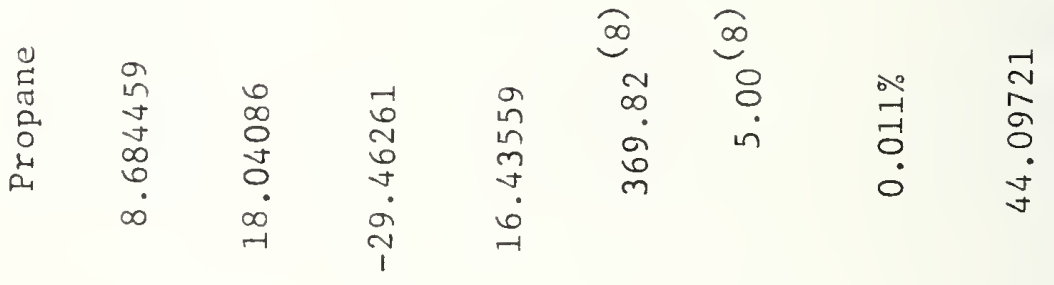

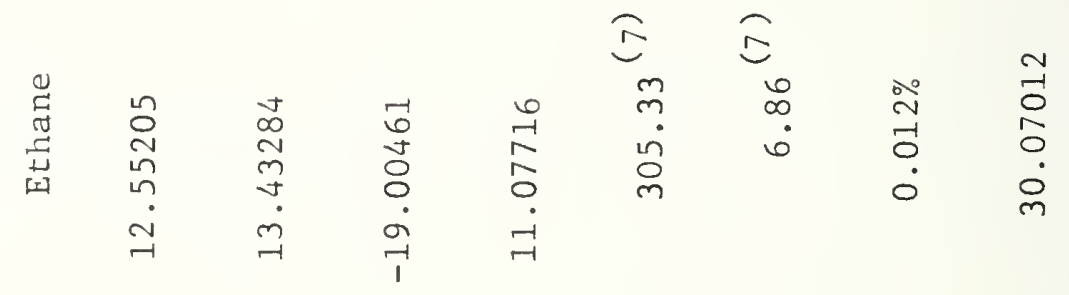

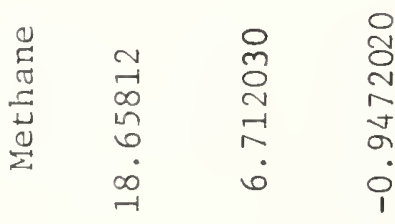

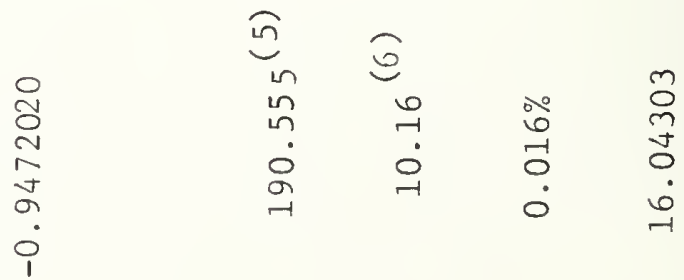

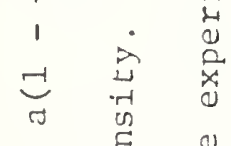

$$
\begin{aligned}
& \text { " ए ए }
\end{aligned}
$$

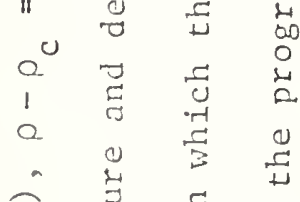

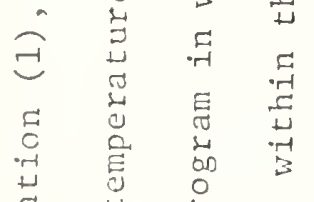

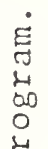

$$
\begin{aligned}
& \stackrel{0}{5}
\end{aligned}
$$

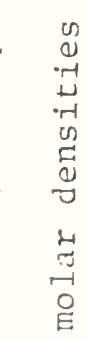

$$
\begin{aligned}
& \text { 운 } \\
& \text { 年 }
\end{aligned}
$$

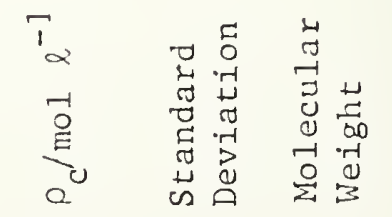


Figure 1. Deviation plot of experimental orthobaric liquid densities of ethane compared with values calculated from equation (1) using parameters Erom table 6; $O$ present data, Shana'a and Canfield (12), $\diamond$ Chui and Canfield ${ }^{(13)}$, Orrit and olives (14), $\triangle$ Rodosevich and Miller ${ }^{(15)}, \square$ McClune ${ }^{(16)}, \square$ Klosek and McKin].ey (17), $\Delta$ Douslin and Harrison ${ }^{(18),} \quad \Theta$ Maass and Wright ${ }^{(19)}, \quad \nabla$ Jensen and Kurata ${ }^{(20)}, \quad \nabla$ Kahre $^{(21)}$.

Figure 2. Deviation plot of experimental orthobaric 1iquid densities of propane compared with values calculated from equation (1) using parameters from table 6; 0 present data, * Sliwinski ${ }^{(8)}$, - Shana'a and Canfield (12), (1) Orxit and 0lives ${ }^{(14), \Delta}$ Rodosevich and Miller ${ }^{(15)}$, $\square$ McClune ${ }^{(16)}$, Klosek and Mckinley (17), $\Theta$ Maass and Wright ${ }^{(19)}, \nabla$ Jensen and Kurata ${ }^{(20)}$, $\nabla$ Kahre $^{(21)}$, $\ominus \operatorname{Tomlinson}^{(22)}, \otimes \operatorname{Seeman}^{(2)}$ Urban $^{(23)}, \otimes$ $\operatorname{NGAA}^{(24)}$, V Van der Vet ${ }^{(25)}$.

Figure 3. Deviation plot of experimental orthobaric liquid densities of isobutane compared with values calculated fxom equation (1) using parameters from table 6; O present data, * Sliwinski ${ }^{(8)}$, (1) Orrit and Olives (14), $\triangle$ Rodosevich and Miller ${ }^{\text {(15), }}$ $\square$ McClune ${ }^{(16)}, \nabla$ Kahre $^{(21)}, \otimes \operatorname{NGAA}^{(24)}, \bigotimes \operatorname{Van} \operatorname{der} \operatorname{Vet}^{(25)}$.

Figure 4. Deviation plot of experimental orthobaric liquid densities of normal butane compared with values calculated from equation (1) using parameters from table 6; O present data, * Sliwinski (8),

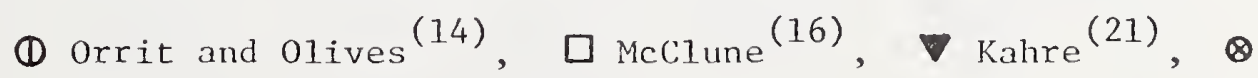
$\operatorname{NGAA}^{(24)}$, V Van der vet ${ }^{(25)}$. 


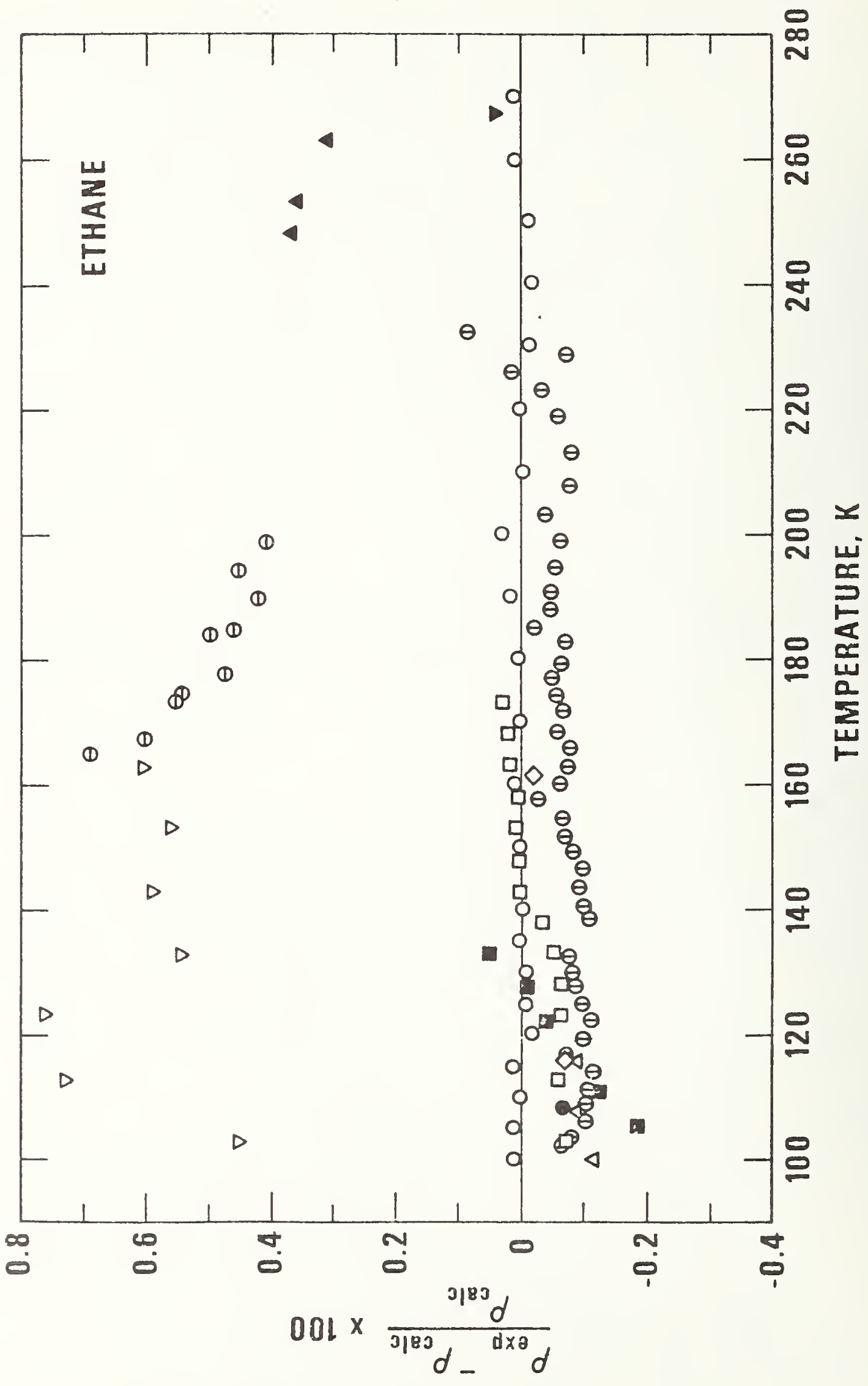




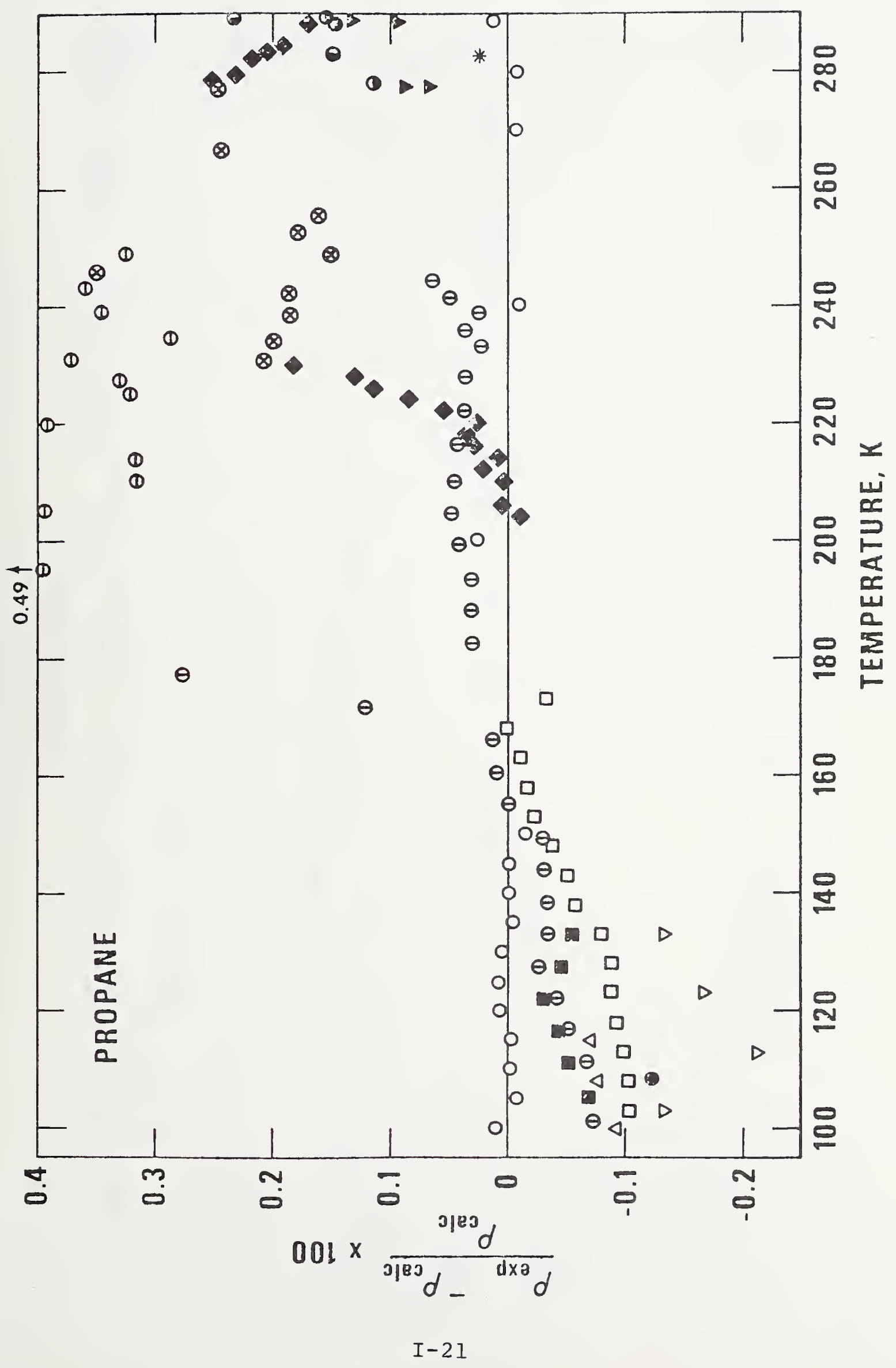




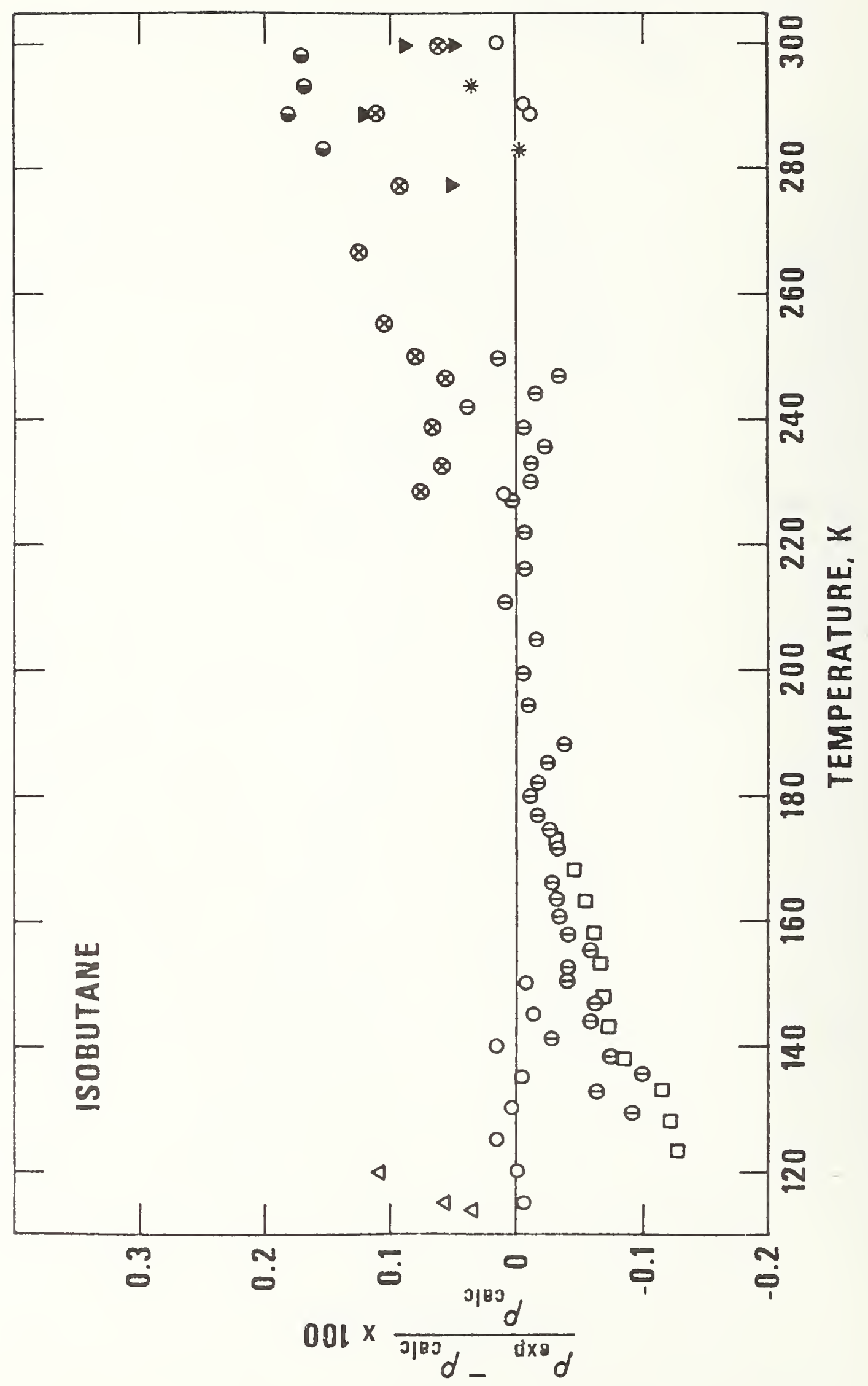




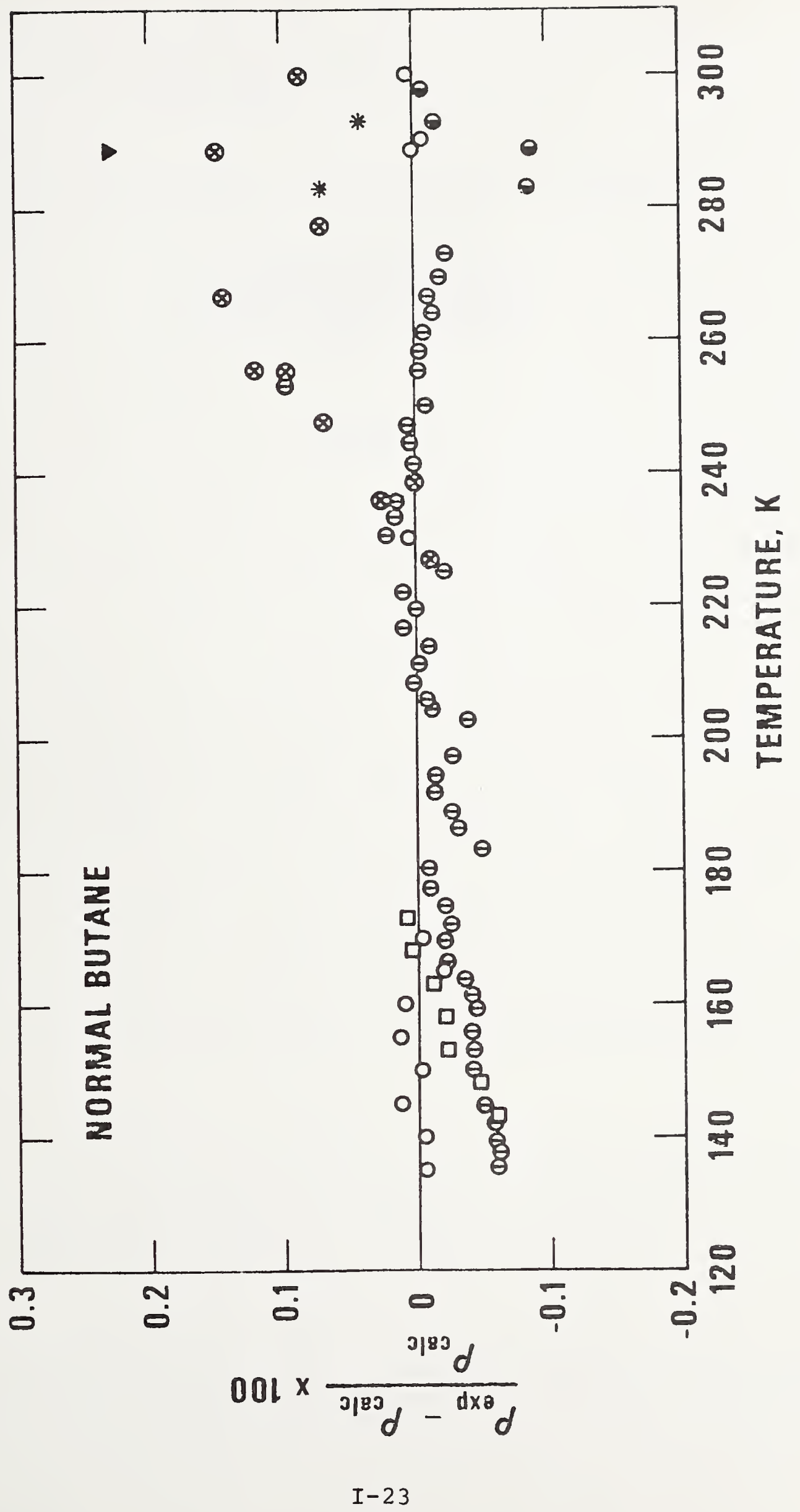



H. J. M. Hanley, W. M. Haynes and R. D. McCarty

\author{
Cryogenics Division \\ Institute for Basic Standards \\ National Bureau of Standards \\ Boulder, Colorado 80302
}

\begin{abstract}
Data for the viscosity and thermal conductivity coefficients of dense gaseous and liquid methane have been evaluated. Selected data were fitted to a function derived in our previous work and tables of values were generated for temperatures from 95 to $500 \mathrm{~K}$ and for pressures up to $50 \mathrm{MPa}$ ( $500 \mathrm{~atm}$ ). The uncertainties of the tabular values are estimated to be approximately $3 \%$ and $5 \%$ for the viscosity and thermal conductivity coefficients, respectively. The contribution for the thermal conductivity enhancement in the critical region is included in the tables. Care has been taken to ensure that the calculated values are consistent with reliable equation of-state data and also with dilute gas transport coefficients determined previously.
\end{abstract}

Key words: Correlation; critical point anomaly; methane; tables; thermal conductivity coefficient; viscosity coefficient.

Publication of the National Bureau of Standards, not subject to copyright. 
The viscosity coefficient (r) and the theral conductivity coefficient () ol several fluids - argon, krypton, zenon, oxygen and nitrogen - have been correlated over a wide range of experimental conditions [1]* The correlation was recently extended to methane [2]. The object of this paper is to expand on reference [2] by presenting tables and to give some further details of the correlation. We will follon closely the outline of reference [I] in which criteria for evaluating systematically literature data were discussed and in which an equation for the viscosity and thermal conductivity coefficients was proposed. The criteria and equations will be used here with only minimal comments.

\section{CORRELATING EQUATIONS}

The correlations are based on the behavior of the transport coefficients with respect to temperature ( $T$ ) and density ( $\rho$ ) according to the equations

$$
\begin{aligned}
& \eta_{1}(\rho, T)=\eta_{0}(T)+\eta_{1}(T) p+\Delta \eta^{\prime}(\rho, T) \\
& \lambda(\rho, T)=\lambda_{0}(T)+\lambda_{1}(T) \rho+\Delta \lambda^{\prime}(f, T)+\Delta \lambda_{C}(\rho, T)
\end{aligned}
$$

for the viscosity and thermal conductivity coefficients, respectively. In these equations, $\eta_{0}(T)$ and $\lambda_{0}(T)$ are the dilute sas values, $\eta_{I}(T)$ and $\lambda_{I}(T)$ represent

\footnotetext{
Numbers in brackets refer to references.
} 
= density corrections for the moderately dense gas, while $\mathrm{Ln}^{\prime}(\rho, T)$ and (.),T) are remainders. The term $n_{1}(T)$ is given by the empirical expression

$1(T)=A+B[C-\ln (T / F)]^{2}$

and similarly for $\lambda_{I}(T)$. The coefficients $A, B, C$ and $F$ can be found from a fit of data but we set $F=\varepsilon / k$ where $\varepsilon$ is the energy parameter of the methane pair potential function and $k$ is Boltzmann's constant. See section 3.

The terms $\Delta \eta^{\prime}(\rho, T)$ and $\Delta \lambda^{\prime}(\rho, T)$ are expressed empirically by the relations

$$
\begin{array}{r}
\Delta n^{\prime}(\rho, T)=E\left\{\operatorname { e x p } [ j _ { 1 } + j _ { 4 } / T ] \quad \operatorname { e x p } \left[\rho^{0.1}\left(j_{2}+j_{3} / T^{3 / 2}\right)\right.\right. \\
\left.\left.+\theta_{\rho}^{0.5}\left(j_{5}+j_{6} / T+j_{7} / T^{2}\right)\right]-1.0\right\}
\end{array}
$$

end

$$
\begin{aligned}
& \Delta x^{\prime}(\rho, T)=D\left\{\operatorname { e x p } [ k _ { 1 } + k _ { 4 } / T ] \operatorname { e x p } \left[\rho^{0.1}\left(k_{2}+k_{3} / T^{3 / 2}\right)\right.\right. \\
&\left.\left.+\rho^{0.5}\left(k_{5}+k_{6} / T+k_{7} / T^{2}\right)\right]-1.0\right\}
\end{aligned}
$$

The parameter $\theta$ is included to account specifically for the high density behavior of the transport coefficients and is a function of the density with respect to the critical density, $\rho_{c}$ :

$\Leftrightarrow=\left(\rho-\rho_{c}\right) / \rho_{c}$ 
ine coeficients, E, $D, j_{1} \ldots j_{7}, k_{1} \ldots k_{7}$, are all to be determined from oxperimental data.

One sees that equation (1) and (2) are of the same structure except that equation (2) includes the term $\Delta \lambda_{c}(0, T)$. This is included to take into account the known enhancement of the thermal conductivity coefficient in the neighborhood of the critical point [3]. [The viscosity coefficient also shows anomalous behavior close to the critical point [4]. The anomaly is small, however, and is not included in the calculated values.]

We have remarked in reference [1] that the form of equations (4) and (5) was independent of the nature of the fluids considered. The behavior of methane [2] is consistent with this characteristic. This apparent generality is a useful feature of the equations but, since they are empirical, each fluid should be treatec on its merits without prior prejudice.

Equation of State. The majority of transport coefficient data in the literature is reported in temperature-pressure coordinates but we emphasized [1] that a correlation of the coefficients should be preferably in terms of density rather than pressure. An accurate equation of state is, therefore, essential to our procedure. The equation of state used here for methane is a modified BenedictWebb-Rubin (BWR), which was introduced and discussed in reference [5]. The equation is, in turn, based on the methane correlation of Goodwin [6]. The form of the Birk and values for its parameters are given in the Appendix of the present paper.

Equation (5) here includes a contribution proportional to $\theta$, unlike the corresponding equation [equation (9)] in reference [1]. In our earlier work with oxygen, nitrogen, and the rare gases, however, the data were either not mfficiently precise, or extensive to justify seven $k$ coefficients. 
3. THE DILUTE GAS

The dilute gas coefficients appear separately in equations (1) and (2). Fie have discussed the calculation of these quantities from statistical mechanics $[7,8,9]$ and have shown, in particular, that statistical mechanics can give a consistent representation of the transport properties and the thermodynamic properties for a given simple gas.

Dilute gas transport coefficient data for methane have been 1 isted and evaluated in reference [10]. Calculated values were obtained via the standard kinetic theory equations [9] using the m-6-8 pair potential function of Klein and Hanley [10]. This potential has the form

$\phi(r)=\frac{\varepsilon}{m-6}\left[6+2 \gamma^{\prime}\right]\left(\frac{r_{m}}{r}\right)^{m}-\frac{\varepsilon}{m-6}\left[m-\gamma^{\prime}(m-8)\right]\left(\frac{r_{m}}{r}\right)^{6}-\gamma^{\prime}\left(\frac{r_{m}}{r}\right)^{8}$

where $r$ is the intermolecular separation, $\varepsilon$ the maximum well-depth of the potential, and $r_{m}$ is defined according to the relation $\phi\left(r_{m}\right)=-\varepsilon$. Repulsive forces between molecules are represented by a $1 / r^{m}$ contribution, while attractive forces are represented by $-1 / r^{6}$ and $-1 / r^{8}$ contributions; $\gamma^{\prime}$ depicts the strength of the latter. Since we have discussed the application of kinetic theory to methane in reference [10], details of the calculation procedure are omitted here. m-6-8 methane parameters are given in table 1 . The dilute gas data were fitted to within their estimated accuracy (approximately $\pm 2 \%$ for the viscosity coefficient and approximately $\pm 5 \%$ for the thermal conductivity coefficient). Recent work [53] has suggested, however, that the m-6-8 potential can lead to small systematic differences between theory and experiment at very low temperatures [T/( $(\varepsilon / \mathrm{k}) \lesssim 0.8]$ and at very high temperatures $[\mathrm{T} /(\varepsilon / \mathrm{k})>20]$. Accordingly we revise our estimate of accuracy for the dilute gas transport coefficients of methane for temperatures 
- sis than $150 \mathrm{~K}$ to $3 \%$ and $6 \%$ for the viscosity and thermal conductivity

coficient, respectively. Ely and Hanley have further discussed [9] the

approximations introduced when a nonspherical molecule, such as methane, is

regarded as spherical from the viewpoint of the pair potential. For methane, we have verified that this assumption does not effect the correlation of a single property (e.g., the viscosity) but effects slightly the consistency between calculated values of different properties.

For computational convenience we fitted the calculated $n_{0}$ and $\lambda_{0}$ to a polynomial in temperature

$\eta_{0}=G V(1) \mathrm{T}^{-1}+G V(2) \mathrm{T}^{-2 / 3}+G V(3) \mathrm{T}^{-1 / 3}+G V(4)+G V(5) \mathrm{T}^{1 / 3}$

$$
+G V(6) \mathrm{T}^{2 / 3}+G V(7) \mathrm{T}+\mathrm{GV}(8) \mathrm{T}^{4 / 3}+\mathrm{GV}(9) \mathrm{T}^{5 / 3}
$$

and similarly for $\lambda_{0}$, but with coefficients $G \mathrm{~T}(i)(i=1 \ldots 9)$ replacing $G V(i)$ in equation (8). Values of the coefficients are listed in table 2.

\section{CALCulation OF THE THERMAL CONDUCTIVITy COEFFICIENT IN THE}

\section{CRITICAL REGION}

The quantity $\Delta \lambda_{c}$ appears as a separate term in equation (2) and represents the anomalous behavior of the thermal conductivity coefficient in the neighborhood of the critical point [3]. There is no doubt that $\Delta \lambda_{c}$ can contribute significantly to the value of the thermal conductivity coefficient and has to be included in a correlation [1]. Conductivity data, however, in the critical region for methane are scarce and we prefer to obtain $\Delta \lambda_{c}$ by calculation.

The calculation follows a procedure suggested by Sengers [3] and expanded by Hanley, Sengers and McCarty [11]. Details are given in reference [11], in 
ction 3.2 of reference [1], and in reference [2]. Our application to methane Lis jiven in appendix $C$ of reference [2].

\section{DATA SELECTION AND CORRELATION}

Since the dilute gas coefficients, $\eta_{0}$ and $\lambda_{0}$, have been calculated previously [10], we considered here data for the dense gas and liquid regions only. A comprehensive search of the world's literature through 1975 turned up references [12] - [37] for the viscosity coefficient and references [38] - [49] for the thermal conductivity. Much of the data prior to 1970 are summarized in references [50] - [52]. The data reported in these papers were examined according to the criteria set out in section 2 of reference [1]. The data used for correlation purposes were chosen on the basis of the procedure described in section 2.3 of reference [1] and table 3 gives the final choices with our accuracy assessments.

We have shown that it is essential to have reliable data close to the saturated liquid boundary and for at least one high temperature (about $2 \mathrm{~T}_{\mathrm{c}}$ ) isotherm if equations (1) to (5) are to give a reliable correlation. Such data are available for methane. [Conversely, if data are available for the saturated liquid boundary and for one high temperature isotherm only, equations (1) to (5) are excellent interpolation functions.]

The experimental coverage for the thermal conductivity coefficient of methane is perhaps the most extensive of any fluid due to the measurements of Uani [39], using a transient hot wire technique, and to those of Le Neindre [38], using a concentric cylinder apparatus. In the region of overlap, data from these two authors differ systematically by about two percent, which is within their estimated uncertainties. 
The parameters for equations (3)-(5) were estimated by the least squares procedure outlined in section 3.1 of reference [1], using the selected data from table 3, and are given in table 4. As remarked, however, thermal conductivity data close to the critical point (from references [39] and [40]) were excluded from the fit; rather $\Delta \lambda_{c}$ was obtained by calculation [2].

\subsection{Deviation Curves}

Representative deviation curves are shown as figures 1-4. In every example the percent deviation has been defined as

percent deviation $=\frac{(\text { expt.-calc. })}{\text { expt. }} \times 100$

The figures are self-explanatory and show that we have been able to fit the data to within the estimated experimental uncertainties with one possible exception: namely, the calculated viscosity coefficient appears too low close to the critical point, see figure 1. Although it is possible that experimental error and/or incorrect density values contribute to the deviation, it is more likely that the deviation is the result of a small enhancement in the viscosity close to the critical point [4], which is excluded in the correlating equation. This feature was also observed in our previous work [1].

\section{CONSTRUCTION OF TABIES}

We constructed tables of values for the viscosity coefficient (table 5) and the thermal conductivity coefficient (table 6) from equations (1)-(5) with the parameters of table 4 using the equation of state in the appendix. The temperature range is 95 to $500 \mathrm{~K}$. The pressures extend to $50 \mathrm{MPa}$ for temperatures 1ess than 
- $5 \mathrm{~K}$, and to $75 \mathrm{MPa}$ for temperatures between 205 and $500 \mathrm{~K}$. These ranges someties correspond to a slight extrapolation of the data. The correlations, howover, are based on the temperature-density behavior of the transport coefficients. Density is the limiting variable. We therefore assured that a P-T entry in the table did not correspond to a density exceeding $0.445 \mathrm{~g} / \mathrm{cm}^{3}[27.8 \mathrm{~mole} / 2]$, which was the upper experimental limit.

For convenience we constructed table 7 which presents values for the saturated liquid.

\subsection{Uncertainty of the Tables and Extrapolation}

Our assessment of the correlating procedure of reference [1] led to the conclusion that the correlation does not give rise to significant systematic deviations between calculated and experimental values of the transport coefficients. This conclusion is reinforced from this work with methane. Hence, an estimate of the uncertainty of the tabulated values is essentially the estimate of the uncertainty of the input data. [We note that the percentage of uncertainty given in table 3 and mentioned here is an assessment of inaccuracy.] For temperatures below $200 \mathrm{~K}$, we assign an uncertainty of $\pm 3 \%$ to the tabulated viscosity values, $\pm 5 \%$ to the tabulated thermal conductivity values. For temperatures above $200 \mathrm{~K}$, the uncertainties are felt to be slightly less: $\pm 2 \%$ and $\pm 4 \%$, respectively. Close to the critical point, our viscosity values are probably too low by about $5 \%$ and our values for the thermal conductivity have an uncertainty of $15 \%$. Extrapolation of the tables is not recommended.

\section{CONCLUSION}

A general equation, identical in form for both transport coefficients (excluding the critical point enhancement for the thermal conductivity coefficient), has been used to represent selected viscosity and thermal conductivity data of 
methane From the dilute gas to the dense liquid. Parameters for the equation wre determined by fitting experimental data. Comprehensive tables of the transport coefficients are presented.

\section{ACKNOWLEDGEMENTS}

We are most grateful for the information given us by many of the authors of the experimental papers. We are also grateful to D. E. Diller, H. M. Roder and J. V. Sengers for comments on the data in the literature. The work was supported in part by the office of Standard Reference Data. 


\section{REFERENCES}

i. Hanley, H. J. M., McCarty, R. D., and Haynes, W. M., J. Phys. Chem. Ref. Data $\underline{3}, 979(1974)$.

2. Hanley, H. J. M., McCarty, R. D., and Haynes, W. H., Cryogenics 15, 413 $(1975)$.

3. Sengers, J. V., in Transport Phenomena - 1973 (AIP, New York) Kestin, J., Ed. (1973) p. 229.

4. Strumpf, H. J., Collings, A. F., and Pings, C. J., J. Chem. Phys. 60, 3109 (1974).

5. McCarty, R. D., Cryogenics 14, 276 (1974).

6. Goodwin, R. D., Nat. Bur. Stand. (U.S.), Tech. Note 653 (1974).

7. Hanley, H. J. M., J. Phys. Chem. Ref. Data 2, 619 (1973).

8. Hanley, H. J. M., and Ely, J. F., J. Phys. Chem. Ref. Data 2, 735 (1973).

9. Ely, J. F., and Hanley, H. J. M., Mol. Phys. 30, 565 (1975).

10. Hanley, H. J. M., and Klein, Max, J. Phys. Chem. 76, 1743 (1972).

11. Hanley, H. J. M., Sengers, J. V., and Ely, J. F., Proc. 14th Int. Conference Therm. Cond. (Pergammon Press, 1976).

12. Haynes, W. M., Physica 70, 410 (1973).

13. Giddings, J. G., Kao, J. T. F., and Kobayash1, R., J. Chem. Phys. 45, 578 (1966).

14. Barua, A. K., Afzal, M., Flynn, G., and Ross, J., J. Chem. Phys. 41, 374 $(1964)$. 
15. Kestin, J., and Leidenfrost, W., Thermodynamics and Transport Properties of Gases, Liquids and Solids, ASME Heat Transfer Division, Publ. by McGrar-Hill, N. Y. (1959), p. 321-38.

16. Boon, J. P., and Thomaes, G., Physica 29, 208 (1963); Boon, J. P., Legros, J. C., and Thomaes, G., Physica 33, 547 (1967).

17. Carmichael, L. T., Berry, V., and Sage, B. H., J. Chem. Eng. Data 10, 57 (1965).

18. Sage, B. H., and Lacey, W., Trans. Am. Inst. Mining. Met. Eng. 127, 118 (1938).

19. Bicher, L., and Katz, D., Ind. Eng. Chem. 35, 754 (1943).

20. Baron, J. D., Roof, J. G., and Wells, F. W., J. Chem. Eng. Data 4, 283 $(1959)$.

21. Ross, J. F., and Brown, G. M., Ind. Eng. Chem. 49, 2026 (1957).

22. Hellemans, J., Zink, H., and Van Paemel, O., Physica 46, 395 (1970); 47, $45(1970)$.

23. Galkov, G. I., and Gerf, S. F., Zhur. Tekh. Fiz. 11, 613 (1941).

24. Gerf, S. F., and Galkov, G. I., Zhur. Tekh. Fiz. 10, 725 (1940).

25. Rudenko, N. S., and Shubnikov, L. N., Physik. Z. Sowjetunion 6 , 470 (1934).

26. Rudenko, N. S., Soviet-Physics-JETP 9, 1078 (1939).

27. Huang, E. T. S., Swift, G. W., and Kurata, F., AIChE J. 12, 932 (1966).

28. Swift, G. W., Lohrenz, J., and Kurata, F., AIChE J. 6, 415 (1960).

29. Carr, N. L., Inst. Gas Tech. Res. Bull. 23 (1953).

30. Comings, E.W., Mayland, R. J., and Egly, R. S., Univ. Illinois, Eug. Exp. Sta. Bull. Serial 354 (1944).

31. Gnezridov, N. E., and Golubev, I. F., Gazov. Prom. 13, 46 (1968).

32. Iwasaki, H., J. Chem. Soc. Japan 62, 918 (1959). 
:3j. Makita, T., J. Chem. Soc. Japan 23, 367 (1959).

34. Pavlovich, N. V. and Timrot, D. L., Teploenergetika 5, 61 (1958).

35. Kuss, E., Z. Agnew. Phys. 4, 203 (1952).

36. Meshcheryakov, N. V., and Golubev, I. F., Trudy GIAP 4 (1954).

37. Timrot, D. L., Serednitskaya, M. A., and Bespalov, M. S., Soviet Physis-Dokl. 20, 107 (1975).

38. Le Neindre, B., "Contribution a I'etude Experimentale de 1a Conductivite Thermique de Quelques Fluides a haute Temperature et a haute Pression," Ph.D. Thesis, Univ. of Paris (1969); Le Neindre,B., Tufeu, R., and Bury, P., Proc. 8th Conf. Thermal Conductivity, Plenum Press, New York, 1969, Eds. Ho, C. Y., et a1., page 75; Le Neindre, B., Int. J. Heat Mass Transfer I5, $1(1972)$.

39. Mani, N., Ph.D. Thesis, University of Calgary (1971).

40. Ikenberry, L., and Rice, S. A., J. Chem. Phys. 39, 1561 (1963).

41. Pavlovich, N. V., Gaz. Prom. 5, (1959).

42. Sokalova, V., and Golubev, I., Tephoenergetika $\underline{4}$ (1967).

43. Lenoir, J., Junk, W., and Comings, E., Cher. Eng. Progr. 49, 539 (1953); Lenoir, J. M., Ph.D. Thesis, Univ. of Illinois (1943); Lenoir, J. M., and Comings, E. W., Chem. Eng. Prog. 47, 223 (1951).

44. Misic, D., and Thodos, G., Physica 32, 885 (1966).

45. Keys, F. G., Trans. Am. Soc. Mech. Eng. 76, 809 (1954); 77, 1395 (1955).

46. Golubev, I. F., Teploenergetika 10, 78 (1963).

47. Carmichael, L. T., Reamer, H. H., and Sage, B. H., J. Chem. Eng. Data 11, $52(1966)$.

48. Borovick, E. S., Manveev, A., and Panina, Y. E., Zhur. Tekh. Fiz. 10, 988 (1940) . 
49. Stoliarov, E. A., Ipatev, V. V., and Teodorovich, V. P., Zhur. Fiz. Khim. 24, $166(1950)$.

50. Golubev, I. F., Viscosity of Gases and Gas Mixtures, Israel Program for Scientific Translations, Jerusalem, 1970. Available from the U. S. Department of Commerce.

51. Zagoruchenko, V. A., and Zhuravlev, A. M., Thermophysical Properties of Gaseous and Liquid Methane, Israel Program for Scientific Translations, Jersulem, 1970. Available from the U. S. Department of Commerce.

52. Vargaftik, N. B., Filippov, L. P., Tarzimanov, A. A., and Yuchak, R. P., Thermal Conductivity of Gases and Liquids (Moscow, 1970).

53. Kestin, J. and Mason, E. A., Reference [3], p 137. 


\section{FIGURE CAPTIONS}

Figure 1. Deviations between experiment and calculation for the viscosity of saturated liquid methane.

Figure 2. Viscosity deviations at several representive temperatures.

Figure 3. Thermal conductivity deviations at low temperature.

Figure 4. Thermal conductivity deviations at representive temperatures above $300 \mathrm{~K}$. 


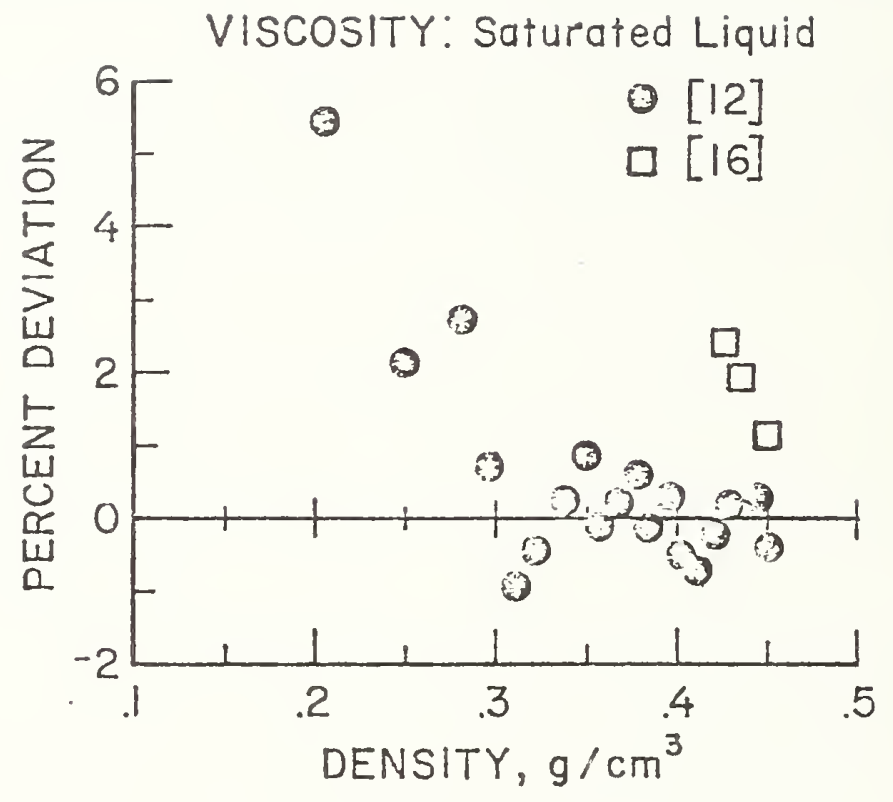

Fig 1 


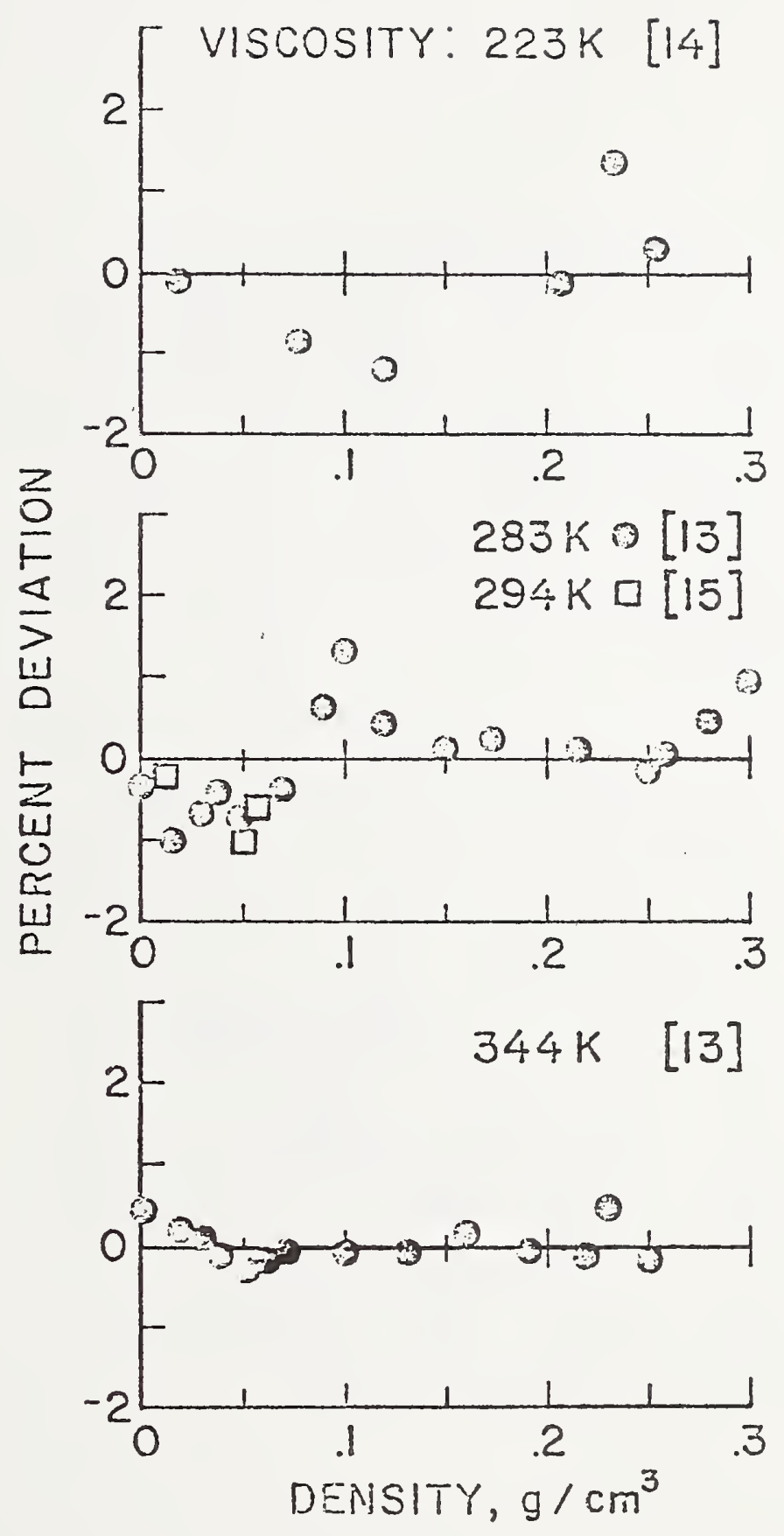

fay 


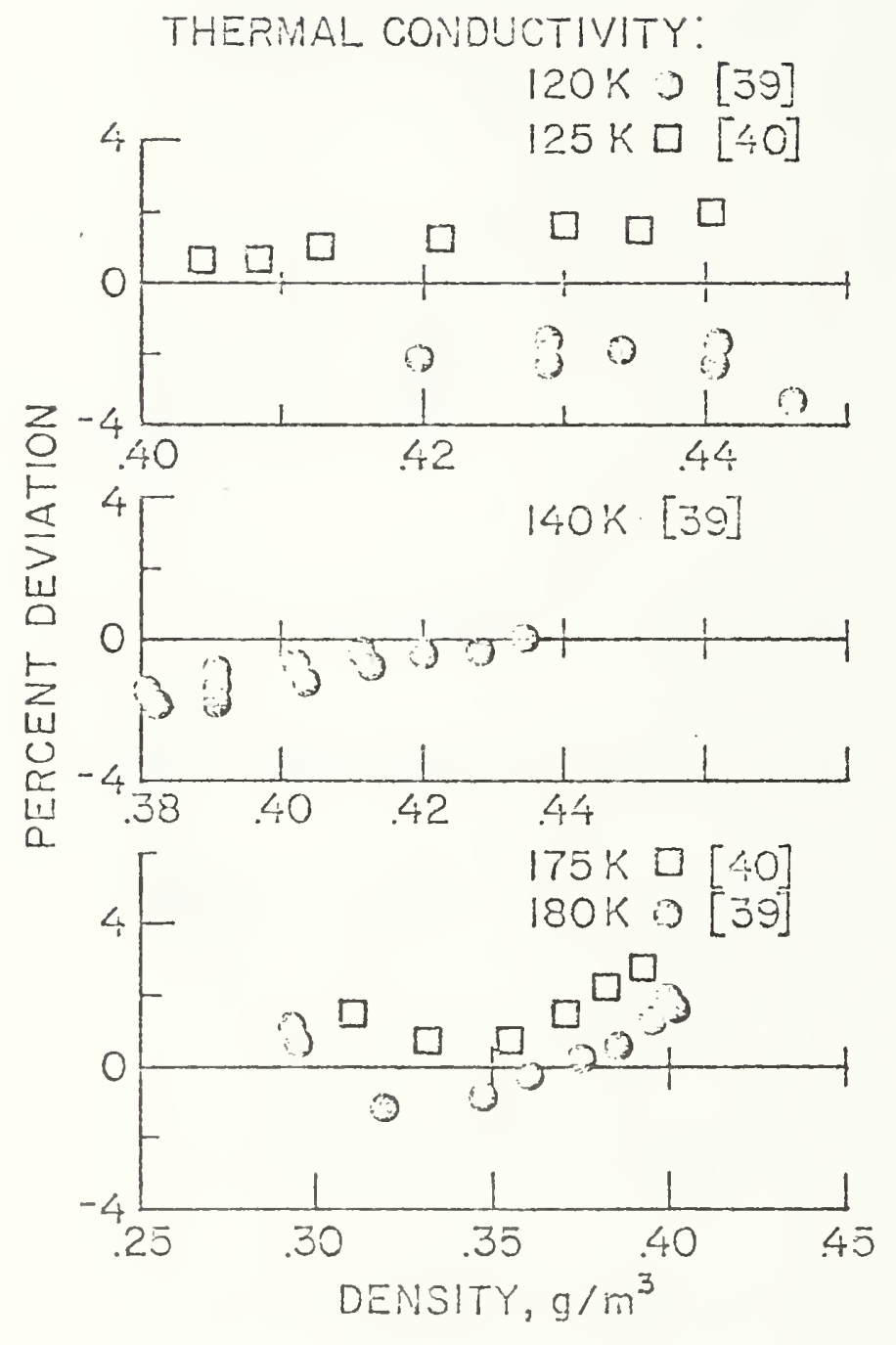




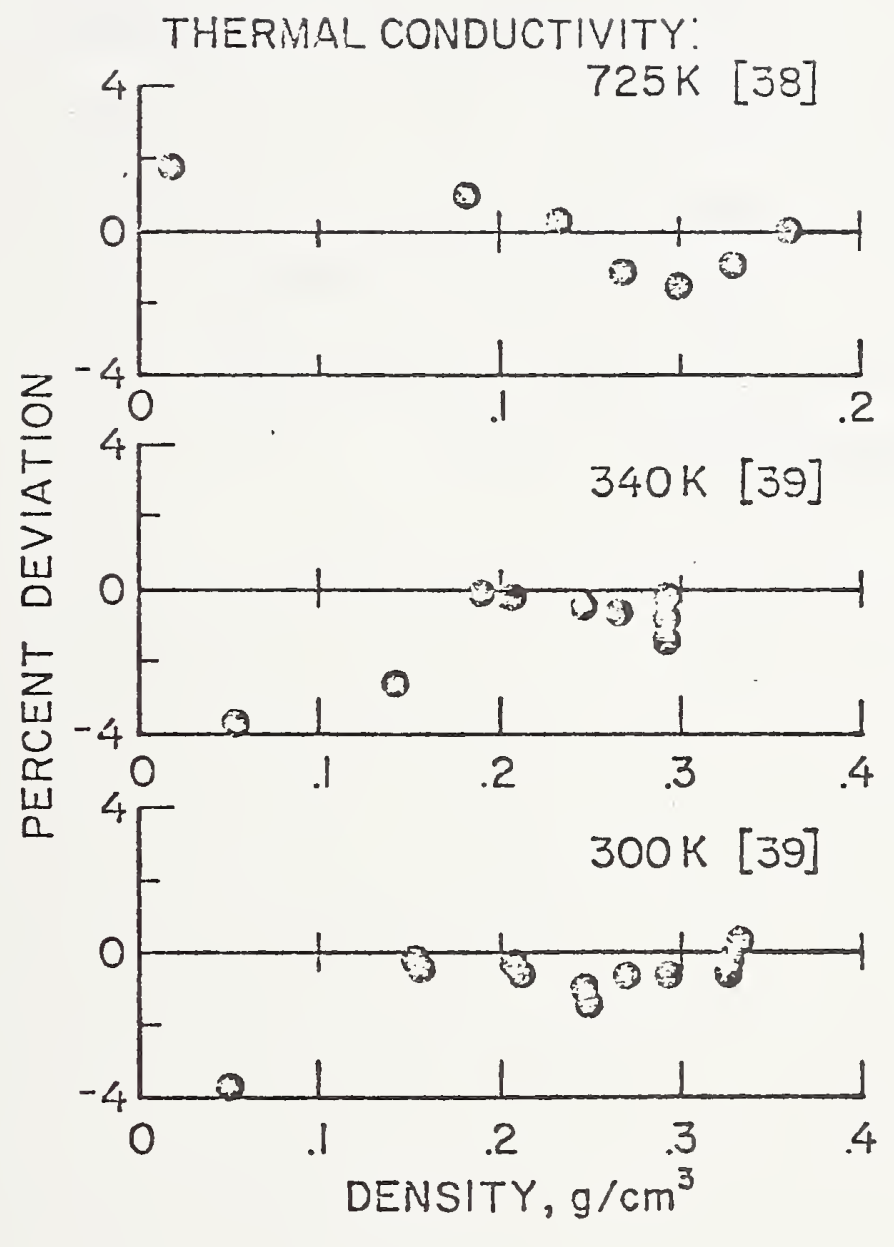

is 4 
TABLE 1. Potential Function Parameters [Equation (7)] and Critical Point Parameters for Nethane

$$
\begin{aligned}
& \mathrm{m}=11 \\
& \gamma^{\prime}=3.0 \\
& \mathrm{r}_{\mathrm{m}}=4.101 \times 10^{-10} \mathrm{~m} \quad\left(\sigma=3.68 \times 10^{-10} \mathrm{~m}\right) \\
& \varepsilon / \mathrm{k}=168.0 \mathrm{~K} \\
& \mathrm{~T}_{\mathrm{C}}=190.55 \mathrm{~K} \\
& \mathrm{P}_{\mathrm{C}}=4.5988 \mathrm{MPa}(45.387 \mathrm{~atm}) \\
& \rho_{\mathrm{c}}=0.1628 \mathrm{~g} / \mathrm{cm}^{3}(10.15 \mathrm{~mole} / \ell) \\
& \text { molecularweight }=16.043
\end{aligned}
$$


TABLE 2. Parameters for the Dilute Gas Equation (8). The units are: Temperature in $K$, viscosity in $\mu g /(\mathrm{cm} \cdot \mathrm{s})$, and thermal conductivity in $\mathrm{mW} /(\mathrm{m} \cdot \mathrm{K})$.

$$
\begin{aligned}
& \text { GV (1) }=-2.090975 \times 10^{5} \\
& \operatorname{GV}(2)=2.647269 \times 10^{5} \\
& \operatorname{GV}(3)=-1.472818 \times 10^{5} \\
& \operatorname{GV}(4)=4.716740 \times 10^{4} \\
& \operatorname{GV}(5)=-9.491872 \times 10^{3} \\
& \operatorname{GV}(6)=1.219979 \times 10^{3} \\
& \operatorname{GV}(7)=-9.627993 \times 10^{1} \\
& \operatorname{GV}(8)=4.274152 \times 10^{-2} \\
& \operatorname{GV}(9)=-8.141531 \times 1 \times 19
\end{aligned}
$$$$
\begin{aligned}
& \operatorname{GT}(1)=-2.147621 \times 10^{5} \\
& \operatorname{GT}(2)=2.190461 \times 10^{5} \\
& \operatorname{GT}(3)=-8.618097 \times 10^{4} \\
& \operatorname{GT}(4)=1.496099 \times 10^{4} \\
& \operatorname{GT}(5)=-4.730660 \times 10^{2} \\
& \operatorname{GT}(6)=-2.331178 \times 10^{2} \\
& \operatorname{GT}(7)=3.778439 \times 10^{1} \\
& \operatorname{GT}(8)=-2.320481 \times 10^{-2} \\
& \operatorname{GT}(9)=5.311764 \times 19
\end{aligned}
$$ 
Authors

Viscosity

Haynes [12]

Giddings, et a1. [13]

Barua, et al. [14]

Kestin and Leidenfrost

[15]

Boon and Thomaes [16]

\section{Thermal conductivity}

Le Neindre [38]

Mani [39]

Ikenberry and Rice [40]
Approxinate

experimental range

Saturated liquid 95-190 K

283-410 K

Pressures to $54 \mathrm{MPa}$

$223-423 \mathrm{~K}$

Pressures to $17 \mathrm{MPa}$

$2296 \mathrm{~K}$

Pressures to $15 \mathrm{MPa}$

Saturated Iiquid 91-114 K

298-723 K

Pressures to $100 \mathrm{MPa}$

$139-400 \mathrm{~K} \cdot$

Pressures to $60 \mathrm{MPa}$

98-235 K

Pressures to $50 \mathrm{MPa}$
Estimated

accuracy $\pm \%$

$2 \%$

$2 \%$

$1 \%$

$3 \%$

$4 \%$

$3.5 \%$

$5 \%$ 
TABLE 4. Parameters for Equations (3) - (5). The units are: Density in $\mathrm{g} / \mathrm{cm}^{3}$, temperature in $\mathrm{k}$, viscosity in $\mu \mathrm{g} /\left(\mathrm{cm}^{\cdot} \mathrm{s}\right)$, thermal conductivity in $\mathrm{m} \cdot \mathrm{N} /(\mathrm{m} \cdot \mathrm{K})$.

Viscosity

Equation (3)

$\begin{array}{lll}\mathrm{A} & = & 1.696985927 \\ \mathrm{~B} & = & -0.133372346 \\ \mathrm{C} & = & 1.4 \\ \mathrm{~F} & = & 168.0 \\ \mathrm{E} & = & 1.0 \\ j_{1} & = & -1.035060586 \times 10^{1} \\ j_{2} & = & 1.7571599671 \times 10^{1} \\ j_{3} & = & -3.0193918656 \times 10^{3} \\ j_{4} & = & 1.8873011594 \times 10^{2} \\ j_{5} & = & 4.2903609488 \times 10^{-2} \\ j_{6} & = & 1.4529023444 \times 10^{2} \\ j_{7} & = & 6.1276818706 \times 10^{3}\end{array}$

Thermal conductivity

Equation (4)

$\begin{array}{rlr}\mathrm{A} & = & -0.25276292 \\ \mathrm{~B} & = & 0.33432859 \\ \mathrm{C} & = & 1.12 \\ \mathrm{~F} & = & 168.0\end{array}$

Equation (5)

$\mathrm{D}=1.0$

$\mathrm{k}_{1}=-7.0403639907$

$\mathrm{k}_{2}=12.319512908$

$k_{3}=-8.8525979933 \times 10^{2}$

$\mathrm{k}_{4}=72.835897919$

$k_{5}=0.74421462902$

$k_{6}=-2.9706914540$

$\mathrm{k}_{7}=2.2209758501 \times 10^{3}$ 
;

TABLE 5. Tabulated values for the viscosity coefficient of methane. The units for the viscosity are $\mu \mathrm{g} /(\mathrm{cm} \cdot \mathrm{s})$.

TABLE 6. Tabulated values for the thermal conductivity coefficient of methane. The units are $\mathrm{mW} /(\mathrm{m} \cdot \mathrm{K})$. 
$\because$ แ

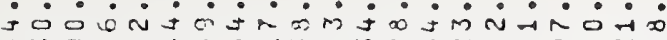
$\rightarrow$ W $⿴ 囗 十 丁$ J

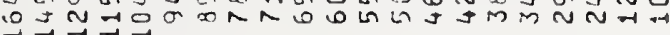

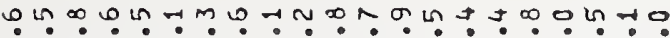

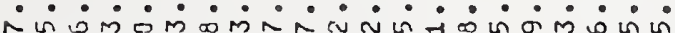
NMR $=M m+人 0$ J

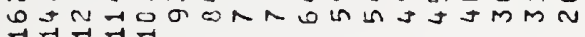

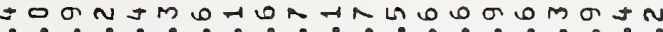

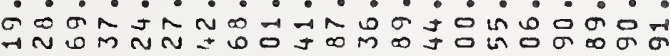

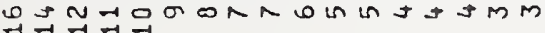

N $-\dot{0} \cdot \dot{0} \dot{0} \dot{0} \dot{0} \dot{0} \dot{0} \dot{0} \dot{0} \cdot$ $\exists \tilde{N}$ 品

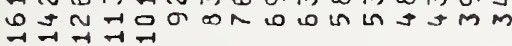

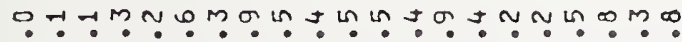

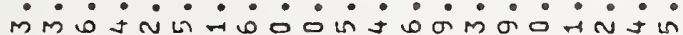

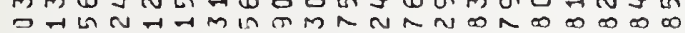

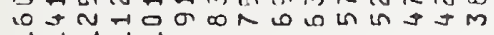

$a^{n}$

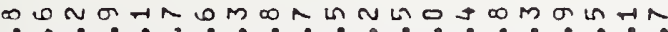

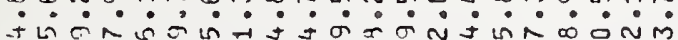
á,

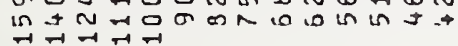

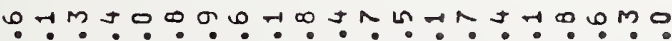

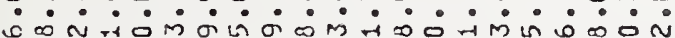

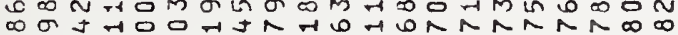

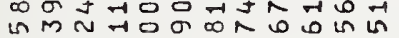

$\lim _{-1} \rightarrow-1$

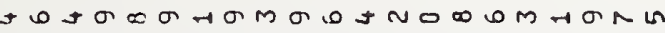

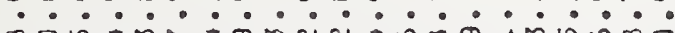

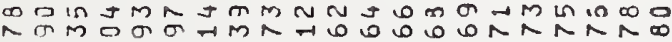

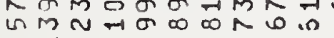

$\rightarrow \rightarrow \rightarrow$

$m N=$ IN口M$\dot{0} \dot{0} \dot{0} \dot{0} \dot{0} \dot{0} \dot{0} \dot{0} \dot{0} \dot{0} \dot{0}$

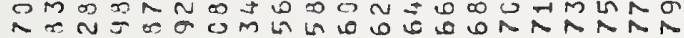

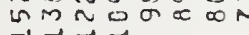

$\rightarrow \rightarrow \rightarrow-1$

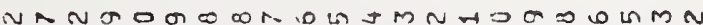

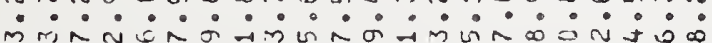
o. in $\lim _{\rightarrow \rightarrow 1} \operatorname{man}^{-1}$

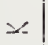

Loinolnow

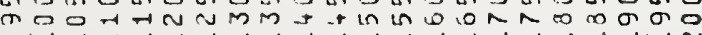

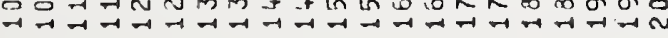


Horom

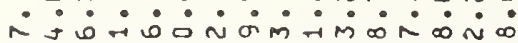

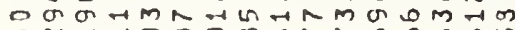

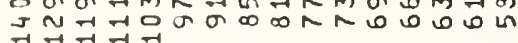

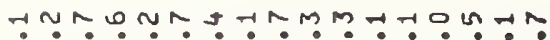

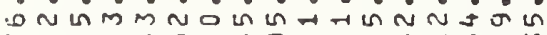

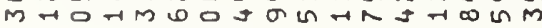
Jn

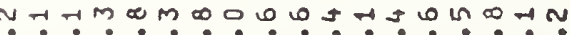

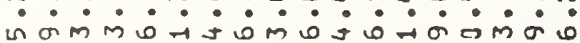
ம NHAN

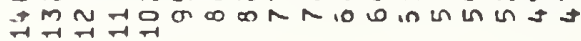

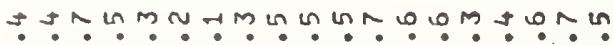

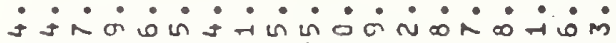
a

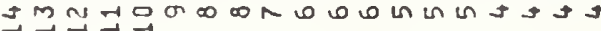

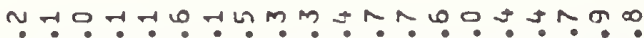
í

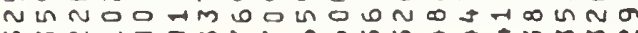
um

? ๆ ᄂ

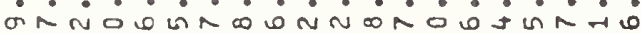

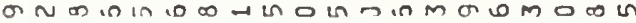

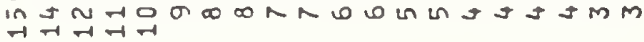

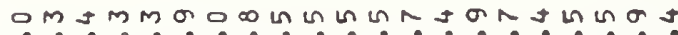

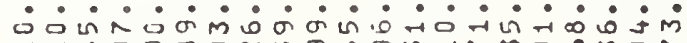

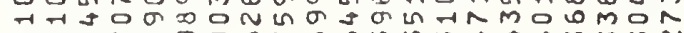

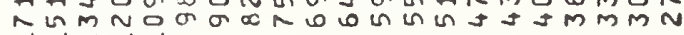

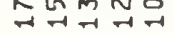

แnmR $\dot{0} \dot{0} \dot{0} \dot{0} \dot{0} \dot{0} \dot{0} \dot{0} \dot{0} \dot{0} \dot{0}$ mañ 0 I $m$ न नन न न

0 $\dot{0} \dot{0} \dot{0} \dot{0} \dot{0} \dot{0} \dot{0} \dot{0} \dot{0} \dot{0} \dot{0}$

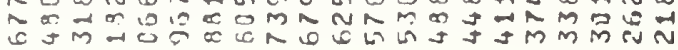
$\rightarrow-1 \rightarrow-1$

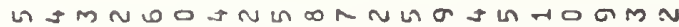
$\dot{0} \dot{0} \dot{0} \dot{0} \dot{0} \dot{0} \dot{0} \dot{0} \dot{0} \dot{0}$

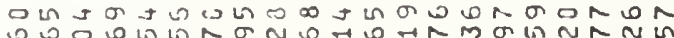
ڤัง $\rightarrow \rightarrow \rightarrow \rightarrow$

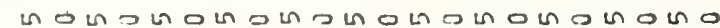
का म 
1 य

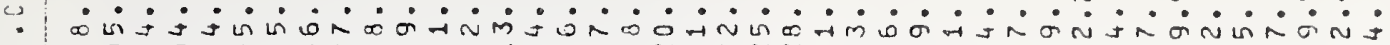

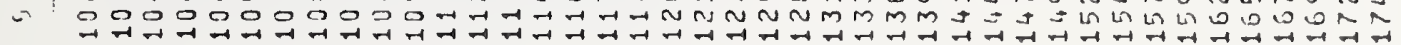

$\stackrel{0}{=}$

in

$\dot{m}$

$\circ$

$\dot{m}$

ᄂ?

n

$\frac{\pi}{\Sigma}$

$a^{\circ}$

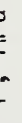

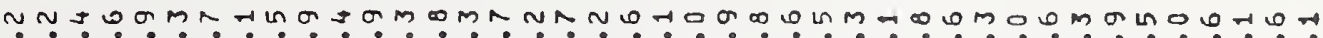
$\dot{\sim} \dot{0} \dot{0} \dot{0} \dot{0} \dot{0} \dot{0} \dot{0} \dot{0} \dot{0} \dot{0} \dot{0} \dot{0} \dot{0} \dot{0} \dot{0} \dot{0} \dot{0} \dot{0} \dot{0} \dot{0} \dot{0} \dot{0} \dot{0}$ б̆

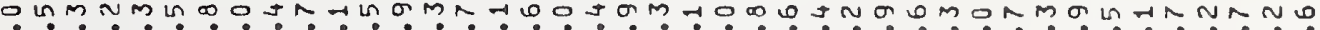

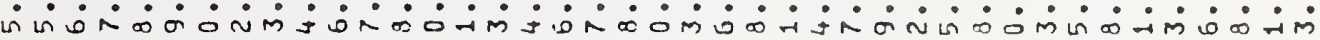
क व

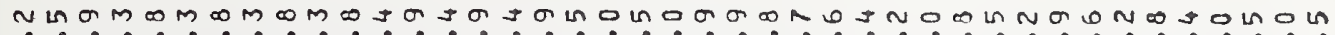

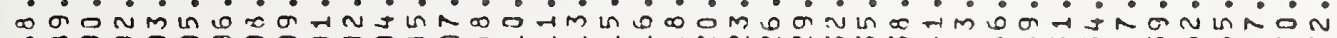

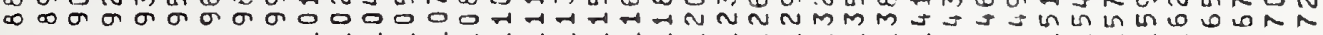

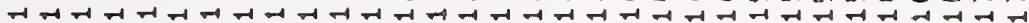

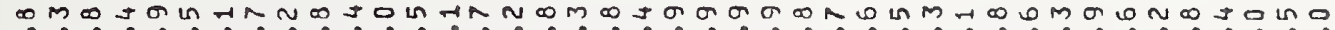

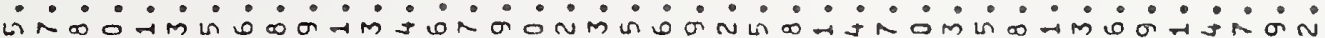
Ln

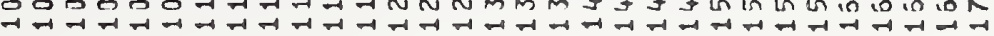

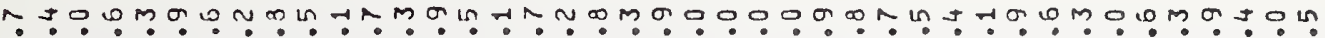

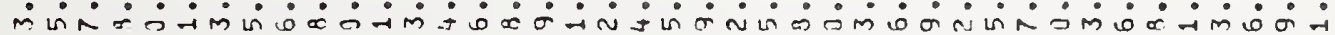

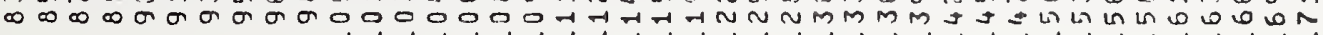

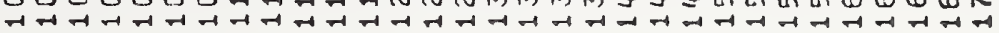

on J H $\dot{i} \dot{1} \dot{0} \dot{0} \dot{0} \dot{0} \dot{0} \dot{0} \dot{0} \dot{0} \dot{0} \dot{0} \dot{0} \dot{0} \dot{0} \dot{0} \dot{0} \dot{0} \dot{0} \dot{0} \dot{0} \dot{0} \dot{0} \dot{0}$

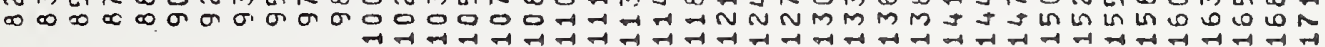

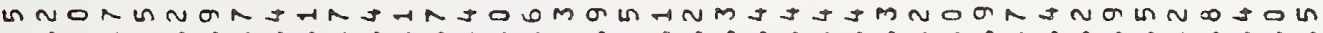
$\omega_{n} \rightarrow \dot{0} \dot{0} \dot{0} \dot{\sigma} \dot{0} \dot{0} \dot{0} \dot{0} \dot{0} \dot{0} \dot{0} \dot{0} \dot{0} \dot{0} \dot{0} \dot{0} \dot{0} \dot{0} \dot{0} \dot{0}$

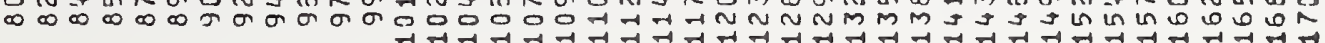

NONLM $\dot{0} \dot{0} \dot{0} \dot{0} \dot{0} \dot{0} \dot{0} \dot{0} \dot{0} \dot{0} \dot{0} \dot{0} \dot{0} \dot{0} \dot{0} \dot{0} \dot{0} \dot{0} \dot{0} \dot{0} \dot{0} \dot{0}$

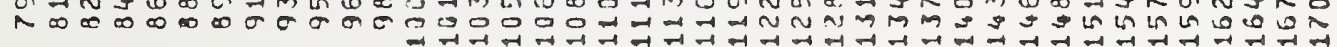

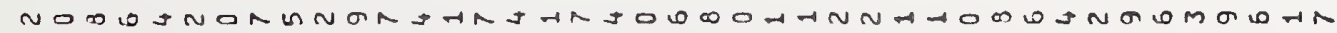

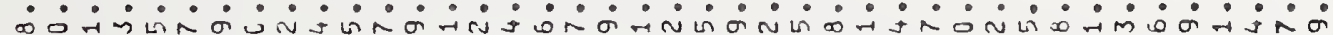

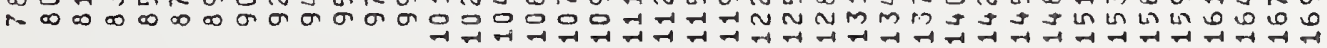

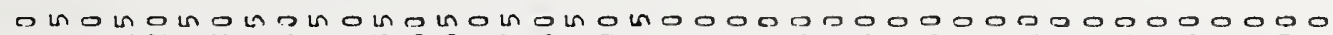

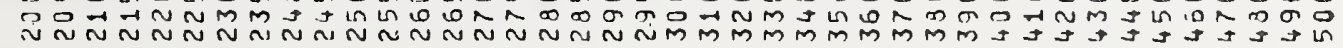




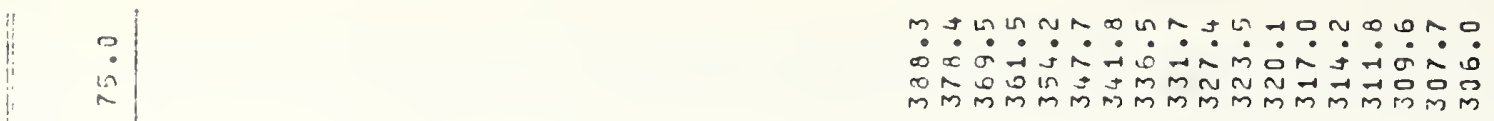

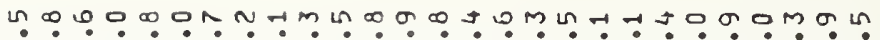

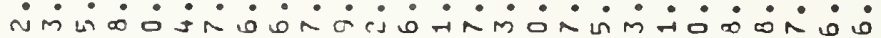

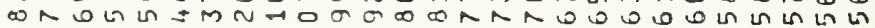

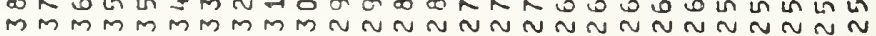

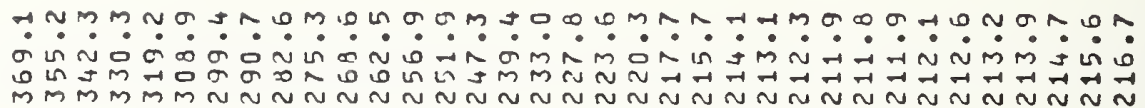

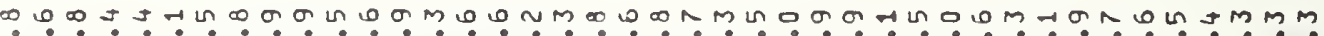

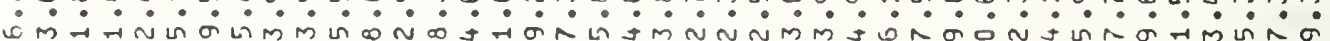

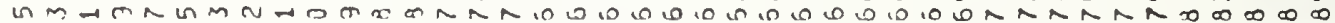

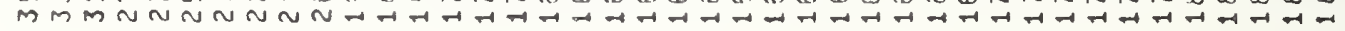

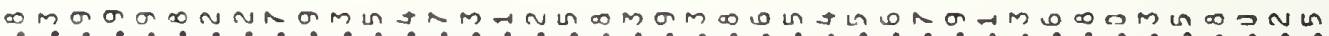

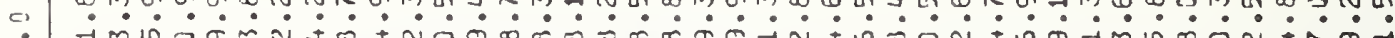

$\therefore$ ăm

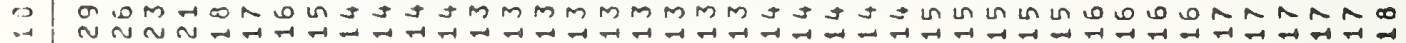

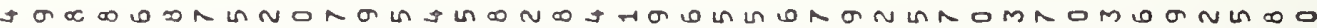

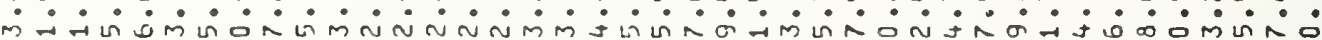

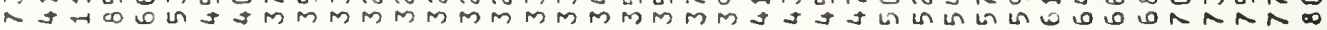

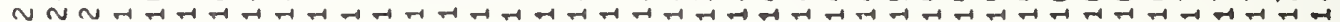

U

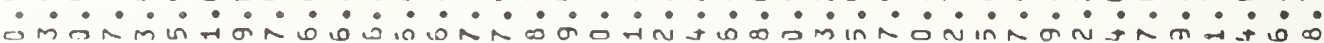

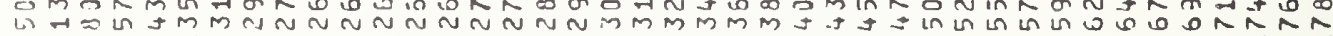

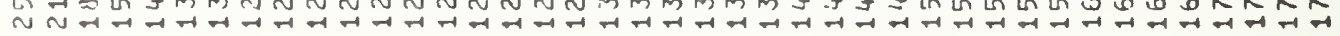

HWO ? $\dot{0} \dot{0} \dot{0} \dot{0} \dot{0} \dot{-} \dot{0} \dot{0} \dot{0} \dot{0} \dot{0} \dot{0} \dot{0} \dot{0} \dot{0} \dot{0} \dot{0} \dot{0}$ $\therefore$ l

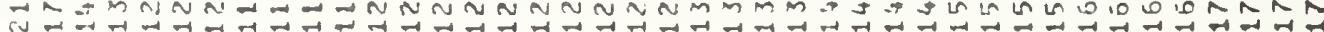

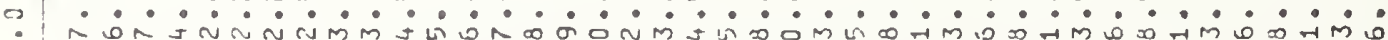

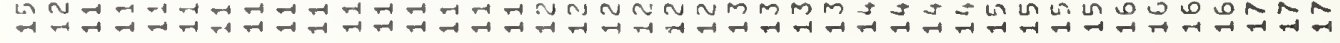

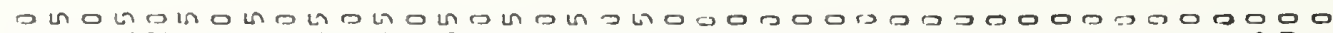
虽 


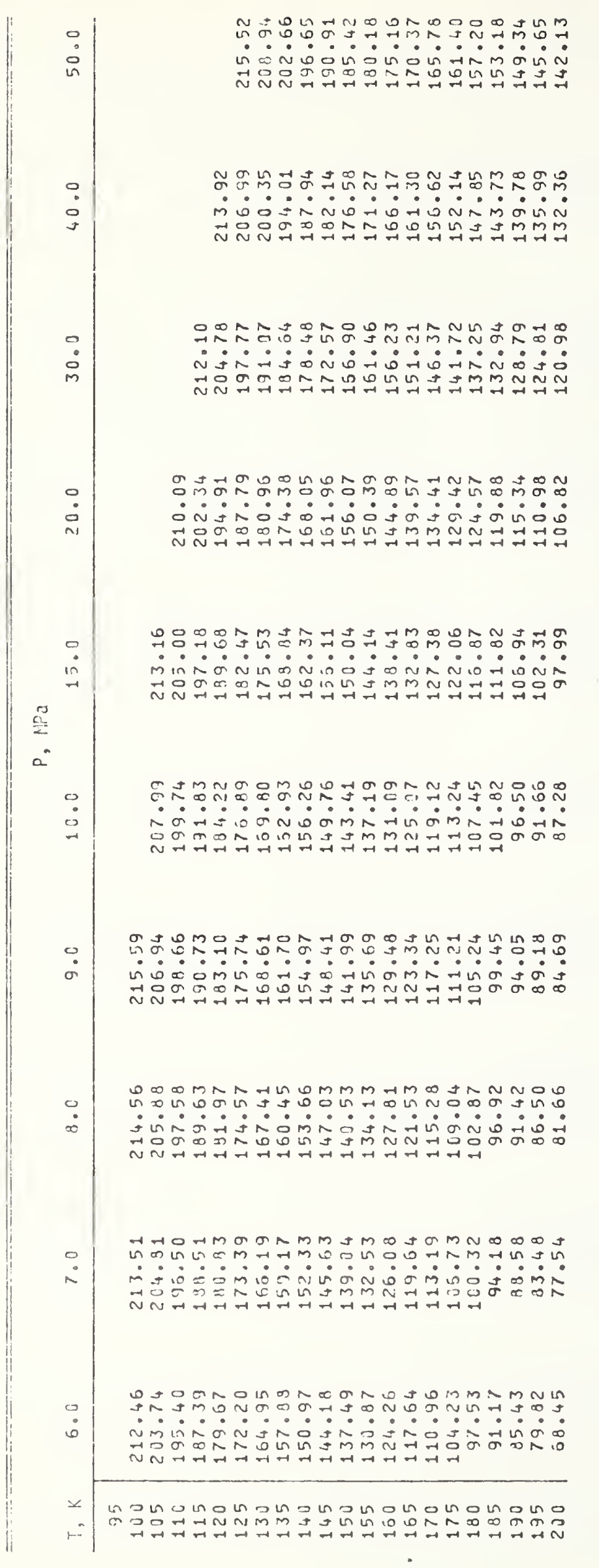


1. $\quad$ t t g t

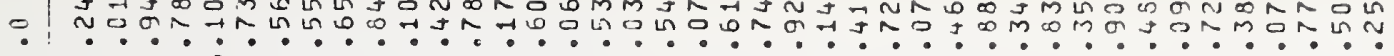

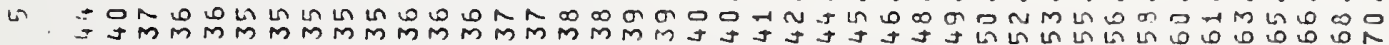

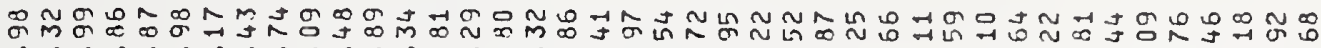

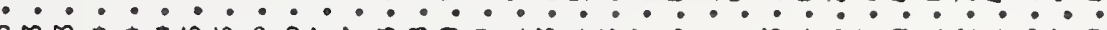

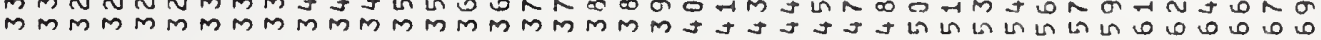

mヘ̃

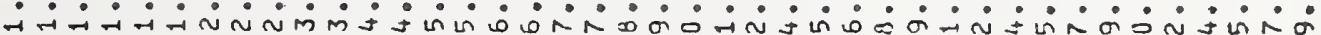

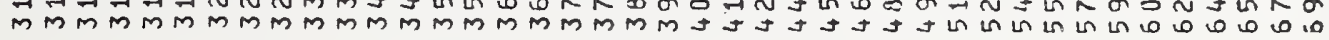

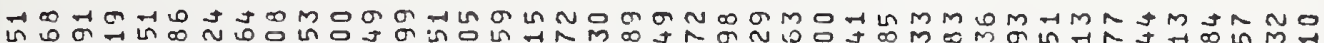

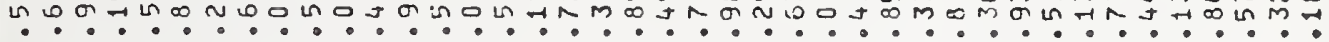

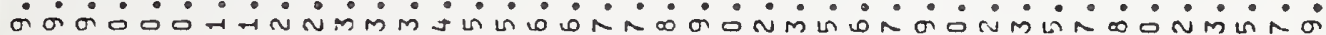
N

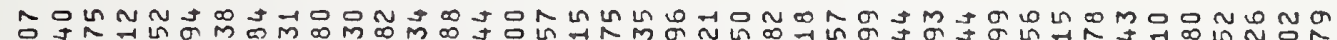

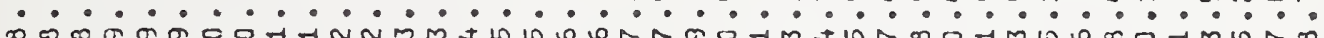

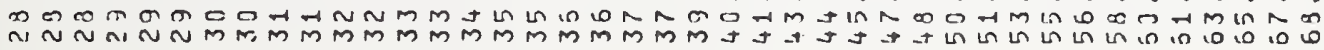

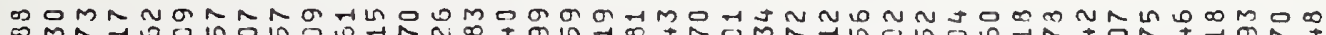
• ?

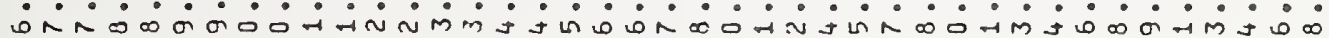

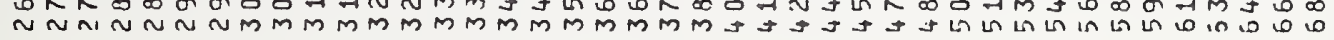

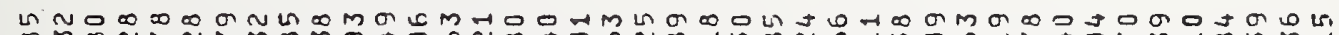

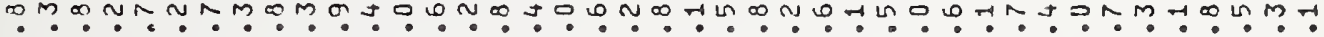

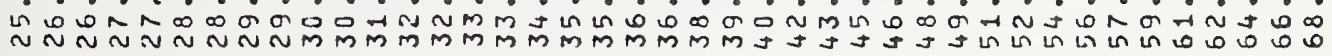

क $\infty m \sigma J \sigma J 0$ J

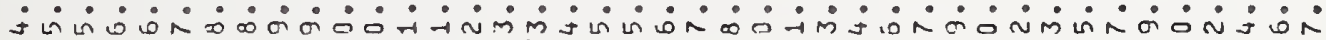

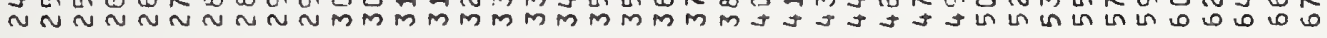

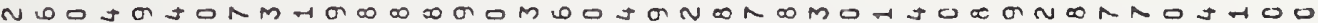
O.t

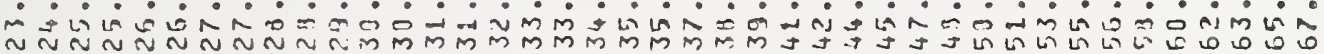

HiDNmLnO

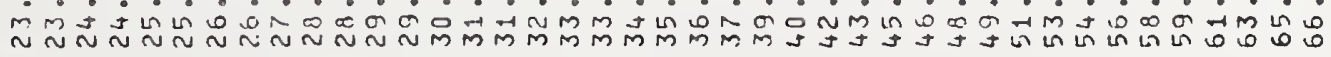

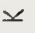

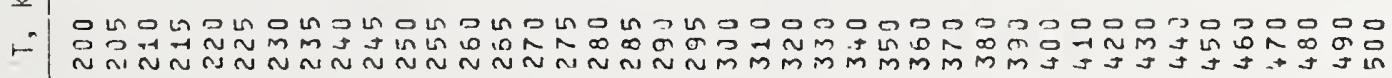




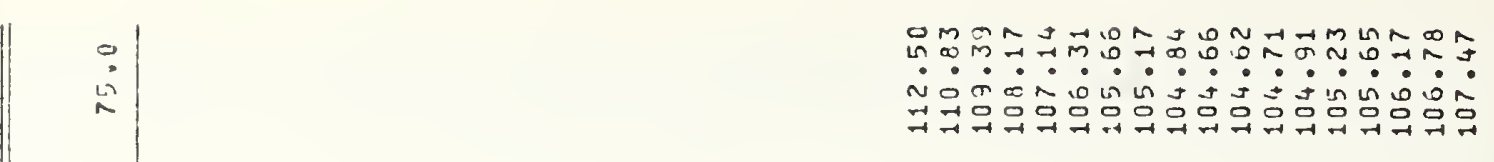

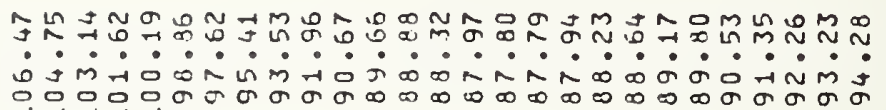

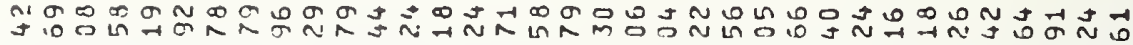

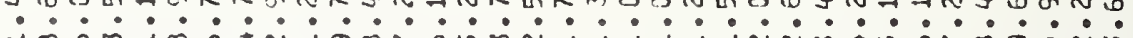

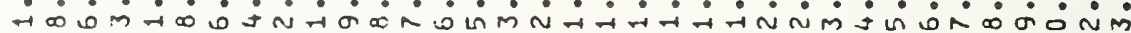

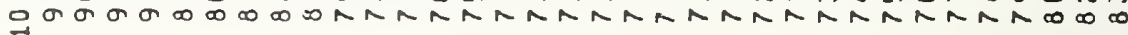

$\stackrel{1}{\Sigma}$

:

$\dot{0}$

$a^{-}$

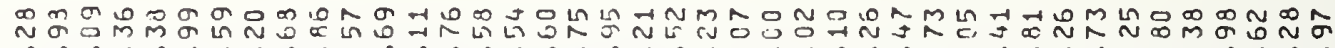

$\sim \sim \dot{\sim} \dot{\sim} \dot{0} \dot{0} \dot{0} \dot{0} \dot{0} \dot{0} \dot{0} \dot{0} \dot{0} \dot{0} \dot{0} \dot{0} \dot{0} \dot{\sim} \dot{0} \dot{0} \dot{0} \dot{0} \dot{0} \dot{0} \dot{0} \dot{0} \dot{0}$

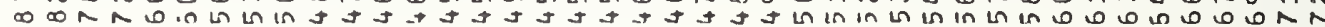

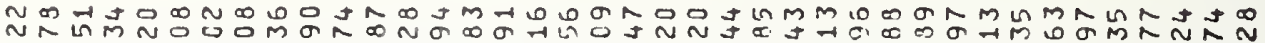
$\dot{0} \dot{0} \dot{0} \dot{0} \dot{-} \dot{0} \dot{0} \dot{0} \dot{0} \dot{0} \dot{0} \dot{0} \dot{0} \dot{0} \dot{0} \dot{0} \dot{0} \dot{0} \dot{0} \dot{0} \dot{0} \dot{0}$

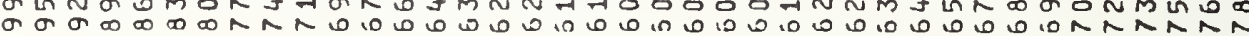

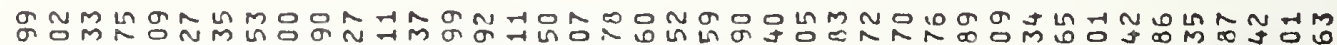

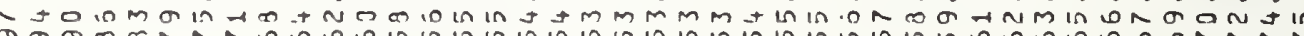

G UN

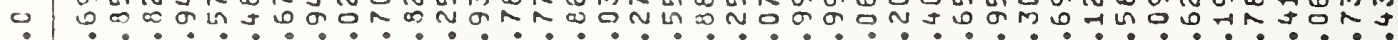

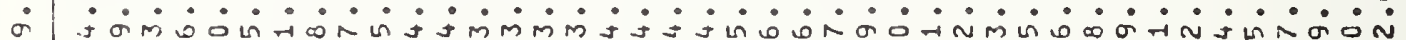

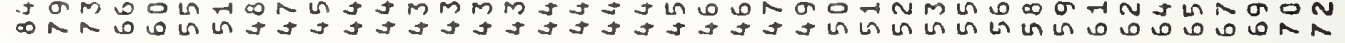

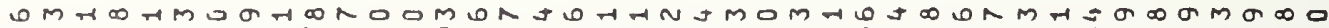
ט.

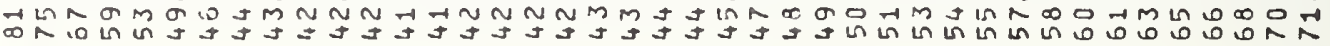

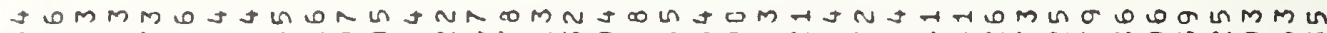
o

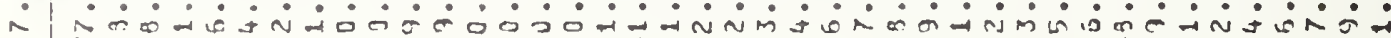

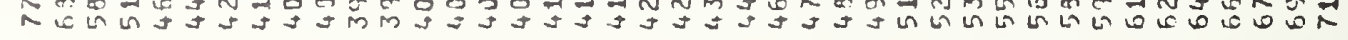

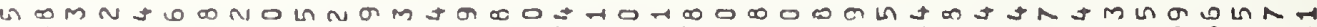
Jง d M N N O

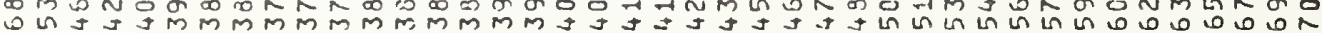

$x$

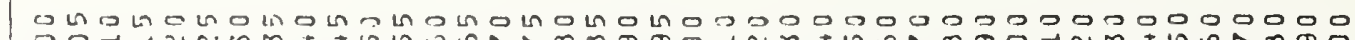

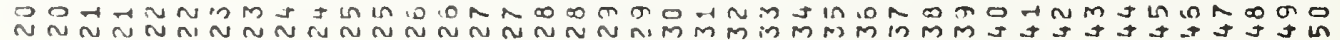


TABLE 7. Transport Coefficients of Saturated Liquid Mathane

\begin{tabular}{|c|c|c|c|}
\hline $\begin{array}{l}\text { Tesperature, } \\
\mathrm{k}\end{array}$ & $\begin{array}{l}\text { Density, } \\
\text { mol/l }\end{array}$ & $\begin{array}{l}\text { Viscosity, } \\
\mu g /(\mathrm{cm} \cdot \mathrm{s})\end{array}$ & $\begin{array}{l}\text { conductivity } \\
\mathrm{m} v /(\mathrm{m} \cdot \mathrm{K})\end{array}$ \\
\hline 95 & 27.789 & 1792 & 215 \\
\hline 100 & 27.367 & 1563 & 206 \\
\hline 105 & 26.934 & 1377 & 197 \\
\hline 110 & 26.491 & 1223 & 189 \\
\hline 115 & 26.035 & 1094 & 181 \\
\hline 120 & 25.566 & 984 & 173 \\
\hline 125 & 25.081 & 889 & 165 \\
\hline 130 & 24.578 & 807 & 158 \\
\hline 135 & 24.055 & 734 & 150 \\
\hline 140 & 23.508 & 669 & 143 \\
\hline 145 & 22.932 & 611 & 136 \\
\hline 150 & 22.322 & 558 & 129 \\
\hline 155 & 21.672 & 509 & 122 \\
\hline 160 & 20.971 & 464 & 115 \\
\hline 165 & 20.206 & 421 & 108 \\
\hline 170 & 19.356 & 380 & 101 \\
\hline 175 & 18.386 & 340 & 94 \\
\hline 180 & 17.226 & 300 & 88 \\
\hline 185 & 15.690 & 256 & 84 \\
\hline 190 & 12.485 & 187 & 89 \\
\hline
\end{tabular}


APPENDIX

METHANE EQUATION OF STATE

The equation of state used in the work is that reported by McCarty in reference [5]. The form of the equation, and its parameters are reproduced in this appendix.

The equation of state is given by the following functional form:

$$
\begin{aligned}
\mathrm{P}=\rho \mathrm{RT} & +\rho^{2}\left(\mathrm{~N}_{1} \mathrm{~T}+\mathrm{N}_{2} \mathrm{~T}^{1 / 2}+\mathrm{N}_{3}+\mathrm{N}_{4} / \mathrm{T}+\mathrm{N}_{5} / \mathrm{T}^{2}\right) \\
& +\rho^{3}\left(\mathrm{~N}_{6} \mathrm{~T}+\mathrm{N}_{7}+\mathrm{N}_{8} / \mathrm{T}+\mathrm{N}_{9} / \mathrm{T}^{2}\right) \\
& +\rho^{4}\left(\mathrm{~N}_{10} \mathrm{~T}+\mathrm{N}_{11}+\mathrm{N}_{12} / \mathrm{T}\right)+\rho^{5}\left(\mathrm{~N}_{13}\right) \\
& +\rho^{6}\left(\mathrm{~N}_{14} / \mathrm{T}+\mathrm{N}_{15} / \mathrm{T}^{2}\right)+\rho^{7}\left(\mathrm{~N}_{16} / \mathrm{T}\right) \\
& +\rho^{8}\left(\mathrm{~N}_{17} / \mathrm{T}+\mathrm{N}_{18} / \mathrm{T}^{2}\right)+\rho^{9}\left(\mathrm{~N}_{19} / \mathrm{T}^{2}\right) \\
& +\rho^{3}\left(\mathrm{~N}_{20} / \mathrm{T}^{2}+\mathrm{N}_{21} / \mathrm{T}^{3}\right) \exp \left(-\gamma \rho^{2}\right) \\
& +\rho^{5}\left(\mathrm{~N}_{22} / \mathrm{T}^{2}+\mathrm{N}_{23} / \mathrm{T}^{4}\right) \exp \left(-\gamma \rho^{2}\right) \\
& +\rho^{7}\left(\mathrm{~N}_{24} / \mathrm{T}^{2}+\mathrm{N}_{25} / \mathrm{T}^{3}\right) \exp \left(-\gamma \rho^{2}\right) \\
& +\rho^{9}\left(\mathrm{~N}_{26} / \mathrm{T}^{2}+\mathrm{N}_{27} / \mathrm{T}^{4}\right) \exp \left(-\gamma \rho^{2}\right) \\
& +\rho^{11}\left(\mathrm{~N}_{28} / \mathrm{T}^{2}+\mathrm{N}_{29} / \mathrm{T}^{3}\right) \exp \left(-\gamma \rho^{2}\right) \\
& +\rho^{13}\left(\mathrm{~N}_{30} / \mathrm{T}^{2}+\mathrm{N}_{31} / \mathrm{T}^{3}+\mathrm{N}_{32} / \mathrm{T}^{4}\right) \exp \left(-\gamma \rho^{2}\right)
\end{aligned}
$$

where, to be consistent with reference [5], $\mathrm{P}$ is in atmospheres, $\rho$ is in $\mathrm{mol} / \ell$, and $\mathrm{T}$ is in kelvins. 
The coefficients $\left(N_{j}, \gamma\right.$ and $R$ ) are

$$
\begin{aligned}
& \mathrm{N}_{1}=-1.8439-86666 \times 10^{-2} \\
& \mathrm{~N}_{2}=1.0510152064 \\
& N_{3}=-1.6057820303 \times 10 \\
& \mathrm{~N}_{4}=8.4844027562 \times 10^{2} \\
& \mathrm{~N}_{5}=-4.2738 .09106 \times 10^{4} \\
& \mathrm{~N}_{6}=7.6565285254 \times 10^{-4} \\
& \mathrm{~N}_{7}=-4.8360724197 \times 10^{-1} \\
& \mathrm{~N}_{8}=8.5195 \div 3835 \times 10 \\
& \mathrm{~N}_{9}=-1.6607 \div 34721 \times 10^{4} \\
& \mathrm{~N}_{10}=-3.7521074532 \times 10^{-5} \\
& \mathrm{~N}_{11}=2.8616309259 \times 10^{-2} \\
& \mathrm{~N}_{\text {]2 }}=-2.8685285973 \\
& \mathrm{~N}_{13}=1.1906973942 \times 10^{-4} \\
& \mathrm{~N}_{14}=-8.5315 \text { i15699 } \times 10^{-3} \\
& \mathrm{~N}_{15}=3.8365063841 \\
& \mathrm{~N}_{16}=2.4986828379 \times 10^{-5} \\
& \mathrm{~N}_{17}=5.7974531455 \times 10^{-6} \\
& \mathrm{~N}_{18}=-7.1648329297 \times 10^{-3} \\
& \mathrm{~N}_{19}^{18}=1.2577353784 \times 10^{-4} \\
& \mathrm{~N}_{20}=2.2240102466 \times 10^{4} \\
& \mathrm{~N}_{21}=-1.4800512328 \times 10^{6} \\
& \mathrm{~N}_{22}=5.0498054887 \times 10 \\
& \mathrm{~N}_{23}=1.6428375992 \times 10^{6} \\
& \mathrm{~N}_{24}=2.1325337196 \times 10^{-1} \\
& \mathrm{~N}_{25}=3.7791273422 \times 10 \\
& \mathrm{~N}_{26}=-1.1857016815 \times 10^{-5} \\
& \mathrm{~N}_{27}=-3.1630780767 \times 10 \\
& \mathrm{~N}_{28}=-4.100579294 \mathrm{I} \times 10^{-6} \\
& \mathrm{~N}_{29}=1.48700 \div 3284 \times 10^{-3} \\
& \mathrm{~N}_{30}=3.1512251532 \times 10^{-9} \\
& \mathrm{~N}_{31}=-2.1670 .74745 \times 10^{-6} \\
& \mathrm{~N}_{32}=2.4000551079 \times 10^{-5} \\
& \gamma=-0.0095 \\
& \mathrm{R}=0.08205616
\end{aligned}
$$





\title{
Prediction of the viscosity and thermal conductivity coefficients of mixtures
}

\author{
H.J.M. Hanley
}

The task of measuring the transport properties for all mixtures of possible practical interest is out of the question, even for simple fluids. Any method, then, which could predict the properties to within the experimental error would be both interesting and useful. Unfortunately, the lack of suitable data, on the one hand, and the theoretical problems that can be encountered in the study of transport phenomena in general, on the other hand, are obstacles which have only been overcome for special cases.

Similar problems come up when one considers the thermodynamic (or PVT) properties of mixtures. In this case, however, the principle of corresponding states has been used widely as a prediction tool and, in particular, the principle has been extended systematically to multicomponent mixtures of polyatomic molecules. It is thus logical to investigate how the corresponding states approach can be broadened to include transport properties and the object of this paper is to do this. Specifically, we discuss an ad hoc procedure, based on the principle of corresponding states, to predict the viscosity coefficient $(\eta)$ and the thermal conductivity coefficient $(\lambda)$ of fluid mixtures given thermodynamic data. We will show that the procedure appears to work (data for comparison are scarce) for a variety of mixtures over a wide range of experimental conditions.

\section{Background}

Some introductory material is summarized in this section.

\section{Simple two-parameter corresponding states}

The basic criterion for two pure fluids to obey the principle of corresponding states, or to 'conform' or 'correspond' is that a given intermolecular potential form, such as

$$
\phi=\epsilon f\left(\frac{r}{\sigma}\right)
$$

The author is with the National Bureau of Standards, Cryogenics Division, Boulder, Colorado 80302, USA. Received 7 July 1976. (where $r$ is the intermolecular separation) is appropriate for both. Each fluid can thus be characterized by an energy parameter, $\epsilon$, and a distance parameter, $\sigma$. If the two fluids do correspond, then the transport coefficients of the one fluid, $\alpha$, at a particular temperature $(T)$ and density $(\rho)$ can be expressed in terms of the coefficients of the other fluid, o. For example, for the viscosity and thermal conductivity coefficients we have ${ }^{1}$

$$
\eta_{\alpha}[\rho, T]=\eta_{0}\left[\rho\left(\frac{\sigma_{\alpha}}{\sigma_{0}}\right)^{3}, T\left(\frac{\epsilon_{0}}{\epsilon_{\alpha}}\right)\right]\left(\frac{M_{\alpha}}{M_{0}}\right)^{1 / 2}\left(\frac{\sigma_{0}}{\sigma_{\alpha}}\right)^{2}\left(\frac{\epsilon_{\alpha}}{\epsilon_{0}}\right)^{1 / 2}
$$

and

$$
\lambda_{\alpha}[\rho, T]=\lambda_{0}\left[\rho\left(\frac{\sigma_{\alpha}}{\sigma_{0}}\right)^{3}, T\left(\frac{\epsilon_{0}}{\epsilon_{\alpha}}\right)\right]\left(\frac{M_{0}}{M_{\alpha}}\right)^{1 / 2}\left(\frac{\alpha_{0}}{\sigma_{\alpha}}\right)^{2}\left(\frac{\epsilon_{\alpha}}{\epsilon_{0}}\right)^{1 / 2}
$$

The coefficients, $\eta_{0}$ and $\lambda_{0}$, which can be taken as reference values, have to be evaluated at the proper density and temperature as indicated. $M$ is the molecular weight.

Since one can write $T^{\mathrm{c}} \sim \epsilon / k, \rho^{\mathrm{c}} \sim \sigma^{-3}$, where the superscript, $c$, refers to the critical point value and $k$ is Boltzmann's constant, alternative expressions for $\eta_{\alpha}$ and $\lambda_{\alpha}$ are

$$
\begin{aligned}
& \eta_{\alpha}(\rho, T)=\eta_{0}\left[\rho\left(\frac{\rho_{0}^{c}}{\rho_{\alpha}^{c}}\right), T\left(\frac{T_{0}^{c}}{T_{\alpha}^{c}}\right)\right]\left(\frac{M_{\alpha}}{M_{0}}\right)^{1 / 2}\left(\frac{\rho_{\alpha}^{c}}{\rho_{0}^{c}}\right)^{3 / 3}\left(\frac{T_{\alpha}^{\mathrm{c}}}{T_{0}^{\mathrm{c}}}\right)^{1 / 2} \\
& \lambda_{\alpha}(\rho, T)=\lambda_{0}\left[\rho\left(\frac{\rho_{0}^{\mathrm{c}}}{\rho_{\alpha}^{\mathrm{c}}}\right), T\left(\frac{T_{0}^{\mathrm{c}}}{T_{\alpha}^{\mathrm{c}}}\right)\right]\left(\frac{M_{0}}{M_{\alpha}}\right)^{1 / 2}\left(\frac{\rho_{\alpha}^{\mathrm{c}}}{\rho_{0}^{\mathrm{c}}}\right)^{2 / 3}\left(\frac{T_{\alpha}^{\mathrm{c}}}{T_{0}^{\mathrm{c}}}\right)^{1 / 2}
\end{aligned}
$$

Equations (4) and (5) are the basis for many of the correlation techniques of transport properties discussed in the literature, ${ }^{2}$ both for pure fluids and for mixtures. However, results can be very inconsistent if the equations are used as predictive tools, and clear-cut procedures have not been proposed. This is particularly true for mixtures for which one needs mixing rules (for the critical parameters, for 
example). Several mixing rules have been suggested, but on essentially intuitive grounds. ${ }^{3}$

Recently, however, the relationship between corresponding states and transport properties of mixtures has been clarified considerably by Mo and Gubbins. ${ }^{4}$ These authors considered a conformal fluid mixture [that is, a mixture ${ }^{5}$ in which each component obeys the universal potential of equation (1)] in the Van der Waals one-fluid approximation. The one-fluid approximation allows the mixture to be equated to an equivalent pure fluid so (4), for example, becomes for mixture $\mathrm{x}$,

$$
\eta_{\mathrm{x}}(\rho, T)=\eta_{0}\left[\rho\left(\frac{\rho_{0}^{\mathrm{c}}}{\rho_{\mathrm{x}}^{\mathrm{c}}}\right), T\left(\frac{T_{0}^{\mathrm{c}}}{T_{\mathrm{x}}^{\mathrm{c}}}\right)\right]\left(\frac{M_{\mathrm{x}}}{M_{0}}\right)^{1 / 2}\left(\frac{\rho_{\mathrm{x}}^{\mathrm{c}}}{\rho_{0}^{\mathrm{c}}}\right)^{2 / 3}\left(\frac{T_{\mathrm{x}}^{\mathrm{c}}}{T_{0}^{\mathrm{c}}}\right)^{1 / 2}
$$

with a similar expression for the thermal conductivity coefficient. Mo and Gubbins derive (6) under well-defined assumptions and show that one possible set of mixing rules for the density and temperature of a binary mixture are (using the notation of Gubbins et al)

$$
\left(\rho_{x}^{c}\right)^{-1}=\varlimsup_{\alpha} \sum_{\beta} x_{\alpha} x_{\beta}\left(\rho_{\alpha \beta}^{c}\right)^{-1}
$$

and

$$
T_{\mathrm{x}}^{\mathrm{c}}\left(\rho_{x}^{\mathrm{c}}\right)^{-1}=\sum_{\alpha} \sum_{\beta} x_{\alpha} x_{\beta} T_{\alpha \beta}^{\mathrm{c}}\left(\rho_{\alpha \beta}^{\mathrm{c}}\right)^{-1}
$$

where $x_{\alpha}$ is the mole fraction of $\alpha$. It is also argued that a mixing rule is needed for the molecular mass, namely for $\eta_{\mathrm{x}}$

$$
M_{\mathrm{x}}^{1 / 2}\left(T_{\mathrm{x}}^{\mathrm{c}}\right)^{1 / 2}\left(\rho_{\mathrm{x}}^{\mathrm{c}}\right)^{2 / 3}=\sum_{\alpha} \sum_{\beta} x_{\alpha} x_{\beta} M_{\alpha \beta}^{1 / 2}\left(T_{\alpha \beta}^{\mathrm{c}}\right)^{1 / 2}\left(\rho_{\alpha \beta}^{\mathrm{c}}\right)^{2 / 3}
$$

and for $\lambda_{x}$

$$
M_{\mathrm{x}}^{-1 / 2}\left(T_{\mathrm{x}}^{\mathrm{c}}\right)^{1 / 2}\left(\rho_{\mathrm{x}}^{\mathrm{c}}\right)^{2 / 3}=\sum_{\alpha} \sum_{\beta} x_{\alpha} x_{\beta} M_{\alpha \beta}^{-1 / 2}\left(T_{\alpha \beta}^{\mathrm{c}}\right)^{1 / 2}\left(\rho_{\alpha \beta}^{\mathrm{c}}\right)^{2 / 3}
$$

The cross parameters of (9) and (10) can be estimated from the relations

$$
\begin{aligned}
& T_{\alpha \beta}^{c}=\xi_{\alpha \beta}\left(T_{\alpha \alpha}^{c} T_{\beta \beta}^{c}\right)^{1 / 2} \\
& \left(\rho_{\alpha \beta}^{c}\right)^{-1}=\psi_{\alpha \beta}\left[\frac{1}{2}\left(\rho_{\alpha \alpha}^{c}\right)^{-1 / 3}+\frac{1}{2}\left(\rho_{\beta \beta}^{c}\right)^{-1 / 3}\right]^{3}
\end{aligned}
$$

and

$$
M_{\alpha \beta}=\frac{1}{2}\left(\frac{1}{M_{\alpha}}+\frac{1}{M_{\beta}}\right)^{-1}
$$

where $\xi_{\alpha \beta}$ and $\psi_{\alpha \beta}$ are binary interaction parameters, which are best obtained from experiment.

The mixing rules. (7) and (8), are consistent with the mixing rules derived for thermodynamic properties using the one-fluid approximation. If, therefore, the binary interaction parameters are assumed to be those valid for thermodvnamic properties, one has a procedure to predict the viscosity and thermal conductivity coefficients of mixture $x$, given the equivalent coefficients of the reference fluid.

\section{Extension to polyatomic fluids and non-conformal mixtures}

Equations (2)-(6) are not general since the assumption of the simple two-parameter corresponding states theory are not valid for polyatomic fluids, or for mixtures containing polyatomic molecules. The situation is, of course, paralleled with respect to the thermodynamic properties and has been discussed extensively in this context. A particularly convenient extension of corresponding states has been developed by Leland ${ }^{6}$ and Rowlinson ${ }^{7}$ and appears relevant to the transport properties of interest here.

According to the Leland approach, a third parameter, $\omega$, which can be taken as the Pitzer acentric factor, ${ }^{8}$ is introduced, but the framework of simple corresponding states is preserved, if one works with the relations

$$
f_{\alpha \alpha, \mathrm{o}}=\left(\frac{T_{\alpha \alpha}^{\mathrm{c}}}{T_{\mathrm{o}}^{\mathrm{c}}}\right) \theta_{\alpha \alpha, \mathrm{o}} ; \quad h_{\alpha \alpha, \mathrm{o}}=\left(\frac{\rho_{\mathrm{o}}^{\mathrm{c}}}{\rho_{\alpha \alpha}^{\mathrm{c}}}\right) \phi_{\alpha \alpha, \mathrm{o}}
$$

for fluid $\alpha$ with respect to o. The terms $\theta_{\alpha \alpha, o}$ and $\phi_{\alpha \alpha, o}$ are called shape factors and are weakly varying functions of temperature and density

$$
\begin{aligned}
& \theta_{\alpha \alpha, o}=1+\left(\omega_{\alpha \alpha}-\omega_{\mathrm{o}}\right) f(T, \rho) \\
& \phi_{\alpha \alpha, o}=1+\left(\omega_{\alpha \alpha}-\omega_{\mathrm{o}}\right) g(T, \rho)
\end{aligned}
$$

where $\omega_{\alpha \alpha}$ and $\omega_{\mathrm{o}}$ are acentric factors for fluids $\alpha$ and $\mathrm{o}$, respectively. [The form of the functions $f(T, \rho)$ and $g(T, \rho)$ are given in reference 6 . A set of numerical values for the parameters of $f$ and $g$, and for $\omega$, are also given. However these parameters are subject to revision depending on the state-of-the-art of the appropriate equation of state data. The set used by us are preliminary but are available from the Cryogenics Division.] Using the shape factors, the compressibility factor (for example) of $\alpha$ would be given by the relation $Z_{\alpha}(\rho, T)=Z_{\mathrm{o}}\left(\rho h_{\alpha \alpha, \mathrm{o}}, T / f_{\alpha \alpha, \mathrm{o}}\right)$. With the appropriate ${ }^{7}$ expression for the Helmholtz free energy, the thermodynamic properties of $\alpha$ are completely defined in terms of the properties of $o$.

Let us introduce shape factors into the expressions for the viscosity and thermal conductivity coefficients. ${ }^{9}$ We then obtain for fluid $\alpha$

$$
\begin{aligned}
& \eta_{\alpha}(\rho, T)=\eta_{\circ}\left[\rho h_{\alpha \alpha, o}, T / f_{\alpha \alpha, o}\right]\left(\frac{M_{\alpha}}{M_{\mathrm{o}}}\right)^{1 / 2} h_{\alpha \alpha, o}^{-2 / 3} f_{\alpha \alpha, o}^{1 / 2} \\
& \lambda_{\alpha}(\rho, T)=\lambda_{\circ}\left[\rho h_{\alpha \alpha, o}, T / f_{\alpha \alpha, o}\right]\left(\frac{M_{\mathrm{o}}}{M_{\alpha}}\right)^{1 / 2} h_{\alpha \alpha, o}^{-2 / 3} f_{\alpha \alpha, o}^{1 / 2}
\end{aligned}
$$

and for the transport properties of the mixture $x$,

$$
\begin{aligned}
& \eta_{\mathrm{x}}(\rho, T)=\eta_{\mathrm{o}}\left[\rho h_{\mathrm{x}, \mathrm{o}}, T / f_{\mathrm{x}, \mathrm{o}}\right]\left(\frac{M_{\mathrm{x}}}{M_{\mathrm{o}}}\right)^{1 / 2} h_{\mathrm{x}, \mathrm{o}}^{-{ }^{2} / 3} f_{\mathrm{x}, \mathrm{o}}^{1 / 2} \\
& \lambda_{\mathrm{x}}(\rho, T)=\lambda_{\mathrm{o}}\left[\rho h_{\mathrm{x}, o}, T / f_{\mathrm{x}, \mathrm{o}}\right]\left(\frac{M_{\mathrm{o}}}{M_{\mathrm{x}}}\right)^{1 / 2} h_{\mathrm{x}, \mathrm{o}}^{-2 / 3} f_{\mathrm{x}, \mathrm{o}}^{1 / 2}
\end{aligned}
$$

where mixing rules for $\mathrm{x}$ are

$$
\begin{aligned}
& h_{\mathrm{x}, \mathrm{o}}=\sum_{\alpha} \sum_{\beta} x_{\alpha} x_{\beta} h_{\alpha \beta, \mathrm{o}} \\
& f_{\mathrm{x}, \mathrm{o}} h_{\mathrm{x}, \mathrm{o}}=\sum_{\alpha} \sum_{\beta} x_{\alpha} x_{\beta} f_{\alpha \beta, \mathrm{o}} h_{\alpha \beta, \mathrm{o}}
\end{aligned}
$$

with

$$
f_{\alpha \beta, o}=\xi_{\alpha \beta}\left(f_{\alpha \alpha, o} f_{\beta \beta, o}\right)^{1 / 2}
$$




$$
h_{\alpha \beta, o}=\psi_{\alpha \beta}\left(\frac{1}{2} h_{\alpha \alpha, o}{ }^{1 / 3}+\frac{1}{2} h_{\beta \beta, o}^{1 / 3}\right)^{3}
$$

Following Gubbins. ${ }^{9}$ a mixing rule for $M_{\mathrm{x}}$ is

$$
M_{\mathrm{x}}^{1 / 2} f_{\mathrm{x}, \mathrm{o}}^{1 / 2} h_{\mathrm{x}}^{-2 / 3}=\sum_{\alpha} \sum_{\beta} M_{\alpha \beta}^{1 / 2} f_{\alpha \beta, o}^{1 / 2} h_{\alpha \beta, o}^{-2 / 3}
$$

for the viscosity coefficient, and an equivalent rule for the thermal conductivity coefficient follows from (10).

\section{Evaluation of the extended corresponding states equations}

One might hope that (16)-(24), which we designate as the extended corresponding state equations, could predict the transport properties of non-conformal fluids given a reference transport property and appropriate thermodynamic data. It was decided to test this assumption. Initially we considered the calculation of the viscosity coefficient for the pure fluids $(\alpha)$ nitrogen, ethane, propane, and carbon dioxide. Methane was chosen as the reference fluid (o): methane viscosity data have been analysed and correlated as a function of temperature and density, ${ }^{10}$ and the methane equation of state of Goodwin ${ }^{11}$ was used $^{12}$ as the basis for the shape factor calculations.

Results for nitrogen are shown in Fig. 1 in which the ratio $\eta(\exp ) / \eta$ (calc) has been plotted as a function of temperature for several reduced densities $\left(\rho / \rho_{\mathrm{c}}\right): \eta$ (calc) refers to values from (16), while values for $\eta(\exp )$ were obtained from our previous correlation of the transport properties of nitrogen. ${ }^{13}$

It is seen that (16) gives a reasonable prediction if $\rho / \rho^{\mathrm{c}} \leqslant 1$ (that is, the viscosity ratio is close to unity) but the re is a strong density dependence in the deviation pattern above the critical density. As a contrast, the temperature dependence is relatively weak for all densities.

As a matter of interest we include Fig. 2 which illustrates the variation of the shape factors $\theta$ and $\phi$ used to obtain $\eta($ calc). The density dependence of these variables is very weak.

Results similar to those shown in Fig. 1 were observed for the other fluids. Thus it appears that (16), with shape factors obtained from thermodynamic data, cannot represent adequately at high densities the viscosity coefficients of fluids which do not correspond with methane. These results for the pure fluids further suggest that (18) will also be un. satisfactory for non-conformal mixtures - with the added complication of mixing rules and binary interaction parameters - and, in fact, this turned out to be the case.

\section{Modified equation for the viscosity coefficient}

The relationship between the experimental viscosity coefficient and values calculated from (16) for the fluids studied in this work suggests that an equation of the form

$$
\eta_{\alpha}(\rho, T)=\eta_{\mathrm{o}}\left(\rho^{\prime}, T^{\prime}\right) F H_{\alpha \alpha, o}^{\eta} X(\rho, T)
$$

might be successful where (16) is re-written as

$$
\eta_{\alpha}(\rho, T)=\eta_{\mathrm{o}}\left(\rho^{\prime}, T^{\prime}\right) F H_{\alpha \alpha, o}^{\eta}
$$

where

$$
\rho^{\prime}=\rho h_{\alpha \alpha, 0}: T^{\prime}=T / f_{\alpha \alpha, o}
$$

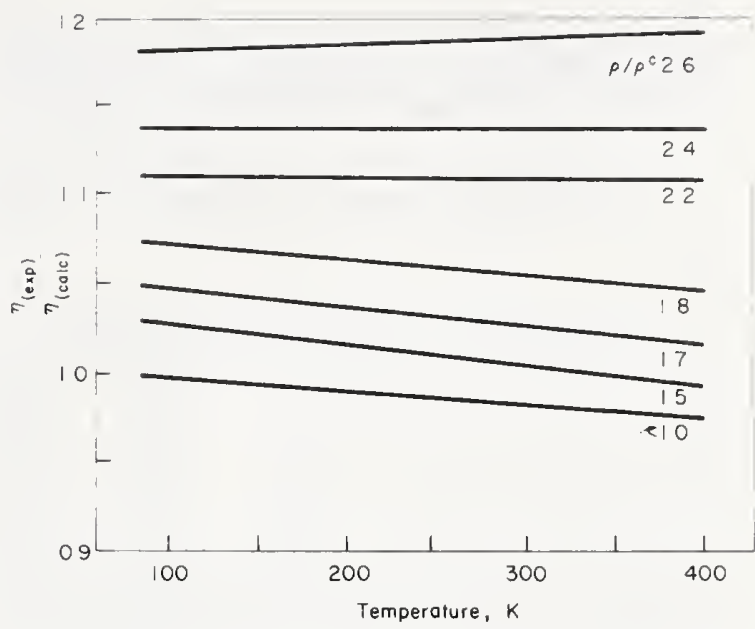

Fig. 1 Ratio of $\eta($ exp $) / \eta$ (calc) for nitrogen plotted schematically as a function of temperature at several densities. Values of $n$ (exp) were extracted from reference 13 while values of $\eta(\mathrm{calc})$ were obtained from the extended corresponding states equation (16). The figure indicates $(16)$ is not satisfactory if $\rho / \rho \mathrm{c} \gtrsim 1 . \rho^{\mathrm{c}}$ is the critical density

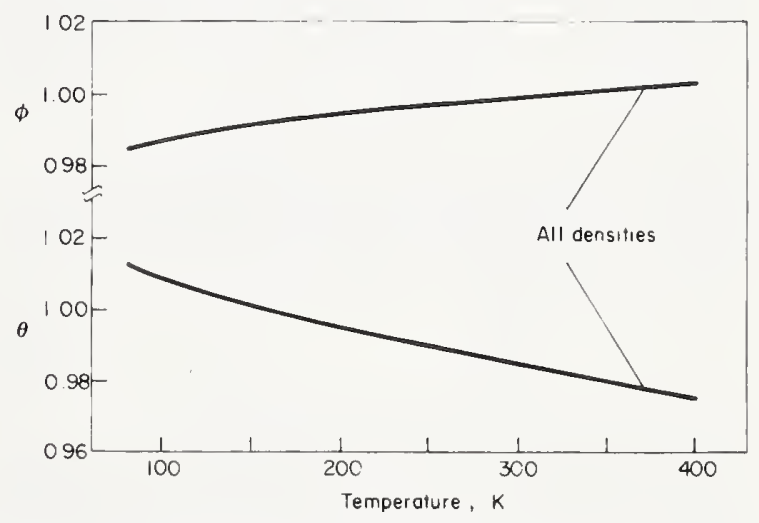

Fig. 2 Plot of the shape factors for nitrogen with respect to methane, $\theta$ and $\phi,[(14)$ and (15)] based on a fit of thermodynamic data. The density dependence is small and can essentially be ignored

and

$$
F H_{\alpha \alpha, o}^{\eta}=\left(\frac{M_{\alpha}}{M_{\mathrm{o}}}\right)^{1 / 2} h_{\alpha \alpha, 0}^{-2 / 3} f_{\alpha \alpha, 0}^{1 / 2}
$$

The correction factor, $X(\rho, T)$, should be unity if fluids $\alpha$ and o follow simple corresponding states, but should be a strong function of density and a weak function of tempera. ture otherwise. However, $X$ should approach unity as the density approaches zero in this latter example (see Fig. 1). Furthermore, if $X$ can be expressed in terms of thermodynamic (PVT) data alone, (25) would have the predictive capability of (5) for fluids in addition to those which obey simple corresponding states.

A suggestion for a convenient form for $X(\rho, T)$ is now discussed.

\section{The modified Enskog theory}

We have shown in references 14,15 , and 16 that an ad hoc modification of the Enskog theory for the hard sphere fluid, 
called the modified Enskog theory (MET), can represent the transport properties of real fluids given only $P V T$ data. The MET expressions for the viscosity and thermal conductivity coefficients of fluid $\alpha$, are,

$$
\eta_{\alpha}^{\mathrm{E}}=\eta_{\alpha}(\mathrm{o}) b \rho\left(\frac{1}{b \rho \chi}+0.8+0.716 b \rho \chi\right)
$$

and

$$
\lambda_{\alpha}^{\mathrm{E}}=\lambda_{\alpha}^{\prime}(\mathrm{o}) b \rho\left(\frac{1}{b \rho \chi}+1.2+0.755 b \rho \chi\right)+\lambda_{\alpha}^{\prime \prime}(\mathrm{o})
$$

where

$$
\lambda_{\alpha}^{\prime \prime}(\mathrm{o})=\rho D_{\alpha}(\mathrm{o}) c_{\mathrm{v}}^{\prime \prime}(\mathrm{o})
$$

In the above equations, $\eta_{\alpha}(0)$ is the dilute gas viscosity of fluid $\alpha$, which can be obtained from experiment or calculated from kinetic theory; $\lambda_{\alpha}^{\prime}(0)$ and $\lambda_{\alpha}^{\prime \prime}(0)$ are contributions to the dilute gas thermal conductivity due to translational and internal degrees of freedom, respectively; $D_{\alpha}(0)$ is the dilute gas self-diffusion coefficient; $c_{\mathrm{v}}^{\prime \prime}(\mathrm{o})$ is the constant volume dilute gas specific heat per unit mass due to internal degrees of freedom.

The term $b \rho \chi$ is obtained from the equation of state written in the form

$$
\frac{V}{R}\left(\frac{\partial P}{\partial T}\right)_{\mathrm{v}}=1+b \rho \chi
$$

which introduces the thermal pressure, $T(\partial P / \partial T)_{V}$, of the fluid $\alpha . b$ is a second virial term. A particular choice for $b$, selected to ensure that (28) and (29) approach the dilute gas limit as the density tends to zero is

$$
b=B+T \frac{\mathrm{d} B}{\mathrm{~d} T}
$$

where $B$ is the second virial coefficient of fluid $\alpha$.

The MET is discussed at length in reference 14-16 so details are unnecessary here but, generally, the MET can predict and represent the transport properties of simple fluids to within about $10-15 \%$ for densities not exceeding about twice the critical density.

One particular feature of the MET can be deduced from our previous work, viz, that a pair of fluids (say $\alpha$ and o) do not necessarily correspond if $\eta^{\mathrm{F}}$ and $\lambda \mathrm{E}$ are reduced according to simple corresponding states. 1n other words, in the context of this paper, suppose we calculate the MET viscosity for fluid $\alpha, \eta_{\alpha}^{\mathrm{t}}$, at a given density and temperature, but also calculate the MET viscosity for $0, \eta_{\mathrm{L}}^{\mathrm{E}}$, at the equivalent density and temperature: $\rho\left(\rho_{\mathrm{o}}^{\mathrm{c}} / \rho_{\alpha}^{\mathrm{c}}\right)$ and $T\left(T_{\mathrm{o}}^{\mathrm{c}} / T_{\alpha}^{\mathrm{c}}\right)$, respectively. According to simple corresponding states one then has,

$$
\eta_{\alpha}^{\mathrm{k}}(1)=\eta_{\mathrm{o}}^{\mathrm{r}}\left[\rho\left(\frac{\rho_{\mathrm{o}}^{\mathrm{c}}}{\rho^{\mathrm{c}}}\right), T\left(\frac{T_{0}^{\mathrm{c}}}{T_{\alpha}^{\mathrm{c}}}\right)\right]\left(\frac{M_{\alpha}}{M_{\mathrm{o}}}\right)^{1 / 2}\left(\frac{\rho_{\alpha}^{\mathrm{c}}}{\rho_{\mathrm{o}}^{\mathrm{c}}}\right)^{2 / 3}\left(\frac{T_{\alpha}^{\mathrm{c}}}{T_{\mathrm{o}}^{\mathrm{c}}}\right)^{1 / 2}
$$

and

$$
\eta_{\alpha}^{\mathrm{E}}=\eta_{\alpha}^{\mathrm{E}}(1)
$$

But the results of references 14 to 16 show that (34) is not always upheld and, moreover, we showed that the lack of correspondence according to the MET arose from the lack of correspondence in the PVT terms of (28), that is, in $b \rho$ and $[1 / b \rho \chi+0.8+0.755 b \rho \chi]$. This being the case, a relationship

$$
\eta_{\alpha}^{\mathrm{E}}=\eta_{\alpha}^{\mathrm{E}}(2)
$$

cannot be expected to hold, where $\eta_{\alpha}^{E}(2)$ is calculated from extended corresponding states, that is, from the relation

$$
\eta_{\alpha}^{\mathrm{E}}(2)=\eta_{\mathrm{o}}^{\mathrm{E}}\left(\rho^{\prime}, T^{\prime}\right) F H_{\alpha \alpha, o}^{\eta}
$$

That $\eta_{\alpha}^{\mathrm{E}}$ was not equal to $\eta_{\alpha}^{\mathrm{E}}(2)$ was in fact, verified. However, as a matter of interest, we repeated, with the MET viscosity coefficients, the procedure which led to the conclusions depicted in Fig. 1 for nitrogen, and to similar conclusions for the other fluids. Hence, the ratio $\eta_{\alpha}^{\mathrm{E}} / \eta_{\alpha}^{\mathrm{E}}(2)$ was examined as a function of temperature and density for the fluids of interest.

The results turned out to be significant. We observed that the temperature and density behaviour of the MET ratio was very similar to the corresponding ratio $\eta_{\alpha}(\exp ) / \eta_{\alpha}$ (calc), and actually indicated a relationship, namely

$$
\frac{\eta_{\alpha}^{\mathrm{E}}}{\eta_{\alpha}^{\mathrm{E}}(2)} \approx \frac{\eta_{\alpha}(\exp )}{\eta_{\alpha}(\mathrm{calc})}
$$

Here $\eta_{\alpha}(\exp )$ is the experimental viscosity and $\eta_{\alpha}(\mathrm{calc})$ is the value from (16) as before.

The significance of (37) is that it leads to an expression for the correction factor $X(\rho, T)$ of (25) since, if one accepts (37) as an apparently empirical fact

$$
\eta_{\alpha}(\exp ) \approx \eta_{\alpha}(\text { calc }) q_{\alpha \alpha, o} G_{\alpha \alpha, o}^{\eta}
$$

where we have used that $\eta_{\alpha}(\mathrm{o})=\eta_{0}(\mathrm{o}) F H_{\alpha \alpha, o}^{\eta}$ for the dilute gas. $q_{\alpha \alpha \text {, o }}$ is the ratio $(b \rho)_{\alpha} /(b \rho)_{0}$ and $G_{\alpha \alpha, o}^{\eta}$ is the ratio []$_{\alpha} /[]_{0}$ where []$=[1 / b \rho \chi+0.8+0.755 b \rho \chi]$ from (28). Note that both $(b \rho)_{\alpha}$ and [ $]_{\alpha}$ for fluid $\alpha$ can be determined from the equivalent terms for fluid o using the shape factor approach. For example, for $b_{\alpha}(T)$

$$
b_{\alpha}(T)=h_{\alpha \alpha, o} B_{o}+T \mathrm{~d} \frac{\left(h_{\alpha \alpha, o} B_{\mathrm{o}}\right)}{\mathrm{d} T}
$$

[The shape factors do not necessarily cancel if one takes the ratio of $b \rho$ since $\theta$ and $\phi$ are, in general, functions of temperature and density.]

Since $\eta_{\alpha}$ (calc) is given by (16) or (16a), $\eta_{\alpha}(\rho, T)$ can be redefined from (38)

$$
\eta_{\alpha}(\rho, T)=\eta_{\mathrm{o}}\left(\rho^{\prime}, T^{\prime}\right) F H_{\alpha \alpha, \mathrm{o}}^{\eta} q_{\alpha \alpha, \mathrm{o}} G_{\alpha \alpha, \mathrm{o}}^{\eta}
$$

Comparison with (25) indicates that

$$
X(\rho, T) \equiv q_{\alpha \alpha, 0} G_{\alpha \alpha, o}^{\eta}
$$

We examined the experimental behaviour of $X(\rho, T)$. The result was that $X$ turned out to be a strong function of temperature and density if fluid $\alpha$ did not correspond with $o$. However, it was observed that the temperature dependence was due largely to $q_{\alpha \alpha, o}$, that is, the ratio of the $b \rho$ terms. This feature suggested a refinement to (41) according to the following reasoning. In the MET, $b$ is defined in a way to ensure that the viscosity coefficient approach the correct zero density limit. Further, $q_{\alpha \alpha, o} G_{\alpha \alpha, o}^{\eta} \approx 1$ in this dilute gas limit. We thus argue that $q_{\alpha \alpha, o}$ imposes an incorrect temperature dependence to the product $q_{\alpha \alpha, o} G_{\alpha \alpha, o}^{\eta}$ for the dense gas and liquid. Since it is not clear how to redefine $b$, 
we replace $q_{\alpha \alpha, \mathrm{o}}$ by $Q_{\alpha \alpha, o}$ where

$$
Q_{\alpha \alpha, \mathrm{o}}=q_{\alpha \alpha, \mathrm{o}}^{\left[1-1 / \exp \left(\rho^{\mathrm{c}} / \rho\right)^{3}\right]}
$$

In this way $Q_{\alpha \alpha, o} \rightarrow q_{\alpha \alpha, o}$ at low densities and the MET format is preserved, but the temperature dependence of $q_{\alpha \alpha, \mathrm{o}}$ becomes insignificant at high densities since $Q_{\alpha \alpha, o} \rightarrow 1$

Our modified equation for the viscosity coefficient of fluid $\alpha$ is thus

$$
\eta_{\alpha}(\rho, T)=\eta_{\mathrm{o}}\left(\rho^{\prime}, T^{\prime}\right) F H_{\alpha \alpha, o}^{\eta} Q_{\alpha \alpha, o} G_{\alpha \alpha, o}^{\eta}
$$

This equation predicts $\eta_{\alpha}$ from $\eta_{0}$ and PVT information.

\section{Test of (43)}

Initially we tested (43) for nitrogen (a) given, as before, the viscosity of methane (o) as a reference. The procedure is summarized as follows: from a fit of the thermodynamic properties of nitrogen using the equation of state for methane. one determines the shape factors and $h_{\alpha \alpha, o}$ and $f_{\alpha \alpha, o}$ and $f_{\alpha \alpha . o}$ defined by (14). Hence one has $\rho^{\prime}, T^{\prime}$ and $F H_{\alpha, 0}^{\prime}$ and $\eta_{\mathrm{o}}\left(\rho^{\prime}, T^{\prime}\right)$. $(b \rho)_{\alpha}$ and []$_{\alpha} Q_{\alpha \alpha, o}$ and $G_{\alpha \alpha, o}$ follow from (30) and (31).

Selected results for nitrogen are given in Tables 1 and 2. Results predicted from (16) are included for comparison. The improvement of (43) over (16) as a representation of the data is significant. Since both the experimental nitrogen viscosities and the reference methane viscosities are judged accurate to about $2 \%$, the agreement between experimental and calculated nitrogen values is considered satisfactory.

Similar agreement between calculation and experiment was observed for the other fluids of interest here; ethane, propane, and carbon dioxide.

\section{Viscosity equation for mixtures}

For mixtures. one modifies (43) to become

$$
\eta_{\mathrm{x}}(\rho, T)=\eta_{\mathrm{o}}\left(\rho^{\prime}, T^{\prime}\right) F H_{\mathrm{x}, \mathrm{o}}^{\eta} Q_{\mathrm{x}, \mathrm{o}} G_{\mathrm{x}, \mathrm{o}}^{\eta}
$$

If $(44)$ is to have the predictive capability of the equation for pure fluids, then the shape factor terms and mixing rules $h_{\lambda, 0}$ and $f_{\mathrm{x}, o}$, have to be defined by (20) and (21) which, in turn. incorporate the equilibrium binary interaction parameters. $\xi_{\alpha \beta}$ and $\psi_{\alpha \beta}$ of (22) and (23). Thus $\phi_{\mathrm{x}, o}, \theta_{\mathrm{x}, o}$, $\xi_{\alpha \beta}$, and $\psi_{\alpha \beta}$ can be found from thermodynamic data alone. [it is not clear what mixing rule to use for the molecular weight. Although (24) has been proposed, the mixing rule that arises naturally from the rmodynamics is

$$
M_{\mathrm{x}}=\Sigma x_{\alpha} M_{\alpha} .
$$

We prefer this rule because we have modified (16) on the basis of the $P V T$ behaviour of the mixtures.]

\section{Comparison between experiments and the viscosity equation for mixtures}

Viscosity data for non-conforming mixtures, apart from the dilute gas, are scarce and their reliability are often difficult to assess. Further, the choice of mixture data suitable for comparisons is somewhat restricted by our previous work on the equation of state. In principle, the shape factors and binary interaction parameters can be estimated for many fluids and their mixtures but, in prac-
Table 1. Nitrogen viscosity: saturated liquid

Deviations between the experimental viscosity coefficients ${ }^{13}$

\begin{tabular}{|c|c|c|c|c|}
\hline \multirow[b]{2}{*}{$\begin{array}{l}T, \\
K\end{array}$} & \multirow[b]{2}{*}{$\rho / \rho^{\mathrm{c}}$} & \multirow[b]{2}{*}{ 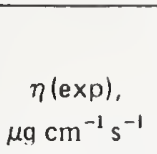 } & \multicolumn{2}{|c|}{$\underline{\eta_{\text {exp }}-\eta_{\text {calc }}} \times 100$} \\
\hline & & & $\begin{array}{c}\eta_{\text {calc }} \\
\text { (43) }\end{array}$ & (16) \\
\hline 75 & 2.61 & 1658 & -8.1 & 20.1 \\
\hline 80 & 2.54 & 1377 & -3.5 & 18.4 \\
\hline 85 & 2.46 & 1160 & 3.0 & 17.1 \\
\hline 90 & 2.38 & 988 & 3.0 & 16.2 \\
\hline 95 & 2.29 & 846 & 4.6 & 15.3 \\
\hline 100 & 2.19 & 726 & 5.0 & 14.4 \\
\hline 115 & 1.84 & 447 & 2.6 & 10.6 \\
\hline 120 & 1.67 & 365 & 2.0 & 8.6 \\
\hline 125 & 1.37 & 259 & 1.5 & 8.0 \\
\hline
\end{tabular}
and values calculated from (43) for saturated liquid nitrogen. Deviations between experiment and the extended corresponding states equation, (16) are also given.

\section{Table 2. Nitrogen viscosity: $220 \mathrm{~K}$ isotherm}

Deviations between the experimental viscosity coefficients ${ }^{13}$ for nitrogen at $220 \mathrm{~K}$ and values calculated from (43) as a function of reduced density. Deviations between experiment and values from (16) are also given.

$\frac{\eta_{\text {exp }}-\eta_{\text {calc }}}{\eta_{\text {calc }}} \times 100$

\begin{tabular}{lrr}
$\rho / \rho^{\mathrm{c}}$ & $(43)$ & $(16)$ \\
\hline 0.1 & 0.5 & 0.8 \\
0.3 & -2.8 & -1.1 \\
1.0 & -7.0 & -4.3 \\
1.6 & -4.0 & 4.0 \\
1.9 & -4.8 & 12.0 \\
2.1 & -5.8 & 18.6 \\
2.5 & -6.9 & 24.0 \\
\hline
\end{tabular}

tice at this time, our work is limited to methane, ethane, propane, n-butane, i-butane, pentane, nitrogen, carbon dioxide, nitrous oxide, and mixtures thereof. Equation (44), however, was checked with data for several representive mixtures over a wide range of experimental conditions.

Table 3 gives typical and representative results for the methane-propane system. The data, perhaps the most extensive and reliable viscosity mixture data available, are those of Huang, Swift, and Kurata. ${ }^{17}$ Approximate critical temperatures and densities of the given mixture ${ }^{18}$ are included in the tables as a measure of the reduced temperature and density involved. Values from extended corresponding states are given in parentheses. The data are judged accurate to within about $3 \%$ so our equation (44) is very satisfact ory.

Table 4 illustrates typical results for the methane-n-butane system. The data are those from reference 19. Agreement is excellent between the predicted values from (44) and experiment. The experimental accuracy is about $6 \%$.

Data for liquid mixtures which contain compunents other than hydrocarbons are scarce and the majority are reproduced in the monograph by Gobubev. ${ }^{20}$ We investigated 
Table 3a. Methane-propane viscosity

Comparison between viscosity data ${ }^{17}$ for a methane $(22.1 \%)$ propane $(77.9 \%)$ mixture at $193.15 \mathrm{~K}$ and the results predicted from (44): $T^{\mathrm{c}} \approx 350 \mathrm{~K}, \rho^{\mathrm{c}} \approx 6.25 \mathrm{~mole}^{-1}$.

\begin{tabular}{|c|c|c|c|}
\hline $\begin{array}{l}\rho, \\
\text { mole } 1^{-1}\end{array}$ & $\eta(\exp )$ & $\begin{array}{r}\eta(\mathrm{calc}) \\
\mu \mathrm{g} \mathrm{cm}^{-1} \mathrm{~s}^{-1}\end{array}$ & \\
\hline 15.39 & 2390 & 2412 & $(2086)^{*}$ \\
\hline 15.63 & 2676 & 2610 & $(2300)$ \\
\hline 15.79 & 2846 & 2750 & $(2441)$ \\
\hline 15.92 & 3020 & 2900 & $(2580)$ \\
\hline 16.06 & 3184 & 3040 & (2717) \\
\hline
\end{tabular}

* Values obtained from extended corresponding states.

Table 3b. Methane-propane viscosity

Comparison between viscosity data ${ }^{17}$ for a methane $(50 \%)$ propane $(50 \%)$ mixture at $153.15 \mathrm{~K}$ and the results predicted for $(44): T^{\mathrm{c}} \approx 319 \mathrm{~K}, \rho^{\mathrm{c}} \approx 7.7 \mathrm{~mole}^{-1}$.

\begin{tabular}{llll}
\hline \multicolumn{5}{c}{$\eta($ exp $)}$, & $\eta($ calc $)$, \\
mole I $^{-1}$ & \multicolumn{3}{c}{$\mu \mathrm{g} \mathrm{cm}^{-1} \mathrm{~s}^{-1}$} \\
\hline 18.69 & 2780 & 2614 & $(2286)^{*}$ \\
18.78 & 2860 & 2710 & $(2360)$ \\
18.96 & 3030 & 2878 & $(2509)$ \\
19.12 & 32000 & 3002 & $(2659)$ \\
19.28 & 3380 & 3232 & $(2807)$ \\
19.42 & 3550 & 3407 & $(2952)$ \\
\hline
\end{tabular}

* Values obtained from extended corresponding states.

Table 3c. Methane-propane viscosity

Comparison between viscosity data ${ }^{17}$ for a methane $(75.3 \%)$ propane $(24.7 \%)$ mixture at $173.15 \mathrm{~K}$ and the results predicted from $(44): T^{\mathrm{c}} \approx 276 \mathrm{~K}, \rho^{\mathrm{c}} \approx 9.8 \mathrm{~mole}^{-1}$.

\begin{tabular}{lrrr}
\hline \multicolumn{5}{c}{$\eta$ (exp), } & $\eta$ (calc), \\
${\text { mole } \mathrm{I}^{-1}}^{5} \mu \mathrm{g} \mathrm{c}^{-1} \mathrm{~s}^{-1}$ \\
\hline 19.52 & 975 & 943 & $(889)^{*}$ \\
13.76 & 1020 & 988 & $(933)$ \\
20.17 & 1090 & 1075 & $(1013)$ \\
20.53 & 1170 & 1156 & $(1090)$ \\
20.84 & 1250 & 1233 & $(1162)$ \\
21.12 & 1320 & 1308 & $(1232)$ \\
\hline
\end{tabular}

- Values obtained from extended corresponding states.

the $\mathrm{N}_{2} / \mathrm{CH}_{4}$ system discussed in that work and Fig. 3 illustrates our prediction from (44) for the equimolar mixture. The data are those of Gerf and Galkov ${ }^{21}$ for the saturated liquid. Our values are generally lower than experiment; the discrepancy increases as the temperature increases. Superficially the prediction appears poor but we can argue that the data are unreliable on the following

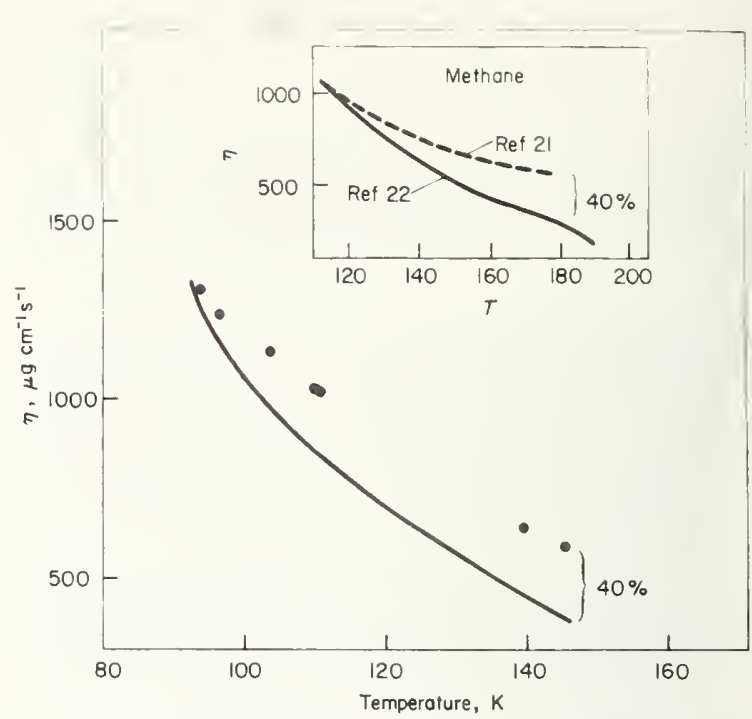

Fig. 3 Saturated liquid viscosity of a $\mathrm{N}_{2} / \mathrm{CH}_{4}$ equimolar mixture. Data (filled circles) from reference 21 , curve from (44). The insert gives a plot of the saturated liquid viscosity of pure methane. It can be argued that the data from reference 21 are unreliable (see text)

\section{Table 4. Methane-n-butane viscosity}

Comparison between viscosity data ${ }^{19}$ for a methane $(50 \%)-$ n-butane $(50 \%)$ mixture at $311 \mathrm{~K}$ and the results predicted from equation (44): $T^{c} \approx 375 \mathrm{~K}, \rho^{c} \approx 7.1$ mole $^{-1}$.

\begin{tabular}{|c|c|c|c|}
\hline $\begin{array}{l}\rho, \\
\text { mole } 1^{-1}\end{array}$ & $\eta(\exp )$ & $\begin{array}{l}\eta(\text { calc }), \\
\mathrm{n}^{-1} \mathrm{~s}^{-1}\end{array}$ & \\
\hline 11.58 & 645 & 675 & $(730)^{*}$ \\
\hline 12.21 & 772 & 730 & (836) \\
\hline 12.66 & 835 & 854 & $(922)$ \\
\hline 13.03 & 920 & 927 & $(1000)$ \\
\hline 13.34 & 993 & 995 & $(1070)$ \\
\hline 13.61 & 1070 & 1056 & $(1136)$ \\
\hline 13.85 & 1115 & 1144 & $(1200)$ \\
\hline 14.07 & 1230 & 1172 & (1258) \\
\hline
\end{tabular}

* Values obtained from extended corresponding states.

grounds. First, it is surprising that the discrepancy increases with temperature since the density decreases. The evidence from pure fluids indicates that the extended corresponding states treatment is reasonable if $\rho / \rho^{c} \lesssim 1$, and the factor $Q_{\mathrm{x}, \mathrm{o}} G_{\mathrm{x}, \mathrm{o}}^{\eta}$ approaches unity as the density approaches the critical density. Second, the insert in Fig. 3 gives a schematic plot of pure methane saturated liquid viscosity. The lower curve is based on the data of Haynes, ${ }^{22}$ which we believe to be accurate to within $\pm 2 \%$, while the upper curve is based on the data of Gerf and Galkov; ${ }^{21}$ the authors of the $\mathrm{N}_{2} / \mathrm{CH}_{4}$ data. The similarity between the methane and nitrogen/methane plots is obvious. We suggest, therefore, that the mixture data of reference 21 are systematically in error.

Table 5 compares our prediction with Golubev and Petrov's data $^{20}$ for a $62 \% \mathrm{~N}_{2}-38 \% \mathrm{CO}_{2}$ gaseous mixture at $289 \mathrm{~K}$.

Note that the mixture does not contain the reference fluid (methane) as a component. 
Finally we include Table 6 which gives a comparison between predicted and experimental values for an LNG gaseous mixture ${ }^{20}$ at $273 \mathrm{~K}$. The mixtures have the following composition: $\mathrm{CH}_{4}-91.5 \% ; \mathrm{C}_{2} \mathrm{H}_{6}-1.8 \% ; \mathrm{C}_{3} \mathrm{H}_{8}-0.8 \%$; $\mathrm{C}_{4} \mathrm{H}_{10}-0.6 \% ; \mathrm{N}_{2}-5 \%$; others $-0.3 \%$. We cannot evaluate the accuracy of the data but the prediction appears reasonable. Although, in fact, the viscosity values for this mixture are very close to those for pure methane under equivalent conditions, Table 6 does illustrate that our procedure can adapt to a six-component mixture without difficulty.

\section{Thermal conductivity equation for mixtures}

We have investigated the prediction of the thermal conductivity coefficient for a pure fluid and for a nonconformal mixture. At this stage our results are to be considered preliminary. There are two principle reasons for this caution: it is not clear how to treat the contribution of internal degrees of freedom to the conductivity (these contributions are known not to follow the corresponding states principle), and the data for thermal conductivity of liquid mixt ures are very limited.

Based on the procedure discussed for the viscosity coefficient, we considered the equations [see (17) and (19)];

$$
\lambda_{\alpha}(\rho, T)=\lambda_{\mathrm{o}}\left(\rho^{\prime}, T^{\prime}\right) \frac{\lambda_{\alpha}^{\mathrm{E}}}{\lambda_{o}^{\mathrm{E}}}
$$

and

$$
\lambda_{x}(\rho, T)=\lambda_{o}\left(\rho^{\prime}, T^{\prime}\right) \frac{\lambda_{\alpha}^{E}}{\lambda_{o}^{E}}
$$

for a pure fluid and mixture, respectively. $\lambda_{\alpha}^{E}$, etc, are the MET expressions from (29). If we substitute from (29) we obtain from (45)

$$
\begin{aligned}
\lambda_{\alpha}(\rho, T)= & \lambda_{\mathrm{o}}\left(\rho^{\prime}, T^{\prime}\right) F H_{\alpha \alpha, o}^{\lambda} q_{\alpha \alpha, o} G_{\alpha \alpha, o}^{\lambda} \\
& \times\left\{1+x\left[\left(\lambda_{\alpha}^{\prime \prime}(0), \lambda_{o}^{\prime \prime}(\mathrm{o})\right]\right\}\right.
\end{aligned}
$$

where the terms $\lambda_{\alpha}^{\prime \prime}(0) / \chi$ and $\lambda_{o}^{\prime \prime}(0) / \chi$ are assumed to give only small contributions to $\lambda_{\alpha}^{E}$ and $\lambda_{n}^{E}$, respectively. This has been verified experimentally. ${ }^{14} F H_{\alpha \alpha, o}^{\lambda}$, analogous to $F H_{\alpha, \alpha, o}^{\eta_{1}}$, is defined from (17)

$$
F H_{\alpha \alpha, 0}^{\lambda}=\left(\frac{M_{0}}{M_{\alpha}}\right)^{1 / 2} h_{\alpha \alpha, o}^{-2 / 3} f_{\alpha \alpha, o}^{1 / 2}
$$

We introduced $F H_{\alpha \alpha, o}^{\lambda}$ into (46) by assuming that $\lambda_{\alpha}^{\prime}(\mathrm{o})=\lambda_{\mathrm{o}}^{\prime}(\mathrm{o}) F H_{\alpha \alpha, o}^{\lambda}$ is valid for the translational contributions in the dilute gas. $G_{\alpha \alpha, o}^{\lambda}$ is the ratio of the MET terms

$$
G_{\alpha \alpha_{0}, \mathrm{o}}^{\lambda}=\frac{[1 / b \rho \chi+1.2+0.755 b \rho \chi]_{\alpha}}{[1 / b \rho \chi+1.2+0.755 b \rho \chi]_{o}}
$$

lgnoring the function, ' $2\left[\lambda_{\alpha}^{\prime \prime}(0), \lambda_{o}^{\prime \prime}(0)\right]$, and introducing the correction for the $b \rho$ ratio, $q_{\alpha \alpha, o},(47)$ becomes

$$
\lambda_{\alpha}(\rho, T)=\lambda_{o}\left(\rho^{\prime}, T^{\prime}\right) F H_{\alpha \alpha, o}^{\lambda} Q_{\alpha \alpha, o} G_{\alpha \alpha, o}^{\lambda}
$$

Similarly for a mixture

$$
\lambda_{\mathrm{x}}(\rho, T)=\lambda_{\mathrm{o}}\left(\rho^{\prime}, T^{\prime}\right) F H_{\mathrm{x}, \mathrm{o}}^{\lambda} Q_{\mathrm{x}, \mathrm{o}} G_{\mathrm{x}, \mathrm{o}}^{\lambda}
$$

Internal degrees of freedom enter into (50) and (51) through $\lambda_{o}\left(\rho^{\prime}, T^{\prime}\right)$.
Table 5. Nitrogen-carbon dioxide viscosity

\begin{tabular}{|c|c|c|c|}
\hline $\begin{array}{l}P, \\
\text { atm }\end{array}$ & $\begin{array}{l}\rho, \\
\text { mole } 1^{-1}\end{array}$ & $\eta(\mathrm{exp})$ & $\begin{array}{r}\eta(\text { calc }) \\
\mu \mathrm{g} \mathrm{cm}^{-1} \mathrm{~s}^{-1}\end{array}$ \\
\hline 20 & 0.9 & 109.3 & 110.0 \\
\hline 60 & 3.1 & 132.2 & 123.6 \\
\hline 100 & 5.8 & 160.2 & 145.8 \\
\hline 200 & 11.8 & 244.5 & 227.7 \\
\hline 300 & 15.0 & 313.7 & 298.8 \\
\hline 400 & 17.0 & 372.3 & 345.0 \\
\hline
\end{tabular}

Comparison between predicted viscosity coefficients for a nitrogen $(62 \%)$-carbon dioxide $(38 \%)$ mixture at $289 \mathrm{~K}$. Data from Golubev. ${ }^{20}$

\begin{tabular}{llcc}
\hline \multicolumn{1}{l}{$\begin{array}{l}\rho \\
\text { atm }\end{array}$} & $\begin{array}{l}\rho, \\
\text { mole }^{-1}\end{array}$ & & $\mu \mathrm{g} \mathrm{cm}^{-1} \mathrm{~s}^{-1}$ \\
\hline 20 & 0.9 & 167.0 & 167.0 \\
60 & 2.8 & 179.5 & 186.5 \\
100 & 4.9 & 200.5 & 213.6 \\
120 & 7.0 & 212.5 & 229.1 \\
\hline
\end{tabular}

Table 6. Viscosity of LNG

Comparison between predicted viscosity coefficients of an LNG mixture at $273 \mathrm{~K}$. Data from Golubev. ${ }^{20}$

Table 7. Nitrogen thermal conductivity: saturated liquid Comparison between experimental data ${ }^{13}$ and values predicted from (50) for the thermal conductivity of nitrogen at the saturated liquid.

\begin{tabular}{lrrr}
\hline \multicolumn{5}{c}{$\lambda(\exp )}$, & $\lambda($ calc $)$, \\
$K$ & \multicolumn{3}{c}{$\mathrm{mW} \mathrm{m}^{-1} \mathrm{~K}^{-1}$} \\
\hline 75 & 137.0 & 142.1 & $(122.2)^{*}$ \\
80 & 129.9 & 128.1 & $(114.2)$ \\
85 & 122.3 & 116.4 & $(106.5)$ \\
90 & 114.4 & 106.4 & $(99.1)$ \\
100 & 98.1 & 89.9 & $(84.9)$ \\
115 & 72.5 & 67.2 & $(63.7)$ \\
120 & 64.6 & 60.1 & $(56.3)$ \\
\hline
\end{tabular}

- Values from extended corresponding states.

\section{Comparison between experiment and the thermal} conductivity equations

As remarked earlier, limited data restricts a comparison of (50) and (51) with experiment, but we followed the procedure discussed with respect to the viscosity coefficient as far as possible. That is, $(50)$ was first used to predict values for the pure fluid, (51) was then used to predict values for a mixture.

Results for nitrogen are reported in Tables 7 and 8 for the saturated liquid boundary and for the $220 \mathrm{~K}$ isotherm; data from reference 13. Also included in parentheses are the results from the extended corresponding states equation (17), that is, without an MET correction. We estimate ${ }^{13}$ 
Table 8. Nitrogen thermal conductivity: $220 \mathrm{~K}$ isotherm

Comparison between experimental data ${ }^{13}$ and values predicted from (50) for the thermal conductivity of nitrogen at $220 \mathrm{~K}$.

\begin{tabular}{lcccc}
\hline \multicolumn{5}{c}{$\lambda$, exp), $\lambda$ (calc), } \\
${\text { mole } \text { I }^{-1}} \rho / \rho^{c}$ & \multicolumn{3}{c}{$\mathrm{mW} \mathrm{m}^{-1} \mathrm{~K}^{-1}$} \\
\hline 1.0 & 0.09 & 21.47 & 22.00 & $(27.90)^{*}$ \\
5.0 & 0.45 & 28.01 & 28.72 & $(33.5)$ \\
9.1 & 0.82 & 35.74 & 36.90 & $(40.14)$ \\
12.1 & 1.09 & 43.17 & 44.06 & $(46.4)$ \\
18.37 & 1.65 & 65.89 & 64.00 & $(65.52)$ \\
22.6 & 2.04 & 90.33 & 88.66 & $(92.37)$ \\
25.7 & 2.32 & 115.8 & 118.2 & $(106.9)$ \\
27.7 & 2.50 & 137.1 & 145.2 & $(124.0)$ \\
\hline
\end{tabular}

* Values from extended corresponding states.

Table 9. Ethane thermal conductivity: $310 \mathrm{~K}$ isotherm

Comparison between experimental data ${ }^{23}$ and values predicted from (50) for the thermal conductivity of ethane at $310 \mathrm{~K}$.

\begin{tabular}{lcccc}
\hline \multicolumn{5}{c}{$\lambda$ (exp), $\lambda$ (calc), } \\
$\begin{array}{l}\rho, \\
\text { mole I }^{-1}\end{array}$ & $\rho / \rho^{\mathrm{c}}$ & \multicolumn{3}{c}{$\mathrm{mW} \mathrm{m}^{-1} \mathrm{~K}^{-1}$} \\
\hline 1.0 & 0.15 & 29.37 & 27.36 & $(19.08)^{*}$ \\
4.0 & 0.60 & 49.94 & 48.90 & $(35.69)$ \\
$7.0 \dagger$ & 1.05 & 79.26 & 74.61 & $(60.6)$ \\
10.0 & 1.49 & 77.90 & 71.03 & $(58.4)$ \\
14.0 & 2.09 & 105.5 & 93.8 & $(83.8)$ \\
17.0 & 2.53 & 145.4 & 137.8 & $(125.7)$ \\
\hline
\end{tabular}

* Values from extended corresponding states.

$\dagger$ Note the anomalously large value of $\lambda$. This arises from the critical point enhancement. ${ }^{24}$

the nitrogen data to be accurate to within about \pm 4 and our predictions are generally within this error band.

Table 9 displays the results for ethane. The data are from a recent correlation ${ }^{23}$ and are accurate to within about $\pm 10 \%$ only, which is the agreement between experiment and prediction

There are two remarks on the results in Tables 8 and 9. The first is that the predictions at low densities are surprisingly good since, as remarked, the internal degrees of freedom enter the calculation through $\lambda_{0}$ only: the internal degrees of freedom are known to contribute up to $50 \%$ of the value of the dilute gas thermal conductivity. The second remark is that Table 9 indicates, for the $\rho / \rho^{c}=1.05$ data point, the critical point enhancement in the thermal conductivity coefficient. ${ }^{24}$ Our prediction will also include the enhancement through the reference thermal conductivity for methane. ${ }^{10}$ The topic is under further investigation, how. ever, and will be discussed in detail separately.

Results similar to those of Tables 7-9 were observed for propane and carbon dioxide.
Two mixtures were selected for study: a liquid methane (39.4\%)-n-butane (60.6\%) mixture discussed by Carmichael, Jacobs and Sage ${ }^{25}$ and a gaseous nitrogen-ethane mixture discussed by Gilmore and Comings. ${ }^{26}$ Tables 10 and 11 give typical comparisons between the data and our predictions from (51). The mixing rules and binary interaction parameters were again determined from thermodynamic information, as for the viscosity.

We estimate the data to be accurate to $5-10 \%$. The agreement, therefore, between experiment and prediction is excellent.

\section{Discussion and conclusions}

A corresponding states procedure to predict the viscosity and thermal conductivity coefficients of a pure fluid or mixture has been presented.

In developing our procedure, we first considered modify. ing the two-parameter ( $T^{\mathrm{c}}$ and $\rho^{\mathrm{c}}$ in this work) conformal fluid corresponding states equations to include non-conformal fluids by introducing the concepts of the extended corresponding state approach of Leland and Rowlinson. We had, however, only, partial success with this approach, which is essentially a technique to include a third parameter, if the necessary parameters were obtained from thermodynamic $(P V T)$ data. We observed, in particular, that deviations between calculated and experimental transport coefficients for the pure fluid could be as much as $20 \%$ at high densities (see Fig. 1, for example). The deviations did suggest, however, a possible modification of the basic corresponding states relationships, (15)-(16), by the inclusion of a term $X(\rho, T)$. The form of $X$ was deduced by observing the behaviour of the transport coefficients according to the modified Enskog theory (MET). Our final equations for a pure fluid, $\alpha$, and for a mixture, $x$, are (43) and (44), and (50) and (51) for the viscosity coefficient and thermal conductivity coefficient, respectively. Note that the calculation of the transport coefficients for a given fluid require corresponding values for a reference fluid and thermodynamic data only. Hence out method is predictive in the sense that transport data of the given fluid are not needed.

With methane as a reference fluid, we calculated the viscosity and thermal conductivity coefficients of nitrogen, ethane, propane, butane, and carbon dioxide and for mixtures of these fluids. Typical results are given in Tables 3-11. Although transport data for mixtures are limited, the results show we have tested our method over a wide range of experimental conditions, including the dense liquid, and we have predicted consistently the data to within the experimental error.

We are very grateful to R.D. McCarty for his considerable help with the equation of state calculations needed in this study. The work was supported by the Office of Standard Reference Data.

\section{References}

1 Hirschfelder, J.O., Curtiss, C.F., Bird, R.B. Molecular Theory of Gases and Liquids, 2nd edn (Wiley, NY, 1964) 617

2 See, for example, Reid, R.C., Sherwood, T.K. The Properties of Gases and Liquids (McGraw-Hill, NY, 1966) Ch 9 and 10, and references therein 
Table 10. Thermal conductivity of a methane-n-butane mixture

Comparisons between thermal conductivity data from reference 25 and the predictions from (51) for a $\mathrm{CH}_{4}$ $(39.4 \%)-n-C_{4} \mathrm{H}_{10}(60.6 \%)$ mixture at $277.6 \mathrm{~K}$. For this mixture ${ }^{18} T^{\mathrm{c}} \approx 390 \mathrm{~K}, \rho^{\mathrm{c}} \approx 6.25$ mole $^{-1}$.

\begin{tabular}{|c|c|c|c|}
\hline \multirow{2}{*}{$\frac{\rho,}{\text { mole } 1^{-1}}$} & \multicolumn{2}{|c|}{$m W m^{-1} K^{-1}$} & \\
\hline & 99.00 & 95.33 & $(92.50)^{*}$ \\
\hline 12.49 & 101.46 & 99.63 & (96.61) \\
\hline 13.01 & 113.39 & 109.99 & $(106.5)$ \\
\hline 13.25 & 114.90 & 115.05 & $(111.3)$ \\
\hline
\end{tabular}

- From extended corresponding states.

Table 11. Thermal conductivity of a nitrogen-ethane mixture

Comparison between thermal conductivity data from reference 26 and the predictions from (51) for a nitrogen $(59.8 \%)$-ethane $(40.2 \%)$ mixture at $348.16 \mathrm{~K}$. For this mixture, ${ }^{18} T^{\mathrm{c}} \approx 260 \mathrm{~K}, \rho^{\mathrm{c}} \approx 12.0$ mole $^{-1}$.

\begin{tabular}{|c|c|c|c|}
\hline $\begin{array}{l}\rho \\
\text { mole } 1^{-1}\end{array}$ & $\lambda(\exp )$ & $\begin{array}{l}\lambda(\text { calc }), \\
{ }^{1} K^{-1}\end{array}$ & \\
\hline 7.34 & 46.0 & 46.11 & $(61.5)^{*}$ \\
\hline 10.16 & 55.2 & 54.69 & (72.65) \\
\hline 13.75 & 70.3 & 69.47 & $(92.4)$ \\
\hline 16.43 & 85.4 & 84.44 & (113.0) \\
\hline
\end{tabular}

" From extended corresponding states.
3 Preston, G.T., Chapman, T.W., Prausnitz, J.M. Cryogenics 7 (1967) 274

4 Mo, K.C., Gubbins, K.E. Chem Eng Commun 1 (1974) 281 ; Molecular Physics (forthcoming)

5 Longuet-lliggins, H.C. Proc Roy Soc (London) A205 (1951) 247

6 Leland, T.W., Chappelear, P.S., Gamson, B.W. AIChE J 8 (1962) 482; Leach, J.W., Chappelear, P.S., Leland, T.W. Proc Am Petrol Inst 46 (1966) 223

7 Mollerup, J., Rowlinson, J.S. Chem Eng Sc 29 (1974) 1373

8 Pitzer, K.S., Curl, R.F. Thermodynamic and Transport Properties of Fluids, (1nst of Mech Eng, London, 1958) 1

9 Haile, J.M., Mo, K.C., Gubbins, K.E. Cry ogenic Eng Conf (1975); Gubbins, K.E. private communication

10 Hanley, H.J.M., McCarty, R.D., Haynes, W.M. Cryogenics 15 (1975) 413

11 Goodwin, R.D. NBS Tech Note (US) No 653 (1974)

12 Mollerup, J. Advances in Cryogenic Engineering 20 (Plenum Press, NY) 172

13 Hanley, H.J.M., McCarty, R.D., Haynes, W.M. J Phys Chem Ref Dato 3 (1974) 979

14 Hanley, H.J.M., McCarty, R.D., Cohen, E.G.D. Physica 60 (1972) 322

15 Hanley, H.J.M., Prydz, R.J Chem Ref Dato 1 (1972) 1101

16 Hanley, H.J.M., Cohen, E.G.D. Physica 83A (1975) 215

17 Huang, E.T.S., Swift, G.W., Kurata, F. AIChE J 13 (1967) 846

18 Hicks, C.P., Young, C.L. Chem Rev 75 (1975) 119

19 Dolan, J.P., Ellington, R.T., Lee, A.L. J Chem Eng Dato 9 (1964) 484: 'Monograph on AP1 Research Project 65, Viscosity of light hydrocarbons', [Lee, A.L. (ed)]

20 Golubev, I.F. Viscosity of Gases and Gas Mixtures, (Israel Programme for Scientific Translations, Jerusalem, 1970)

21 Gerf, S.F., Galkov, G.I. Zhur Tekh Fiz 11 (1941) 801

22 Haynes, W.M. Physica 70 (1973) 410

23 Hanley, H.J.M., Gubbins, K.E. (forthcoming); data available from the Cryogenics Division, NBS, Boulder

24 Sengers, J.V., Hanley, H.J.M., Ely, J.F. Proc 14th lnt Conf Thermal Conductivity (Pergamon Press, NY, 1976)

25 Carmichael, L.T., Jacobs, J., Sage, B.H. J Chem Eng Data 13 (1968) 489

26 Gilmore, T.F., Comings, W.E. AIChE J 12 (1966) 1172

New from IPC Science and Technology Press

Contents:
The current state of play
Edward Armitage CB (Comptroller-General of the UK
Patent Office)
The defects and limitations of the present system
Basil Bard (Executive Director, First National Finance
Corporation; formerly Managing Director, National
Research Development Corporation)
The engineering viewpoint
Mervyn Fine (IIead of Legal Depurtment, Joseph Lucas
Ltd)
Illustrations from industry
John Aubrey (General Manager, Legal, Patent and Trade
Marks Service, Courtaulds Lid,
A licensing viewpoint
John Gay (UK Atomic Energy Authority, Harwell)
A5 size ISBN 0 902852 507
Price £5.50



FRACTURE MECHANICS PARAMETERS FOR A 5083-0

ALUMINUM ALLOY AT LOW TEMPERATURES †

R. L. Tobler and R. P. Reed

Cryogenics Division

Institute for Basic Standards

National Bureau of Standards

Boulder, Colorado 80302

\section{ABSTRACT}

The fatigue crack growth and fracture resistance of a 5083-0 aluminum alloy plate were investigated at four temperatures in the ambient-to-cryogenic range -- $295,111,76$, and $4 \mathrm{~K}$. J-integral test methods were applied using compact specimens $3.17 \mathrm{~cm}$ thick, and the value of $J$ required to initiate crack extension $\left(J_{I C}\right)$ is reported as an index of fracture toughness. The fracture toughness was orientation dependent, with anisotropy accounting for $J_{I c}$ variations of up to a factor of 2. For specimens having fracture planes parallel to the rolling direction, $J_{I c}$ increases progressively from 9 to $25 \mathrm{kJm}^{-2}$ as temperature decreases between 295 and $4 \mathrm{~K}$. In contrast, the fatigue crack growth rates $(\mathrm{da} / \mathrm{dN})$ are insensitive to specimen orientation. The fatigue crack growth rates at cryogenic temperatures are up to 10 times lower than in air at room temperature, but are virtually constant between 111 and $4 \mathrm{~K}$. These results should be useful in fracture mechanics analyses of cryogenic structures, including liquified natural gas tankers.

Key words: Aluminum alloys; cryogenics; crack propagation; fatigue; fracture; low temperature tests; mechanical properties.

Tontribution of NBS, not subject to copyright. 
The aluminum alloy designated $5083-0$ is strengthened by solid solution additions of magnesium and used in the annealed condition. Excellent formability, weldability, toughness, and relatively low cost are some advantages that make this alloy an attractive low temperature structural material. Applications include storage and transport tanks for cryogenic fluids. Currently, thousands of tons of 5083-0 alloy are destined for use in liquefied natural gas (LNG) tankers at service temperatures as low as $111 \mathrm{~K}$. Emerging applications may include structural components for superconducting machinery. These structures are costly, and in the case of LNG tankers, the transported cryogen is flammable. Design engineers and regulatory agencies therefore require efficient and fail-safe design.

Extensive mechanical property data exist for 5083-0 aluminum [1-7]. Between room and liquid helium temperatures (295 to $4 \mathrm{~K}$ ), the yield and ultimate strengths increase by $25 \%$ and $70 \%$, respectively, with most of the improvement occurring at lower temperatures [2]. Ductility also improves at low temperatures, and precracked specimens retain the ability to deform prior to fracture. Nevertheless, quantitative fracture toughness data for this alloy are lacking. Several attempts to measure the critical stress intensity factor, $K_{\text {IC }}$, have been unsuccessful. As defined by the ASTM testing method for plane strain fracture toughness of metallic materials (ASTM E 399-74), the parameter K IC applies to linear-elastic loading behavior. Kaufman, Nelson, and Wygonik [3] showed that 5083-0 alloys in section thicknesses up $20 \mathrm{~cm}$ remain sufficiently plastic to invalidate direct $K_{\text {Ic }}$ measurements. 
This study employs an alternative approach to fracture toughness characterization. The method is based on Rice's formulation of the J-integral [8], which is the rate of change of potential energy with respect to crack area. In applications of the J-integral, Begley and Landes identify a parameter denoted $J_{\text {Ic }}$ which, unlike $K_{\text {IC }}$, can be measured under nonlinear-elastic conditions $[9,10]$. Since experimental results for aluminum alloys support the hypothesis that $J_{I c}$ is a material constant $[11,12]$, the J-resistance curve test method [10] was applied here to a 5083-0 aluminum plate. The J Ic values and fatigue crack growth rates reported in this study should assist fracture mechanics analyses of 5083-0 structures at temperatures in the ambientto-cryogenic range.

\section{PROCEDURES}

\section{Material and Specimens}

A $4.32 \mathrm{~cm}$ thick 5083-0 aluminum alloy plate was obtained from a commercial source and tested in the as-received condition. The microstructure is shown in Figure 1. The ASTM specification B 209-66 gives the chemical composition of this alloy in wt\% as: $4.0-4.9 \mathrm{Mg}, 0.3-1.0$ $\mathrm{Mn}, 0.05-0.25 \mathrm{Cr}, 0.4 \max . \mathrm{Si}, 0.4 \mathrm{max}$. Fe, $0.10 \max . \mathrm{Cu}, 0.25 \max . \mathrm{Zn}$, $0.15 \mathrm{max} . \mathrm{Ti}$, and $0.15 \mathrm{max}$. of other impurities.

After machining $0.44 \mathrm{~cm}$ of metal from each surface of the stock plate, $3.17 \mathrm{~cm}$ thick compact specimens were fabricated with the geometry shown in Figure 2. The specimen width, $W$, was $7.62 \mathrm{~cm}$. The width-tothickness ratio, W/B, was 2.4. Knife edges were machined integral to the notch to enable clip gage attachment and deflection measurements at the loadline. Most of the specimens were machined in the TL orientation (fracture plane normal to the long transverse direction), but 
several specimens of the LT orientation (fracture plane normal to the longitudinal or rolling direction) were also tested.

Tensile tests of unnotched, longitudinally-oriented specimens were performed at room and liquid nitrogen temperatures, following ASTM Method E 8-69. Two tests were performed at each temperature. The yield and ultimate strengths, elongation, and reduction of area results, shown in Table 1, agree with other data for similar 5083-0 products [13]. Fatigue Crack Growth

A $100 \mathrm{kN}$ servo-hydraulic test machine adaptable for cryogenic service was used in all fatigue and fracture tests. Room temperature tests were conducted in unconditioned air at a relative humidity, $\mathrm{H}$, of approximately $30 \%$. Low temperatures were achieved by enclosing the load frame, specimen, and clip gage in a dewar of liquid helium $(4 \mathrm{~K})$, liquid nitrogen $(76 \mathrm{~K})$, or nitrogen gas $(111 \pm 4 \mathrm{~K})$. The low temperature apparatus and techniques were previously described $[14,15]$. The clip gage satisfied ASTM Method E 399-74 linearity requirements, and its sensitivity changed by no more than $5 \%$ over the temperature range investigated.

The compact specimens were precracked at their test temperatures using maximum fatigue stress intensity factors of from 10 to $22 \mathrm{MPa} \cdot \mathrm{m}^{1 / 2}$. The minimum-to-maximum load ratio, $R$, was 0.1 . Some fatigue crack growth rates were measured during precracking, but additional rates at relatively high stress intensity factors or $\mathrm{R}$ values were measured using specimens not intended for J-tests. All precracking and fatigue crack growth tests used sinusoidally-varying loads at a frequency of $20 \mathrm{~Hz}$.

A correlation between crack length (a) and specimen compliance 
(deflection per unit load, $\delta / P$ ) was established using measurements from fractured specimens. Crack length was defined as the average of three measurements at the middle and quarter points of specimen thickness. The fatigue tests were then interrupted periodically to record compliance, and the inferred crack length was plotted as a function of load cycles, N. The fatigue crack growth rates, da/dN, were calculated by graphical differentiation of a-versus $-N$ curves, while the corresponding stress intensity factor ranges, $\Delta K$, were calculated from the maximum and minimum fatigue loads:

$$
\dot{E} K=\left(P_{\max }-P_{\min }\right) B^{-1} W^{-1 / 2}[f(a / W)]
$$

According to ASTM Method E 399-74,

$f(a / W)=29.6(a / W)^{1 / 2}-185.5(a / W)^{3 / 2}+655.7(a / W)^{5 / 2}-1017.0(a / W)^{7 / 2}+638.9(a / W)^{9 / 2}$.

The uncertainty in crack growth rates is estimated at less than $\pm 25 \%$. Fracture Toughness

At each test temperature, a series of specimens having similar precrack lengths were loaded to selected deflections at the stroke rate of $0.05 \mathrm{mms}^{-1}$. These loadings were sufficient to cause stable crack extensions of up to $0.25 \mathrm{~cm}$. Each specimen was then unloaded and refatigued using cyclic loads no greater than $70 \%$ of the maximum static load. After the refatigue crack was propagated several millimeters, the specimens were fractured into halves by a single loading.

The fracture surfaces showed, in succession: (1) a precrack zone, (2) a crack extension increment due to static loading, and (3) a refatigue 
crack zone. The relatively coarse and less reflective increment of static crack extension was measured to the nearest $0.003 \mathrm{~cm}$ with a traveling microscope at the center and quarter points of specimen thickness, the three-point average being defined as $\Delta a$. The corresponding values of $\mathrm{J}$ were calculated for each test, using the approximate solution for deeply cracked compact specimens [16]:

$$
J=2 A / B b \text {. }
$$

Here, $A$ is the total area (energy) under the test record up to the point of unloading, and $b$ is the original ligament depth $(b=w-a)$. The uncertainty in $\mathrm{J}$ measurements was not greater than $\pm 2 \%$.

To obtain critical $\mathrm{J}$ values, the resistance curves of $\mathrm{J}$-versus- $\Delta \mathrm{a}$ were back-extrapolated to $\Delta \mathrm{a}=0.005 \mathrm{~cm}$. In tests of a 2219-T6 aluminum alloy, Read and Reed [12] suggested that defining J Ic at $0.005 \mathrm{~cm}$ crack extension leads to reproducible results. The uncertainty in the $\mathrm{J}_{\mathrm{Ic}}$ values obtained in this way for 5083-0 aluminum is estimated at $\pm 15 \%$.

\section{RESULTS AND DISCUSSION}

\section{Fatigue Crack Growth}

Fatigue crack growth data at $4,76,111$, and $295 \mathrm{~K}$ for 5083-0 aluminum specimens of the $T L$ orientation at $R=0.1$ are shown in Figure 3 . The results span two orders of magnitude from $5 \times 10^{-6} \mathrm{~mm} /$ cycle to $2.5 \times$ $10^{-3} \mathrm{~mm} /$ cycle. For a given $\Delta K$ value, the rates of crack growth at 111 , 76 , and $4 \mathrm{~K}$ are equivalent within the degree of scatter among replicate tests. However, the rates at room temperature are up to 10 times faster than the rates at cryogenic temperatures. 
As plotted on logarithmic coordinates, the low temperature fatigue crack growth data describe an approximately linear trend over the entire $\Delta K$ range, whereas the room temperature data do not. The Tinear approximation to the data at 111,76 and $4 \mathrm{~K}$, shown in Figure 3 , is consistent with a Paris equation of the form:

$$
\frac{d a}{d N}=C(\Delta K)^{n}
$$

Here $\mathrm{da} / \mathrm{dN}(\mathrm{mm} / \mathrm{cycle})$ is a power law function of $\Delta K\left(M P a \cdot \mathrm{m}^{1 / 2}\right)$. The constants $\mathrm{C}$ and $\mathrm{n}$ correspond to the ordinate intercept at $\Delta K=1$, and the slope, respectively. A graphical solution for the equation of the line drawn through the 111,76 and $4 \mathrm{~K}$ data yie $1 \mathrm{ds}$ :

$$
\frac{\mathrm{da}}{\mathrm{dN}}=1.3 \times 10^{-10}(\Delta \mathrm{K})^{5.2} .
$$

The room temperature data fail to conform to a single power-law equation, due to the appearance of a "shoulder" on the da/dN-versus- $\Delta K$ plot at $\Delta K$ values between 10 and $15 \mathrm{MPa} \cdot \mathrm{m}^{1 / 2}$. This shoulder brings the room and low temperature crack growth rates into closer agreement at higher $\Delta K$ values. Consequently, the room temperature fatigue crack growth resistance is only slightly inferior at stress intensity factor ranges greater than $15 \mathrm{MPa} \cdot \mathrm{m}^{1 / 2}$.

Figure 4 shows additional crack growth data for the TL orientation at 295 and $111 \mathrm{~K}(R=0.3)$, as well as data on specimens of the LT orientation at $111 K(R=0.1)$. Scatterbands representing the data of Figure 3 are superimposed on Figure 4 for comparison. This comparison indicates that the change in $R$ from 0.1 to 0.3 had no effect on the 
room temperature fatigue crack growth rates, whereas, at $111 \mathrm{~K}$, this change increased the rates by nearly a factor of 2 . Also the data obtained for specimens of the LT orientation at $111 \mathrm{~K}$ fall within the band for $T L$ orientations for the same stress ratio, $R=0.1$. Thus, specimen orientation has no measureable effect on fatigue crack growth rates. Kaufman and Kelsey [17] also noted relatively isotropic fatigue crack growth in their tests of a 5083-0 aluminum alloy.

Comparisons of fatigue crack growth data reported in the literature for compact specimens of 5083-0 aluminum are shown in Figures 5 and 6 . Although these data show considerable variance, most results can be rationalized in terms of the different test variables and procedures. Usualiy, higher $R$ values lead to increased fatigue crack growth rates. Other significant factors to be considered include the procedure used to obtain a-versus- $\mathrm{N}$ data, and the relative humidity at room temperature.

In reference to Figures 5 and 6 note first that the present study yielded somewhat lower rates at a given $\Delta K$ value as compared with other investigations $[6,17-19]$. In our study, the crack length was defined as an average of measurements at the center and quarter points of thickness. Other studies used measurements of the crack at specimen edges. In our study the edge crack lengths were typically 5 to $8 \%$ shorter than the average crack lengths. If edge crack lengths had been used, the $f(a / W)$ values of Eq. (1) would have been reduced, and the $\Delta K$ value for a given growth rate would have been 10 to $17 \%$ lower than actualily reported. This would shift the bands of Figures 5 and 6 into good agreement with the bulk of previously published results.

As shown in Figure 5 , at least three other laboratories report a shoulder in roon temperature fatigue crack growth rates [17-19]. This 
shoulder occurs at rates near $3 \times 10^{-4} \mathrm{~mm} /$ cycle, for tests conducted in air with appreciable moisture contents. Kelsey, Nordmark and Clark's [4] room temperature results at $90 \%$ relative humidity and $R=0.33$ are nearly in agreement with Argy, Paris, and Shaw's [18] results at $\sim 50 \%$ relative humidity and $R=0.4$. However, as the relative humidity is decreased to less than $10 \%$, the shoulder is eliminated and fatigue crack propagation resistance at low $\Delta K$ is improved. Note in Figure 5 that the overall agreement of data is better at high $\Delta K$ values where differences in relative humidity are less influential.

Deleterious effects on the fatigue crack growth resistance of this alloy due to moisture are not surprising in view of the trends exhibited by other aluminum alloys [20]. Hartman and Schijve's [21] data for a 7075-T6 alloy derionstrate trends analogous to the behavior indicated in Figure 5. In dry air, their logarithmic plots of $d a / d N$-versus- $\Delta K$ display a linear trend for growth rates in the range $10^{-5}$ to $10^{-3} \mathrm{~mm} / \mathrm{cycle}$; in moist air (relative humidity $=45 \%$ ), a shoulder appears in the data at $\angle K \simeq 15 \mathrm{MPa} \cdot \mathrm{m}^{1 / 2}$, and the rates at lower $\Delta K$ are accelerated by up to a factor of 10 . Again, the rates at high $\Delta K$ are not sensitive to moisture.

Thus, the effects of moisture on the room temperature fatigue crack growth behavior of 5083-0 and 7075-T6 alloys are remarkably similar. The trend of the Kelsey et a1. [4] data for 5083-0 aluminum in a dry air environment probably represents the true trend of room temperature results when moisture effects are practically eliminated. Note from Figures 5 and 6 that the rates reported by Kelsey et a1. [18] for tests in dry air at $295 \mathrm{~K}$ are nearly equivalent to but slightly faster than their rates at $76 \mathrm{~K}$. Based on these observations, it may be concluded 
that moisture effects at $295 \mathrm{~K}$ are predominant, and temperature variations between $295 \mathrm{~K}$ and $4 \mathrm{~K}$ intrinsically have little effect on the fatigue crack propagation resistance of 5083-0 aluminum. This is consistent with results for other face-centered cubic alloys which show only modest improvements of fatigue crack growth resistance at low temperatures [22].

\section{Fracture Toughness}

Plasticity and stable crack extension caused nonlinearity in the fracture test records at all temperatures, and unstable cracking was never observed. As expected, the linearity requirements of sections 9.1 .2 and 9.1 .5 of ASTM Method E 399-74 could not be satisfied using our specimens of aluminum alloy 5083-0, so it was appropriate to conduct $\mathrm{J}$-integral tests. Table 2 lists the $\mathrm{J}$-integral test results for both the $L T$ and $T L$ specimen orientations.

Resistance curves (J-versus- $\Delta$ a graphs) for the $T L$ orientation are shown in Figure 7 . The results at $295,111,76$, and $4 \mathrm{~K}$ show that higher $J$ values are required for a given crack extension as temperature decreases. The J $J_{\text {Ic }}$ values obtained at $\Delta a=0.005 \mathrm{~cm}$ progressively increase from 9 to $25 \mathrm{kJm}^{-2}$ between 295 and $4 \mathrm{~K}$. Moreover, the rate of increase of $\mathrm{J}$ with respect to $\Delta \mathrm{a}$ is greater at 111,76 , and $4 \mathrm{~K}$ than at room temperature. Thus, greater energy is expended in fracture initiation and propagation at cryogenic temperatures. Kahn-type tear and dynamic tear tests render a similar conclusion [5-7, 23].

Figure 8 compares the J-resistance curves for the TL and LT orientations at $111 \mathrm{~K}$, demonstrating the anisotropy of fracture toughness for this alloy. Based on these curves, J Ic for the LT orientation is approximately $39 \mathrm{kJm}^{-2}$ at $117 \mathrm{~K}$, or twice the value for the TL orientation. The superiority of the LT orientation in comparison with the TL 
orientation is typical of many alloys, and the tear test results and projected $K_{I c}$ values reported by Kaufman et al. $[3,5,6]$ indicate a similar orientation dependence for 5083-0 aluminum.

The fracture anisotropy is also evident in Figure 9, which shows TL and LT specimens that were tested at $111 \mathrm{~K}$. The LT specimen was fatigue cracked and fractured in a single loading. The TL specimen was used in a J-test, and it shows an increment of crack extension, $\Delta a$, located between two fatigue cracks. The LT specimen displays shear fracture portions ar.ounting to $30 \%$ of specimen thickness; delaminations are also visible at mid-thickness. In comparison, the TL specimen exhibits a flat fracture mode requiring less energy for crack extension. The fracture surface appearance of the TL orientation was not significantly influenced by test temperature.

The $J_{I c}$ data listed in Table 2 can be used to estimate $K_{\text {Ic }}$ values by using the equation:

$$
K_{I C}^{2}=\frac{{ }^{E J}{ }_{I C}}{1-v^{2}}
$$

In this equation, $E$ is Young's modulus of elasticity and $v$ is Poisson's ratio. The values of $E$ and $v$ at temperatures between 295 and $4 \mathrm{~K}$ are known from Naimon, Weston, and Ledbetter's study [24]. The $K_{I c}$ estimates based on these data at 295, 111, 76 and $4 \mathrm{~K}$ are plotted in Figure 10 , along with the corresponding $J_{I C}$ values.

As shown in Figure 10 , the $K_{I c}$ estimates converted from $J_{I c}$ data range from 27.0 to $60.2 \mathrm{MPa} \cdot \mathrm{m}^{1 / 2}$, depending on temperature and specimen orientation. For the TL orientation, the $K_{I C}$ estimates at 295 and $76 \mathrm{~K}$ are 27.0 and $43.4 \mathrm{MPa} \cdot \mathrm{m}^{1 / 2}$, respectively. These are lower than Kaufman 


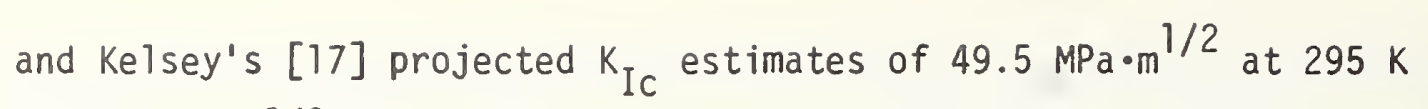
and $55 \mathrm{MPa} \cdot \mathrm{m}^{1 / 2}$ at $77 \mathrm{~K}$. Kaufman and Kelsey's $\mathrm{K}_{\mathrm{Ic}}$ estimates also pertain to specimens of the TL orientation, but their $K$ calculations are based on the maximum load observed in fracture tests. Their procedure does not account for the fact that crack extension occurs prior to maximum load.

Finally, it should be noted that Merkle and Corten's method [25] of $J$ calculation could have been used in this study. When applied to the 5083-0 aluminum experiments described in the text, that method amounts to replacing the coefficient 2 in Eq. (3) by higher factors from 2.2 to 2.3. The J Ic values would have been increased by about $10 \%$; the $\mathrm{K}_{\mathrm{Ic}}$ estimates, by $5 \%$. Read and Reed [12] found from measuring both $\mathrm{K}_{\mathrm{IC}}$ and $\mathrm{J}_{\mathrm{Ic}}$ at $76 \mathrm{~K}$ for the aluminum alloy 22199-T87 that $\mathrm{J}_{\mathrm{Ic}}$ as calcuiated from the measured $K_{I c}$ was about $40 \%$ greater than the measured $J_{I c}$. Thus, the $J_{I c}$ data and $K_{I c}$ estimates reported here for 5083-0 may be considered conservative.

\section{SUMMARY AND CONCLUSIONS}

The fatigue crack growth behavior and J-integral fracture toughness of a 5083-0 alumirum alloy have been investigated at 295, 111, 76 and $4 \mathrm{~K}$, a wider range of temperatures than previously studied. Specifically:

1. Fatigue crack growth resistance at $111 \mathrm{~K}$ was insensitive to specimen orientation, but improves at decreasing $R$ ratios.

2. Although the fatigue crack growth rates in ambient air at room temperature exceed the rates at cryogenic temperatures by up to a factor of 10, the rates between 111 and $4 \mathrm{~K}$ are nearly equivalent. The high rates in ambient air can be attributed to the presence of moisture, rather than temperature effects per se. 
3. Results for the TL orientation at decreasing temperatures between $295 \mathrm{~K}$ and $4 \mathrm{~K}$ indicate nearly a three-fold increase of $\mathrm{J}_{\text {IC }}$ from 9 to $25 \mathrm{kJm}^{-2}$.

4. Anisotropy in rolled plate caused a $J_{I c}$ variation of a least $2: 1$ at the LNG temperature of $111 \mathrm{~K}$.

5. In view of the favorable low temperature effects on tensile, fatigue, and fracture properties, it is apparent that the structural reliability of flawed or unflawed 5083-0 alloy components will not be decreased by cryogenic temperatures.

\section{ACKNOWLEDGMENTS}

This work was sponsored by the Maritime Administration and the Advanced Research Projects Agency of the U.S. Department of Defense. The authors gratefully acknowledge the assistance of R. L. Durcholz and Dr. R. P. Mikesell in conducting the tensile tests. We also wish to thank Dr. R. A. Kelsey of the Alcoa Technical Center for reviewing the manuscript. 


\section{REFERENCES}

1. Properties of Materials for Liquefied Natural Gas Tankage, ASTM STP 579, Amer. Soc. Test. Mater., Philadelphia, 1975, pp. 1-204.

2. Rice, L. P., Campbe11, J. E., and Simmons, W. F., in Advances in Cryogenic Engineering, Vo1. 8, 1963, pp. 671-677.

3. Kaufman, J. G., Nelson, F. G., and Wygonik, R. H., in Fatigue and Fracture Toughness -- Cryogenic Behavior, ASTM STP 556, Amer. Soc. Test. Mater., 1974, pp. 125-158.

4. Kelsey, R. A., Nordmark, G. E., and Clark, J. W., in Fatigue and Fracture Toughness -- Cryogenic Behavior, ASTM STP 556, Amer. Soc. Test. Mater., 1974, pp. 159-185.

5. Kaufman, J. G., Nelson, F. G., and Wanderer, E. T., Mechanical Properties and Fracture Characteristics of 5083-0 Products and 5183 Welds in 5083 Products, Proceedings of the International Congress of Refrigeration, Washington, D.C., Vol. 1, 1971, pp. 651-658.

6. Nelson, F. G., Kaufman, J. G., and Wanderer, E. T., Tear Tests of 5083 Plate and of 5183 Welds in 5083 Plate and Extrusions, Paper D-1 in Adv. in Cryo. Eng., K. D. Timmerhaus, Ed., pp. 91-101.

7. Judy, R. J., Jr., and Goode, R. J., Fracture Resistance of Thick Plate 5083-0 Alloy, Report of NRL Progress, December 1974, pp. 36-38.

8. Rice, J. R., J. Appl. Mechs., Trans. ASME, Vol. 35, 1968, pp. 379-386.

9. Begley, J. A. and Landes, J. D., in Fracture Toughness, ASTM STP 514, Amer. Soc. Test. Mater., 1972, pp. 1-39.

10. Landes, J. D. and Begley, J. A., in Fracture Analysis, ASTM STP 560, Amer. Soc. Test. Mater., 1975, pp. 170-186. 
11. Griffis, C. A. and Yoder, G. R., Application of the J-Integral to Crack Initiation in a 2024-T351 Aluminum Alloy, Naval Research Report 7676, 1974, pp. 1-25.

12. Read, D. T. and Reed, R. P., Effects of Specimen Thickness on Fracture Toughness of Some Aluminum Alloys, submitted to Int. J. Fract. (1976).

13. Bogardus, K. 0. and Malcolm, R. C., in Ref. 1, pp. 190-204.

14. Fowlkes, C. H. and Tobler, R. L., Fracture Testing and Results for a Ti-6Al-4V Alloy, Eng. Fract. Mechs., to be published.

15. Tobler, R. L., Mikesel1, R. P., Durcholz, R. L., and Reed, R. P., in Ref. 1, pp. 261-287.

16. Rice, J. R., Paris, P. C., and Merkle, J. G., in Progress in Flaw Growth and Fracture Toughness Testing, ASTM STP 536, Amer. Soc. Test. Mater., 1973, pp. 231-244.

17. Kaufman, J. G. and Kelsey, R. A., in Ref. 1, pp. 138-158.

18. Argy, R., Paris, P. C., and Shaw, F., in Ref. 1, pp. 96-137.

19. Person, N. L. and Wolfer, G. C., in Ref. 1, pp. 80-95.

20. Hei, R. P., Eng. Fract. Mechs., Vol. 4, 1970, pp. 633-651.

21. Hartman, A. and Schijve, NLR Tech Note No. MP 68001 U, 1968; see also Fig. 11 of Reference 17.

22. Materials Research in Support of Superconducting Machinery, Vols. III, IV, and V, Reed, R. P., Clark, A. F., and van Reuth, E. C., Eds., National Bureau of Standards, Boulder, CO.

23. Zinkham, R. E. and Ashton, R. F., in ASTM STP 579, Ref. 1, pp. 159-175.

24. Weston, H. F., Naimon, E. R., and Ledbetter, H. M., in Ref. 1, pp. 397-420.

25. Merkle, J. G. and Corten, H. T., "A J-Integral Analysis for the Compact Specimen, Considering Axial Force as Well as Bending Effects," presented at the Pressure Vessels and Piping Conference with Nuclear Engineering and Mechanical Divisions, American Society of Mechanical Engineers, Paper No. 74-PVP-33, 1974. 


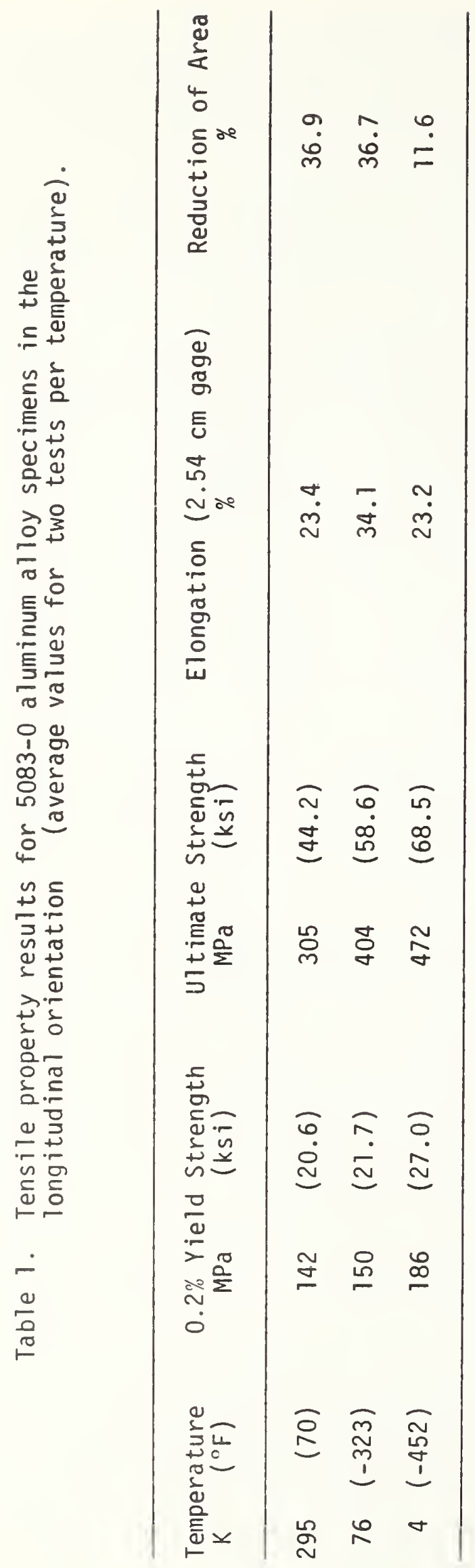


Table 2. J-integral test results.

\begin{tabular}{|c|c|c|c|c|c|c|c|}
\hline$\underset{K}{\text { Temperature }}$ & Specimen & Orientation & $\begin{array}{c}K_{f \max } \\
M P a \cdot \mathrm{m}^{1 / 2}\end{array}$ & $\begin{array}{l}\mathrm{a} / \mathrm{W} \\
\mathrm{cm}\end{array}$ & $\begin{array}{l}\Delta \mathrm{a} \\
\mathrm{cm}\end{array}$ & $\mathrm{kJm}^{-2}$ & $\begin{array}{l}J_{I C} \\
k J^{-2}\end{array}$ \\
\hline 295 & $\begin{array}{r}13 \\
28 \\
9 \\
8 \\
31 \\
7 \\
14\end{array}$ & $\begin{array}{l}\text { TL } \\
T L \\
T L \\
T L \\
T L \\
T L \\
T L \\
T L\end{array}$ & $\begin{array}{l}14 \\
21 \\
15 \\
21 \\
13 \\
15 \\
22\end{array}$ & $\begin{array}{l}.642 \\
.647 \\
.647 \\
.620 \\
.641 \\
.644 \\
.611\end{array}$ & $\begin{array}{l}.010 \\
.020 \\
.029 \\
.036 \\
.059 \\
.070 \\
.109\end{array}$ & $\left.\begin{array}{l}10.3 \\
15.8 \\
20.1 \\
22.9 \\
27.5 \\
30.5 \\
41.6\end{array}\right\}$ & 9 \\
\hline 111 & $\begin{array}{l}2 \\
3 \\
4 \\
5\end{array}$ & $\begin{array}{l}\text { LT } \\
\text { LT } \\
\text { LT } \\
\text { LT }\end{array}$ & $\begin{array}{l}16 \\
18 \\
18 \\
18\end{array}$ & $\begin{array}{l}.622 \\
.612 \\
.622 \\
.619\end{array}$ & $\begin{array}{l}.033 \\
.019 \\
.033 \\
.053\end{array}$ & $\begin{array}{l}65.6 \\
54.2 \\
60.8 \\
76.0\end{array}$ & 41 \\
\hline 111 & $\begin{array}{l}30 \\
20 \\
22 \\
10 \\
11\end{array}$ & $\begin{array}{l}T L \\
T L \\
T L \\
T L \\
T L\end{array}$ & $\begin{array}{l}19 \\
13 \\
14 \\
20 \\
20\end{array}$ & $\begin{array}{l}.622 \\
.630 \\
.617 \\
.629 \\
.617\end{array}$ & $\begin{array}{l}.010 \\
.023 \\
.056 \\
.103 \\
.253\end{array}$ & $\begin{array}{r}23.6 \\
36.4 \\
59.1 \\
78.5 \\
122.4\end{array}$ & 19 \\
\hline 76 & $\begin{array}{r}20 \\
17 \\
19 \\
16 \\
14 \\
9\end{array}$ & $\begin{array}{l}\text { TL } \\
\text { TL } \\
\text { TL } \\
\text { TL } \\
\text { TL } \\
\text { TL }\end{array}$ & $\begin{array}{l}15 \\
14 \\
16 \\
14 \\
17 \\
21\end{array}$ & $\begin{array}{l}.629 \\
.623 \\
.631 \\
.633 \\
.628 \\
.632\end{array}$ & $\begin{array}{l}.010 \\
.019 \\
.026 \\
.039 \\
.083 \\
.093\end{array}$ & $\begin{array}{l}27.9 \\
31.2 \\
40.5 \\
54.7 \\
72.5 \\
77.3\end{array}$ & 21 \\
\hline 4 & $\begin{array}{l}15 \\
11 \\
10 \\
17 \\
16 \\
18\end{array}$ & $\begin{array}{l}T L \\
T L \\
T L \\
T L \\
T L \\
T L\end{array}$ & $\begin{array}{l}19 \\
18 \\
20 \\
19 \\
18 \\
18\end{array}$ & $\begin{array}{l}.602 \\
.597 \\
.608 \\
.602 \\
.602 \\
.597\end{array}$ & $\begin{array}{l}.003 \\
.003 \\
.010 \\
.019 \\
.030 \\
.056\end{array}$ & $\left.\begin{array}{l}13.7 \\
17.6 \\
30.2 \\
38.3 \\
47.3 \\
61.4\end{array}\right\}$ & 25 \\
\hline
\end{tabular}




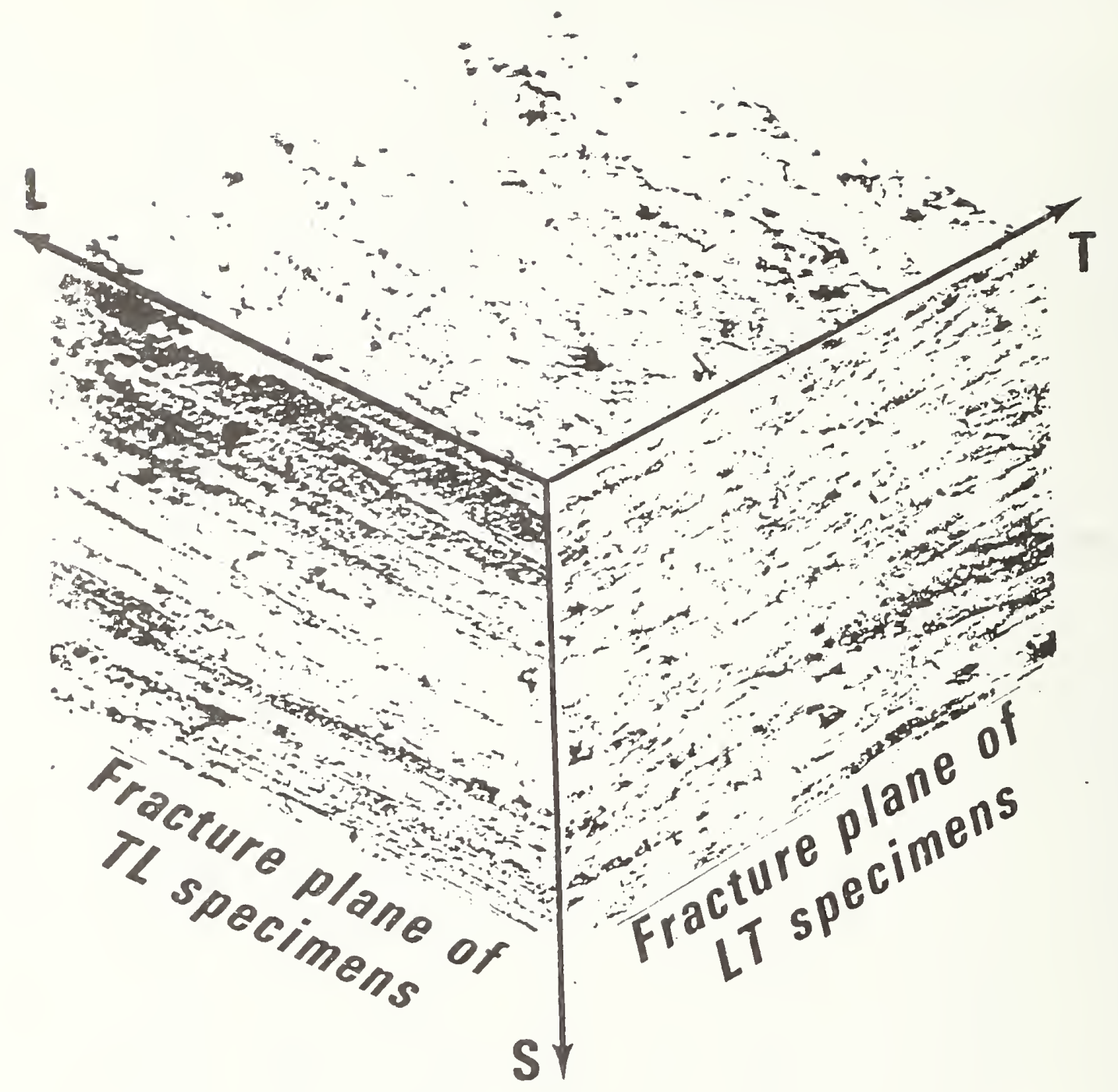

\section{$\mathrm{L}$-longitudinal or rolling direction T-long transverse direction} S-short transverse or plate thickness direction

Figure 1. Microstructure of 5083-0 after rolling and annealing, 100X. 


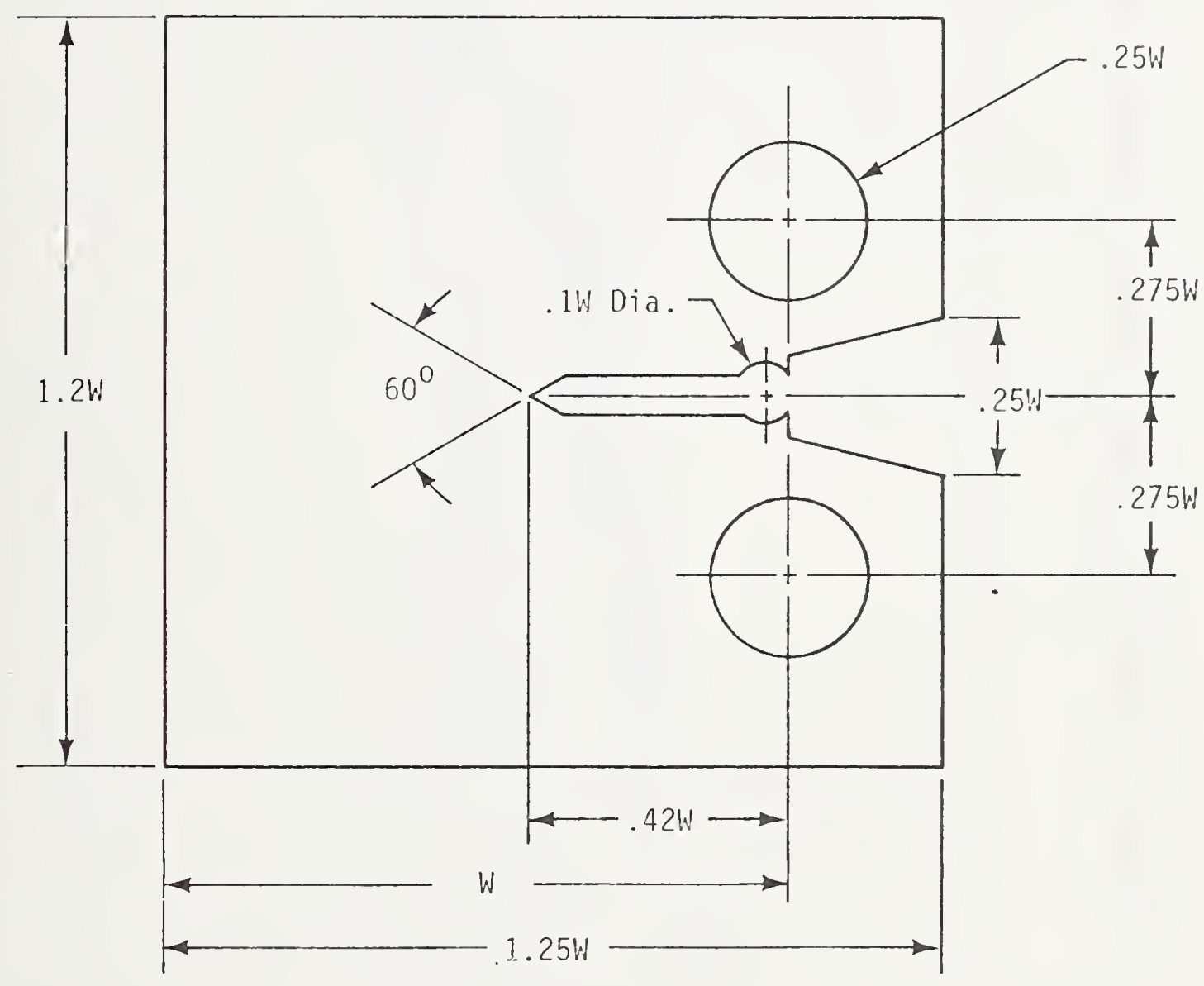

Figure 2. Compact specimen used in fatigue and fracture tests (thickness, $B=3.17 \mathrm{~cm}$; dimensions are in $\mathrm{cm}$ ). 


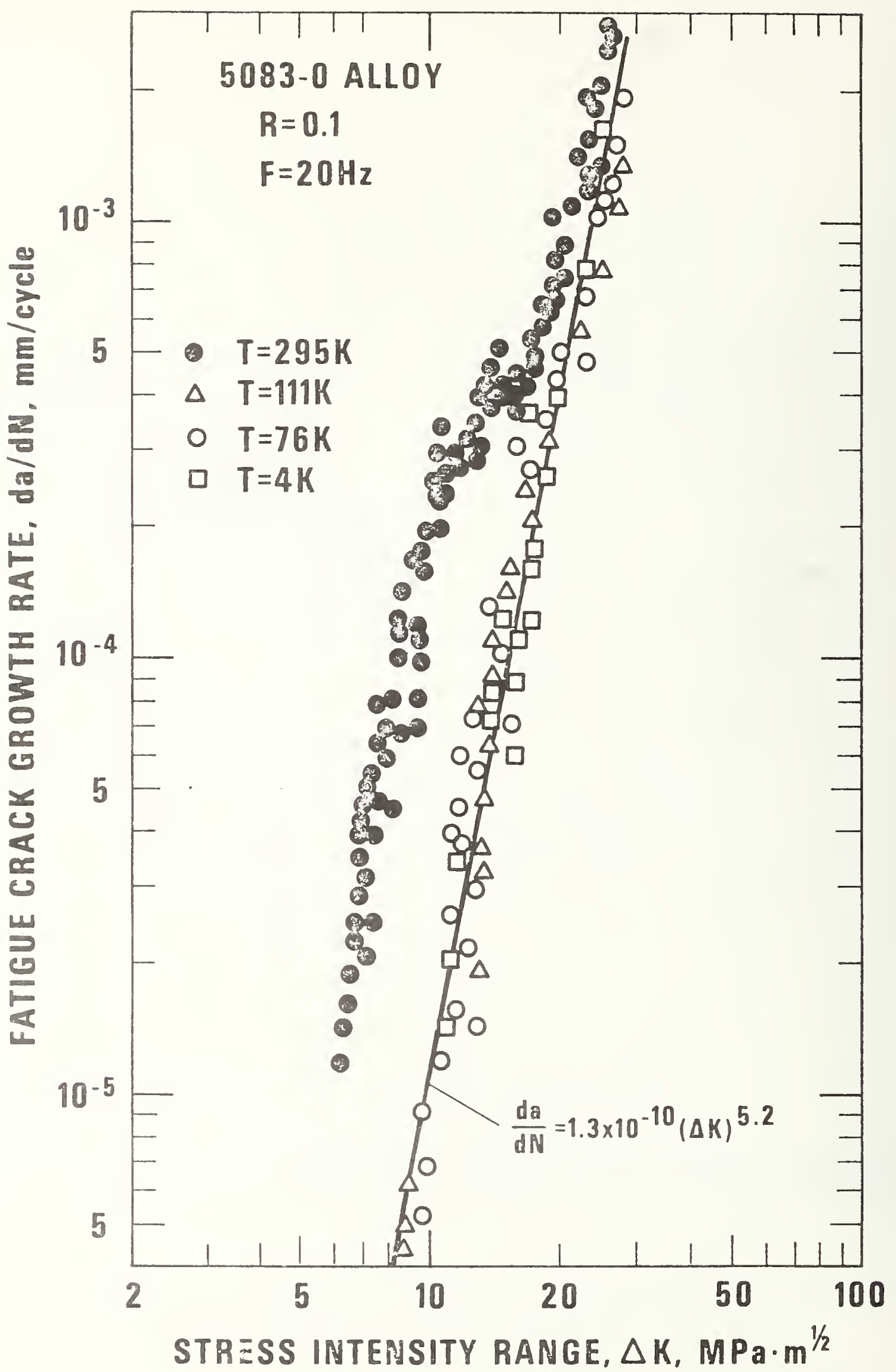

Figure 3. Fatigue crack growth rate results for TL orientations at $295,111,76$ and $4 \mathrm{~K}$. 


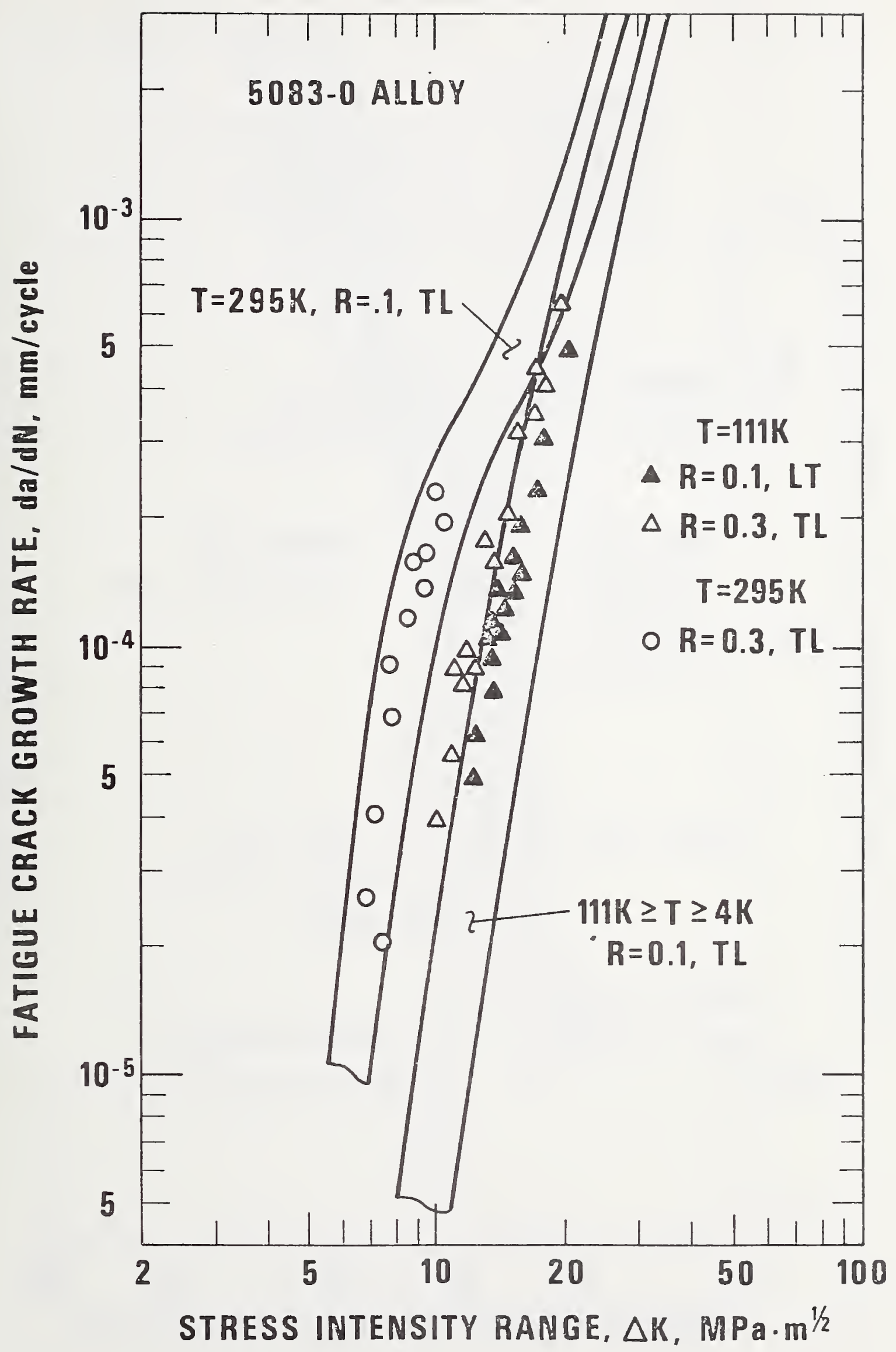

Figure 4. Fatigue crack growth rate results at 295 and $111 \mathrm{~K}$, showing the effects of orientation and $R$ ratio variations. 


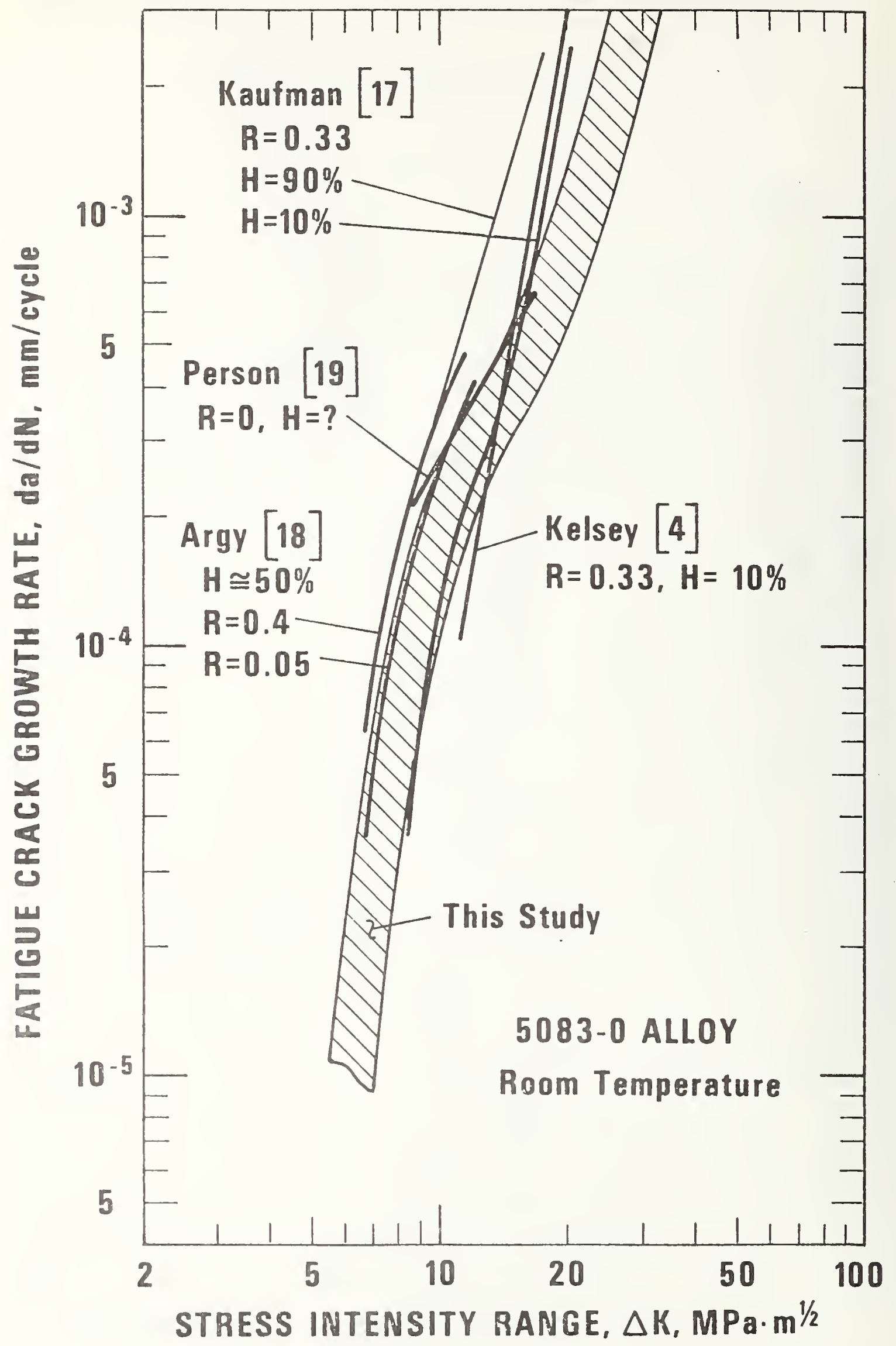

Figure 5. Comparison of fatigue crack growth data at $295 \mathrm{~K}$. 


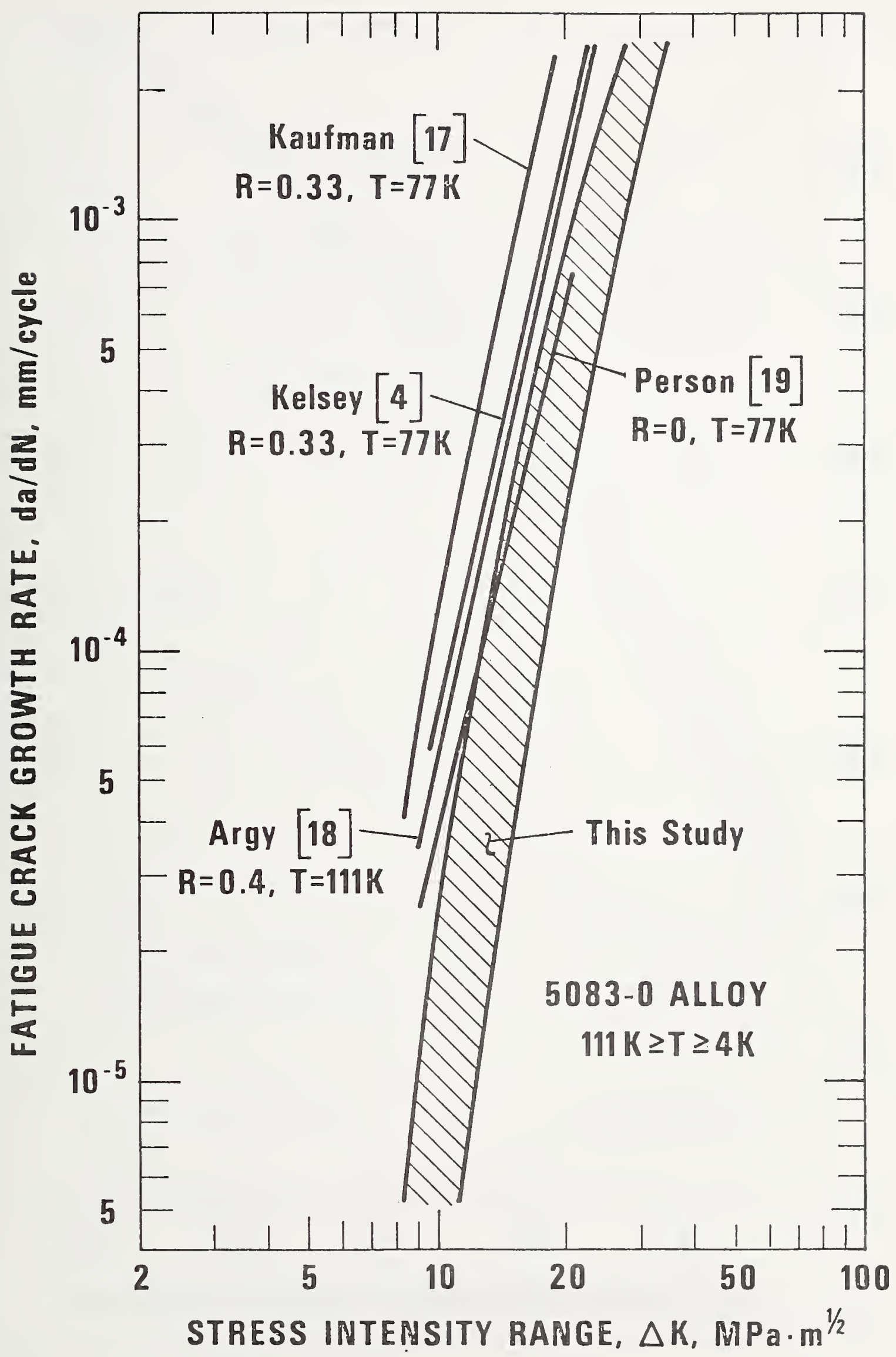

Figure 6. Comparison of fatigue crack growth data at low temperatures. 


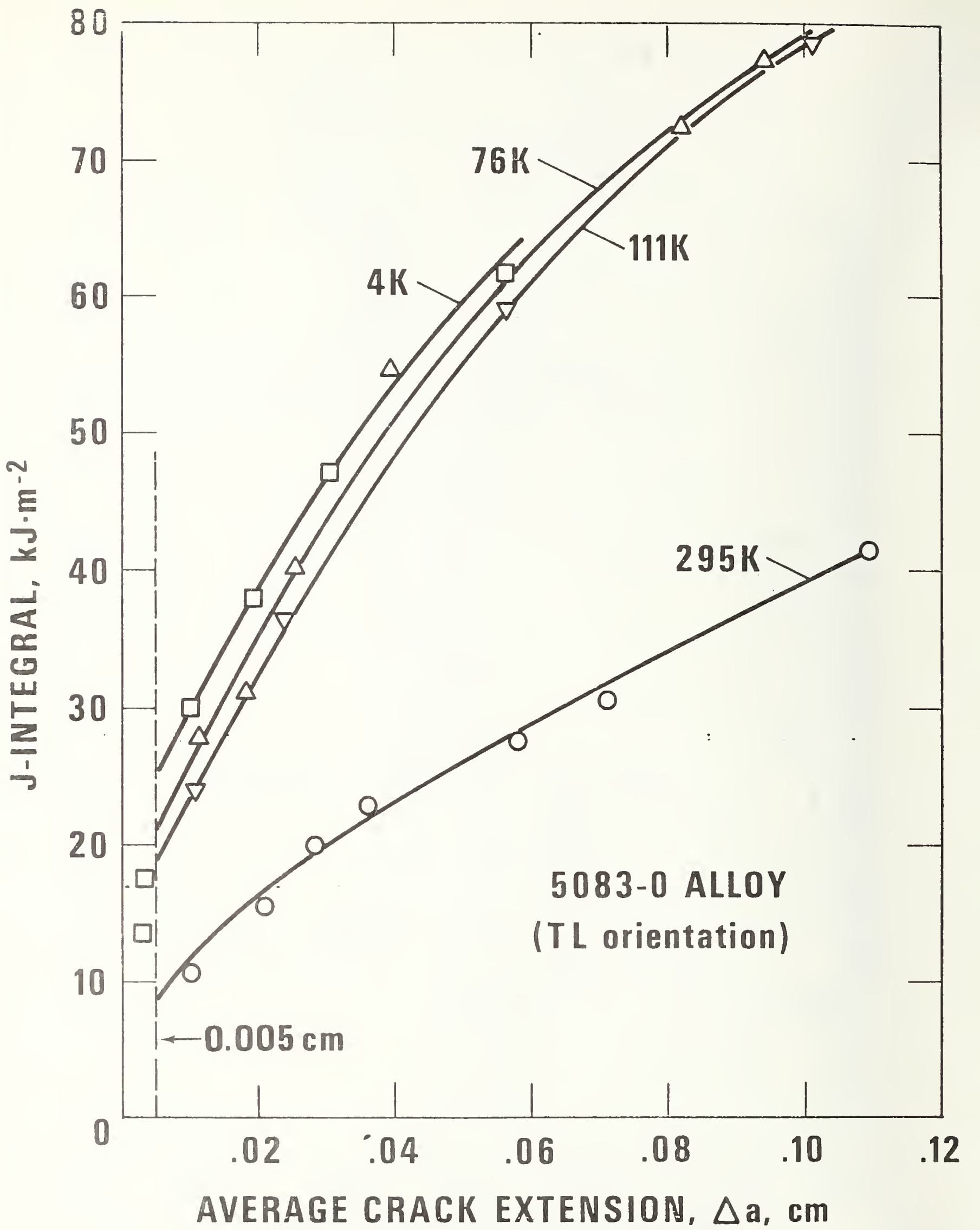

Figure 7. J-integral resistance curves for 5083-0 aluminum, showing the effect of temperature. 


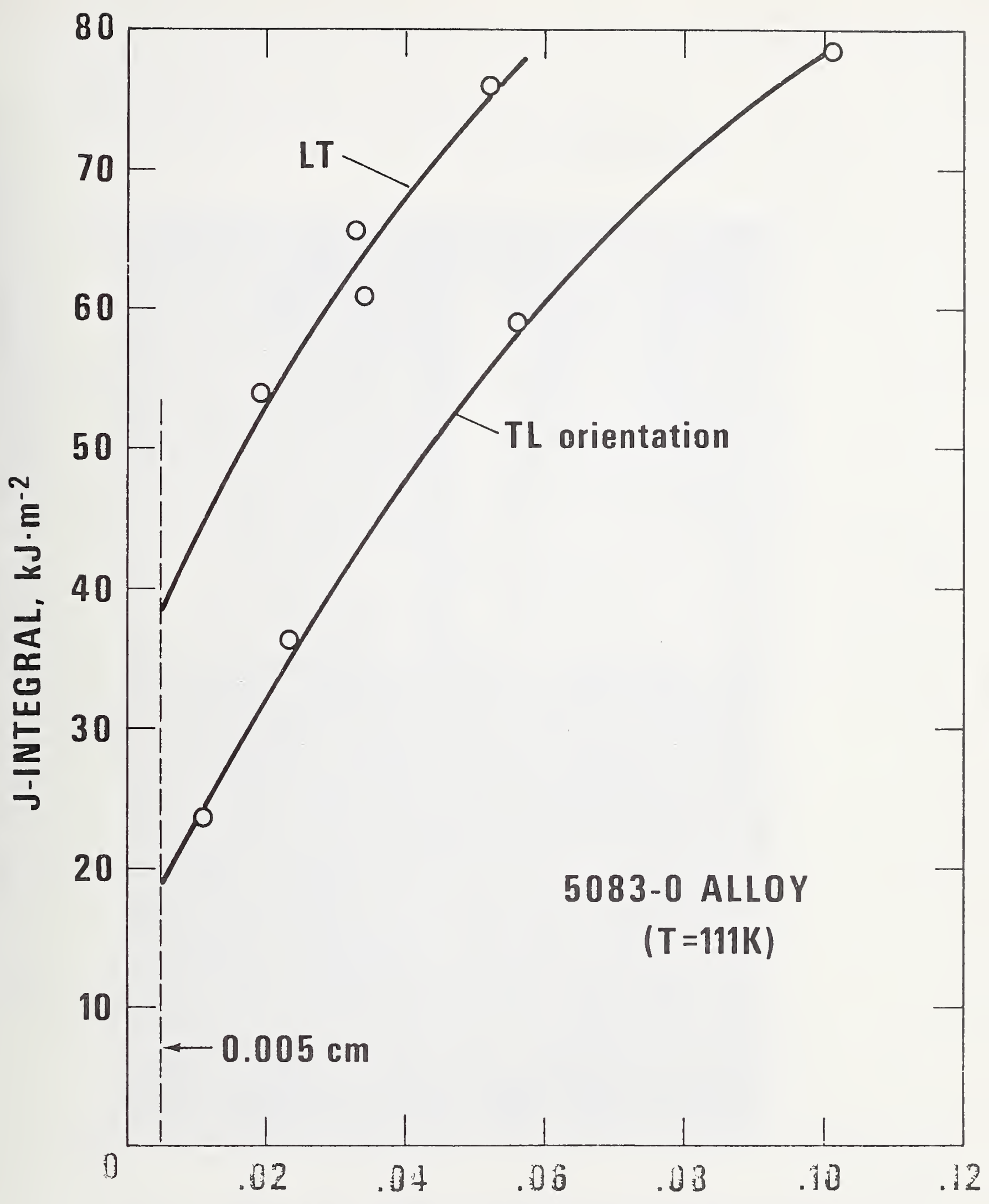

AVERAGE CRACK EXTENSION, $\triangle \mathrm{a}, \mathrm{cm}$

Figure 8. J-integral resistance curves for 5083-0 aluminum at $111 \mathrm{~K}$, showing the effect of orientation. 


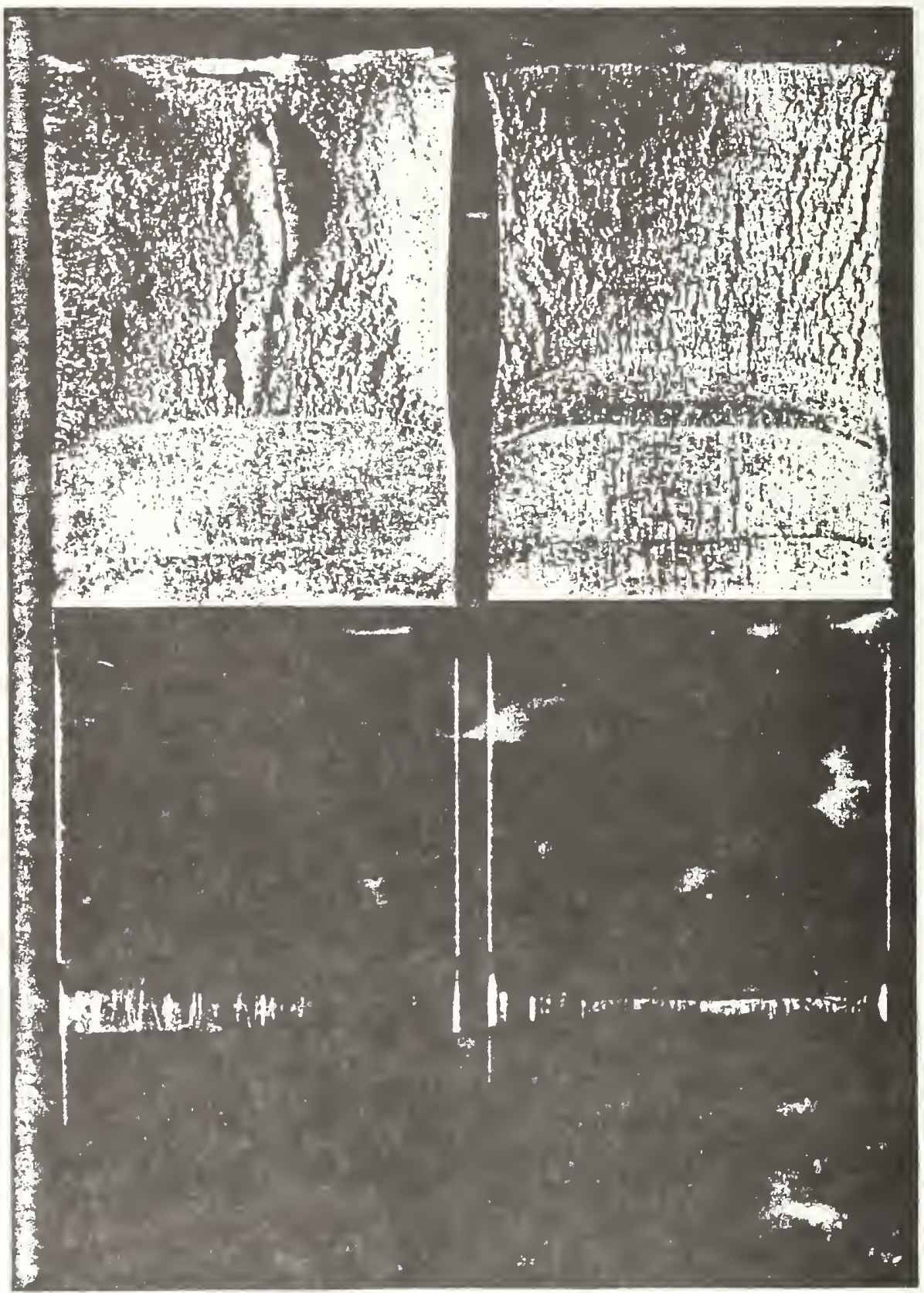

Figure 9. Fracture appearance of LT (left) and TL (right) specimens tested at $111 \mathrm{~K}$. 

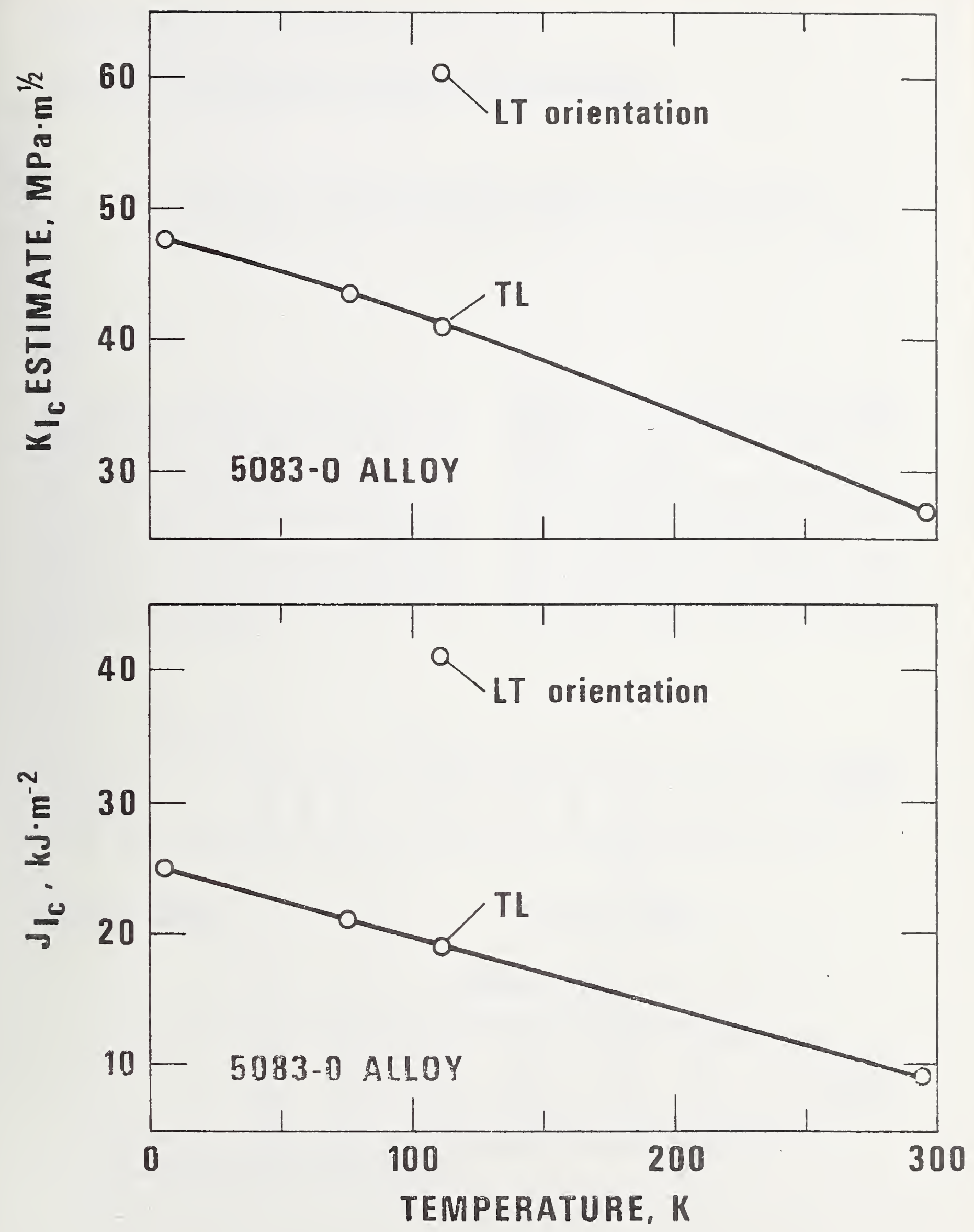

Figure 10. Temperature dependences of $\mathrm{J}_{\mathrm{IC}}$ data and $\mathrm{K}_{\mathrm{IC}}$ estimates. 



\title{
Ship Steel Weldments for
}

\section{Low Temperature Service}

\author{
Cooperation among shipyards, regulatory agencies and \\ steelmakers may lead the way to higher welding productivity
}

\section{BY M. I. MCHENAY}

A large fleet of tankers is under construction for the marine transport of liquefied natural gas (LNG). In LNG ships, significant portions of the huil are cooled by the cryogenic cargo to temperatures ranging from 0 to -46 C. At these temperatures many ship steels exhibit brittle behavior. Consequently, the U.S. Coast Guard (Ref. 1), the American Bureau of Shipping (Ref. 2) and comparabie regulatory agencles around the world have estabiished strict requirements on the ship steels and weld procedure qualifications for weidments subjected

H. I. MCHENRY is associated with the Cryogenics Division, National Bureau of Standards, U.S. Department of Commerce, Boulder Colorado 80302. to low temperatures. To meet these requirements, shipyards generaily employ low heat input, multipass welding practices. As a result, welding productivity is being IImited to a level far below the capability of the equipment and facilities.

The Maritime Administration (MarAd) was advised of the increased costs of welding LNG ship hulis by the Welding Panel of the Shlp Production Committee, a group of industry experts organized by the Society of Naval Architects and Marlne Engineers to advise MarAd on how to improve shipyard productivity. In their efforts to reduce the cost of ship construction, MarAd requested the Natlonai Bureau of Standards to conduct a survey to establish the feasibility of improving

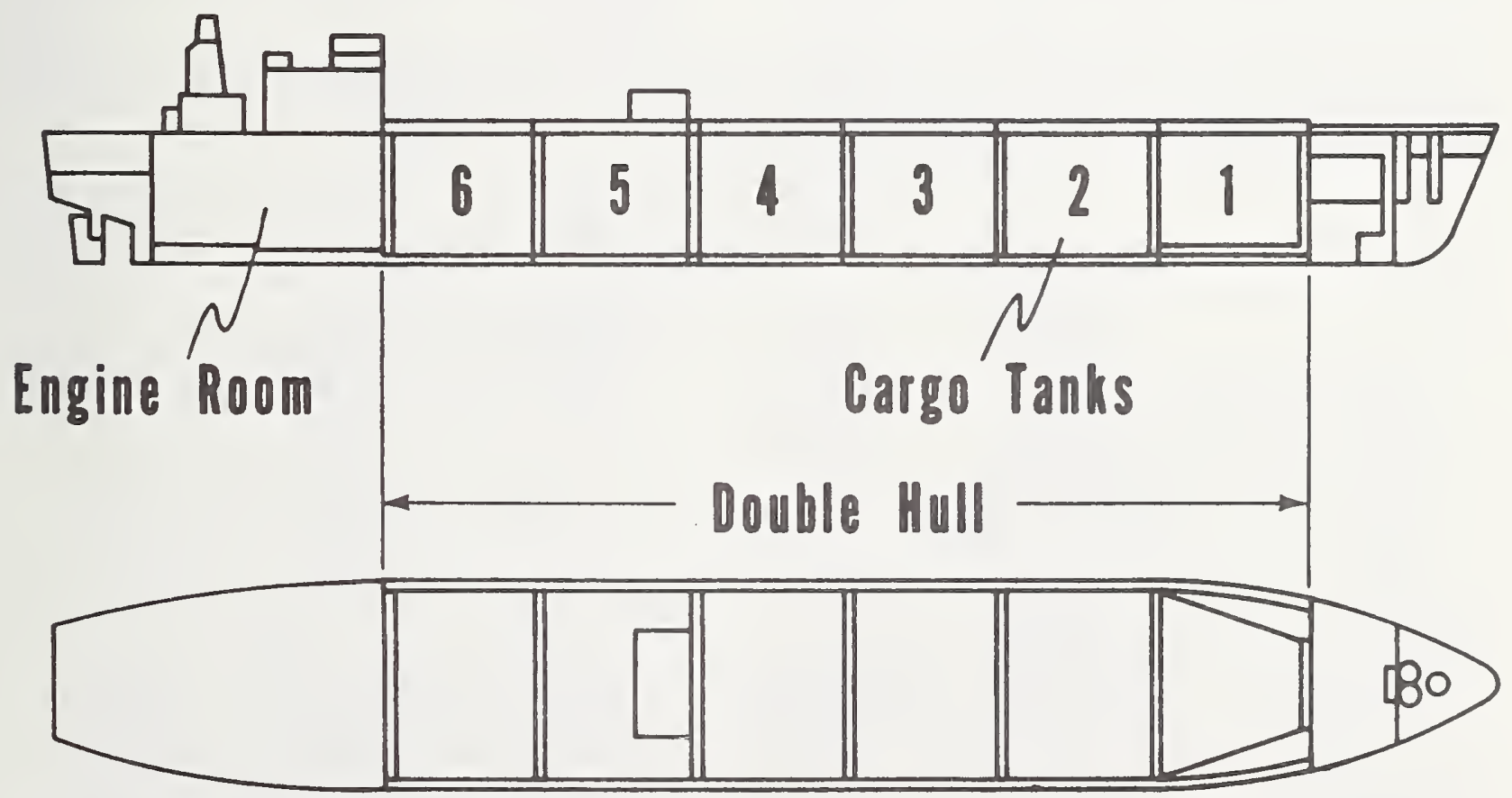

Fig. 1 - Structural arrangement of an LNG ship hull (Ref. 3) 
the efficiency of welding ship steels for low temperature service. The survey included visits to the shipyards involved in LNG construction, to the appropriate regulatory agencies, to the steel plate producers and to other companies engaged in fabricating structures for low temperature service. These visits clarified the problem and the rules, and provided a review of the technology available for improving welding efficiency. The survey has been completed and the results are presented herein.

\section{Shipyard Practice}

The LNG ships under construction in the United States are approximately $280 \mathrm{~m}$ long, $42 \mathrm{~m}$ wide and 30 $\mathrm{m}$ deep and have a cargo capacity of 125,000 cubic meters. The ships are double-hull vessels with transverse bulkheads dividing the ship into several cargo bays as shown in Fig. 1 (Ref. 3). The cryogenic containment system fitted within each cargo bay consists of the cargo tank, the insulation and generally a secondary barrier to contain the LNG in case of tank failure. Thomas and Schwendtner (Ref. 4) have described eight types of containment systems in use or under consideration worldwide. In the U.S., three designs are under construction: The Conch free-standing prismatic tank, the Gazocean membrane prismatic tank and the Kvaerner-Moss free-standing spherical tank. For each system, the insulation is sufficient to permit transport of the LNG at approximately $-162 \mathrm{C}$ and atmospheric pressure with boil-off rates less than $0.25 \%$ per day.

The temperature environment within the hull is a function of the ambient air and water conditions, the effectiveness of the insulation system and the proximity of the cargo. For North Atlantic routes, the USCG specifies that the design temperatures be based on assumed ambient conditions of $-18 \mathrm{C}$ air, a $5 \mathrm{mph}$ $(2.33 \mathrm{~m} / \mathrm{s})$ wind and still water at $0 \mathrm{C}$. The inner hull, the transverse bulkheads and the tank support structure are the principal areas cooled by proximity to the cargo. Minimum design temperatures in these areas range from $0 \mathrm{C}$ to $-46 \mathrm{C}$. The coldest locations are the inner side-shell above waterline and parts of the tank support structure.

\section{Steel selection}

The chemistry, processing and testing requirements of steels used in LNG ships being made in the U.S. are summarized in Table 1. These steel selections are generally in accordance with the proposed (1975) regulations of the International Maritime Consultive Organization (IMCO) as outlined in Tables 2 and 3. For temperatures below $-10 \mathrm{C}$, fully killed, aluminum treated, fine grain, C-Mn-Si steels are used. For temperatures below $-25 \mathrm{C}$, the steel must also be either normalized or quenched and tempered. The most commonly used steels are the ABS ordinary strength grades; $C N$ is used for temperatures to $-23 \mathrm{C}, \mathrm{CS}$ for temperatures to $-34 \mathrm{C}$ and $\mathrm{V}-051$ for temperatures to $-46 \mathrm{C}$. For high strength applications, ABS grade EH steel is commonly used for temperatures to $-34 \mathrm{C}$ and ASTM grade A537 Modified is used for temperatures to $-46 \mathrm{C}$.

Approximately 28,000 metric tons of steel are required for the hull of a 125,000 cubic meters LNG ship. The tonnage requirements for all grades of hull steel and for low temperature steels are summarized in Table 4. These data are indicative of the total usage of low temperature steels and include significant tonnage selected for improved toughness and used in parts of the ship not exposed to temperatures below $0 \mathrm{C}$.

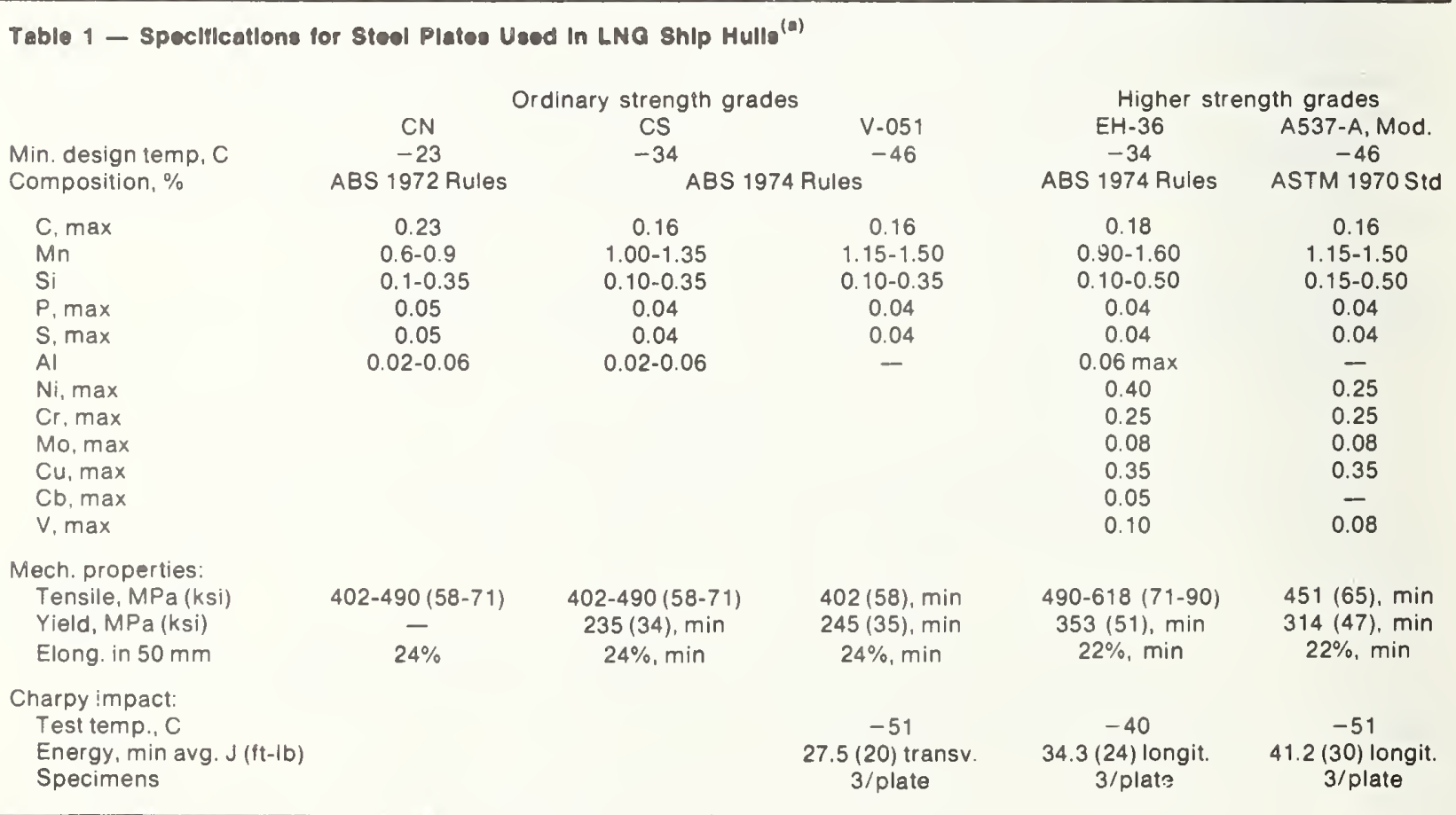

(a) Haat Traatmant. all gradas normallzad. Daoxidation: all gradas aluminum klllad, fina graln practica 


\section{Weld Procedure Quallfication}

For service temperatures less than $-18 \mathrm{C}$, the welding procedures must be qualified in accordance with USCG and ABS requirements. Procedures are specific for each base metal, filler metal and flux combination and must be established for each welding process and position. The joint edge preparation, preheat and interpass temperatures, and other aspects of the procedure must be representative of the procedures used in production. Generally, two qualifications are required to cover the range of plate thicknesses: $9.5<t$ $\leq 19 \mathrm{~mm}$ and $\mathrm{t}>19 \mathrm{~mm}$. Test plates for these qualifications are usually $19 \mathrm{~mm}$ thick for the lower thickness range and the maximum thickness used in production for thicknesses greater than $19 \mathrm{~mm}$. The test plates are oriented such that the weld axis is parallel to the rolling direction.

The qualification requirements include the room temperature tensile and guided bend tests specified by ABS for all weld procedure qualifications plus a series of Charpy $V$-notch impact tests. The Charpy tests are conducted at $5.5 \mathrm{C}$ below the minimum service temperature in accordance with ASTM A 370 , using type A specimens. The specimens are cut transverse to the weld axis with the notches normal to the plate surface. Three specimens are tested for each of the following notch locations: centered in the weld metal; on the fusion line; and in the heat-affected zone (HAZ) 1, 3 and $5 \mathrm{~mm}$ from the fusion line. The impact specimen location requirements are summarized in Fig. 2. The aver-

Toble 2 - IMCO Requirements for LNG Hull Steols

$\begin{array}{ccc}\begin{array}{l}\text { Minimum design } \\ \text { temp., } T, C\end{array} & \begin{array}{c}\text { Plate thickness, } \\ \mathrm{t}, \mathrm{mm}\end{array} & \begin{array}{c}\text { Approved ABS } \\ \text { steel grades }\end{array} \\ T \geq 0 & - & \text { Normal Practice } \\ 0>T \geq-10 & t \leq 12.5 & \mathrm{~B} \\ & 12.5<\mathrm{D} \leq 25.5 & \mathrm{E} \\ -10>\mathrm{T} \geq-25 & \mathrm{t}>25.5 & \mathrm{D} \\ -25>T \geq-55 & \mathrm{t} \leq 12.5 & \mathrm{E} \\ & \mathrm{t}>12.5 & \text { See table 3 }\end{array}$

\footnotetext{
Table 3 - IMCO Requlrements for LNG Hull 8teele for Deelgn Temperatures of -25 to $-55 \mathrm{C}$

Chemical composition

$\begin{array}{cccccc}\mathrm{C} & \mathrm{Mn} & \mathrm{Si} & \mathrm{S} & \mathrm{P} & \\ .16 \% & 0.70- & 0.10- & 0.035 \% & 0.035 \% & \\ \text { max } & 1.60 \% & 0.50 \% & \max & \max & \\ \text { ptional additions: } & & & & \\ \mathrm{Ni} & \mathrm{Cr} & \mathrm{Mo} & \mathrm{Cu} & \mathrm{Cb} & \mathrm{V} \\ 0.80 \% & 0.25 \% & 0.08 \% & 0.35 \% & 0.05 \% & 0.10 \% \\ \max & \max & \max & \max & \max & \max \end{array}$

Heat Treatment: normalized or quenched and tempered

Deoxidation:

fully killed, aluminum treated, fine grain practice

Toughness requirements:

Temperature: $5 \mathrm{C}$ below design temperature

Specimens: Charpy V-notch-transverse

Energy, min. avg: $27.5 \mathrm{~J}(20 \mathrm{ft}-\mathrm{lb})$

No. of Tests: 3 from each plate
}

age Charpy value must equal or exceed $27.5 \mathrm{~J}(20 \mathrm{ft}$ $\mathrm{Ib})$; the minimum value for one specimen is $18.6 \mathrm{~J}(13.3$ ft-lb).

\section{Welding Processes and Consumablee}

Conventional shipyard welding practices are generally being used to fabricate low temperature steels; however, the heat inputs are restricted in order to meet the Charpy impact requirements. Consequently, the deposition rates are far below the equipment capabilities. The principal welding processes are submerged arc (SA), shielded metal-arc (SMA) and gas metal-arc (GMA) welding. For flat position welds and horizontal fillet welds, SA welding is the most efficient and reliable process, and therefore is widely used on automated panel lines. Both SMA and GMA welding are used for most of the other applications; the selection of one process over the other varies widely from yard to yard. Variations of these processes such as one-side welding, gravity welding, tandem arc and 3 o'clock SA welding are used in specific instances depending on the capabilities of the shipyard. High heat input processes such as the electroslag and electrogas processes are not approved by ABS for use on low temperature steels.

A wide range of electrodes and fluxes are used to weld ship steels for low temperature service. For submerged arc welding, two approaches have been taken: (1) use of a mild steel electrode and an alloy flux, or (2) use of an alloy electrode and a neutral flux. The mild steel electrodes conform to AWS specification A5.17-69 Class EM12K, and the alloy fluxes are of a proprietary nature. The alloy electrodes, which contain 1 to $2 \% \mathrm{Mn}$, 0.1 to $0.5 \% \mathrm{Mo}$ and 0.5 to $2.0 \% \mathrm{Ni}$, are welded with a neutral flux suitable for multipass welding. For SMA welding, the most common electrode is AWS E 8018 C3 which contains $1 \% \mathrm{Ni}$. In some cases, E 7018 electrodes, which contain $0.5 \%$ Mo, are used for moderately low temperatures and E 8018-C1 electrodes, which contain 2 to $2.75 \% \mathrm{Ni}$, are used for the lowest temperatures. Both solid and flux-cored electrodes are used for GMA welding. The solid electrodes are alloyed with $\mathrm{Mn}, \mathrm{Mo}$ and Ni for low temperature toughness and

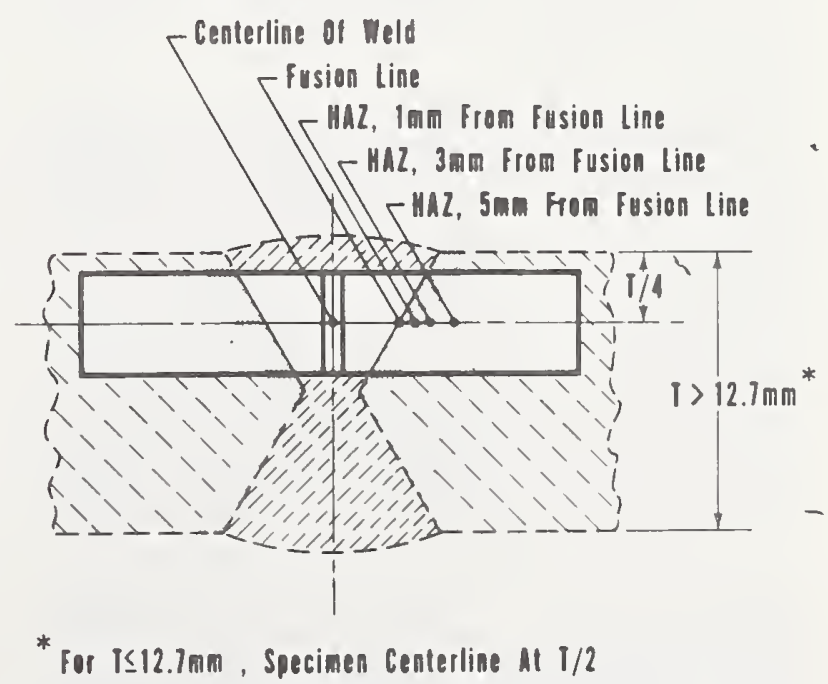

Fig. 2 - Charpy V-notch specimen locations for weld procedure qualification (Rof. 1) 
Table 4 - Usage of Low Temperature Stecls In LNG Ship Hulls

\begin{tabular}{|c|c|c|c|c|}
\hline $\begin{array}{l}\text { Ship } \\
\text { design }\end{array}$ & Steel & $\begin{array}{l}\text { Weldment } \\
\text { test temp., } \\
\text { C }\end{array}$ & $\begin{array}{l}\text { Tonnage, } \\
\text { long tons }\end{array}$ & Applications \\
\hline $\begin{array}{l}\text { Gazocean } \\
\text { Membrane } \\
\text { Prismatic }\end{array}$ & $\begin{array}{l}\text { All grades } \\
\text { ABS CS } \\
\text { ABS V-051 }\end{array}$ & $\begin{array}{l}- \\
-34 \\
-43\end{array}$ & $\begin{array}{r}29,573 \\
9,666 \\
2,695\end{array}$ & $\begin{array}{l}\text { Total hull plus scrap and spare } \\
\text { Inner bottom, web frames, gunwale, bilge } \\
\text { Inner side shell, transverse decik box }\end{array}$ \\
\hline $\begin{array}{l}\text { Conch } \\
\text { Free standing } \\
\text { Prismatic }\end{array}$ & $\begin{array}{l}\text { All grades } \\
\text { ABS CN } \\
\text { ABS CS } \\
\text { ASTM A678-A }\end{array}$ & $\begin{array}{c}\overline{-} \\
-23 \\
-21 \text { to }-32 \\
-45\end{array}$ & $\begin{array}{r}17,810 \\
6,058 \\
4,602 \\
418\end{array}$ & $\begin{array}{l}\text { Midbody (hull less bow and stern) } \\
\text { Trans. Bu!khead, inner side shell, deck } \\
\text { Inner bottom, gunwale, bilge } \\
\text { Roll key }\end{array}$ \\
\hline $\begin{array}{l}\text { Kvaerner-Moss } \\
\text { Free standing } \\
\text { Spherical }\end{array}$ & $\begin{array}{l}\text { All grades } \\
\text { ABS CN } \\
\text { ABS CS } \\
\text { ABS EH-36 } \\
\text { ASTM A537 (Mod) }\end{array}$ & $\begin{array}{l}- \\
-23 \\
-33 \\
-29 \\
-51\end{array}$ & $\begin{array}{r}17,393 \\
1,408 \\
1,602 \\
1,515 \\
1,185\end{array}$ & $\begin{array}{l}\text { Midbody } \\
\text { Inner huil } \\
\text { Transverse bulkheads } \\
\text { Deck girders } \\
\text { Cylindrical tank support }\end{array}$ \\
\hline
\end{tabular}

the flux cored generally has a mild steel sheath and a proprietary flux.

Low heat input welding practices are necessary to meet the USCG impact requirements in the HAZ of low temperature ship plate weldments. This poses a signif- icant productivity problem to the LNG shipyards because deposition rate is proportional to heat input, and their welding equipment is capable of far greater deposition rates than are possible using the low heat input practices. Consider, for example, the welding procedures that are representative for welding $19 \mathrm{~mm}$ plate. For $x$-ray quality welds in steels such as ABS grade $B$, the following conditions are recommended (Ref. 5):

Joint preparation: double $V$-groove with an $8 \mathrm{~mm}$ root face

Backing weld: $850 \mathrm{~A}, 33 \mathrm{~V}, 16 \mathrm{in.} / \mathrm{min}(6.8 \mathrm{~mm} / \mathrm{s})$, $105 \mathrm{~kJ} / \mathrm{in}$.

Finishing weld: $1150 \mathrm{~A}, 35 \mathrm{~V}, 13 \mathrm{in.} / \mathrm{min}(5.5 \mathrm{~mm} / \mathrm{s})$, $186 \mathrm{~kJ} / \mathrm{in}$.

In contrast, $19 \mathrm{~mm}$ ship plate for low temperature service must be multipass welded with the heat input limits ranging from about 40 to $80 \mathrm{~kJ} / \mathrm{in}$. 1024-20skJtern depending on the particular combination of steel grade and service temperature. At heat input levels within this range, anywhere from 4 to 14 passes may be required to weld $19 \mathrm{~mm}$ plate.

Two approaches to solving the productivity problem are apparent: either change the weldment toughness requirements or improve the tolerance of the base metal to higher heat input welding practices. Changing the rules is not a viable solution to the problem, because strict requirements are appropriate for hazardous cargo such as LNG. In addition, the requirements have recently been adopted by IMCO as standards acceptable to all major shipping countries. Thus, any change in the existing requirements would probably be contingent upon agreement by both the USCG and IMCO, certainly a long term proposition. The alternative solution would be to make available an economical steel which, when welded using efficient procedures, provides the required level of toughness. This potential solution is attractive because it is based on steelmaking technology and shipyard economics instead of international agreements. The feasibility of this solution is addressed in the next section.

\section{Steelmaklng Technology}

Current steelmaking technology offers several methods for providing improved toughness at low temperatures. The methods include alloying, rolling practice, sulfide shape control and heat treating. The extent to which the improvements are reflected in HAZ toughness of high heat input welds is not well documented. Nevertheless, there exists reason to believe that one or a combination of the available metallurgical treatments will permit higher heat inputs than currently being used. Whether or not the improvement will be economically justifiable depends on the cost increment added to the price of the steel and the extent of the improvement. Because of the large tonnages involved, the added cost of an improved ship steel will likely be limited to a maximum of $\$ 20$ to $\$ 60$ per metric ton $(\mathrm{Mg})$, depending on the specific application.

\section{Alloying}

The use of additional alloying to improve ship steels is severely constrained by steel pricing practices. Steel prices are comprised of a base price and extras for the specification, plate dimensions and quantity. There are two base prices; the carbon steel base and the alloy steel base, the latter of which is about $40 \%$ higher. The carbon steel base price is applicable to all the steels used in LNG ship hulls. The American Iron and Steel Institute (AISI) considers a steel to be an alloy steel when either (1) the maximum of the range given for the content of alloying elements exceeds one or more of the following limits: $\mathrm{Mn}, 1.65 \%$; Si, $0.60 \%$; $\mathrm{Cu}, 0.60 \%$; or (2) a definite range or a definite minimum quantity of any other element is specified to obtain a desired alloyed effect (Ref. 6).

The chemistry specification for ABS EH 36 shown in Table 1 is typical of the degree of alloying permissible in carbon steels. Notice that there are no minimum requirements on alloying elements such as $\mathrm{Cr}, \mathrm{Mo}, \mathrm{Ni}, \mathrm{V}$ and $\mathrm{Cb}$. Thus, the steelmaker has flexibility on how best to achieve the required tensile and impact properties. These pricing practices preclude the use of 0.4 to $0.8 \%$ $\mathrm{Ni}$ additions that are frequently specified for low temperature applications by Japanese and European shipbuilders. However, the transition temperature of 
YIELD STRENGTH, MPa

Fig. 3 - Strength toughness vectors for structural steels (Ret. 7)
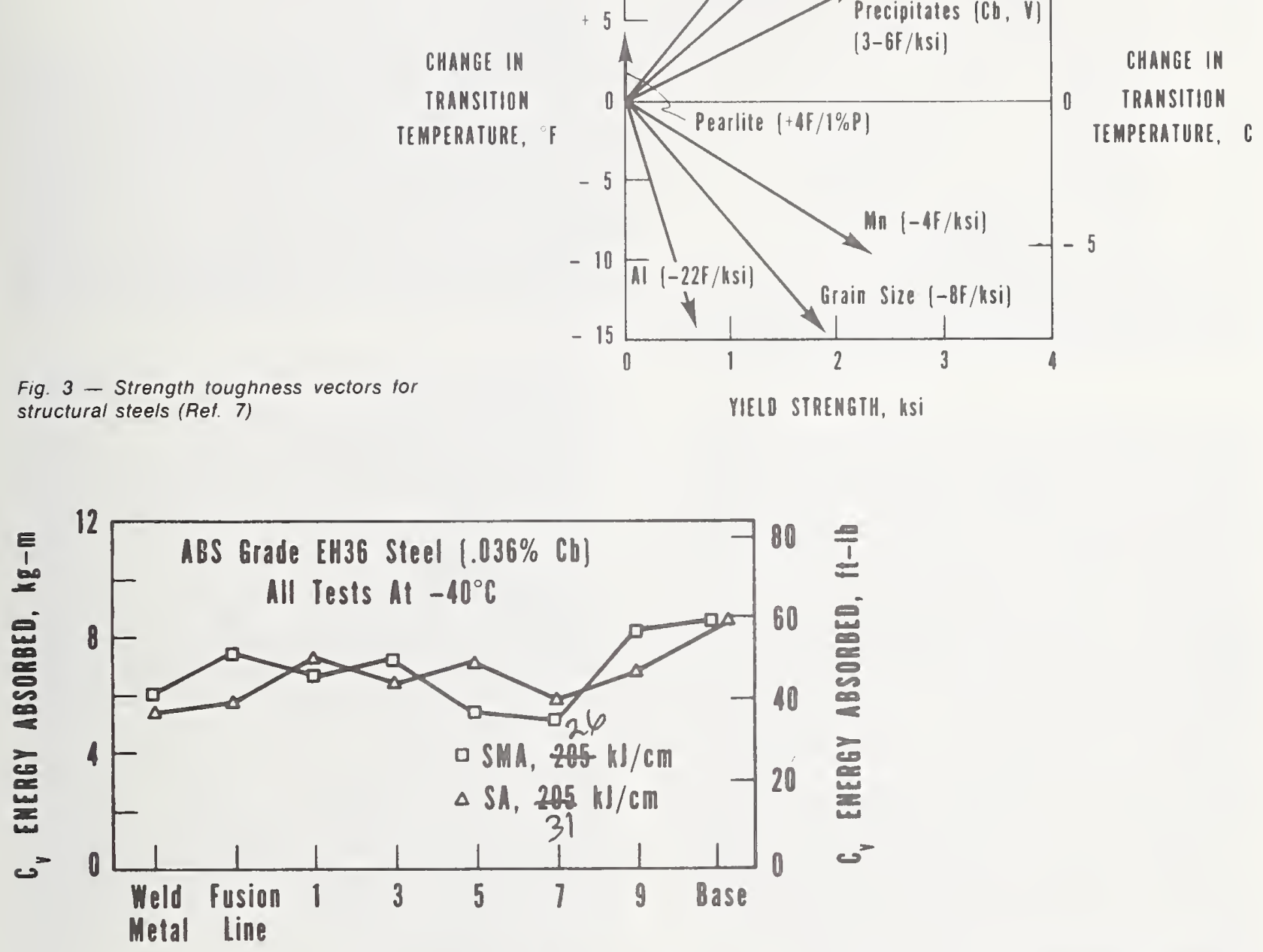

DISTANCE FROM FUSION LIME, mm

Fig. 4 - Charpy toughness traverse for Cb-treated EH-36 weldment (Ref. 10) ship steels can be reduced by alloy adjustments within the AISI limits for carbon steels. As shown in Fig. 3, the transition temperature is reduced by increasing the $\mathrm{Mn}$ content and by lowering $\mathrm{C}, \mathrm{Si}$ and $\mathrm{N}$ (Ref. 7).

Microalloying with $\mathrm{Cb}$ or $\mathrm{V}$ is an economical approach to providing strength and good low temperature properties in the base plate, and is currently used in EH 36 and A537 Modified steels. Strengthening is provided by a combination of reduced grain size and precipitation hardening. The low temperature toughness is improved because of the small grain size - an improvement that is only partially offset by the precipitation hardening effect shown in Fig. 3. However, the $H A Z$ toughness near the fusion line is adversely affected by grain coarsening and further reduced by the strengthening effect of carbonitride precipitation (Refs. 8. 9). This embrittlement is almost always observed in simulated HAZ specimens, but is frequently not evident in Charpy specimens taken from weldments. The absence of embrittlement in high heat input weldments such as shown in Fig. 4 suggests that the high toughness material surroundlng the embrlttled region substantially reduces the embrlttlemient (Ref. 10). It is not clear at this time whether this can be attributed to an averaging effect, i.e., the Charpy impact specimen samples a composite of high and low toughness material, or to a reductlon of constraint provided by the ductile material surrounding the embrittled region. In either case, it appears that the problem of $\mathrm{Cb}$ or $\mathrm{V}$ embrittlement in the HAZ may not be as significant in real weldments as suggested by some investigators (Refs. $8,9)$ on the basis of simulated HAZ studies.

\section{Inclusion Control}

Nonmetallic Incluslons are an intrlnsic constituent of all steels. There are two maln types of inclusions: (1) the indigenous incluslons whlch precipltate in the molten or 


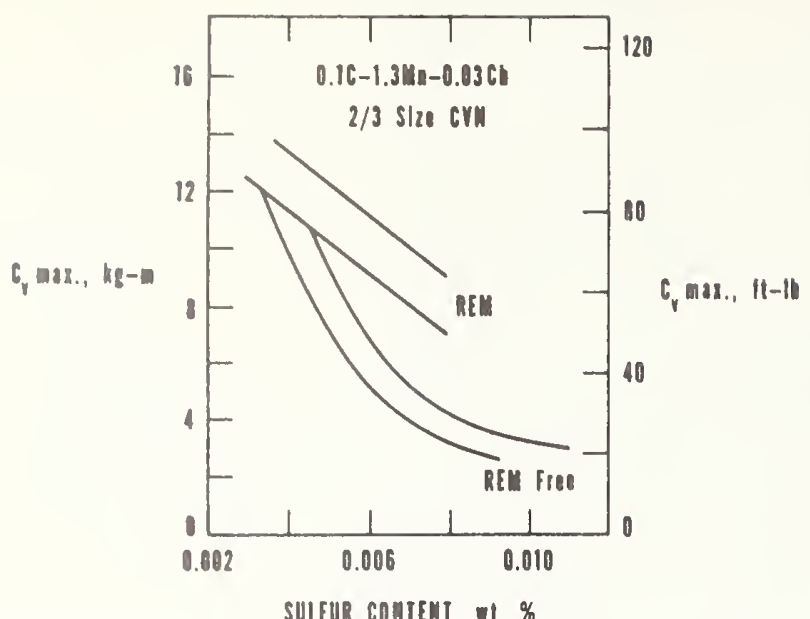

Fig. 5 - The effect of rare earth metal treatments on the transverse shelf energy of low sulfur C-Mn steel (Ref. 12)"

solidifying metai due to decreased solubility of oxygen and sulfur upon cooling, and (2) the exogenous inclusions which are introduced into the steel from materials such as the refractories which come in contact with the molten steel. The indigenous incluslons are far more numerous and predictable in their behavior than the exogenous types, which occur sporadically. The principal types of indigenous inclusions are oxides and sulfides. In $\mathrm{Al}$ killed steels, the dom nnant oxide Is $\mathrm{Al}_{2} \mathrm{O}_{3}$, which precipitates as small refractory crystals that do not agglomerate and do not change shape appreciably during rolling operations.

The principal sulfide inclusion in C-Mn steels is MnS. In iow oxygen steels (e.g., Al killed), the MnS inclusions are quite plastic and tend to elongate during rolling. These stringer shaped inclusions separate readily from the steel matrix, and have a higher surface-to-volume ratio and a shorter interparticle spacing than globular inciusions. Consequently, the MnS stringers serve as initiation sites for low energy fracture when the steel Is ioaded transverse to the directlon of rolling.

Sulfide shape controi is rapidly emerging as a practical tool for eliminating stringers and thereby Improving the transverse toughness of structural steels (Ref. 11). The process generally consists of lowering the sulfur content of the heat below $0.015 \%$ and then adding elements to the melt which form refractory sulfides. The refractory sulfides take on a spherical shape in the liquid steel and tend to retain this shape upon solidification and during the rolling process. Several elements, including $\mathrm{Ti}, \mathrm{Zr}, \mathrm{Ca}, \mathrm{Mg}$ and the rare earth metals, form refractory sulfldes. Although practlces vary widely, sulfide shape control by the ladle addition of rare earth metal (REM) in the form of mischmetal, a mixture of rare earths containing about $50 \% \mathrm{Ce}$, appears to be gaining favor. The rare earths are preferred over $\mathrm{Ti}$ and $\mathrm{Zr}$ because, in addition to shape control, an appreciable reduction In sulfur content occurs due to the solution of rare earth sulfides and oxysulfides in the slag. Calcium and magnesium are effective. for both sulfide shape control and sulfur reduction;

- Reprinted with perm/ssion of the Metallurg/cal Soclety of AIME. however, $\mathrm{Mg}$ is difficult to introduce into molten steel because of its high vapor pressure; and $\mathrm{Ca}$, which is not soluble in liquid iron, does not mix readily enough to assure complete sulfide shape control. The influences of sulfur content and REM additions on toughness are shown in Fig. 5 (Ref. 12).

\section{Rolling Practice}

Significant toughness improvements can be obtained by altering the rolling practice. Cross rolling can improve transverse properties at a moderate increase in steel cost; however, substantial improvements require rolling ratios that approach unity. Steel specifications rarely include cross rolling requirements; however, a guaranteed transverse Charpy requirement generally implies that cross rolling will be used. Thus, the principal use for cross rolling is to make moderate improvements in transverse properties to assure conformance to a transverse toughness guarantee.

Controlled roliing can improve strength and low temperature toughness by substantlally reducing the austenlte graln size and the fineness and nature of the transformation products (Ref. 13). It Involves a schedule of reductions at specified temperatures, sometlmes coupled with controlled cooling between passes and after the final pass. Most commonly, controlled rolling Is IImlted to performing the final reduction at a speclfled temperature whlch is lower than normally employed. As shown in Fig. 6, the reduction below $900 \mathrm{C}$ causes a signiflcant decrease In transitlon temperature. It Is partlcularly useful for the productlon of llne plpe, where the large tonnage Involved permlts optImizatlon of the rolling schedules on an economical bas!s. For shlp steels, the large varlety of plate slzes, thickness and grades, and the lack of facllitles for producing controlled-rolled plates greater than $16 \mathrm{~mm}$ thlck, IImlt the practicabillty of controlled rolling. In addition, the large varlety of rolling schedules can lead to more scatter In the materlal properties than Is assoclated with more easily controlled procedures such as normallzing. Due to these IImltations, controlled rolling is not considered practlcal for Improving the toughness of shlp plate.

\section{Heat Treatment}

Nearly all the ship steels used for low temperature (to -46 C) applicatlons are normallzed. The typlcai normallzing heat treatment involves heating the as-rolled plate to $925 \pm 25 \mathrm{C}$ and alr coollng to room temperature. As shown in Fig 7, the low temperature toughness of these steels could be Improved by a quench and temper ( $Q$ and $T$ ) heat treatment (Ref. 14). For $C$ $\mathrm{Mn}$ steels such as shlp plate, $Q$ and $T$ involves heating to $925 \pm 25 \mathrm{C}$, quenching In water and subsequently tempering at $650 \pm 50 \mathrm{C}$. Thls heat treatment is nearly twlce as expensive as normallzing. Although $Q$ and $T$ improves base plate toughness, It is not clear whether thls benefit will be apparent in the heat-affected zone of weldments. It is consldered Ilkely that the reheat treatment caused by the weld thermal cycle will impart the same toughness to the heat-affected zone regardless of prior heat treatment. Thus, the extra cost of $Q$ and $T$ over normallzing, $\$ 30$ to $\$ 40 /$ metrlc ton $(\mathrm{Mg})$, Is not considered a cost effectlve means of Improving heataffected zone toughness. 


\section{Work In Progress}

On the basis of the shipbuilding and steel industry survey, MarAd requested NBS to conduct a follow-on program in cooperation with the LNG shipbuilders to evaluate improved ship steels for low temperature service. In this program. the major steel companies are providing the LNG shipyards with production heats of ABS steels, modified to possess improved transverse fracture properties at the appropriate test temperatures. The shipyards will evaluate these steels by qualifying optimum weld procedures in accordance with the USCG requirements. A comparison of the optimized procedures with those currenily employed will be indicative of the cost reduction possible through the use of improved steels. As a result, each participating shipyard will be in a position to make a rational decision regarding the cost effectiveness of premium quality steels. The program. currently in the formative stages. will be completed in mid-1977, and the results will be published shortly thereafter.

\section{Summary}

A survey of the U.S. shipyards engaged in LNG ship construction, the major steel plate producers and the maritime regulatory agencies has been conducted to establish the feasibility of improving the efficiency of welding ship steels for low temperature service. The results of this survey suggest that application of state-ofthe-art steelmaking technology can substantially improve the low temperature toughness of ship steels. A program is being conducted to determine if steels with improved toughness retain satisfactory toughness in the $H A Z$ when higher heat input welding practices are used.

\section{Acknowledgments}

This work was sponsored by the U.S. Maritıme Administration. The author wishes to acknowledge the many contributions of $M$. B. Kasen and R. P. Reed of NBS who collaborated on all aspects of the program described herein. The author also expresses appreciation to $R \mathrm{~W}$. Schaffran of the U.S. Maritime Administration and W. C. Brayton of Bethlenem Steel Corporation who were responsible for initiating the program.

\section{References}

1. USCG, U.S. Coast Guard Marine Engineering Regulations. Subchapter F. CG-115, July 1970

2. ABS. Rules for Building and Classing Steol Vessels, American Bureau of Shipping. New York, 1974.

3. Emery II, W. B., Sterrett. E. L. and Moore, C. S.. "Alaskan Liquefaction Plant to Supply Gas for Japanese Use." Oil and Gas Journal, 66(1), 55-59.

4. Thomas. W. D. and Schwendtner. A. H. "LNG Carriers: The Current State of the Art," 1971 Annual New York Meeting. The Soclety of Naval Architects and Marine Engineers, 1971.

5. Anon. Submerged Arc Welding Hanabook, Linde Reference Library. Unıon Carbide Corp., New York. 1974.

6. Anon., "Alloy Steel Plates." American Iron and Steel Institute. New York. April 1970.

7. Cordea. J. N. "Niobium-and Vanadium-Containing Steels for Pressure Vessel Service," Welding Research Council Bulletin No. 203. February 1975.

8. Hannerz, N. E.. "Effect of $\mathrm{Cb}$ on HAZ Ductility in Constructional HT Steels," Welding Journal, 54, (5) May 1975. Res. Suppl., pp 162-s to 168-s.

9. Hannerz, N. E. and Jonsson-Holmquist, B. M.. "Influ-

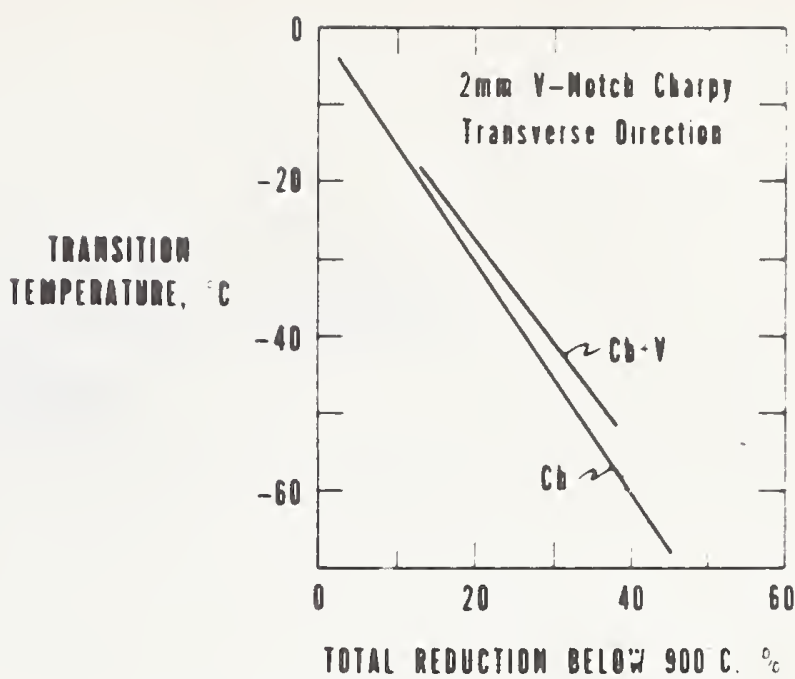

Fig 6 - The effect of rolling reduction below $900 \mathrm{C}$ on the tracture appearance transition temperature (Ret. 13$)^{\circ}$

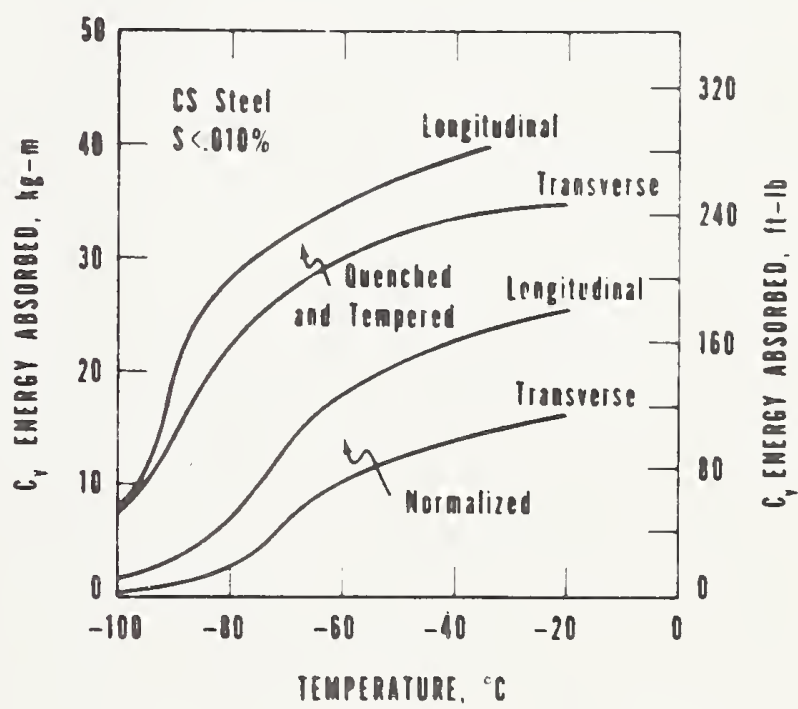

Fig. 7 - Charpy impact transition curves for normalized and for quenched and tempered CS steel (Ret. 14)

ence of $V$ on the HAZ Properties of Mild Steel." Metal Science 8 (1974) 228-233

10. Alia, B. L., Stern, I. L. and Null, C.. "Toughness Evaluation of Electrogas and Electroslag Weldments." Project Report. The National Shipbuilding Research Program. US Marıtıme Administration. March 1975

11. Korchynsky. M., "The Relationships Between Sulfide Composition Morphology and Distribution on Mechanical Properties of HSLA Steels," presented at the International Symposium on Sulfide Inclusions in Steel. American Society for Metals. Port Chester, N.Y.. November 1974

12. Kozasu, I. and Osuka, T. "Processing Condirions and Properties of Control-Rolled Steel Plates." in Processing and Properties of Low Carbon Steel, Gray, J M. (editor). The Metallurgical Society of AIME. New York, 1973

13. Gray, J. M., "Columbium (Niobium) as a Graın Refiner in Hot Rolled Steels," in Processing and Properties of Low Carbon Steel, Gray, J. M. (editor), The Metallurgical Society of AIME, New York, 1973.

14. Anon., "N-Tuf, Low Temperature Steels," Nippon Steel Corp., Tokyo, 1972. 



\section{CRYOGENIC FLUIDS DENSITY REFERENCE SYSTEM: PROVISIONAL ACCURACY STATEMENT}

B.A. Younglove

J.D. Siegwarth

Cryogenics Division

Institute for Basic Standards

National Bureau of Standards

Boulder, Colorado 80302

January 1977

Prepared for:

American Gas Association, Inc.

1515 Wilson Boulevard

Arlington, Virginia 22209

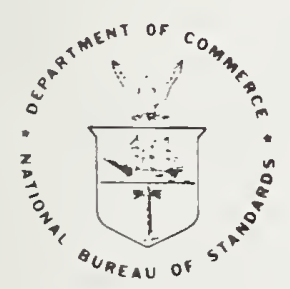

U.S. DEPARTMENT OF COMM'ERCE, Elliot L. Richardson, Secretary

Edward 0 . Vetter, Under Secretary

Dr. Betsy Ancker-Johnson, Assistant Secretary for Science and Technology

NATIONAL BUREAU OF STANDARDS, Ernest Ambler, Acting Director 


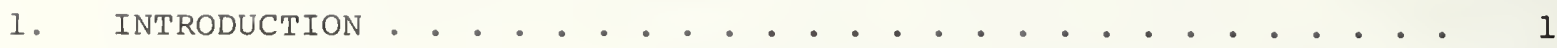

1.1. Symbols . . . . . . . . . . . . . . . . . . . . . 2

2. DESCRIPTION OF THE BASIC MEASUREMENT PROCESS . . . . . . . . . . 4

2.1. Density . . . . . . . . . . . . . . . . . . . . . . . . 4 4

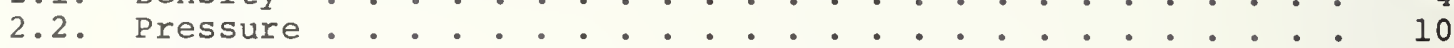

2.3. Temperature . . . . . . . . . . . . . . . . . . 10

2.4. Composition . . . . . . . . . . . . . . . . . . . 11

3. MEASUREMENT PROCESS PARAMETERS • • • . . . . . . . . . . . . . . 12

3.1. Bounds for Systematic Errors . . . . . . . . . . . . . . . 12

3.2. Random Error from Measurements on Methane . . . . . . . 15

3.3. Uncertainty Statement . . . . . . . . . . . . . . . 16

4. MEASUREMENT PROCESS CONTROL • • • • • • . . • • . . . . . . . . 16

5. SUMMARY •. • • • . . . . . . . . . . . . . . . . . . . . . . 19

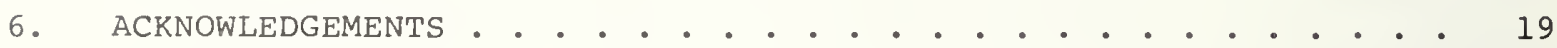

7. $\operatorname{REFERENCES~.~.~.~.~.~.~.~.~.~.~.~.~.~.~.~.~.~.~.~.~.~.~.~} 20$

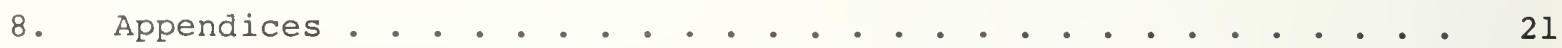

8.1. The Change in Volume of the silicon Crystal from

Hydrostatic Compression and Temperature . • . . . . . . . 22

8.2. Silicon Crystal Weighings in Air . . . . . . . . . . . . . 23

8.3. Densities of Single-Crystal Silicon . . . . . . . . . . . 24

8.4. Weight Certificate . . . . . . . . . . . . . . 25

8.5. Linearity Check of the Balance . . . . . . . . . . . . . 27 
B. A. Younglove and J. D. Siegwarth

\author{
Cryogenics Division \\ Institute for Basic Standards \\ National Bureau of Standards \\ Boulder, Colorado 80302
}

The measurement capability of the density reference system (DRS) of the National Bureau of Standards, Cryogenics Division, is described. This system measures density, pressure, and temperature of LNG mixtures for the purpose of testing densimeters which are contained in the liquid sample. Sample composition is determined by weighing the gas samples separately before condensing them into the sample. The DRS measures density by weighing a single-crystal of silicon immersed in the LNG mixture. This process is described and the equations used in the computation of density are discussed.

At this time the estimate of sample standard deviation for a single density measurement made on this system is +0.0628 (at $0.4 \mathrm{~g} / \mathrm{cc})$. Using three times this standard deviation as a limit for random error and adding +0.0268 as an upper bound for known sources of possible systematic error, the uncertainty of a single determination by this system is +0.218 . This statement of accuracy applies for the density range 380 to $430 \mathrm{~kg} / \mathrm{m}^{3}$ and 1200 to $1400 \mathrm{~kg} / \mathrm{m}^{3}$, pressures to $7 \mathrm{bar}$, and temperatures from $80 \mathrm{~K}$ to $140 \mathrm{~K}$. This statement is expected to be correct in the intermediate density range and for all temperatures up to $300 \mathrm{~K}$.

Measurement uncertainties for temperature, pressure, and composition are discussed. Comparison of measurements for liquid argon densities with the results of other laboratories is given.

Key words: Densimeters; density reference system; liquid methane; LNG .

\title{
1. INTRODUCTION
}

The density reference system (DRS) was evolved to determine the uncertainty of measurements made by several field type densimeters capable of operating at cryogenic temperatures in liquefied natural gas (LNG). The project was performed under a grant from the American Gas Association, Inc. (A.G.A.) on behalf of its membership.

This system has the capability at present of operating from room temperature to near the boiling point of liquid nitrogen ( $300 \mathrm{~K}$ to $80 \mathrm{~K})$, and at pressures of 7 bar (100 psi) to vacuum. In this work we covered densities of $390-500 \mathrm{~kg} / \mathrm{m}^{3}$, a range normally found in LNG work. Some additional density measurements were made on liquid argon. Only methane density measurements were used in the determination of the system uncertainty.

At this time the value of the sample standard deviation for a single density measurement made on this system is \pm 0.0628 (at $0.4 \mathrm{~g} / \mathrm{cc}$ ), based on measurements made using samples of liquid methane (99.97\%). Using three 
times the standard deviation as a limit for the random error, and adding $0.026 \%$ as an upper bound for known sources of possible systematic error, the uncertainty of a single determination by this system is $\pm 0.21 \%$.

Density is determined in the DRS by weighing an extremely pure (semiconductor grade) single-crystal of silicon in the liquid whose density is to be determined. The density of the liquid is calculated from the apparent weight of the silicon submerged in the liquid using Archimedes principle.

It is appropriate that silicon was used in this work as its density has been recommended by Bowman [1] of NBS as the primary standard for solid densities. His work which uses Archimedes principle discusses the several advantages that this type of silicon has for accurate measurements of liquid densities: relatively low density (compared to other solids), high thermal conductivity, reasonably low electrical resistance, and low compressibility. of course Bowman's work and others [2] provide accurate values for silicon density.

\section{1, symbols}

g

k

I

$\mathrm{L}_{298}$

$\mathrm{L}_{\mathrm{T}}$

Ma

Mak

Mo

$\mathrm{M}_{\mathrm{b}}$

${ }^{M}$ bg

M b

$M_{C}$

${ }^{M} \mathrm{Cg}$

$\mathrm{M}_{\mathrm{h}}$

${ }^{M}$ hg

$\mathrm{M}_{\mathrm{k}}$

${ }^{M_{k g}}$

${ }_{r}$

${ }^{M}$ rg

acceleration of a freely falling body

compressibility factor

length

length at reference temperature $298 \mathrm{~K}$

length at absolute temperature $\mathrm{T}$

apparent mass

apparent mass as read by balance during calibration

apparent mass as read by balance for zero mass load

buoy mass, silicon crystal + tungsten wire + stainless steel wire immersed in liquid

apparent mass of buoy in gas

apparent mass of buoy in liquid

counterweight mass

apparent mass of counterweight in gas

hanger mass

apparent mass of hanger in gas

calibration mass

apparent mass of calibration mass in gas

range mass

apparent mass of range mass in gas

$$
\mathrm{N}-4
$$




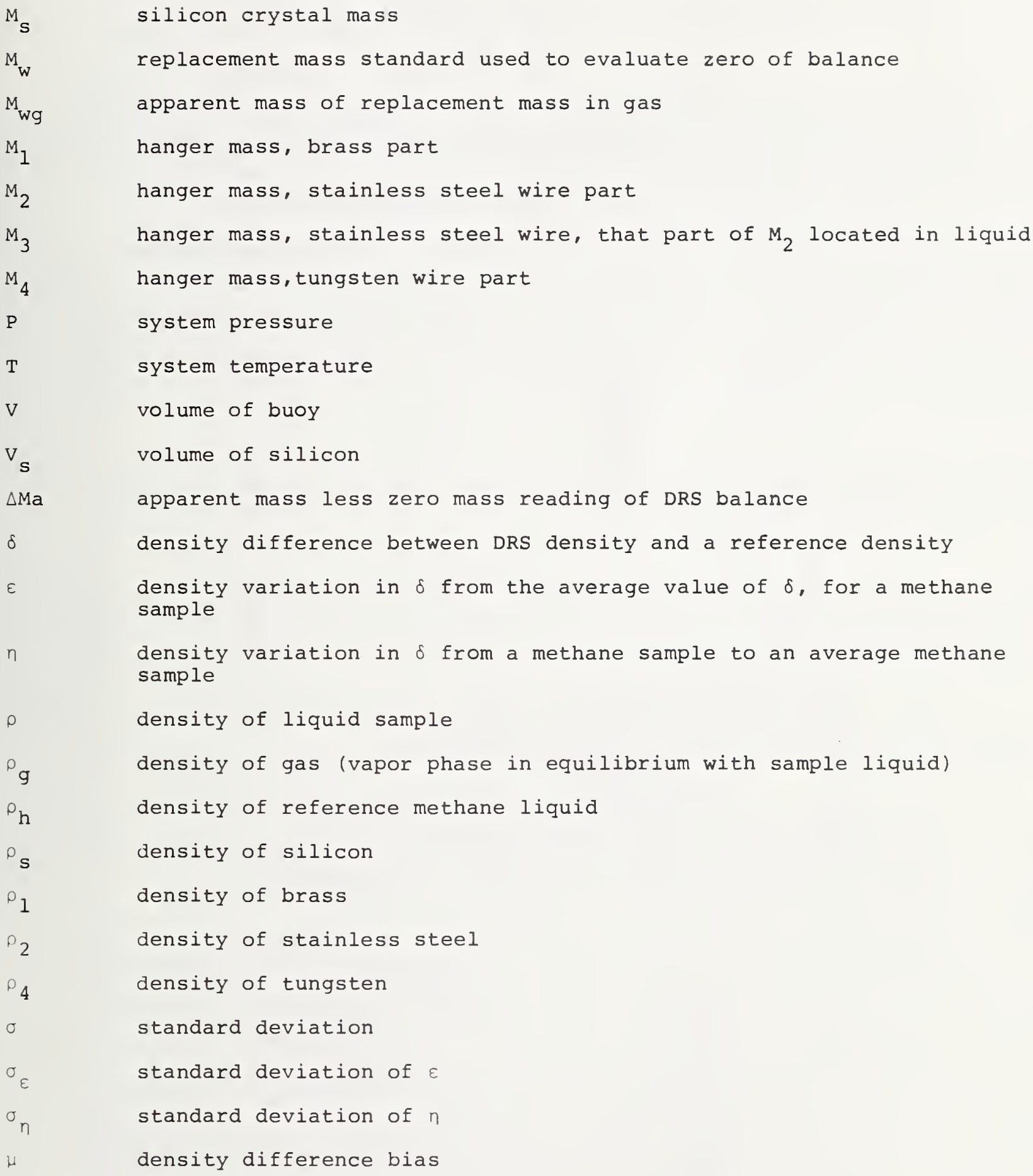




\section{DESCRIPTION OF THE BASIC MEASUREMENT PROCESS}

\subsection{Density}

The density reference system determines density via the Archimedes principle, which is that a body submerged wholly or partially in a liquid is buoyed by a force equal to the weight of the fluid displaced. The net force on the object is the difference between its weight and the buoyant force.

The basic arrangement of the silicon crystal, the weighing balance, and sample holder can be seen in figure 1. Figures 2 and 3 are photographs of the partially disassembled reference system. A silicon crystal, is weighed immersed in the test liquid. Its apparent weight is the difference in its true weight and the buoyant force exerted by the liquid.

$$
\mathrm{M}_{\mathrm{a}} \mathrm{g}=\left(\mathrm{M}_{\mathrm{s}}-\rho \mathrm{V}_{\mathrm{s}}\right) \mathrm{g} \cdot
$$

In the following relations we have removed the factor, $g$, as it is common in all terms. Solving for density

$$
p=\left(M_{s}-M_{a}\right) \frac{1}{V_{s}} .
$$

Using the measured value for the silicon mass and the value for single-crystal pure silicon density, $\rho_{s}$, we have

$$
\mathrm{M}_{\mathrm{S}}=\rho_{\mathrm{s}} \mathrm{V}_{\mathrm{S}} \cdot
$$

Combining equations (2) and (3) to eliminate $\mathrm{V}_{\mathrm{S}^{\prime}}$

$$
\rho=\rho_{s}\left(1-M_{a} / M_{s}\right) \cdot
$$

This is the basic form of the measurement equation. The one actually used is more elaborate and is developed in the following sections.

Density from actual readings using a balance.

In practice we measure density using an automatic balance. This balance uses magnetic force to achieve balance. It has the advantage of speed and convenience of operation. On one side of the balance we have a movable counterweight $M_{C}$ which can be initially adjusted to put the system in balance. Ordinarily one would adjust its moment arm to precisely balance the system. Here we leave a slight unbalance so that the automatic system will always react in one direction initially. For purpose of clarity we take the small initial unbalance of the system as being $\mathrm{M}_{{ }}$' however this will subtract out subsequently as seen below. The force generated by the magnetic balancing system is considered to be an equivalant mass $\mathrm{M}_{\mathrm{a}}$ (or apparent mass), and is the reading of the automatic balance. Here we have

$$
\mathrm{M}_{\mathrm{a}}+\mathrm{M}_{\mathrm{cg}}=\mathrm{M}_{\mathrm{rg}}+\mathrm{M}_{\mathrm{hg}}+\mathrm{M}_{\mathrm{bl}} \cdot
$$




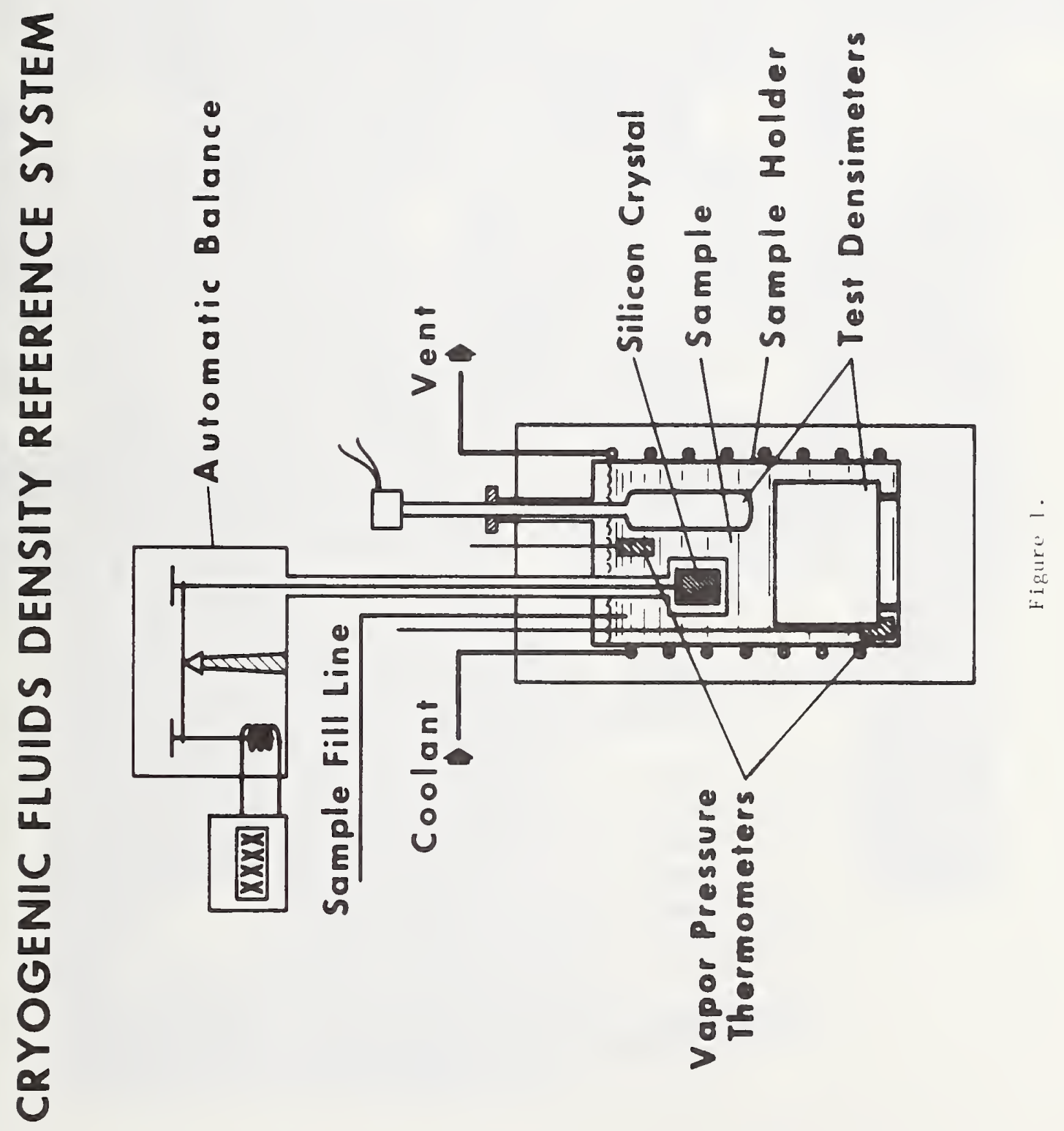




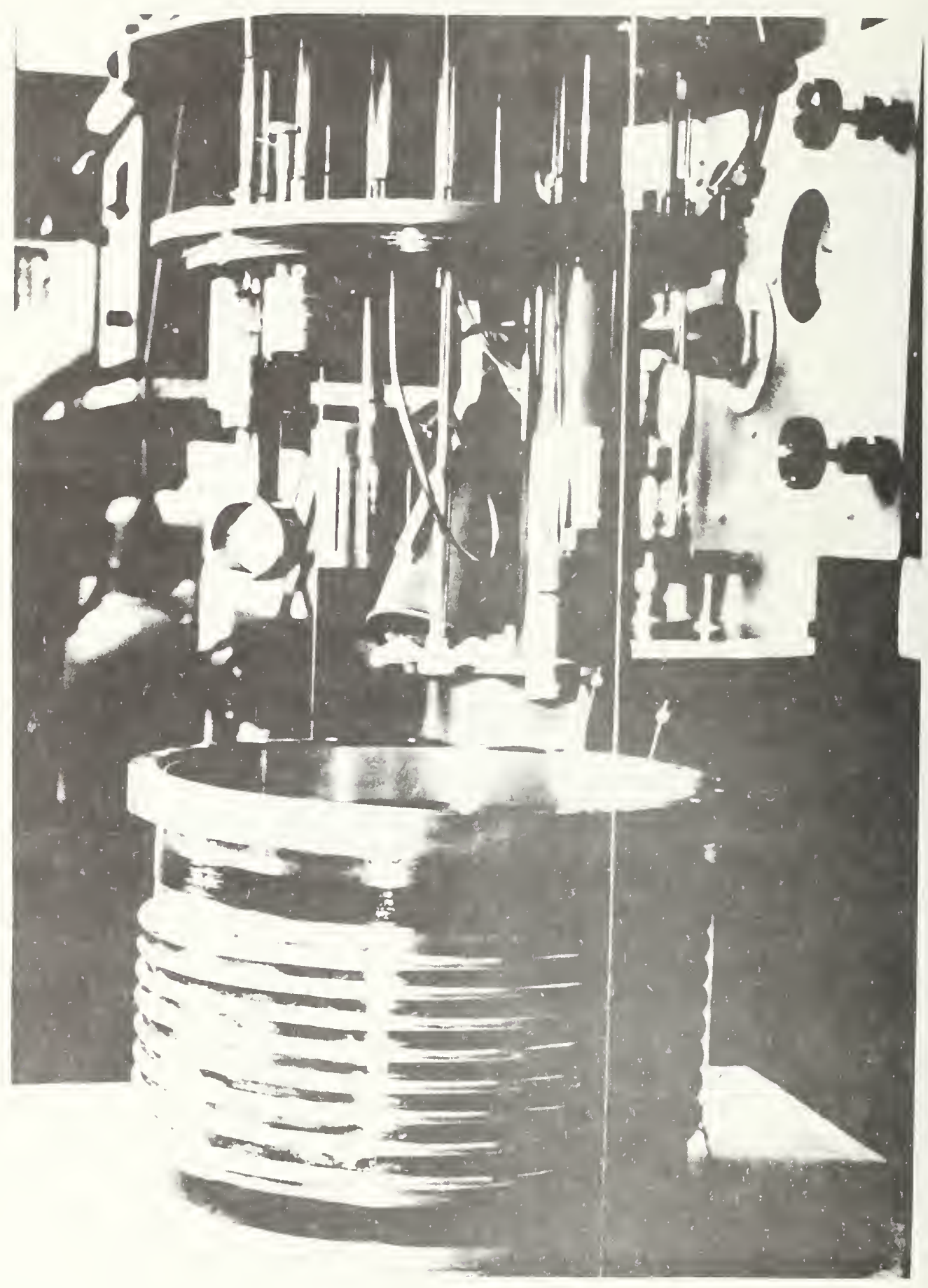

F1gure 2. Density Reference System showing small sample holder. 


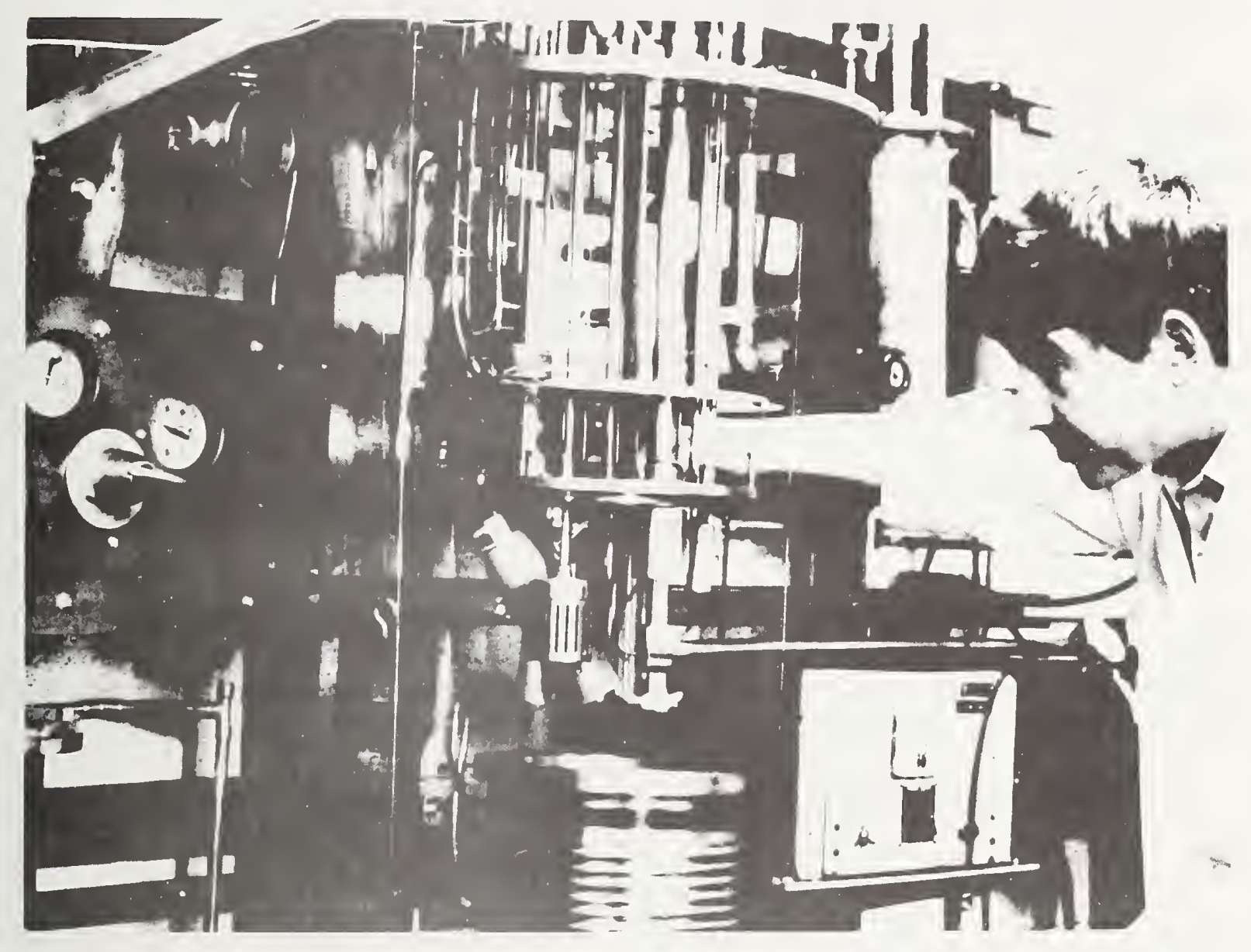

Figure 3. Partially disassembled Density Reference System. 
Notice that $M_{C}$ is now $M_{C g}$ ' as we have a buoyant effect of the gas pushing upwards on the masses in the gas.

The value of $\mathrm{M}_{r}$ was chosen for a given $\mathrm{M}_{h}$ and $\mathrm{M}_{\mathrm{s}}$ to be large enough to give a reading on-scale ( 0 to 20 grams) for the automatic balance for the range of densities of LNG under consideration. When more dense liquids were measured, for example liquid argon, a heavier range weight was used.

\section{Zeroing the balance.}

Experience with the balance showed that the zero would change although the calibration did not. In order to zero the balance the silicon crystal and its wire hanger and brass support piece were lifted off manually via a mechanical contrivance that could be operated outside the enclosure through a sliding vacuum seal.

This decrease in weight was compensated for by placing the weight $M_{w}$ on the balance pan, again with a mechanical device such that

$$
M_{\text {ao }}+M_{c g}=M_{r g}+M_{w g}
$$

where $M_{a o}$ is the zero reading of the balance. Here the range weight is still on the pan as before. Since this measurement occurs just before the measurement described by equation (5) then we may subtract out ${ }^{M}{ }_{c g}$ and ${ }^{M}{ }_{r g}$ giving

$$
M_{a}-M_{a o}=M_{h g}+M_{b l}-M_{w g}
$$

or

$$
\Delta M_{a}=M_{h g}+M_{b l}-M_{w g} \cdot
$$

Calibration of the balance.

The linearity was verified using a procedure recommended by the statistical Engineering Laboratory of NBS. See appendix 8.5. A continual check of the calibration was performed using a $10 \mathrm{gram}$ weight. Provision was made for lowering this calibration weight onto the balance pan by a thermally actuated bi-metallic strip. This allowed a very gentle and precise method of placing this weight onto the balance pan.

The calibration was checked under the zero check procedure. Immediately after checking the zero, as described by equation (6), the calibration weight, ${ }^{M_{k}}$, was placed on the balance pan so that the apparent mass (the $M_{\text {ao }}$ in equation (6)) is now Mak'

$$
M_{\text {ak }}+M_{c g}=M_{r g}+M_{w g}+M_{k g} \cdot
$$

Subtracting equation (6) from (7a),

$$
M_{a k}-M_{a o}=M_{k g} .
$$

$$
\mathrm{N}-10
$$


As long as equation ( $7 b$ ) holds, no adjustment was needed for the balance. In practice it was found that adjustment of the balance was rarely needed.

The measurement equation.

As in equation (4), the final measurement equation can be put in the form

$$
\rho=\rho_{\mathrm{S}}\left(1-\mathrm{f}\left(\mathrm{M}_{1}, \mathrm{M}_{2}, \ldots \rho_{1}, \rho_{2} \ldots\right)\right)
$$

where the independent variables are all known. In actual practice the hanger $\mathrm{M}_{\mathrm{h}}$ ' consisted of a brass part $\left(\mathrm{M}_{1}, \rho_{1}\right)$ and a stainless steel wire suspended from this brass hanger $\left(M_{2}, P_{2}\right)$. However, part of the stainless steel wire was immersed in the liquid. The part in the gas is $M_{2}-M_{3}$ and the part in the liquid is $\mathrm{M}_{3}$. Therefore,

$$
M_{h}=M_{1}+M_{2}-M_{3}
$$

and,

$$
M_{h g}=\left(M_{1}+M_{2}-M_{3}\right)-\rho_{g}\left(\frac{M_{1}}{\rho_{1}}+\frac{M_{2}-M_{3}}{\rho_{2}}\right) .
$$

Also the mass $M_{b}$ breaks down into

$$
\mathrm{M}_{\mathrm{b}}=\mathrm{M}_{\mathrm{s}}+\mathrm{M}_{3}+\mathrm{M}_{4} \text {, }
$$

where $\mathrm{M}_{4}$ is a short length of tungsten wire $\left(\mathrm{M}_{4}, \mathrm{p}_{4}\right)$ wrapped around the silicon crystal $\left(\mathrm{M}_{\mathrm{b}}, \mathrm{P}_{\mathrm{s}}\right)$ so we have

$$
M_{b \ell}=M_{s}+M_{3}+M_{4}-\rho\left(\frac{M_{s}}{\rho_{s}}+\frac{M_{3}}{\rho_{2}}+\frac{M_{4}}{\rho_{4}}\right) .
$$

Putting these relations into equation (7)

$$
\begin{gathered}
\Delta M_{a}=M_{1}+M_{2}-M_{3}-\rho_{g}\left(\frac{M_{1}}{\rho_{1}}+\frac{M_{2}-M_{3}}{\rho_{2}}\right) \\
+M_{s}+M_{3}+M_{4}-\rho\left(\frac{M_{s}}{\rho_{s}}+\frac{M_{3}}{\rho_{2}}+\frac{M_{4}}{\rho_{4}}\right)-M_{w}+\rho_{g} \frac{M_{w}}{\rho_{1}} \\
D=\frac{M_{s}+M_{1}+M_{2}+M_{4}-M_{w}-\Delta M_{a}-\rho_{g}\left[\left(M_{1}-M_{w}\right) / \rho_{1}+\left(M_{2}-M_{3}\right) / \rho_{2}\right]}{\left(M_{s} / \rho_{s}+M_{3} / \rho_{2}+M_{4} / \rho_{4}\right)}
\end{gathered}
$$

the form of equation (8) may be obtained by factoring out $\rho_{s}$ and $M_{b}$ to obtain

$$
\frac{1+\frac{M_{1}+M_{2}+M_{4}-M_{w}-\Delta M_{a}}{M_{s}}-\frac{\rho_{g}}{M_{s}}\left[\left(M_{1}-M_{w}\right) / \rho_{1}+\left(M_{2}-M_{3}\right) / \rho_{2}\right]}{\left(1+\frac{M_{3}}{M_{s}} \frac{\rho_{s}}{\rho_{2}}+\frac{M_{4}}{M_{s}} \frac{\rho_{s}}{\rho_{4}}\right)} .
$$


The following are the measured values of the masses used in equation (13). Literature values of the densities were used, the possible effect this could have on measurement accuracy is discussed below.

$$
\begin{array}{lll}
M_{S}=127.4330 \mathrm{~g}, \rho_{S}=2.33078 \mathrm{~g} / \mathrm{cm}^{3} & \begin{array}{l}
\text { the silicon crystal. } \\
M_{1}=4.2441 \mathrm{~g}, \rho_{1}=8.5 \mathrm{~g} / \mathrm{cm}^{3}
\end{array} \\
M_{2}=0.2121 \mathrm{~g}, \rho_{2}=7.9 \mathrm{~g} / \mathrm{cm}^{3} & \begin{array}{l}
\text { the brass hanger. } \\
\text { the stainless steel suspen- } \\
\text { sion wire. } \\
M_{3}=0.026 \mathrm{~g}
\end{array} \\
M_{4}=0.055 \mathrm{~g}, \rho_{4}=18.8 \mathrm{~g} / \mathrm{cm}^{3} & \begin{array}{l}
\text { stanless steel suspension } \\
\text { wire submerged in liquid. }
\end{array} \\
M_{W}=100.9296 \mathrm{~g} & \begin{array}{l}
\text { the tungsten wire tied about } \\
\text { the brass replacement weight. }
\end{array}
\end{array}
$$

The denominator of equation (13), $M_{S} / \rho_{s}+M_{3} / \rho_{2}+M_{4} / \rho_{4}$ is the total volume of the submerged material. From the above it is

$$
\begin{aligned}
& \mathrm{V}=54.674+0.00329+0.00293 \mathrm{~cm}^{3} \\
& \mathrm{~V}=54.680 \mathrm{~cm}^{3} .
\end{aligned}
$$

The total equation (13) becomes

$$
\rho=\frac{31.0146-\Delta M_{a}+\rho_{g}(11.351)}{54.6802} \mathrm{~g} / \mathrm{cm}^{3} \text {. }
$$

The value for the silicon mass is an average of several weighings in air, corrected to weight in vacuum. (See appendix 8.2, page 23).

The density of silicon of $2.33078 \mathrm{~g} / \mathrm{cm}^{3}$ has been corrected for thermal contraction to LNG temperatures (appendix 8.3) from the literature values (appendix 8.1). Pressure dependence of $\rho_{S}$ is negligible (appendix 8.1).

\subsection{Pressure}

The system pressure was measured using a quartz-spiral bourdon tube. During the first series of measurements (data taken before December 1975), the system used a 500 psi* gage, the data after that used a 200 psi gage. The calibration of all pressure gages used was checked at this laboratory using an air-dead weight gage, which is accurate to $0.015 \%$, with the accuracy traceable to NBS. Pressure uncertainty was found to be within the $0.015 \%$ of full scale pressure specified by the manufacturer.

\subsection{Temperature}

Temperature was measured using vapor pressure thermometers. One thermometer bulb was located at the bottom of the sample volume and the other near the top. Each thermometer contains about $5 \mathrm{~cm}^{3}$ of liquid methane. Pressure * $1 \mathrm{psi}=6.895 \mathrm{kPa}$. 
communicates from the thermometers to a quartz-spiral bourdon tube (100 psi maximum) via 1/16" O.D. stainless capillary tubing. The temperature range was $100 \mathrm{~K}$ to $140 \mathrm{~K}$. Sensitivity and precision of this device is the same as specified for the gages in section 2.2. This pressure uncertainty is equivalent to $0.03 \mathrm{~K}$ at $100 \mathrm{~K}$ and $0.003 \mathrm{~K}$ at $140 \mathrm{~K}$ for the $100 \mathrm{psi}$ gage used to measure vapor pressure.

Temperature gradients as measured by the vapor pressure thermometers were generally $0.030 \mathrm{~K}$ and on rare occasions approached $0.3 \mathrm{~K}$. The density difference resulting from this temperature difference can be calculated by using methane

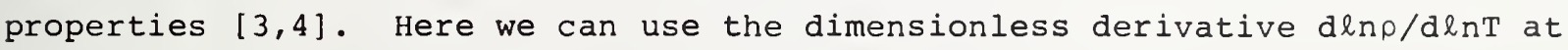
saturation:

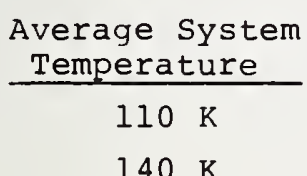

$140 \mathrm{~K}$

$\frac{d \ln \rho / d \ln T}{0.38}$
0.26

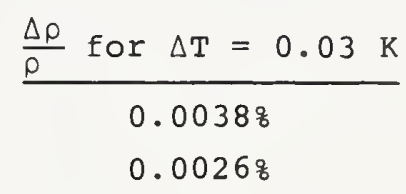

In the worst instance the difference was only $0.04 \%$. The densimeters under test were actually physically closer to the DRS density probe (the silicon crystal) than were the two vapor pressure thermometers, implying a lower density difference.

\subsection{Composition}

When mixtures were used for the density measurements, the compositions (mole fractions) were determined by accurate measurement of the mass of the separate constituents and subsequently applying corrections for the effect of gas phase to the total system composition to obtain liquid phase compositions.

The samples were weighed in metal cylinders. After transfer to the DRS cryostat, the cylinders were again weighed and the amount transferred computed from the difference.

The balance used for this purpose is a high-resolution and high-capacity balance (resolution better than $0.01 \mathrm{~g}$, with maximum capacity of $20 \mathrm{~kg}$ ). Class $S$ weights were used (see appendix 8.4).

Upon condensation in the cryostat the sample separates into a liquid and gas phase. The volume of the gas phase was two to four times the volume of the liquid. The large volume of the gas phase was required to house the automatic balance used in weighing the silicon crystal which measured the liquid density.

The composition of the liquid phase was calculated from the total composition by subtracting the amount of the vapor phase. The total composition is that computed from the amounts of sample gas transferred into the system. If the composition of the gas and liquid phase were the same, then the liquid composition would be the same as the total composition. 
For mixtures of methane with ethane, propane and butane the vapor phase was assumed to be methane. The vapor phase densities in the balance volume sample chamber and interconnecting tube are computed from a virial equation of state [3] using the system pressure and temperatures. The calculated quantities of methane are then subtracted from the total amount of methane in the system and the result is used to compute the liquid phase composition.

For mixtures with nitrogen, the vapor phase is assumed to be methane and nitrogen. The densities of the vapor phase were computed from a mixture virial equation which included terms to the second virial coefficient. Since this equation used the mixture second virial coefficient, it was computed from the second virial coefficients of the pure components and the interaction second virial coefficient for the mixture, as well as the vapor phase compositions. The vapor phase compositions were estimated from phase-equilibria data for methane-nitrogen of this laboratory [5] using enhancement factors. The resulting computation of vapor densities allows a first estimate of the amount of nitrogen and methane in the vapor phase. From this, a corresponding first estimate of the liquid phase composition is made. The estimate is improved by iterating the computation using the results of the preceding evaluation.

In the instance of a binary mixture the composition could be computed from another approach. Dielectric constant density measurements of the liquid and with the assumption that the polarizability of the methane-nitrogen mixture could be computed from ideal mixing, allows one to compute the mole fraction of the binary mixture. Agreement between the calculation described in the above paragraphs and the dielectric constant calculation was found to be about 0.2 to 0.4 mole percent when the nitrogen composition was less than 2 mole percent.

Because of the additional uncertainties of mixtures discussed above, only pure methane results were used in the random error determination.

\section{MEASUREMENT PROCESS PARAMETERS}

3.1. Bounds for Systematic Errors

A listing of the primary sources of uncertainty in density measurement can be obtained from examination of the measurement equation. If one has knowledge of the basic uncertainties of the separately measured quantities such as the masses and densities, then these can be combined to give an estimate of the systematic errors in the density as measured by the density reference system.

However, until experimental evidence of the actual effect is obtained by introducing an offset in these factors, both singly and jointly, this analysis is just that, an estimate of undemonstrated validity. 
Equation (13), the measurement equation, has the density $\rho$ as a function of several independent variables.

$$
\rho=\rho\left(M_{s}, M_{1}, M_{2}, M_{3}, M_{4}, M_{w^{\prime}}, \Delta M_{a}, \rho_{s}, \rho_{1}, \rho_{2}, \rho_{4}\right) \text {. }
$$

The uncertainty in $\rho$, arising from uncertainty in $\rho_{s}$, for example, can be evaluated from

$$
\delta \rho=\frac{\delta \rho}{\delta \rho_{s}} \delta \rho_{s}
$$

or as a dimensionless ratio,

$$
\frac{\delta \rho}{\rho}=\frac{\partial \ln \rho}{\partial \ln \rho_{s}} \frac{\delta \rho_{s}}{\rho_{s}},
$$

which has the advantage of expressing the independent and dependent variables as dimensionless ratios. The total uncertainty in density is the square root of the sum of the squares of the various contributions.

$$
\frac{\delta \rho}{\rho}=\sum\left(\frac{\partial \ln \rho}{\partial \ln x_{i}} \frac{\delta x_{i}}{x_{i}}\right)^{2} 1 / 2 .
$$

This is the propagation of error relationship for systematic error [6] when the variables are independent and the magnitudes of the relative errors are small so that second order terms are negligible.

Table 1 is a summary of the most significant contributions to the total systematic uncertainty in density as estimated from the various contributing sources. The first column, labelled $x$ identifies the variable for which the uncertainty is calculated. The second column is the total logarithmic partial derivative of the liquid density with respect to the variable of the first column. The column labelled $\delta \mathrm{x} / \mathrm{x}$ is the ratio of the estimated worst possible uncertainty of that variable.

The systematic error, $\delta \mathrm{x} / \mathrm{x}$, due to mass determinations is estimated from the uncertainty generated by the balance and weights used to determine the masses. The estimate of the systematic error of the apparent mass is the uncertainty of the electronic balance reading as specified by the manufacturer. Linearity measurements (appendix 8.5) indicate this number is conservative. The error estimate of the silicon crystal density covers uncertainties due to the temperature and pressure effects (appendix 8.1) as well as uncertainties in published densities (appendix 8.3). The metal density uncertainties of which $M_{W}$ is the dominant term are estimated from volume and weight. The gas density is required for bouyancy corrections, contains all gas pressure, temperature and composition uncertainties and is the leading systematic error for mixtures containing $\mathrm{LN}_{2}$. The uncertainties due to temperature gradients is discussed in section 2.3. An additional systematic error results from the uncertainty in the absolute value of $T$. This is not included in the table since it makes no contribution to the systematic error when densimeters are

$$
N-15
$$


being compared. When density measurements are being compared with those of other workers, however, there is an 0.018 maximum contribution to the systematic error at the lowest temperature that decreases to less than 0.0018 at the highest temperatures.

Table 1. Systematic errors.

Variable, $\mathrm{x}$ $\partial \ell \rho / \partial \ln x$ $\delta x / x$ $\delta \rho / \rho$ in $q$

silicon crystal mass

brass hanger mass

steel wire mass

steel wire mass in liquid

tungsten wire mass

apparent mass

silicon density

metal densities

gas density

$$
\left(p_{s}-p\right) M_{s} / p_{s} V \ldots \ldots .31 .6 \times 10^{-5} \pm 0.0062
$$$$
\left(\rho_{1}-\rho_{g}\right) M_{1} / \rho_{1} V . .1 .8 \times 10^{-1} 2.4 \times 10^{-4}
$$$$
\pm 0.0043
$$$$
\left(\rho_{2}-\rho_{g}\right) M_{2} / \rho \rho_{2} V .8 .9 \times 10^{-4}
$$$$
4.7 \times 10^{-3}
$$$$
\pm 0.00042
$$$$
\left(\rho-\rho_{g}\right) M_{3} / \rho \rho_{2} V \ldots 6.0 \times 10^{-5}
$$$$
3.8 \times 10^{-4}
$$$$
\left(\rho_{4}-\rho_{g}\right) M_{4} / \rho \rho_{4} V . .5 .4 \times 10^{-5}
$$$$
1.8 \times 10^{-2}
$$

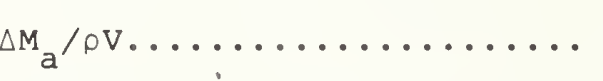

$1.0 \times 10^{-4}$

$\pm 0.010$

$M_{s} / \rho_{s} v \ldots \ldots \ldots \ldots \ldots \ldots \ldots .61 .6 \times 10^{-5}$

$\pm 0.0016$

$\left(M_{1}-M_{w}\right) \rho_{g} / \rho_{1} \rho V \cdot 2.0 \times 10^{-3}$

$2.3 \times 10^{-2}$

$\pm 0.0046$

temperature $\rho_{g}\left(\left(M_{1}-M_{w}\right) / \rho_{1}+\right.$

$$
\left.\left(M_{2}-M_{3}\right) / \rho_{2}\right) / \rho V . .2 .2 \times 10^{-3}
$$

$1.0 \times 10^{-1 *}$

$\pm 0.022$

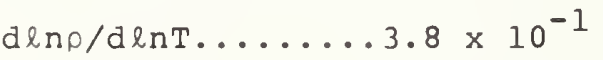

$1.0 \times 10^{-4}$

$\pm 0.0038$

gradient

Total, from equation (18) $\ldots \pm 0.0268$.

* The large uncertainty for gas density results from the large uncertainty of the methane-nitrogen vapor densities. The uncertainty due to gas density is only $0.002 \%$ for methane and the total from equation (18) is $\pm 0.014 \%$.

Some of the systematic errors listed above will be eliminated in future measurements. By moving the point the silicon float disconnects from the balance down into the liquid such that the float disconnects from all suspension hardware, all systematic errors associated with the brass hanger and the steel and tungsten hanger wires will be eliminated. The uncertainty of the silicon mass was determined from the uncertainty of the measuring weights and the density uncertainty comes from literature values of the density. The uncertainty in apparent mass is due to the balance and has been determined experimentally (see appendix 8.2). The temperature gradient was measured to determine that uncertainty. Only the uncertainty due to the density of the replacement weight and the gas density correction has yet to be examined experimentally. This can be done by using a more dense mass for the replacement weight. However, any effect due to changing 
this weight should be very small compared to the random error. If any change in the estimated systematic error is warranted after experimentally checking for replacement weight buoyancy effects, this correction will be made in the updated uncertainty statements.

\subsection{Random Error from Measurements on Methane}

The random error of the density reference system was determined experimentally by measurements on liquid methane.

Density measurements on pure methane were compared to densities computed from the Haynes-Hiza relation for density versus temperature for saturated liquid methane [4]. The vapor pressure measurements were converted to temperature [3] and the resulting temperature converted to densities as described.

The present estimates of the precision for density determinations made using the DRS are based on measurements of the density of eight different samples (fillings) of liquid methane. For the eight samples there was a total of seventy-one density measurements of saturated methane in the temperature range $100 \mathrm{~K}$ to $140 \mathrm{~K}$-- for the last four samples the temperatures were $110 \mathrm{~K}$, $125 \mathrm{~K}$, and $140 \mathrm{~K}$.

The model used to analyze the methane data is

$$
\mathrm{Y}_{(\mathrm{T}) i j}-\mathrm{H}_{(\mathrm{T})}=\mu_{(\mathrm{T})}+\alpha_{i}+\mathrm{e}_{i j}
$$

where $Y_{(T)} i j$ is the jth density determination by the DRS on the ith methane sample for temperature $\mathrm{T} ; \mathrm{H}(\mathrm{T})$ is the corresponding density value derived from the Haynes-Hiza relationship, $\mu_{(T)}$ represents the long term relative bias, $\alpha_{i}$ is the random contribution to all measurements made using the $i t h$ sample, and $e_{i j}$ is the random contribution to the $j$ th measurement made on the ith sample. The standard deviation (SD) for the $\alpha_{i}$ is called the between sample SD, and the SD for the $e_{i j}$ is called the within sample SD. The SD of measurements $Y_{(T)} i j$ is the square root of the sum of the squares of these two SD.

There were seventy-one least squares estimates of the $e_{i j}$ for the liquid methane measurements. The variability among the estimate samples -the last twenty-two, e.g. -- is less than among the preceeding forty-nine. The point estimate for the within SD for the first six samples is $\pm 0.074 \%$ (using $400 \mathrm{~kg} / \mathrm{m}^{3}$ as reference) and that for the last two is \pm 0.0348 . The corresponding 998 confidence intervals are $(0.057,0.101)$ and $(0.024,0.055)$. This change in variability is attributed to the cleaning of the knife edges on the DRS's balance. The point estimate for the between samples SD for the eight samples is \pm 0.0528 , a 998 confidence interval is $(0.029,0.13)$. The cleaning of the knife edges has not effected this component of the variability. The estimated SD for a single measurement made on the DRS 
previous to the cleaning of the balance is $\pm 0.090 \%$. For measurements made after that time the SD is estimated to be \pm 0.0628 .

Only the within SD's after the knife edges were cleaned are taken to correctly reflect the precision of the within sample density measurements. A comparison of these data with the Haynes-Hiza densities is shown in Figure 4 as well as a comparison to the work of Goodwin [3].

For the methane data the DRS measurements of density shows a bias with the Haynes-Hiza relationship which is a linear function of density. For a density of $0.38 \mathrm{~g} / \mathrm{cc}$ the bias is $-0.062 \%$ with an estimated SD of $0.021 \%$; a $99 \%$ confidence interval is $(-0.12 \%,-0.006 \%)$. For a density of $0.43 \mathrm{~g} / \mathrm{cc}$ the bias is $-0.11 \%$ with an estimated SD of $0.018 \%$; a $99 \%$ confidence interval is $(-0.16 \%,-0.062 \%)$.

Figure 5 shows a comparison of densities for two samples of liquid argon as measured by the density reference system to those measured by the HaynesHiza apparatus, as well as other laboratories as indicated in the caption. As can be seen in this figure, the agreement with Haynes and Hiza is generally within $0.1 \%$.

\subsection{Uncertainty Statement}

While the use of three times the estimated SD is commonly used in reporting the limits of random error, because of the small number of observations (eight) relating to the sample-to-sample error, the limits using $3 \times 0.062 \%$ will provide a $98 \%$ confidence interval rather than one of $99 \%$. When the samples of liquid methane measured by the DRS exceed fifteen, the use of the factor 3 will give confidence intervals of better than 998 . The limit. of possible sources of systematic error has been judged to be $\pm 0.026 \%$ (see section 3). This systematic limit of $0.026 \%$ plus $3 \times 0.062 \%$ gives the present estimated limit of total uncertainty for a single density measurement made on the DRS as $\pm 0.21 \%$

\section{MEASUREMENT PROCESS CONTROL}

As future measurements are made, the random errors will be continually checked and the systematic error estimates will be confirmed experimentally or the error source eliminated where possible as described below.

Each time a set of density reference measurements are made using the system, measurements on at least two separate fillings of pure liquid methane will be included in the tests. Density measurements will be made at temperatures around $110 \mathrm{~K}, 125 \mathrm{~K}, 130 \mathrm{~K}$ and $140 \mathrm{~K}$. Three measurements will be made at each temperature in random order. The remeasured methane densities can be compared to the Haynes-Hiza results and to the earlier reference system measurements to determine whether the system has shifted. This reliability of the system will be checked only in conjunction with density comparison

$$
\mathrm{N}-18
$$




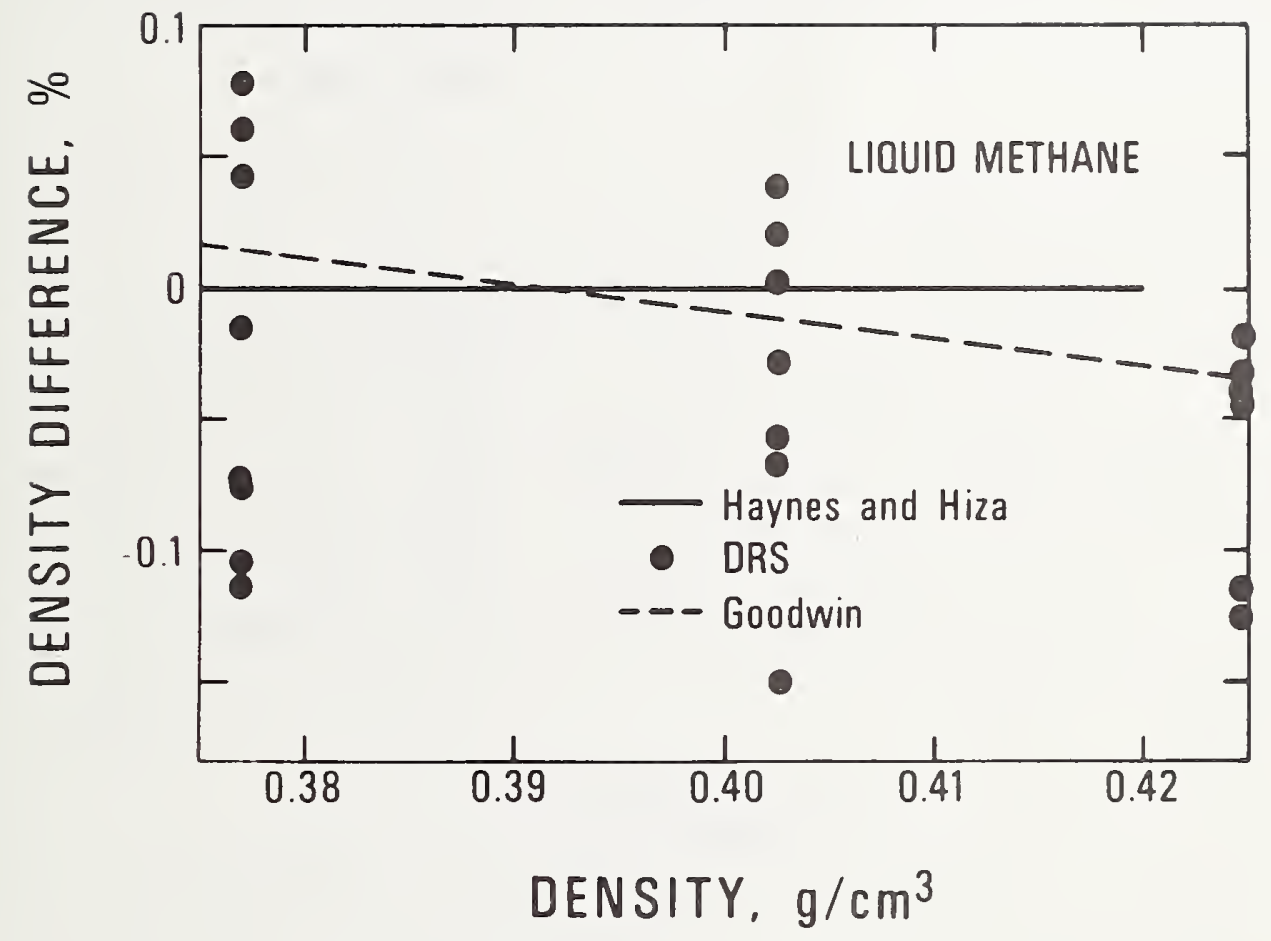

Figure 4. Liquid methane density results of this work relative to the work of Haynes, et a1.[4]. The data are the 22 points taken after the knife edges were cleaned. 


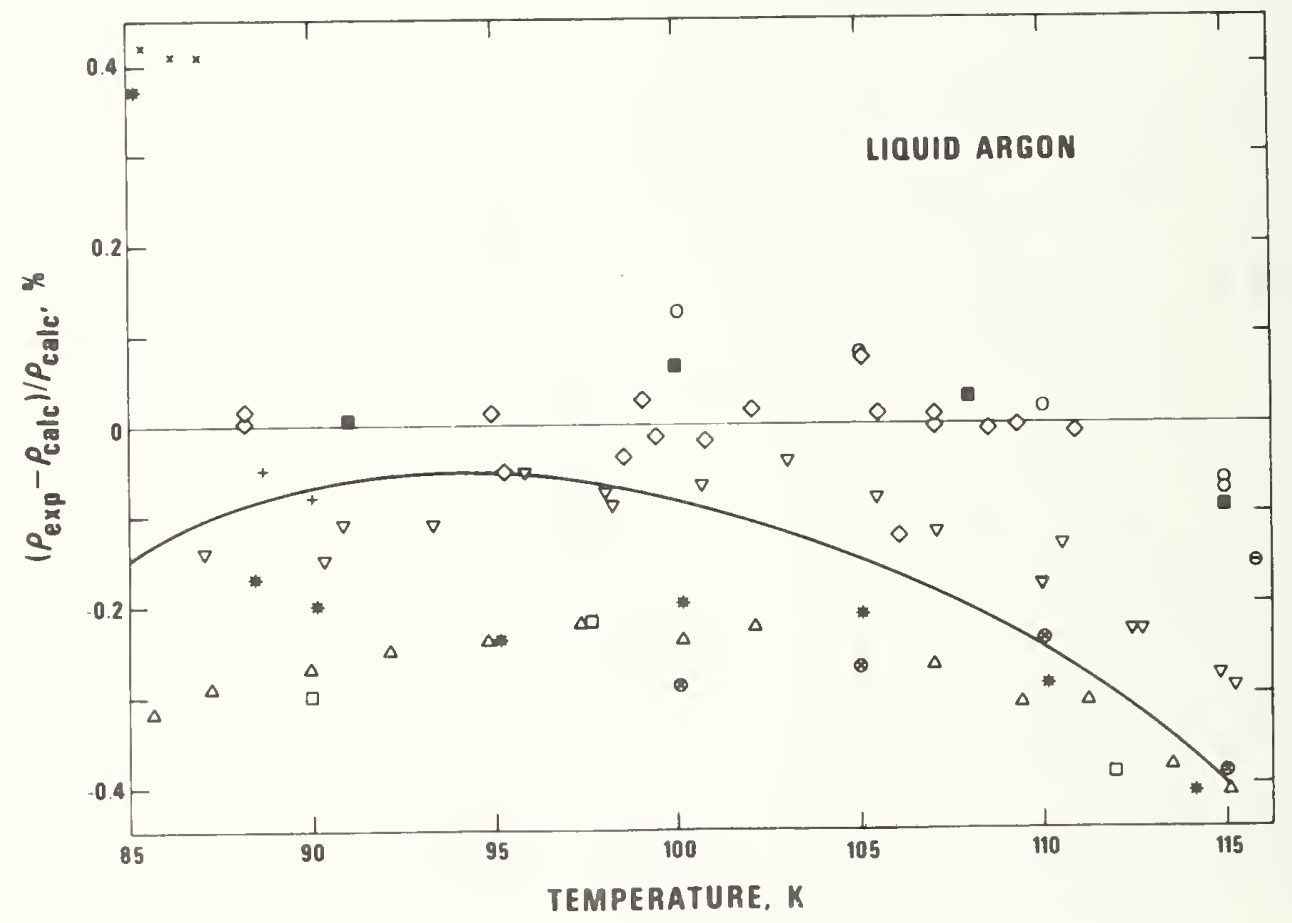

Figure 5. Liquid argon densities of other workers compared to a least squares fit to this work.

$\diamond$ Younglove, this work.

- Haynes and Hiza [9].

- Pan, et al. [14].

$\Theta \quad$ Chui and Canfield [10].

+ Van Itterbeek and Verbeke

$\nabla$ Goldman and Serase [15].

* Saji and Kobayashi [16].

- Mathias, et al. [17]. [11].

$\triangle$ Terry, et al. [12].

- Street and Staveley [18].

* Dobrovolskii and Golubev [19].

- Gosman, et al. [13]. 
work rather than periodically because of the expense of making density measurements.

For these occasions the within SD's will be compared statistically to those of previous occasions for any change in this measure of precision, and the occasion-to-occasion shifts, $\alpha_{i}$ (see 3.2), will be tested for any change in their variability or for signs of non-random behavior (e.g., drifting). If there is no apparent change, the data from previous occasions will be combined with the new data to obtain updated estimates. Any statistically verifiable changes in the DRS process will call for corrective action with respect to the process. A revised uncertainty statement will be presented as further calibration measurements are completed.

\section{SUMMARY}

The density reference system of the National Bureau of Standards, Cryogenics Division is described. Since the density determination by the DRS is basically a weighing process, the details of calculation of this process are described in detail. The procedure for determining the density from weighing, zeroing and calibrating the balance is discussed.

The uncertainty of the density reference system is $\pm 0.21 \%$. The contribution from the estimated systematic error in density was \pm 0.0268 . The estimated uncertainty caused by random error is three times the standard deviation of $\pm 0.062 \%$ and is based on the measurements of the densities [4] of liquid methane taken on eight samples and on 22 independent measurements. The total density uncertainty was taken to be the sum of the systematic and random errors.

\section{ACKNOWLEDGEMENTS}

Special acknowledgement is given to John LaBrecque of the NBS Statistical Engineering Laboratory for the considerable help and advice given this project during its various phases. Acknowledgement is also given to Janet Donaldson of the same group for her recommendations on the method of acquiring data from the automatic balance.

Jim Holste contributed very heavily in the construction and start up phase of this project. He designed and built several important features of the DRS. 


\section{REFERENCES}

[1] Bowman, H. A., Schoonover, R. M., and Jones, M. V., Procedure for high precision density determinations by hydrostatic weighing, J. of Research, NBS C, 71C, 178 (1967).

[2] Henins, I., and Bearden, J. A., Silicon crystal determination of the absolute scale of x-ray wavelengths, Phys. Rev. 135, A890 (1964).

[3] Goodwin, R. D., The thermophysical properties of methane, from 90 to $500 \mathrm{~K}$ at pressures to 700 bar, NBS Tech. Note 653, Apr. 1974.

[4] Haynes, W. M., Hiza, M. J., and Frederick, N. V., A magnetic suspension densimeter for measurements on fluids of cryogenic interest, to be submitted to Review of Scientific Instruments.

[5] Parrish, W. R. and Hiza, M. J., Liquid-vapor equilibria in the nitrogenmethane system between 95 and $120 \mathrm{~K}$, Advances in cryogenic Engineering (Proc. 1973 CEC), Vol. 19 (Plenum Press, NY, 1974).

[6] Cook, N. H. and Rabinowicz, E., Physical Measurement and Analysis, AddisonWesley Publishing Co., Inc., 1963.

[7] MCSkimmin, H. J., J. Appl. Phys. 24, 988 (1953).

[8] Corruccini, R. J. and Gniewek, J. J., Thermal expansion of technical solids at low temperatures, Nat. Bur. of Stand. (U.S.) Monograph 27, May 1961.

[9] Private communication.

[10] Chui, C. and Canfield, F. B., Trans. Faraday Soc. 67, 2933 (1971).

[11] Van Itterbeek, A., Verbeke, O., and Staes, K., Physica 29, 742 (1963).

[12] Terry, M. J., Lynch, J. T., Bunclark, M., Mansell, K. R., and Stavely, L. A. K., J. Chem. Thermodyn. I, 413 (1969).

[13] Gosman, A. L., MCCarty, R. D., and Hust, J. G., Thermodynamic properties of argon from the triple point to $300 \mathrm{~K}$ at pressures to 1000 atmospheres. NSRDS-NBS 27 (1969).

[14] Pan, W. P., Mady, M. H. and Miller, R. C., AIChE J. 21, 283 (1975).

[15] Goldman, K. and Scrase, N. G., Physica 45, 1 (1969).

[16] Saji, Y. and Kobayashi, S., Cryogenics 4, 136 (1964).

[17] Mathias, E., Onnes, H. K., and Crommelin, C. A., Ann. Phys. 17, 442 (1922).

18 ] Street, W. B. and Staveley, L. A. K., J. Chem. Phys. 50, 2302 (1969).

[19] Dobrovolskii, O. A., and Golubev, I. F., Tr. Nauch.-Issled. Proekt. Inst. Azion. Prom. Prod. Org. Sin. 8 , 14 (1971). 
8. APPENDICES

$\mathrm{N}-23$ 
8.1. The Change in volume of the Silicon Crystal from Hydrostatic Compression and Temperature

The buoyant force of the liquid on the silicon crystal will be reduced by the effect of its volume being decreased by hydrostatic compression. This is described by

$$
V=v_{0}(1-k P)
$$

where $V_{0}$ is the volume at the reference pressure, in this case about one atmosphere or one bar. $P$ would be the pressure in excess of this and $k$ the compressibility;

$$
\left.k=-\frac{1}{v} \frac{\partial v}{\partial P}\right)_{t}
$$

This correction was found to be negligible since $\mathrm{k}=1.01 \times 10^{-6} \mathrm{bar}^{-1}$ and at $110 \mathrm{~K}$ and $\mathrm{P} \simeq 6$ bar, $\frac{\Delta \mathrm{V}}{\mathrm{V}}=6 \times 10^{-6}$. In this case $\mathrm{k}$ was computed from silicon data on velocity of sound by McSkimmin [7] using the usual relations for bulk modulus and elastic constants as evaluated from sound velocities.

The change in volume was computed from the thermal contraction of silicon values from Corruccini and Gniewek [8]. We have

$$
\frac{L_{298}-L_{T}}{L_{298}}=25.5 \times 10^{-5}
$$

for the change from $298 \mathrm{~K}$ to $100 \mathrm{~K}$. This value is essentially unchanged over the temperature interval $100 \mathrm{~K}$ to $140 \mathrm{~K}$.

$$
\begin{aligned}
& \frac{\Delta v}{v}=3 \frac{\Delta L}{L}, \\
& \rho_{s}=232.90(1.000765) \mathrm{kg} / \mathrm{m}^{3} \\
& \rho_{S}=233.08 \mathrm{~kg} / \mathrm{m}^{3} .
\end{aligned}
$$


8.2. Silicon Crystal Weighings in Air

\begin{tabular}{ccccc} 
Date & $\begin{array}{c}\text { Silicon Weight } \\
\text { in Air } \\
\text { gram }\end{array}$ & $\begin{array}{c}\text { Temperature } \\
\text { Celsius }\end{array}$ & $\begin{array}{c}\text { Pressure } \\
\text { mm Hg }\end{array}$ & $\begin{array}{c}\text { Silicon Weight } \\
\text { in Vacuum } \\
\text { gram }\end{array}$ \\
\hline $01-10-74$ & 127.3947 & 21 & 633 & 127.4335 \\
$01-15-74$ & 127.3950 & 20 & 631 & 127.4339 \\
$01-27-74$ & 127.3941 & 20 & 625 & 127.4335 \\
$02-28-74$ & 127.3945 & 21 & 620 & 127.4334 \\
$04-02-74$ & 127.3926 & 21 & 628 & 127.4320 \\
$04-05-74$ & 127.3941 & 20 & 630 & 127.4338 \\
$10-27-74$ & 127.3930 & 23 & 625 & 127.4319 \\
$10-28-75$ & 127.3927 & 21 & 620 & 127.4316 \\
& \multicolumn{4}{c}{ Average } \\
\end{tabular}


8.3. Densities of Single-Crystal Silicon

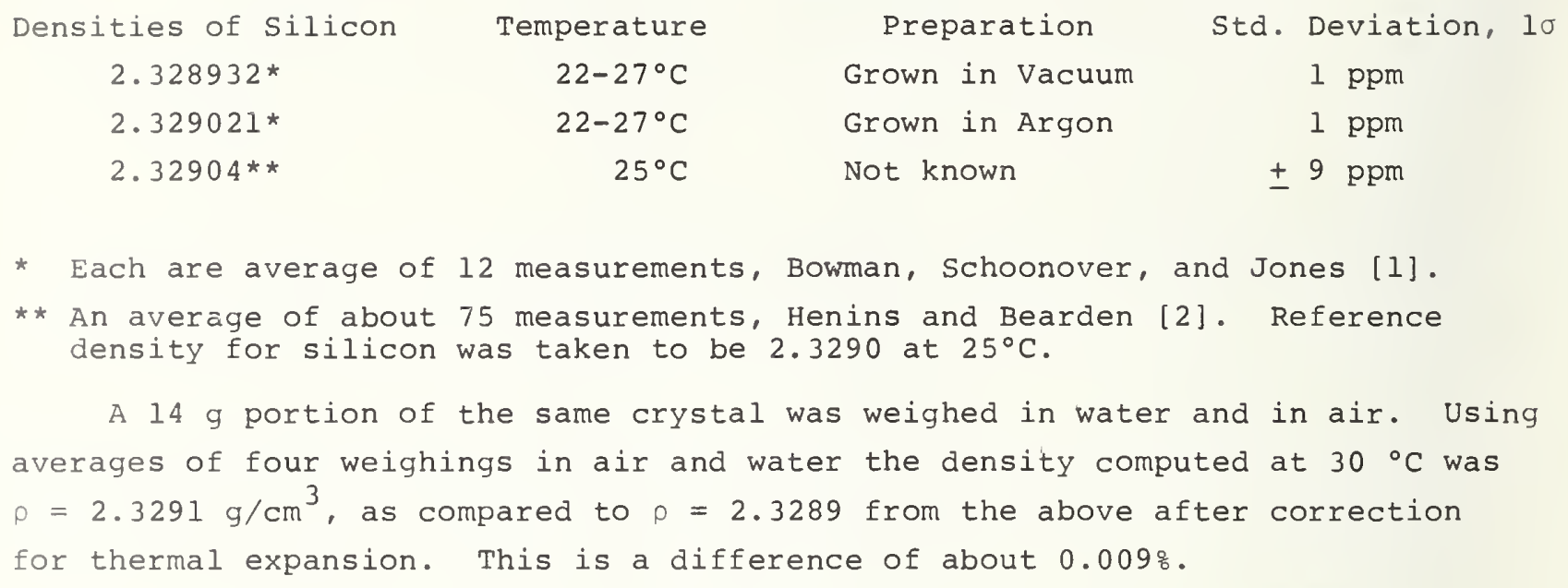

Preparation

Grown in Vacuum

Grown in Argon

Not known

Std. Deviation, $1 \sigma$

$1 \mathrm{ppm}$

$1 \mathrm{ppm}$

$\pm 9 \mathrm{ppm}$

* Each are average of 12 measurements, Bowman, Schoonover, and Jones [1].

* An average of about 75 measurements, Henins and Bearden [2]. Reference density for silicon was taken to be 2.3290 at $25^{\circ} \mathrm{C}$.

A $14 \mathrm{~g}$ portion of the same crystal was weighed in water and in air. Using averages of four weighings in air and water the density computed at $30{ }^{\circ} \mathrm{C}$ was $p=2.3291 \mathrm{~g} / \mathrm{cm}^{3}$, as compared to $\rho=2.3289$ from the above after correction for thermal expansion. This is a difference of about 0.009 . 


\section{HeV TROEMNER, InC.}

MANUFACTURERS OF PRECISION BALANCES AND WEIGHTS and LABORATORY APPARATUS G825 GREenWAY AVENUE, PHILAdELPHIA, PA. 19142

PHONE 215 SA 4.0800

TRACEABLE, CERTIFI CA TE

Voland Corporation

27 Centre Ave.

New Rochelle, N. Y. 10802

Attn: Robert C. Luce

Order 1695

This is to certify that the weights furnished on your referenced order have been calibrated to Class $S$ of the National Bureau of Standards tolerances under our N.B.S. Certificate No. as follows:

Weight Set $5 \mathrm{~kg}-1 \mathrm{~g}$

$5 \mathrm{~kg} .2 \mathrm{~kg} \cdot 2 \mathrm{~kg} .1 \mathrm{~kg}$

$500 \mathrm{~g}, 200 \mathrm{~g}, 200 \mathrm{~g}, 100 \mathrm{~g}$

$50 \mathrm{~g}, 20 \mathrm{~g}, 20 \mathrm{~g}, 10 \mathrm{~g}$

$5 \mathrm{~g}, 2 \mathrm{~g}, 2 \mathrm{~g}, 1 \mathrm{~g}$

Dated: March 28, 1974

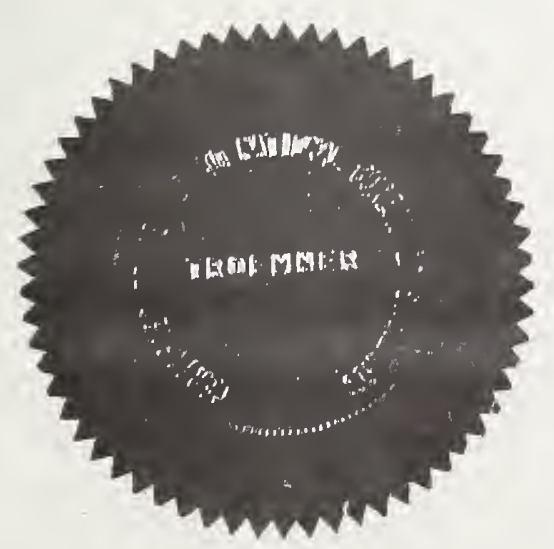

N.B.S. Certificate No.

$232.09 / 209275$ Set A

232.09/209275 Set A

232.09/209275 Set A

$232.09 / 209275$ Set A

By:

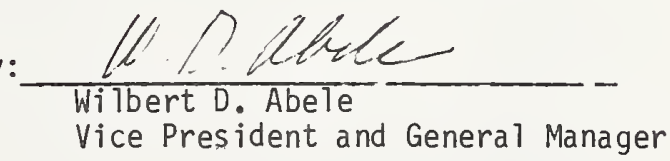




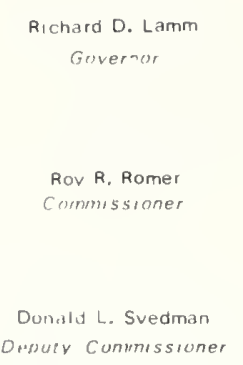

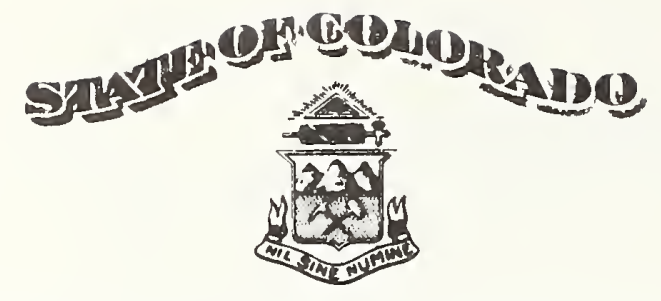

\section{COLORADO DEPARTMENT OF AGRICULTURE \\ 406 STATE SERVICES BUILDING \\ 1525 SHERMAN STREET \\ DENVER, COLORADO 80203}

June 9, 1976

REPORT OF TEST
AGRICULTURAL COMMISSION

Clarence Stone, Center Chairman

William A. Stephens, Gypsum Vice-Chairman

Ben Eastman, Hotchkiss John L. Malloy. Denver M. C. McCormick, Holly Elton Miller, Fort Lupton Kay D. Morison, Fleming William H. Webster, Greeley kenneth G. Wilmore. Denver

OWNER: National Bureau of Standards

Certification No. 3087 Cryogenic Laboratory Boulder, Colorado

DESCRIPTION: Seven weights from NBS Kit No. 143922

The standards described below have been tested and compared with the standards of the state of Colorado, and have been found to be within the tolerances as prescribed by the National Bureau of Standards for Class S weights. The effect of air bouyancy has been considered negligible.

$\begin{array}{llcc}\text { ITEM } & \text { APPARENT MASS CORRECTION } & \text { UNCERTAINTY } & \text { CLASS S ADJUSTMENT } \\ 20 . \text { gram } & -0.0080 \mathrm{mg} & .022 \mathrm{mg} & 0.074 \mathrm{mg} \\ 20 . . & +0.016 & .022 & 0.074 \\ 10 & +0.009 & .020 & 0.074 \\ 5 & -0.0403 & .0134 & 0.054 \\ 2 . & +0.0216 & .0134 & 0.054 \\ 2 . & +0.0431 & .0134 & 0.054 \\ 1 & +0.0229 & .0093 & 0.054\end{array}$

The uncertainty figure is an expression of the overall uncertainty using three standard deviations as a limit to the effect of random errors of measurement, the magnitude of systematic errors from known sources being negligible.

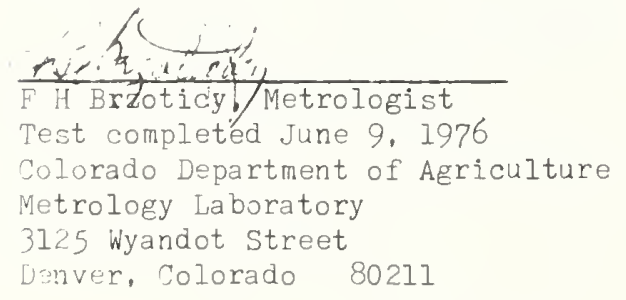

$$
\begin{array}{ll}
\text { Baro. Press. } & 627.0 \mathrm{~mm} \\
\text { Temp. } & 23.4^{\circ} \mathrm{C} \\
\text { Rel. Hum. } & 45.5 \%
\end{array}
$$

THESE CERTIFICATIONS ARE TRACEABLE TO THE NATIONAL BUREAU OF STANDARDS.

ALL CERTIFICATION CERTIFICATES ISSUED BY THE COLORADO DEPARTMENT OF AGRICULTL'RE-1:E!C!:\%; AND MEASURES-FOR STANDARDS HE:E LIEIET. EXPIRE AS INDICATED BELUIV:

(a) PRIMARY STENDFRDS. File Years Altcr Date et Ciril rition

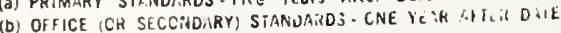

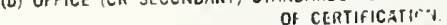

(c) Working (or Field) Standards. One Year Alter Date of Cerllf celion 


\subsection{Linearity Check of the Balance}

The linearity of the balance was verified by weighing $1,2,2,5,10$, and $20 \mathrm{~g}$ class $\mathrm{S}$ weights (see weight certificate in appendix 8.4) in combinations to produce weights of $1,2,3,4,5,6, \ldots 20 \mathrm{~g}$ in a random order. These weighings were analyzed by the Statistical Engineering Laboratory of NBS.

Their interpretation was that the residual standard deviation is $0.0008 \mathrm{~g}$ based on 37 degrees of freedom. The linearity coefficient was 0.99960 .

A summary of these measurements are shown below.

\section{Independent \\ Variable}

$\begin{array}{rr}4.000 & 4.000 \\ 15.998 & 15.998 \\ 10.999 & 10.997 \\ 2.000 & 2.001 \\ 6.999 & 7.000 \\ 1.000 & 1.002 \\ 8.999 & 9.000 \\ 17.998 & 17.998 \\ 8.999 & 9.000 \\ 18.998 & 18.999 \\ 10.999 & 11.000 \\ 11.999 & 11.999 \\ 14.998 & 14.999 \\ 19.998 & 18.998 \\ 4.000 & 4.000 \\ 12.999 & 12.997 \\ 4.999 & 5.000 \\ 12.999 & 12.999 \\ 1.000 & 1.002 \\ 11.999 & 12.000 \\ 18.998 & 18.999 \\ 13.998 & 14.000 \\ 19.998 & 19.999 \\ 17.998 & 17.999 \\ 7.999 & 8.000 \\ 15.998 & 15.999 \\ 1.999 & 2.002 \\ 5.999 & 6.001 \\ 9.998 & 10.000 \\ 14.998 & 15.000 \\ 6.999 & 7.001 \\ 3.000 & 3.001 \\ 16.998 & 17.000 \\ 5.999 & 6.002 \\ 3.000 & 3.001 \\ 9.999 & 10.000 \\ 16.998 & 16.999 \\ 7.999 & 8.001 \\ 13.998 & 13.998 \\ 4.999 & 5.000 \\ & \\ 109 & \end{array}$

\section{Predicted Values}

$$
\begin{array}{r}
4.001 \\
15.998 \\
11.000 \\
2.001 \\
7.000 \\
1.001 \\
9.000 \\
17.999 \\
9.000 \\
18.998 \\
11.000 \\
12.000 \\
14.999 \\
19.998 \\
4.000
\end{array}
$$$$
12.999
$$$$
5.001
$$$$
12.999
$$$$
1.001
$$$$
12.000
$$$$
18.998
$$$$
13.999
$$$$
19.998
$$$$
17.999
$$$$
8.000
$$$$
15.999
$$$$
2.001
$$$$
6.000
$$$$
10.000
$$$$
14.999
$$$$
7.000
$$$$
3.000
$$$$
16.999
$$$$
6.000
$$$$
3.001
$$$$
10.000
$$$$
16.999
$$$$
8.000
$$$$
13.999
$$$$
5.001
$$

Standard Deviation of Predicted Values

$.20 \mathrm{E}-03$
$.19 \mathrm{E}-03$
$.12 \mathrm{E}-03$
$.24 \mathrm{E}-03$
$.16 \mathrm{E}-03$
$.26 \mathrm{E}-03$
$.14 \mathrm{E}-03$
$.22 \mathrm{E}-03$
$.14 \mathrm{E}-03$
$.24 \mathrm{E}-03$
$.13 \mathrm{E}-03$
$.14 \mathrm{E}-03$
$.17 \mathrm{E}-03$
$.26 \mathrm{E}-03$
$.20 \mathrm{E}-03$
$.15 \mathrm{E}-03$
$.19 \mathrm{E}-03$
$.15 \mathrm{E}-03$
$.26 \mathrm{E}-03$
$.14 \mathrm{E}-03$
$.24 \mathrm{E}-03$
$.16 \mathrm{E}-03$
$.26 \mathrm{E}-03$
$.22 \mathrm{E}-03$
$.15 \mathrm{E}-03$
$.19 \mathrm{E}-03$
$.24 \mathrm{E}-03$
$.17 \mathrm{E}-03$
$.13 \mathrm{E}-03$
$.17 \mathrm{E}-03$
$.16 \mathrm{E}-03$
$.22 \mathrm{E}-03$
$.20 \mathrm{E}-03$
$.17 \mathrm{E}-03$
$.22 \mathrm{E}-03$
$.13 \mathrm{E}-03$
$.20 \mathrm{E}-03$
$.15 \mathrm{E}-03$
$.16 \mathrm{E}-03$
$.19 \mathrm{E}-03$ 
NBS-IILA (REV.7.73)

\begin{tabular}{|c|c|c|c|}
\hline $\begin{array}{l}\text { U.S. DEPT. OF COMM. } \\
\text { BIBLIOGRAPHIC DATA } \\
\text { SHEET }\end{array}$ & $\begin{array}{l}\text { 1. PUBLICATION OR REPORT NO. } \\
\text { NBSIR 77-852 }\end{array}$ & $\begin{array}{l}\text { 2. Gov't Accession } \\
\text { No. }\end{array}$ & 3. Recipient's Accession No. \\
\hline \multicolumn{3}{|l|}{ 4. TITLE AND SUBTITI.E } & $\begin{array}{l}\text { 5. Publication Date } \\
\text { January } 1977\end{array}$ \\
\hline \multicolumn{3}{|c|}{$\begin{array}{l}\text { CRYOGENIC FLUIDS DENSITY REFERENCE SYSTEM: PROVISIONAL } \\
\text { ACCURACY STATEMENT }\end{array}$} & $\begin{array}{l}\text { 6. Performing Organization Code } \\
275.08\end{array}$ \\
\hline \multicolumn{3}{|l|}{$\begin{array}{l}\text { 7. AUTHOR(S) } \\
\text { B. A. Younglove }\end{array}$} & 8. Performing Organ. Report No. \\
\hline \multirow{2}{*}{\multicolumn{3}{|c|}{$\begin{array}{l}\text { 9. PERFORMING ORGANIZATION NAME AND ADDRESS } \\
\text { NATIONAL BUREAU OF STANDARDS } \\
\text { DEPARTMENT OF COMMERCE } \\
\text { WASHINGTON, D.C. } 20234\end{array}$}} & $\begin{array}{l}\text { 10. Project/Task/Work Unit No. } \\
2750161\end{array}$ \\
\hline & & & 11. Contract/Grant No. \\
\hline \multirow{2}{*}{\multicolumn{3}{|c|}{ 12. Sponsoring Organization Name and Complete Address (Street, City, State, ZIP) }} & $\begin{array}{l}\text { 13. Type of Report \& Period } \\
\text { Covered }\end{array}$ \\
\hline & & & 14. Sponsoring Agency Code \\
\hline
\end{tabular}

15. SUPPL.EMENTARY NOTES

16. ABSTRACT (A 200-word or less factual summary of most significant information. If document includes a significant bibliography or literature survey, mention it here.)

The measurement capability of the density reference system (DRS) of the National Bureau of Standards, Cryogenics Division, is described. This system measures density, pressure, and temperature of LNG mixtures for the purpose of testing densimeters which are contained in the liquid sample. Sample composition is determined by weighing the gas samples separately before condensing them into the sample. The DRS measures density by weighing a single-crystal of silicon immersed in the LNG mixture. This process is described and the equations used in the computation of density are discussed.

At this time the estimate of sample standard deviation for a single density measurement made on this system is $\pm 0.062 \%$ (at $0.4 \mathrm{~g} / \mathrm{cc}$ ). Using three times this standard deviation as a limit for random error and adding $\pm 0.026 \%$ as an upper bound for known sources of possible systematic error, the uncertainty of a single determination by this system is $\pm 0.21 \%$. This statement of accuracy applies for the density range 380 to $430 \mathrm{~kg} / \mathrm{m}^{3}$ and 1200 to $1400 \mathrm{~kg} / \mathrm{m}^{3}$, pressures to $7 \mathrm{bar}$, and temperatures from $80 \mathrm{~K}$ to $140 \mathrm{~K}$. This statement is expected to be correct in the intermediate density range and for all temperatures up to $300 \mathrm{~K}$.

Measurement uncertainties for temperature, pressure, and composition are discussed. Comparison of measurements for liquid argon densities with the results of other laboratories is given.

17. KFY WORDS (SIX to twelve entries; alphabetical order; capitalize only the first letter of the first key word unless a proper name; separated by semicolons)

Densimeters; density reference system; liquid methane; LNG

\section{AVAII.ABHLITY [X Unlimited}

For Official Distribution. Do Not Release to NTIS

Order From Sup. of Doc, U.S. Government Printing Office Washington, D.C. 20402, SD Cat. No.C13

$[X]$ Order From National Technical Information Service (NTIS) Springfield, Virginia 22151

\begin{tabular}{|l|c|}
\hline $\begin{array}{l}\text { 19. SECURITY CLASS } \\
\text { (THIS REPURT) }\end{array}$ & 21. NO. OF PAGES \\
UNCL ASSIFIED & 30 \\
\hline $\begin{array}{l}\text { 20. SECURITY CLASS } \\
\text { (THIS PAGE) }\end{array}$ & 22. Price \\
UNCLASSIFIED & $\$ 4.00$ \\
\hline
\end{tabular}




\section{What's new in LNG measurement methods and instrumentation}

\section{Industry supported research programs at National Bureau of Standards provide data on cryogenic metering devices}

D. B. Mann, Coordinator of LNG Programs, Cryogenics Division, Institute for Basic Standards, National Bureau of Standards, Boulder, Colo.

Characterization, instrumentation and measurement of liquefied natural gas are the primary objectives of the LNG Program at the National Bureau of Standards (NBS).

Characterization involves the deterinination of accurate PVT, thermodynamic, electromagnetic and transport properties data for multi-component inixtures of liquefied hydrocarbon gases. Instrumentation and measurement are essential to the safe and economic liquefaction, transport storage and custody transfer of this form of fossil fuel.

Although the main purpose of this article is to report on current progress in instrumentation and measurements, it should be emphasized that basic reference quality property data are fundamental to accurate, precise field measurements for pressure, temperature, density, liquid level and flow.

Data development. The NBS approach to development of thermophysical properties data for LNG has been to concentrate initially on providing accurate wide range data and calculation methods for the pure components. These include methane, ethane, propane, iso and normal butane and nitrogen.

The range. of interest is from the triple point conditions to temperatures above ambient at pressures to at least $34,500 \mathrm{kPa}(5,000 \mathrm{psi})$. This work is being carried out primarily in the Properties of Cryogenic Fluids Section under the supervision of D. E. Diller.

Accomplishments to date under an American Gas Association (AGA) funded grant include published reports on comprehensive thermophysical properties data for methane, dielectric constant and polarizability of methane, velocity of sound in methane, specific heats of methane, provisional thermodynamic functions for ethane, dielectric constant of ethane, PVT and vapor pressure measurements on ethane, phase transitions of ethane and a comprehensive accurate equation of state

$\begin{array}{cc}\text { - Pure Components } & \\ \text { Methane } & \text { Isobutane } \\ \text { Ethane } & \text { n-butane } \\ \text { Propane } & \text { Nitrogen }\end{array}$

for the thermodynamic properties of fluids.

Related accomplishments funded by NBS and other agencies include publications on refractive index data for methane, viscosity and thermal conductivity equations for methane and saturation densities of liquefied normal butane.

Additional publications influenced by the quality of the data are available and are classic illustrations of the diffusion and widespread use of accurate and precise property data generated as a result of an original AGA grant.

Another NBS project is concerned with prediction of densities of LNG, at or near saturation as a function of pressure, temperature and mixture composition. This project is funded by the LNG Density Project Steering Committee, through a grant administered by the AGA.

Objectives of the project are to mea-

TABLE 1-Densities of liquefied natural gas mixtures Scope of work on project

- Binary Mixtures

Methane-Ethane Methane-Propane Methane-Isobutane Methane-n-butane Methane-Nitrogen

- Multicomponent Mixtures Methane-Ethane-Propane Methane-Ethane-Nitrogen Methane-E thane-Propane-n-butane Methane-Ethane-Propane-Nitrogen Methane-E thane-Propane-n-butane-Nitrogen Typical LNG Mixtures
Ethane-Propane Ethane-n-butane Ethane-Nitrogen Ethane-Isobutane
Propane-Isobutane Propane-n-butane Ethane-Nitrogen 


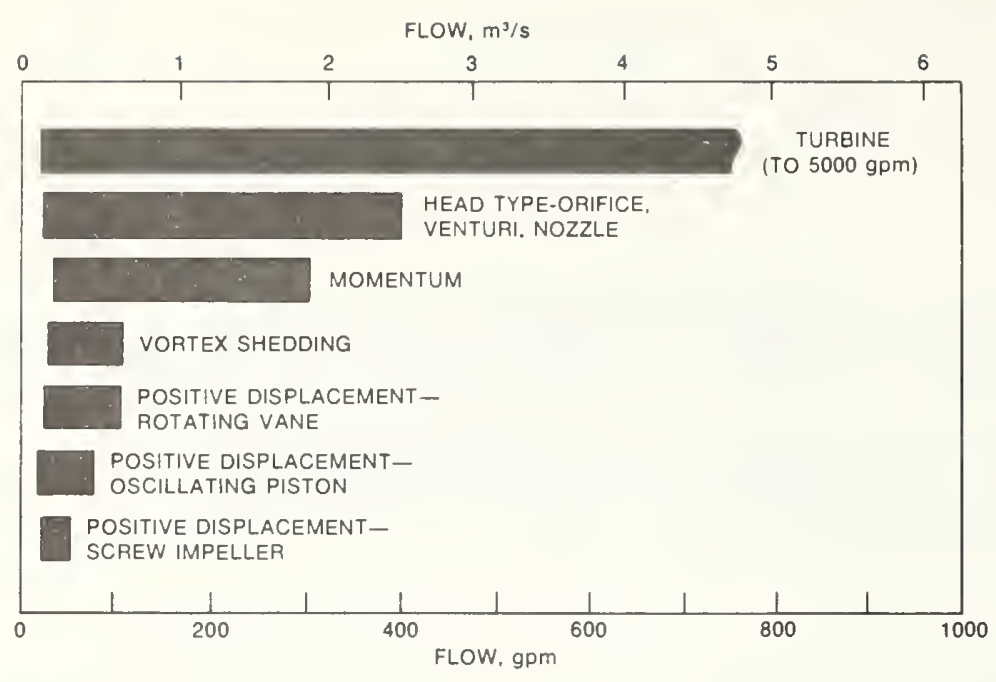

Fig. 1-Flow range of cryogenic flowmeters confirmed by experiment.

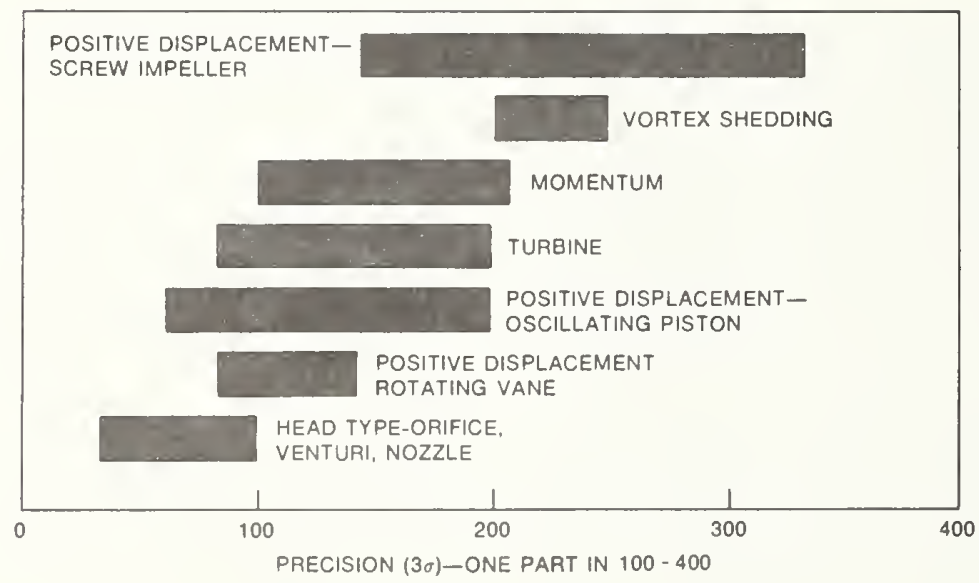

Fig. 2-Precision of flowmeters for cryogenic service based on experimental data.

sure the saturated liquid densities of LNG type mixtures with an inaccuracy and imprecision of less than 0.1 percent and to evaluate and optimize three existing density calculation methods using this experimental data as the measurement base. Table 1 outlines the content and scope of the experimental program.

The approach involves precise measurements of the pure fluid and binary mixture densities throughout a temperature range of 110 to $140 \mathrm{~K}$. Optimization of the correlation methods are then evaluated by comparing calculated densities with precise density measurements for selected multi-component (including I,NG type) mixtures. The project is nearing comple- mounted, custody transfer meters. An 8-year joint NBS-industry effort has provided extensive data on the performance of volumetric and mass flow devices, both under well controlled laboratory conditions and in the field.

The program was begun in 1968 as a cooperative effort involving NBS and members of the Compressed Gas Association. Accomplishments include:

- An evaluation of generic classes of flowmetering devices over a broad range of expected operating conditions

- Initial work on establishment of specifications, tolerances and recommended practices for flow devices used in commerce

- Promulgation of transfer standards traceable to NBS for field certification of new meters to be put in service or recertification of in-service meters.

More than 60 meters, based on five different generic types, were included in the program. A summary of experimental cryogenic performance of these meters is shown in Fig. 1. Documented performance for various cryogenic volumetric flow ranges is shown in Fig. 2, which includes experimental results from the literature in addition to that developed under the NBSCGA program.

Active work under this program is drawing to a close with the development of a model code (NBS, 1972) and conclusion of field tests of transfer standards to be used for field certification. The model code will be submitted to the National Conference on Weights and Measures this year for approval as a permanent code.

Members of the LNG industry, particularly those interested in road trailer operation involving custody transfer, could take advantage of the results of this work. Actual code and recommended practices specifically exclude LNG, primarily because the industrial cryogenic fluids-hydrogen, oxygen, argon and nitrogen-are more adequately characterized than I.NG mixtures. As mentioned above, this situation is changing and most other aspects of the flow metering program could prove useful.

flow measurements. Within genera advances in the state-of-the-art, instrumentation for LNG flow measurements can draw on a well-developed research and field experience of cryogenic industrial gases (liquid nitrogen, argon, oxygen, hydrogen), specifically in the area of small diameter, truck
Densimeter evaluation. Prediction of LNG densities by using a computer program which relates pressure, temperature and mixture fraction to pre- 
cise accurate density measurements is most probably the method which provides the least possibility of error. However, accomplishing this inferred density calculation will require meticulous attention to detail in the sample extraction, gas analysis and temperature and pressure measurments.

These activities, in most cases, can be handled best in a well equipped laboratory environment where all elements are under careful control. If such measurements are made in the ficld where sampling, gas analysis, etc. are made under varying or severe conditions, then uncertainties associated with sampling and analysis may be unacceptable.

An alternative to this approach would be to use, in the field, a direct reading densimeter evaluated and calibrated under the most accurate and precise laboratory conditions. The densimeter could be placed in the LNG directly, avoiding sampling errors, and the calibration would be based on accurate, precise measurements needed for correlations of density with pressure, temperature and mixture fraction. A direct reading densimeter would also eliminate the need for field gas analysis for density determination.

A program designed to evaluate performance of several different types of commercial densimeters has recently been completed at NBS. This work is being carried out primarily in the Metrology Section under the supervision of R. S. Collier.

Funded under an AGA grant, the program provided a reference system of such size as to allow installation of everal densimeters. The measurement of the performance of each densimeter under various pressure, temperature .nd L.VG mixture composition condilions was made with a comparison to in accurate Archimedes principle deninieter and continuously monitored and referenced to precise laboratory density measurements.

Three types. Three generic types of Iensimeters were investigated. Changes "If dielectric properties with density were incorporated in a capacitance densineter and in a microwave resollant cavity. Changes in damping of a vibrating element with density provided a second generic type densimeter and the changes in the forces acting on an element submerged in I.NG provided the third type.

The work at NBS will be reported in two parts. The first will be a detailed description of the density reference system with particular attention to accuracy and precision of the system. The second part will be performance data for the three generic types of densimeters.

A number of summary statements can be made which provide a preview of the program results (in general, the density ranged from 390 to $490 \mathrm{~kg} / \mathrm{m}^{3}$ for the densimeters under test):

1) Dielectric Cell Densimeter. Analysis of the data for density difference versus density computed from vapor pressure measurements for pure methane, using

$$
\left(\rho_{\varepsilon}-\rho_{\mathrm{NBS}}\right)=\mathrm{A}+\mathrm{B} \rho_{\mathrm{NBS}}
$$

shows an over-all standard deviation of about 1 percent.

From the mixture data other than the butane and nitrogen mixtures, the data all lie in a band \pm 0.24 percent with butane mixture data below the median line by about 0.4 percent. The nitrogen mixtures are outside this range and further work needs to be done on mixtures containing nitrogen.

2) Vibrating Element Densimeter. The performance of the two types of densimeters when fitted to the relation in (1) above varied over a range of 0.2 percent to 1.6 percent for pure fluids and mixtures.

3) Displacement or Archimedes Densimeter. All of the data taken for this device lie in a band \pm 0.2 percent wide. From a median line the data have a standard deviation of about \pm 0.1 percent. The measurements taken on this device are less extensive than for the others but include pure methane, a methane-nitrogen mixture and a five component hydrocarbon mixture.

A detailed analysis of the dielectric constant densimeter will be published. Under this Maritime Administration funded program, densities of LNG type mixtures under saturation and subcooled conditions were calculated by means of the Mollerup [Mollerup, 1975] computer program; the corresponding density-dielectric constant relationship was determined from the Clausius-Mosotti relationship for the mixture using ideal mixing rules for the C.M function.

The results show that a nearly unique and linear relationship between saturation density and dielectric constant exists for both constant pressure and constant teniperature conditions independent of mixture. Furthermore.

\section{About the author}

DOUGLas B. MANN is coordinator of $L N G$ Programs at the Cryogenics Division, NBS Institute for Basic Standards, Boulder Colo. A mechanical engineer (B.S. and M.S., Colorado University), he has more than 20 years experience in the field of cryogenic engineering. He led the joint NBS-Compressed Gas Association program at NBS which assessed the performance of cryogenic flowmeters in commercial service, developed the model code for their use in commcrce and aided in the acceptance of this type of measurement in the U.S. and Europe. His interests are primarily in measurement and instrumentation for determining density, pressure, temperature, liquid level and flow of cryogenic fluids. Since 1968, he has been involved with the application of these cryogenic measurement techniques to liquefied natural gas. He holds three patents on cryogenics devices and has authored or co-authored more than 45 papers on cryogenic subjects.

it is shown that the linear relationship is not a segment of the ClausiusMosotti function, but results from the more fundamental thermodynamic properties of the mixture.

Also, the nitrogen composition of the mixture is predicted to have a pronounced effect on the saturation density versus dielectric constant, the increase in nitrogen causes an increase in saturation density for the same dielectric constant. There is also a substantial decrease in the saturation temperature with an increasing nitrogen content. This allows a temperature compensation for the nitrogen content.

For the normal range of 1 NG; type mixtures, it is possible to determine the density to \pm 0.3 percent independent of a knowledge of the composition from an exact measurement of dielectric constant and temperature. Further improvements can be made if the exact composition of the mixture is known.

Therm meter. A current program for therm meter for flowing L.VC; funded by the Pipeline Research Consmittee of AG.1, is an illustration of objectives from one measurement's requirement being inet by output from other ongoing measurements and artivities. The therm meter program goals are to demonstrate and assess the accuracy and precision of a threeelement measurement system for pre- 


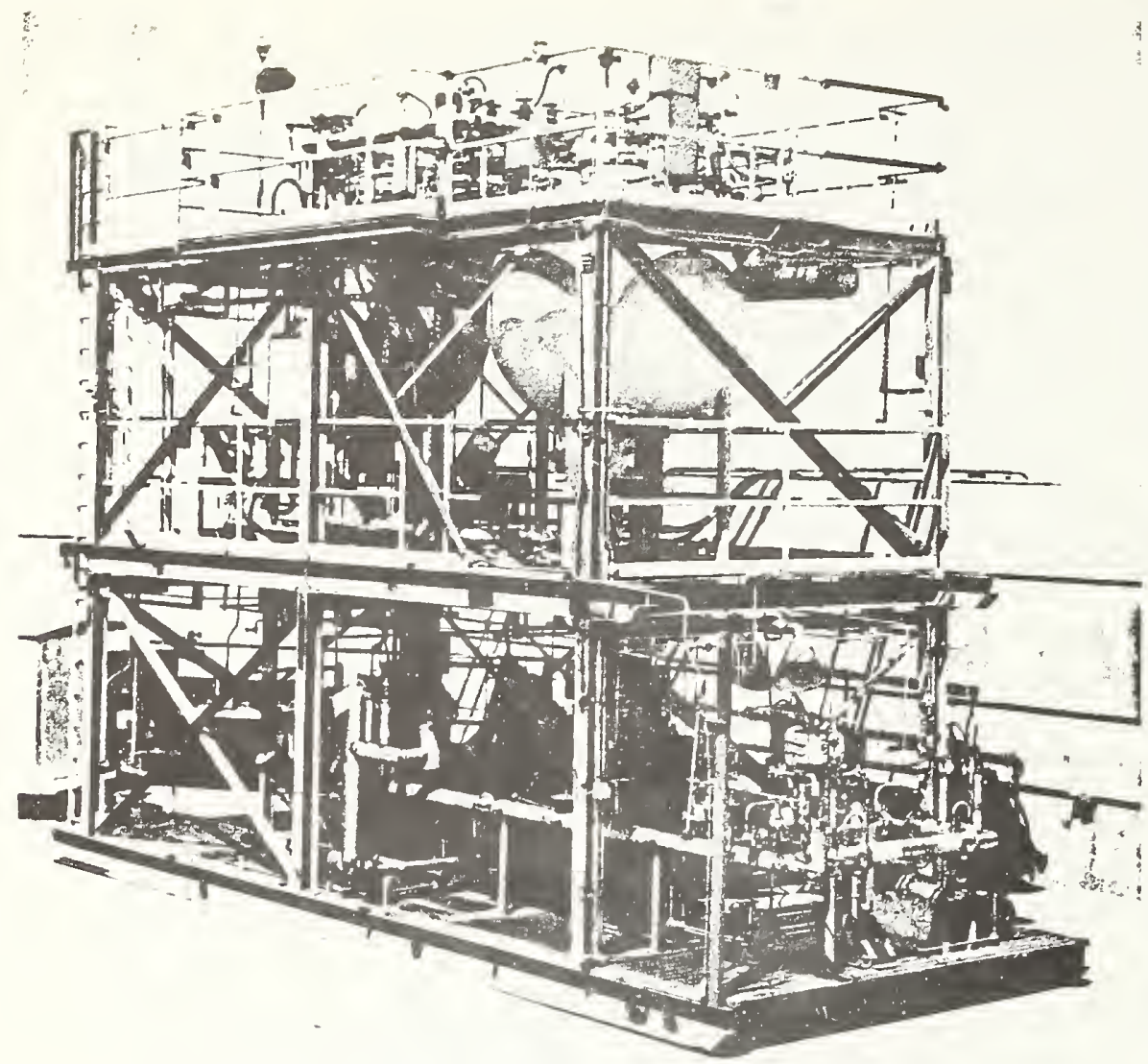

Fig. 3-LNG flow facility at National Bureau of Standards, Boulder, Colo.

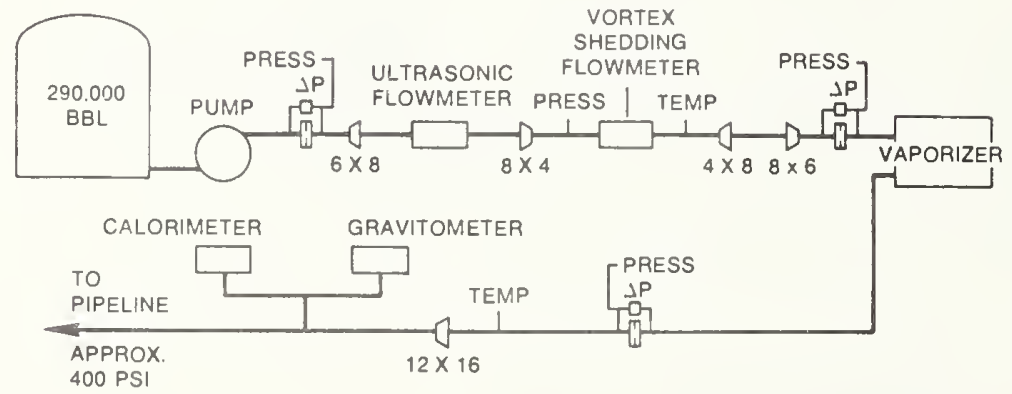

Fig. 4-Flow schematic of Transco field tests in New Jersey.

dicting the gross heating value of I.NC flowing in a pipe line

This is a minimum risk approach combining existing performance data of volumetric flowmeters NBS-CGA Programl. performance and calibration data for a direct reading densitometer (density reference system) and the industry compatible combustion calorinveter.

Therefore the volumetric flow may be measured in cubic meters per hour - combined with measured density ment components under flow conditions with L.FG. Conditions of pressure, temperature, flow and mixture fraction can be controlled, and the recently installed calorimeter with gravitometer provides the complete "breadboard" of the therm flow measurement system.

The wide application and use of this measurement system for L.VG must consider scaling to large pipe diameters $(0.6$ to $0.9 \mathrm{~m})$. It is believed that for single phase fully developed turbulent flow, the densitometer and combustion calorimeter will not be affected by line size.

However, the performance of cryogenic flowmeters is generally documented only at diameters less than about $0.1 \mathrm{~m}$. Therefore, a second goal of the NBS-PRC program is directed at defining the scaling laws when increasing the meter diameters to the 0.6 to $0.9 \mathrm{~m}$ size.

Demonstration of the methods used to scale the flowmeters is complicated by not having cryogenic flow reference systems of a size or capacity required. The NBS facility is limited by a maximum line size of $0.1 \mathrm{~m}$ and a flow rate of $45 \mathrm{~m}^{3}$ per hour. Larger capacity LNG flow rates are available at industrial LNG peak shaving plants, and gas flow measurement after LNG vaporization could provide a reference system for the liquid flow.

A three-step program to define the scaling laws was selected. A volumetric vortex flowmeter was chosen based on the performance on this meter type under the NBS-CGA flowmetering program and the potential for scaling to larger sizes. Water and liquid nitrogen calibrations were used for both the LNG and gas flowmeters where applicable.

In this cooperative effort, Transcontinental Gas Pipeline Corp. allowed the installation of a 0.1 and $0.2 \mathrm{~m}$ diameter flowmeter (4 and 8-in. diameter) at its New Jersey peak shaving facility and testing of these two meters was conducted last winter. A flow schematic of the installation is shown in Fig. 4.

Data from these tests are currently being analyzed but indicate an agreement of near \pm 1.5 percent with the gas flow measurements. Current plans under this program include the selection of a large capacity LNG site for the installation and testing of meters of greater than $0.4 \mathrm{~m}$ in diameter. 


\begin{tabular}{|c|c|c|}
\hline \begin{tabular}{c|c} 
U.S. DEPT. OF COMM. & 1. PUIBI.ICATION OR REPORT NO. \\
BIBLIOGRAPHIC DATA & NBSIR 77-854 \\
SHEET & NBSI
\end{tabular} & $\begin{array}{l}\text { 2. Gov't Accession } \\
\text { No. }\end{array}$ & 3. Recipient"s Accession No. \\
\hline \multirow{2}{*}{\multicolumn{2}{|c|}{$\begin{array}{l}\text { 4. TITLE AND SUBTITLE } \\
\text { LIQUEFIED NATURAL GAS RESEARCH AT THE NATIONAL } \\
\text { BUREAU OF STANDARDS }\end{array}$}} & $\begin{array}{l}\text { 5. Publication Date } \\
\text { March } 1977\end{array}$ \\
\hline & & 6. Performing Organization Code \\
\hline $\begin{array}{l}\text { 7. AUTHOR(S) } \\
\text { D. E. Diller, Editor }\end{array}$ & & 8. Performing Organ. Report No. \\
\hline $\begin{array}{l}\text { 9. PERFORMING ORGANIZATION NAME AND ADDRESS } \\
\qquad \begin{array}{l}\text { NATIONAL BUREAU OF STANDARDS } \\
\text { DEPARTMENT OF COMMERCE } \\
\text { WASHINGTON, D.C. } 20234\end{array}\end{array}$ & & $\begin{array}{l}\text { 10. Project/Task/Work Unit No. } \\
2750104 \\
\text { 11. Contract/Grant No. }\end{array}$ \\
\hline $\begin{array}{l}\text { 12. Sponsoring Organization Name and Complete Address (Street, City, } \\
\text { Same as Item \#9. }\end{array}$ & State, ZIP) & $\begin{array}{l}\text { 13. Type of Report \& Period } \\
\text { Covered } \\
\text { Semi-Annual -- } \\
\text { 1] July-31. December } 2976 \\
\text { 14. Sponsoring Agericy Codc }\end{array}$ \\
\hline
\end{tabular}

16. ABSTRACT (A 200-word or less factual summary of most significant information. If document includes a significant bibliography or literature survey, mention it here.)

Twenty-five cost centers, supported by six other agency sponsors in addition to NBS, provide the basis for liquefied natural gas (LNG) research at NBS. During this six-month reporting period the level of effort was 20 man-years/year with funding expenditures of over $\$ 500,000$. This integrated progress report to be issued in January and July is designed to:

1) Provide all sponsoring agencies with a semi-annual and annual report on the activities of their individual programs.

2) Inform all sponsoring agencies on related research being conducted at the Cryogenics Division of NBS-IBS.

3) Provide a uniform reporting procedure which should maintain and improve communication while minimizing the time, effort and paperwork at the cost center level.

The contents of this report will augment the quarterly progress meetings of some sponsors, but will not necessarily replace such meetings. Distribution of this document is limited and intended primarily for the supporting agencies. Data or other information must be considered preliminary, subject to change and unpublished; and therefore not for citation in the open literature.

17. KEY WORDS (six to twelve entries; alphabetical order; capitalize only the first letter of the first key word unless a proper name; separated by semicolons)

Cryogenics; liquefied natural gas; measurement; methane; properties; research.
18. AVAILABILITY
Unlimited

X For Official Distribution. Do Not Release to NTIS

Order From Sup. of Doc., U.S. Government Printing Office Washington, D.C. 20402, SD Cat. No. C13

Order From National Technical Information Service (NTIS) Springfield, Virginia 22151

\begin{tabular}{|l|l|}
\hline $\begin{array}{l}\text { 19. SECURITY CLASS } \\
\text { (THIS REPURT) }\end{array}$ & 21. NO. OF PAGES \\
UNCLASSIFIED & \\
\hline $\begin{array}{l}\text { 20. SECURITY CLASS } \\
\text { (THIS PAGE) } \\
\text { UNCLASSIFIED }\end{array}$ & 22. Price \\
\hline
\end{tabular}


